\title{
Working in the Service Sector
}

It is generally agreed by economists that future employment growth in developed countries will be heavily reliant on the tertiary sector. The reasons behind this important change in employment structure have been the subject of much debate and controversy. The outcomes of these discussions are of decisive importance for economic policy and the quality of working and living conditions in the future.

Working in the Service Sector adds to this ongoing debate, using original research and empirical analysis from a wide range of countries. The book examines core issues such as working time, country regimes, working conditions in different employment sectors and flexibility as well as gender and work. The reader is presented with case studies and accompanying analysis for various service industries across different nations.

Working in the Service Sector provides an engaging and comprehensive account of this shift in employment structure and will be of great interest to students and academics of economics and essential reading for policy makers.

Gerhard Bosch is an economist and sociologist, Professor at the University Duisburg-Essen and Vice-President of the Institute of Work and Technology (Institut Arbeit und Technik, IAT), Gelsenkirchen/Germany. Steffen Lehndorff is an economist and Director of the Working Time and Work Organisation Research Unit at the Institute of Work and Technology, Gelsenkirchen/Germany. 


\section{Routledge studies in business organizations and networks}

1 Democracy and Efficiency in the Economic Enterprise

Edited by Ugo Pagano and Robert Rowthorn

\section{Towards a Competence Theory} of the Firm

Edited by Nicolai J. Foss and

Christian Knudsen

3 Uncertainty and Economic

Evolution

Essays in honour of

Armen A. Alchian

Edited by John R. Lott Jr

4 The End of the Professions?

The restructuring of

professional work

Edited by Jane Broadbent, Michael

Dietrich and

Jennifer Roberts

\section{Shopfloor Matters}

Labor-management relations in twentieth-century American

manufacturing

David Fairris

6 The Organisation of the Firm

International business

perspectives

Edited by Ram Mudambi and

Martin Ricketts
7 Organizing Industrial Activities Across Firm Boundaries

Anna Dubois

8 Economic Organisation, Capabilities and Coordination

Edited by Nicolai Foss and Brian J. Loasby

9 The Changing Boundaries of the Firm

Explaining evolving inter-firm relations

Edited by Massimo G. Colombo

10 Authority and Control in Modern Industry

Theoretical and empirical

perspectives

Edited by Paul L. Robertson

11 Interfirm Networks

Organization and industrial

competitiveness

Edited by Anna Grandori

12 Privatization and Supply Chain Management

Andrew Cox, Lisa Harris and

David Parker

13 The Governance of Large

Technical Systems

Edited by Olivier Coutard 
14 Stability and Change in HighTech Enterprises

Organisational practices and routines

Neil Costello

15 The New Mutualism in Public Policy

Johnston Birchall

16 An Econometric Analysis of the Real Estate Market and Investment

Peijie Wang

17 Managing Buyer-Supplier Relations

The winning edge through specification management Rajesh Nellore

18 Supply Chains, Markets and Power Mapping buyer and supplier power regimes Andrew Cox, Paul Ireland, Chris Lonsdale, Joe Sanderson and Glyn Watson

19 Managing Professional Identities

Knowledge, performativity, and the 'new' professional Edited by Mike Dent and Stephen Whitehead

20 A Comparison of Small and Medium Enterprises in Europe and in the USA

Solomon Karmel and Justin Bryon

21 Workaholism in Organizations Antecedents and consequences Ronald J. Burke
22 The Construction Industry An international comparison Edited by Gerhard Bosch and Peter Philips

23 Economic Geography of Higher Education

Knowledge, infrastructure and learning regions

Edited by Roel Rutten, Frans Boekema and Elsa Kuijpers

24 Economies of Network Industries

Hans-Werner Gottinger

25 The Corporation

Investment, mergers and growth

Dennis C. Mueller

26 Industrial and Labour Market Policy and Performance Issues and perspectives Edited by Dan Coffey and Carole Thornley

27 Organization and Identity Edited by Alison Pullen and Stephen Linstead

28 Thinking Organization Edited by Stephen Linstead and Alison Linstead

29 Information Warfare in Business Strategies of control and resistance in the network society Iain Munro

30 Business Clusters An international perspective Martin Perry 
31 Markets in Fashion

A phenomenological approach

Patrik Aspers

32 Working in the Service Sector

A tale from different worlds

Edited by Gerhard Bosch and

Steffen Lehndorff
33 Strategic and Organizational Change

From production to retailing in UK brewing 1950-1990

Alistair Mutch

34 Transportation Economics

Towards better performance

systems

Edited by Bart Jourquin,

Piet Rietveld and Kerstin Westin 


\section{Working in the Service Sector A tale from different worlds}

Edited by Gerhard Bosch and Steffen Lehndorff

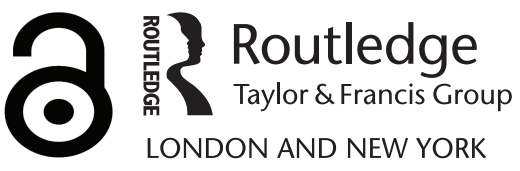


First published 2005 by Routledge

Published 2017 by Routledge

2 Park Square, Milton Park, Abingdon, Oxon OX14 4RN

711 Third Avenue, New York, NY 10017, USA

Routledge is an imprint of the Taylor $\mathcal{E}$ Francis Group, an informa business

Copyright $\odot 2005$ Selection and editorial matter, Gerhard Bosch and Steffen Lehndorff; individual chapters the contributors

Typeset in New Baskerville by Wearset Ltd, Boldon, Tyne and Wear

The Open Access version of this book, available at www. tandfebooks. com, has been made available under a Creative Commons Attribution-Non Commercial-No Derivatives 4.0 license.

British Library Cataloguing in Publication Data

A catalogue record for this book is available from the British Library

Library of Congress Cataloging in Publication Data

A catalog record for this book has been requested

ISBN 978-0-415-28322-9 (hbk) 


\section{Contents}

List of illustrations xii

Notes on contributors $\quad$ xvi

Acknowledgements xix

1 Introduction: service economies - high road or low road? 1

GERHARD BOSCH AND STEFFEN LEHNDORFF

Different service societies in Europe 5

The different worlds of service work 10

Institutions matter 16

Conclusions 23

PART I

Different service societies in Europe

2 Measuring economic tertiarisation: a map of various

European service societies

GERHARD BOSCH AND ALEXANDRA WAGNER

Introduction 35

Indicators of employment in services 36

Sectoral and functional tertiarisation 38

The absolute level of tertiarisation 42

The structure of services 44

Country profiles 48

Conclusions 51 
viii Contents

3 The incidence of new forms of employment in service activities

MARK SMITH

Introduction 54

Non-standard work and services 55

Service growth and non-standard work 57

Service jobs and access to work 66

Conclusions 70

4 Why do countries have such different service-sector employment rates?

GERHARD BOSCH AND ALEXANDRA WAGNER

Introduction 74

Services and the cost disease 79

Household structures and services 82

The welfare state, welfare state regimes, and services 84

The demand for services in manufacturing industry 86

Quality of the supply 88

Employment intensity in the service sector 89

Different development paths: societies with high and low volumes of market services 92

Conclusions 96

5 Services and the employment prospects for women

ALEXANDRA WAGNER

Introduction 10

Tertiarisation, women's employment and part-time work what do the data say? 103

Women's employment and the service society: the various configurations 114

Some political implications of the 'high road' 121

Conclusion 127 
PART II

The organisation of service work: an analysis of five sectors

6 The family, the state, and now the market: the organisation of employment and working time in home care services for the elderly

DOMINIQUE ANXO AND COLETTE FAGAN

Introduction 133

Gender, care, and welfare state regimes 135

The dynamics of change in the organisation of home care services 146

The dynamics of change: findings from the organisational case studies 149

Conclusions 161

7 The reluctant nurses: labour shortage and recruitment crisis in the hospital sector - a comparison of Belgium, Italy, France, the Netherlands, Sweden and the United Kingdom

CHRISTOPHE BARET

Introduction 165

Theoretical framework based on societal analysis 167

Employment and working time organisation: figures and reforms 168

The evolution of employment and working time and the context of change 181

Conclusion 185

8 Work hard, play hard? Work in software engineering JANNEKE PLANTENGA AND CHANTAL REMERY

Introduction 189

Socio-economic environment and organisational structure 190

Employment profile and actual working-time patterns 193 Beyond the statistics: determining factors of IT work organisation and working time 197

Conclusion 207 
9 Work organisation and the importance of labour markets in the European retail trade

FLORENCE JANY-CATRICE AND STEFFEN LEHNDORFF

Introduction 211

The restructuring of the industry and of employment by the large retail companies 212

The influence of the labour supply on personnel strategies 218

Personnel management on the 'shop-floor' - a tightrope act 223

Conclusion 233

10 Lean banking: retail and direct banking in France and Germany

THOMAS HAIPETER AND MARTINE PERNOD-LEMATTRE

Introduction 237

International financial markets and the strategy of lean banking 238

Impact of national regulations on company strategies 241

The case studies: new forms of flexibility in call centres and branch offices 247

Conclusion 254

\section{PART III}

\section{Common challenges}

11 The shaping of work and working time in the service sector: a segmentation approach

JILL RUBERY

Introduction 261

Revisiting segmentation theory 262

Organisational employment practices: new requirements, and new conflicts and contradictions 272

Introducing the supply side: mutual interactions, path dependency and constraints on adjustment 276

Societal effects and segmentation 279

Conclusions 283 
12 The delegation of uncertainty: flexibility and the role of the market in service work

STEFFEN LEHNDORFF AND DOROTHEA VOSS-DAHM

Introduction 289

Flexibility through competition 290

Imposing markets on workers 295

The risks of flexibility 304

Conclusions 311

13 Can trade unions meet the challenge? Unionisation in the marketised services

JON ERIK D ØLVIK AND JEREMY WADDINGTON

Introduction 316

Tertiarisation of labour and union membership 317

Changing conditions for collective organisation in services 322

Trade union challenges and the search for solutions 325

Conclusions 334

14 Diversity and regulation of markets for services

JEAN GADREY

Introduction 342

The 'pure' market is a normative myth 344

The utopia of a market without rules 345

The case of the labour market 347

The other markets: all regulated to a greater or lesser extent 348

Two types of justifications for rules 350

A society has the markets it creates for itself 351

Conclusion 352

Index 


\section{Illustrations}

\section{Figures}

1.1 Factors influencing service work organisation 11

4.1 Causes of service-sector expansion 78

4.2 Income distribution (1994) and the weekly volume of services per head of population of working age (1999)

4.3 Income distribution (1994) and the weekly volume of social and personal services per head of population of working age (1999)

80

4.4 Volume of work done by women per head of population of working age in hours per week and weekly volume of services per head of population of working age in social/ socially oriented services

4.5 Average weekly working times of both partners and weekly volumes of work in socially oriented/social services per head of population of working age

4.6 Expenditure on social protection and the weekly volume of work in social services per person in working age

4.7 Research expenditure per capita in purchasing power parities (1997) and weekly volume of production-related services per person in working age (1999)

4.8 Proportion of economically active individuals with low qualification levels in the economy as a whole and proportion of economically active individuals engaged in service activities

4.9 The employment effect of shorter working times in services relative to manufacturing

4.10 Adjusted backward-bending labour supply curve 94

6.1 The dynamics of change in the home care service sector $\quad 147$

12.1 Forms and methods of personnel flexibility 291

12.2 Proportion of employees working usually $48+$ hours per week, IT services and all sectors (1999) 


\section{Tables}

2.1 Indicators of employment in services 38

2.2 Sectoral analysis of tertiarisation by numbers of employees and work volume (1999)

2.3 Breakdown of the employment structure (1999) by sector and activity

2.4 Dependent employees in the secondary sector

2.5 Employment rates by sector as percentage of working-age population (1999)

2.6 Employment rates, working times and volume of work per head of population in working age (1999)

2.7 Volume of services per individual of working age compared with manufacturing sector (1999)

2.8 Allocation of individual industries to service groups

2.9 Shares of the volume of service-sector work by service category (1999)

2.10 Volume of work in the various service categories per individual of working age in hours per week (1999)

2.11 Employment rates in the various service categories (1999)

2.12 Profiles of EU service economies

3.1 Concentration of employment and non-standard employment by sector (1999)

3.2 Decomposition of the percentage point change in the proportion of non-standard workers by country (1994 to 1999)

3.3 Top five sectors contributing most to net new jobs (1994 to 1999)

3.4 Top sectors contributing most to new entrants (age twenty-five to fifty-nine) to employment and the contribution of non-standard work from men and women (1998 to 1999 average)

4.1 Correlations between income inequality (1994) and weekly volume of work in services per head of population of working age (1999)

4.2 Annual working time, employment rates and productivity in selected OECD countries (1999)

4.3 Actual and preferred employment rates and work volumes per person of working age in hours per week EU $15+$ Norway (1998)

5.1 Average weekly working hours of male and female employees in EU member states

5.2 Employment and part-time rates for men and women in EU member states (2000) 


\section{xiv Illustrations}

5.4 Women and service employment in EU member states: comparison of the use of various indicators

5.5 Gender segregation by industrial sector in EU member states

5.6 Women's presence in each occupational group by country (2000)

5.7 Working times in manufacturing and services (1999)

5.8 Part-time rate and women's employment in the service sector

5.9 Country typology based on differences between men's and women's working hours and women's employment rate

5.10 Women's employment and the extent of social services by country group

5.11 Actual and desired female employment rates in fifteen EU member states (1998)

6.1 Residential and home care services for older people by country

6.2 Schematic summary of the legal obligations and rights in the state eldercare policy of the EU member states

6.3 Main strategies undertaken in order to cope with the growing demand of home care services and cost constraints, case studies

6.4 Women's employment patterns in the countries in the study

7.1 The hospitals investigated

7.2 Weekly working time for full-time personnel in the health service

7.3 Part-time rate among employed nurses and midwives at national level (men and women)

7.4 Part-time rates among midwives, nurses, and nursing auxiliaries in obstetrics departments

7.5 Part-time rate among nursing staff in orthopaedic departments

7.6 Managing the labour shortage: the solutions adopted in the case studies

8.1 Share of IT in total labour force, employment growth in IT and size of firms (NACE 72)

8.2 Employment in the IT sector (NACE 72) and the total labour force by gender, age, distribution of educational level and position in the labour market (1999)

8.3 Labour force in the IT sector (NACE 72) and the total labour force by (long) working hours, working time and labour contract (1999)

9.1 Proportion of part-time employees in the retail trade (1996, 1999) and of salespersons 
9.2 Breakdown of part-time employees in the retail trade by short weekly working hours (1999)

9.3 Proportion of workers under age twenty-five (1996 and 1999)

9.4 Proportion of students and pupils as percentage of the labour force

9.5 Job tenure in the retail trade as compared to all sectors (1999)

10.1 Temporary and permanent employment in the banking industry

10.2 Duration of actual average weekly working time of financial intermediaries

10.3 Proportion of full- and part-time employees in the banking industry by sex

10.4 Opening hours of retail branch offices 248

10.5 Service times of call centres 248

10.6 Forms of internal flexibility 253

13.1 Net trade union densities by major economic sectors $\quad 318-19$

\section{Box}

1.1 The NESY case studies $4-5$ 


\section{Contributors}

Dominique Anxo is Co-director of the Centre for European Labour Market Studies (CELMS) and Professor at the Department of Economics and Statistics at the University of Växjö. His research interests fall broadly into the areas of labour economics and industrial relations, gender and time allocation studies, and evaluation of employment policy.

Christophe Baret is Professor of Management Sciences at the Institute of Business Administration, University Nancy 2, France. His major research interests include international comparative studies of human resources management practices in services.

Gerhard Bosch is Professor of Sociology at the University Duisburg-Essen, and Vice-President of the Institute for Work and Technology. He is an expert on labour market policy, working time and employment policy.

Jon Erik Dølvik is a sociologist, and Research Director of Fafo, Institute for Labour and Social Research, Oslo, Norway. His major research interests include international comparative studies of employment relations and labour market governance.

Colette Fagan is a sociologist and Co-director of the European Work and Employment Research Centre at the University of Manchester, UK. Her major research interests include international comparative studies of gender relations, employment, working time and public policy.

Jean Gadrey is Emeritus Professor of Economics at the University of Lille (France). His major research interests include international comparative studies of the so-called service economy and service society, including comparisons of productivity, employment and work, and the main 'societal' characteristics in which economic variables are embedded.

Thomas Haipeter is an economist, and Researcher at the Working Time and Work Organisation Research Unit at the Institute of Work 
and Technology (Institut Arbeit und Technik, IAT), Gelsenkirchen/ Germany. His major research interests include industrial relations, organisational developments and qualification.

Florence Jany-Catrice is an economist, Assistant Professor and Researcher at the CLERSE-CNRS, Lille/France. Her major research interests include international comparative studies of levels of employment in service economies, including quality of work and gender issues.

Steffen Lehndorff is an economist and Director of the Working Time and Work Organisation Research Unit at the Institute of Work and Technology (Institut Arbeit und Technik, IAT), Gelsenkirchen/Germany. His major research interests include international comparative studies of employment and working-time structures and regulation, and of working time, work organisation and industrial relations in services and manufacturing.

Martine Pernod-Lemattre is Lecturer at the University of Science and Technology of Lille I and member of the laboratory Centre Lillois d'Études et de Recherches Sociologiques et Économiques, CLERSÉ, Lille/France. Her major research interests include employment and work in the service sector.

Janneke Plantenga is an economist working at the Utrecht School of Economics in the Netherlands. Her major research interests include international comparative studies of employment and working-time structures, social security and the reconciliation of work and family life. She is the Dutch member and co-ordinator of the EU Experts Group on Gender, Social Inclusion and Employment (EGGSIE).

Chantal Remery is a sociologist employed as a researcher at the Utrecht School of Economics. Her areas of interest include gender, ageing, flexibility issues and personnel strategies.

Jill Rubery is Professor of Comparative Employment Systems at the Manchester Business School, University of Manchester. Her research focuses on the interdisciplinary comparative analysis of employment systems, including the organisation of internal labour markets, wage structures and payment systems, working-time arrangements and welfare systems. She has a particular interest in the role of gender in the shaping of labour markets, and is co-ordinator of the European Commission's expert group on gender and employment.

Mark Smith is a lecturer in employment studies at the Manchester Business School and a member of the European Work and Employment Research Centre, also in the University of Manchester. He has research interests in working time, women's employment, family-friendly work and new working patterns. He has co-authored two books as well as a 


\section{xviii Contributors}

number of book chapters and journal articles on working time, atypical work and women's employment.

Dorothea Voss-Dahm is an economist and researcher in the Working Time and Work Organisation Research Unit at the Institute of Work and Technology (Institut Arbeit und Technik (IAT)), Gelsenkirchen/ Germany. Her major research interests include changes of employment systems, in an international comparative perspective in general, and work organisation and working-time policy in the service sector in particular.

Alexandra Wagner is a social scientist and managing director of the FIA Forschungsteam Internationaler Arbeitsmarkt (International Labour Market Research Team) located in Berlin. Her major research interests include studies of working-time structures and regulation of working time as well as studies on labour market and labour market policy. In both fields questions of gender differences are one of the major subjects.

Jeremy Waddington is Professor of Industrial Relations within the People, Management and Organisations Division of the University of Manchester, and Project Co-ordinator for the European Trade Union Institute, Brussels, Belgium. His major research interests include international comparative studies of trade union structure, organisation and activity, together with studies of the development, operation and functioning of European Works Councils. 


\section{Acknowledgements}

This book is based on the results of a research project entitled 'News Forms of Work in the Service Economy' (NESY), which was conducted from 1999 to 2001. The project was implemented on two levels. On the macro level, it focused on the changes in employment structures connected with the process of tertiarisation. On the micro level, it examined changes in work organisation and working time in five service industries. The project covered ten European Union countries, namely Belgium, Denmark, Finland, France, Germany, Italy, the Netherlands, Portugal, Sweden and the United Kingdom.

The authors would like to express their thanks to all thirty researchers who contributed to the success of the project. We also thank the EU Commission, Directorate General Research, for financial support, and in particular Ronan O'Brien, who supported our project and helped us in many ways. Last but not least, we are grateful to the many managers, workers' representatives and employees in service organisations all over Europe who gave up time for our research.

We have enjoyed the collective work process both in the course of the project and in the production of the present volume. We would like to thank each contributor for their efforts and patience. Many thanks also to Andrew Wilson from Manchester, who provided translation services to his usual high level, to Sandra McIntyre from Los Angeles, who took care of the editing process with great meticulousness, and to Terry Clague and Robert Langham at Routledge who, in managing the production of the book, proved to be wonderfully supportive and cooperative. 



\title{
1 Introduction \\ Service economies - high road or low road?
}

\author{
Gerhard Bosch and Steffen Lehndorff
}

Fourastié, writing in 1949, heralded the transition from the industrial to the service society as the great hope of the twentieth century. After a long period of economic crisis and social conflict, the advent of the service society would, he argued, usher in a period of economic, social and political stability. The 'hunger for services' was insatiable, so that all workers who lost their jobs as a result of structural change would find new and possibly even better employment. For many other observers as well, services were the better activities. They came to be associated with more pleasant working and employment conditions, such as higher pay, a clean work environment, fewer stresses and strains, greater opportunities for employee participation or higher qualification and skill requirements. Furthermore, they were said to offer women better employment opportunities and to be 'intended to produce benefit or well-being for the recipient, either affectively or cognitively' (Gartner and Riessman 1974: 33). Daniel Bell (1973: 15) made a distinction between conventional services, such as retailing, transport and banking and finance, and postindustrial services, such as health, education and research. He predicted that the latter would grow particularly strongly, and with them the qualifications and skills of the new technical elites.

The academic debate on working and employment conditions in service activities reflected the spirit of the times in the period following the Second World War. Many generations of industrial workers hoped that their children would have a better future and supported them as they moved into service occupations, which they saw as a form of upward social mobility. The image of service work has now become tarnished to some extent. That many service jobs are poorly paid and offer no promotion opportunities or security of employment are facts that cannot be ignored. The industrial age of mass production, which many industrial workers were all too keen to leave behind them, is now even glorified as a 'golden age' because of the full employment that then prevailed. This of course ignores other, less appealing characteristics of that period, such as the inherent rigidity of the Taylorist mode of work organisation, which offered workers virtually no scope to influence working practices, or the 
physical arduousness of manual work, which meant that many workers did not reach the normal retirement age.

Idealisation of the past makes it easier to dramatise the anticipated break in a previously continuous process of industrial development. Many authors today associate the transition to the service economy with the beginning of a period of uncertainty and instability arising out of the destandardisation of employment relationships. Such destandardisation seems almost to arise out of the vary nature of services and of a society organised around their production, which marks a profound break with the era of industrial mass production. Differentiated consumer expectations have made customer orientation the key element around which the successful organisation of service activities revolves. Personnel flexibility not least with regard to working hours - is said to lie at the heart of this customer orientation. However, as a result of greater differentiation of personal situations, employees' expectations of their working and employment conditions have also become considerably more individualised compared with the relatively homogeneous set of employee interests that were regarded as a typical feature of the large-scale factories of the twentieth century.

In the light of this differentiation, the standard forms of regulation governing employment and working conditions that emerged in the industrial age are assumed no longer to exist, or at least only in considerably attenuated forms. Full-time employment for life, with stable companies and regulated labour markets protecting workers from the risks of the market, is said to be a remnant of the long-lost 'golden age' of industrial capitalism in the decades after the Second World War, and one that is doomed to extinction. Castells, for example, forecasts that 'the traditional form of work, based on full-time employment, clear-cut occupational assignment, and a career pattern over the lifecycle is being slowly but surely eroded away' (Castells 1996: 268). Carnoy et al. (1997) see traditional employment forms being replaced by 'human capital portfolios'.

Ultimately, this raises the question of what place there will be in the world of work of the future for uniform labour standards, whose function is to take the establishment of basic employment and working conditions for all employees out of the sphere of competition and market processes, thereby 'decommercialising' (Briefs 1927) or 'decommodifying' (Polanyi 1957) labour. At the macroeconomic level, labour standards are regarded as virtually an obstacle to raising the employment rate to the USA level. The message of many mainstream examinations of the service society is that a highly developed service sector is not compatible with rigorous labour standards. Rather, such tertiarisation requires the acceptance not only of differentiation but also of a polarisation of employment and working conditions. The choice, it is argued, is between high unemployment in Europe or high inequality in the USA. 
In this way, the demand for a stronger service sector is surreptitiously taking on the status of a programme with wide-ranging implications. It is becoming nothing less than a vehicle for a levelling of the institutional differences between the various forms of capitalism, which in turn suggests that the social compromises of the twentieth century are fragile. Ultimately it has to be decided whether structural change is forcing very different national employment models to converge towards a single competitive model characterised by high levels of inequality or whether service work, like industrial work before it, can be organised in different ways with similar levels of economic success. Both development paths bring into play the relationship between labour and product markets. On the so-called 'high road', there is a positive reciprocal relationship between the manufacture of quality products, high service quality and good employment conditions, such as reasonable pay, good social protection and high skill levels. This development path is underpinned by institutions that open up longer term investment prospects in both markets. On the 'low road', a vicious circle is created by the combination of shorttermism in the markets, encouraged by a weak institutional framework, and poor working and employment conditions (Sengenberger and Campbell 1994).

In order to break away from deterministic convergence theories and the associated 'certainties' about future development, it is necessary to examine the differences in the development of employment and work in services in different countries and in different industries, and to identify the causes of this diversity as well as any possible opportunities for alternative development paths. The aim of our EC-funded project on new forms of work in the service economy (NESY), the results of which are presented in this volume, was to contribute to this effort. The project was intended to provide answers to the following three questions:

1 Must we really accept greater social inequality in order to extend the service sector or is the so-called 'high road' development path a real option?

2 Does an increase in service activities necessarily go hand in hand with the destandardisation or even polarisation of employment and working conditions?

3 Are service societies and service work converging towards a single, uniform model?

Since the theories alluded to above concern both the macro and micro levels, analyses at both levels are required. Our project was in fact characterised by precisely this combination of macro- and micro-level analysis. The macro-level analyses will be found in Part I of the book. At the micro level, case studies on the organisation of service work were carried out in various industries. In order to obtain as broad a picture as possible of the 
reality of service work, a distinction was made between well- and poorly paid jobs in both old and new and public and private services. Case studies were carried out in five different industries in a total of ten countries, although not all the industries were investigated in all countries (see Box 1.1). Individual teams report on the results of the country studies in a total of five comparative industry studies in Part II of the book. Part III, finally, takes up several cross-cutting themes which emerged from the case studies in the five industries and that were addressed in the industry studies.

Box 1.1

The NESY case studies

- Home care for the elderly: Country reports on Finland (Timo Anttila and Jouko Nätti), Sweden (Dominique Anxo and Håkan Nyman), Denmark (Agi Csonka and Joachim Lynggaard Boll), the UK (Colette Fagan and Darren Nixon), the Netherlands (Janneke Plantenga, M. van Everdingen and Chantal Remery) and Italy (Petra Degasperi and Paola Villa). Two local organisations providing home care for the elderly were surveyed in each country. Dominique Anxo co-ordinated the research and compiled the summary report together with Colette Fagan.

- Hospitals: Country reports on Sweden (Dominique Anxo and Håkan Nyman), the UK (Jill Rubery, Mark Smith and Marilyn Carroll), the Netherlands (Janneke Plantenga and Chantal Remery), Belgium (Robert Plasman and Julie Lumen), France (David Piovesan) and Italy (Paola Villa and Elisabetta Zeni). The research teams in each country conducted surveys in two public hospitals and more specifically in two departments: gynaecology and obstetrics, and orthopaedics. The population surveyed was that of medical care staff other than doctors (i.e. nurses, nursing assistants and midwives). The summary report was compiled by Christophe Baret, who also co-ordinated the research.

- IT services: Country reports on Finland (Timo Anttila and Jouko Nätti), Denmark (Agi Csonka and Joachim Lynggaard Boll), the UK (Mark Smith), the Netherlands (Janneke Plantenga and Chantal Remery) and Germany (Dorothea Voss-Dahm). In each country, the IT companies studied all had their core business in the field of systems development, analysis and software services. The case studies included small as well as large IT firms. In four countries, we had access to the same global company. The summary report was compiled by Janneke Plantenga and Chantal Remery, who also co-ordinated the research. 
- Retail trade: Country reports on Finland (Timo Anttila and Jouko Nätti), Sweden (Dominique Anxo and Håkan Nyman), Denmark (Joachim Lynggaard Boll), Germany (Thomas Haipeter), France (Florence Jany-Catrice and Martine Pernod-Lemattre) and Portugal (Alberto de Castro, Hugo Figueiredo and Pilar González). Two case studies were carried out for each country, one in a hypermarket and self-service supermarket and one in a clothing store; these included two European clothing chains. Steffen Lehndorff co-ordinated the research and compiled the summary report together with Florence Jany-Catrice.

- Banking: Country reports on Germany (Thomas Haipeter) and France (Martine Pernod-LeMattre, François-Xavier Devetter and Florence Jany-Catrice). Thomas Haipeter and Martine PernodLemattre compiled the joint summary report. Two banks were examined in each country, each one represented by one high street branch and one telephone banking service.

The results of the case studies are documented in Mermet and Lehndorff (2001).

Our aim in this introduction is to outline the most important findings contained in the various contributions to the book and to explain how they help to answer the three questions that formed the starting point for the project.

\section{Different service societies in Europe}

'Even in an optimistic forecast, it cannot be supposed that the tertiary sector will employ more than 85 per cent of the economically active population, which would leave only 5 per cent for agriculture and 10 per cent for manufacturing', wrote Jean Fourastié in 1949 (2nd German edn 1969: 113). True, more than half of all employees in European Union (EU) member states work in the service sector or in service occupations. However, Fourastié's assumed upper limit for the evolution of servicesector employment has to date not been reached by any European country, although a few countries are rapidly approaching that level.

In their first chapter, Bosch and Wagner use a number of indicators to describe the various service societies of the EU, identifying the features they have in common and the differences between them. As might be expected, the degree of tertiarisation differs considerably, not only in sectoral but also in functional terms, although the differences are greater than anticipated. The rapid growth of functions such as design, research and development, marketing and customer services means that the 


\section{G. Bosch and S. Lehndorff}

volume of services produced within manufacturing industry is also increasing. However, the differences in the shares of service activities depending on whether a functional or sectoral viewpoint is adopted are greater in some countries than in others. This is due to differences in the industry and product mix, and in country-specific forms of the division of labour within and between firms.

The two indicators of tertiarisation mentioned so far take account solely of the number of employees. Yet similar employment rates may conceal different volumes of paid service work, since the shares of parttime employment in the service sector and full-timers' working hours vary from country to country. In order to clarify these differences, Bosch and Wagner introduce a new indicator into the debate, namely the volume of service work per economically active person. This indicator makes clear the considerable differences among countries in the degree of tertiarisation. Thus in Denmark, the country with the highest value for this indicator, the volume of paid service work, analysed in sectoral terms, is around 50 per cent greater than in Italy, the country with the lowest value. Even within the EU, therefore, service societies differ considerably.

How can such differences between countries be explained? The theories advanced to date, which have tended to be universalistic in character, have adduced differences in levels of economic development as the main reason for national differences in service sector development. It is assumed in these theories that, as incomes rise, employment shifts towards services, due to both the positive demand and the productivity bias (Klodt et al. 1997; Anxo and Storrie 2001: 27). The positive demand bias means that, as household incomes rise, a growing share of that income is spent on services, once basic needs have been met. Fourastié spoke of an 'insatiable need for the tertiary' (1969: 112), which develops when the basic needs for food and manufactured goods have been satisfied. At the same time, since service activities are less easily rationalised than agriculture and manufacturing, the productivity bias works in favour of service employment. Those who take an optimistic view of economic growth have not tended to regard the lower productivity increases associated with increases in the relative cost of services as an impediment to growth. Finally, reductions in the price of food and manufactured goods free up purchasing power for services. Since demand for services really takes off when the other basic needs have been met, they are to some extent luxury items that cannot be afforded until a certain level of prosperity has been attained and which themselves help to improve well-being.

This optimistic view of the future evolution of services has now become considerably more troubled. At a very early stage, Baumol (1967) advanced the notion of a 'cost disease' afflicting services, which are labour-intensive and resistant to rationalisation, particularly when wage increases in the service sector keep pace with those in the more easily rationalised manufacturing sector. Since the services in question were 
primarily public services, which in the USA are provided by municipal and other local authorities, he forecast that city finances would enter a period of crisis, a prophecy that was later to come true. Apart from Baumol himself, many economists have subsequently suggested that this obstacle to growth could be overcome to some extent by greater wage differentiation, particularly low pay rises in labour-intensive services. Gershuny (1978), on the other hand, saw higher price rises for services as a reason to substitute industrial products for services and to develop a self-service economy.

Both the optimistic and pessimistic visions of the service society shared a universalistic approach that has only been challenged in recent years. Esping-Andersen (1990) identified various types of welfare state. Depending on the welfare state regime and household structures, personal and social services in advanced societies can be provided within the family, either via the market or by the state. The convergence that the universalists argued would take place as prosperity increased was thus called into question, with the co-existence of different types of service society being regarded as possible.

In their second chapter, Bosch and Wagner tap into these theoretical debates to develop a multi-dimensional explanatory model of the development of services that also makes it possible to go beyond the nature of the welfare state regime in interpreting national differences. To this end, they examine the influence of a wide range of factors on service employment by correlating the volume of work in services as a whole and in individual subgroups with various influencing factors. They show that the transition to knowledge-intensive, high-quality production in the manufacturing sector is one of the most significant forces driving the growth of businessoriented services, that shorter working times in service activities increase the employment intensity of growth and that many EU member states have specialised in the international division of labour and are exploiting their comparative advantages. Probably the most striking correlation is that between women's employment and social services. The outsourcing of services from households is one of the most important sources of growth in social services. However, many of these social services suffer from cost disease because they are highly labour-intensive yet, because of their paramount importance in the formation and maintenance of human capital, they cannot be left entirely to the market. Without accepting a loss of social cohesion and capacity for economic development, the state cannot allow such services to be unavailable to large numbers of its citizens on cost grounds. Consequently, various instruments have been put in place to ensure that all citizens can avail themselves of such services. They range from the provision of services free at the point of delivery via social security to support for low-income households. Service quality, employees' working conditions and the possibilities for expansion are all strongly linked to the definition of public goods and the level of social 
expenditure, and ultimately, therefore, as Gershuny (1978: 91) has pointed out, to political decisions.

Probably the most surprising finding of the empirical analysis is the negative correlation between the level of service employment and high income differentiation. Up until now, the high income differentiation and social inequality that characterise the USA have been regarded as the price that has to be paid by countries seeking a similar employment dynamic and the same high employment rates as the USA. The fact that countries such as Sweden, Denmark, Norway and Finland have employment rates similar to those in the USA, but with less social inequality, has been ignored. Because working times are longer, similar employment rates in the USA conceal the existence of a significantly larger volume of work. The high-volume service economy in the USA, in which economic pressures force every economically active individual to offer more hours' labour than in the EU, requires the weakening of all institutions, such as the welfare state and trade unions, that restrict the supply of labour. On the other hand, the shorter working times in many European countries permit a combination of high employment rates and a highly developed self-service economy.

The principal aim of the first two chapters was to describe and explain the different level of service employment in Europe. Mark Smith (Chapter 3 ), for his part, is concerned with the dynamic of employment growth in Europe in the 1990s. He shows that in all EU member states service industries made the greatest contribution to employment growth, not only among women but among men as well. Only in a few countries (e.g. Italy or Portugal) did the top five job-creating industries include activities other than services, such as construction. The industries in which job creation was strongest were health and social work (NACE 85), business services (NACE 74), education (NACE 80) and computer and related activities (NACE 72). Next in line were retailing and hotels. Thus the growth areas included both high valued-added, well-paid activities, such as business services or computer and related services, and low valued-added, poorly paid activities. True, low valued-added activities offer good employment opportunities for new labour market entrants, but they hold out little prospect of promotion and, above all, little in the way of job stability. This is illustrated by the fact that the retail trade is included among the top five only if the analysis of job creation is based on the number of new entrants or returners to the labour market, that is, on the short-term employment dynamic. If it is based rather on the net job increase over the medium term, then IT services replaces retailing in the rankings.

Smith further investigates whether the growth of services is connected with the increase in non-standard employment forms. Here, too, there are striking differences between the countries. In countries with high levels of non-standard employment forms, such forms are found throughout the economy and not just in services. Moreover, the share of non-standard 
employment forms is not increasing in all countries. In the Scandinavian countries, for example, the share of part-time workers has been declining for a number of years. With such heterogeneous patterns of development, therefore, there can be nothing in the nature of services themselves that might account for the high share of temporary and part-time employment in service activities, as is frequently argued in the literature (Townsend 1995: 15).

One reason for the different levels of temporary employment is differences in national labour standards and forms of labour market regulation. The greatest differences between countries in the level of service employment and in the most widely used forms of employment are to be observed among women. In her chapter on services and employment prospects for women (Chapter 5), Alexandra Wagner shows that part-time employment among women depends not only on the degree of equality women enjoy in working life but also on national approaches to the work/life balance. True, part-time rates are higher in services than in manufacturing in all EU countries, and the overwhelming proportion of new jobs for women are part-time. However, it cannot be assumed that a triangular relationship between services, part-time work and women's employment exists in all countries. Service work is not necessarily parttime work, as is proved in the industry studies in Part II of this volume, nor is women's work necessarily part-time work. However, institutional arrangements in the labour market, as well as tax, social and family policy, can offer strong incentives for women to opt for either full-time or parttime employment. Of particular significance are, first, the level of childcare provision and the length of the school day, second, incentives in tax and social security systems that support either the classic single male breadwinner model with derived social security entitlements or more egalitarian forms of the gender division of labour and, finally, the level of women's pay relative to that of men. The whole set of institutional incentives and the underlying notions of men's and women's roles in society have given rise to various models of the gender division of labour, which Wagner typologises, drawing on the work of Rubery et al. (1999) and Fagan (2001). These models are linked not only with different employment forms for men and women but also with differences in the size of the service sector.

Certain employment policy conclusions may be drawn from the results of the four macro-level studies in the first part of the book. The EU's ambitious goal of raising the employment rate within the Union to 70 per cent by 2010 will not be achieved with simple remedies, such as wage differentiation. Countries with a more evenly balanced earnings structure, such as the Scandinavian countries, have the highest employment rates in Europe and have already exceeded the EU target figure. This is expressly referred to in the interim report on implementation of the EU's employment strategy (Employment Taskforce 2004). Moreover, the share of 
non-standard employment forms is declining in these countries, and in any event part-time work has long been coupled with high levels of social protection in the Scandinavian countries and has become a normal part of individuals' employment histories, increasingly in alternation with fulltime employment.

In other countries, particularly the continental and Southern European countries, the greatest potential, in addition to specialisation in the international division of labour, lies in the development of women's employment and in innovation policy. If such an approach is to bear fruit, knowledge-intensive manufacturing has to be encouraged and the quality of service provision ensured. Overcoming the cost disease that afflicts important social and personal services through the introduction of new welfare state instruments is a valuable starting point. The social sphere is not an obstacle to but rather a possible source of economic development.

As knowledge plays an increasingly important role in economic development, services that help to develop and maintain human capital have become a focus of attention. The main activities involved here are education, training, health and care services. Making explicit reference to the increasing importance of human capital in member states' economic development, the OECD and EU, for example, have begun to compare and assess education systems and to make recommendations for reform. Since high-quality social services cannot go hand in hand with low pay and unreasonable working conditions, the debate on wage inequality is beginning to shift somewhat.

As a result, increasing attention is being paid to the quality of service jobs. This is the theme of the industry studies that make up the second part of the book.

\section{The different worlds of service work}

In their traversal of the different worlds of service work at company level, the industry teams used common guidelines to investigate the demands the market typically makes on organisations in the five industries, the characteristics of work organisation, employment and working time structures and industrial relations. The industries selected for investigation could not be more different from each other with regard to work requirements and employment forms and conditions. The retail trade, on the one hand, and IT services, on the other, represent the two poles of service work, namely 'simple' services and 'knowledge-intensive work'. Two further areas - customer services in banking and hospital nursing - represent classic service activities with intermediate skill levels, while home care services for the elderly are an example of a relatively new service activity in which an occupational labour market is rapidly gaining in importance. Thus constituted, our sample enabled us to identify the major, contradictory trends currently operating in service work: standardisation and 
responsiveness to individual customer preferences, self-organisation and 'Taylorisation', deskilling and professionalisation. The only characteristic shared by the five service activities investigated is that they all involve 'front-line work'. Since such work is 'people-centered, albeit frequently mediated by technology', it encompasses interaction with customers in the creation of the end-product (Frenkel 2000: 469).

When we set about analysing the five activities, we agreed on an analytical framework that facilitated the task of identifying the factors shaping work in the five industries in our sample. Our aim was to take account not simply of industry effects but also of a wide range of societal influences (Maurice et al. 1986). Figure 1.1 shows one of the ways of describing this framework. Let us look briefly at the four spheres of influence, beginning top left and proceeding in a clockwise direction.

First, the nature of the product and the specific characteristics of the market in which that product is offered are crucial factors in shaping service work. Account has to be taken of how the product market is regulated. In more and more areas, such regulation depends on EU guidelines.

Second, service organisations operating in these markets draw on a particular supply of labour to produce their services. This brings into play labour market institutions, which directly structure and regulate the labour supply and relations in the labour market. Companies and publicsector service organisations must adjust to such institutions, but can at the same time help to change them.

Third, the recruitment of female workers is particularly important in many service industries. Consequently, the organisation of service work is

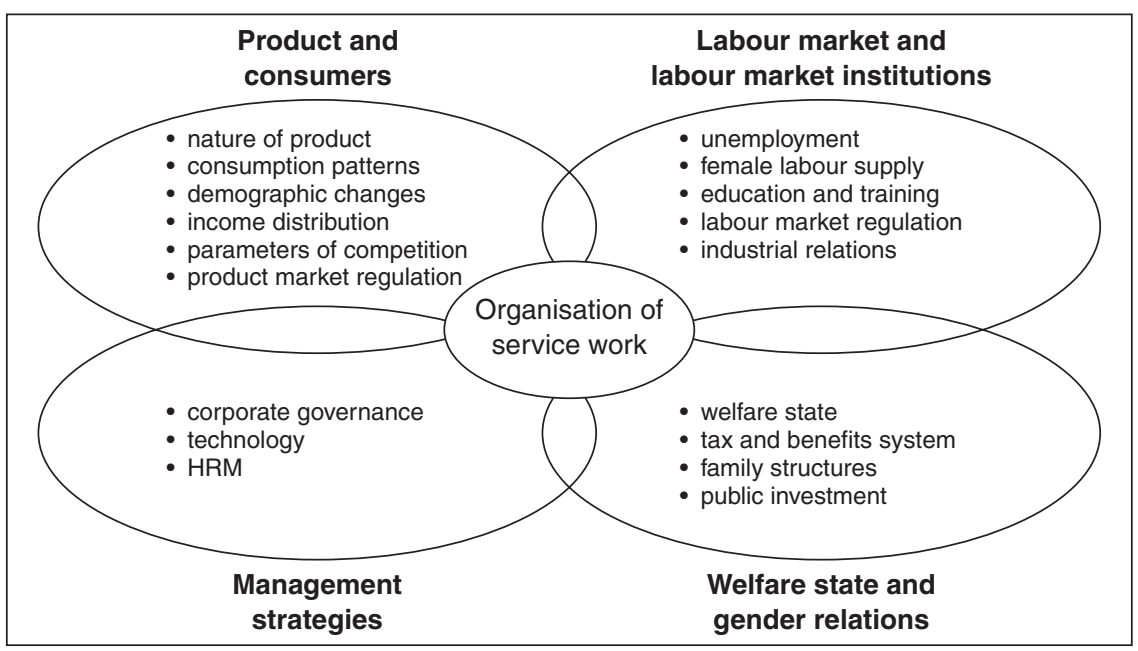

Figure 1.1 Factors influencing service work organisation (source: own representation drawing on various contributions to the present volume). 
strongly influenced by the gender relations and household structures prevailing in a given society, together with the related cultural attitudes and the type of welfare state.

Fourth, these spheres of influence do not determine, for example, the organisation of service work; rather, they influence the management policies adopted in service organisations. The way in which management processes the signals emanating from the external environment shapes the conditions under which service work is performed in these organisations.

The various spheres of influence are connected to each other. Product markets and consumption patterns are influenced by income distribution, and these in turn are shaped by labour market regulation, corporate strategies, the welfare state and other areas of state policy (Froud et al. 1997; Anxo and Storrie 2001). The labour supply depends on, among other things, demographic changes, income distribution, labour market institutions, tax and social security systems and other welfare state institutions. However, it also reacts to company personnel strategies. Another example is the role of the state, which is directly active in three spheres and at the same time restricted in its freedom of action by, among other things, the labour market, income distribution and corporate strategies. Thus there are not only one-sided dependencies between the four spheres of influence and the organisation of service work, but interdependencies as well. These are liable to change over time, which may give rise to discontinuities and to shifts in development paths.

Against this background, the five chapters in Part II seek first to identify the factors that contribute to the formation across national boundaries of typical industry profiles of service work in each of the five areas of activity. These include the competitive environment and budgetary restrictions impacting on working and employment conditions, changes in qualificational and skill requirements, employment and working-time forms and the main trends in work organisation in each of the five industries. Supermarket check-out operators in Lisbon are subject to more or less the same conveyor-belt conditions as their counterparts in Copenhagen. Nurses in Gothenburg are affected by the same cost-saving imperatives as their colleagues in Rome. Software engineers in Helsinki have to contend with markets that are just as fiercely competitive as those in which their counterparts in Manchester operate. Let us look briefly at these five service activities.

Home care services for the elderly (Dominique Anxo and Colette Fagan, Chapter 6) are emerging as a rapidly growing industry positioned between the two traditional forms of care for the elderly, namely residential care or nursing homes and privately organised care within the family. This development has gone hand in hand with a pronounced trend towards the professionalisation of this kind of care, which has led to the emergence for the first time of an occupational labour market of some 
size. In the countries investigated, the nature of home care provision has hitherto been determined to a large extent by local authorities, either as providers or as regulatory bodies. However, private providers are playing an increasing role. The boundaries between informal and professional work in this industry are still ill-defined. As a result, the professional status of employees is not unambiguous or uncontested and there is a considerable degree of diversity in both organisational structures and the forms taken by the division of labour. Home care services are only just emerging as a major industry, but this development is taking place in an environment characterised by scarce public funds, considerable experimentation with structures on both the supply and demand sides, very high labour turnover and enormous labour shortages.

Hospital nursing services (Christophe Baret, Chapter 7), on the other hand, have long been the preserve of professionally qualified staff, and the job description and work requirements are regarded as clearly defined. Nurses in hospitals provide a round-the-clock service, and the work places considerable demands on their commitment and ability to work under pressure. The need to deal with new technology and the devolvement of responsibility for budgets and work processes emphasise the increasing skill requirements, but restrictive public expenditure policies have led to staffing levels becoming one of the favoured targets of cost-reduction measures. A gulf is opening up between the responsibilities placed on nurses' shoulders and the ethos of their profession, on the one hand, and the staffing levels with which they are expected to work, on the other. This is giving rise to increasing tension in the workplace and, in some cases, to the departure of skilled workers from the sector.

Three distributive or business-oriented areas of service activity stand in contrast to these two social services. Here, too, one of them - IT services (Janneke Plantenga and Chantal Remery, Chapter 8) - is a recently established industry. This business-oriented service activity may be carried on within large-scale industrial structures but also in small, independent service organisations. Software development and support require a high degree of technical skill and autonomy in order to deal with the demands of the work. An organisational environment in which greater than average reliance is placed on 'total commitment' on the part of employees encourages the especially long working hours for which this industry is notorious, which in some cases escape all formal regulation. For some observers, this makes the sector a trailblazer pointing the way to the world of work of the future; however, it does not make it any more attractive for the new recruits, particularly women, whom the industry urgently requires in order to stabilise its long-term development.

Sales work in large retail stores (Florence Jany-Catrice and Steffen Lehndorff, Chapter 9) constitutes the opposite pole to IT services, the flagship of the new economy, and is regarded as a standard example of 'simple', poorly paid service work. Work in this large-scale business, 
exposed to intense price competition, is largely the preserve of women in the low and intermediate qualification/skill segment. There is a great demand for time flexibility in the industry, which has played a leading role in the expansion of part-time work. The rationalisation of goods management and branch organisation is strongly influenced by Taylorist models, with the result that standardised activities organised around a highly detailed division of labour play a major role and the fragmentation of employment and working times is proceeding apace. At the same time, however, sales staff in large retail outlets have increasingly to ensure that the goods management system is functioning smoothly and to know where and when they are needed, in order to prevent customers from drifting over to the competition. They have to manage this against a background of extremely tightly calculated staffing budgets and are therefore doing a job that may be described as 'simple' service work only with reservations.

Customer services in high street banks (Thomas Haipeter and Martine Pernod-Lemattre, Chapter 10), on the other hand, have traditionally been associated with a high share of full-time employment and high skill and qualificational levels. Here, too, however, nothing is the same as it once was. The banking industry is undergoing radical change and new areas of activity such as call centres are calling into question the job profile normally associated with customer services. Bank employees are no longer 'counter clerks'. Rather, they are becoming entrepreneurs within the company, making appointments with their customers and submitting offers to them. Their careers depend on the volume of sales they make to these customers. At the same time, routine mass business is being increasingly differentiated from customer advice services, which in turn is leading to the emergence of more sharply contrasting working time and employment structures.

However, over and above such industry-wide characteristics, pronounced differences between countries and their national profiles may be discerned.

Let us begin with the retail trade. When French researchers investigate retailing in their own country, they assume - quite naturally of course that the retail trade is dominated by part-time employment. From the perspective of their German or Danish colleagues, however, the French retail trade seems to be characterised rather by full-time employment, since retailers in France are encountering considerable resistance in the labour market to their objective of expanding part-time employment. True, the part-time rate is increasing everywhere, but at very different levels. If German or Danish researchers investigating the retail trade had believed that very short, fragmented working times were virtually a law of nature in a mass-market service industry characterised by very high time flexibility requirements and intense price competition, then the large firms in the highly rationalised and relatively profitable French retail sector, in which part-time rates are only half those in Germany and 
Denmark and part-timers in any case work considerably longer hours, pose a number of riddles.

Such differences in national profiles are not confined to the retail trade. Part-time rates in hospitals, for example, differ from country to country in very much the same way as they do in retailing. In this case, however, the differences are associated with very different management strategies. In some countries, retail managers complain that part-time rates are too low. Hospital managers, however, are trying to prevent trained nurses, who are in any case in short supply in the labour market, from opting to work part-time. Their efforts have met with only limited success, since the differences between countries with high and those with low part-time rates persist. And in the banking industry, where market strategies are increasingly geared to globalised financial markets, comparison of France and Germany reveals considerable differences in personnel strategies. German banks rely to a greater extent than their French counterparts on their employees' functional flexibility, since they are able to draw on a more highly developed system of vocational training.

We also encountered differences in employment structures caused by the level of professionalisation in home care services and the use of outsourcing in such disparate sectors as care of the elderly and IT services. Tasks that, in a Finnish software project, are performed as a matter of course within the team tend in the UK to be outsourced to external oneman companies. British and German software engineers also seem to be equally prey to the notion that it is impossible to survive in the industry without working long hours every week. Hence, during the dot-com boom, they could be presented in the media as the protagonists of the world of work of the future, so committed to their professional goals that they would even, when necessary, set up a camp bed next to their computers. In contrast, the working time structures of Finnish software engineers differ much less from the average for the service sector as a whole in Finland, where IT projects are planned on the assumption that the specialists charged with implementing them will not work on average much longer than forty hours per week. Are Finnish software houses perhaps operating in a less intense competitive environment, while collective agreements and health and safety legislation are 'necessarily' becoming obsolete for their German or British counterparts? In view of the fact that the Finnish IT industry is a world leader, this would seem unlikely.

The industry chapters provide an initial answer to the question posed at the beginning, namely whether the increase in service activities automatically goes hand in hand with the destandardisation or even polarisation of working and employment conditions. As the overlapping industry and country profiles show, it is only under certain political and institutional conditions that service work is associated with increasing social inequality and the polarisation of employment conditions and of employment and working time forms. Even the differentiation of employment and working 
time forms does not in itself tell us very much about the extent of the decline in standardised working and employment conditions. Part-time work, for example, can be both poorly paid, second-class work offering little in the way of social protection and a temporary option that is part of the normal employment history. Finally, it is clear that working and employment conditions can also be destandardised from within, for example, through increases in working time, even when the standard employment relationship remains apparently unchanged. Whether or to what extent the standard employment relationship is being eroded in what might be called a process of 'internal recommodification' also depends on politics, policy-making and institutions. It is precisely these overlapping processes and the forces they generate and that also act upon them that are the focus of the cross-cutting analyses in Part III of this book.

\section{Institutions matter}

The four chapters in the final part of the book are concerned with the changing employment relationship in service activities, with the establishment of external and internal markets as instruments for the control of service work, with the difficulties facing trade unions in the private service sector and with the regulation of product and labour markets in services. The various chapters investigate the empirical material from different perspectives. However, they do have one common denominator, in that they all show how much the link between job quality and service quality is influenced by the institutional environment in which service work is performed.

Drawing on the empirical material gathered in the course of the project, Jill Rubery (Chapter 11) analyses the fundamental change in the employment relationship that is becoming apparent in service activities. To this end, she embarks on a thoroughgoing reformulation of labour market segmentation theory. The particular value of this approach for our investigation is that it offers an explanation for the differentiation of working and employment conditions and of job quality. The starting point for her analysis is the central role that organisations play in shaping work and structuring labour markets. And since the analysis includes a comparison of different countries, the influence of the outside world on organisational structure and policy is also brought into play. Welfare state regimes, product and labour market regulation and changes in the conditions and forms of competition all impact upon organisations. In many service industries, privatisation policy plays a key role. Consequently, the balance of power between employers and dependent employees, which lies at the heart of the employment relationship, is to a large extent 'shaped by both the societal system and by the new strategies of competition'. And yet the influence of the outside world on the interior world of organisations is always mediated by management actions. Thus organisations can take 
advantage of changes in competitive conditions in order actively to pursue changes in the internal balance of power. Furthermore, large organisations can bring their influence to bear in order to change the institutions and competitive conditions in their external environment in such a way that they can be used to reshape the employment relationship and give greater control to management and owners. Consequently, even seemingly well-entrenched development paths via the 'high road' are repeatedly being called into question and even 'good jobs' are constantly under threat.

This analysis of the forces that influence the organisation and structuring of work stands in sharp contrast to the extensive literature on best practice in organisations which, by creating local win-win situations, have improved both working and employment conditions and operating profits. Such win-win situations certainly exist, but it is debatable whether they can realistically be expected to exert much influence on the overall development of entire service industries. Whether or not practices that combine good working and employment conditions with good service quality can establish themselves in the market will not be decided solely by the play of competitive forces. Rather, Rubery regards a 'strong institutional environment' as necessary

to push most organisations in a similar direction.... The analysis presented suggests that there is a need for re-regulation rather than deregulation if we want to improve the ability of organisations to pursue the type of high road employment and product strategy necessary to secure both European competitiveness and European living standards within the new service economy.

In both its analysis and conclusions, Rubery's chapter sets out a critical counter-argument to the mainstream notion that, ultimately, everything is best regulated through the market. Other contributions to the book also draw attention to the consequences of a perspective and approach in which the market mechanism is seen as the highest animating or controlling principle, one that can be universally applied to the delivery of both private and public services. This is the perspective from which Steffen Lehndorff and Dorothea Voss-Dahm investigate the changing employment relationship in service activities. In this chapter too, the main concern is to analyse the connection between the inner world of service organisations and their external environment. Competition in product markets, which has been created in part by politically inspired deregulation, is being brought to bear by management on the inner workings of service-providing organisations. This trend is by no means specific to services. The just-in-time principle adopted in the automobile industry, for example, is a manifestation of the same thinking, with cars and components being produced directly to order. Like their counterparts in 
manufacturing, service workers are not being confronted directly by market competition but rather by economic and financial indicators and other targets, which senior management derives from its interpretation of market processes. However, many service workers deal directly with customers, with the result that they frequently find themselves stuck between a rock and a hard place, with customers on one side and the financial indicators expressing corporate business targets on the other.

However, it is not simply pressure from the product market that is being brought to bear on organisations. An important role is also being played by the increase in external personnel flexibility as a result of the extended use of so-called non-standard employment forms which can make a significant contribution to the 'opening-up' of service organisations. External and internal personnel flexibility are not alternative options; rather, management can exploit the interaction between the two. Thus the internalisation of external pressures can bring about radical changes within the standard employment relationship. The results-driven approach is increasingly placing dependent employees - from software engineers via care assistants to sales assistants in the retail trade - in a situation in which they themselves have to secure their jobs through careful self-management. The shaping of organisations' competitive environment and the establishment by management of markets within service organisations are intended to expose employees to the constraints of competition and thereby induce them to increase their job performance. Resources are made scarce and more responsibility for finding a way out of the difficulties is devolved to employees. This in no way means that earlier forms of labour control have disappeared. It is true that control through the market fits almost seamlessly into an environment characterised by highly skilled knowledge work, in which a high degree of individual autonomy in the organisation of work processes can blur the boundaries between dependent employment and self-employment. However, elements of market control can gain ground even when bureaucratic, technical or direct personal forms of control (Edwards 1979) persist. And even when market control is associated with greater autonomy in work organisation, such 'empowerment' does not extend to control by individual employees of the conditions under which they operate.

Lehndorff and Voss-Dahm (Chapter 12) emphasise the ambivalent nature of the 'delegation of uncertainty' to employees that goes hand in hand with the market control of labour. On the one hand, it leads in many cases to a self-managed process of work intensification, and sometimes also to work 'extensification', that is, increases in working time made by employees acting on their own initiative. On the other hand, it is precisely in the terms 'self-managed' and 'on their own initiative' that the explosive nature of the delegation of uncertainty lies. The whole purpose of exerting control through the market is to mobilise individual employees' problem-solving capabilities. These capabilities are quite con- 
siderable, as is shown by the daily efforts to overcome the difficulties in many service organisations that are exacerbated by scarce resources. However, this mobilisation of dependent employees' creative capacities is associated with considerable individual and social costs.

As is shown by the examples cited by Rubery, Lehndorff and VossDahm and the authors of the preceding industry analyses, these costs may be reduced by an appropriate institutional and political environment. Control through the market has always to be implemented under the conditions that happen to prevail in the particular social environment, even when the objective of such control is to change that environment. True, the internal logic of market-based control tends towards the recommodification of labour, but this logic cannot assert itself fully until the countervailing social and political forces and institutional counterweights have been sufficiently weakened. However, these are not necessarily weak, nor are they enfeebled everywhere. There are certainly countervailing forces and counterweights, albeit of variable strength from country to country, acting against the unchecked advance of product market competition (or shortage of resources in public budgets) and the consequent impact on the working and employment conditions of service workers.

One particularly important indicator is the significance of vocational training. In all the countries under investigation, the professionalisation of service work is being accompanied by the reproduction of simple activities. And yet in the course of this process, poorly paid, low-skill activities are being separated off to an extent that varies, not only from country to country but also from industry to industry. Thus, for example, a general trend towards the professionalisation of home care services may be discerned. In the UK, however, this trend is only in its early infancy. At the same time, the UK is the country in which the increase in skill levels among nurses, another generally observable trend, is most evidently offset by the outsourcing of simple, poorly paid care tasks. In Sweden, on the other hand, the number of trained nurses, who today have to have a university degree, has increased in absolute terms, although the budget crisis of the 1990s led to a reduction in the total number of nursing personnel in the Swedish health care system. In several countries, the 'upskilling' process has exacerbated disputes about the excessively low pay levels of nursing personnel. In response, the Netherlands, for example, embarked upon a structural reform of hospital pay grades that led to the upgrading of around a quarter of all nurses.

Besides the organisation of training, which is a labour market institution, service work is also influenced by product market regulation. Here, too, there are considerable differences between the countries. Thus in the Scandinavian countries and the Netherlands, there is widespread outsourcing of home care services to the private sector, but the state lays down quality standards or restricts subcontracting to the provision of ancillary services. In Sweden, local authorities award care contracts only to 
specialist personnel with three years' training. In a number of traditionally highly professionalised services, the concern with service quality has, since time immemorial, resulted in severe restrictions on access to the labour market. This link between access and service quality now applies to a wider circle of occupational groups, particularly in social services, and is having an effect on working and employment conditions. Labour market regulation and production market regulation, therefore, are closely linked to each other.

The role played by trade unions in the service sector in European countries impacts directly upon working and employment conditions. The relatively high degree of influence wielded by the Scandinavian trade unions, even in a sector like IT services, which for the trade unions in some other countries is still more or less terra incognita, is a very significant factor in embedding labour standards such as a general forty-hour week so firmly in the wider society that even employers and employees in software houses do not regard them as completely irrelevant. The effectiveness of strong trade union influence may also be observed at the opposite end of the spectrum, in retailing. One example is the liberalisation of shop opening hours in Sweden, which has led to considerably less flexibilisation of individual working hours than in the UK, for example, since the trade unions were able to push through new, collectively agreed protective provisions.

Does such an example reflect a gradual erosion of trade union power or the emergence of new approaches and strategies from which trade unions in other countries seeking opportunities for regeneration could learn? Jon Erik Dølvik and Jeremy Waddington, who analyse the problems faced by trade unions in the private service sector, are somewhat sceptical in this regard. The two authors show how trade unions are experiencing the current change primarily as a major additional difficulty. Great effort is being expended on organisational reforms, such as mergers or internal restructurings, the benefits of which remain uncertain. Dølvik and Waddington suggest that trade unions should take account of the interests and reactions of consumers, clients and the wider public. This is not in any sense a call for clever tactics or a skilful PR strategy: 'The need to win customer support and public legitimacy, and to build ties with broader societal groups, is a prerequisite for success.' Dølvik and Waddington are pointing here to the nexus of working and employment conditions and service quality that is of fundamental importance in any analysis of national differences, in the identification of opportunities to shape service work and for the trade unions' future role in the service sector.

Ironically, the very enforcement of market-based control in service work - that is, the delegation of uncertainty to employees - may perhaps prompt the trade unions to rethink their own approaches to service work (Bosch 2001) both at company level and at that of the wider society. When workers find themselves squeezed between customers and corporate financial indicators, they have to cope on their own initiative with complicated 
and difficult situations in an environment in which working conditions are becoming increasingly burdensome. This makes them experts in the work process. They are the ones best able to identify the points at which service quality begins to suffer when resources are scarce. They are also in a position to judge how working conditions would have to be shaped in order to produce good-quality service. Such workers constitute a source of knowledge and skills for trade unions in a service society seeking, in their capacity as trade unions, to re-invent themselves as the champions of good services. Poorly trained, dissatisfied workers do not provide good services.

It is at this point that the limits of the studies on which the present volume is based become evident. True, they formulate indicators, such as those referred to above, that show how the 'high road' route towards the service society at the macro level is correlated with the quality of working and employment conditions within service organisations. Yet the extent to which the industrial relations system, labour and product market regulation and the welfare state actually impacts upon individual service organisations and directly or indirectly influences work processes could not be satisfactorily investigated in a research project of this scope and duration. The best that could be achieved was to identify starting points for future research, which can be formulated as follows. The gulf between the demands of service work and the resources available to service workers, which is the core problem in all five areas of service work investigated, is viewed just as critically in the Scandinavian industry studies as it is in the Italian, German or British studies, for example. And yet indicators such as those alluded to above reveal significant differences between these countries. This suggests, first, that awareness of the problem is heightened when the 'high road' approach is adopted. Furthermore, however, it shows that the struggle for better working and employment conditions must go on, even under the conditions that exist in Scandinavia, which must undoubtedly be regarded as favourable compared to the European average. Gains already achieved in this area are constantly under threat and every step forward is a starting point for further disputes.

This dynamic manifests itself, for example, in the quality of largely feminised jobs in social services, which is a key factor in the choice between the 'low road' and 'high road' routes towards the service society. Yeandle (1999: 160) draws on the example of Denmark to investigate the contradictory nature of the shifting of personal support and care activities out of the informal household sphere and into the formal labour market:

Gender divisions have not been eliminated in Denmark - indeed there is a very high level of occupational sex segregation in the Danish labour force, and Danish women continue to provide the majority of personal care for those in need of it. But the lifelong economic dependence of Danish women on an individual man - upon the status of wife - has been reduced. 
This is, as Alexandra Wagner shows in her chapter at the end of Part I, an important precondition for making the infringements of gender equity associated with this process an object of public debate. This is also reflected in employment conditions. One unambiguous indicator is the earnings of female workers in social services. In most countries, wage discrimination is particularly high in precisely those groups of activities in which women's employment is most concentrated. When part-timers' hourly wage rates are also taken into account, the UK is the EU member state with the widest gender pay gap. The Scandinavian countries, on the other hand, head the European gender pay equality table. One explanation for this is the high level of employment in public services, where the gender pay gap is significantly narrower than in the private sector (Grimshaw and Rubery 1997, 2001; Winberg 2000). Thus political decisions on the expansion of the welfare state can also be a very significant factor in the development of working and employment conditions.

Gender pay discrimination is the most visible tip of a social policy iceberg. It indicates the extent to which social services, provided mainly by women, are undervalued. In many European countries, the dichotomy between professional requirements and standards and the human and material resources made available manifests itself sometimes in very high turnover rates (care of the elderly) and sometimes in a retreat into parttime work (hospital nursing staff). The cumulative impact of these two phenomena further exacerbates the already widespread labour shortage in care services, which is threatening to become a highly explosive issue, particularly in view of the shift in the age pyramid. The more it is taken for granted that highly skilled women operate at the same level as their male counterparts in the workplace, the less societies can be sure of obtaining an adequate supply of labour to meet the growing demand for social services at the prices that have prevailed hitherto. Already, such services are beset by the threat of a collapse into a vicious circle of unsatisfying working conditions, persistent labour shortages and poor service quality. A fundamental conflict is gradually taking shape, one that will have consequences for government budgets, tax and social security systems and, inevitably, for the tax burden on companies and households. Even further privatisation of social services will not resolve this problem if high quality and qualification standards are to be maintained. European societies are literally being confronted with the question of how highly they value the provision by skilled personnel of high-quality social services.

It is true that this risk of a crisis in care services has not yet been averted, even on the 'high road'. Taken overall, however, the macro and micro analyses give grounds for concluding that the chances of avoiding or averting this risk are considerably better on the 'high road' than on the 'low road'. Public awareness of the route to be taken, together with the social pressure and the institutional preconditions for going down that route, are more strongly developed in the conditions that prevail in the 
Scandinavian welfare states than in many other European countries. There is no way back to the traditional single-earner family that resolved the care problem in a private, socially invisible way. The way forward will inevitably involve 'a fair amount of defamilialisation of welfare responsibilities' (Esping-Andersen 2000: 357). Thus the socialisation of the work traditionally done by women is becoming a platform on which the debate about how to avert the threatened care crisis can be conducted.

How working and employment conditions in social services evolve is ultimately a political question. The political issue at stake is the quality of products urgently needed by society but which only a small minority of purchasers are able to purchase at market prices. Ultimately, the same applies to private business and consumer services as well, even if not so directly. Those who place their faith in the market as the sole means of managing service work have also to accept the risk of market failure.

This is the upshot of Jean Gadrey's critique of the myth of the market outlined in his concluding chapter (Chapter 14), in which he draws together the threads of the previous chapters:

If the costs of quality are driven out of the door by refusing to pay a fair price for them, then they simply come back in through the window, either within the organisation itself (in the form of turnover costs, absenteeism or a loss of motivation that eventually undermines quality) or elsewhere in society (illness, queues, poverty).

The consequences of this insight are not confined to the regulation of working and employment conditions. Drawing on the findings of the empirical studies that form the basis of the book, Gadrey emphasises the need for 'joint regulation of markets for services and of labour markets with a view to sharing out gains in individual and collective quality'.

The core of Gadrey's argument is that the delegation of political decisions to the market mechanism is justified by an abstract model of the market. In reality, however, this market simply does not exist. If they are to function properly, markets always require regulation, and the nature of that regulation is shaped by the ways in which market participants, ultimately society as a whole, envision the purposes the market is intended to fulfil. There is no market without regulation. When Gadrey argues that 'a society has the markets it creates for itself', he is taking aim at the same ideological construct that Stiglitz (2003: 13) recently attacked when he wrote that 'one of the reasons that the invisible hand may be invisible is that it is simply not there'.

\section{Conclusions}

The various contributions to this book show two things. The first is that very different routes are being taken in Europe towards the expansion of 
service activities: the service society takes no one single form. The second is that each of the various forms of service work, from autonomous knowledge work to repetitive forms of work, can be organised very differently depending on the country in question. These national differences, at both the macro and micro levels, are primarily the consequences of different institutional structures. Thus service work is more heavily influenced by social institutions outside the labour market than work in the manufacturing sector. One important reason for this is the high share of women in the service sector, whose labour supply is shaped by household structures and the welfare state institutions that interact with them. Furthermore, the state also exerts considerable influence, particularly on social services, which is the most significant segment of the service sector in employment policy terms. It is true that social services suffer from 'cost disease' because they are highly labour-intensive and relatively difficult to rationalise. However, they are fundamental to the formation and maintenance of human capital. If the provision of such services were to be left solely to the market, many people would be denied access to them. This is why these services are, to varying degrees, organised, regulated or subsidised by the state. The key role played by the state in this regard points up the responsibility politicians bear for the quantitative and qualitative evolution of service work.

There are correspondences but also contradictions between the macroand micro-level structures of service work. In some important areas, such as the gender pay gap or the social protection of part-time work, the "high road' - that is, a route to the service society supported by the welfare state - is reflected in the working and employment conditions of many service workers. However, even when an institutional framework for the 'high road' has been created at the macro level, contrary developments may still occur in individual areas of service work. Such discontinuities can be greater in services than in manufacturing, because many service activities are still in the emergent phase. Whether or not such new activities become integrated into the dominant national structures depends on the strength of those structures and on the ability of the national actors to extend them to new areas. However, given the low level of trade union density in new and emerging service activities, the reduced power of existing institutions to influence pay, qualifications, work organisation and working time and, not least, the widespread illusions about the markets' capacity for self-regulation, a strong desire to exert influence and a readiness to develop institutions further are required. As academic studies, including those in this volume, have frequently observed, the path dependency that characterises the evolution of national employment models is not an automatic process (Rubery and Grimshaw 2003). And structural change also always contains within it the potential for system change if this further development does not occur.

The various contributions to this book offer unambiguous answers to 
some of our initial questions. Thus it has become evident that the transition to the service society is not necessarily associated with greater social inequality. Rather, there are alternative routes towards the 'high road' that are not only models for further discussion but also empirically discernible. We also feel ourselves confirmed in our view that service work is not necessarily associated with the disappearance of standardised working and employment conditions. However, the old standards cannot simply remain unchanged. A new standard employment relationship is required for women as well as for men, one that is more flexible and, as is already the case in Scandinavia, makes part-time work and parental leave socially protected episodes in normal employment histories rather than atypical interruptions to the standard career path (Bosch 2004).

The answer to our third question about the convergence of service societies and service work in Europe is considerably less certain. In what direction might such convergence develop? It could conceivably be towards the American-influenced Anglo-Saxon market model, or alternatively towards the European social model heralded in the EU employment strategy. The possibilities for convergence in one or the other direction depend primarily on the degree of gender equality and the role of the state in the provision of social services.

Examination of the discrepancies in women's labour market participation within the EU makes it very difficult to believe that the different national models of the family reflected in the differing female participation rates - and particularly the North-South gap - will continue to coexist unchanged. The continuous increase in women's qualifications, which they will seek to exploit in the labour market, together with the European employment strategy, which has as one of its main planks an increase in the female participation rate, suggest that the development paths which have prevailed hitherto will not continue unchanged in future. Both reflect the social and economic crisis of the singlebreadwinner model. This crisis finds expression not only in the declining social esteem accorded to housework but also in declining birth rates and the growth forgone because of underuse of the considerable stock of female human capital, particularly in countries without adequate support services for parents (Rubery and Grimshaw 2003).

However, high female participation rates can obviously be achieved in very different ways. With the exception of only a few countries, it is true that part-time work has hitherto provided an entry point to the labour market for very many women. In the Mediterranean countries, therefore, the initial objective would be to improve these opportunities by creating more part-time jobs. However, this does not determine the path to be pursued subsequently. The example of the Northern European countries would suggest that part-time employment may be seen as a historical period of transition to a labour market that, in the longer term, will be characterised by greater gender equality and in which full-time 
employment will be combined with part-time employment or career breaks for child-raising or further education and/or training. And yet other societal models of gender equality or even of socially accepted gender inequality are conceivable. In the Netherlands, permanent longhours part-time work for both partners is being discussed, which would provide a family wage above the current level of the single-breadwinner model $(2 \times 0.75=1.5)$. The UK, on the other hand, pays for its position among the leading European countries for female labour market participation and service employment with a high level of social inequality, and particularly with a high degree of polarisation among women in respect of pay and working time.

In drawing up its employment strategy, the EU has left open a loophole that would allow various models to co-exist. The strategy lays down targets for female participation rates but not for the underlying volumes of work. The differences may turn out to be so great that women could remain on the periphery of the labour market despite high employment rates. On this 'low road', high female participation rates would go hand in hand with a high degree of gender segregation. True, pay rates in femaledominated service jobs are lower than average even on the 'high road', but heavily subsidised and better paid social services mean that the gender wage gap is narrower than the European average. Segmentation in the labour market for service workers is less pronounced than in the market service model. Ultimately, the successful realisation of a 'high road' strategy, in which women's integration into the labour market becomes irreversible, requires the elimination of labour market segregation by gender. And indeed, this question is a topic of serious discussion in the political and social life of the Scandinavian countries.

For this reason, it cannot be assumed that there will be a convergence in the quality of service activities either. True, the shift of domestic and informal work into the formal labour market offers opportunities for professionalisation, which would improve the quality not only of jobs but also of the services provided to customers. However, these opportunities for quality improvements are currently being exploited only in the Scandinavian public service model. This makes it all the more worrying that the Green Paper on Services of General Interest, recently published by the Commission of the European Communities (2003), affords a blanket welcome to the privatisation of such completely different industries as telecommunications, postal services, electricity supply and railways on the grounds that it represents a major gain in terms of price levels and employment without any detectable deterioration in service quality. Even though the general privatisation of social services is not explicitly proposed in the Green Paper, the theoretical path from telecommunications to hospitals may be a short one. Some of the studies in this book show quite plainly how problematic it is to ignore the fact that services such as health care or care of the elderly are in fact public goods. The problem lies not in the goal of providing such ser- 
vices efficiently and economically but rather in a possible surreptitious shift in their purpose: it may become a matter for debate whether the operational efficiency achieved is intended to ensure the economical provision of a high-quality service or whether it may gradually become the service provider's paramount objective. To date, at any rate, the differences of opinion in Europe as to the role of the state and its responsibility for the provision of services in the public interest have been so serious that convergence cannot be expected in the near future (Wickham 2002).

Thus, for the time being, the linkage between increasing female labour market participation and services continues to take very diverse forms in Europe. In a number of European countries, convergence towards the Anglo-Saxon market model could not take place without considerable social upheaval. To judge from the employment and working time preferences expressed by European citizens (Bielenski et al. 2002), there would seem to be a general desire for more egalitarian arrangements. However, even convergence towards a 'social Europe' that has different social profiles from the USA is difficult to imagine under current circumstances. A stronger political will would be required to bring about such convergence. In the thinking that currently prevails, the chances of such an alternative are considerably underestimated. Given the 'constraints of the global market', public poverty seems inevitable and greater social inequality a simple economic imperative. It may be useful to note that the high unemployment that prevails in many EU member states in no way precludes the contrary strategy of developing services. Joan Robinson (1965: 109) got to the heart of the matter some forty years ago when she argued that 'the existence of unemployed resources should be regarded not as a troublesome problem but as a glorious opportunity - an opportunity to do something useful'. Unemployed resources are certainly there in abundance, and there is definitely a need for useful services. But where are the actors who see this as a glorious opportunity?

\section{References and further reading}

Anttila, T. and Nätti, J. (2000a) 'Home care in Finland', country report for the New Forms of Employment and Working Time in the Service Economy (NESY) project, Jyväskylä: University of Jyväskylä.

- (2000b) 'Information technologies in Finland', country report for the New Forms of Employment and Working Time in the Service Economy (NESY) project, Jyväskylä: University of Jyväskylä.

- (2000c) 'The retail trade sector in Finland', country report for the New Forms of Employment and Working Time in the Service Economy (NESY) project, Jyväskylä: University of Jyväskylä.

Anxo, D. and Nyman, H. (2000a) 'The health sector in Sweden', country report for the New Forms of Employment and Working Time in the Service Economy (NESY) project, Gothenberg: Centre for European Labour Market Studies, Göteborgs Universitet. 
(2000b) 'Home care in Sweden', country report for the New Forms of Employment and Working Time in the Service Economy (NESY) project, Gothenberg: Centre for European Labour Market Studies, Göteborgs Universitet.

- (2000c) 'The retail trade sector in Sweden', country report for the New Forms of Employment and Working Time in the Service Economy (NESY) project, Gothenberg: Centre for European Labour Market Studies, Göteborgs Universitet.

Anxo, D. and Storrie, D. (eds) (2001) The Job Creation Potential of the Service Sector in Europe: Final Report 2000, European Commission, Employment Observatory Research Network, Luxembourg: Office for Official Publications of the European Communities.

Baumol, W.J. (1967) 'Macroeconomics of unbalanced growth: the anatomy of urban crisis', American Economic Review 57: 416-26.

Bell, D. (1973) The Coming of Post-industrial Society: A Venture in Social Forecasting, New York: Basic Books.

Bielenski, H., Bosch, G. and Wagner, A. (2002) 'Working time preferences in sixteen European countries', Dublin: European Foundation for the Improvement of Living and Working Conditions. Available online at: www.eurofound. ie/publications/Working\%20Conditions.htm.

Boll, J.L. (2000) 'The retail trade sector in Denmark', country report for the New Forms of Employment and Working Time in the Service Economy (NESY) project, Copenhagen: Danish National Institute of Social Research.

Bosch, G. (2001) 'Leitbilder für die Dienstleistungsgewerkschaften', WSI-Mitteilungen 9: 538-45.

— (2004) 'Towards a new standard employment relationship in Western Europe?', British Journal of Industrial Relations 42(4): 617-36.

Briefs, G. (1927) 'Gewerkschaftswesen und Gewerkschaftspolitik', Handwörterbuch der Staatswissenschaften 4(4): 1108-50.

Carnoy, M., Castells, M. and Benner, C. (1997) 'Labour markets and employment practices in the age of flexibility: a case study of Silicon Valley', International Labour Review 136(1): 27-48.

Castells, M. (1996) The Rise of the Network Society, Oxford-Malden: Blackwell.

Commission of the European Communities (2003) Green Paper on Services of General Interest, Brussels: CEC.

Csonka, A. and Boll, J.L. (2000a) 'Home care in Denmark', country report for the New Forms of Employment and Working Time in the Service Economy (NESY) project, Copenhagen: Danish National Institute of Social Research.

— (2000b) 'Information technologies in Denmark', country report for the New Forms of Employment and Working Time in the Service Economy (NESY) project, Copenhagen: Danish National Institute of Social Research.

de Castro, A., Figueiredo, H. and González, M. do Pilar (2000) 'The retail trade sector in Portugal', country report for the New Forms of Employment and Working Time in the Service Economy (NESY) project, Porto: Universidade Catolica Portugesa.

Degasperi, P. and Villa, P. (2000) 'Home care in Italy', country report for the New Forms of Employment and Working Time in the Service Economy (NESY) project, Trent: Department of Economics, Università degli Studi di Trento.

Edwards, R. (1979) Contested Terrain: The Transformation of the Workplace in the Twentieth Century, New York: Basic Books. 
Employment Taskforce (2004) Jobs, Jobs, Jobs: Creating More Employment in Europe, Report of the Employment Taskforce chaired by Wim Kok, Luxembourg: Official Publications of the European Communities.

Esping-Andersen, G. (1990) The Three Worlds of Welfare Capitalism, Cambridge: Polity Press.

- (2000) 'Multi-dimensional decommodification: a reply to Graham Room', Policy and Politics 28(3): 353-9.

Fagan, C. (with Warren, T. and McAllister, I.) (2001) Gender, Employment and Working Time Preferences in Europe, Dublin: European Foundation for the Improvement of Living and Working Conditions.

Fagan, C. and Nixon, D. (2000) 'Home care in the United Kingdom', country report for the New Forms of Employment and Working Time in the Service Economy (NESY) project, Manchester: Department of Sociology, University of Manchester.

Fourastié, J. (1949) Le Grand Espoir du XXème siècle: Progrès technique, progrès économique, progrès social, Paris: Presses Universitaires de France (German edition (1969) Die große Hoffnung des zwanzigsten Jahrhunderts, Köln: Bund Verlag).

Frenkel, S.J. (2000) 'Introduction: Service work and its implications for HRM', International Journal of Human Resource Management 11(3): 469-76.

Froud, J., Haslam, C., Johal, S., Williams, J. and Williams, K. (1997) 'From social settlement to household lottery', Economy and Society 26: 3.

Gartner, A. and Riessman, F. (1974) The Service Society and the Consumer Vanguard, New York: Harper \& Row.

Gershuny, J. (1978) After Industrial Society? The Emerging Self-service Economy, London: Macmillan, New York: Humanities Press.

Grimshaw, D. and Rubery, J. (1997) 'The concentration of women's employment and relative occupational pay: a statistical framework for comparative analysis', Paris: OECD, Labour Market and Social Policy Occasional Papers no. 26.

— (2001) 'The gender pay gap: a research review', Manchester: Equal Opportunities Commission, Research Discussion Series. Available online at: www.eoc.org.uk/cseng/research/gender_pay_gap_research_review_report.pdf.

Haipeter, T. (2000a) 'Banking in Germany', country report for the New Forms of Employment and Working Time in the Service Economy (NESY) project, Gelsenkirchen: Institut Arbeit und Technik.

- $(2000 \mathrm{~b})$ 'The retail trade sector in Germany', country report for the New Forms of Employment and Working Time in the Service Economy (NESY) project, Gelsenkirchen: Institut Arbeit und Technik.

Jany-Catrice, F. and Pernod-Lemattre, M. (2000a) 'The retail trade sector in France', country report for the New Forms of Employment and Working Time in the Service Economy (NESY) project, Lille: Centre Lillois d'Études et de Recherches (CLERSE), Université de Lille 1.

— (2000b) 'Banking in France', country report for the New Forms of Employment and Working Time in the Service Economy (NESY) project, Lille: Centre Lillois d'Études et de Recherches (CLERSE)/Université de Lille 1.

Klodt, H., Maurer, R. and Schimmelpfennig, A. (1997) Tertiarisierung in der deutschen Wirtschaft, Kieler Studien 283, Institut für Weltwirtschaft an der Universität Kiel, Tübingen: Mohr Siebeck.

Maurice, M., Sellier, F. and Silvestre, J-J. (1986) The Social Foundations of Industrial Power, Cambridge, MA: MIT Press. 
Mermet, E. and Lehndorff, S. (eds) (2001) New Forms of Employment and Working Time in the Service Economy (NESY): Country Case Studies Conducted in Five Service Sectors, documents compiled for the conference organised by the European Trade Union Institute (ETUI) and the Institut Arbeit und Technik (IAT), Brussels, 26 and 27 April, Report, Vol. 69, Brussels: European Trade Union Institute.

Piovesan, D. (2000) 'The health sector in France', country report for the New Forms of Employment and Working Time in the Service Economy (NESY) project, Lyon: Université Jean Moulin - Lyon 3.

Plantenga, J. and Remery, C. (2000) 'The health sector in the Netherlands', country report for the New Forms of Employment and Working Time in the Service Economy (NESY) project, Utrecht: University of Utrecht Institute of Economics.

- (2001) 'Information technologies in the Netherlands', country report for the New Forms of Employment and Working Time in the Service Economy (NESY) project, Utrecht: University of Utrecht Institute of Economics.

Plantenga, J., van Everdingen, M. and Remery, C. (2000) 'Home care in the Netherlands', country report for the New Forms of Employment and Working Time in the Service Economy (NESY) project, Institute of Economics, Utrecht.

Plasman, R. and Lumen, J. (2000) 'The health sector in Belgium', country report for the New Forms of Employment and Working Time in the Service Economy (NESY) project, Brussels: Département de l'Économie Appliquée, Université Libre de Bruxelles.

Polanyi, K. (1957) The Great Transformation, Boston, MA: Beacon Press.

Robinson, J. (1965) 'Beyond full employment', Collected Economic Papers, Vol. 3, Oxford: Blackwell, pp. 103-12.

Rubery, J. and Grimshaw, D. (2003) The Organisation of Employment. An International Perspective, Basingstoke: Palgrave Macmillan.

Rubery, J., Smith, M. and Fagan, C. (1999) Women's Employment in Europe: Trends and Prospects, London: Routledge.

Rubery, J., Smith, M. and Carroll, M. (2000) 'The health sector in the United Kingdom', country report for the New Forms of Employment and Working Time in the Service Economy (NESY) project, Manchester: Manchester School of Management, University of Manchester Institute of Science and Technology (UMIST).

Sengenberger, W. and Campbell, D. (eds) (1994) The Role of Labour Standards in Industrial Restructuring, Geneva: International Institute for Labour Studies.

Smith, M. (2001) 'Information technologies in the United Kingdom', country report for the New Forms of Employment and Working Time in the Service Economy (NESY) project, Manchester: Manchester School of Management, University of Manchester Institute of Science and Technology (UMIST).

Stiglitz, J. (2003) The Roaring Nineties: A New History of the World's Most Prosperous Decade, New York: W.W. Norton.

Townsend, A.R. (1995) Making a Living in Europe: the Geography of Economic Change, London: Routledge.

Villa, P. and Zeni, E. (2000) 'The health sector in Italy', country report for the New Forms of Employment and Working Time in the Service Economy (NESY) project, Trent: Department of Economics, Università degli Studi di Trento.

Voss-Dahm, D. (2000) 'Information technologies in Germany', country report for the New Forms of Employment and Working Time in the Service Economy (NESY) project, Gelsenkirchen: Institut Arbeit und Technik. 
Wickham, J. (2002) 'The end of the European social model: before it began?', Briefing paper for 'Infowork' Accompanying Measure (mimeo).

Winberg, M. (ed.) (2000) 'Highlighting pay differentials between women and men', Stockholm, Government Offices. Available online at: europa.eu.int/ comm/employment_social/equ_opp/statistics_en.html

Yeandle, S. (1999) 'Gender contracts, welfare systems and non-standard working: diversity and change in Denmark, France, Germany, Italy and the UK', in A. Felstead and N. Jewson (eds) Global Trends in Flexible Labour, Basingstoke: Macmillan, pp. 141-65. 

Part I

Different service societies in Europe 



\title{
2 Measuring economic tertiarisation
}

\section{A map of various European service societies}

\author{
Gerhard Bosch and Alexandra Wagner
}

\section{Introduction}

International comparison is playing an increasingly important role in the theoretical and economic policy debate on the tertiarisation of modern economies. One group of authors (e.g. Klös 1997; Scharpf 1997; Anxo and Storrie 2001) claims to have identified a 'service gap' between several European countries and the USA, and regards the convergence of employment structures as both desirable and feasible. The implicit assumption here is that there is a sequence of similar stages in the development of the service economy that all countries must go through. On the other hand, at least since the publication in 1990 of Gøsta EspingAndersen's book, The Three Worlds of Welfare Capitalism, there has been a debate on the various types of capitalist welfare states, which, due to institutional differences and the phenomenon of path dependency, are not converging. This debate has recently been extended by the development of the notion of 'varieties of capitalism' (Hall and Soskice 2001). Taken together, these two notions suggest that 'there is no convergence of systems in the commonly accepted sense of the term but rather an extension and specialisation of their comparative advantages within the various types of capitalism' (Hoffmann 2003: 130).

Before addressing the difficult theoretical questions posed by international comparisons of the development of service societies, we must first accurately describe the actual situation. Any attempt to do so is rendered more difficult by the fact that different publications use very different indicators to measure tertiarisation. The European Commission (1998) compares European Union (EU) member states' service-sector employment rates. In arguing against the notion that Germany is suffering from a service gap, the German Institute for Economic Research (Deutsches Institut für Wirtschaftsforschung (DIW) in Berlin (Haisken-DeNew et al. 1996; Schupp et al. 1997) uses the shares of service activities within all economic activities. The DIW showed that the share of service activities in total economic activity is just as high in Germany as in the USA but that the sectoral distribution is different. In Germany, a higher share of service 
activities is to be found in the manufacturing sector, because fewer activities have been contracted out from this sector than in the USA. Only by comparing the shares of service activities in the various sectors has it been possible to identify the differing production structures in the two countries (Bosch 2001). For this reason, the OECD made it clear in its Employment Outlook of June 2000 that a distinction should be made between the share of service activities by sector and that by service activities in the whole economy (OECD 2000).

Thus in any discussion of economic tertiarisation and in any attempt to compare countries, it is essential to specify what is actually being compared and which indicators are being used. Our aim here is to inject some clarity into this increasingly confusing debate. We will begin by explaining in greater detail the various indicators used to measure tertiarisation (section 2). In doing so, we will add a further indicator to those already in use. Since working time varies considerably from country to country, an international comparative approach produces new findings if employment in services is measured in terms not only of numbers employed but also of hours worked. In the following two sections ( 3 and 4), these indicators are used to analyse the degree of tertiarisation from an international comparative perspective. A distinction is made here between sectoral, activity, and level effects, with account being taken in each case not only of numbers employed but also of hours worked. In section 5, the structure of services in the various countries is compared. Finally, in order to reduce the multiplicity of comparisons based on different indicators to manageable proportions, the differences are summarised in a typology of countries (section 6). Our international comparisons are based on own calculations of the data from the 1999 European Labour Force Survey. This chapter focuses mainly on measurement problems and on the meaningfulness of various indicators. Only the essential characteristics of the differences between the countries are described. In our second contribution, ${ }^{1}$ the indicators developed here will be used to explain those differences.

\section{Indicators of employment in services}

Like the OECD and the EU, we make a distinction between sectoral and functional breakdowns of employment. However, instead of merely calculating employment rates, we include work volumes as well and measure the absolute level of employment in services. In so doing, we are developing a more comprehensive approach to the measurement of employment in services, one that enables us to incorporate the following dimensions into our analysis:

1 Breakdown by sector and by function

- A sectoral breakdown of employment serves to measure the share of employment in services on the basis of the sector in which workers 
are employed, irrespective of whether they are engaged in production or service activities. Thus, a manual worker in the retail trade is treated as a service worker and a white-collar worker in manufacturing industry as an industrial worker.

- A functional breakdown of employment serves to measure the share of service activities in all activities, irrespective of which sector they are assigned to. In a breakdown of this kind, a white-collar worker in the manufacturing industry is assigned to service activities and a manual worker in the service industry to industrial activities.

2 Breakdown by numbers employed and by volume of work

- The number of service workers captures those individuals who provide services, irrespective of how long their working time is.

- The number of hours of work devoted to the provision of services serves to measure the volume of services and eliminates differences between countries attributable to differences in working time and/or employment rates.

3 Breakdown by relative level and by absolute level

- The relative level of employment in services may be measured by the relationship between the number of service workers and/or the number of hours of work devoted to the provision of services and the total number of economically active individuals and/or the total volume of work.

- The absolute level of employment in services can be measured by the relationship to the total number of individuals of working age. In this way, differences between countries due to different participation rates and/or employment rates and different working times can be eliminated.

Consequently, we use a total of eight indicators to measure employment in services (Table 2.1). Clearly, these indicators are describing and comparing very different things. Comparing employment in services on the basis of the number of hours worked, on the one hand, and of the number of workers, on the other, brings into play the role of working-time policy. Data on the functional structure of employment may be used to analyse structural change within sectors. Comparing employment in services on the basis of a sectoral breakdown, on the one hand, and of activities, on the other, tells us something about the organisation of the value-added chain; such a comparison reveals whether services tend to be outsourced from manufacturing companies or are produced internally as part of firms' core business. The volume of hours worked per individual of working age in individual industries or activities provides information about the absolute level of paid service work. However, such data can also show that the same absolute level may be attained in very different ways. When working times are very long, fewer workers will be employed to provide a certain volume of services than when working times are shorter. 
Table 2.1 Indicators of employment in services

\begin{tabular}{|c|c|c|}
\hline $\begin{array}{l}\text { Analytical } \\
\text { dimension }\end{array}$ & $\begin{array}{l}\text { Employment by } \\
\text { numbers employed }\end{array}$ & $\begin{array}{l}\text { Employment by } \\
\text { volume of work }\end{array}$ \\
\hline $\begin{array}{l}\text { Employment in } \\
\text { services as a share } \\
\text { of total employment }\end{array}$ & $\begin{array}{l}1 \text { sectoral breakdown: share } \\
\text { of employees in service } \\
\text { sector }\end{array}$ & $\begin{array}{l}3 \text { sectoral breakdown: share } \\
\text { of volume of work in service } \\
\text { sector }\end{array}$ \\
\hline Relative level & $\begin{array}{l}2 \text { functional breakdown: } \\
\text { share of employees in } \\
\text { service activities }\end{array}$ & $\begin{array}{l}4 \text { functional breakdown: } \\
\text { share of volume of work in } \\
\text { service activities }\end{array}$ \\
\hline $\begin{array}{l}\text { Employment in } \\
\text { services relative to } \\
\text { working-age } \\
\text { population }\end{array}$ & $\begin{array}{l}5 \text { sectoral breakdown: } \\
\text { employees in service sector } \\
\text { relative to working-age } \\
\text { population }\end{array}$ & $\begin{array}{l}7 \text { sectoral breakdown: hours } \\
\text { worked in service sector } \\
\text { relative to working age- } \\
\text { population }\end{array}$ \\
\hline Absolute level & $\begin{array}{l}6 \text { functional breakdown: } \\
\text { employees in service } \\
\text { activities relative to } \\
\text { working-age population }\end{array}$ & $\begin{array}{l}8 \text { functional breakdown: } \\
\text { hours worked in service } \\
\text { activities relative to working- } \\
\text { age population }\end{array}$ \\
\hline
\end{tabular}

Source: Own representation.

However, data on the level of service work (hours of paid work per individual of working age) cannot provide conclusive evidence of the total level of service provision within a given society, since a certain proportion of services is provided through unpaid work, particularly in households, or through informal work that is paid but not captured by official statistics. ${ }^{2}$ Thus, neither the share of services in total employment nor employment rates are an adequate indicator of service quality or even of a society's attitude to services. To develop such an indicator would require an even more comprehensive approach. Our second contribution to this volume (Chapter 4) will investigate one of these aspects, namely the increasing outsourcing of domestic activities.

\section{Sectoral and functional tertiarisation}

\section{Sectoral differences}

In 1999, the share of service-sector employees in total employment was between 52 and 74 per cent and was highest in the Scandinavian countries, the Benelux countries, and in the United Kingdom and France, with values around and in excess of 70 per cent. The lowest values are found in the Southern European countries (Portugal, Greece, Spain and Italy), where the shares in 1999 were between 52 and 62 per cent (Table 2.2).

In all EU member states, the service sector's share of the total volume of work in the economy ${ }^{3}$ is lower than its share of total employment. This is because average working times in the service sector are shorter than in 
Table 2.2 Sectoral analysis of tertiarisation by numbers of employees and work volume (1999)

\begin{tabular}{|c|c|c|c|c|c|}
\hline Country & $\begin{array}{l}\text { Employees } \\
\text { in the service } \\
\text { sector as a } \\
\text { share of total } \\
\text { employment } \\
(\%)\end{array}$ & $\begin{array}{l}\text { Share of } \\
\text { service } \\
\text { activities/ } \\
\text { occupations } \\
\text { in total } \\
\text { employment } \\
(\%)\end{array}$ & $\begin{array}{l}\text { Share of } \\
\text { service } \\
\text { activities/ } \\
\text { occupations } \\
\text { in the total } \\
\text { volume of } \\
\text { work in the } \\
\text { economy } \\
(\%) \\
3\end{array}$ & $\begin{array}{l}\text { Difference } \\
\text { column } 2 \\
\text { minus } \\
\text { column } 1\end{array}$ & $\begin{array}{l}\text { Difference } \\
\text { column } 2 \\
\text { minus } \\
\text { column } 3\end{array}$ \\
\hline Belgium & 71.8 & 75.3 & 73.9 & 3.5 & 1.4 \\
\hline Denmark & 69.8 & 76.2 & 74.7 & 6.4 & 1.5 \\
\hline Germany (East) & 64.3 & 67.4 & 66.8 & 3.1 & 0.6 \\
\hline Germany (West) & 63.1 & 69.9 & 68.1 & 6.8 & 1.8 \\
\hline Finland & 65.9 & 71.2 & 69.5 & 5.3 & 1.7 \\
\hline France & 69.4 & 70.5 & 69.1 & 1.1 & 1.4 \\
\hline Greece & 59.2 & 61.3 & 60.6 & 2.1 & 0.7 \\
\hline Great Britain & 72.4 & 79.3 & 76.8 & 6.9 & 2.5 \\
\hline Ireland & 62.9 & - & - & - & - \\
\hline Italy & 62.2 & 66.1 & 64.4 & 3.9 & 1.7 \\
\hline Netherlands & 74.5 & 82.0 & 79.9 & 7.5 & 2.1 \\
\hline Austria & 64.0 & 68.5 & 66.6 & 4.5 & 1.9 \\
\hline Portugal & 52.1 & 56.0 & 56.2 & 3.9 & -0.2 \\
\hline Spain & 62.0 & 65.4 & 64.1 & 3.4 & 1.3 \\
\hline Sweden & 72.0 & 73.5 & 71.9 & 1.5 & 1.6 \\
\hline
\end{tabular}

Source: European Labour Force Survey, own evaluation.

the primary and secondary sectors. There are two reasons for this. First, more overtime is worked in the primary and secondary sectors, with their high shares of male workers. Second, women are concentrated primarily in the service sector, and they are more likely to work part-time than are workers in manufacturing industry.

The difference between the service sector's share in total employment and its share of the total volume of work is greatest in the UK. The reason for this is the particularly great difference in the UK between working times in manufacturing and in services; at 42.8 hours on average, weekly working times in the secondary sector are long, while the high share of part-timers in the service sector means that weekly working times there are 36.4 hours on average. It is striking that the difference in the Netherlands, which has the highest part-time rate in the world at 30.4 per cent, ${ }^{4}$ and the shortest average weekly working time in the service sector at 32.2 hours, is no greater than it is in the UK. This is due primarily to shorter working times in Dutch manufacturing (37.1 hours per week), which does not have the British overtime culture. The smallest difference between the two points of view is in Portugal, Greece and East Germany, where the 
differences in working time between manufacturing and services are also relatively low.

Thus our first finding is that the service sector in all countries is more employment-intensive than the manufacturing sector; this is due to the redistributive effect of shorter working times. However, the extent of this redistributive effect is highly variable. It is greater in countries with a high part-time rate, since there are more part-time jobs in services than in manufacturing. In countries in which working times have been reduced across the economy as a whole, the difference is relatively smaller, as it is in West Germany, for example, where the average weekly working time in manufacturing is 38.3 hours, only slightly greater than that in the service sector (36 hours).

\section{Functional differences}

In contrast to the sectoral approach to employment analysis, the functional approach is based on the assignment of employees to particular groups of occupations and activities. ${ }^{5}$ Following Cornetz (1998), these groups are divided into agricultural, manufacturing and service activities, depending on the main focus of the activity in question. In the functional approach, individuals engaged in research and development (R\&D) in manufacturing companies, for example, or working in the sales departments of such companies, are assigned to the service sector.

The first point to note is that from this functional perspective tertiarisation is further advanced everywhere (with the exception of Portugal) than it is when viewed from a sectoral perspective (Table 2.3). This is hardly surprising, since many of the service activities that take place upstream and downstream of the actual manufacturing process emerged within the manufacturing sector. Of course there are also industrial activities within the service sector, although they account for a smaller share of total activity in that sector. In the Netherlands, the country in which the difference between sectoral and functional tertiarisation is greatest, 82 per cent of all activities fall within the definition of services if the number of employees is taken as the deciding criterion, 7.5 percentage points more than if a sectoral approach is adopted.

The difference between sectoral and functional tertiarisation by share of employees (column 4) is greatest in the Netherlands, the UK and West Germany; it is smallest in France and Sweden. Examination of the West German and Swedish cases shows how important the choice of indicators is. A sectoral approach shows that the share of services is 8.9 percentage points higher in Sweden than in West Germany, while an analysis based on activity reduces the difference by more than 60 per cent to only 3.6 percentage points. And because of the shorter working times in service activities, the shares of services in all activities when analysed by work volume (column 3) are lower than when they are analysed by share of 
Table 2.3 Breakdown of the employment structure (1999) by sector and activity

\begin{tabular}{|c|c|c|c|c|c|}
\hline Country & $\begin{array}{l}\text { Employees } \\
\text { in the service } \\
\text { sector as a } \\
\text { share of total } \\
\text { employment } \\
(\%)\end{array}$ & $\begin{array}{l}\text { Share of } \\
\text { service } \\
\text { activities/ } \\
\text { occupations } \\
\text { in total } \\
\text { employment } \\
(\%)\end{array}$ & $\begin{array}{l}\text { Share of } \\
\text { service } \\
\text { activities/ } \\
\text { occupations } \\
\text { in the total } \\
\text { volume of } \\
\text { work in the } \\
\text { economy } \\
(\%)\end{array}$ & $\begin{array}{l}\text { Difference } \\
\text { column } 2 \\
\text { minus } \\
\text { column } 1\end{array}$ & $\begin{array}{l}\text { Difference } \\
\text { column } 2 \\
\text { minus } \\
\text { column } 3\end{array}$ \\
\hline & 1 & 2 & 3 & 4 & 5 \\
\hline Belgium & 71.8 & 75.3 & 73.9 & 3.5 & 1.4 \\
\hline Denmark & 69.8 & 76.2 & 74.7 & 6.4 & 1.5 \\
\hline Germany (East) & 64.3 & 67.4 & 66.8 & 3.1 & 0.6 \\
\hline Germany (West) & 63.1 & 69.9 & 68.1 & 6.8 & 1.8 \\
\hline Finland & 65.9 & 71.2 & 69.5 & 5.3 & 1.7 \\
\hline France & 69.4 & 70.5 & 69.1 & 1.1 & 1.4 \\
\hline Greece & 59.2 & 61.3 & 60.6 & 2.1 & 0.7 \\
\hline Great Britain & 72.4 & 79.3 & 76.8 & 6.9 & 2.5 \\
\hline Ireland & 62.9 & - & - & - & - \\
\hline Italy & 62.2 & 66.1 & 64.4 & 3.9 & 1.7 \\
\hline Netherlands & 74.5 & 82.0 & 79.9 & 7.5 & 2.1 \\
\hline Austria & 64.0 & 68.5 & 66.6 & 4.5 & 1.9 \\
\hline Portugal & 52.1 & 56.0 & 56.2 & 3.9 & -0.2 \\
\hline Spain & 62.0 & 65.4 & 64.1 & 3.4 & 1.3 \\
\hline Sweden & 72.0 & 73.5 & 71.9 & 1.5 & 1.6 \\
\hline
\end{tabular}

Source: European Labour Force Survey; own evaluation.

employees (column 2), as is also the case with a sectoral analysis. However, the difference is not as pronounced as from a sectoral point of view, since the functional approach includes many service activities in the secondary sector, such as R\&D in manufacturing industries, in which working times are very long.

The most important reason why the functional approach produces higher shares for services is tertiarisation within the manufacturing sector. The differences within the EU are considerable (Table 2.4). In the Netherlands, almost half (46.7 per cent) of all employees in the secondary sector are engaged in service activities, while the share in Portugal is less than a quarter (23.4 per cent). Because of the low part-time rate in manufacturing, analysis in terms of work volume produces more or less the same values, and so they are not given here.

These differences in the shares of service activities in the secondary sector may be attributable to very different causes. High shares of service activities in the secondary sector may be the consequence of a move to high-quality production, in which the actual production process is highly rationalised, and other activities, such as design or customer service, are becoming increasingly important. Second, they may reflect a low level of 
Table 2.4 Dependent employees in the secondary sector

\begin{tabular}{lll}
\hline Country & Production activities (\%) & Service activities (\%) \\
\hline Belgium & 64.0 & 35.8 \\
Denmark & 61.9 & 37.9 \\
Germany (East) & 69.1 & 30.8 \\
Germany (West) & 62.1 & 37.9 \\
Finland & 62.7 & 37.1 \\
France & 67.1 & 32.5 \\
Greece & 74.3 & 25.7 \\
Great Britain & 56.7 & 43.2 \\
Ireland & - & - \\
Italy & 70.4 & 29.6 \\
Luxembourg & 65.8 & 34.0 \\
Netherlands & 52.3 & 46.7 \\
Austria & 70.2 & 29.7 \\
Portugal & 76.4 & 23.4 \\
Sweden & 67.6 & 31.9 \\
Spain & 74.3 & 25.6 \\
\hline
\end{tabular}

Source: European Labour Force Survey; own evaluation.

Note

National figures do not necessarily add up to 100 per cent due to the absence of agricultural activities.

outsourcing of service activities. Third, however, they may also indicate that the country in question actually produces very little itself but imports and sales are high. Fourth, they may be explained by national differences in the structure of the manufacturing industry. Thus the same figures may well be concealing completely different phenomena, which can be clarified only by detailed international comparisons.

\section{The absolute level of tertiarisation}

Of every 100 individuals of working age, between 52.8 per cent (Spain) and 76.9 per cent (Denmark) are in employment. In a number of European countries (Denmark, Spain, UK, the Netherlands and Portugal), the employment rate is over 70 per cent, largely because of higher female participation rates and less extensive use of early retirement. Portugal and West Germany have the highest secondary-sector employment rates in the EU; however, their service-sector employment rates are only in the lower mid-range. Denmark, Sweden and the UK have the highest service-sector employment rates, in excess of 50 per cent. It is clear from Table 2.5 that, despite considerable differences in the share of the first two sectors, overall employment rates are influenced primarily by service-sector employment rates.

If the extent of gainful employment is measured in terms not of employment rates but of volume of work per individual of working age, a 
Table 2.5 Employment rates by sector as percentage of working-age population (1999)

\begin{tabular}{lllll}
\hline Country & Total & Agriculture & Secondary sector & Service sector \\
\hline Belgium & 59.4 & 1.4 & 15.3 & 42.7 \\
Denmark & 76.9 & 2.6 & 20.6 & 53.5 \\
Germany (East) & 63.0 & 2.5 & 20.0 & 40.5 \\
Germany (West) & 66.0 & 1.7 & 22.6 & 41.6 \\
Finland & 67.9 & 4.3 & 18.8 & 44.6 \\
France & 60.7 & 2.6 & 16.0 & 42.1 \\
Greece & 57.2 & 10.2 & 13.2 & 33.9 \\
Great Britain & 71.6 & 1.1 & 18.6 & 51.8 \\
Ireland & 63.9 & 5.5 & 18.1 & 39.9 \\
Italy & 53.4 & 2.9 & 17.3 & 33.2 \\
Netherlands & 71.4 & 2.2 & 15.1 & 50.4 \\
Austria & 68.8 & 4.3 & 20.5 & 44.0 \\
Portugal & 71.3 & 9.0 & 25.2 & 37.2 \\
Spain & 52.8 & 3.9 & 16.1 & 32.7 \\
Sweden & 71.6 & 2.1 & 17.9 & 51.5 \\
\hline
\end{tabular}

Source: European Labour Force Survey; own evaluation.

different picture is obtained (Table 2.6), which is best clarified by comparing the Netherlands with Greece and then with France. The general employment rate in the Netherlands in 1999 was approximately 14.2 percentage points higher than in Greece. Despite this considerably higher employment rate, the Netherlands had a smaller volume of work per week and per capita than Greece (1.8 hours per week less). Thus the higher employment rate in the Netherlands is the result of distributing a smaller volume of work among a larger number of people. Or, to look at it from another perspective, just as much paid work is done in France as in the Netherlands, when measured in terms of the volume of work. However, since working times in France are longer than in the Netherlands, relatively fewer people are employed in France than in the Netherlands.

Examination of the volume of work done per individual of working age by sector also reveals considerable differences between the countries (Table 2.7). These can be illustrated by means of a few country comparisons. About 25 per cent more hours of paid work per individual in working age are done in the service sector in Sweden, Denmark and the UK than in Germany, Portugal or Greece. Moreover, while the West German employment rate in the secondary sector is four percentage points higher than the British rate, the difference shrinks considerably if the volume of work per individual of working age done in the secondary sector is taken into account (8.7 hours per week in West Germany compared with 8.0 hours in the UK). The more or less similar volume of work per individual of working age done in the British secondary sector is achieved by relatively fewer workers with considerably longer working hours. 
Table 2.6 Employment rates, working times, and volume of work per head of population in working age (1999)

\begin{tabular}{llll}
\hline Country & $\begin{array}{l}\text { Employment } \\
\text { rate (\%) }\end{array}$ & $\begin{array}{l}\text { Average weekly } \\
\text { working time in } \\
\text { economy as a } \\
\text { whole in hours }\end{array}$ & $\begin{array}{l}\text { Volume of work } \\
\text { per individual } \\
\text { of working age } \\
\text { in hours }\end{array}$ \\
\hline Belgium & 59.4 & 38.3 & 22.8 \\
Denmark & 76.9 & 36.6 & 28.1 \\
Germany (East) & 63.0 & 39.1 & 24.6 \\
Germany (West) & 66.0 & 37.1 & 24.5 \\
Finland & 67.9 & 39.1 & 26.5 \\
France & 60.7 & 39.1 & 23.7 \\
Greece & 57.2 & 44.0 & 25.2 \\
Great Britain & 71.6 & 38.3 & 27.4 \\
Ireland & 63.9 & 39.7 & 25.4 \\
Italy & 53.4 & 39.4 & 21.0 \\
Netherlands & 71.4 & 32.8 & 23.4 \\
Austria & 68.8 & 39.2 & 27.0 \\
Portugal & 71.3 & 40.9 & 29.2 \\
Spain & 52.8 & 40.5 & 21.3 \\
Sweden & 71.6 & 37.6 & 26.9 \\
\hline
\end{tabular}

Source: European Labour Force Survey; own evaluation.

From the functional perspective, the volume of service work per individual of working age is greater in all EU member states than it is if a sectoral approach is adopted. This is due to the high share of service work in the secondary sector. The country rankings differ considerably compared with the sectoral perspective. Thus the volume of hours worked in the secondary sector in the UK, for example, is greater than average (8.0 hours per week). From this perspective, the UK lies in joint fourth place with East Germany, but plummets to eleventh position when the functional perspective is adopted.

\section{The structure of services}

In view of their heterogeneity, the shares or levels of service activities may conceal completely different structures. Services include high-skill activities in R\&D as well as low-skill activities, technical occupations and activities involving close customer contact. Depending on their function within the process of social reproduction, services may be classified as either production-oriented, distributive, consumer-oriented or social in nature. The structure of services differs considerably from country to country in Europe. To illustrate this, we have divided services into four groups (Table 2.8). On the basis of this classification, we first examine the distribution of the total volume of work in the service sector among the four groups. We then examine the volume of work per individual of working age in each 


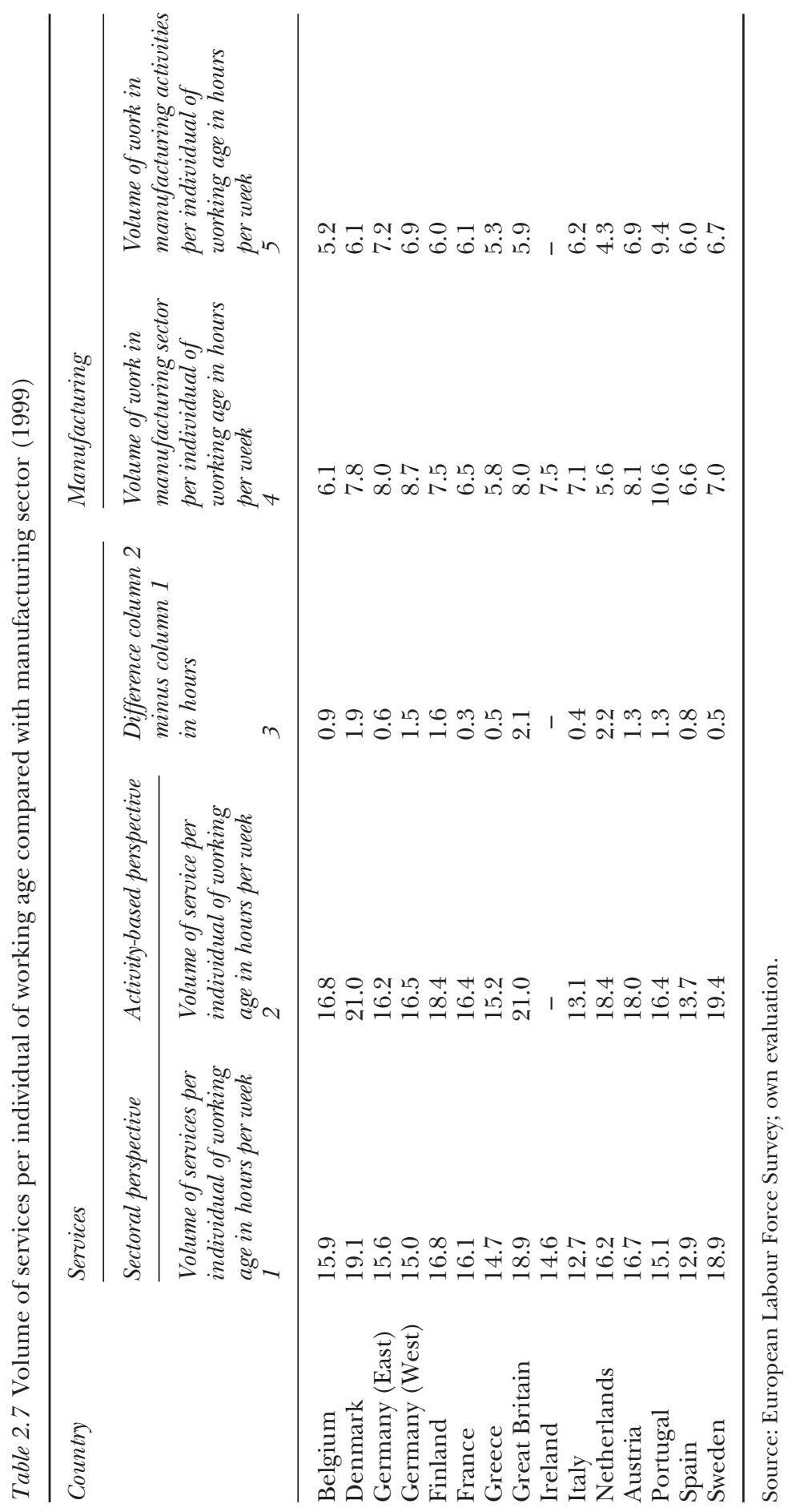


Table 2.8 Allocation of individual industries to service groups, classified according to the Nomenclature Générale des Activités Economiques dans I'Union Européenne (NACE)

Service groups

1 Distributive services

Sale and maintenance of motor vehicles and motorcycles; retail sale of automotive fuel (50)

Wholesale trade and commission trade (51)

Retail trade (52)

Land transport; transport via pipelines (60)

Water transport (61)

Air transport (62)

Supporting and auxiliary transport activities; activities of travel agencies (63)

Post and telecommunications (64)

2 Public and social services

Public administration and defence; compulsory social security (75)

Education (80)

Human health, veterinary and social work activities (85)

Sewage and refuse disposal, sanitation and similar activities (90)

Activities of membership organisations and church and other religious

organisations (excluding social work and sporting activities) (91)

Recreational, cultural and sporting activities (92)

Other service activities (93)

3 Business-oriented services

Financial intermediation (65)

Insurance and pension funding (66)

Activities auxiliary to financial intermediation (67)

Real estate activities (70)

Renting of machinery and equipment without operator (71)

Computer and related activities (72)

Research and development (73)

Other business activities (74)

4 Consumer-oriented services

Hotels and restaurants (55)

Activities of households (95)

5 Other services

Extra-territorial organisations and bodies (99)

Note

The NACE classification system is based on a European standard for industrial classification. It was introduced in 1970 and revised in 1990. At that time, it became the only statistical classification of economic activities in force in Europe.

service group. Finally, we compare the corresponding employment rates with each other.

Table 2.9 shows that the Southern European countries (Portugal, Greece, Spain and Italy) and East Germany have the lowest share of business-oriented services, whereas the share of such services is higher than average in Luxembourg, the Netherlands and the UK. If we leave aside 
Table 2.9 Shares of the volume of service-sector work by service category (1999) $($ Service sector $=100)$

\begin{tabular}{llccc}
\hline Country & $\begin{array}{l}\text { Business-oriented } \\
\text { services }\end{array}$ & $\begin{array}{l}\text { Consumer-oriented } \\
\text { services }\end{array}$ & $\begin{array}{l}\text { Distributive } \\
\text { services }\end{array}$ & $\begin{array}{l}\text { Social } \\
\text { services }\end{array}$ \\
\hline Belgium & 16.3 & 3.0 & 31.0 & 48.0 \\
Denmark & 16.9 & 2.7 & 28.7 & 51.5 \\
Germany (East) & 13.0 & 4.9 & 28.9 & 52.9 \\
Germany (West) & 17.3 & 4.6 & 31.8 & 46.1 \\
Spain & 15.7 & 12.9 & 32.1 & 39.4 \\
Finland & 16.7 & 4.9 & 28.5 & 49.9 \\
France & 18.6 & 6.9 & 29.0 & 45.4 \\
Greece & 11.8 & 12.5 & 33.3 & 42.3 \\
Great Britain & 21.9 & 5.1 & 30.7 & 42.2 \\
Ireland & 20.6 & 9.5 & 31.5 & 38.3 \\
Italy & 14.8 & 6.4 & 28.9 & 49.8 \\
Luxembourg & 24.5 & 6.2 & 26.9 & 35.3 \\
Netherlands & 22.6 & 3.4 & 29.4 & 44.5 \\
Austria & 15.9 & 8.2 & 35.6 & 40.0 \\
Portugal & 11.7 & 14.2 & 29.7 & 44.2 \\
Sweden & 17.1 & 3.0 & 25.8 & 54.1 \\
\hline
\end{tabular}

Source: European Labour Force Survey; own evaluation.

Note

Basis: dependent employees. The shares do not sum to 100 per cent because 'other services' have been omitted due to their relative insignificance in quantitative terms.

the tiny state of Luxembourg, with its idiosyncratic and unreproducible structure, the highest value (UK) is 87 per cent higher than the lowest (Portugal). Consumer-oriented services are particularly strong in Portugal, Greece and Spain, while business-oriented and social services are less highly developed in these countries. Consumer-oriented services still have low shares in Denmark, Sweden, Belgium and the Netherlands. The differences between the countries are even greater in consumer-oriented services than in business-oriented services. The highest value (Portugal) is more than five times greater than the lowest (Denmark). The shares of distributive services are around 30 per cent in virtually all the countries and do not differ so much from each other. Clearly, these are basic activities, for which a similar share in total service output is required in all societies. In all the countries, social services account for the highest share of the total volume of services. However, the absolute differences between the group of countries with the highest values (Denmark, East Germany, Finland and Sweden) and those with the ten percentage points.

There may be many reasons for these differences. High shares for business-oriented services may reflect a highly developed financial industry (as in Luxembourg and the UK) or a high-quality manufacturing sector with many services upstream and downstream of the production process (as in West Germany, France, Sweden and Finland). The figures 
for consumer-oriented services presumably reflect the specialisation of Southern European countries in tourism. The high share of social services in the Scandinavian countries is undoubtedly linked to their highly developed welfare states.

Comparison of the volume of work per individual of working age in the various service categories also reveals considerable differences between the countries in the demand for paid work in the individual groups of services (Table 2.10). In Portugal, Spain, Greece and Italy, for example, the level of hours worked is low in business-oriented services, high in consumer-oriented services (except in Italy) and low in social services. The Scandinavian countries have the highest level of hours worked in employment-intensive social services and a lower level in consumer-oriented services.

Examination of the employment rates in the individual service categories (Table 2.11) shows that social services are the most employmentintensive sector in all countries. The role of working-time policy is evident from a comparison of the values shown in Tables 2.10 and 2.11. The volume of hours worked in social services in the Netherlands, for example, is considerably lower than in the UK (a difference of 0.77 hours per week, or around 10 per cent), but the employment rate in the Netherlands is higher than in the UK due to the shorter working hours.

\section{Country profiles}

With such a multiplicity of indicators, it can be easy to lose sight of the overall picture. For this reason, we will attempt to make the differences and similarities between the countries more transparent by summarising them in four different country profiles (Table 2.12). To this end, we drew together the results of our descriptive analysis and then revisited the various country typologies in the literature. These typologies were developed in order to highlight differences in certain subsections of societal systems, such as welfare state regimes and household structures (e.g. Esping-Andersen 1990) or innovation systems (e.g. Hall and Soskice 2001). Restricted typologies of this kind prove to be inadequate when it comes to explaining the differences in overall employment in services. ${ }^{6}$ However, the assignment of countries to our profiles also has its limitations, since individual states have developed their own characteristic service structures. Luxembourg, where the financial industry is very strong and 'other services' (international bodies) play a very significant role, is as atypical as the Netherlands, with its very short working times and the enormous employment intensity of its service activities, which are actually quite modest in volume. In many respects, East Germany is similar to the Southern European countries, but differs from them due to the higher share of social services and the lower share of consumer-oriented services. 
Table 2.10 Volume of work in the various service categories per individual of working age in hours per week (1999)

\begin{tabular}{lllll}
\hline Country & $\begin{array}{l}\text { Business-oriented } \\
\text { services }\end{array}$ & $\begin{array}{l}\text { Consumer-oriented } \\
\text { services }\end{array}$ & $\begin{array}{l}\text { Distributive } \\
\text { services }\end{array}$ & $\begin{array}{l}\text { Social } \\
\text { services }\end{array}$ \\
\hline Belgium & 1.98 & 0.93 & 3.77 & 6.69 \\
Denmark & 2.90 & 0.63 & 4.91 & 9.18 \\
Germany (East) & 1.78 & 0.88 & 3.96 & 7.78 \\
Germany (West) & 2.19 & 0.90 & 4.01 & 6.40 \\
Spain & 1.54 & 1.87 & 3.16 & 4.19 \\
Finland & 2.47 & 0.89 & 4.21 & 7.78 \\
France & 2.60 & 1.31 & 4.05 & 6.90 \\
Greece & 1.10 & 2.19 & 3.10 & 4.51 \\
Great Britain & 3.67 & 1.04 & 5.13 & 7.64 \\
Ireland & 2.49 & 1.55 & 3.81 & 5.09 \\
Italy & 1.26 & 0.99 & 2.46 & 4.84 \\
Luxembourg & 3.93 & 1.32 & 4.32 & 6.14 \\
Netherlands & 3.18 & 0.69 & 4.14 & 6.87 \\
Austria & 2.34 & 1.65 & 5.22 & 6.31 \\
Portugal & 1.35 & 2.46 & 3.42 & 5.47 \\
Sweden & 2.85 & 0.73 & 4.32 & 9.48 \\
\hline
\end{tabular}

Source: European Labour Force Survey; own evaluation.

Note

Basis: economically active individuals.

Table 2.11 Employment rates in the various service categories (1999)

\begin{tabular}{lclcll}
\hline Country & $\begin{array}{l}\text { Business- } \\
\text { oriented } \\
\text { services }\end{array}$ & $\begin{array}{l}\text { Consumer- } \\
\text { oriented } \\
\text { services }\end{array}$ & $\begin{array}{l}\text { Distributive } \\
\text { services }\end{array}$ & $\begin{array}{l}\text { Social } \\
\text { services }\end{array}$ & $\begin{array}{l}\text { Share of social } \\
\text { services in total } \\
\text { employment rate }\end{array}$ \\
\hline Belgium & 5.3 & 1.2 & 10.1 & 18.0 & 30.0 \\
Denmark & 8.0 & 1.6 & 14.0 & 25.6 & 33.3 \\
Germany (East) & 4.8 & 1.8 & 10.6 & 19.4 & 30.8 \\
Germany (West) & 6.3 & 1.9 & 11.5 & 17.0 & 25.8 \\
Spain & 4.0 & 3.7 & 7.8 & 10.5 & 19.9 \\
Finland & 6.7 & 2.1 & 11.2 & 20.0 & 29.5 \\
France & 6.7 & 2.9 & 10.5 & 17.9 & 29.5 \\
Greece & 2.7 & 2.7 & 7.2 & 10.9 & 19.1 \\
Great Britain & 9.4 & 2.9 & 14.1 & 20.1 & 28.1 \\
Ireland & 6.6 & 3.7 & 10.5 & 13.7 & 21.4 \\
Italy & 3.4 & 1.5 & 6.3 & 12.6 & 23.6 \\
Luxembourg & 10.1 & 2.8 & 11.1 & 15.9 & 25.7 \\
Netherlands & 9.3 & 2.2 & 13.3 & 20.6 & 28.9 \\
Austria & 6.4 & 3.3 & 14.1 & 15.6 & 22.7 \\
Portugal & 3.5 & 4.2 & 8.2 & 13.5 & 18.9 \\
Sweden & 7.7 & 1.6 & 11.9 & 25.4 & 35.5 \\
\hline
\end{tabular}

Source: European Labour Force Survey; own evaluation. 
50 G. Bosch and A. Wagner

Table 2.12 Profiles of EU service economies

\begin{tabular}{|c|c|c|c|c|}
\hline Indicator & $\begin{array}{l}\text { Southern } \\
\text { European } \\
\text { countries: } \\
\text { Greece } \\
\text { Italy } \\
\text { Portugal } \\
\text { Spain }\end{array}$ & $\begin{array}{l}\text { Scandinavian } \\
\text { countries: } \\
\text { Denmark } \\
\text { Finland } \\
\text { Sweden }\end{array}$ & $\begin{array}{l}\text { Continental } \\
\text { European } \\
\text { countries: } \\
\text { Belgium } \\
\text { Germany } \\
\text { France } \\
\text { Austria* }\end{array}$ & $\begin{array}{l}\text { English- } \\
\text { speaking } \\
\text { countries: } \\
\text { Great Britain } \\
\text { Ireland }\end{array}$ \\
\hline $\begin{array}{l}\text { Total volume of work in } \\
\text { economy }\end{array}$ & low & high & moderate & high \\
\hline $\begin{array}{l}\text { Employment rate overall } \\
\text { and in particular in social } \\
\text { services }\end{array}$ & low & high & moderate & high \\
\hline $\begin{array}{l}\text { Share of service activities } \\
\text { in secondary sector }\end{array}$ & low & high & high & high \\
\hline $\begin{array}{l}\text { Volume of work in business- } \\
\text { oriented services }\end{array}$ & low & high & moderate & high \\
\hline $\begin{array}{l}\text { Volume of work in consumer- } \\
\text { oriented services }\end{array}$ & high & slight & moderate & moderate \\
\hline $\begin{array}{l}\text { Working times in the service } \\
\text { sector }\end{array}$ & long & short & moderate & short \\
\hline $\begin{array}{l}\text { Employment intensity of } \\
\text { employment in services } \\
\text { compared to the secondary } \\
\text { sector (influence of } \\
\text { difference in working time) }\end{array}$ & low & moderate & moderate & high \\
\hline
\end{tabular}

Source: Own representation.

Note

* Luxembourg, with its strong financial industry, and the Netherlands, with its short working times, fall outside the scope of these profiles.

The four groups of countries may be broadly characterised as follows:

1 The Southern European countries have predominantly traditional industrial structures, with high shares of production-related activities and low shares of services and low demand for business-oriented services. One peculiarity here is the high share of consumer-oriented services, probably a consequence of the important role played by tourism. Traditional household structures combined with low female participation rates and an undeveloped welfare state are the reasons why many services are still produced by households.

2 The Scandinavian countries have technologically innovative manufacturing sectors with high shares of service activities and high demand for business-oriented services. Modern household structures (high 
female participation rates) and a highly developed welfare state require - and make possible - the provision by the state of a comprehensive array of social services.

3 In the Continental European countries (with the exceptions of the Netherlands and Luxembourg), industrial structures are also modern. As a result, there is a high level of service activities within the manufacturing sector in these countries as well as a high level of businessoriented services. However, since household structures in some of these countries are still traditional in nature and the state in many cases provides transfer payments for families rather than services, the level of social services lags behind that in the Scandinavian countries.

4 In the English-speaking countries, the reason for the high level of business-oriented services, in addition to industrial structures, is specialisation within the international division of labour (i.e. a strong financial industry). Despite traditional household structures, the level of consumer services is still moderate, which may be linked to long working hours and the consequent restrictions on opportunities for self-provision of services. In this 'residual welfare state', the benefits (unemployment, pensions and so on) are low but state services such as education and health are provided at a high level.

\section{Conclusions}

We have been able to show that the extent of the tertiarisation of employment may be described in very different ways and that international comparisons are based on very different indicators. International comparisons have hitherto been conducted almost exclusively on a head-count basis. This would be adequate if working times were similar. However, precisely because working times in services are extremely variable, the working-time effect has to be neutralised. To this end, we have added a volume component to each of the three standard analytical dimensions (sectoral, functional and level) of the indicators. Our country comparison is based on seven of the indicators outlined above rather than on those commonly used, which opens up completely new perspectives for comparison. The results vary depending on which indicator is being used. The following conclusions may be drawn from our descriptive analysis using data from the European Labour Force Survey:

1 In all EU member states except Portugal, tertiarisation is further advanced than is shown by the traditional, purely sectoral approach, since service activities have now spread to the manufacturing industry. By combining the sectoral and functional approaches, the extent of tertiarisation within the secondary sector can be assessed. It is evident from our analysis that in some countries business services tend to be provided by manufacturing firms themselves, while in others they 
tend to be bought in from the tertiary sector. Our analysis provides information on national production structures.

2 Comparison of employment rates with the volume of work per individual of working age helped us to identify the strong influence of working times on employment levels. A number of countries, in particular the Netherlands, have succeeded in distributing what in international terms are not very high volumes of work among a large number of workers, thereby achieving high employment rates. Since average working times in the service sector in all EU member states are lower than in manufacturing, structural change towards the service economy has been accelerated by these working time factors.

3 In all the countries, social services account for the greatest share of all services in terms of both employment and volume of work. The differences between the countries in social services explain to a large extent the differences in employment rates and volumes of work in the service sector.

4 Four country profiles (the Southern European, Scandinavian, Continental Europe and English-speaking profiles) can be identified within the EU. In turn, these profiles may be used to identify variations in work volumes, employment rates, tertiarisation within the manufacturing industry, and the distribution of employment in services among individual categories of services.

\section{Notes}

1 Chapter 4 in this volume: G. Bosch and A. Wagner, 'Why do countries have such different service-sector employment rates?'

2 Two further indicators could be calculated, namely employment rates and the volume of work in services per capita of population. This also makes sense, since a society's demand for services also depends on the ratio of economically active individuals to inactive younger and older individuals. We have not examined this aspect in this study. However, it will become increasingly important as the population in Western societies ages.

3 The volume of work was calculated on the basis of the number of hours usually worked per week. This gives rise to some inaccuracies, since no account is taken of differences in the number of days off (due to sickness and holidays). As a result, the figures would presumably be slightly different if calculated on an annual basis. However, weekly working times seem to us to provide a sufficiently sound basis for an initial attempt at calculating work volumes.

4 The part-time rate among Dutch women is as high as 55.5 per cent. In the OECD as a whole, the part-time rate (for men and women) is 15.8 per cent; in Germany, 17.1 per cent; and in the UK, 23 per cent (OECD 2000: 218).

5 Eurostat uses the International Standard Classification of Occupations (ISCO).

6 Only in more recent publications have attempts been made to fit these various typologies together (e.g. Rubery and Grimshaw 2003). 


\section{References}

Anxo, D. and Storrie, D. (eds) (2001) The Job Creation Potential of the Service Sector in Europe: Final Report 2000, European Commission, Employment Observatory Research Network, Luxembourg: Office for Official Publications of the European Communities.

Bosch, G. (2001) 'Germany: A service gap?’ in J.E. Dølvik (ed.) At Your Service? Comparative Perspectives on Employment and Labour Relations in the European Private Sector Services, Brussels/New York/London: PIE-Peter Lang, pp. 53-101.

Cornetz, W. (ed.) (1998) Chancen durch Dienstleistungen. Ansatzpunkte einer aktiven Gestaltung struktureller Prozesse, Wiesbaden: Deutscher Universitäts-Verlag.

Esping-Andersen, G. (1990) The Three Worlds of Welfare Capitalism, Cambridge: Polity Press.

European Commission (1998) Employment Rates Report 1998: Employment Performance in the Member States, COM (98) 572, Luxembourg: Office for Official Publications of the European Communities.

Haisken-DeNew, J., Horn, G., Schupp, J. and Wagner, G. (1996) 'Keine Dienstleistungslücke in Deutschland: Ein Vergleich mit den USA anhand von Haushaltsbefragungen', DIW-Wochenbericht 14: 221-6.

Hall, P.A. and Soskice, D. (eds) (2001) Varieties of Capitalism: The Institutional Foundations of Comparative Advantage, Oxford: Oxford University Press.

Hoffmann, J. (2003) 'Der kleine Unterschied: Varieties of Capitalism', WSI-Mitteilungen 2003(2): 124-30.

Klös, H.P. (1997) 'Dienstleistungslücke und Niedriglohnsektor in Deutschland', iw-trends 3: 33-59.

Organisation for Economic Co-Operation and Development (OECD) (2000) Employment Outlook 2000, Paris: OECD.

Rubery, J. and Grimshaw, D. (2003) The Organization of Employment: An International Perspective, New York: Palgrave Macmillan.

Scharpf, F.W. (1997) 'Beschäftigungsfreundlich und sozial - ein Widerspruch?', Die Mitbestimmung 4: 36-9.

Schupp, J., Schwarze, J. and Wagner, G. (1997) 'Erwerbsstatistik unterschätzt Beschäftigung um 2 Millionen Beschäftigte’, DIW-Wochenbericht 38: 689-94. 


\title{
3 The incidence of new forms of employment in service activities
}

\author{
Mark Smith
}

\section{Introduction}

Structural change in demand for labour in developed economies has radically altered available job opportunities for individuals seeking employment. It is these changes in the patterns of employment opportunities that are generating much of the current interest in the impact of labour market restructuring and employment policy. The concerns are not only with the level of employment generated by the new and expanding sectors and with whether these new jobs will be sufficient to offset the declines in traditional sectors (Anxo and Storrie 2001). Of equal concern is whether the new jobs will offer as high a quality of employment as in the past (OECD 2001) and will be able to absorb all demographic groups in search of work. These additional concerns come about as the process of employment restructuring is involving not only a sectoral and skill dimension but also changes to the contractual nature of jobs and to the sources of mobilised labour supplies. New jobs are being largely generated in services, but these can involve a disproportionate share of non-standard jobs and may also involve new sources of labour supply. However, the extent to which the service sector creates non-standard jobs can vary across countries. The shift towards service activities has often been placed at the forefront of creating new forms of employment (Bruegel and Hegewisch 1994; Townsend 1995), but it is important to explore the different use of nonstandard work within different parts of the service sector as well as differences between countries. The growth in services may not always mean growth in non-standard work, and, even where it does, differences in nonstandard work occur across countries.

This chapter uses data from the European Labour Force Survey to explore the impact of the growth of services on the types of jobs created and on labour market participants. Following this introduction, section 2 provides an overview of the different patterns of non-standard work in European Union (EU) countries. Section 3 focuses on the role of services in net job growth and the trends in non-standard work, paying particular attention to the specific areas of the service sector that have accounted for 
new employment growth. The fourth section makes the distinction between non-standard jobs in net employment growth and non-standard jobs for entrants to the labour market, and explores the role of the service sector in the integration of men and women into work. The final section draws some conclusions and highlights country- and gender-specific differences in non-standard work in the growth of services.

\section{Non-standard work and services}

There is an assumption that the growth of services is closely linked with the growth of non-standard forms of employment and a general decline in employment terms and conditions (see OECD 2001). While this chapter has set out to address this issue, it is worth considering what is meant by the term 'non-standard work'. Authors have used a range of terms to describe jobs that do not meet the characteristics of the standard full-time employment relationship, including flexible, non-standard and atypical (De Grip et al. 1997; Felsted and Jewson 1999; Rodgers and Rodgers 1989). In this chapter, we consider all jobs that are not full-time and permanent as non-standard, and, while their 'newness' may differ between countries, these jobs may be regarded as differing from the standard employment relationship: part-time work due to limited hours and income; temporary work due to the absence of a long-term employment relationship; and self-employment due to the use of market transactions which reinforce the lack of security. Any survey data analyses of new forms of work are limited by the definitions used in the original survey. As with other analyses, the definition of non-standard work used here includes part-time work, temporary work, self-employed and family workers for statistical ease (see De Grip et al. 1997; Rubery et al. 1999). ${ }^{1}$ It should be noted that there is further variation within these groups, for example, between stable part-time and marginal part-time (O'Reilly and Fagan 1998), between different forms of temporary work (Gallie et al. 1998), and between high and low income self-employed (Meager 1996). However, identification of these variations is constrained by the availability of data and the relatively small size of some of these groups.

To some extent, the association of service sector employment with nonstandard employment may be related to the characteristics of some service activities. Many services cannot usually be stored so that the delivery of services requires the presence of employees. This may make the management of staffing arrangements sensitive to shifts in demand (Frenkel 2000) and may be associated with the growth of non-standard working-time patterns in the service sectors. Some service activities may also require new skills from workers in terms of communication, teamwork and social skills; and these may be more important for workers handling clients and customers than has traditionally been the case in industrial work (Gallie et al. 1998). Because of these new demands on employees and cost competition in 
highly labour-intensive services, employers in the service sector have been regarded as leading the way in what Townsend (1995: 15) calls the 'flexibilisation' of employment.

Differences in the overall service sector employment shares are important in explaining the extent of non-standard work as well as the overall employment rates. For example, differences between European and US employment rates result from a higher share of US women and men employed in both lower value sectors such as hotels and restaurants and in higher value activities such as business services (CEC 1999: 13; OECD 2001). Although rates vary, non-standard work is concentrated mainly in service parts of the economy, particularly part-time work (Table 3.1). With the exception of the two Southern European countries, the distribution of part-time work shows quite similar patterns across the selected EU countries. In seven of the ten countries in this study, no more than one-tenth of part-timers are found in industry, and the share in agriculture is also very small. The wholesale and retail sector has relatively high concentrations of both part-timers and the self-employed across nearly all countries except Italy and Portugal. Here there are high concentrations of selfemployment but lower concentrations of part-timers. In all countries, there are also high concentrations of self-employment in agriculture. However, there are also signs of self-employment spreading to new parts of the economy with high concentrations in real estate and business services in the Scandinavian countries, Germany, the Netherlands and the UK. In Italy and Portugal, where part-time work is less developed, the distribution of part-time jobs follows a different pattern: in Italy, part-time work is more common in industry; and in Portugal, a high proportion over a quarter of part-time jobs - are in private households.

EU countries tend to have larger public sectors than the US, although the size of these also varies considerably between member states. The large public sector in Scandinavian countries, particularly Denmark and Sweden, means that the proportion of the workforce in health and social services is nearly twice that in Germany and the UK and three times higher than in Italy and Portugal. In some countries the public sector has also been at the forefront of promoting new forms of work. Elsewhere, new forms of work have expanded in the public sector but more in response to tight public sector spending (Bruegel and Hegewisch 1994). The concentration of temporary workers in public administration, education and health indicates the significance of temporary work in the public sector in nearly all countries. In the UK and Belgium, one-fifth of all temporary workers are in the education sector, double the share for all persons in employment. In health and social work, however, there tend to be higher concentrations of part-timers rather than temporary workers. This sector accounts for one-fifth or more of all part-time work in Sweden, Denmark, Belgium, the Netherlands and the UK.

There are only four countries - France, the UK, Italy and Portugal - 
where at least 1 per cent of the workforce is employed in private households. Although the variations in the overall share of services to private households may relate to differences in both levels of development and levels of wage inequality, there are higher than expected concentrations of part-time work in all countries. This is particularly the case in France, Portugal and Italy. By contrast, the concentration of part-time work in the industrial sectors is low, and temporary work is the most common type of non-standard work used. However, the concentration of temporary work in industry is still lower than for all in employment, with the exception of Portugal. Thus, although we find similar patterns within some parts of the service sector, we also see strong country-specific differences in the share and distribution of non-standard work. However, our interest in the service sector also derives from its strong contribution to employment growth, and it is to this that we now turn.

\section{Service growth and non-standard work}

Services not only account for the majority of jobs in the EU but also for a disproportionate share of job growth (CEC 2002; Rubery et al. 1998). Furthermore, the expansion of employment for women in services has been a larger contributor to employment growth than the contribution from men. Nevertheless, service employment contributed more to male employment growth than other sectors, and in some cases has compensated for declines in industrial employment (Rubery et al. 1998).

\section{Service sector growth and structural change}

In order to analyse the extent to which the growth of services results in a greater proportion of the workforce being affected by non-standard work, Table 3.2 presents a shift-share analysis of the changing share of nonstandard employment. The proportion of the workforce in non-standard employment has increased at the same time as the expansion of services, so that by 1999 at least one-third of the workforce was employed on nonstandard contracts. In many countries this proportion was close to twofifths, rising to nearly half in the Netherlands. The analysis here covers the period 1994 to $1999 .{ }^{2}$ A shift-share analysis simply decomposes the change in the share of employment into two effects: (1) the effect of the changing structure of employment, holding constant the share of non-standard jobs within each sector; and (2) the effect of the increasing share of nonstandard work within sectors, holding constant the structure of employment. Finally, there is also an interaction term that represents the effect of the changing structure and changing share of non-standard workers. These share and structure effects have been further subdivided into effects for employees in non-standard jobs (part-time and temporary jobs) and for non-employees in non-standard jobs (family workers and self-employed). 


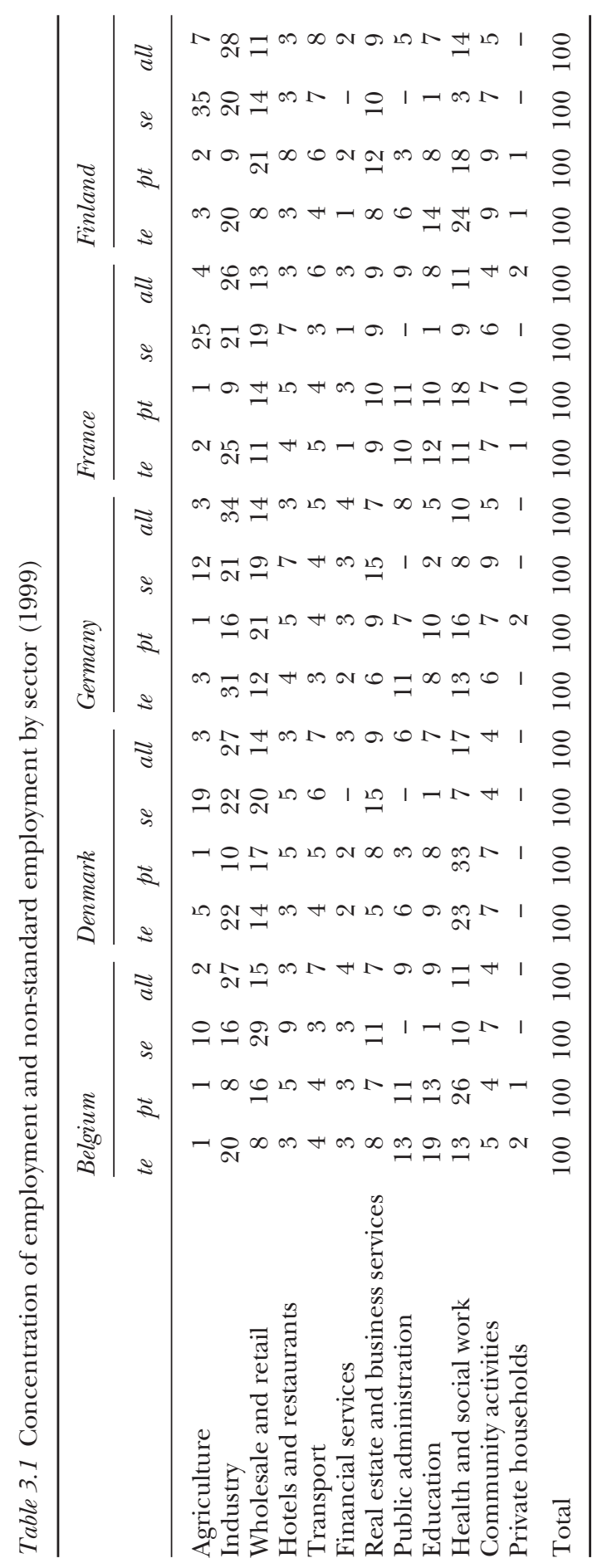




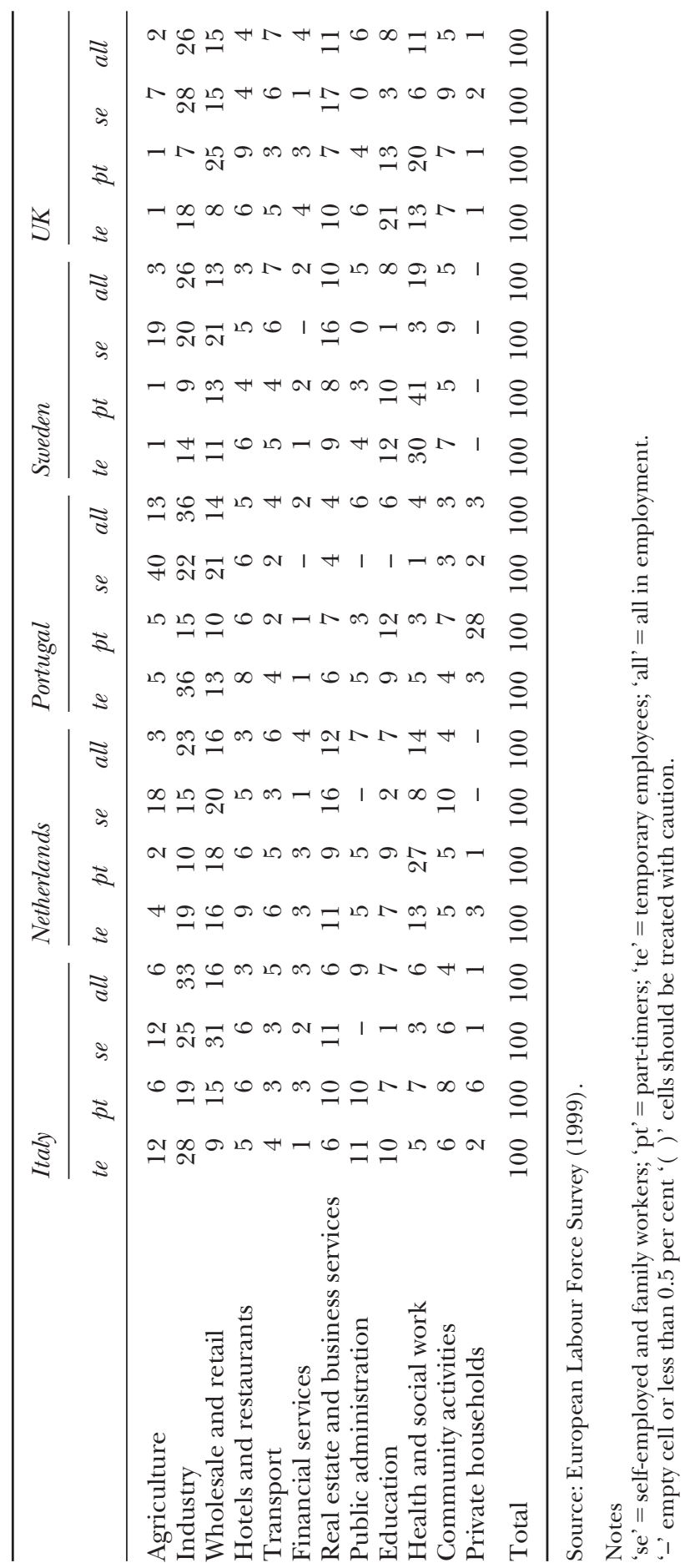




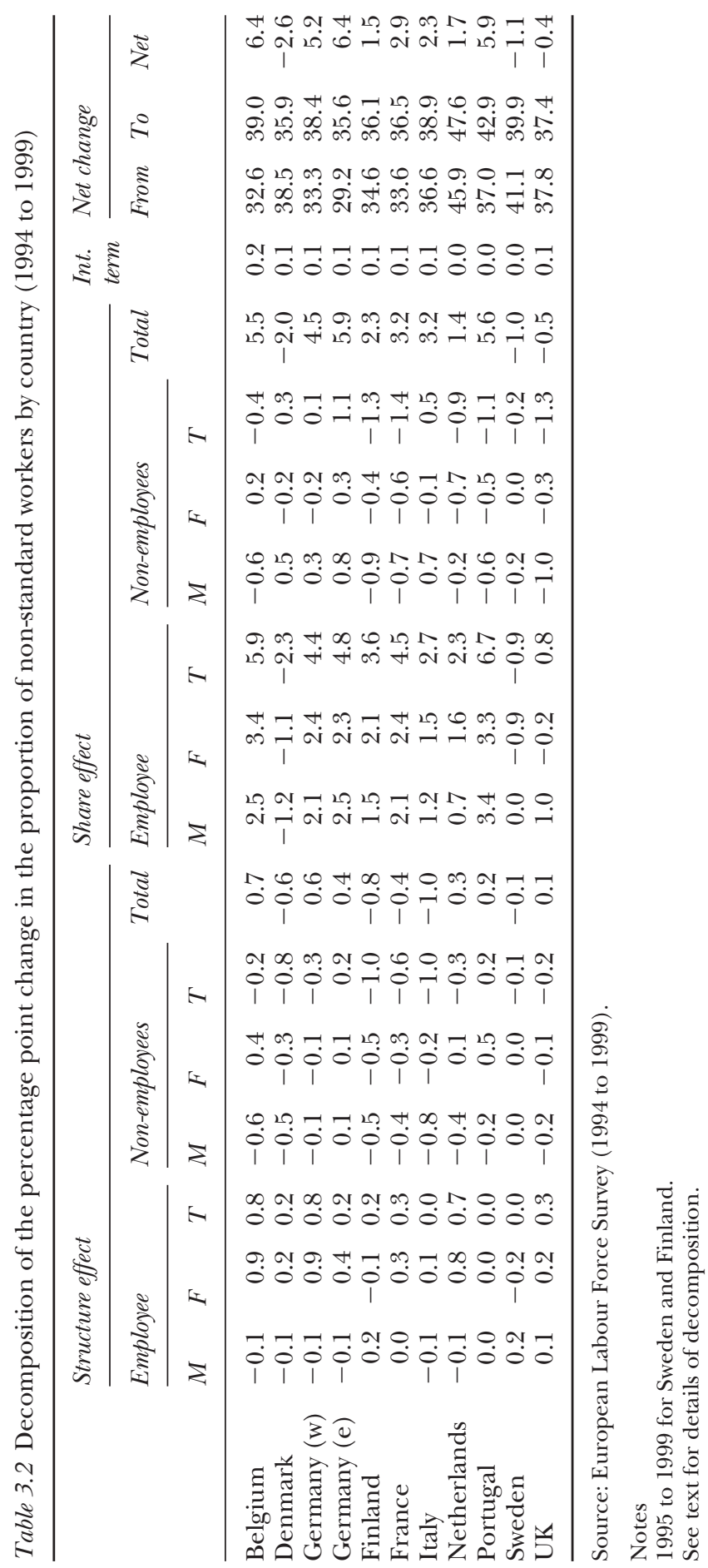


This further subdivision reflects the different trends of these different forms of employment. The effects are also disaggregated by gender.

Of the eleven countries in this study (East Germany and West Germany being treated as separate countries), eight countries experienced a positive increase in the share of workers in non-standard jobs. The UK, Sweden and Denmark experienced negative changes in non-standard worker shares. For the UK this was merely a small decline after a period of upward growth, but for Denmark the decline was both significant and followed on an earlier period of persistent decline in non-standard work shares, associated primarily with a decline in part-time work, albeit from very high levels (Boje 1996). We do not have longitudinal data on Sweden, but this recent small decline may herald the beginning of a trend decline in Sweden too (Gonäs and Spånt 1996). Of the eight countries with positive increases in shares, four recorded changes above five percentage points. For West and East Germany, and for Belgium, the strong growth in this period built upon upward trends in the earlier part of the decade. However, for Portugal, the positive growth towards the end of the decade followed a period of steep decline in non-standard working in the earlier part of the decade, possibly associated with changes in employment legislation in relation to both permanent and temporary contracts (González and Castro 1995). The increases in the remaining four countries were more modest, at between one and three percentage points.

Decomposing the changes into structural and share effects, we find that structure has had a relatively limited impact over the period. For all eleven countries, structural effects varied between only +0.6 and -1 percentage point of the change in the proportion of non-standard jobs. This variable impact of structural change between 1994 and 1999 was more significant than during the period prior to 1994 (data not shown). Where positive structural effects were found, these were related almost exclusively to employees. Similarly, negative structural effects were related primarily to the experience of non-employees (self employed and family members), reflecting, in particular, changing shares of self-employment in agriculture. If we turn to an analysis by gender, we find that negative structural effects were more common for men for both non-standard employees and non-employees. Nevertheless, the size and consistency of the negative structural effects were considerably greater for non-employees, suggesting that men's traditional areas of self-employment have been in decline. For women, there were fewer negative structural effects than for men, but, as for men, negative structural effects were more common for nonemployees.

Much more significant were the largely positive share effects. Employee share effects were particularly significant, with positive effects in excess of 2 percentage points found in seven out of eleven countries and in excess of 4 percentage points in five of the eight. Denmark also recorded significant employee share effects in the opposite direction of -2 percentage 
points. Only in Sweden, the UK and Finland was there relatively little change resulting from the change in the share of non-standard employees within sectors. The share effects for non-employees were both similar across countries and more likely to be negative. Only East Germany recorded a positive effect of more than 1 percentage point. If we look at share effects for men and women, we find fairly even contributions to the positive share effects of employees, although usually, with just two exceptions, the female positive share effect slightly exceeded the male share effect. The share effects associated with non-employees were more varied both by country and between men and women. It is not, in fact, possible to identify a pattern, and more countries recorded negative share effects for women than was the case for men.

This analysis suggests that any predictions of long-term upward growth in non-standard jobs associated with structural change towards services must be treated with caution. The impact of the changing structure of employment towards services and away from agriculture and industry does not have a consistent effect, tending to have a negative effect on the proportion of non-standard workers for men while the opposite is true for women. In some countries women are beginning to work more in fulltime jobs, and, although young people and students may provide alternative labour supplies, changes in labour market behaviour may lead to a decline in non-standard employment, at least in high-use countries. However, the analyses also show that, where there is a growth in the use of non-standard work, it is increasingly affecting men as well as women as the proportion of the workforce employed on part-time or temporary contracts rises. This is particularly affecting young men faced with limited labour market opportunities.

\section{Service sector growth in detail}

The service sector as a whole is making a larger contribution to employment growth than other sectors for both women and men in Europe, but using this broad classification of sectors disguises trends at the detailed level. A more detailed analysis may find some expanding industrial sectors as well as contracting parts of the service sector but also further differentiation in the trends in non-standard employment. Table 3.3 identifies the NACE twodigit (Rev. 1) sectors that contributed most to employment growth over the period 1994 to 1999 and also identifies the role of non-standard work. ${ }^{3}$ There are sixty codes at the NACE two-digit (Rev. 1) level, and here we present the five sectors contributing most to employment growth.

Overall there is considerable similarity in the sectors contributing to employment growth: in most countries all the sectors that appear in the top five are in the service sector; only in Italy and Portugal do industrial sectors account for more than one of these. Four sectors appear consistently at the top of the distribution across these countries - health and 
Table 3.3 Top five sectors contributing most to net new jobs (1994 to 1999)

\begin{tabular}{|c|c|c|c|c|c|c|}
\hline & Total & $\begin{array}{l}\text { Non- } \\
\text { standard }\end{array}$ & $\begin{array}{l}\text { Full- } \\
\text { time } \\
\text { temp }\end{array}$ & $\begin{array}{l}\text { Part-time } \\
\text { perm }\end{array}$ & $\begin{array}{l}\text { Part-time } \\
\text { temp }\end{array}$ & $\begin{array}{l}\text { Self- } \\
\text { employed }\end{array}$ \\
\hline \multicolumn{7}{|l|}{ Belgium } \\
\hline Health and social (85) & 26 & 32 & 4 & 18 & 6 & 3 \\
\hline Business services (74) & 24 & 14 & 2 & 3 & 3 & 6 \\
\hline $\begin{array}{l}\text { Basic metal } \\
\text { manufacture (27) }\end{array}$ & 12 & 5 & 3 & - & - & 1 \\
\hline Education (80) & 9 & 13 & 6 & 2 & 4 & 1 \\
\hline Land transport $(60)$ & 8 & 3 & - & 2 & - & - \\
\hline \multicolumn{7}{|l|}{ Denmark } \\
\hline Health and social (85) & 43 & 14 & 1 & 6 & 4 & 4 \\
\hline Retail (52) & 21 & 2 & - & 2 & - & 2 \\
\hline Construction (45) & 19 & 7 & 2 & 3 & -1 & 3 \\
\hline Computer and related (72) & 10 & 2 & $-\overline{1}$ & 1 & - & 2 \\
\hline Business services (74) & 9 & 7 & 1 & 2 & 1 & 4 \\
\hline \multicolumn{7}{|l|}{ Germany (u) } \\
\hline Health and social (85) & 152 & 132 & 44 & 69 & 6 & 15 \\
\hline Business services (74) & 129 & 83 & 15 & 39 & 4 & 27 \\
\hline Education (80) & 49 & 48 & 23 & 10 & 10 & 5 \\
\hline Recreation (92) & 42 & 29 & 7 & 11 & 1 & 11 \\
\hline Computer and related (72) & 35 & 10 & 2 & 3 & - & 5 \\
\hline \multicolumn{7}{|l|}{ France } \\
\hline Health and social (85) & 22 & 20 & 5 & 14 & 2 & -1 \\
\hline Business services (74) & 17 & 13 & 4 & 5 & 2 & 1 \\
\hline Private households (95) & 13 & 11 & 1 & 9 & 1 & - \\
\hline Education $(80)$ & 12 & 8 & 4 & 2 & 1 & 1 \\
\hline Recreation (92) & 6 & 4 & 1 & 1 & 1 & 1 \\
\hline \multicolumn{7}{|l|}{ Finland } \\
\hline Health and social (85) & 12 & 6 & 3 & 3 & -1 & - \\
\hline Construction (45) & 12 & 3 & 3 & - & - & - \\
\hline Business services (74) & 10 & 3 & 1 & 2 & -1 & 1 \\
\hline Retail (52) & 9 & 8 & 2 & 3 & 1 & 2 \\
\hline Hotels (55) & 9 & 5 & 1 & 3 & - & - \\
\hline \multicolumn{7}{|l|}{ Italy } \\
\hline Business services (74) & 56 & 40 & 3 & 6 & 3 & 27 \\
\hline Public admin (75) & 41 & 20 & 6 & 3 & 10 & 1 \\
\hline Health and social (85) & 26 & 12 & 3 & 3 & 2 & 4 \\
\hline Machine manufacture (29) & 19 & 6 & 1 & 1 & - & 3 \\
\hline Textile manufacture (17) & 16 & 5 & - & 1 & - & 2 \\
\hline \multicolumn{7}{|l|}{ Netherlands } \\
\hline Business services (74) & 19 & 8 & 1 & 4 & 1 & 2 \\
\hline Health and social (85) & 16 & 21 & - & 22 & 1 & -1 \\
\hline Construction (45) & 13 & 5 & - & 2 & 1 & 3 \\
\hline Computer and related (72) & 10 & 3 & - & $\overline{1}$ & - & - \\
\hline \multirow[t]{2}{*}{ Education $(80)$} & 7 & 4 & -1 & 7 & -1 & -1 \\
\hline & & & & & & continued \\
\hline
\end{tabular}


64 Mark Smith

Table 3.3 continued

\begin{tabular}{|c|c|c|c|c|c|c|}
\hline & Total & $\begin{array}{l}\text { Non- } \\
\text { standard }\end{array}$ & $\begin{array}{l}\text { Full- } \\
\text { time } \\
\text { temp }\end{array}$ & $\begin{array}{l}\text { Part-time } \\
\text { perm }\end{array}$ & $\begin{array}{l}\text { Part-time } \\
\text { temp }\end{array}$ & $\begin{array}{l}\text { Self- } \\
\text { employed }\end{array}$ \\
\hline \multicolumn{7}{|l|}{ Portugal } \\
\hline Construction (45) & 46 & 30 & 16 & - & - & 12 \\
\hline Agriculture (1) & 18 & 18 & 4 & - & - & 17 \\
\hline Hotels $(55)$ & 14 & 10 & 8 & - & - & - \\
\hline Private households (95) & 13 & 10 & - & 3 & 3 & 3 \\
\hline $\begin{array}{l}\text { Metal product } \\
\text { manufacture }(28)\end{array}$ & 9 & 3 & - & - & - & - \\
\hline \multicolumn{7}{|l|}{ Sweden } \\
\hline Computer and related (72) & 38 & - & - & - & - & - \\
\hline Business services (74) & 28 & - & - & - & - & - \\
\hline Education (80) & 12 & - & 13 & -11 & - & - \\
\hline $\begin{array}{l}\text { Radio, television } \\
\text { manufacture (32) }\end{array}$ & 11 & - & - & - & - & - \\
\hline \multicolumn{7}{|l|}{$U K$} \\
\hline Business services (74) & 19 & 4 & - & 1 & - & 2 \\
\hline Health and social (85) & 18 & 5 & - & 3 & 1 & 1 \\
\hline Education (80) & 15 & 9 & 1 & 5 & 2 & 2 \\
\hline Computer and related (72) & 13 & 4 & 1 & 1 & - & 2 \\
\hline Retail (52) & 12 & 6 & - & 10 & -1 & -3 \\
\hline
\end{tabular}

Source: European Labour Force Survey (1994 to 1999).

Note

'-' empty cell or '( )' cells should be treated with caution.

social work (NACE 85), business services (NACE 74), education (NACE 80 ), and computer and related activities (NACE 72). Other service sectors that made a major contribution to employment growth in these European countries were the retail sector (three countries), hotels (two countries), and recreation and private households (two countries each). Thus, the main contributors to employment growth include both higher valueadded services - such as services to business including computer and related activities together with communal services such as health and education - and lower value-added services such as retail and hotels.

Health and social work appeared in the top five sectors contributing to employment growth in all countries except Sweden and Portugal. In Germany, this sector accounted for over 150 per cent of the net increase in employment, while in other countries it accounted for between 12 per cent and 43 per cent of the increase. These new jobs are disproportionately associated with the non-standard employment, exceeding 50 per cent of the contribution in five countries and more than 100 per cent in two (Belgium and the Netherlands). In Belgium, France, Germany and the Netherlands, permanent part-time work was particularly important in job 
growth, while in Italy there were more equal contributions from full- and part-time temporary workers as well.

Business services appeared in the top five sectors in nine out of ten countries and was among the top ten in the remaining country, Portugal. The role of non-standard jobs in business services differs across countries, from a majority contribution in Germany, Belgium, Denmark, France and Italy to only a minority share in Finland, the UK and the Netherlands. Furthermore, the composition of these non-standard jobs varies. As one might expect, permanent part-time work plays a relatively important role in the Netherlands and Germany, while in France it is temporary work, particularly full-time work, which accounts for much of the growth. Interestingly, in Germany and Italy, and to a lesser extent in Denmark and Belgium, self-employment plays a major role in new jobs from business services. The only other incidence of self-employment making such a major contribution is in agriculture and construction in Portugal.

Another public service, education, also made a major contribution to employment growth, appearing in the top five sectors in six countries and accounting for between 7 per cent and 15 per cent of the net increase in employment with the exception of Germany (49 per cent). Across these countries, temporary positions tend to be important. In Belgium, Germany, France and Sweden, temporary jobs tend to be full-time, but in the UK and the Netherlands part-time positions are more important. The final sector to appear regularly was computer and related activities, which made a significant contribution to employment growth in five countries, contributing between 10 per cent and 38 per cent to net increases in employment. Computer and related activities also appeared in the top ten sectors in a further three countries and only failed to appear in the top quartile in Portugal. Here non-standard work accounted for only a minority of new jobs, and those that were not full-time permanent were most likely to be for the self-employed, particularly in Germany and Denmark. Where the retail sector is identified as a major contributor to employment growth, quite different patterns are found between the UK where permanent part-time positions accounted for 10 of the 12 percentage points while in Denmark the same positions contributed only 2 of the 21 percentage points. In contrast, again, the contribution of the Finnish retail sector was mainly through non-standard work but made up of a mix of fulltime temporary, part-time permanent, part-time temporary, and the selfemployed.

Although service sectors dominate the lists of sectors contributing most to net job growth, there are a number of industrial groups that appear regularly in the top five sectors. Construction (NACE 45) makes an important contribution, particularly in Portugal, Finland, the Netherlands and Denmark, reflecting the fact that this period constituted the up phase of the business cycle. Compared to services, non-standard work was much less important in the high-growth manufacturing sectors. Where there 
were non-standard workers, they tended to be full-time temporary workers (except for Italy where self-employment played an important role). In construction, full-time temporary workers were also important in Finland and Portugal, as were permanent part-timers and the self-employed in the Netherlands and Denmark.

Although similar sectors tend to be contributing to the increases in overall employment, there is a diverse role within these sectors for different forms of non-standard work, both within and between countries. In some countries or sectors, the rise in non-standard work is linked with larger contributions to net employment while in other countries this may not be the case. This diversity raises the issue of whether the growth of non-standard employment in services is associated primarily with the characteristics of the jobs and the services provided or whether it reflects the regulation of the labour market or the nature of the labour supply employed. We return to this question in the final section after the consideration of another important aspect of the composition of service jobs: the extent to which they are open to those without work.

\section{Service jobs and access to work}

To examine the role that new jobs in services play in the operation of the labour market it is important to consider transitions into employment. Dynamic analyses of the labour market can also shed more light on the impact of new forms of work on labour market participants (O'Reilly et al. 2000). In particular, it is important to consider the role of new jobs in services for labour market participants and the extent to which non-standard work in services affects new entrants.

The European Labour Force Survey collects retrospective information on the activity status of respondents one year prior to the survey, and, using this data, we can gain some understanding of the flows out of nonemployment into jobs in the service sector. Unfortunately, from the data that are collected now, we are able to provide only a limited classification of labour market activity status for the period one year earlier. In particular, there is no information on the working time or contractual status of those employed a year earlier. In the analyses presented here, we combine the unemployed and inactive into a single non-employed category. This regrouping recognises that many of those individuals entering work, especially non-standard work, come from inactivity (O'Reilly and Bothfeld 1996; Rubery et al. 1999). These measures of labour market transitions will be, to some extent, an underestimation of the true level of dynamism in the labour market, since only information on activity status at the two points is available. For example, an individual may have been without work at the two points in time but may have experienced a number of short spells of employment over the year. Furthermore, someone who was in employment in the reference week and one year earlier may have 
experienced one or more spells of non-employment during the year, which will not appear in the data. In addition, this type of data is unable to identify job-to-job transitions. Nevertheless, these data are still a rich source of information on the flows between activity statuses, and here they provide useful information on the flows into non-standard jobs in the service sector. We concentrate our analysis on women and men aged twenty-five to fifty-nine years: this age range is chosen to avoid the effect of young people, particularly students, in some countries, actively seeking and entering short-term jobs and thus exaggerating the integrating role of non-standard work.

Table 3.4 shows the NACE two-digit sectors that contribute most to new labour market entrants for each country. ${ }^{4}$ The sectors are ranked by the two-digit sector that accounted for the largest share of individuals who were out of work a year earlier. Here once again, we have presented the top five sectors for each country. The results show a considerable degree of similarity for the sectors across countries. Four sectors - health and social work (NACE 85), education (NACE 80), retail (NACE 52) and other business services (NACE 74) - appear in the top five sectors in seven of the eight countries for which we have data. In Italy, only two of these four sectors appear in the top five, but the other two appear in the top ten (data not shown). Construction, public administration and agriculture also appear in the top five in Italy, and two of these sectors also appear regularly in the top employment access sectors in other countries, namely construction (four countries) and public administration (three countries). Other service sectors that make a major contribution to access to work across countries include hotels (UK), wholesale (the Netherlands) and agriculture (Italy). In contrast to the results for the contribution to net employment growth (Table 3.3), non-service sectors appear even less frequently here. The exceptions are construction (NACE 45), which appears in six countries, and agriculture in one country, which may indicate the casual nature of some work in these areas that is open to the nonemployed.

In addition to showing the contribution that each sector makes to new labour market entrants, Table 3.4 also shows the proportion of the contribution made up of women and men and the type of jobs they hold. In many cases, women dominate labour market new entrants in these sectors. For example, women dominated new entrants to health and social work, an important source of new entrant jobs; in France this sector accounted for 12 per cent of new entrants and three-quarters of these were women. Furthermore, a high share of these women were also in non-standard jobs. Women in permanent part-time jobs in health and social work contributed 6 per cent, 6 per cent and 9 per cent of all new entrants in Denmark, the UK and the Netherlands respectively. Women in part-time temporary positions in this sector also made strong contributions to all new entrants, particularly in Finland, Belgium, the Netherlands and 


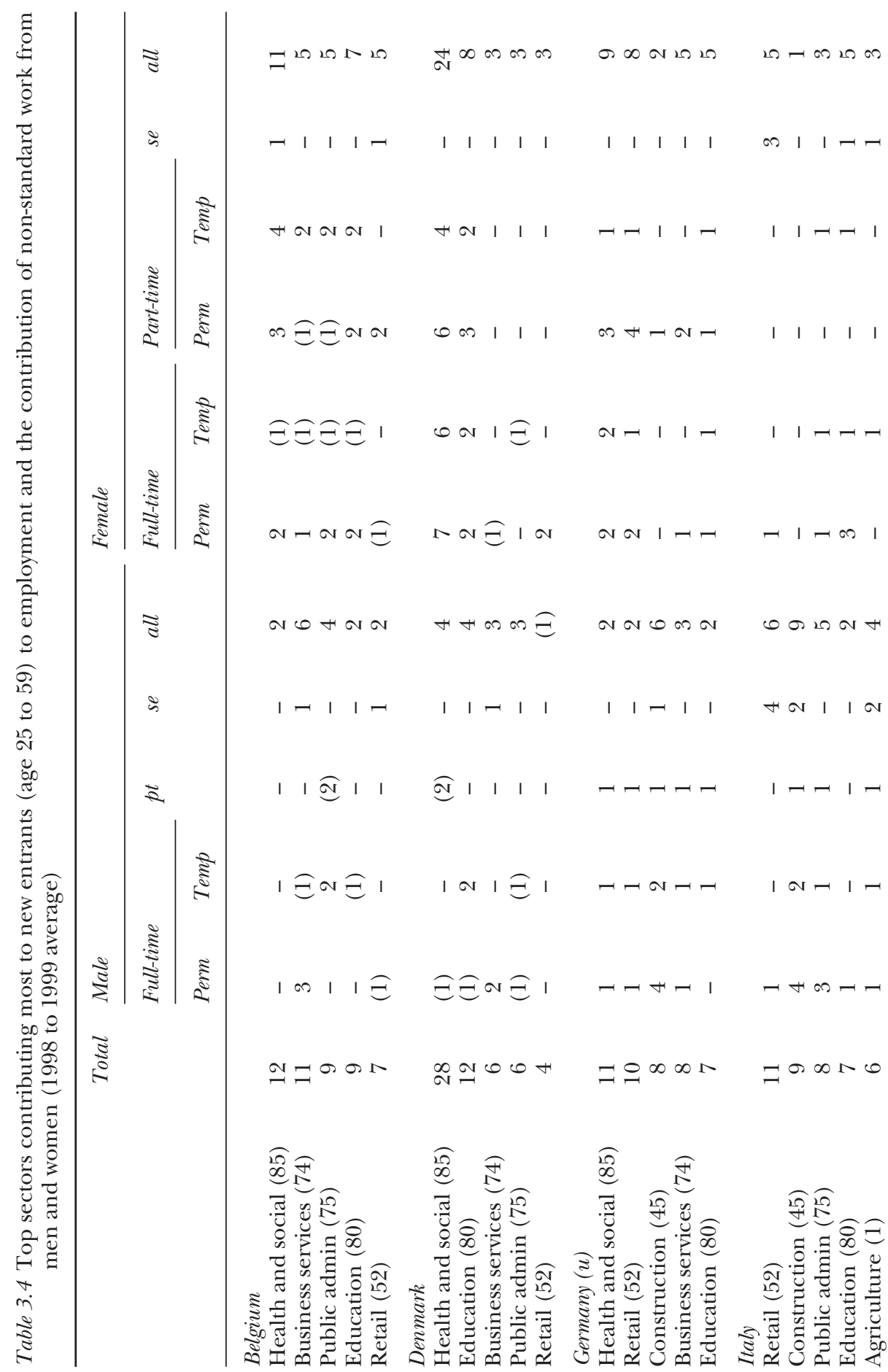




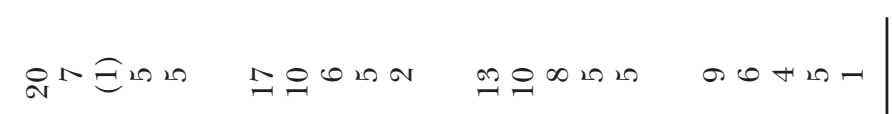

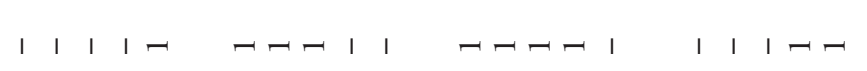

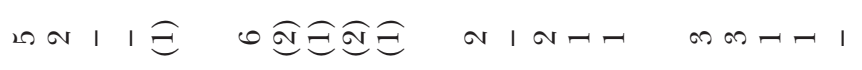

$$
\begin{aligned}
& 1 \text { 1 } 1 \text { है }
\end{aligned}
$$

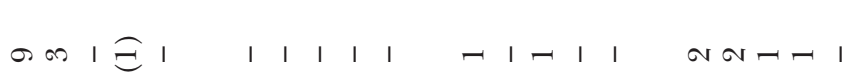

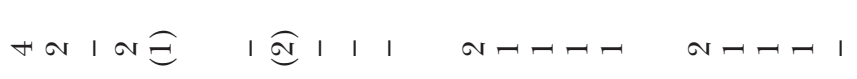

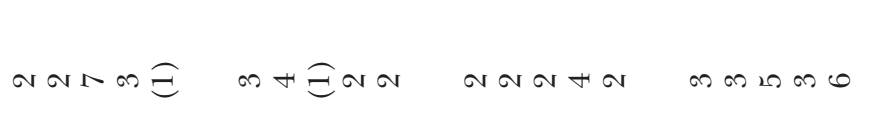

$$
\begin{aligned}
& \begin{array}{lllllllllllllllll}
1 & 1-1 & 1 & 1 & 1 & 1 & 1 & 1 & 1 & -1 & 1 & -1 & 1 & 1 & 1 & 1 & -
\end{array}
\end{aligned}
$$

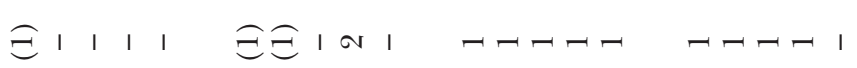

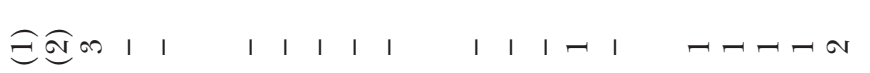

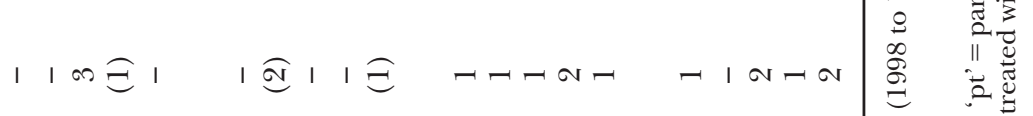

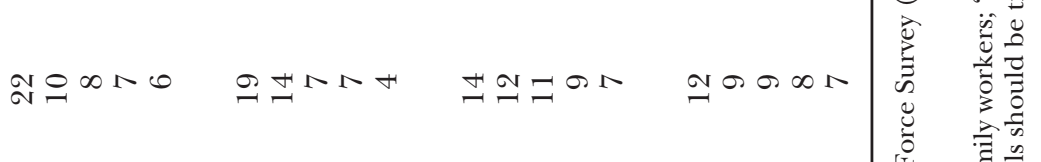

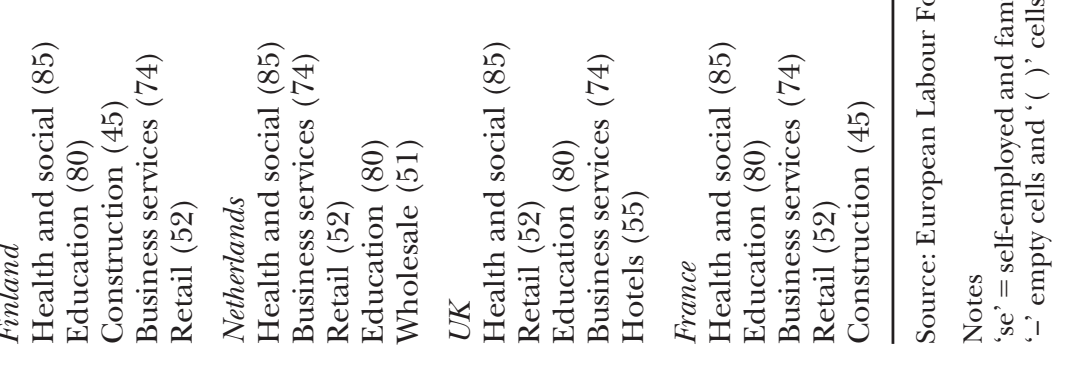


France. The small contribution made by men in this sector was also mainly from non-standard jobs, and these tended to be divided evenly between full-time temporary workers and part-timers (with temporary and permanent aggregated). In business services, there is a more even gender balance in many countries and the share entering on non-standard contracts is not as high. For men, there tend to be some full-time permanent positions combined with a mix of self-employed, full-time temporary positions and part-timers, but these vary by country. For women, there tends to be a higher share entering work on non-standard contracts, particularly parttime (either permanent, as in the UK, the Netherlands and Germany, or temporary, as in Belgium). Retail appears in the top five sectors in all countries for which we have data, with women accounting for most of the new entrants except in Italy, but, again, the non-standard contribution varies. In Italy, the higher male share comes from self-employment, although there is a strong contribution from the female self-employed. Elsewhere the strong female contribution comes from permanent parttime work with the exception of Denmark, where full-time permanent positions are the main contributor. In construction, men dominate those entering the sector, and, although many of these are in full-time permanent positions, self-employed and full-time temporary workers account for around half of new entrants.

The sectors that contributed most to new labour market entrants in 1998 to 1999 are similar to those that contributed most to net employment growth over the period 1994 to 1999 . However, we find that there is an even stronger role for services, with construction the only non-service sector consistently in the top five sectors contributing most new entrants. However, higher value-added sectors such as computing are less important in providing new entrants with work compared to lower value-added work such as retail. New entrants in these sectors have a high probability of entering via non-standard work, but this probability is mediated both by national specificity and by the pattern of gender segregation of employment opportunities. In the female-dominated sectors, there is greater use of part-time work compared to the mixed sectors where use of full-time temporary positions and self-employment is also common. However, this gender make-up and organisation of sectors also varies at the national level. These results do, however, suggest that entry routes into service sector employment remain highly gendered, even for those who are by definition disadvantaged on the labour market - that is, they are without employment.

\section{Conclusions}

Services dominate new job growth for women and men, but the link with the share of all jobs that do not meet the 'standard' full-time permanent criteria that was typical of industrial employment is not simple. First, the 
overall level of non-standard work and the use of particular non-standard jobs follow country-specific patterns even within the same part of the service sector. Second, although there is a high level of consistency between countries in the sectors contributing most to net job growth, the non-standard composition of these sectors is less consistent. Third, nonstandard workers are often closely associated with services, but the evidence suggests that where the overall shares of non-standard workers are increasing it tends to be through increased use of these forms within sectors rather than structural shifts in employment. This diffusion of nonstandard jobs within sectors might be expected to reflect universal trends in the employer demands, but again the analyses presented here highlight the importance of country and sector specificity.

Although new entrants tend to have a higher probability of entering employment via non-standard work and there is similarity between countries in the sectors providing jobs for new entrants, the importance of national and gender influences should not be ignored. Furthermore, while there are parallels between the sectors that are contributing most to net job growth and those providing jobs to new entrants, the latter are more likely to be in lower value-added sectors than in higher value. Jobs in the information technology (IT) sector make a strong contribution to net job growth, but the sector does not appear among those that provide access for the non-employed. However, we have no information on whether exit from non-employment via these jobs leads to more secure positions in the labour market in the future or rather results in further spells of either non-employment or insecure work. Greater openness to the non-employed may also be associated with high job turnover, resulting from high exit rates from employment to non-employment. Nevertheless, the strong gender- and country-specific patterns of integration highlighted here have implications both for employment growth targets and patterns of labour market segmentation. The use of non-standard job forms, particularly part-time work, remains strongly gender-related, suggesting that the employment form may be influenced by the pattern of gender segregation as well as demands of the service. Although both women and men are entering non-standard jobs and the service sector is providing jobs for both genders, the gender segregation of employment means that employment opportunities in services differ for labour market groups. Access to the labour market through services depends upon the way jobs are created and how these employment forms interact with the national segmentation of the labour supply.

\section{Notes}

1 In this chapter, family workers are included with self-employed as nonemployees.

2 For Sweden and Finland the data are available only for 1995 to 1999. 


\section{Mark Smith}

3 This approach is less sensitive to the effects of large proportional changes in the size of small but fast-growing sectors and is also less likely to be affected by the Eurostat reliability guidelines for small cells.

4 Data for Sweden and Portugal have been excluded due to the small sample sizes.

\section{References}

Anxo, D. and Storrie, D. (eds) (2001) The Job Creation Potential of the Service Sector in Europe: Final Report 2000, European Commission, Employment Observatory Research Network, Luxembourg: Office for Official Publications of the European Communities.

Boje, T. (1996) 'Trends and Prospects for Women's Employment in Denmark in the 1990s', Manchester: Manchester School of Management, University of Manchester Institute of Science and Technology.

Bruegel, I. and Hegewisch, A. (1994) 'Flexibilisation and Part-time Work in Europe', in P. Brown and R. Crompton (eds) A New Europe? Economic Restructuring and Social Exclusion, London: UCL Press.

Commission for the European Communities (CEC) (1999) Employment in Europe 1999, Luxembourg: Office for the Official Publications of the European Communities.

- (2002) Employment in Europe 2002, Luxembourg: Office for the Official Publications of the European Communities.

De Grip, A., Hoevenberg, J. and Willens, E. (1997) 'Atypical Employment in the European Union', International Labour Review 136 (1): 49-71.

Dølvik, J.E. (2001) 'Determinants of Service Employment: An Overview', in J.E. Dølvik (ed.) At your Service? Comparative Perspectives on Employment and Labour Relations in the European Private Sector Services, New York: Peter Lang.

Felsted, A. and Jewson, N. (1999) Global Trends in Flexible Working, Basingstoke: Macmillan Business.

Frenkel, S.J. (2000) 'Introduction: Service Work and its Implication for HRM', International Journal of Human Resource Management 11 (3): 469-76.

Gallie, D., White, M., Cheng, Y. and Tomlinson, M. (1998) Restructuring the Employment Relationship, Oxford: Oxford University Press.

Gonäs, L. and Spånt, A. (1996) Trends and Prospects for Women's Employment in the 1990s in Sweden, Manchester: Manchester School of Management, University of Manchester Institute of Science and Technology.

González, P. and Castro, A. (1995) 'The Portuguese Labour Market: Did European Integration Make A Difference?', paper presented at the 17th Conference of the International Working Party on Labour Market Segmentation, University of Siena (July).

Meager, N. (1996) 'From Unemployment to Self-employment: Labour Market Policies for Business Start-Up', in G. Schmid, J. O'Reilly and K. Schömann (eds) International Handbook of Labour Market Policy and Evaluation, Cheltenham: Edward Elgar.

O'Reilly, J. and Bothfeld, S. (1996) 'Labour Market Transitions and Part-time Work', InforMISEP 54 (summer): 20-7.

O'Reilly, J. and Fagan, C. (1998) Part-time Prospects: Part-time Employment in Europe, North America and the Pacific Rim, London: Routledge. 
O'Reilly, J., Cebrian, I. and Lallement, M. (2000) Working Time Changes: Social Integration through Transitional Labour Markets, Cheltenham: Edward Elgar.

Organisation for Economic Co-Operation and Development (OECD) (2001) Employment Outlook 2001, Paris: OECD.

Rodgers, J. and Rodgers, G. (1989) Precarious Jobs in Labour Market Regulation: The Growth of Atypical Employment in Western Europe, Geneva: International Institute for Labour Studies.

Rubery, J., Smith, M., Fagan, C. and Grimshaw, D. (1998) Women and European Employment, London: Routledge.

Rubery, J., Smith, M. and Fagan, C. (1999) Women's Employment in Europe: Trends and Prospects, London: Routledge.

Townsend, A.R. (1995) Making a Living in Europe: The Geography of Economic Change, London: Routledge. 


\title{
4 Why do countries have such different service-sector employment rates?
}

\author{
Gerhard Bosch and Alexandra Wagner
}

\section{Introduction}

Compared with the USA, many European Union (EU) member states have low employment rates and a persistent employment deficit. This has generated much discussion of whether, where and how jobs can be created for those who are currently involuntarily excluded from paid work. Since employment levels in agriculture and the manufacturing industry have been declining continuously for years, the main opportunities for job creation are seen to lie in the service sector, which for many is now to all intents and purposes the only hope of finding employment. However, the reasons for the growth in service-sector employment and the ways in which such growth might be encouraged are now the subject of much controversy.

Economic theory suggests that the causes of the growth in service-sector employment lie primarily in the productivity and demand bias (Klodt et al. 1996; Anxo and Storrie 2001: 27). The demand bias means that, as incomes rise, the demand for services increases disproportionately (increasing income elasticity of demand). The starting point for the notion of productivity bias is that there are limits to the productivity gains that can be achieved in the service sector and that the opportunities for rationalisation are therefore not as great as in the other two sectors. Consequently, personnel requirements are greater, which in turn explains why the service sector's share in total employment is increasing. The conjunction of these two effects in an expanding economy gives rise to strong growth in the service sector. The notions of productivity and demand bias are helpful in the description of long-term macroeconomic trends. However, they do not explain why the level and structure of service-sector employment varies so much in countries with similar levels of economic development. This raises the question of why both demand elasticity and the productivity bias have very different effects in different countries. In order to understand these differences, we will have to dig deeper and look to the various countries as well as the various segments of the service sector itself for explanations for the differences in demand behaviour and the evolution of productivity. 
An initial opportunity to nuance the demand bias argument may be created by examining not only income growth but also the evolution of working time. The high-income elasticity of the demand for services is explained by the 'hunger for services' (Fourastie 1949): once demand for the products of the primary and secondary sectors has been satisfied, demand for services rises. Some services are luxuries that cannot be afforded until basic needs have been met. However, as incomes rise, people can also afford to reduce their working hours. A reduction in working time has both braking and accelerating effects on the demand for services. The braking effects are produced, first, by workers forgoing increased income, and hence purchasing power for services, in favour of free time, and, second, by the increased scope for engaging in activities that can replace the purchase of services. Scharpf (1990), however, observed some time ago that the consumption of many services is timeintensive and thus requires the consumer to have free time. This being the case, shorter working hours can also have a positive effect on the demand for certain services. Finally, a reduction in working time in the service sector can increase the employment intensity of growth in this area. Ultimately, the way in which increasing prosperity affects the demand for services can only be ascertained empirically. It is likely that different development paths are associated with different working time and income preferences, which are also influenced by cultural traditions and changing values. It is also likely that these different preferences influence not only the level of demand for services but also the structure of that demand. In societies with strong income preferences and long working times, demand is likely to be much more strongly concentrated on services that are less time-intensive and substitute for do-it-yourself activities (particularly daily reproduction work) than in societies with shorter working hours, in which people have more time to produce their own routine services as well as to consume more time-intensive and cultural and leisure services.

The productivity bias may also be broken down further, particularly by focusing not on the service sector in its entirety but rather on its various subsectors. A large part of all services can be rationalised to a great extent. Consequently, employment in these services will not grow as a result of below-average productivity increases. If it does grow, it will only be due to above-average increases in demand. In those services that are more resistant to rationalisation, the productivity bias may even restrict the growth in employment, since the relative price of these services will increase and demand remain low due to the high price elasticity. In order to ascertain whether this 'cost disease' (Baumol 1967) actually exists, price elasticities will have to be examined more closely.

The sociological debate on the service society also provides a number of indications as to the development of services. The typology we drew on in our first contribution to this volume is a product of sociological analysis 
of welfare states and it shows that not all services automatically grow as prosperity increases, as is assumed in the arguments based on the notions of income and productivity bias. Depending on the nature of the distribution of wealth, of the family division of labour and of welfare state transfers, services may be provided within or outside of the household. In the traditional single breadwinner model, for example, most women stay at home and provide services for themselves and the other household members. In dual-earner households, those services have to be purchased due to the shortage of time. On the other hand, the welfare state can fund services or subsidise households that provide their own. Thus the size of the service sector may to some extent depend on the model on which the welfare state is based.

Most theories on the growth of services are based on the standard juxtaposition of the three sectors of the economy. As a result, both economic and sociological theories have tended to ignore the fact that part of the growth in services is a direct consequence of changes within the first two sectors. The transition from mass production to high-quality production has increased the demand in agriculture and the manufacturing industry for services that firms can provide themselves internally or buy in from the service sector. This is now clearly recognised with respect to manufacturing industry and its demand for services that directly support the production process. However, the not inconsiderable volume of services provided to agriculture - agricultural research or certain areas of biotechnology, to cite just two examples - has received scant attention to date.

In many cases, the driving force on the supply side has also remained underexposed. The utility value of many services is far more difficult to estimate than that of manufactured or agricultural products. Potential purchasers of a car, for example, can examine the product and come to a decision on the basis of perceptible or measurable criteria, such as fuel consumption, design, engine power or consumer tests. In this case, it is an end-product that is being purchased. In the case of services, on the other hand, what is being purchased initially is often only the promise of a product. According to one common definition, services cause 'a change in the condition of a person, or a good belonging to some economic unit, which is brought about as the result of the activity of some other economic unit, with the prior agreement of the former person or economic unit' (Hill 1977). In the case of a haircut or a massage, the result can still be assessed directly, but the effects of education or advice services, for example, can often be ascertained only at some point in the future, if at all. Why should customers spend considerable sums of money on services whose effects they can scarcely evaluate? Since many services are purchased on trust, as it were, demand depends essentially on the confidence the customer has in the provider. The provider's professionalism, quality and reputation are some of the most important confidence-building attributes, and can therefore increase demand for the services provided. 
A final aspect that often receives little attention in the debate on services is individual countries' specialisation in certain services. Services can be imported and exported in open markets. It is by no means only services not tied to location that can be exported. The export of services that are tied to location takes place through sales to foreign tourists and business travellers. This specialisation emerges particularly clearly from a comparison of the service structures of small countries, since such countries are unable to develop the entire range of services equally. As in the case of manufactured goods, there is an international division of labour in a number of services. Thus, for example, not all countries can become international financial centres, while tourism will be more strongly concentrated in those countries that are most attractive in terms of climate, scenery and infrastructure. Large countries such as the USA can offer all these functions, although they are likely to be concentrated in certain locations. Because of the differences in size alone, there is little point in comparing the service structures of the USA with those of European countries. At best, individual states in the USA might be compared with individual EU member states.

This brief survey of the service debate in various disciplines has brought to light a number of possible reasons for the expansion of services. The following conclusions may be drawn.

The expansion of services is not an automatic by-product of economic growth but is also dependent on individual and societal decisions on values. Such decisions primarily affect the distribution of prosperity, the family division of labour, working-time preferences and the design of the welfare state. Consequently, it is likely that individual countries will have their own national development paths.

Since the level of service-sector employment also depends on societal decisions on values, which may be taken in very different ways, national differences in the level and structure of service-sector employment are to be expected. To that extent, it makes little sense to conclude from such differences - between the employment rate in the service sector in the USA and the EU, for example - that there is a 'service gap'. Such language is simply a temptation to draw hasty political conclusions, since 'gaps' have to be filled. ${ }^{1}$ It is necessary first of all to understand and explain differences. It then has to be ascertained whether there are forces driving developments in such a way as to produce convergence between the developed industrialised countries or whether deliberate decisions have been taken to follow different routes.

The service sector is itself very heterogeneous. The causes shown in Figure 4.1 affect individual subsectors in very different ways. It remains to be established which of these causes is important to the development of individual subsectors and to what extent they exert their influence.

The rest of this chapter is given over to an investigation of the link between the influencing factors summarised in Figure 4.1 and the level of 


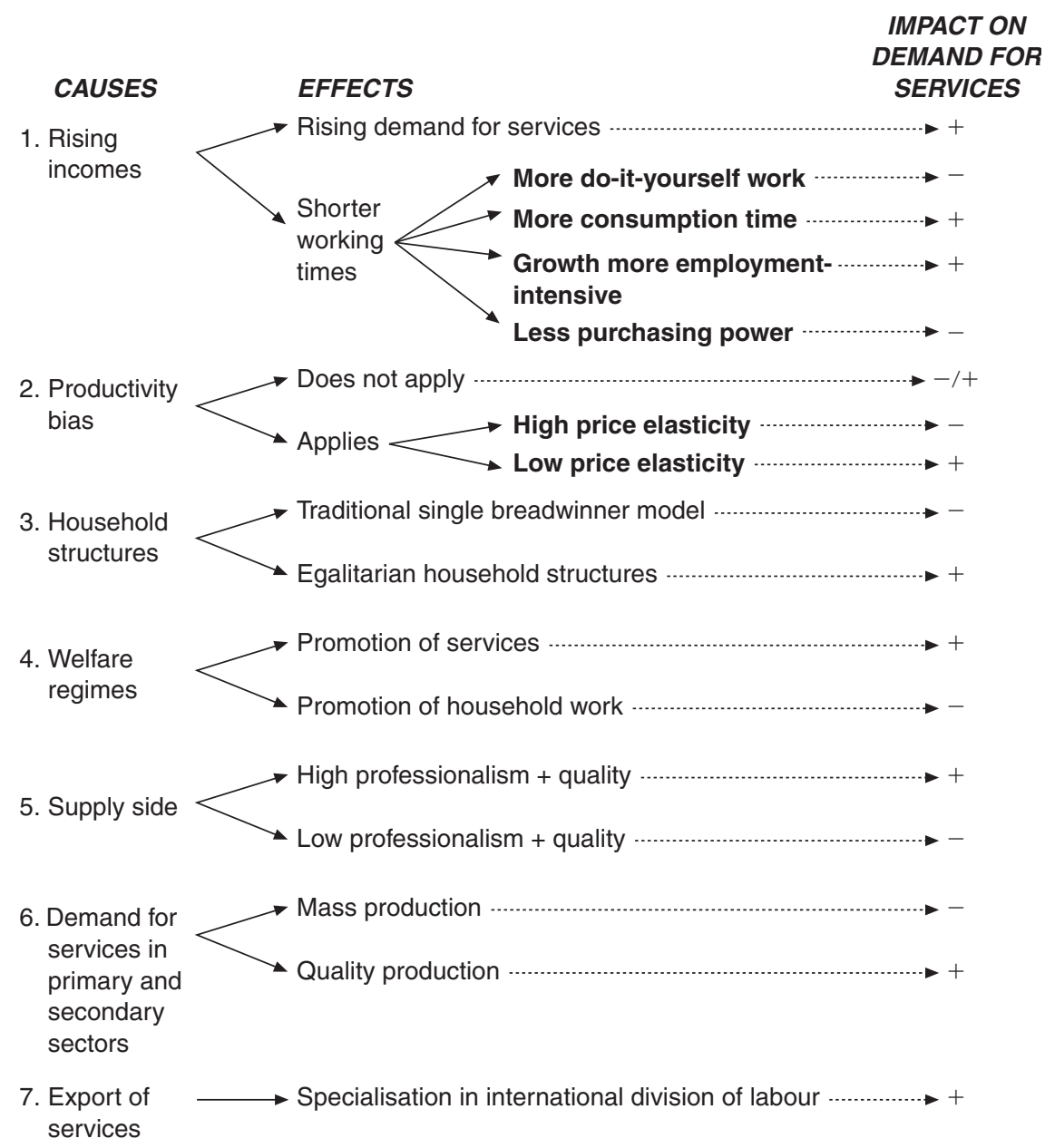

Figure 4.1 Causes of service-sector expansion (source: own representation).

service-sector employment in EU member states as a whole and in individual subsectors. We start by examining the notions of productivity bias and cost disease. Attention then turns to the connection between household structures and service-sector employment in the third section, and between the welfare state, welfare state regimes and the demand for services in the fourth section. The fifth section deals with the impact on service-sector employment of the transition from mass to customer-driven, high-quality production. The sixth section focuses on the effects of the supply side on the demand for services. In the seventh section we investigate the contribution of working time to the evolution of employment in the service sector. In the eighth section developments in the USA are 
brought into the picture in order to show that there are two different development paths. By way of a conclusion, some observations are offered on a viable service-sector strategy for the European Union.

We use data from Eurostat's European Labour Force Survey and other sources in order to establish, by means of correlation calculations, the connection between individual influencing factors, and the volume of service-sector work. ${ }^{2}$ The volume of service-sector work is measured by weekly hours per person in working age. We referred to this indicator instead, using employment rates because it is not influenced by the different duration of working hours in the various countries, which we analyse separately. ${ }^{3}$ Multivariate analyses cannot be carried out due to the small number of cases (fifteen EU member states) and the reciprocal interconnection between the influencing factors. Since the industrial structure cannot be disaggregated to the level required for a detailed analysis and because it is also impossible to assign industries unambiguously to individual factors, ${ }^{4}$ the connections can be only approximately depicted. In some cases, contrary and therefore partially compensatory trends ${ }^{5}$ are concealed behind a connection established by a correlation calculation. Furthermore, the variables used in the correlation calculations may themselves contain further influencing factors that cannot be isolated. Consequently, the correlation calculations have the mainly heuristic function of verifying and extending the theoretical deliberations outlined above.

\section{Services and the cost disease}

Baumol (1967) was the first to advance the notion of cost disease in respect of services. He makes a distinction between a sector in which there is scope for intensive rationalisation and a sector that is resistant to rationalisation. If wages in the latter rise at the same rate as in the former, then prices will have to increase considerably due to the lower productivity gains. Because of these higher prices, the demand for services in the sector resistant to rationalisation will decline. Baumol's cost-disease principle has been attacked many times. Many authors (e.g. Klös 1997; Scharpf 1997) see the high wages and low pay differentials in many European countries as an important - if not the decisive - restraint on the expansion of labour-intensive personal and social services. There is virtually no possibility, it is argued, of reducing the cost of these services through rationalisation measures. Since the demand for services is also very price-sensitive, these services will be squeezed out of the market. In order to increase the potential demand, so the argument runs, costs have to be reduced by increasing the pay differentials between manufacturing and service-sector workers, in other words, by cutting wages in the service sector in relative terms. ${ }^{6}$

In order to test the soundness of these arguments, we correlated the 
income distribution in EU member states - measured by the relationship of the top 10 per cent of the wage hierarchy to the bottom 10 per cent (P90/P10) - with the volume of work in the service sector as a whole and in personal and social services, measured in hours per week per person of working age. In doing so, we were testing whether or not there is a connection between a highly unequal income distribution and the volume of services. We took as our starting point the distribution of net rather than gross income, since individual purchasing power depends on disposable income. The net incomes calculated by Eurostat include all state transfer payments.

The link between income inequality and the general weekly volume of services per person in working age is negative and significant (Figure 4.2) but not especially strong. The same applies to the link between income inequality and the volume of production-oriented and distributive services. This means that greater income inequality tends to be accompanied by a lower volume of services in the areas in question, although the link is not very strong.

On the other hand, the correlation between income inequality and the volume of work in social and personal services is strongly negative and highly significant (Figure 4.3). The more unequal the income distribution, the lower the volume of work in such services, while the more egalit-

Correlation: -0.52

$p=0.034$ (significant at the 0.05 level)

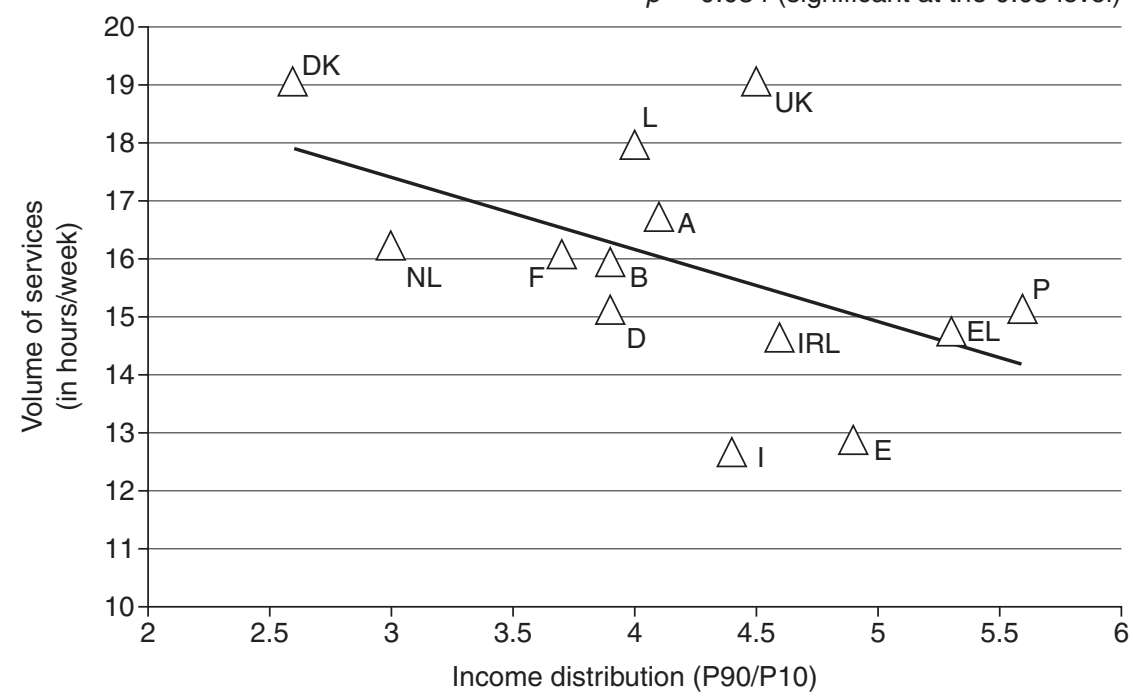

Figure 4.2 Income distribution (1994) and the weekly volume of services per head of population of working age (1999) (source: European Labour Force Sample Survey (1999); European Household Panel (Eurostat 1998: 176) and own evaluation). 


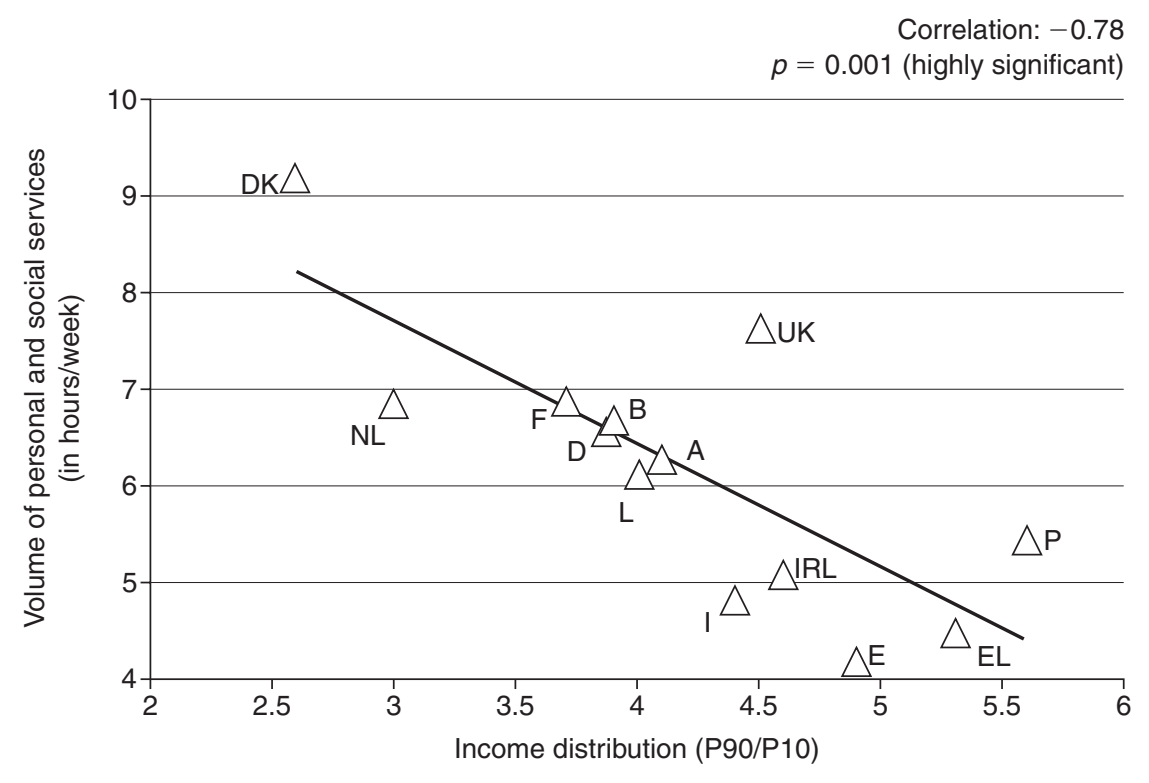

Figure 4.3 Income distribution (1994) and the weekly volume of social and personal services per head of population of working age (1999) (source: European Labour Force Sample Survey (1999); own evaluation; European Community Household Panel 2 (Eurostat 1998: 176)).

arian the income structures, the greater the demand for social and personal services and the corresponding volume of work.

For individual subsectors, however, positive correlations may be found between income inequality and the volume of work (Table 4.1). The correlation between income inequality and the volume of work in consumeroriented services (NACE 95 and 55 - hotels, restaurants, private households) is strongly positive $(+0.86)$ and highly significant. However, we suspect that in the case of hotels and restaurants (NACE 55) the wage spread is not the decisive influencing factor. In the European division of labour, the Southern European countries, with their high income inequalities, have specialised in tourism. The situation is different in the case of services to private households. It seems a likely supposition that in countries with greater pay differentials, there will tend to be a demand from wealthier households for such services, while at the same time the labour supply for such low-paid work will be greater than in countries with more equal income distributions.

These findings are consistent with Organisation for Economic Cooperation and Development (OECD) calculations, although they differ somewhat in the details. The OECD was unable to find any link between wage differentiation and the general employment or unemployment rate 
Table 4.1 Correlations between income inequality (1994) and weekly volume of work in services per head of population of working age (1999)

\begin{tabular}{llc}
\hline $\begin{array}{l}\text { Volume of work in hours per week } \\
\text { per person of working age }\end{array}$ & \multicolumn{2}{l}{ Correlation with income distribution P90/P10 } \\
\cline { 2 - 3 } & Strength of correlation & Significance \\
\hline Service sector as a whole & -0.520 & $*$ \\
Social and personal services & -0.776 & $* * *$ \\
Services to private households & 0.645 & $* *$ \\
Consumption-oriented services & 0.864 & $* * *$ \\
Distributive services & -0.512 & $*$ \\
Production-oriented services & -0.573 & $*$ \\
\hline
\end{tabular}

Source: Eurostat (1998); own calculations.

Notes

* $\quad$ significant at the 0.05 level.

** significant at the 0.01 level.

$* * *$ significant at the 0.001 level.

(OECD 1996). It is important at this point to give some indication of orders of magnitude. In those countries in which social and personal services are highly developed (Denmark, Finland, Sweden and the UK), the volume of work in this area is seven to thirteen times higher than in consumer-oriented services and more than 100 times higher than in services to private households. Greater income inequality would presumably be positively reflected only in services to private households, but such services have only a small share in the total volume of services. On the other hand, the particular conditions in those Southern European countries where the tourist industry is highly developed (Portugal, Greece, Italy and Spain) cannot of course be transferred to other EU member states.

\section{Household structures and services}

The overall level of services provided in a society may be calculated by summing paid (commercially provided) and unpaid (produced by household work) services. Many services are produced in households or in informal networks without any money changing hands. They play a very important role in social reproduction and welfare. In a report for the United Nations, Goldschmidt-Clermont and Pagnossin-Aligisakis (1995) evaluated time budget studies from various countries and attempted to establish the share of paid and unpaid work. They make a distinction between (1) personal (non-economic) activities such as personal care, education/training, social activities, hobbies and so on, (2) paid work, and (3) unpaid economic work such as the production and preparation of food, childcare, care of the sick or elderly, building and repair work, and community work. Unlike a personal activity, an economic activity can be delegated to a third party. Meal preparation, for example, can be dele- 
gated, whereas listening to music cannot. At the beginning of the 1990s in West Germany, for example, around 60 per cent of men's economic activities consisted of paid work and 40 per cent of unpaid activities. For women, the situation was reversed; because of their low employment rate and shorter working times, the shares were 30 and 70 per cent respectively. On the other hand, in Denmark where the female employment rate is higher, women spent more time on paid than on unpaid economic activities.

We assume that the growth of paid services is also connected with the outsourcing of economic activities from households. The most important reason for such outsourcing is probably the rising employment rate among women. As women are becoming better qualified and changing their aspirations, they are entering the labour market in ever greater numbers. However, men are not reducing their paid working time to the same extent. As a result, the time available to households for do-it-yourself work is diminishing. Households are then obliged to acquire services in the market or forgo them altogether. The declining birth rates in many European countries indicate that not all services are being outsourced from households but are being dispensed with altogether, presumably due to a lack of available or affordable services. Similarly, standards of cleanliness or the quality of meals can be reduced, or time-consuming household services can be replaced by industrial products, such as non-iron clothes, washing machines and dishwashers, ready-made meals, paper flowers or low-maintenance artificial lawns. Since the relative prices of such industrial products have fallen, as Ott demonstrated impressively by taking the example of ready-made meals (Ott 1997), services are to some extent being substituted (Gershuny 1983).

In order to investigate the connection between the female employment rate and the level of paid employment in social services, we correlated the volume of work done by women with the volume of work in social services, per person of working age in each case. We also monitored the effect of the expansion of the welfare state, since the demand for social services is shaped by the arrangements put in place by the welfare state. The correlation between the level of female employment (measured in weekly working hours per woman in working age) and the weekly volume of social services is 0.65 , which nevertheless explains 43 per cent of the variation (Figure 4.4). This means that as women enter the labour market, social services can be developed on a commercial basis. On the other hand, there is, as expected, no significant correlation between women's economic activity and other services.

The same result is obtained if account is taken not solely of the volume of work done by women but of that done by both partners in two-adult households. The average weekly working time of both partners in twoadult households is also positively correlated with the volume of personal and social services (Figure 4.5). The reason why the correlations between 


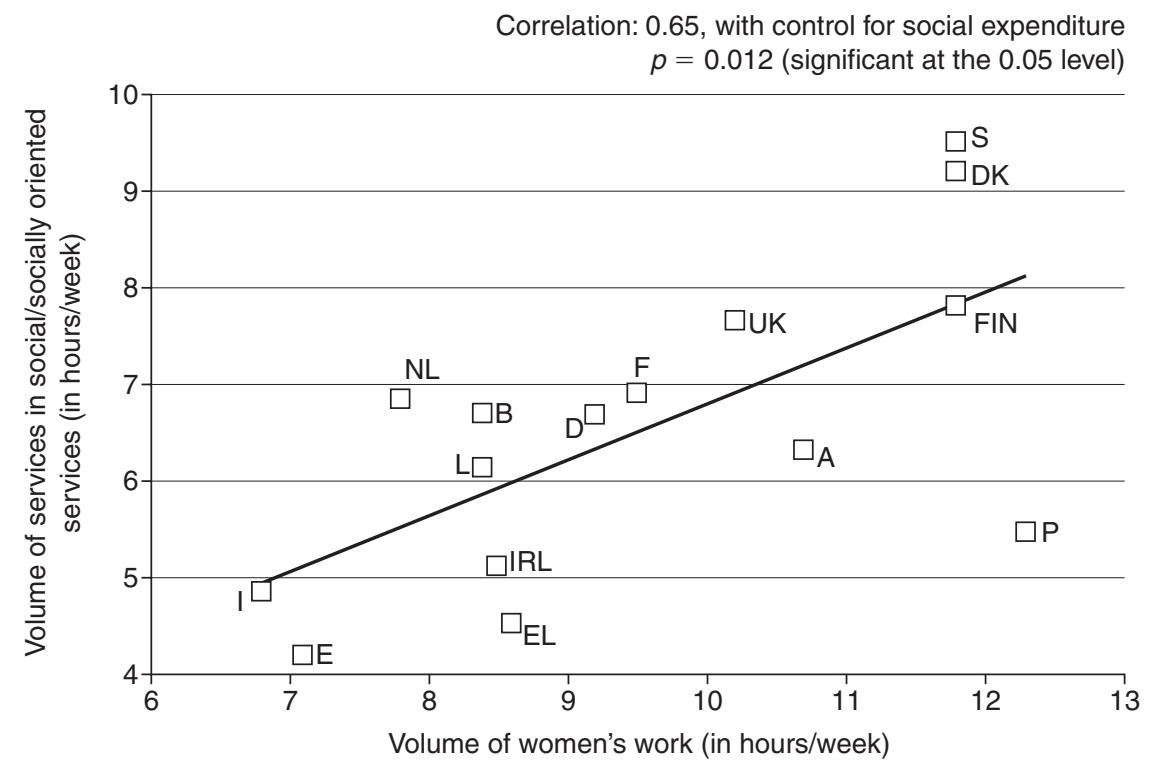

Figure 4.4 Volume of work done by women per head of population of working age in hours per week and weekly volume of services per head of population of working age in social/socially oriented services (source: European Labour Force Sample Survey (1999)).

women's volume of work and the volume of paid work in two-adult households on the one hand, and the volume of work of personal and social services on the other is not even stronger is to be found in other influencing factors. In many countries, couples with high work volumes have fewer children than couples in which the woman either does no paid work or is employed only part-time. Furthermore, the demand for personal and social services is also influenced by other factors, such as - in particular income level and the desire for services of reliable quality. Thus not only is the outsourcing of care for the elderly from households necessary due to households' increasingly tight time budgets but it also requires the availability of services of a quality acceptable to customers (cf. Chapter 6 by Anxo and Fagan, this volume).

\section{The welfare state, welfare state regimes and services}

With the emergence of a society in which human knowledge is playing an increasing role, services necessary to the formation, maintenance, reproduction and protection of human capital are becoming more and more important. These services cannot generally be adequately provided through the market. Most social services are labour-intensive and can be 
Correlation: 0.59

$p=0.012$ (significant at the 0.05 level)

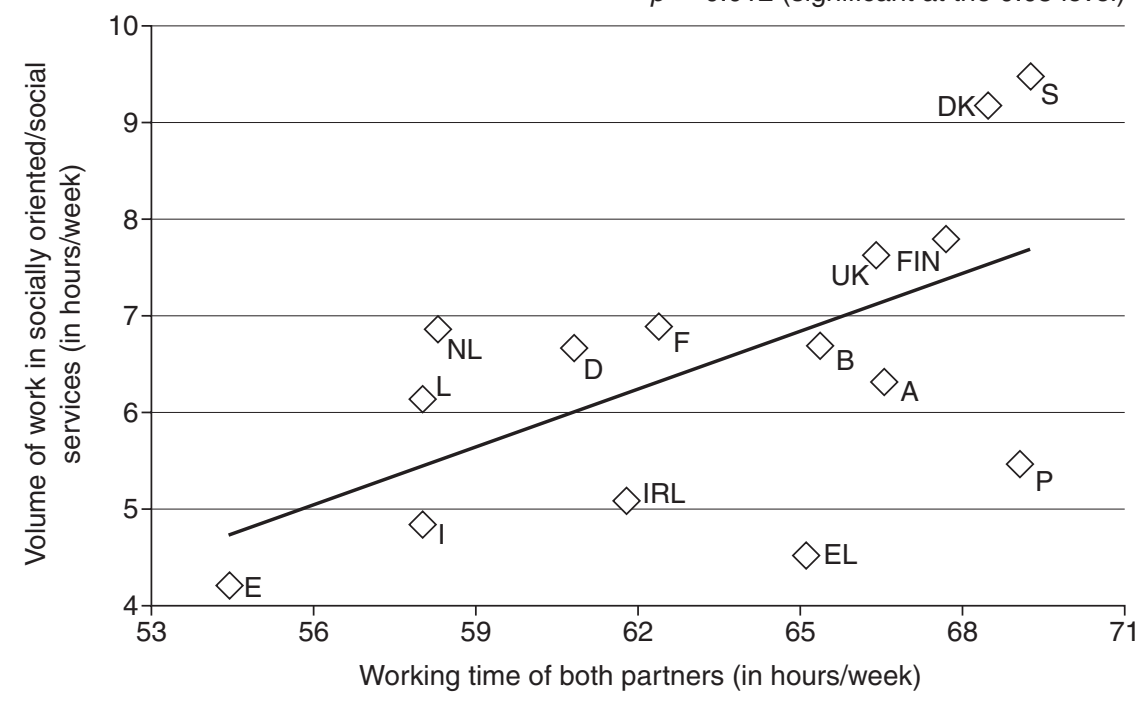

Figure 4.5 Average weekly working times of both partners and weekly volumes of work in socially oriented/social services per head of population of working age (source: European Labour Force Sample Survey (1999); own evaluation; household data from the Work Options of the Future conducted by the European Foundation for the Improvement of Living and Working Conditions in Dublin (Bielinski et al. 2002)).

rationalised only to a limited extent. Many of them require high skill levels, which further increases their price. For many such services, such as those required in the event of a risk occurring (e.g. illness, unemployment, accident), demand is sporadic but intense when it actually materialises. Because of their high cost, many potential consumers could not afford such services if they had to pay the full price themselves. The high cost of individual risk insurance also acts as a deterrent. And for certain risks, such as unemployment, the private market does not in any case offer any appropriate insurance. To that extent, the notion of cost disease certainly applies to such services. If they were provided solely through the market, many of those in need of them could not avail themselves of them. This inability to make use of education, health and care services would have considerable negative consequences on the quality of human capital as well as on national prosperity and social cohesion. In a purely market-driven education system, demand would depend on individual income. The result would be a system segmented by income group, with all the social inequalities that would entail. The same would apply to the healthcare system, health and safety at work, and care services. In many 
cases, there would not actually be any demand because households could not afford the services. Parental income would be reflected directly in the state of children's teeth or their educational level. Equality of opportunity would be fundamentally restricted and the ensuing social inequality could give rise in turn to social tensions and political instability. In order to improve equality of opportunity, to increase economic efficiency by treating human capital more carefully, and to avoid social conflict, various instruments have been developed with a view to overcoming cost disease as it applies to these cost-sensitive services. They range from services funded out of taxation so that they are free at the point of delivery (e.g. education), via insurance schemes (e.g. health, retirement, unemployment and nursing insurance) and levies on employers (e.g. occupational health and safety) to means-tested grants, contributions or vouchers. These funding mechanisms help not only to create demand in the first place but also to ensure that services of suitable quality are provided to satisfy that demand and that it is distributed in a socially equitable way. Because of their fundamental importance for the individual and the individual's immediate and wider social environment, demand for these services, or provision against risk, is not a matter of choice but obligatory (e.g. compulsory education or insurance).

For the reasons outlined above, it may reasonably be assumed that the demand for social services is closely linked to social expenditure. In fact, the correlation between the share of social expenditure in GDP and the volume of work in social services is very high and highly significant (Figure 4.6). The coefficient of correlation is 0.87 and explains 76 per cent of the variation. There are probably two reasons why the correlation is not even higher. First, welfare states are different. In some countries, the tendency is to subsidise household work rather than provide paid services. Thus the employment intensity of the German welfare state model, for example, with its tax 'splitting' for married couples and child-raising allowance, is lower than that of the Swedish model in which there is a good supply of childcare facilities, and staying at home for women is no longer encouraged by the tax system. Second, regulations can be put in place to ensure that substitutes are provided through the market (e.g. an obligation to take out insurance in a private insurance system), which is not reflected in government social expenditure. Nevertheless, the results clearly show that the welfare state is one of the key mechanisms in overcoming cost disease.

\section{The demand for services in the manufacturing industry}

The sectoral shift in employment and the creation of value-added does not mean that services are expanding wholly independently of the production of material goods in agriculture and industry. Despite the decline in employment levels, no fewer goods are produced in the primary and 
Correlation: 0.87

$p=0.000$ (significant at the 0.001 level)

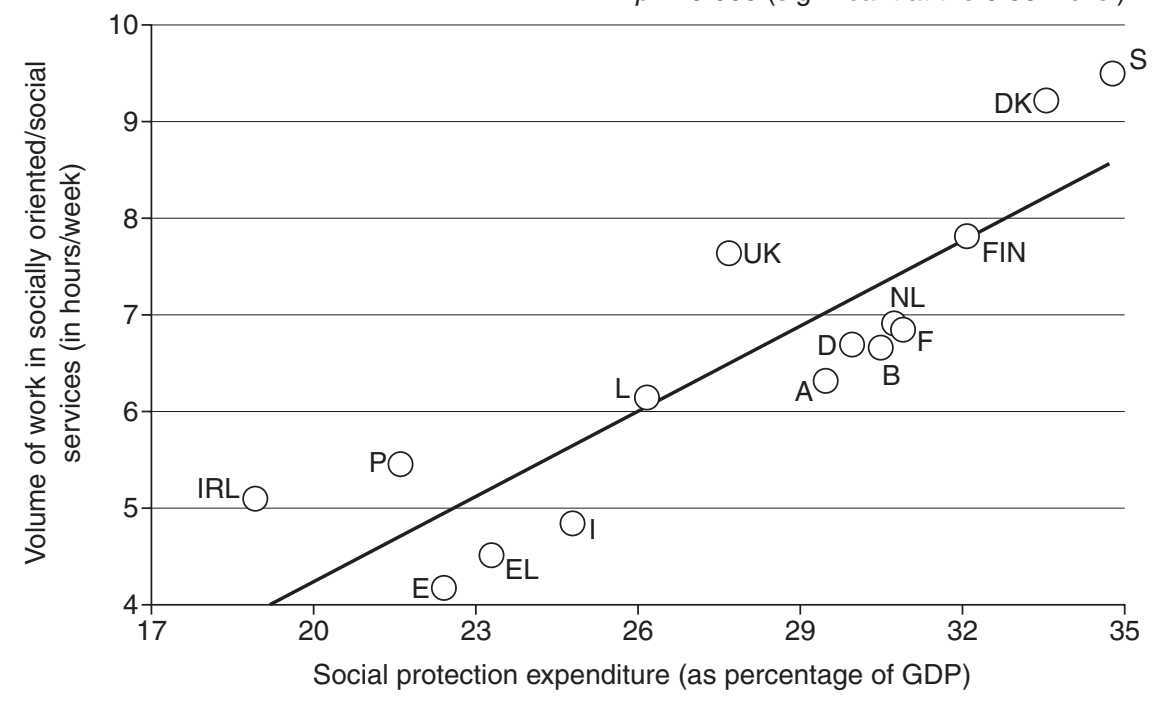

Figure 4.6 Expenditure on social protection and the weekly volume of work in social services per person in working age (source: European Labour Force Sample Survey (1999); own evaluation; Eurostat: European system of integrated social security statistics (ESSOSS) (1997)).

secondary sectors than in the past. Indeed, quite the opposite: if input and output in these two sectors is measured in material rather than monetary terms, then it is clear that, when it comes to the consumption of natural resources, we are most certainly not living in a dematerialised service society but in an agrarian and industrial society whose environmental 'footprint' is actually increasing (Hennicke 2002). The enormous increase in productivity in the first two sectors, the development of global valueadded chains and even the improvement in product quality are increasingly linked to services, whether upstream (e.g. R\&D and design) or downstream (e.g. sales, advice, after-sales service) of the production process or concomitant with it (e.g. accountancy and personnel services, advertising, production management). Producers can source these services internally or externally.

Martinelli (1991) identifies capital concentration, the development of multinational groups, the increasing globalisation of markets and competition, and the development of ICTs as the forces driving the growing demand for services. It is undeniable that the expansion of markets requires more services and that large companies operating globally have to expend more on coordination. However, the nature of the products plays an equally important role. If only uncomplicated, 
standard products are being marketed, then expenditure on $\mathrm{R} \& \mathrm{D}$, design, consultancy and customer services can be kept within reasonable limits. One important force driving demand for production-oriented services is the transition from standardised mass products to customer-oriented, high-quality products. High-wage countries, such as most EU member states, have already concentrated on such service-intensive products and will have to do so to an increasing extent in future.

This link between high-quality production and the internal tertiarisation of manufacturing companies has already been established in a number of studies. Lay and Rainfurth (2002), for example, show that, in the case of Germany, firms in the capital goods industry that manufacture one-off products deploy 11.2 per cent of their workforce on support services for the production process, while those engaged in large-batch/mass production allocate only 6 per cent to such services. In addition to manufacturing industry's need for internally produced services, demand is also growing for externally sourced services. In view of the increasing integration of the sectors, it is hardly surprising that the service sector is growing most in those countries where manufacturing industry is strong. This has been established by Eberts and Erickzek (2001) in the case of the USA, and by Dathe and Schmid (2001) in the case of Germany.

Our data also show a clear connection between the weekly volume of work in production-oriented services and research expenditure per person of working age, which is one of the indicators of innovation in industry, at whose processes and products the greatest share of $R \& D$ spending is targeted (Figure 4.7). ${ }^{7}$ The correlation is even greater if special influences are excluded. Thus, despite its only moderate level of R\&D expenditure, Great Britain has the highest volume of work in production-related services by virtue of its specialisation as an international financial centre. If Great Britain is excluded, the correlation between the volume of work in production-oriented services and research expenditure per person of working age is actually 0.82 .

\section{Quality of the supply}

The effect of many services, particularly consultancy, education and the health service, cannot be directly evaluated since it does not manifest itself until long after the service has been provided, and even then it can scarcely be isolated from other effects. Demand for such services often exists only when they are professionally provided and the customer has confidence in the employees providing the service, who offer not a standardised product but one tailored to individual wishes and requirements. The quality of such services is increasingly dependent on the organisational and technical support that the service providers receive. One only needs to think of the multifarious technical support services provided for 
Correlation: 0.71

$p=0.002$ (significant at the 0.01 level)

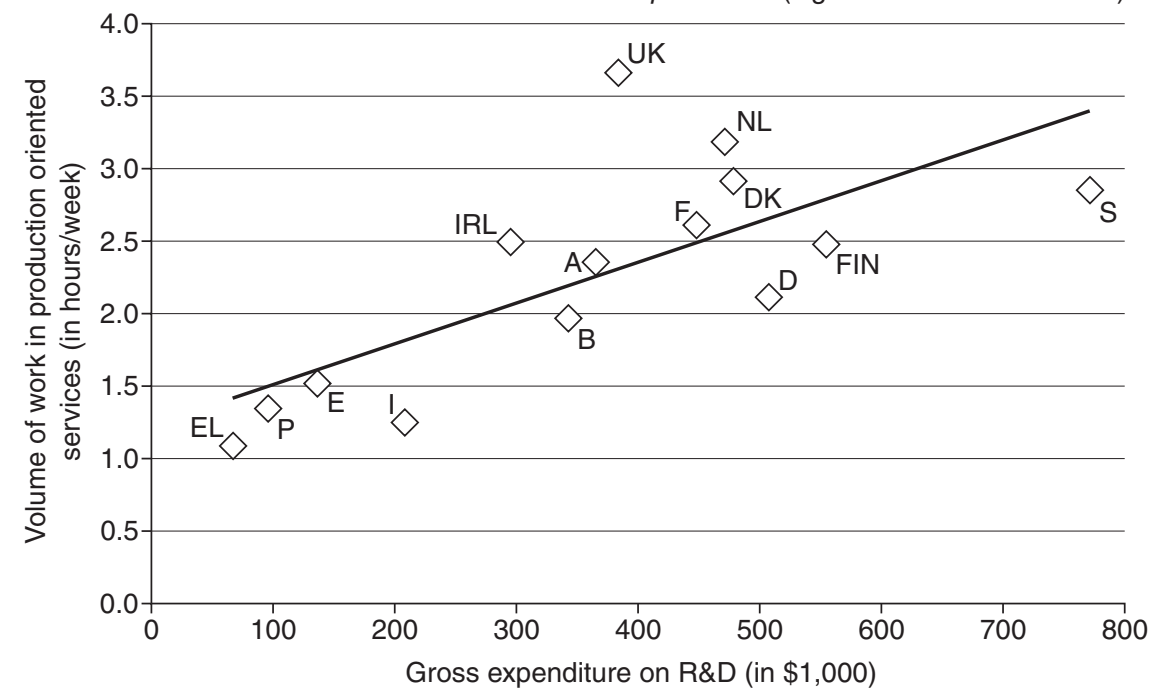

Figure 4.7 Research expenditure per capita in purchasing power parities (1997) and weekly volume of production-related services per person in working age (1999) (source: Eurostat; OECD).

the medical profession. This organisational and technical embedding is also an important instrument for rationalising these services and making them affordable. Thus, professionalism, quality and innovation not only help to develop demand but are also means of stemming the cost disease that afflicts many services (Beyer et al. 2002; Tronti et al. 2001; Weinkopf 2000).

We chose employee qualifications as a rough indicator of the professionalism and quality of services. Since the qualification systems of the various countries differ considerably and many activities are regarded as high level in one country and intermediate level in others, we tested only the correlation between the proportion of employees with low-level qualifications and the proportion of employees in the service sector. As expected, the correlation is strongly negative and highly significant (Figure 4.8). The higher the proportion of workers with low qualificational levels in the economy as a whole, the lower the proportion of economically active individuals engaged in service activities.

\section{Employment intensity in the service sector}

In all EU member states, average working times are shorter in the service sector than in manufacturing. The reasons for this are to be found on 


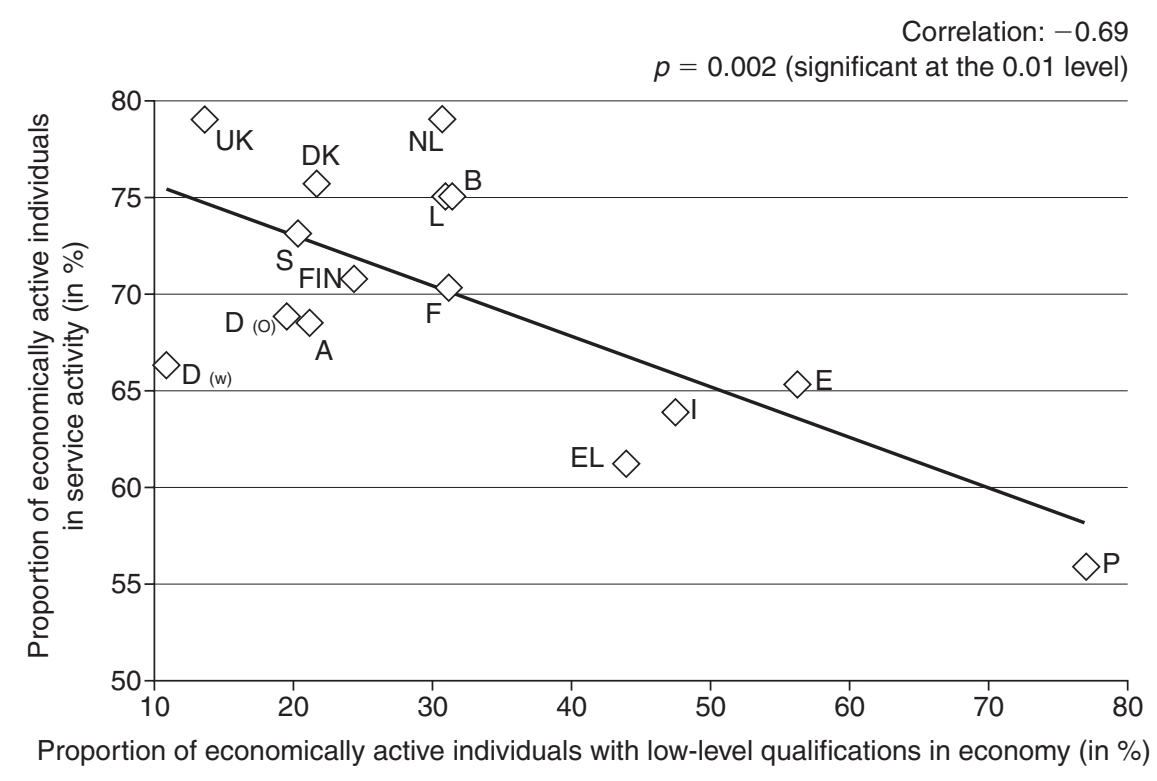

Figure 4.8 Proportion of economically active individuals with low qualificational levels in the economy as a whole and proportion of economically active individuals engaged in service activities (source: Eurostat; own evaluations).

both the supply and demand sides. First, the service sector employs aboveaverage numbers of women as well as high-school and university students who, for various reasons (perceptions of gender roles, child-rearing, studies, housework), are available for work only on a limited basis and have a preference for shorter than normal working hours (Voss-Dahm 2002). Second, firms - particularly those in labour-intensive service industries with high price elasticity of demand - seek to cut their costs by precisely adjusting working times to workloads. When demand fluctuates considerably over the course of the day or week, such adjustment is easier if the total volume of hours required is broken down into small time units (Lehndorff 2002).

In all EU member states apart from Portugal and Sweden, the difference in working time between the manufacturing and service sectors has increased in recent years. In 1999, the biggest differences were in Great Britain and the Netherlands (6.4 and 4.9 hours per week respectively). Thus the expansion of service-sector employment is being sustained by a greater reduction in working time in that sector in most countries, particularly as a result of the increase in part-time working and the smaller volume of overtime worked in highly feminised service industries than in the male-dominated manufacturing sector. The correlation between the difference in working time between manufacturing and 
services and employment rates in the service sector is significant and positive. In 1999 it was 0.53.

The relatively shorter working times in the service sector have consequently contributed to the sectoral shift in employment shares. The employment rate in the service sector would be lower in all EU member states if working times there were as long as in manufacturing (Figure 4.9). This effect is particularly marked in Great Britain and the Netherlands. If working times in the service sector were the same as in manufacturing, employment rates in the service sector would be, respectively, 7.7 and 6.6 percentage points lower than the current values.

However, the employment effects of working times cannot be extrapolated into the future. As women become increasingly integrated into the labour market, as the childcare infrastructure is developed (including, in some countries, the introduction of all-day school), and as men's workingtime patterns change, it is quite possible that the differences in working time between men and women and between the various sectors will decline or at least not become any greater. Thus in Sweden and Denmark, part-time rates have declined in recent years and part-timers' average working times have increased considerably. However, in other countries, particularly in those where female employment rates have hitherto been low (Spain, Greece and Italy) and traditional household structures remain in place (Great Britain, Ireland, Germany and the Netherlands), the employment effect generated by working time may make an even greater contribution to the expansion of services in future.

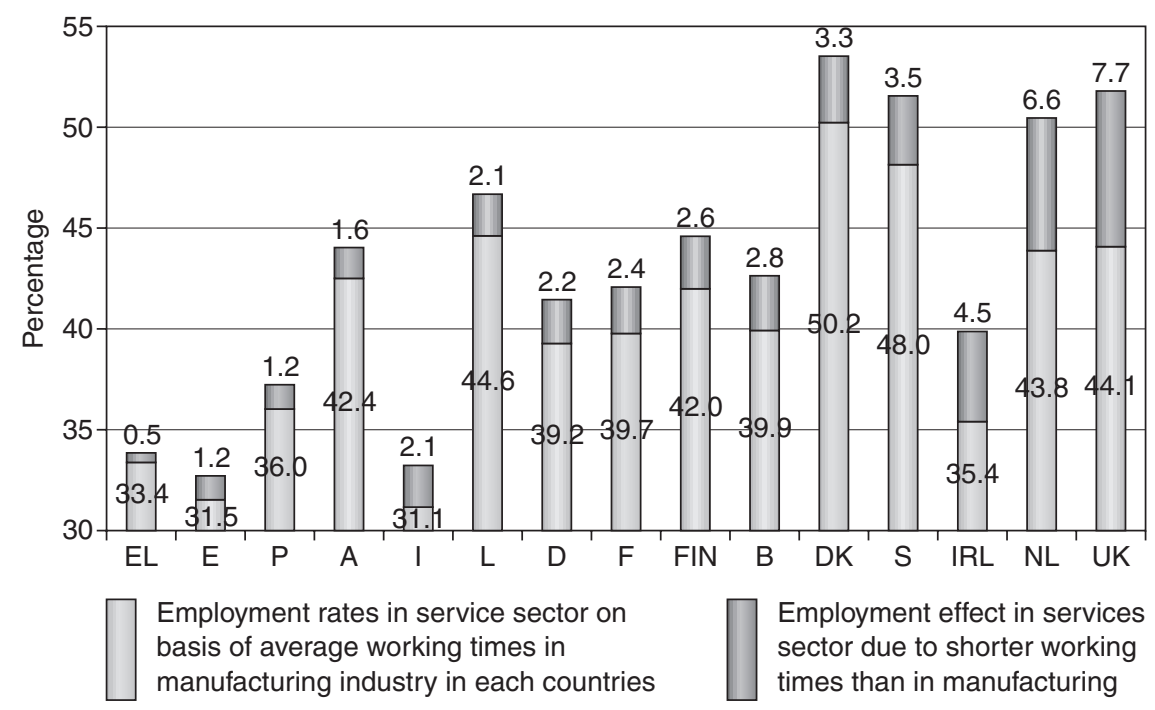

Figure 4.9 The employment effect of shorter working times in services relative to manufacturing (source: Eurostat; own calculations). 


\section{Different development paths: societies with high and low volumes of market services}

Up to this point, our analysis has focused on Europe. This obviously restricts the range of conclusions about a universal theory of services that may be drawn from the data presented to date. Under different institutional, social and economic conditions, different cause-effect chains may well develop. This becomes clear if the USA, for example, is included in the analysis. ${ }^{8}$

The USA is characterised by a combination of a high employment rate and long and, in the past, rapidly increasing working times. A number of European countries (Denmark, Norway and Sweden) have comparable or, in some cases, even higher employment rates than the USA. These countries have already achieved the EU's declared objective of bringing member states' employment rates up to the US level (European Commission 2004). However, if one examines the volumes of work performed with comparable employment rates, enormous differences between the countries become apparent. The average working times of employees in Europe are considerably shorter than in the USA, and in many cases would be regarded there as part-time work.

No attempt has yet been made to explain these differences in the volumes of work done with similar employment rates in societies of comparable levels of economic development. These differences could be attributed to causes on both the supply and demand side. On the demand side, one could point to the far higher demand per head of population of working age in the USA. The savings rate in the USA is far lower than that in most European countries. Investment is funded not from domestic savings but from capital imports, which are giving rise to increasing indebtedness (OECD 2001a: 169ff.). Financial and monetary policy in the USA has been more expansionary than in most EU member states. However, we do not intend to investigate this aspect in any depth here. The supply side is of greater significance for the arguments developed below. The annual volumes of work per head of population of working age are around 14 per cent higher in the USA than in Sweden, around 30 per cent higher than in Germany and the Netherlands, and around 38 per cent higher than in Italy (Table 4.2). The explanation for these differences would be simple if they were converted into correspondingly higher unemployment rates in those countries with lower volumes of work. However, this is generally not the case. In the Netherlands, for example, the unemployment rate is actually lower than it is in the USA. Thus, we have to explain how there can be points at which the supply and demand curves in the labour market intersect with completely different volumes of paid work.

The key to the puzzle lies in the notion of the backward-bending labour supply curve (Prasch 2000; see also Figure 4.10). In traditional economic theory, the labour supply declines as wages fall, since it is no longer 


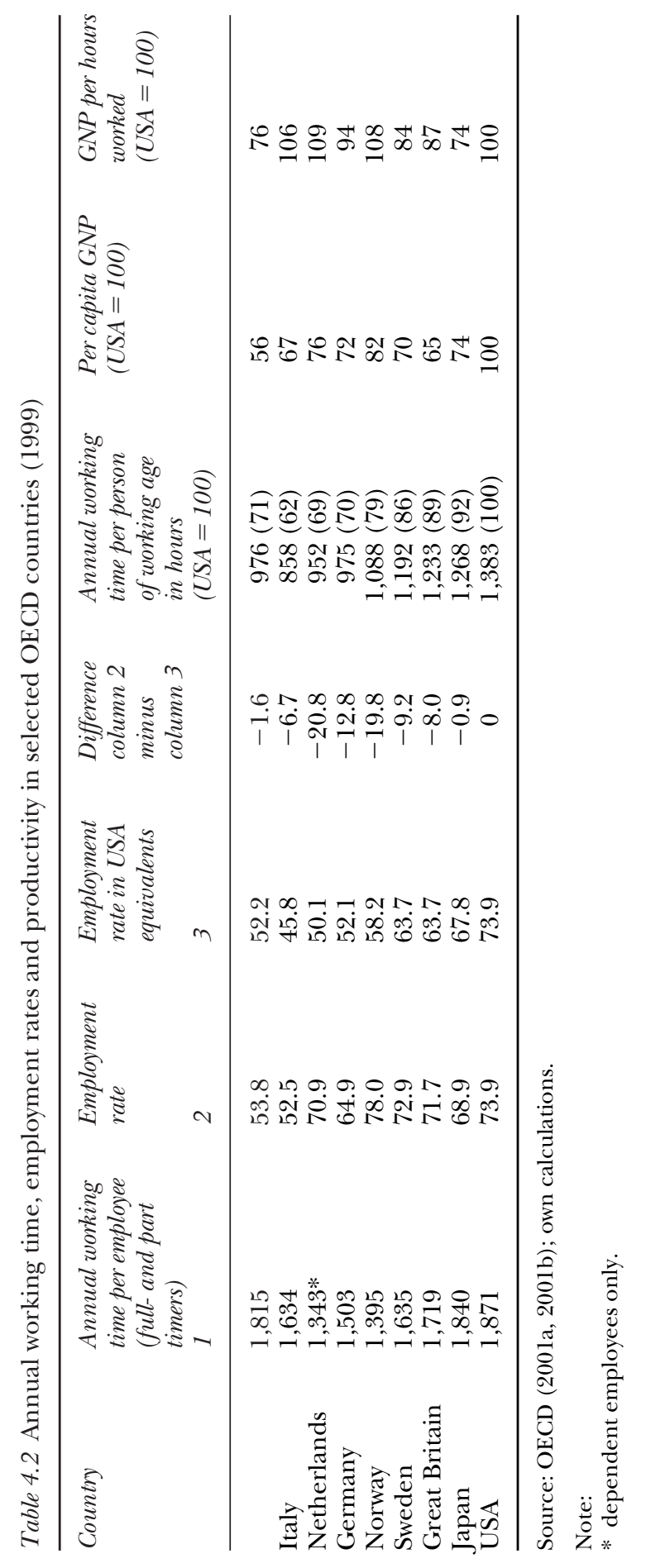




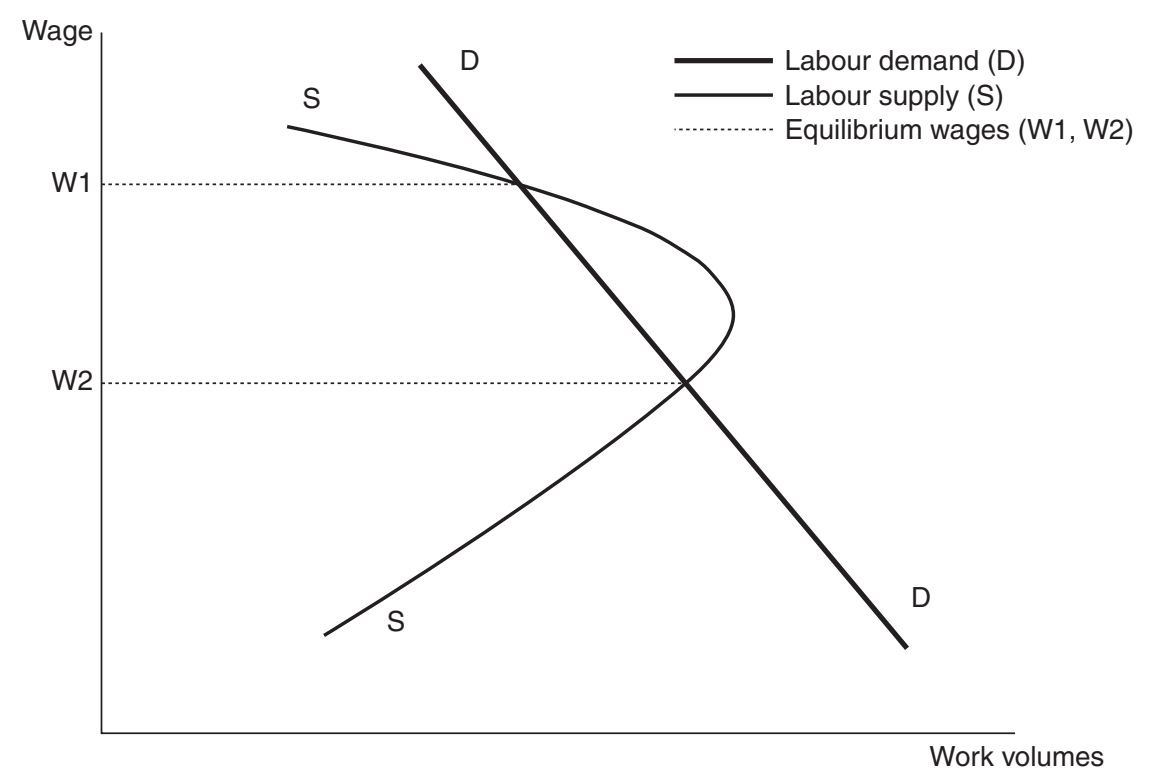

Figure 4.10 Adjusted backward-bending labour supply curve (source: own representation).

worthwhile working, and increases again as wages rise. This theory assumes the existence of an individual who can decide whether and how much he or she should work. As is well known, this is not what happens in actuality. In fact, when wages fall below a level that can provide a standard of living regarded as appropriate, households increase their labour supply and do not reduce it again until it reaches a lower level that makes begging or criminal activity more worthwhile. When wages are increasing very rapidly, the labour supply initially rises, since workers are keen to take advantage of the opportunity to improve their income considerably. However, when wages are rising quickly, free time also becomes relatively more important. In such circumstances, households can afford to reduce their labour supply again in order to have more free time.

As a result, the supply and demand curves intersect at two different points, with very different wages. The Scandinavian and continental European countries are closer to the upper intersection point, while the USA and Great Britain are closer to the lower intersection point. The reason for the considerable expansion of the US labour supply and the shift to the lower equilibrium point is to be found in the increasing competition in the labour market as a result of the high level of labour commodification. Because of the sharp growth in the labour supply in recent decades and the increasing competition in the labour market, pay negotiations have become tougher. As a result of the decline in trade union influence 
and a less highly developed system of labour market regulation and social protection, workers in the USA are more directly exposed to the market than their counterparts in European countries. Consequently, wages have fallen. Many workers have increased their labour supply in order to maintain their standard of living, which has driven wages even lower, particularly for unskilled labour where competition is most intense. Working times and employment rates have increased to such an extent that the time available for do-it-yourself work in households has fallen drastically. Even the poorer members of American society are increasingly using services in the lower price segment (e.g. fast food instead of cooking). As wages have fallen, many labour-intensive services have become cheaper, with a consequent rise in demand.

In most EU member states, with their pronounced 'decommodification' of labour, tougher competition in the labour market does not impact directly upon wages and working time. The labour supply has not been increased because of falling wages. On the contrary: working time has been reduced, partly on a collective basis and partly individually, through voluntary part-time work. Since wages remain high, workers have been able to afford to reduce their working hours. Because of the high wages, services have remained expensive. At the same time, shorter working times have enabled households to retain their capacity for do-ityourself work and to continue to do many of the things that are left to the market in the USA. Higher wages have forced service providers to rationalise and become more professional (that is, to improve both efficiency and quality) in order to make services affordable. In consequence, hourly productivity is high and sometimes even higher than in the USA. This emphasis on innovation acts as a restraint on cost disease and stimulates demand. As a result of the greater productivity increases, work volumes have remained constant or even declined slightly. Job losses have been avoided by a reduction in working time.

In order to switch from the European to the US development path, the volume of work would have to be increased considerably. This could be done only by eliminating many of the institutions that support the decommodification of labour. In view of the conflicts this would unleash and the negative side effects on the highly innovative manufacturing sector, which is dependent on high-quality services, it is more than debatable whether the same result would be achieved as in the USA. The only certainty is that the quality of life would deteriorate. In order to achieve the same standard of living as today, working time would have to be increased considerably. The quality of life that may be achieved with the European combination of 'high hourly productivity and short working times' is probably more favourable than the alternative combination of 'low hourly productivity and long working times'.

Both the US model, with its high volume of work, and the European model, with its lower volume of work, are economically viable. In order to 


\section{G. Bosch and A. Wagner}

be socially accepted, however, they must match the preferences of the working-age population. In 1998, the European Foundation for the Improvement of Living and Working Conditions in Dublin commissioned a representative survey of employment preferences for the future within the EU 15 + Norway. A total of 30,000 workers and economically inactive individuals who had expressed a desire to seek work within the next five years were questioned about their employment and working-time preferences. The results indicate that the general preference in Europe is indeed for a considerable increase in the employment rate to about the US level but with only a very moderate increase in the volume of work (Table 4.3). This combination was the result of employees' strong preferences for shorter working hours. What is desired, above all, is a more egalitarian (though not identical) distribution of paid work between men and women.

\section{Conclusions}

Our empirical investigations have enabled us to identify the forces driving the growth in service-sector employment in the EU. They are: (1) rising incomes; (2) the move to high-quality production in the manufacturing

Table 4.3 Actual and preferred employment rates and work volumes per person of working age in hours per week EU $15+$ Norway (1998)

\begin{tabular}{lllll}
\hline Country & $\begin{array}{l}\text { Actual } \\
\text { employment } \\
\text { rate }\end{array}$ & $\begin{array}{l}\text { Preferred } \\
\text { employment } \\
\text { rate }\end{array}$ & $\begin{array}{l}\text { Actual volume of } \\
\text { of work per person } \\
\text { in working age }\end{array}$ & $\begin{array}{l}\text { Preferred } \\
\text { volume } \\
\text { of work* }\end{array}$ \\
\hline Belgium & 64 & 70 & 23.9 & 24.0 \\
Denmark & 80 & 83 & 29.5 & 26.9 \\
Germany & 69 & 79 & 26.0 & 26.4 \\
Finland & 69 & 77 & 26.9 & 26.5 \\
France & 63 & 74 & 23.6 & 24.9 \\
Greece & 56 & 65 & 21.6 & 23.8 \\
Great Britain & 70 & 76 & 26.4 & 25.1 \\
Ireland & 70 & 81 & 28.1 & 28.2 \\
Italy & 50 & 65 & 18.6 & 26.2 \\
Luxembourg & 72 & 75 & 28.1 & 24.1 \\
Netherlands & 71 & 77 & 24.4 & 28.1 \\
Austria & 72 & 78 & 29.7 & 27.5 \\
Portugal & 67 & 75 & 27.1 & 29.6 \\
Sweden & 80 & 86 & 30.2 & 23.4 \\
Spain & 48 & 68 & 17.7 & 28.6 \\
Norway & 82 & 88 & 30.0 & 25.0 \\
EU + Norway & 63 & 74 & 23.7 & \\
\hline
\end{tabular}

Source: Bielenski et al. (2002).

Note

* The preferred volume of work was calculated by including the working-time preferences of those not currently in employment. 
industry; (3) the integration of women into the labour market; (4) the development of the welfare state and other funding mechanisms for overcoming the effects of cost disease in socially important services; (5) the improvement of the supply of services through greater professionalism and innovation; (6) the relatively greater reduction in working time in the service sector; and (7) specialisation at country level in services for export. No positive correlation could be found, on the other hand, between income inequality and service-sector employment. The existing differences between countries may be largely explained by the different forms these seven influencing factors take.

A second key finding that emerges from our analysis is that servicesector employment does not automatically increase as economies grow. Societies with similar levels of economic development may have very different value systems. Women's integration into the labour market requires the restructuring of all the social institutions geared to the single male breadwinner model. These institutions range from the tax system (e.g. income splitting for married couples) and social security arrangements (e.g. joint insurance for married women) to the education system (all-day school, day nurseries) or working-time structures in the workplace. The development of service-sector employment is linked much more strongly to social innovations than is commonly assumed. Incidentally, this also applies to high-quality, customer-oriented production, which requires completely different education and science systems and forms of work organisation to those needed for standardised mass production.

Third, and finally, bringing the USA into the comparison enabled us to show that very different volumes of services can be concealed behind identical employment rates. The economic and social mechanisms that drive the high-volume service society of the USA are fundamentally different from those in the low-volume service societies in the EU (with the exception of Great Britain). Both models are practicable from a purely economic point of view. Socially, the US model can survive only with a weak welfare state and weak trade unions, since the extensive commodification of labour - an essential prerequisite for this model - would otherwise be called into question. The European welfare state is associated with a highly developed welfare state, strong trade unions and forms of social dialogue that make it possible to adapt its institutions to the social innovations outlined above.

Analysis of the various principles animating the two models makes it possible to test more precisely the overall coherence of proposals on service-sector policy. Incompatibilities can be quickly identified. For example, the development of a low-wage sector is incompatible with the increase in voluntary part-time work and the development of do-it-yourself work, since households will increase their labour supply if wages fall. Furthermore, it raises the question of whether the deterioration in service quality in the longer term that is inevitably associated with reduced wages is compatible with an innovation-oriented manufacturing sector. 
Finally, it has become clear that a shift from the European to the US model is not possible in the short and medium term because of the considerable differences in economic and social systems, and hence is not a proven means of fighting unemployment. Quite apart from that, it cannot be ignored that living standards would decline considerably if a third more work had to be done for the same pay.

Conclusions concerning economic and social policy measures likely to promote service-sector employment in Europe may also be drawn from our study. We consider the following combination of measures to be promising.

1 Because of the high-income elasticity of the demand for services, economic growth is the most important prerequisite for expansion of the service sector.

2 It is necessary to reach agreement on public responsibility for the provision or funding of services. A large part of social services amounts to investment in the human capital of both employees and their dependent family members. This is true, for example, of childcare, education, health and nursing care. These services are labourintensive and suffer from the 'cost disease' described by Baumol (1967). Since universal access to such services is necessary for reasons not only of social justice but also of economic efficiency and competitiveness, it is the duty of the state to take the measures required to ensure such access.

3 In quantitative terms, the greatest employment potential lies in the promotion of women's labour market participation (although of course it varies considerably from country to country, depending on the initial level of female participation). To this end, various resources available to the welfare state that have hitherto been used passively must be put to more active use. The various subsidies that support the traditional male breadwinner model, such as the 'splitting' system of taxing married couples' earnings and derived social security entitlements, must be gradually replaced by arrangements that promote economic activity. The most important element here is the improvement of public childcare provision.

4 In the international division of labour, many European countries have specialised in high-value manufactured products. As high-wage countries, they can maintain this role only by being strongly innovation oriented. Consequently, it is crucial that those services that play a key role in supporting high-quality production, including all innovation systems (R\&D, education and training), should be further developed. This focus on innovation will also help to strengthen services that can be exported.

5 The working-time effect should be exploited for employment policy purposes. All working-time surveys show that most Europeans now 
want to work in more egalitarian household structures, which for men would often mean shorter working hours and for many women would involve longer working hours - or indeed entry or re-entry into the labour market (Bielenski et al. 2002). It will be impossible to exploit this working-time effect on a permanent basis if the rigid distinction between part-time and full-time jobs is maintained, since many workers do not want to be pushed into traditional part-time work. What is needed is flexible working hours that allow workers themselves to determine the length of their working week and, above all, to vary them over the life course.

6 Support must be given to attempts to improve service quality through professionalisation and technical and organisational innovations. On the one hand, innovations can considerably reduce the cost of services - one needs only to think of ironing machines, which have cut the price of ironing a shirt from $€ 3$ to $€ 1.5$. Quality marks, quality tests and other standards, together with improved vocational training, may be used to build consumer confidence in good services and strengthen demand.

7 Targeted subsidies could be paid to employers hiring low-skilled workers. Some groups, such as people with health problems, will require permanent subsidies in order to find work in the primary labour market, others will require initial funding, and yet others labour market policy services such as counselling, training or placement (Weinkopf 1999, 2000).

\section{Notes}

1 Thus Storrie, for example, writes: 'Despite a long period of increased service employment share relative to the United States, full convergence has yet to be reached' (Storrie 2001: 35). The setting of such targets no longer seems to require justification.

2 Since the additional variables were not always available for all EU member states, individual countries are occasionally absent from the following figures.

3 The meaning of this indicator compared to other indicators of the expansion of services is explained in Chapter 2 (this volume).

4 Thus the demand for hotel and catering services (NACE 55) comes from private households as well as from companies (business travel) and from abroad (tourists).

5 For example, high social security expenditure can promote both public services (childcare facilities) and do-it-yourself work at the expense of market services (by extending and subsidising parental leave, for example).

6 Various forms of wage reduction have been proposed. The suggestions range from subsidies for social security contributions to the deregulation of labour markets and cuts in unemployment benefit and other welfare payments.

7 We also calculated the correlation between the share of employees in high-tech industries (European Commission 2000: 59) and the volume of work in production-oriented services. The correlation, at around 0.57 , is also positive. The correlation between the share of employees in high-tech industries and the volume 
of work in social services is as high as 0.63 , which suggests that demand is very high among such highly skilled workers for social services such as education and health.

8 In order to develop a universal theory of services in developed countries, the developed Asian counties would also have to be included.

\section{References}

Anxo, D. and Storrie, D. (eds) (2001) The Job Creation Potential of the Service Sector in Europe: Final Report 2000, European Commission, Employment Observatory Research Network, Luxembourg: Office for Official Publications of the European Communities.

Baumol, W.J. (1967) 'Macroeconomics of unbalanced growth: the anatomy of urban crisis', American Economic Review 57: 416-26.

Beyer, L., Hilbert, J., Micheel, B. and Treinen, H. (2002) 'Soziodemographischer Wandel: Triebkraft für die Entwicklung neuer Dienstleistungen', in G. Bosch, P. Hennicke, J. Hilbert, K. Kristof and G. Scherhorn (eds) Die Zukunft von Dienstleistung: Ihre Auswirkungen auf Arbeit, Umwelt und Lebensqualität, Frankfurt/New York: Campus Verlag.

Bielenski, H., Bosch, G. and Wagner, A. (2002) 'Working time preferences in sixteen European countries', Dublin: European Foundation for the Improvement of Living and Working Conditions. Available online at: www.eurofound. ie/publications/Working\%20Conditions.htm.

Dathe, D. and Schmid, G. (2001) 'Determinants of business and personal services: evidence from the German regions', in D. Anxo and D. Storrie (eds) The Job Creation Potential of the Service Sector in Europe: Final Report 2000, European Commission, Employment Observatory Research Network, Luxembourg: Office for Official Publications of the European Communities.

Eberts, R. and Erickzek, G. (2001) 'The nature and determinants of service sector growth in the United States', in D. Anxo and D. Storrie (eds) The Job Creation Potential of the Service Sector in Europe: Final Report 2000, European Commission, Employment Observatory Research Network, Luxembourg: Office for Official Publications of the European Communities.

European Commission (2000) Beschäftigung in Europa, Luxembourg: Office for Official Publications of the European Communities.

- (2004) More and Better Jobs for All: The European Employment Strategy, Luxembourg: Office for Official Publications of the European Communities.

Eurostat (1997) European System of Integrated Social Security Statistics (ESSOSS), Luxembourg: Statistical Office of the European Communities.

- (1998) Social Portrait of Europe, Luxembourg: Statistical Office of the European Communities.

Fourastié, J. (1949) Le Grand Espoir du XX ème siècle: Progrès technique, progrès économique, progrès social, Paris: Presses Universitaires de France.

Gershuny, J. (1983) Social Innovation and the Division of Labour, Oxford: Oxford University Press.

Goldschmitt-Clermont, L. and Pagnossin-Aligisakis, E. (1995) 'Measures of unrecorded economic activities in fourteen countries', New York: Human Development Report Office.

Hennicke, P. (2002) 'Jenseits der Grenzen des Wachstums: Begründen 
“Naturschranken” einen "Vorrang” für die Ökologie?' in G. Bosch, P. Hennicke, J. Hilbert, K. Kristof and G. Scherhorn (eds) Die Zukunft von Dienstleistungen: Ihre Auswirkungen auf Arbeit, Umwelt und Lebensqualität, Frankfurt/New York: Campus Verlag.

Hill, T.P. (1977) 'On goods and services', Review of Income and Wealth 4: 315-38.

Klodt, H., Maurer, R. and Schimmelpfennig, A. (1996) Tertiarisierung in der deutschen Wirtschaft, Kieler Studien, Tübingen: Institut für Weltwirtschaft, Universität Kiel.

Klös, H.P. (1997) 'Dienstleistungslücke und Niedriglohnsektor in Deutschland', iw-trends 3: 33-59.

Lay, G. and Rainfurth, C. (2002) 'Zunehmende Integration von Produktions- und Dienstleistungsarbeit', in P. Brödner and M. Knuth (eds) Nachhaltige Arbeitsgestaltung, Trendreports zur Entwicklung und Nutzung von Humanressourcen, Munich and Mering: Rainer Hampp Verlag.

Lehndorff, S. (2002) “Tertiarisierte”: Arbeit und nachhaltige Entwicklung des Arbeitsvermögens - Über die Zukünftige Bedeutung von Arbeitszeitregulierung', in G. Bosch, P. Hennicke, J. Hilbert, K. Kristof and G. Scherhorn (eds) Die Zukunft von Dienstleistungen: Ihre Auswirkungen auf Arbeit, Umwelt und Lebensqualität, Frankfurt/New York: Campus Verlag.

Martinelli, F. (1991) 'Producer services location and regional development', in P.W. Daniels and F. Moulaert (eds) The Changing Geography of Advanced Producer Services, London and New York: Belhaven Press.

Organisation for Economic Co-operation and Development (OECD) (1996) Employment Outlook 1996, Paris: OECD.

- (2001a) Wirtschaftsausblick No. 70, Paris: OECD.

(2001b) Science, Technology and Industry Scoreboard, Paris: OECD.

Ott, N. (1997) 'Beruf, Kinder, Familie - ein Spannungsfeld aus ökonomischer Sicht', in U. Behning (ed.) Das Private ist ökonomisch: Widersprüche der Ökonomisierung privater Familien- und Haushalts-Dienstleistungen, Berlin: Edition Sigma.

Prasch, R.E. (2000) 'Revising the supply curve: implications for work time and minimum wage legislation', in L. Golden and D.M. Figart (eds) Working Time: International Trends, Theory and Policy Perspectives, London and New York: Routledge.

Scharpf, F.W. (1990) 'Structures of post-industrial society or does mass unemployment disappear in the service and information economy?', in E. Appelbaum and R. Schettkat (eds) Labor Market Adjustments to Structural Change and Technological Progress, New York: Praeger.

— (1997) 'Beschäftigungsfreundlich und sozial: ein Widerspruch?', Die Mitbestimmung 4: 36-9.

Storrie, D. (2001) 'Service employment, productivity and growth', in D. Anxo and D. Storrie (eds) The Job Creation Potential of the Service Sector in Europe: Final Report 2000, European Commission, Employment Observatory Research Network, Luxembourg: Office for Official Publications of the European Communities.

Tronti, L., Sestini, R. and Toma, A. (2001) 'Unbalanced growth and employment in services', in D. Anxo and D. Storrie (eds) The Job Creation Potential of the Service Sector in Europe: Final Report 2000, European Commission, Employment Observatory Research Network, Luxembourg: Office for Official Publications of the European Communities. 


\section{G. Bosch and A. Wagner}

Voss-Dahm, D. (2002) 'Erwerbstätigkeit von SchülerInnen und Studierenden nimmt zu', IAT-Report 2002-06, Gelsenkirchen.

Weinkopf, C. (1999) Schaffung von Arbeitsplätzen für Geringqualifizierte: Überarbeitete und aktualisierte Fassung eines Gutachtens für die Staatskanzlei von Schleswig-Holstein, Graue Reihe, 1999-06, Gelsenkirchen: Institut Arbeit und Technik.

(2000) 'Von der Dienstleistungslücke zu neuen intelligenten Angebotsformen? Strategien zur Ausweitung der Dienstleistungsbeschäftigung', in C. Schäfer (ed.) Geringere Löhne - mehr Beschäftigung? Niedriglohn-Politik, Hamburg: VSA-Verlag. 


\title{
5 Services and the employment prospects for women
}

\author{
Alexandra Wagner
}

\section{Introduction}

Services are playing an increasingly important role in all EU member states and account for the largest share of employment growth. At the same time, women's participation and employment rates are also on the rise in all European countries, and it is mainly women who are taking the increased number of service-sector jobs now being created. Does this mean that the expansion of the service sector is creating new employment opportunities for women? Is Esping-Andersen correct when he declares that there is an indissoluble link between women's employment and the post-industrial society? This at least is what he suggests in arguing that 'at the risk of exaggeration, one might claim that women are becoming the axial principle of the post-industrial society, just like males were the indisputable protagonists of high industrialism' (Esping-Andersen 2002: 109).

In this chapter, we draw on empirical findings in order to examine this argument, and to investigate whether there is a link between service work and women's labour market participation and how any such link might operate. In doing so, we will also examine, in the second section, the differences between EU member states, which in some cases are very considerable. The third section is given over to the question of how the empirical findings, and particularly the differences between countries, might be explained. The final section looks at the political implications of agreeing to the assertion that women are becoming the axial principle of post-industrial society.

\section{Tertiarisation, women's employment and part-time work - what do the data say?}

Women's employment: rates are growing faster than volumes

Between 1995 and the year 2000, a net total of 6.2 million new jobs were taken up by women in EU member states, while only 4.3 million new jobs went to men (European Commission 2001: 16). The female employment 


\section{Alexandra Wagner}

rate grew during this period in all EU member states, reaching an average of 54 per cent ${ }^{1}$ and thereby reducing the gap between men and female employment rates. The impact of this development is mitigated, however, by the fact that a large proportion of the increase in women's employment has been part-time. Between 1994 and 1999, some 70 per cent of the new jobs taken by women in the EU were part-time positions (European Commission 2000: 30; Smith, Chapter 3, this volume). Thus female employment rates are much lower when working time is taken into account (Table 5.1) and when women's employment rates are expressed in terms of full-time equivalents (Table 5.2). The most extreme example is the Netherlands, the country with the highest share of part-timers (70 per cent), where the employment rate for women falls from 63.7 per cent to just 40 per cent when calculated on the basis of full-time equivalents. Thus consideration of rising employment rates alone leads to an overestimation of the rate and extent to which women have 'caught up' with men.

The differences between countries are, none the less, considerable. One important finding is that these differences are much greater for women than for men. As shown in Table 5.2, the 32 percentage point range in women's employment rates (i.e. the difference between 39.6 per cent in Italy and 71.6 per cent in Denmark) is more than twice as great as

Table 5.1 Average weekly working hours of male and female employees in EU member states

\begin{tabular}{llll}
\hline & $\begin{array}{l}\text { Hours of male } \\
\text { employees }^{a}\end{array}$ & $\begin{array}{l}\text { Hours of female } \\
\text { employees }^{a}\end{array}$ & $\begin{array}{l}\text { Difference (column 1 } \\
\text { minus column 2) } \\
3\end{array}$ \\
\hline Belgium & 1 & 2 & 7.7 \\
Denmark & 39.1 & 31.4 & 4.9 \\
Germany West & 37.8 & 33.0 & 8.9 \\
Germany East & 39.6 & 30.6 & 4.0 \\
Germany (total) & 39.9 & 36.0 & 8.0 \\
Greece & 39.6 & 31.7 & 3.7 \\
Spain & 41.9 & 38.2 & 4.9 \\
France & 40.7 & 35.9 & 6.0 \\
Ireland & 40.3 & 34.3 & 8.2 \\
Italy & 40.6 & 32.4 & 5.4 \\
Luxembourg & 39.5 & 34.1 & 6.7 \\
Netherlands & 40.6 & 33.9 & 10.7 \\
Austria & 36.2 & 25.5 & 6.3 \\
Portugal & 40.6 & 34.3 & 3.9 \\
Finland $_{\text {Sweden }}^{42.1}$ & 38.2 & 3.5 \\
UK $_{\text {Range }}^{b}$ & 39.4 & 35.9 & 3.9 \\
\hline
\end{tabular}

Notes

a Own calculations based on ELFS.

b Difference between highest and lowest national value (in hours). 


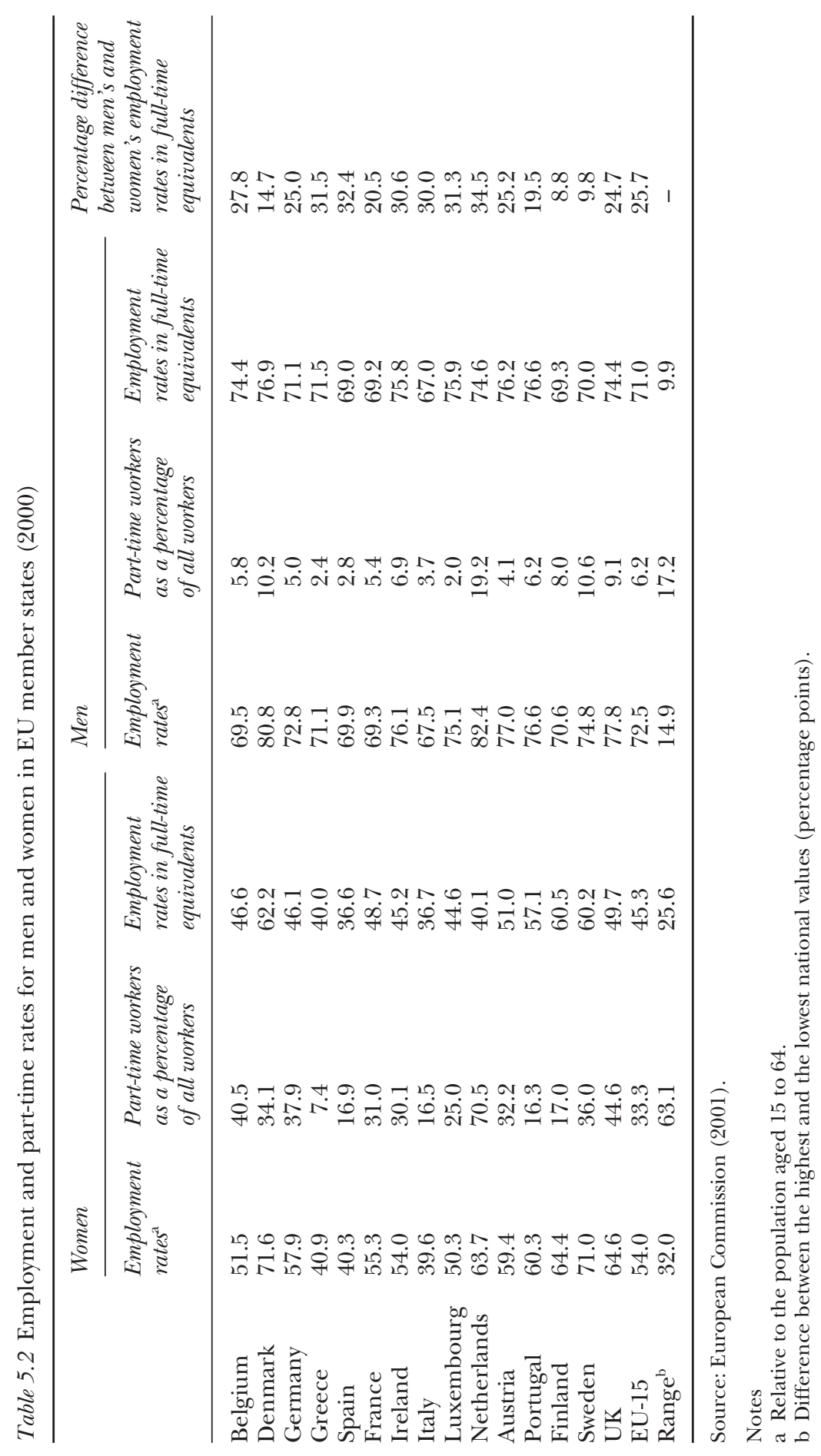




\section{Alexandra Wagner}

the range for men (the 14.9 percentage point difference between 67.5 per cent in Italy and 82.4 per cent in the Netherlands). This difference between men and women increases still further when expressed in terms of full-time equivalents. Calculated in this way, the range for male employment rates is relatively small (between 67 per cent in Italy and 76.9 per cent in Denmark), while that for women is very wide indeed (between 36.6 per cent in Spain and 62.2 per cent in Denmark).

The same is true of working time. While the range for men's average working time is seven hours (between 43.2 hours in the UK and 36.2 hours in the Netherlands), for women it is 12.7 hours (between 38.2 hours in Greece and Portugal and 25.5 hours in the Netherlands). Due to the rather low incidence of part-time work among men, their average working hours are determined principally by the standard full-time norm, which differs little from one country to another. ${ }^{2}$ Among women, on the other hand, the incidence of part-time work and the widely differing volumes of hours worked by part-timers give rise to greater differentials. Under these circumstances, it is not just the greater degree of fluctuation in female employment rates from one country to another but also the considerable differences in the volume of hours worked by women that determine national differences in the total volume of employment.

It is clear from Table 5.3, which shows men's and women's share in the total volume of labour, that the differences between countries are considerable, although in all EU countries women do less paid work than men.

Table 5.3 Gender shares in the total volume of labour

\begin{tabular}{lll}
\hline & Women & Men \\
\hline Belgium & 37.5 & 62.5 \\
Denmark & 44.3 & 55.7 \\
Germany & 39.6 & 60.4 \\
Greece & 37.2 & 62.8 \\
Spain & 34.9 & 65.1 \\
France & 42.4 & 57.6 \\
Ireland & 39.9 & 60.1 \\
Italy & 35.9 & 64.1 \\
Luxembourg & 35.1 & 64.9 \\
Netherlands & 34.9 & 65.1 \\
Austria & 40.1 & 59.9 \\
Portugal & 43.3 & 56.7 \\
Finland & 47.6 & 52.4 \\
Sweden & 47.1 & 52.9 \\
UK & 39.6 & 60.4 \\
EU-15 & 39.4 & 60.6 \\
\hline
\end{tabular}

Source: Own calculations based on ELFS.

Note

Basis: employees, 1999. 
In Sweden and Finland, women do close to half the total of paid labour in the economy, whereas in the Netherlands, Spain, Luxembourg and Italy they are responsible for just over one-third.

Examination of the link between women's labour market participation and the development of the service sector produces a similarly differentiated picture.

\section{Service sector not dominated by women}

The expansion of service-sector employment is taking place not only at the same time as the increase in women's employment but also to a large extent in the form of increasing female employment. The majority of jobs created in the service sector in recent years have been taken by women, who accounted for no less than 61 per cent of the growth in employment in services between 1994 and 1999 (European Commission 2000: 37). However, this raises two questions. How far have women really 'caught up'? And is the service sector (now) a female-dominated sphere of employment?

To judge solely from the share of economically active women employed in the service sector, it would indeed seem reasonable to conclude that women account for the greater share of employment in that sector. In all European countries, the majority of employees are now working in services. Across the $\mathrm{EU}$ as a whole, the average share of all female employees working in services is 82.5 per cent, which is significantly higher than the share of male employees, which stands at 58.3 per cent (Table 5.4). With the exception of women in Greece, Portugal and Italy, which are all countries with relatively underdeveloped service sectors, between 80 and 90 per cent of economically active women work in service industries (Table 5.4). This means that the majority of those women who are economically active find employment in the service sector, primarily in social services, which in all countries is the part of the service sector that is displaying by far the strongest employment growth.

However, if we look at women's share in total dependent employment in the service sector, the picture changes. Across Europe, the range is between only 46 per cent in Greece and 61 per cent in Finland; in most countries, women's share in total service-sector employment is between 50 and 55 per cent (Table 5.4). Thus only slightly more than half of dependent employees in the service sector are women. The share is even lower when it is calculated in terms not of the number of employees but rather of hours worked, that is, the volume of services provided. In most countries, women's share in the volume of work in the service sector is below the 50 per cent mark, in some cases significantly so. Only in Finland, Denmark and Sweden is somewhat more than half of the total work in services done by women. In none of the other countries, however, can the service sector be said to be a female-dominated sphere. 
108 Alexandra Wagner

Table 5.4 Women and service employment in EU member states: comparison of the use of various indicators

\begin{tabular}{lllll}
\hline Country & $\begin{array}{l}\text { Percentage } \\
\text { share of women } \\
\text { employed in } \\
\text { service sector } \\
\text { in total female } \\
\text { employment }\end{array}$ & $\begin{array}{l}\text { Women's share } \\
\text { in total dependent } \\
\text { employment in } \\
\text { service sector } \\
(\%)^{\mathrm{b}}\end{array}$ & $\begin{array}{l}\text { Women's share } \\
\text { in total volume } \\
\text { of work in } \\
\text { service sector } \\
(\%)^{\mathrm{b}}\end{array}$ & $\begin{array}{l}\text { For comparison: } \\
\text { percentage share } \\
\text { of men employed } \\
\text { in service sector } \\
\text { in total male } \\
\text { employment }^{\mathrm{a}}\end{array}$ \\
\hline Belgium & 88.2 & 52.3 & & 63.9 \\
Denmark & 85.9 & 56.5 & 44.8 & 62.3 \\
Germany & 82.4 & 56.9 & 51.0 & 56.3 \\
West Germany & - & 56.0 & 47.6 & - \\
East Germany & - & 60.6 & 45.8 & - \\
Finland & 81.9 & 61.0 & 55.2 & 51.6 \\
France & 84.6 & 54.9 & 56.0 & 61.6 \\
Greece & 65.7 & 46.3 & 48.3 & 53.4 \\
Great Britain & 87.3 & 55.9 & 39.1 & 51.7 \\
Ireland & 82.5 & 56.1 & 45.5 & 58.9 \\
Italy & 76.8 & 47.3 & 46.2 & 76.6 \\
Luxembourg & 92.3 & 47.5 & 39.4 & 67.4 \\
Netherlands & 89.0 & 50.5 & 42.4 & - \\
Austria & - & 55.8 & 40.6 & 60.6 \\
Portugal & 67.8 & 55.1 & 49.3 & 52.7 \\
Sweden & 87.5 & 60.3 & 50.0 & 58.3 \\
Spain & 81.3 & 50.0 & 53.8 & 43.6 \\
EU15 & 82.5 & 54.2 & 48.9 & \\
\hline
\end{tabular}

Notes

a 2000, Employment in Europe (2001).

b 1999, own analysis of the European Labour Force Survey.

In short, women's employment is dominated by service work but service work is not dominated by women. There is one major exception to this, namely social services.

\section{Women predominate in social services}

A comparison of the distribution of men and women in the various parts of the economy shows that women's employment, unlike male employment, is concentrated in just a few areas of economic activity (Table 5.5). The gender mix of service employment also varies sharply between the service subsectors. The shares in producer and distributive services are similar for men and for women, but personal and social services are provided mainly by women.

Virtually all employees in private households are women, and women also account for three-quarters of all employees in health, social and educational services (Fagan and Burchell 2002: 23; Table 5.5). However, women also represent the majority of employees in other 


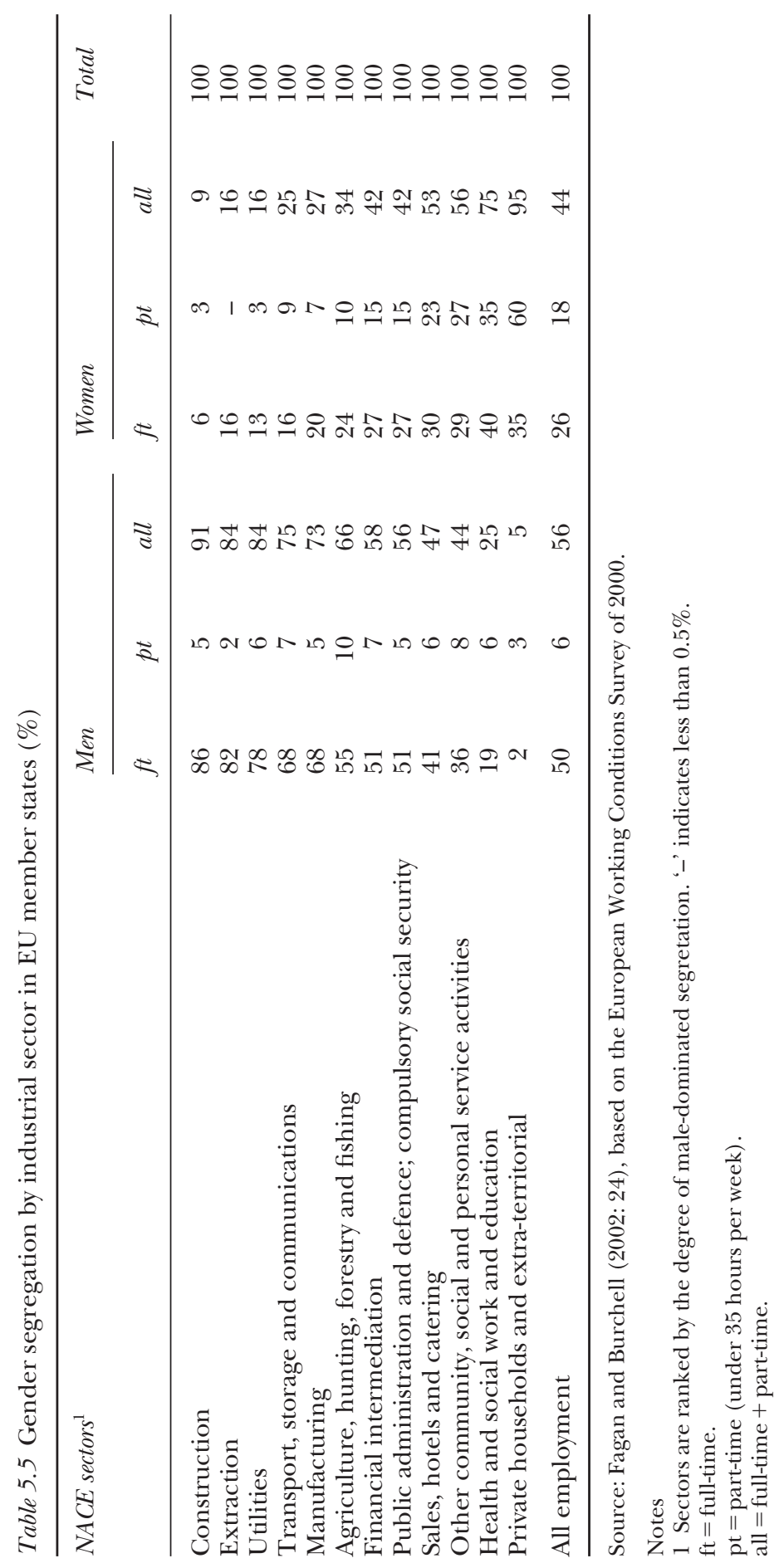


community, social and personal service activities as well as in sales, hotels and catering.

This is also reflected in the occupational structure. Table 5.6 shows the representation of women in the major occupational groups in EU member states. They are particularly underrepresented in craft and related jobs and in plant and machinery operating, whereas in all EU countries clerical and service work is to a large extent dominated by women, with the exception of service work in Spain. In particular, women account for the vast majority of workers in social and personal services, which in all the countries is the area of the service sector where employment is strongest. Their share in the total volume of services ranges from 54 per cent in Sweden to 35 per cent in Luxembourg. Social services also employ by far the highest share of service workers, accounting for between 54.5 per cent (Sweden) and 37 per cent (Luxembourg) of all servicesector employees. Bosch and Wagner (Chapter 4, this volume) have demonstrated this link between the volume of female employment and the volume of employment in social and personal services by means of correlation estimates.

\section{Women's employment, service work and part-time work: no conclusive link}

The empirically verifiable gender division of part-time work is frequently invoked in support of the argument, for which no further proof is adduced, that there is a link (and, implicitly, a causal one) between service work and part-time work. This argument is reflected, for example, in forecasts of the expected employment effects in these areas, many of which assume the high part-time rate is already high and hence conclude that such part-time work is a necessary concomitant of such activities. Is this argument justified?

The first thing to be noted is that, in all fifteen EU member states, part-time rates are higher in the service sector than in manufacturing (Table 5.7). Here too, however, there are considerable differences between the countries. The part-time rate in the service sector ranges between 6 per cent in Greece and 45 per cent in the Netherlands. It is true that this rate has risen since 1993 in virtually all countries, with the exception of Denmark and Sweden. In these latter two countries, the parttime rate in the service sector has actually declined slightly, as it has in manufacturing.

Nevertheless, despite the fact that the part-time rate in the service sector is higher than it is in manufacturing, full-time employment continues to predominate within the service sector. The considerable variations in national part-time rates and their differing evolutions over time suggest that it is not the particularities of service-sector work itself that determine the extent of part-time working but rather the various national 


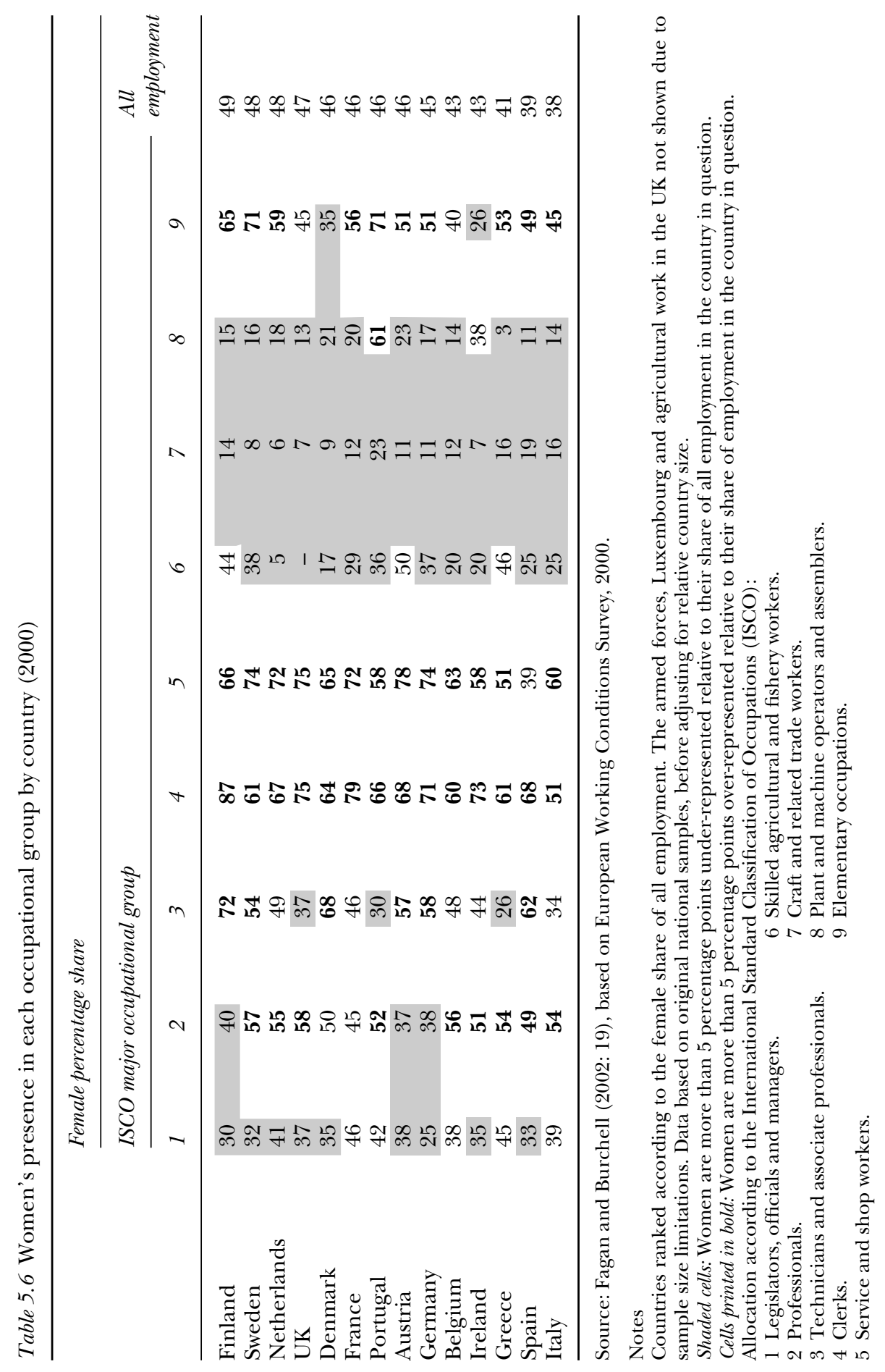




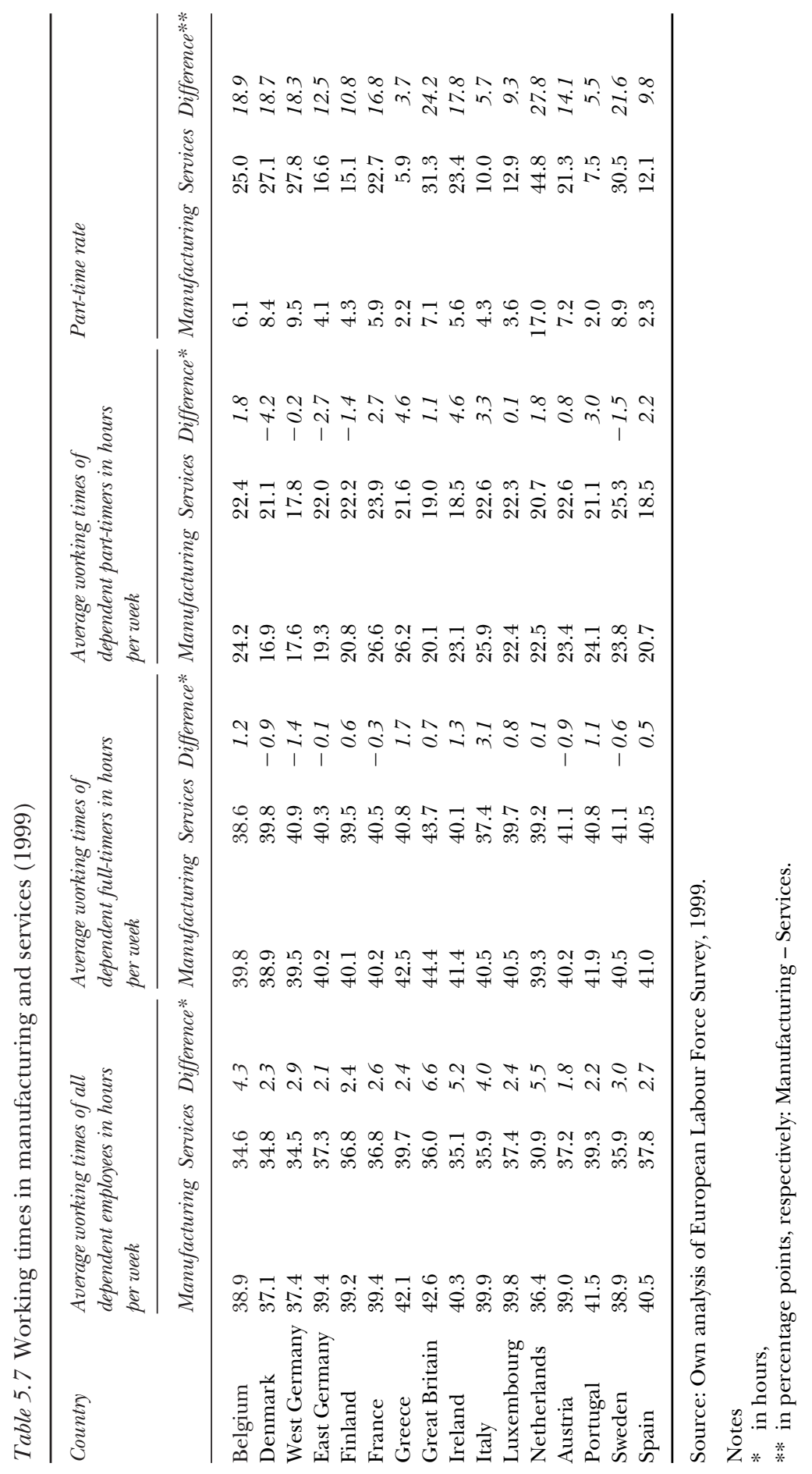


regulatory frameworks governing part-time work and the opportunities for men and women to choose their working times.

What is more, and contrary to widespread belief, the differences in working time between the sectors cannot be explained by women's share in service-sector employment either. As is clear from Table 5.8, a high female share in total employment may be associated with a low part-time rate, as in Finland, Eastern Germany and Portugal, while a (relatively) low proportion of women in total employment may go hand in hand with a (very) high part-time rate, as in the Netherlands. Women's work is by no means necessarily part-time work, and part-time work is not in itself women's work. If high-quality and affordable childcare is available, many women, particularly the more highly qualified, choose to work full-time. ${ }^{3}$ In countries where many high school and university students are economically active (e.g. Denmark) or part-time working is an increasingly accepted employment form (the Netherlands), more men also work part-time. Finally, part-time work may have very different functions. In countries in which the (modernised) single breadwinner model predominates, it can facilitate women's entry into the labour market. On the other hand, in countries that already have a high (full-time) employment rate, it may offer women opportunities for economic activity on a reduced basis in certain phases of the life cycle.

Table 5.8 Part-time rate and women's employment in the service sector

\begin{tabular}{|c|c|c|c|c|}
\hline \multirow[t]{2}{*}{ Country } & \multirow{2}{*}{$\begin{array}{l}\text { Percentage share of } \\
\text { part-time employment } \\
\text { relationships in } \\
\text { service sector }\end{array}$} & \multirow{2}{*}{$\begin{array}{l}\text { Percentage share } \\
\text { of women in all } \\
\text { service-sector } \\
\text { employees }\end{array}$} & \multicolumn{2}{|c|}{$\begin{array}{l}\text { Female employees in } \\
\text { service sector }(=100 \%)\end{array}$} \\
\hline & & & $\begin{array}{l}\text { of which } \\
\text { full-time (\%) }\end{array}$ & $\begin{array}{l}\text { of which } \\
\text { part-time (\%) }\end{array}$ \\
\hline Belgium & 25.0 & 52.3 & 58.0 & 42.0 \\
\hline Denmark & 27.1 & 56.4 & 62.6 & 37.4 \\
\hline Germany & 25.7 & 56.9 & 60.4 & 39.6 \\
\hline West Germany & 27.8 & 56.0 & 56.3 & 43.7 \\
\hline East Germany & 16.6 & 60.6 & 76.5 & 23.5 \\
\hline Finland & 15.1 & 61.0 & 81.6 & 18.4 \\
\hline France & 22.7 & 54.9 & 65.1 & 34.9 \\
\hline Greece & 5.9 & 46.3 & 90.9 & 9.1 \\
\hline Great Britain & 31.3 & 55.9 & 53.5 & 46.5 \\
\hline Ireland & 23.4 & 56.1 & 66.9 & 33.1 \\
\hline Italy & 10.0 & 47.3 & 83.3 & 16.7 \\
\hline Luxembourg & 12.9 & 47.5 & 74.6 & 25.4 \\
\hline Netherlands & 44.8 & 50.4 & 30.3 & 69.7 \\
\hline Austria & 21.3 & 55.8 & 65.7 & 34.3 \\
\hline Portugal & 7.5 & 55.1 & 88.9 & 11.1 \\
\hline Sweden & 30.5 & 59.6 & 57.0 & 43.0 \\
\hline Spain & 12.1 & 50.0 & 80.0 & 20.0 \\
\hline
\end{tabular}

Source: Own analysis of European Labour Force Survey; data for 1999. 


\section{Alexandra Wagner}

In sum, it is true that the part-time rate in service activities is higher than in manufacturing in all EU member states and that women in all EU countries are more likely to work part-time than men. And yet the question of whether there is a triangular relationship between service work, women's work and part-time work must be answered in the negative. Service work is not in itself women's work, nor is it necessarily part-time work. What is more, women's employment is by no means synonymous with part-time employment. The considerable differences between countries and the decline in part-time work in Denmark and Sweden, which has taken place against the general trend, point to the need to focus more sharply on the differences between countries or groups of countries. This is our task in the following section.

\section{Women's employment and the service society: the various configurations}

As our analysis of the data has shown, the statement that women's employment is the axial principle of the post-industrial society cannot be said to hold true in respect of the current situation in the EU. However, the high share of women in the total volume of paid work and their greater share (relative to men) in the volume of social services provided in some Scandinavian countries point to developments that might spread in future in other countries. For this reason, this section is given over to an examination of how the differences between countries outlined in the preceding section might be explained.

\section{Various forms of the gender division of labour}

The differences that exist between the countries in respect of women's employment will be illustrated by means of two indicators: participation and/or employment rates, first, and, second, the difference between men's and women's working times. Table 5.9 shows the link between these two indicators. It will be seen that where women's employment rates are low, the differences between men's and women's working hours are slight (Belgium, Greece, Italy, Spain, Luxembourg). In countries with low female employment rates, women evidently tend to have to choose between occupational inactivity or a job entailing relatively long hours; insofar as part-time work is rather uncommon, access to the labour market is more difficult for women. On the other hand, in Austria and Germany, and even more so in the United Kingdom and the Netherlands, higher employment rates for women coincide with shorter working hours for women (and high proportions of part-time work). In these countries, the greater opportunities for part-time work make it easier for women with children to gain access to the labour market insofar as, generally speaking, the inadequate supply of childcare facilities means that they are in a position to work only half-days. 
Table 5.9 Country typology based on differences between men's and women's working hours and women's employment rate

\begin{tabular}{llll}
\hline \multirow{2}{*}{$\begin{array}{l}\text { Gender difference in } \\
\text { actual working hours }\end{array}$} & \multicolumn{2}{l}{ Female employment rate (per capita) } \\
\cline { 2 - 4 } & Low & Medium & High \\
\hline Large & Ireland & Austria & UK \\
& & Germany & Netherlands \\
Small & Belgium & Portugal & Denmark \\
& Greece & France & Finland \\
& Italy & & Sweden \\
& Spain & & \\
\hline
\end{tabular}

Source: Own calculations on basis of ELFS.

Notes

Female employment rate: low if below $54 \%$; medium if between 54 and $60 \%$; high if above $60 \%$.

Gender difference: small if less than 8.0 hours; large if more than 8.0 hours.

In Denmark, Finland and Sweden, the working-time differentials between the sexes are as low as the employment rates of women are high. In these countries, women need only to overcome relatively weak institutional barriers in order to increase their labour market participation. In Denmark and Sweden, particularly among younger women, the proportion of women working part-time has been falling continuously since the 1980s. ${ }^{4}$ In Finland, full-time work has long been the predominant form of work for women, irrespective of the age of the youngest child. In many countries, short working hours are a means for women to gain access to the labour market; in Scandinavian countries, this is no longer the case. Where women in countries with good opportunities for combining work and family are working part-time, this tends to be an expression of genuine freedom of choice for parents and, as is clear from the longer part-time working hours in Sweden, frequently amounts to a shortened form of the full-time norm. In countries with only limited opportunities for reconciling work and family life, on the other hand, the classic half-day working predominates.

The differences in female labour market participation from one country to another are attributable to different national social institutions and conditions. The extent to which women are in paid work is principally influenced or determined by the following factors:

- The social policy support available to families in caring for and bringing up children, particularly the supply of childcare facilities and their opening hours. The better the supply, the more women - and particularly mothers - will take up paid employment. The nature of 


\section{Alexandra Wagner}

the measures put in place to support families also play a role. Depending on the particular combination of benefits and entitlements for parents and children, they may either make it easier for parents, particularly mothers, to work or encourage a (temporary) exit from the labour market (cf. Thenner 2000).

- The tax and social security arrangements that create the incentives for a particular division of paid work between couples (cf. Dingeldey 1999). These systems may approximate either to a traditional or an egalitarian division of paid work between spouses (cf. Anxo et al. 1999). In the Scandinavian countries there are often additional incentives for parents (of small children) to combine paid work and family life, such as, for example, parental part-time work, flexible parental leave and so on (Thenner 2000).

- The wage and salary structure, in particular its gender-specific features. In some countries, for example, the United Kingdom, there is a strongly gendered wage and salary structure that generates a highly unequal distribution of paid labour, since it is of greater financial benefit to the household for the man to work overtime than for the woman to increase her working hours (cf. Clarke 2001; Grimshaw and Rubery 2001).

- The supply of jobs offering working hours below the full-time standard and opportunities for individual working-time flexibility. The more closely working time can be harmonised with non-work demands, the easier it is to combine paid work and family life.

On the basis of men's and women's employment patterns and the way they are fashioned by different welfare state arrangements in Europe, Rubery et al. (1999) and Fagan (2001) have drawn up a typology of countries with the following features:

1 Universal breadwinner model (Denmark, Finland, Norway and Sweden):

The social institutions - an extensive system of childcare, opportunities for extended leave, individualised taxation, small pay differentials between men and women and so on - encourage high employment levels among men and, especially, women.

2 Modified male breadwinner model (Belgium, France):

Various institutions, and above all a well-developed system of public childcare, promote labour market equality for men and women; other factors (such as major pay differentials between men and women) tend to produce, on the contrary, a gendered segmentation, with the result that female employment rates are lower, and their working hours shorter, than under the first model.

3 Male breadwinner plus woman in part-time work (Austria, Germany, the Netherlands, United Kingdom, Ireland, Luxembourg): 
In these countries, public childcare provision is poorly developed; thanks to the development of a service sector with a large share of part-time jobs, part-time work has developed as a typical employment form for women, particularly mothers, alongside the traditional single breadwinner model.

4 Male breadwinner + dual full-time (Greece, Italy, Spain, Portugal)

In these countries, on account of traditional family structures, the proportion of households with a single male breadwinner is particularly high. ${ }^{5}$ In addition, there are also many households with two persons in full-time paid work. The reasons for the high proportion of full-timers are the low levels of pay and the inadequate number of part-time jobs on offer. The low female employment rate is associated with the inadequate development of the service sector.

Columns 1 to 3 of Table 5.10 show women's working times and employment rates in the various groups of countries. As far as employment rates are concerned, the two poles are formed by the countries in the universal breadwinner group and by those in the male breadwinner + dual full-time group (with the exception of Portugal). The other countries tend to have somewhat higher employment rates than the Southern European countries but significantly lower rates than the Scandinavian countries. On the other hand, however, they have shorter working times for women and higher part-time rates. The conditions under which men and women operate in the labour market and the facilities that exist to support them depend on the social role models and paradigms that are adopted in the individual countries or groups of countries. Policy in Sweden and Denmark, for example, officially supports the dual-earner family model, whereas in Germany the home-based family care model still receives strong institutional encouragement. In most countries there are now competing family models and, to some extent, mutually contradictory welfare state incentives (high value placed on housework and childcare, on the one hand, and encouragement for mothers to participate in the labour market, on the other). This reflects changes in men's and women's values, to which policy-makers are attempting to respond.

As will be shown below, these various forms of the gender division of labour are associated with different routes to the service society.

\section{The 'high road' and 'low road' to higher female participation and more} services

The relationship between women's employment and service-sector employment is a reciprocal one. On the one hand, working women need the service sector to relieve them of household tasks; on the other hand, the service sector actually provides employment opportunities for women entering the labour market. Their earnings supplement household 


\section{Alexandra Wagner}

Table 5.10 Women's employment and the extent of social services by country group

\begin{tabular}{|c|c|c|c|c|c|}
\hline & $\begin{array}{l}\text { Average } \\
\text { female } \\
\text { working times } \\
\text { (hours per } \\
\text { week) }\end{array}$ & $\begin{array}{l}\text { Female } \\
\text { employment } \\
\text { rates** }\end{array}$ & $\begin{array}{l}\text { Part-time } \\
\text { workers as } \\
\text { a percentage } \\
\text { of all female } \\
\text { workers*** }\end{array}$ & $\begin{array}{l}\text { Volume of } \\
\text { labour (hours } \\
\text { per week) } \\
\text { in social } \\
\text { services*** } \\
\text { per head of } \\
\text { working age } \\
\text { population }{ }^{* * * * *} \\
\text { (men and } \\
\text { women)* } \\
4\end{array}$ & $\begin{array}{l}\text { Women's } \\
\text { share in total } \\
\text { volume of } \\
\text { work in } \\
\text { service sector } \\
(\%)^{*}\end{array}$ \\
\hline \multicolumn{6}{|c|}{ Universal Breadwinner Model } \\
\hline Denmark & 33.0 & 71.6 & 34.1 & 9.18 & 51.0 \\
\hline Sweden & 35.9 & 71.0 & 36.0 & 9.48 & 53.8 \\
\hline Finland & 35.9 & 64.4 & 17.0 & 7.78 & 56.0 \\
\hline \multicolumn{6}{|c|}{ Modified Male Breadwinner Model } \\
\hline Belgium & 31.4 & 51.5 & 40.5 & 6.69 & 44.8 \\
\hline France & 34.3 & 55.3 & 31.0 & 6.90 & 48.3 \\
\hline \multicolumn{6}{|c|}{ Male Breadwinner + Woman Part-time } \\
\hline Austria & 34.3 & 59.4 & 32.2 & 6.31 & 49.3 \\
\hline Germany & 31.7 & 57.9 & 37.9 & 6.66 & 47.6 \\
\hline Netherlands & 25.5 & 63.7 & 70.5 & 6.87 & 40.6 \\
\hline UK & 31.6 & 64.6 & 44.6 & 7.64 & 45.5 \\
\hline Ireland & 32.4 & 54.0 & 30.1 & 5.09 & 46.2 \\
\hline Luxembourg & 33.9 & 50.3 & 25.0 & 6.14 & 42.4 \\
\hline \multicolumn{6}{|c|}{ Male Breadwinner + Dual Full-time } \\
\hline Greece & 38.2 & 40.9 & 7.4 & 4.51 & 39.1 \\
\hline Spain & 35.9 & 40.3 & 16.9 & 4.19 & 43.6 \\
\hline Italy & 34.1 & 39.6 & 16.5 & 4.84 & 39.4 \\
\hline Portugal & 38.2 & 60.3 & 16.3 & 5.47 & 50.0 \\
\hline
\end{tabular}

Notes

* Own calculations on basis of ELFS 1999.

** Source: European Commission 2001.

*** These include the following sectors in the NACE classification: Public administration and defence; compulsory social security (75), Education (80), Health and social work (85), Sewage and refuse disposal, sanitation and similar activities (90), Activities of membership organisations (excl. social services and sport) (91), Recreational, cultural and sporting activities (92), Other service activities (93).

**** This method of calculation serves to neutralise the influence of country-specific employment and working time structures and also the different sizes of population, thereby enabling comparison of volume of services between countries.

incomes and may be used to purchase services previously performed by the women themselves. Thus the spread of certain services, particularly those of a social nature, is a precondition for as well as a consequence of increasing labour market participation among women (cf. Bosch and Wagner, Chapter 1, this volume). 
It is clear from column 4 of Table 5.10 that the volume of paid work in social and personal services is very strongly influenced by the relative pervasiveness of the male breadwinner model. Countries in which the universal breadwinner model prevails have the largest volume of social services (7.8 to 9.5 hours per week the head of working age population), while countries with the modified breadwinner model and the male breadwinner + woman in part-time work model have somewhat smaller volumes (6.8 and 5.0 to 7.6 hours respectively). The smallest volumes of social services (4.2 to 5.5 hours) are provided under the Southern European male breadwinner + dual full-time model (see country values in Table 5.10). This observation is supported by the OECD Employment Outlook findings, according to which 'higher female participation and a larger welfare state are associated with higher employment shares for social and producer services' (OECD 2000: 80).

Obviously, the development of women's labour market activity and of the service sector are very closely linked with the development of the welfare state (Häußermann and Siebel 1995; cf. Schmid 1992, 2003). Drawing on the well-known typology of welfare states developed by EspingAndersen (1990, 1996, 2002), Anxo and Fagan (2001: 97) identify three forms of the social organisation of women's economic activity and social services: the individual breadwinner and public sector service model, the market service model, and the household service model.

The individual breadwinner and public sector service model (Sweden, Denmark and Finland) is the result of a welfare state developed by means of high taxation with a high proportion of public employment. Social services are organised predominantly within a public-sector framework and characterised by a high level of professionalism (particularly among women). The Swedish model guarantees adequate earnings and minimum health provision for all, ensuring an independent existence for every adult and a high rate of training and employment. The funding of the welfare state and hence of collective infrastructures is also guaranteed by contributions from the population at large. ${ }^{6}$ The welfare state system has developed in such a way that every member of the population is expected to become economically active. As a result, Swedish society is characterised by high female participation rates, particularly among women with children, and relatively egalitarian distribution structures. The welfare state has become a female labour market, providing good pay and the kind of job security and flexibility that make careers compatible with having children (Esping-Andersen 2002: 112).

In the market service model (represented in Europe by the UK), the expansion of services is founded upon the polarised growth of highly paid professional services for the corporate sector, on the one hand, and lowskill, low-paid consumer-oriented services, on the other. The prerequisites for this model are a high degree of wage dispersion, so that the well paid can afford to pay market rates for the services offered by low earners, and a 
low level of welfare state provision, which means that those with few skills have no alternative but to work in ill-paid jobs. The negative consequences of this arrangement are a polarisation of society and increasing poverty. This model also produces high female employment rates but, unlike in Sweden, they are employed not in the public sector but in the private services sector. Childcare facilities are available, it is true, but standards vary considerably from provider to provider, and consequently the quality of children's care and education depends on their parents' financial means.

The household service model is based on the traditional gendered division of labour between spouses, with derived social security rights for the economically inactive wife and family allowances that are not subject to prior earnings. There is less employment in services in both the private and public sectors than in the previous two models, since a large proportion of services are performed unpaid in the home. The growth in female labour market participation runs very much counter to the prevailing institutional environment.

The focus of this typology lies in social and consumer services and in the link between such services, female labour market participation and the welfare state. Other forces driving the expansion of the service sector are to a large extent ignored, as are areas of service work, such as distributive services and the rapidly expanding production-oriented services. Despite this limitation, this typology derives its value from the fact that it is indeed social services that currently account for the greatest share of employees in the service sector and are likely to see the largest employment increases in future.

Which of the three ideal-typical routes to the service society countries actually adopt has decisive effects on employment conditions? While the individual breadwinner and public service model promotes a high level of female employment with relatively good working conditions, employment conditions in the market service model are generally inferior in terms of both extent and quality of provision. This latter model is geared to the provision of services within private households, and tends to represent an obstacle to the spread of professionally organised social and householdrelated services.

Thus the Swedish and US paths may be seen as two contrasting models for the linking of increasing labour market participation among women and social services in Europe (Lehndorff 2002: 493ff.). On the 'low road', which in Europe is represented by the UK, female participation rates are relatively high, but economically active women receive only limited support from public services. Furthermore, income levels in these services are low. Consequently, high female employment levels and high gender segregation go hand in hand. The 'high road' taken by the Scandinavian countries, on the other hand, is characterised by highly developed social services and average pay levels for women working in social services that are high relative to those in other European countries. In these countries, 
and despite a slowdown in the 1990s, the co-ordinated growth of female labour market activity and social services has contributed to the gradual reduction of social and gender inequality (Lehndorff 2002).

On the 'low road', just as the informal housework performed by economically inactive housewives is socially 'invisible', the activity of most of the home helps, who are generally female and often illegally employed, also remains outside the scope of public perception. Their employment is fostered not only by a wide gulf in earnings and the possibility of shorthours jobs on favourable tax and social security terms, but also by the seldom acknowledged existence of legal and illegal immigrants with very few rights. The employment of migratory domestic workers, who have organised their livelihood as long-distance commuters, is the living counter-evidence to the frequently uttered assertion that household services are protected from 'globalisation tendencies' (Rerrich 2000: 50). That some of these women have a higher qualification gained in their home country but not usable in Western Europe, and which may be expected to be useful when they are illegally employed in the home, makes their employment even more attractive. This could be one reason why attempts to establish socially acceptable working conditions in the field of household services have made limited progress to date.

This delegation of household tasks to domestic workers and cleaners gives rise to a division of labour between women who establish careers in well-paid positions and others who give them the freedom to do so by taking over their childcare and household tasks in return for low pay. In this way, women's labour is freed up for their professional activities, while the labour of other women substitutes for the labour previously deployed in the home. 'The division of labour between the sexes that came in with industrial urbanisation is being replaced by a similarly hierarchical division of labour among women' (Häußermann and Siebel 1995).

As Anxo and Fagan (2001: 98) note, the public service model is, in contrast, the most favourable of the three in terms of the integration of women into the labour market. On the one hand, the employment conditions (e.g. pay, dismissal protection) are in general better in the public than in the private sector and, on the other hand, high-quality public services are accessible to all. Regulated public standards may be expected to be in the best interests of women in their capacity not only as employees but also as consumers. Clearly, then, these are the social policy conditions that have to be met if Esping-Andersen's argument that women are the axial principle of the post-industrial society is to acquire validity.

\section{Some political implications of the 'high road'}

The link between increasing female labour market participation and increasing employment (among women) in social and personal services has its roots in a changing relationship between housework and care 


\section{Alexandra Wagner}

activities, including childcare, on the one hand, and paid work, on the other. The current demarcation and differentiation between housework and paid work is the outcome of industrialisation, which 'led to the dissolution of the household-based economy. Two spheres developed: paid labour and, separated from it, housework. Each form, none the less, makes implicit reference to the other' (Meyer 1997: 191). The development of the capitalist mode of production led, in the course of time, to the spread of wage labour and the decline of the subsistence economy in private households. One of the forces driving the expansion of the service sector is the transfer of certain activities previously carried out within households into the formal labour market. Häußermann and Siebel (1995: 174) describe this as an 'internal acquisition of territory'. The socialisation of women's labour and of women's work in the home runs in parallel to this process of acquisition (ibid.: 172), with activities previously organised as paid labour and then carried out by housewives on an informal basis without pay reverting once more to the public sphere of market and state: 'from the nanny via the mother to the day nursery' (ibid.: 174).

This socialisation of women's domestic work is taking place for two main reasons. First, women are becoming better qualified, and as a result more of them are seeking to enter the labour market, as is shown by the differences between actual and desired employment rates (Table 5.11).

Table 5.11 Actual and desired female employment rates in fifteen EU member states (1998)

\begin{tabular}{lllcc}
\hline Country & $\begin{array}{l}\text { Actual } \\
(\%)\end{array}$ & $\begin{array}{l}\text { Desired } \\
(\%)\end{array}$ & $\begin{array}{l}\text { Absolute change } \\
\text { (percentage points) }\end{array}$ & $\begin{array}{l}\text { Relative change } \\
\text { (as percentage of } \\
\text { actual employment } \\
\text { rates) }\end{array}$ \\
\hline Belgium & 53 & 62 & 9 & 17.0 \\
Denmark & 76 & 79 & 3 & 3.9 \\
Germany & 63 & 72 & 9 & 14.3 \\
Greece & 40 & 60 & 20 & 50.0 \\
Spain & 29 & 59 & 30 & 103.4 \\
France & 55 & 68 & 13 & 23.6 \\
Ireland & 56 & 72 & 16 & 28.6 \\
Italy & 37 & 59 & 22 & 59.5 \\
Luxembourg & 62 & 66 & 4 & 6.5 \\
Netherlands & 59 & 65 & 6 & 10.2 \\
Austria & 61 & 70 & 9 & 14.8 \\
Portugal & 56 & 68 & 12 & 10.1 \\
Finland & 69 & 76 & 7 & 12.0 \\
Sweden & 75 & 84 & 9 & 9.5 \\
UK & 63 & 69 & 6 & 8.9 \\
Norway & 79 & 86 & 7 & 24.1 \\
EU and Norway & 54 & 67 & 13 & \\
\hline
\end{tabular}

Source: Bielenski et al. (2002). 
Employment rates are generally much higher, and the gender gap lower, among women with a higher educational qualification than among women with a low level of educational achievement (OECD 2002: 64). On the other hand, improved technologies and greater professionalism mean that many services can be performed better and more cost-effectively outside the household. In the case of childcare, for example, standards may be laid down and providers monitored in order to ensure that children from poorer backgrounds are not disadvantaged. Thus the professionalisation of services hitherto provided informally promotes the interests of women as both employees and consumers.

It should be pointed out that it is, of course, quite impossible for professional services to substitute completely for all housework, care and upbringing that takes place within the home. Nor would it be desirable, since care and upbringing have important emotional and communication aspects. It is not the full conversion of homework into professional work but rather improved compatibility between paid work and other activities that is the most important prerequisite for ensuring that an appropriate work/life balance is achieved when both men and women are economically active.

However, even in those countries where female employment rates have risen, the gendered division of labour still prevails. There is, therefore, an urgent need to examine all proposed reforms of the employment and social systems for their gender repercussions. The effects on the gains that have already been made must be an independent criterion in evaluating attempts at social reform.

\section{Risks and contradictions}

Women carry out a disproportionate share of welfare work, whether it is provided by the state, private organisations, corporations or the family. This imbalance is reflected also in a pronounced and chronic sectoral and occupationally related gendered segmentation of the labour market. This is accompanied by a relative devaluation of the activities typically carried out by women (see e.g. Winter and Krell 1997; Stiegler 1999), which manifests itself in lower pay and poorer career opportunities in female-dominated sectors relative to those dominated by men. Even in Scandinavian countries, where female employment rates are high and the vast majority of women work full-time, there has been no fundamental change in the structural positions of men and women in the labour market. In Sweden, the occupational upgrading of women was accompanied by continued segregation (Orloff 1993: 313). More than three-quarters of all public-sector workers are women and more than half of all economically active women are employed in the public sector. Female economic activity is also, for many families, an economic necessity and places a heavy burden on women, who continue to perform more than their fair share of essential household and childcare tasks. ${ }^{7}$ 


\section{Alexandra Wagner}

Thus the integration of women into the labour market and the transformation of informal household tasks into professional services appears to reproduce, in new forms, the hierarchical, gendered division of labour. This is one of the reasons for the persistence of the gender pay gap in all EU member states. In 1999, across the EU as a whole, the average gross monthly earnings of female full-timers in manufacturing industry and private services were 75 per cent of those of male employees (Clarke 2001) ${ }^{8}$ It is true that, in Scandinavian countries, the gender pay gap is less marked than elsewhere, which is largely attributable to the fact that it is generally smaller in public services than in the private sector (Winberg 2000: 19; cf. also Morrell et al. 2001). However, the persistent difference between men's and women's earnings may help to maintain the unequal division of domestic work between spouses.

The abolition of gendered segmentation in the labour market is not desirable solely for reasons of equality. It is also an important prerequisite for ensuring that the degree of emancipation already achieved by women as a result of their integration into the labour market is consolidated and made irreversible. If women were represented in all sectors of the economy, it should at least become more difficult to dismantle women's jobs wholesale at times of economic difficulty. At present, it is women's jobs that tend to be threatened by cuts in the provision of public services. Thus from 1990 to 1995, the number of people employed in the public services in Sweden was cut by 300,000, with more women affected than men, and it became particularly difficult for young women to gain access to the labour market. At the same time, the birth rate fell from 2.13 in 1990 to 1.52 in 1997 (Ellingsæter 2000: 342 and 348).

The level of female employment is also at risk if economic growth stagnates and jobs are lost in the male-dominated sectors. As is clear from the experience of transformation in Eastern Germany, women can, under such circumstances, be pushed out by men, even from jobs in their previous employment strongholds (Quack and Maier 1993). For this reason, general economic growth and/or a policy of work redistribution are other important prerequisites for the spread of women's employment.

\section{New models for economic activity and social security}

In considering how to reduce the gender gap in the volume of paid work by adjusting women's employment rates and working times to those of men, the long-established form of male employment is often accepted as a yardstick. This is problematic, since women's entry into the labour market has led to the breakdown of the separation that used to prevail between paid work and unpaid domestic work, thereby weakening what was a decisive prerequisite for the standard form of male employment. If women are economically active and no longer available around the clock for domestic work, the question arises of how to organise the tasks they once did. 
'Nowhere in the industrialised West can married women and mothers choose not to engage in caring and domestic labour (unless they are wealthy enough to purchase the service of others)' (Orloff 1993: 313). Since the tasks in question cannot be completely 'outsourced', those with domestic responsibilities are bound to have only limited availability for paid work. This affects not only economically active women and mothers but also, potentially, their partners.

Consequently, the search for a genuine balance between economic activity and domestic responsibilities calls into question the entire system that has prevailed to date. Only if this challenge is taken seriously can Esping-Andersen's argument that women are becoming the axial principle of the post-industrial society be regarded as correct, since women's entry into the labour market not only creates whole new areas of service work but also puts pressure on the employment and social system to take account of these new conditions. What is required is a new principle for the organisation, distribution and regulation of paid work. The main elements of this new organising principle must be consideration for and social valuation of the unpaid reproduction work that used to be invisible because it was done by women and from which the traditional male wage worker was exempt. The need and desire experienced by increasing numbers of women (and men) to combine economic activity and domestic and family responsibilities calls for a revision of the notion of 'normal' or 'standard' work that has prevailed hitherto. However, if these challenges are to be taken up, then political decisions are required, since there is no way the new demands will be met automatically. What is more likely to happen is that, once women have been drawn into paid work in addition to the domestic and family work they do, the social debates that are required on the reorganisation of the employment and social system with a view to establishing gender equality will last some time before they lead to concrete reforms.

Current practices are associated with various shortcomings that vary in significance from country to country. The Swedish example shows that economic activity among women does indeed foster their independence and help to fulfil their aspirations. However, it also brings with it considerable time pressures and stress, and misgivings about the effects it may be having on children (Jönsson 2002: 182). In other countries, many women work part-time, that is, in a form of employment that enables them to combine their paid work with domestic responsibilities. Thus it is no accident that part-time work is advocated in some countries as the ideal means of reconciling paid work and family life, although without any acknowledgement of the fact that the consequence of such a policy is to sustain the juxtaposition of full-time or part-time economic activity for women and social policy measures that promote the male breadwinner family model (Wagner 2000). At the same time, changes to labour law intended to improve the work/life balance, such as the right to work part-time that 
already exists in the Netherlands and has recently been introduced in Germany as well, are being resisted by employers' associations on the grounds that they constitute obstacles to flexibility and an unacceptable increase in labour costs. Consequently, gender equality in the labour market seems to be a long way off (Buchholz-Will and Schratzenstaller 2002: 202, 683).

Representative surveys of employment and working-time preferences clearly show that many women, and not a few men, in EU member states would like to see changes that point in the direction of a new concept of 'normal' or 'standard' work based on gender equality. The preferences expressed by those surveyed in the fifteen EU member states and Norway (Bielenski et al. 2002) reveal a desire not only for shorter working hours but also for a less unequal division of working time between men and women in general and between household partners in particular. There is some evidence that an employment model for the future could consist of two partners working what, by today's standards, would be considered as part-time. Employment and working-time preferences in Scandinavia point particularly in this direction, while preferences in other countries seem to be directed more to the current Scandinavian model.

This finding makes it clear that gender equality is a moving target. Men and women in the Scandinavian countries, starting from a position in which full-time employment for both genders is taken for granted, would prefer shorter working hours for both; in other countries, in contrast, both genders, but particularly women, are looking initially to the Swedish model, which has obviously been able to adjust to external pressures without having to abandon its fundamental qualities (Ellingsæter 2000: $357)$.

Häußermann and Siebel (1995: 203) are obviously right in stating that

It is to be assumed that an equal distribution of paid work and domestic work between the sexes will not be achieved until men are no longer expected to participate in what for them is a negative exchange of high-status paid work for low-status domestic work, thereby enabling women to get something in return for a change. Thus the cultural question as to how best to divide up activity between the formally and informally organised spheres cannot be discussed with any seriousness until both sexes are fully integrated into the labour market, by which time of course the road to total socialisation - something that was actually to be avoided - will already have been taken.

Orloff (1993: 317) similarly argues that decommodification must be viewed against the background of gender relations. She further proposes that the analysis should be extended to take account not only of the 
extent to which states guarantee women access to paid employment and to services that facilitate the work/life balance but also of the mechanisms and institutions that implement those guarantees. In other words, the right to be commodified in order to ensure access to the labour market is, from this point of view, a precondition for the emancipation of women. Outside the labour market, as housewives, women are virtually completely dependent; by entering the labour market, they acquire greater freedom for their own development and more social rights. Only when the housework and care work performed by women has been brought fully into the formal social sphere does it become a subject of public interest and political influence.

If this approach is pursued to its conclusion, therefore, women's emancipation takes place in lengthy stages. The initial challenge is to gain access to paid work and to reconcile labour market participation with women's traditional obligations in the domestic sphere. Only from this point onward does it seem possible to effect a gradual change in the gender division of labour that has prevailed hitherto. The Scandinavian model offers the most favourable conditions yet seen for developing and establishing a new standard form of employment.

\section{Conclusion}

We have sought to show in this chapter that the development of both women's employment and the service sector is shaped to a large extent by conditions in the wider society, which in turn depend on political decisions. Comparison of the various routes to the service society shows that the individual breadwinner and public service models promote a high level of female employment with relatively good employment and working conditions, while both the level and quality of such employment are lower in the market service model. However, the integration of women into the labour market and the conversion of informal housework into paid work have tended to date to reproduce the hierarchical gender division of labour in new forms. Real gender equality and the genuine opportunities to reconcile paid work and family responsibilities that are essential as more and more women become economically active require a change in the notion of 'standard' work that has hitherto prevailed. For these reasons, Esping-Andersen's notion of a link between women's employment and the post-industrial society is to be interpreted primarily as an indication of the need to refashion the societal regulation of employment in order to accommodate the expansion in women's employment and work in services. 


\section{Alexandra Wagner}

\section{Notes}

1 The increase in activity rates, which show the proportion of women who, successfully or otherwise, are seeking paid work, was even steeper. These rates rose during this same period by a total of 3 percentage points to reach 59.9 per cent in the year 2000 (European Commission 2001: 38). The participation rates indicate the share of women of working age who are seeking paid work in the labour market, irrespective of whether or not they succeed in doing so. The employment rates, on the other hand, indicate the share of women actually in employment. There is, however, a link between the two: the higher the participation rate, the higher the unemployment rate in most cases.

2 The average collectively agreed working week in 1999 ranged between thirtyseven hours in Denmark and the Netherlands and forty hours in Greece, Luxembourg and Sweden (ETUI 2001: 36).

3 On the differing causes of the low part-time rates in Portugal and Spain, which lie outside this explanatory model (cf. Ruivo et al. 1998).

4 In Denmark, from 43.9 per cent in 1985 to 34.1 per cent in 2000; in Sweden, from 46.6 per cent in 1985 to 36.0 per cent in 2000 (European Commission 2000, 2001).

5 Portugal is to some extent an exception in this group, since employment rates among Portuguese women are significantly higher than in the other three countries. This is attributable both to the low hourly wages - by far the lowest in the EU - and to historical reasons - long period of colonial wars, emigration of male labour force, rapid increase in women's level of vocational training (Castro and González 1999).

6 The welfare state is not financed predominantly by non-wage labour costs but rather out of taxation, with a high proportion of consumer taxes and levies on all members of the population.

7 The campaign for the introduction of the six-day week launched by the Swedish Social Democratic Women's League, which was particularly active in the late 1960s and early 1970s, ultimately failed because of opposition from the trade union movement (Lewis 1992: 170).

8 However, the data sources for such earnings comparisons are incomplete. Thus with a few exceptions, one of which is Grimshaw and Rubery's study for the OECD (Grimshaw and Rubery 1997), public services are not included.

\section{References}

Anxo, D. and Fagan, C. (2001) 'Service employment: a gender perspective', in D. Anxo and D. Storrie (eds) The Job Creation Potential of the Service Sector in Europe: Final Report 2000, European Commission, Employment Observatory Research Network, Luxembourg: Office for Official Publications of the European Communities.

Anxo, D., Flood, L. and Rubery, J. (1999) 'Household income distribution and working time patterns: an international comparison', Graue Reihe des Instituts Arbeit und Technik 199-05, Gelsenkirchen: Institut Arbeit und Technik.

Bielenski, H., Bosch, G. and Wagner, A. (2002) Wie die Europäer arbeiten wollen: Erwerbs- und Arbeitszeitwünsche in 16 Ländern, Frankfurt/New York: Campus Verlag.

Buchholz-Will, W. and Schratzenstaller, M. (2002) 'Barrieren für die Erhöhung der Frauenbeschäftigung in der EU', WSI-Mitteilungen 11: 678-84.

Castro, A. and González, M. do Pilar (1999) 'The Portuguese and Spanish labour 
markets: so alike yet so different', in J. Christiansen, P. Koistinen and A. Kovalainen (eds) Working Europe: Reshaping European Employment Systems, Aldershot: Ashgate.

Clarke, S. (2001) 'Earnings of men and women in the EU: the gap narrowing but only slowly', Statistics in Focus, theme 3, no. 3, Luxembourg: Eurostat.

Dingeldey, I. (1999) Begünstigungen und Belastungen familialer Erwerbs- und Arbeitszeitmuster in Steuer- und Sozialversicherungssystemen: ein Vergleich zehn europäischer Länder, Graue Reihe no. 004, Gelsenkirchen: Institut Arbeit und Technik.

Ellingsæeter, A.L. (2000) 'Scandinavian transformations: labour markets, politics and gender divisions', Economic and Industrial Democracy 21 (3): 335-59.

Esping-Andersen, G. (1990) The Three Worlds of Welfare Capitalism, Princeton, NJ: Princeton University Press.

— (1996) Welfare States in Transition, London: Sage.

_ (2002) 'Towards a post-industrial gender contract', in P. Auer and B. Gazier (eds) The Future of Work, Employment and Social Protection, Geneva: International Labour Organization/International Institute for Labour Studies.

European Commission (2000) Employment in Europe 2000, Luxembourg: European Commission.

- (2001) Employment in Europe 2001: Recent Trends and Prospects, Luxembourg: European Commission.

European Trade Union Institute (ETUI) (2001) Benchmarking Working Europe, Brussels: ETUI.

Fagan, C. (2001) Gender, Employment and Working Time Preferences in Europe, Dublin: European Foundation for the Improvement of Living and Working Conditions.

Fagan, C. and Burchell, B. (2002) Gender, Jobs and Working Conditions in the European Union, Luxembourg: European Foundation for the Improvement of Living and Working Conditions.

Grimshaw, D. and Rubery, J. (1997) 'Workforce heterogeneity and unemployment benefits: the need for policy reassessment in the European Union', Journal of European Social Policy 7(4): 291-315.

- (2001) The Gender Pay Gap: A Research Review, Research Discussion Series, Manchester: Equal Opportunities Commission. Available online at: www.eoc.org. $\mathrm{uk} / \mathrm{cseng} /$ research/gender_pay_gap_research_review_report.pdf (accessed 24 June 2004).

Häußermann, H. and Siebel, W. (1995) Dienstleistungsgesellschaften, Frankfurt/ Main: Suhrkamp.

Jönsson, I. (2002) 'Vereinbarkeit von Berufs- und Familienleben in Schweden', WSI-Mitteilungen 3: 176-83.

Lehndorff, S. (2002) 'Auf dem Holzweg in die Dienstleistungsgesellschaft? - gute Dienstleistungsgesellschaft als Politikum', WSI-Mitteilungen 9: 491-7.

Lewis, J. (1992) 'Gender and the development of welfare regimes', Journal of European Social Policy 2 (3): 159-73.

Meyer, T. (1997) "Wider "Selbstbedienungsökonomie" und "Brotverdienermodell”? Beschäftigungspolitische Chancen der Subventionierung haushaltsnaher Dienstleistungen in Deutschland', in U. Behning (ed.) Das Private ist ökonomisch: Widersprüche der Ökonomisierung privater Familien- und Haushaltsdienstleistungen, Berlin: Edition Sigma.

Morrell, J., Boyland, M., Munns, G. and Astbury, L. (2001) Gender Equity in Pay Practices, Manchester: Equal Opportunity Commission. 


\section{Alexandra Wagner}

Organisation for Economic Co-Operation and Development (OECD) (2000) Employment Outlook, Paris: OECD.

- (2002) Employment Outlook, Paris: OECD.

Orloff, A.S. (1993) 'Gender and the social rights of citizenship: the comparative analysis of gender relations and welfare states', American Sociological Review 6: 303-28.

Quack, S. and Maier, F. (1993) 'Verliererinnen der Vereinigung? Entwicklungen der Frauenbeschäftigung in Ostdeutschland', Beschäftigungsobservatorium Ostdeutschland 9: 3-5.

Rerrich, M.S. (2000) 'Neustrukturierungen der Alltagsarbeit zwischen Lohn und Liebe: Überlegungen zu möglichen Entwicklungspfaden bezahlter häuslicher Dienstleistungen', in M. Friese (ed.) Modernisierung personenorientierter Dienstleistungen: Innovationen für die berufliche Aus- und Weiterbildung, Opladen: Leske und Budrich.

Rubery, J., Smith, M. and Fagan, C. (1999) Women's Employment in Europe: Trends and Prospects, London: Routledge.

Ruivo, M., González, M. do Pilar and Varejao, J. (1998) 'Part-time work in Portugal and Spain: why is it so low?', in J. O'Reilly and C. Fagan (eds) Part-Time Prospects, London: Routledge.

Schmid, G. (1992) 'Die Frauen und der Staat: Beschäftigungspolitische Gleichstellung im öffentlichen Sektor aus internationaler Perspektive', WZB Discussion Papers FS I: 91-12.

— (2003) 'Gleichheit und Effizienz auf dem Arbeitsmarkt: Überlegungen zum Wandel und zur Gestaltung des "Geschlechtervertrags", WZB-Paper SP I: 2003-102.

Stiegler, B. (1999) Welcher Lohn für welche Arbeit? Über die Aufwertung von Frauenarbeit, Bonn: Friedrich-Ebert-Stiftung.

Thenner, M. (2000) 'Familienpolitik als Politik zur Vereinbarkeit von Familie und Beruf - Geldwerte Leistungen, zeitwerte Anrechte, familienunterstützende Infrastruktur und ihre Auswirkungen auf das Familienverhalten', in I. Dingeldey (ed.) Erwerbstätigkeit und Familie in Steuer- und Sozialversicherungssystemen: Begünstigungen und Belastungen verschiedener familialer Erwerbsmuster im Ländervergleich, Opladen: Leske und Budrich.

Wagner, A. (2000) 'Krise des "Normalarbeitsverhältnisses"? Über eine konfuse Debatte und ihre politische Instrumentalisierung', in C. Schäfer (ed.) Geringere Löhne - mehr Beschäftigung? Niedriglohn-Politik, Hamburg: VSA Verlag.

Winberg, M. (ed.) (2000) Highlighting Pay Differentials Between Women and Men. Stockholm: Government Offices. Available online at: europa.eu.int/comm/ employment_social/equ_opp/documents/paydiff_en.pdf (accessed 24 June 2004).

Winter, R. and Krell, G. (1997) Aufwertung von Frauentätigkeiten, Stuttgart: Ein Gutachten im Auftrag der ÖTV. 
Part II

The organisation of service work

An analysis of five sectors 



\title{
6 The family, the state, and now the market
}

\author{
The organisation of employment \\ and working time in home care \\ services for the elderly
}

Dominique Anxo and Colette Fagan

\section{Introduction}

Our aim in this chapter is to identify the dominant features and recent developments in the provision of home care services for the elderly, based on a comparison of the arrangements in six European countries: Denmark, Italy, Finland, the Netherlands, Sweden and the United Kingdom.

Home care services contribute to the broader category of activities and responsibilities associated with care work that are necessarily undertaken in any society. ${ }^{1}$ Care work includes raising children and helping elders and other adults with their daily lives when they are in poor health, have disabilities or are fragile due to advanced age. Home care services are intended to help adults who live in private households and who need assistance with self-care (e.g. washing, dressing, eating, taking medication), domestic tasks (e.g. cleaning, cooking, managing finances), or rehabilitation following illness. Most of the recipients are elderly, but these services are also provided for younger adults and children with disabilities or chronic sickness. Residential homes provide a more intense form of care service for those who are unable to live in private households due to illhealth, fragility or lack of suitable accommodation.

The way that care work is arranged in any society rests upon the articulation of three social institutions: the family, the state and the market (Daly and Lewis 2000). The family provides informal care, largely undertaken by women in their roles as mothers, daughters and neighbours. The state structures care work in a number of ways. It attempts to regulate family responsibilities and obligations, whether explicitly or in implicit normative assumptions that underpin policies. It may also set regulatory standards for providers of care services. Most welfare states provide some public sector care services, and many finance other services through fiscal transfers to the family and/or service providers (e.g. tax allowances, subsidies, home care benefits). Market providers of care-related services include private (for-profit) companies as well as voluntary (non-profit) 


\section{D. Anxo and C. Fagan}

companies, where unpaid volunteers as well as employees may undertake the work in the latter.

It is the dynamics and tensions within and between the family, the state and the market that define the responsibilities for, and organisation of, care-related services. Tensions and unintended outcomes are an inherent part of this institutional articulation. For example, the state's role in funding and regulating home care services has grown historically in response to various pressures and demands from professional care workers, and from elderly people and their families (Hutton and Kerkstra 1996; Sipilä 1997; Walker and Maltby 1997). State policies continue to prescribe certain family responsibilities and obligations to elderly relatives, whether in explicit regulations or implicitly in the scope of policy provision (Millar and Warman 1996). However, families may be less willing or able to comply with this ideology than perhaps they were in earlier periods (for example, because women are more involved in paid work or because families' living arrangements are more dispersed). Families may respond to this situation in a number of ways, for example, as consumers, purchasing services from the market to bridge this gap in state provision, or through collective political demands on the welfare state to fund more care services. Another example is that market provision of certain services has developed in some countries to fill specific, specialist niches in home care services, sometimes as subcontractors to municipal providers (local authorities). In later periods, the expansion of market companies may stimulate the restructuring of public sector provision of home care services, perhaps driven by national state policy.

In this study, our first hypothesis is that the organisation and developments in home care services for the elderly in each country are shaped by the national welfare and employment regime. We explore how the service is organised in each country, the pressures for change that are affecting the service, and the responses and developments occurring as a result of these pressures. Our second hypothesis is that, while there may be similar pressures for change occurring in each society, the magnitude of this pressure and the form of restructuring that is occurring vary among countries - in other words, distinct national solutions are emerging.

Our analysis is based on national reports produced for the six countries included in the study (Anttila and Nätti 2000; Anxo and Nyman 2000; Csonka and Boll 2000; Degasperi and Villa 2000; Fagan and Nixon 2000; Plantenga et al. 2000). Each report provides a detailed description of how the national home care system is organised. It summarises the legal and normative framework that establishes home care needs, entitlements, and the division of responsibilities between the family, the national and local state, private companies, and non-profit organisations. The labour market for home care work is described in terms of the profile of workers (gender, age, qualification), career structure, material working conditions (contract, working time, wage levels), and industrial relations (union 
density and coverage of collective bargaining). Organisational case studies in two local authorities were carried out in each country in order to deepen our understanding of the work organisation and working-time patterns in this service, and to identify any new developments.

In the following section, we discuss the gendered arrangement of care responsibilities in relation to welfare state regimes and the legal and normative framework for home care services in the countries in this study. The third section analyses the dynamics of change in the organisation of home care services. The main findings of the countries' organisational case studies are presented in the fourth section. The concluding section summarises the main features and developments in the organisation of home care services in the six countries.

\section{Gender, care and welfare state regimes}

Care work is highly gendered. Women are the main providers of eldercare, on an informal basis within the family or as neighbours, and in formal services as employees. However, men also make considerable contributions to informal care, mainly in the form of caring for a spouse in poor health, which indicates that men do take on caring roles in particular household circumstances. For example, 17 per cent of men and 22 per cent of women aged forty-five to sixty-four in the UK are carers, and onethird of all carers spend at least twenty hours a week on this activity (Fagan and Nixon 2000). Women also constitute the majority of elderly recipients of home care services due to their greater life expectancy. For example, they account for two-thirds of users in Italy (Degasperi and Villa 2000: 5).

While the state and the market have taken on many of the activities that the family used to undertake in earlier historical periods, informal care provided by family members, more specifically by women, is still crucially important as the main source of eldercare. Even where formal services are most developed, such as in Sweden and Finland, informal care makes a significant contribution, although the type of informal care provided may be different (Anttila and Nätti 2000; Anxo and Nyman 2000, Sipilä 1997). When practical tasks are undertaken by formal services, the role of informal carers may be focused on providing social contact, support, and mediation between the elder person and the formal services (European Commission 1999: 6-7).

The probability of having eldercare responsibilities increases once people are in their late forties and falls off once the age of sixty-five years is reached. Thus it is older employed persons and the 'young retired' who undertake most of the informal care. Eldercare responsibilities may lead some employed carers to reduce their working hours or leave employment, and may be one of the factors contributing to early retirement decisions. However, the impact of caring on employment patterns depends on the time intensity of care required. 


\section{D. Anxo and C. Fagan}

In conjunction with informal care systems, home care services for the elderly are provided by a combination of local municipal public services, private companies and non-profit organisations in the market. As we shall see below, the relative weight and extent of the various forms of eldercare provided by these different sources vary according to the framework of the national welfare state regime.

The welfare states that have evolved in different countries are the product of complex political, economic, social and cultural factors. The welfare state regime that emerges is the result of negotiations, conflicts and compromises between social actors with different power resources. A large number of studies have attempted to classify countries according to their welfare state regimes. The debate was opened by Esping-Andersen's (1990) influential typology of welfare state regimes. He identified three country clusters. 'Social democratic welfare regimes', such as those in the Nordic countries, are based on the promotion of the integration of the whole adult population into employment and a relatively high level of universal social rights. 'Conservative welfare regimes', such as those in West Germany, Austria, and France, provide less extensive social rights linked to employment status and are accompanied by strong incentives for women to stay at home when they are married. 'Liberal welfare regimes', such as those in the UK, are based on a low level of social rights and create a moderate level of labour force participation among women. This typology was criticised by feminists for its focus on the income security of wage earners, and the relative neglect of other benefits and services that are important to women in their roles as carers (Lewis 1993, 1998; PfauEffinger 2000; Rubery et al. 1998; Sainsbury 1994). The introduction of these other criteria of classification produces more differentiated country groupings, particularly among countries in the 'conservative welfare regime' cluster. These studies also showed that national variation in women's labour force participation patterns could not be accounted for simply in terms of the welfare state regime. It is important to incorporate other societal features such as employment conditions into the explanation.

Our aim here is simply to draw attention to the differences in emphasis in the eldercare systems among the welfare state regimes in the countries in our study. The cross-national data on eldercare services is quite limited, more so than in relation to childcare services, for example; and there is no reliable source of data on the employment patterns of carers (European Commission 1999). However, the available data do indicate national differences in the rate of residential and home care services for the elderly. This is illustrated in Table 6.1, where the countries in this study are emphasised in bold. It should be noted that Table 6.1 provides no indication of the quality of services or the actual volume relative to need. In particular, the number of hours of home care services received by elder persons varies between countries. For example, elder persons in Sweden 
Table 6.1 Residential and home care services for older people by country

\begin{tabular}{lcl}
\hline & $\begin{array}{l}\text { Percentage of people aged } \\
\text { over 65 years in residential } \\
\text { (institutional) care }\end{array}$ & $\begin{array}{l}\text { Percentage of older people } \\
\text { receiving home care } \\
\text { (domiciliary) services }\end{array}$ \\
\hline Nordic 'universalist' model & & \\
Finland & 7.2 & 24.0 \\
Denmark & 5.7 & 17.0 \\
Norway & 7.1 & 14.0 \\
Sweden & 5.4 & 13.0 \\
Iceland & High & High \\
UK & 5.1 & 13.0 \\
Netherlands & 10.0 & 8.0 \\
Belgium & 4.0 & 6.0 \\
France & 3.0 & 7.0 \\
Austria & 4.7 & 3.0 \\
Germany & 5.0 & 3.0 \\
Ireland & 5.0 & 3.0 \\
Southern 'family-based' model & \\
Portugal & 5.0 & 1.5 \\
Spain & 2.8 & 1.0 \\
Italy & 2.0 & 1.3 \\
Greece & 0.5 & small pilot projects set up \\
\hline
\end{tabular}

Sources: Bettio and Prechal (1998); drawing on OECD (1996); Anttonen and Sipilä (1996).

receive more hours of home care services than elsewhere in the EU (Anxo and Nyman 2000). However, the broad message of Table 6.1 is supported by the more detailed work of Anttonen and Sipilä (1996), which shows that home care service provision tends to be more widely available in the Nordic 'universalist' model of extensive public services and least developed in the 'family-based' model characteristic of the southern EU member states (Italy, Greece, Spain and Portugal). On all indicators of care services, these two country groups are 'consistently found at opposite ends of the spectrum' (European Commission 1999: 6; see also OECD 1996). The other two countries in our study - the UK and the Netherlands - rank mid-table in terms of the rate of home care service provision. Anttonen and Sipilä (1996) have identified the UK as a particular 'AngloSaxon' model of eldercare services where the emphasis is on means-tested service entitlements, while the Netherlands has more in common with the Nordic model (Plantenga et al. 2000). The other message from this table is that national eldercare policies cannot be categorised as being centred on either a home care (domiciliary) or a residential (institutional) focus. Instead, as we discuss below, there has been a common shift in the emphasis in eldercare policy in most countries to minimise the use of residential homes and to provide home care services instead. 


\section{D. Anxo and C. Fagan}

\section{The Nordic social democratic 'universalist' system of eldercare}

The most extensive care services are in the Nordic countries, following substantial expansion during the 1970s that continued into the 1980s. In these countries, most of the retired also receive better pensions (relative to average wages) than in most of the other member states, where pensions are lower or entitlements are more unevenly held (Bettio and Prechal 1998).

In the Nordic countries, individualisation has been a key part of the welfare state, and the basic principle of the institutional model is entitlement based on citizenship (universal citizen right). The individual, and not the family, has for many years been the unit for taxation and receipt of social benefits as social rights. As far as home care is concerned, the social legislation abolishing the obligation of children to take care of their parents in Finland and Sweden is an illustration of these efforts. Concomitant with the growth of public childcare, this change in responsibility is an element of a general policy aiming to outsource the activities traditionally performed by women from the household to the public sphere and to favour the growth of female employment.

Hence, the dominant feature of the Nordic home care regime is that the overall responsibilities and provisions for elderly home care services lie with local authorities, with clearer legal entitlements to this care than exist in most of the other EU member states (Table 6.2). Home care services are financed by the general (national) taxation system and local municipal taxes. Service allocation is based on an assessment of the individual needs of elderly persons, who make some income-tested contribution (Anttila and Nätti 2000; Anxo and Nyman 2000; Csonka and Boll 2000).

Table 6.2 Schematic summary of the legal obligations and rights in the state eldercare policy of the EU member states

\begin{tabular}{|c|c|c|c|c|}
\hline \multirow{2}{*}{$\begin{array}{l}\text { Elder people have legal } \\
\text { entitlements to state support }\end{array}$} & \multicolumn{4}{|c|}{ Family obligation to care for elders specified in legislation } \\
\hline & Yes & & No & \\
\hline $\begin{array}{l}\text { No clear entitlement to a } \\
\text { minimum level of service }\end{array}$ & $\begin{array}{l}\text { Austria } \\
\text { Belgium } \\
\text { France } \\
\text { Germany }\end{array}$ & $\begin{array}{l}\text { Italy } \\
\text { Spain } \\
\text { Greece } \\
\text { (Netherlands) }\end{array}$ & $\begin{array}{l}U K \\
\text { Ireland }\end{array}$ & \\
\hline $\begin{array}{l}\text { More explicit individual } \\
\text { entitlement }\end{array}$ & & & $\begin{array}{l}\text { Denmark } \\
\text { Finland } \\
\text { Norway }\end{array}$ & $\begin{array}{l}\text { Sweden } \\
\text { Iceland } \\
\text { Netherlands }\end{array}$ \\
\hline
\end{tabular}

Sources: Bettio and Prechal (1998); Millar and Warman (1996).

Note

The legal obligation is not enforced in the Netherlands in practice. The entitlements to care in Finland are established via the responsibilities placed on local government by legislation. Information is not available for Portugal or Luxembourg. 
In recent years, the services in the Nordic countries have faced competing pressures, mirroring those found in the other countries in our study as well as in many other European countries (Hutton and Kerkstra 1996; Walker and Maltby 1997). On the one hand, service demand has increased due to the growing elder population. On the other hand, public expenditure constraints were tightened severely in the 1990s due to deteriorating macroeconomic conditions compounded by an erosion of the tax base in municipalities as unemployment rose. In response, public sector services enacted a number of rationalisation measures that were intended to enhance productivity and improve efficiency. In Sweden, local income tax is the main source of social service revenue, and the rates were frozen in the early 1990s by the Swedish Parliament. This obliged municipalities to increase service fees and reduce the number of eldercare personnel. In Denmark, rationalisation has been combined with Taylorisation, or task fragmentation, and tighter time-management of tasks in home care services within a broader policy direction of providing nursing flats, thus 'striking a compromise between individual care and residential institutionalisation' (Bettio and Prechal 1998: 34).

One element of this service restructuring has been a general tendency during the past decade to deregulate and privatise public services through subcontracting arrangements. In Finland, the state subsidy system for social and health care services was reformed in the early 1990s and decentralised to local authorities. In response, almost all municipalities have introduced a new welfare mix between public sector and other service providers (Kovalainen 1999). A large share of these Finnish subcontractors are non-profit organisations, which in budget terms now provide 10 per cent of the total spent on elderly home care services (Anttila and Nätti 2000). Commercial services have a growing but still limited role. In Sweden, public service delivery has been decentralised in parallel with a decentralisation of industrial relations, so that the regulatory framework permits greater diversification in the work organisation practices at the municipal level (Anxo and Nyman 2000). Similar to the trend in Finland, in Sweden, subcontracting arrangements with for-profit companies have increased, but they remain a minority source of provision. The percentage of Swedish eldercare services provided by a subcontractor increased from 2 per cent in 1990 to 8 per cent in 1998. There is also a small but growing number of elder persons who purchase some of their own care services in Sweden, particularly highly educated elder women (Anxo and Nyman 2000).

Thus, although an increased use of subcontractors may be noted, home care services remain dominated by the public sector in terms of financing and provision. The municipalities remain the main providers, and they continue to retain overall responsibility in terms of eligibility criteria and decisions about the content of services to be performed for clients. In other words, the major changes that occurred during the past two decades 
have not significantly challenged the basic principles governing the provision of home care services.

However, there have been significant modifications with regards to work organisation. There has been a clear tendency to reduce the number of clients and to focus on elderly persons with the most intensive needs. The eligibility criteria have been tightened and a reallocation of resources has been made in favour of individual care - i.e. more health-related functions - to the detriment of household-related services, such as cleaning and shopping.

This reallocation of services, combined with rising professional standards of eldercare services, has placed a higher demand on employees in terms of qualifications, and levels of responsibility and competence. The qualification levels required for entry to home care work have generally been rising in Nordic countries, from a base that is already high compared to the situation in some other countries such as the UK (see below). Thus in Finland and Sweden, three years of training in upper secondary school is now a typical entry requirement (Anttila and Nätti 2000; Anxo and Nyman 2000). In Denmark, this has implications for working-time arrangements in the sector, since the more highly qualified home care workers are more likely to work full-time (Csonka and Boll 2000). There has also been a general professionalisation of home care jobs, fostered by a move towards greater unification of home care services and home nursing and other social services in Finland and Sweden. Increased training, job enlargement (for example, to include routine nursing tasks), more autonomy and teamwork are typical. In Finland, there is much emphasis on increasing the use of information technologies for service workers and users (Anttila and Nätti 2000), which is 'modernising' the image and content of the job.

At the same time as this enhancement of the professional status of the service, there are recruitment difficulties for personnel with adequate qualifications, particularly in areas where unemployment is low or falling. This is linked partly to low entry wages and limited wage progression, the demanding emotional labour of working with older people and the relatively low status of these jobs.

\section{The Dutch social democratic 'hybrid' system of eldercare}

The Dutch welfare state model has much in common with the Nordic social democratic model in terms of comprehensive individual citizenship rights and levels of social benefits (see Table 6.2). One differentiating factor is that the welfare state has, until recently, provided fewer incentives and services to encourage women to enter employment, since, unlike the situation in the Nordic countries, there was no explicit public policy to encourage women's employment. Instead, the 'housewife' arrangement of gender relations remained dominant until a much later period. For 
example, parental leave entitlements have only been introduced in recent years and public funding of childcare remains much lower than in the Nordic countries, although it has been expanded quite rapidly in recent years. Another, broader distinction is the 'pillarisation' of Dutch society and the historic role of religious and other non-state agencies in the delivery of welfare services.

Home care services are well developed, closely regulated by the state, of high quality and more extensive in coverage than most other member states. The system has a number of distinctive features (Plantenga et al. 2000). In the Netherlands, home care is part of the health sector, whereas in most of the other European countries, home care services are the responsibility of social services. Home nursing and home help services used to be provided by separate organisations, but these were merged in the 1990s into home care organisations in order to increase service efficiency and quality. Home care jobs in the Netherlands are organised into five categories, with the proportion of the job that entails care rather than household tasks increasing in the higher categories. About one-third of the home care jobs are in the lowest categories (A and B). Specialist community nursing grades provide home nursing.

Home care is financed through a compulsory public insurance scheme, with contributions made by employers and employees, although the government sets the budget to be spent. The insurance system currently covers 85 per cent of the home care services, with the balance made up by government subsidies. Clients make a financial contribution to the service dependent upon their age, household composition and income.

Each Dutch citizen has a right to home care, intended as a supplement to informal provision. In practice, 80 per cent of clients are over the age of sixty-five. The average client receives three and a half hours of home care per week. The amount of home help a client can receive is not limited in principle, but there is a maximum limit of three hours per day on home nursing; the policy is that more intensive nursing should be delivered in a nursing home. Home care needs are assessed by an independent Regional Assessment Organisation (Regionaal Indicatie Orgaan or RIO). Once the RIO has decided on the client's needs, the client contacts a home care organisation of the client's choice to provide the care. Home care organisations are regulated by the government and contracted to the Care Offices. They include the traditional public sector organisations and, more recently, private sector for-profit organisations that the government permitted to enter the sector in order to stimulate lower costs and higher quality through competition. When the selected home care organisation is not able to provide the care on time, it is obliged to contact the Care Office in the area, which co-ordinates the supply of care to find a solution. This solution may mean joining a waiting list, finding an alternative provider, or adjusting the service package provided.

Thus, in practice, the receipt of care services is rationed by the service 


\section{D. Anxo and C. Fagan}

available and, in recent years, labour shortages have become a major constraint on service supply. The long waiting lists have produced a public debate concerning the division of responsibility between the state and the insurance companies, culminating in a few lawsuits. The legal rulings have confirmed that the state is responsible for setting entitlements and the budget, and the care insurance organisations are responsible for organising care services through agreements with the home care organisations.

In sum, there are four main developments in the Dutch eldercare system. The first is the reorganisation of the service to promote costefficiency, innovation and a better quality of care. The merger between home help services and home nursing services was an important part of this process, followed by the government's encouragement of for-profit home care organisations to enter the sector and compete with public sector providers. Although the home care organisations already worked under a contract to the Care Offices, the entry of for-profit organisations represents a new form of subcontracting. The second development is that the Dutch government has recently increased the budget in order to reduce long waiting lists. However, attempts to reduce the waiting list are frustrated by the severe labour shortages in this sector. The third development includes attempts to overcome labour shortages through restructuring the training system, enhancing career opportunities and wage levels, and recruitment drives.

The fourth development includes a number of initiatives that have been established to attempt to overcome the labour shortage by introducing a greater role for home care providers from the private or informal sector. This includes the introduction of 'alpha helps' in 1977, whose numbers have grown in subsequent years. These workers are employed directly by the client for a maximum of twelve hours per week. This is the threshold for exemption from social security taxes paid for employees employed by private households. Formally, they are not employed by home care organisations, but in practice, most organisations act as an intermediary. The use of temporary and on-call workers has also increased. A system of Personal Care Budgets (persoonsgebonden budget or PGB) for clients has been introduced, which gives them the resources to hire traditional home care or private help. This system is contributing to the creation of a new category of formalised (paid) informal help.

\section{The UK's liberal 'marketised' system of eldercare}

The UK welfare state model still rests on the presumption that care for elders and children is primarily the responsibility of families, particularly women, rather than the state. Most of this care is provided informally, rather than through market purchases. There are growing demands on the state to provide more care services, but in recent years this has focused mainly on childcare services. 
In Britain, the local authorities (municipal government) are responsible for providing home care services, with a budget allocated by the central government and financed from general taxation. These services are intended to supplement rather than replace the care provided by family members or to substitute when the elderly person does not have family support. The services are client-oriented and designed to enable elders to live independently in their own homes, reflecting the "community care' emphasis in eldercare policy that was developed by professionals and adopted by government. The local authority assesses the elder person's needs for home care services. In practice, this definition of 'service need' is contained by the local service demand and by budget constraints, which produces waiting lists or a scaling down of the service that is offered. The elder client makes an income-related payment for the service, with the scale of charges set by each local authority rather than one centrally determined scale.

Several pressures, but particularly an explicit shift in government policy in favour of 'privatisation', have resulted in a marked increase in subcontracting arrangements whereby the local authorities purchase home care service provision from private and non-profit organisations. At a national level, in 1992, nearly all home care service hours were provided by home care employees from the public sector, but by 1998 nearly half were from the 'independent sector' (both non-profit and private companies). Most of the subcontracted providers are for-profit companies.

In order to remain competitive as service providers, local authorities have had to fundamentally reassess the organisation of their home care services. The focus has been on enhancing service coverage through increasing flexibility and efficiency. To this end, new working-time schedules and contracts have been introduced, and there has been a Taylorisation of services into fragmented, time-budgeted tasks. The local authorities still play an important regulatory role in setting the standards of service delivery through service agreements with subcontractors and through 'benchmarking' as a provider.

Home care service jobs are classed as manual work, currently require no formal qualifications for entry (in line with many manual jobs in the UK labour market), and are relatively low paid. There is a new government initiative to introduce some formal training and qualifications among home care workers as part of a national policy of introducing more formal vocational training. However, the training required for home care workers is still limited compared to that required in the other countries in this study and starts from a low base. Even so, meeting this training target is presenting logistical problems for some of the already hardpressed social service departments. There are recruitment problems in areas where alternative manual employment jobs offering similar wages for women are widely available. 


\section{D. Anxo and C. Fagan}

\section{The Italian 'family-based' system of eldercare}

The lowest public providers of home care and residential services for the elderly are found in Italy and the other three Southern European countries (see Table 6.1). Services are increasing slowly in each of these countries but are still limited (Bettio and Prechal 1998).

The Italian welfare system is based largely on monetary public transfers, with the family assigned the role as the main pivot of the care system, particularly for elder persons (Degasperi and Villa 2000). The welfare state model is designed on an implicit 'male breadwinner' conception of the family, guaranteeing a sufficient redistribution of financial resources to households via employment protection and high levels of social security coverage (i.e. for unemployment, illness, retirement) for those who are in the formal labour market. Financial transfers account for around 90 per cent of all care expenditures for the elderly, mainly through pensions (Degasperi and Villa 2000). The role of the private sector is limited.

The family remains the main provider of care and primary mediator negotiating the system of public and private resources on behalf of elderly relatives. Families provide the sole care for three-quarters of all elderly persons who require assistance (Degasperi and Villa 2000: 5). This family working-time-based care system rests upon an explicit legal obligation, in contrast to the situation in a number of other countries (see Table 6.2). The low percentage of elderly people living in residential care has remained substantially unchanged since the 1950s.

In recent decades, the Italian family has changed profoundly and become more heterogeneous, so it is now more accurate to talk about Italian families instead of 'the Italian family' (Degasperi and Villa 2000). This is evidenced in the dramatic fall in rates of fertility and marriage and increased marital instability (Bettio and Villa 1998), a growing trend for elderly persons to live on their own rather than with children, ${ }^{2}$ and the growing involvement of women in employment. Taken together, these factors mean that there are shrinking resources within the family system to provide eldercare. The growing proportion of the population that is elderly exacerbates this shortfall (Degasperi and Villa 2000).

In recent years the sector has been changing, due largely to tighter public expenditure constraints amid increased service demand. Since the 1970 s, a process of deinstitutionalisation has been underway to reduce the long-term hospitalisation of elders (ricoveri impropri) on the basis that this is both costly and a poor form of care for those without serious health problems. This policy shift reflected a changing ethos towards enabling the elderly to live socially integrated, independent and active lives supported by customised services to address specific personal needs. More recently, there has been a decentralisation of the administration of welfare, stimulated by a combination of legislation and budget reform to the health care system. This has fostered an expansion of home care services. 
Home care services are financed through general taxation and managed by local municipalities. The home care services cover four main areas: assistance with self-care, domestic work, social care (establishing a positive relationship), and co-ordination with health and other services. Access to home care services is based on a social worker's assessment of the elder person's need according to that person's health, social situation and economic resources. Clients make an income-related contribution, calculated on the basis of their own income, spousal income and the income of any relatives living in the same household. There is no legislation establishing uniform provision across the country, and the amount and type of services available vary markedly across regions. The service is delivered mainly by non-profit organisations, which are increasingly called upon to make up for the shortcomings of public welfare and to substitute for informal networks. The supply of home services is still very scarce relative to demand. After the family, the most important supplier of home care services is the informal economy provided by female workers who are unable to enter regular employment, including immigrants (Degasperi and Villa 2000).

Since the 1990s, the contribution of non-profit organisations has grown, partly as subcontractors to the municipal authorities. A recent survey suggests that over 60 per cent of municipal home care services are fully or partly subcontracted and nearly 90 per cent of these subcontractors are 'social co-operatives', which are a particular form of non-profit organisation defined in law. ${ }^{3}$ As well as fulfilling its traditional role of trying to fill the gaps left by the shortcomings of public welfare, the nonprofit sector increasingly provides an innovative role, since it is able to operate in the service market more flexibly than the public sector, notably in providing evening and weekend services. Its use of voluntary workers and greater use of unqualified home care assistants makes it a cheaper service (Degasperi and Villa 2000).

\section{Different national models of home care services}

It is evident from this overview of the main features of the public sector home care services in the six countries of our study that there are common features as well as differences in the way that this sector is organised.

One common, fundamental feature is that women provide most of the informal and formal care services in each country. A second shared organisational feature is that home care services are generally financed by a combination of national and local taxation, and are the responsibility of local municipal governments. The Dutch system of funding is slightly different, since the majority of funds come from a public insurance system to which employers and employees contribute. A third common feature is that in each country the municipalities are responsible for managing the public budget for home care services and for allocating service provision. 


\section{D. Anxo and C. Fagan}

Home care services are allocated based on an assessment of the individual needs of the elderly person, and the elderly person makes some incometested contribution to the service cost. However, a key organisational difference is that in the Nordic and Dutch models of eldercare provision, there is a more explicit individual entitlement to a minimum level of service, and provision is generally more extensive than in the UK, and greater still than that provided in Italy.

There also appear to be common pressures of growing demand on the service in conjunction with tighter public expenditure constraints on budgets. These pressures are leading to a number of restructuring measures designed to enhance productivity and improve efficiency; however, the type and degree of restructuring appears to vary among the countries. These pressures on home care services and the changes that are occurring in response are explored in more detail in the rest of this chapter.

\section{The dynamics of change in the organisation of home care services}

There are a number of social and economic changes unfolding in most societies that are creating pressures for a restructuring of the organisation and delivery of home care services for the elderly (Figure 6.1). The first set of pressures is the demand for home care services from elders and their carers, arising from socio-demographic changes. This gives rise to the second pressure of changes in the supply of informal care. The third set of pressures are the policy and regulatory standards that provide the national framework for the home care service, and the fourth are the organisational pressures on the service at the local level.

The demand for home care services has increased due largely to the demographic pressure of a continuing increase in the proportion of the population that is older (sixty years and above) or elderly (seventy-five years and above). It is the latter group that is most in need of care due to a sharp age-related rise in disabling conditions. The 'young retired' in their fifties and sixties are increasingly likely to assume dual care responsibilities for their grandchildren and their own frail relatives, since they are in better health themselves. This demographic pressure has been growing since the 1970s in each of the countries in this study, as in the EU member states generally (European Commission 1999; Hutton and Kerkstra 1996; Walker and Maltby 1997).

A second factor contributing to the increasing demand for home care services is a growing deficit in the capacity of informal care systems to meet the care needs of elders, which is straining the existing division of eldercare responsibilities between families and the state. This 'informal care deficit' is growing due to long-term changes in women's employment and family relationships. One change is the increasing involvement of women in employment throughout their lives. Today it is more common 


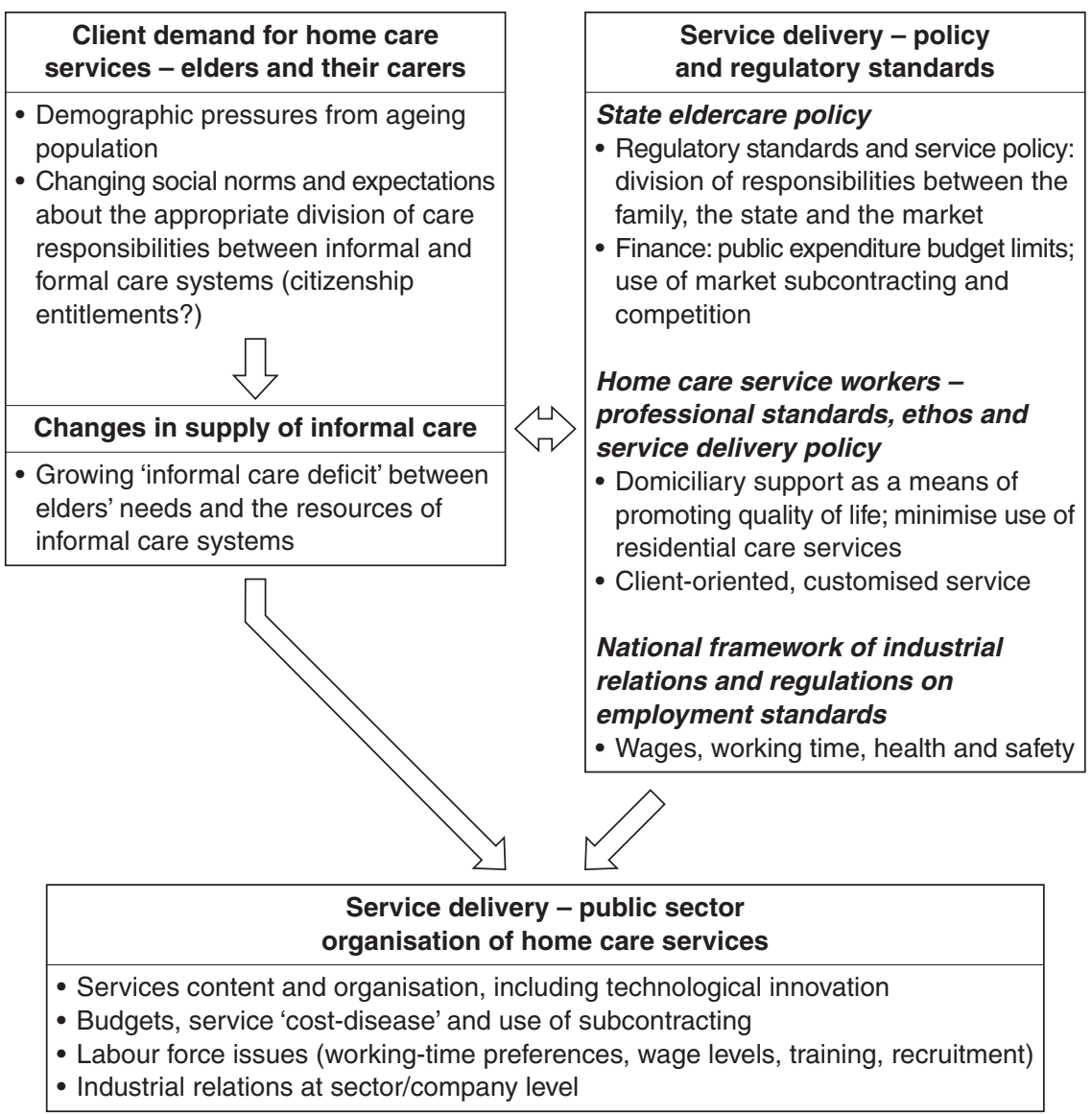

Figure 6.1 The dynamics of change in the home care service sector.

for working-age women to be in the situation of juggling looking after their elders with the demands of employment, in contrast to earlier periods when there was a larger pool of non-employed women who provided informal care. Furthermore, there has been a contraction in the pool of women in the peak eldercare years (forty-five to sixty-four years) with respect to the size of the elderly population (seventy-five years plus) (Bettio and Prechal 1998). Another change in the organisation of the family is that the supply of informal carers may also be shrinking as elder people have fewer children, are less likely to live with or near their children, and marital break-up makes issues of family loyalties and responsibilities between generations more complex.

An additional, more speculative pressure is that social norms and expectations about the amount and form of informal care that is 


\section{D. Anxo and C. Fagan}

appropriate may be adapting among elders and their carers, shifting preferences for some aspects of care to be acquired formally through citizenship entitlements or market purchases. This may be a pragmatic response in light of the reduced capacity of families to provide informal care. Norms may also shift if the quality of care offered in some home care services is good quality and perceived to be superior to that which informal carers can provide, perhaps associated with innovation and specialisation in eldercare services.

Alongside, and partly in response to, these socio-demographic pressures, the policy and regulatory standards that frame the organisation of home care services are changing. The first policy pressure is that the service standards and philosophy advocated by home care professionals has shifted in emphasis towards providing domiciliary services and 'community care' to enable elders to remain in their own homes where possible rather than extended stays in hospitals or moving into residential care. This shift in the objectives of home care services is linked with innovations in service delivery to promote health maintenance, rehabilitation and independent living (e.g. mobility aids, household technology, medical treatment, safe lifting techniques). An important component of this shift is the transformation of the service towards a more client-centred approach, with services tailored to the individual needs of the elderly. In many cases domiciliary (home-based) care is cheaper to provide than residential (institutional) care, making this service policy attractive to budget holders and government ministers alike. The result has been a general shift in state policy in favour of domiciliary care services and a slowing down or reversal of the expansion of residential services for the elderly that had occurred in the 1970s and 1980s in most member states.

The second policy pressure is the wider process of welfare state restructuring in many European countries designed to curtail public expenditure, and to increase productivity and cost efficiency through service reorganisation. Here the 'cost disease' argument can be invoked, which states that it is more difficult to reduce the costs of labour-intensive services through productivity gains than for less labour-intensive activities. In addition, the demand for public services is not rationed by market price mechanisms, but by citizen entitlements or claims, which tend to outstrip service availability. In this context, many European states have attempted to externalise eldercare through subcontracting or encouraging families to make their own informal provision or private purchases (European Commission 1999: 7; Meyer 2000). Some countries (e.g. Austria, France, Finland) have also introduced new social benefits and personal tax allowances to increase elder persons' resources to purchase domestic help. Germany has introduced a 'long-term care insurance' similar to a pension scheme to cover the purchase of future care services, and a similar scheme is due to be introduced in Luxembourg (Bettio and 
Prechal 1998: 31). These initiatives will provide a stimulus to the development of market provision of home care services (for-profit and non-profit companies). The state provides some financial support to informal carers through social benefits and tax allowances in a number of other countries (Bettio and Prechal 1998: Table 7 and appendix tables).

The third policy pressure to consider is the national framework of industrial relations and employment regulation that shapes work organisation in the home care services. This national framework is changing in many countries. For example, in relation to working time, new legislation and agreements have been implemented in a number of countries, and there has been a general shift towards a greater role for decentralised bargaining at sector and firm level.

These different pressures of increased demand for home care services, in conjunction with the changing service requirements and tighter public expenditure constraints set by national state policy, may be expected to create a number of pressures on service delivery at the municipal level. These include changes in the content and organisation of home care services, perhaps involving technological innovation. Related developments that can be expected are new budget limits and costing mechanisms, including subcontracting. New personnel issues may also be present such as the negotiation of new working-time arrangements, new training requirements or recruitment problems.

In the next section, we turn to the organisational case studies to see how home care services are being provided and developed in this context of rising demand and changing service policy.

\section{The dynamics of change: findings from the organisational case studies}

To obtain a closer understanding of how the various changes in national policy and service demand described in the previous section were affecting the delivery of home care services, research in all countries was carried out in two local authorities. The main findings from the organisational case studies are summarised in Table 6.3.

In order to cope with public expenditure constraints and the growing demand of elderly home care partly linked to the ageing of the population and the deinstitutionalisation of elderly care, the local authorities in the countries analysed have followed various strategies, some in common and some divergent. These strategies are to some extent linked and shaped by the nature of welfare and employment regimes described previously. However, the analysis of the country case studies reveals that the set of measures undertaken by the local authorities exhibits some crosscountry similarities that do not necessarily fit with the overall philosophy of the various home care regimes described previously. Furthermore, the emphasis of policy often diverges among municipalities within countries 


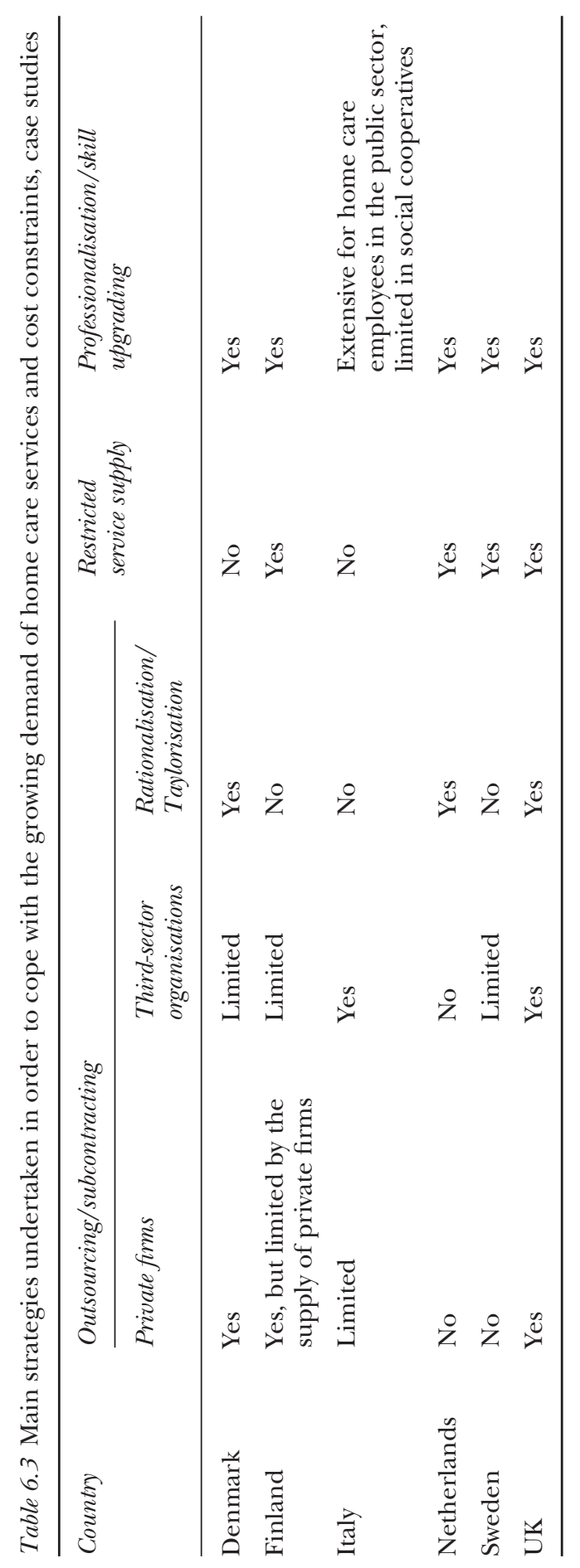


in relation to local economic and political conditions. Hence, even though some form of national path dependency prevails, certain similarities are evident in the measures undertaken, such as common tendencies to subcontract part of home care services to private and/or non-profit organisations or efforts to professionalise home care work by creating more formal training and skills enhancement programmes.

The major changes and strategies undertaken in the six countries may be classified in six themes: organisational restructuring, service rationing and subcontracting, work reorganisation (rationalisation and Taylorisation), working-time restructuring, recruitment problems and professionalisation, and, finally, technological innovation.

\section{Organisational restructuring}

During the past decade, municipal responsibilities for home care services have been substantially restructured and reorganised. One common trend in the countries studied is decentralisation of the public sector home care services combined with an emphasis on unification or co-ordination of various health and social services. These changes were instigated by the various health care and eldercare reforms enacted during the 1990s. The aim of this restructuring is to establish a more integrated supply of eldercare tailored to local conditions and requirements, combined with productivity and efficiency gains accrued from the rationalisation of service delivery. This has often involved a restructuring of functional and financial responsibilities at the municipal level. In the municipalities studied in Denmark, Finland, and the UK, the home care services have been reorganised to create a clear-cut distinction between those who are responsible for assessing the home care needs of elder persons and those who are responsible for providing the services.

This restructuring of functional and administrative responsibilities has been accompanied by a number of other changes in service delivery, although the extent and nature of these changes varies among the countries. It has facilitated the use of subcontractors to deliver home care services, with the most extensive use having occurred in the UK. It has also affected work organisation. In some countries (Finland, the Netherlands and Sweden), the emphasis has been upon the introduction or extension of teamwork, implying greater autonomy and increased responsibilities for the employees. In others, the tendency in work reorganisation has been towards a more intensive Taylorisation and fragmentation of tasks rather than more autonomy and responsibility. Finally, the task content of home care work has been modified to encompass more care-intensive activities. In other words, these organisational changes have to some extent paved the way for an upgrading or 'upskilling' of home care work through occupational changes such as the introduction of more training and the creation of new career grades among home care employees. 


\section{D. Anxo and C. Fagan}

\section{Service rationing and subcontracting}

To curb public expenditure, the local authorities in some countries (the Nordic countries and the UK) have tried to restrain the supply of home care services by reducing the volume of clients and concentrating their efforts on very old persons in need of help. The eligibility criteria have become more severe and a reallocation of resources has been made in favour of individual care (e.g. health care at home, personal hygiene) to the detriment of household-related services (e.g. cleaning, errands). In Finland, and to some extent in Sweden, the local authorities no longer provide cleaning services and the customers who need less demanding care are redirected to the third-sector or private firms.

Partly because of a growing overall emphasis on market and client orientation, some countries (e.g. Denmark, Finland, the UK) have, during the past decade, shown a marked tendency to outsource home care services to private firms or third-sector organisations. In the Nordic countries, this trend coincides with the overall debate on the restructuring of the welfare state. This debate has focused primarily on issues related to the rationalising and reorganising of welfare services in order to reduce costs and maintain, or even improve, the quality of the services provided in a context of growing public expenditure constraints and increased demand for elderly care.

The Danish and Finnish case studies show that the local authorities have increasingly subcontracted part of their home care activities to private companies. To illustrate, in one of the Danish municipalities, private firms now provide all home care activities. In Finland, the tendency to subcontract the provision of home care services, prevalent in one of the municipalities surveyed, is constrained by the availability of private service providers. In contrast, in Sweden, home care remains clearly dominated by public sector both in terms of financing, need assessment and provision of services, and subcontracting to either private or nonprofit organisations remains limited.

The two Danish case studies are also good illustrations of intra-country variations in home care provision. The two local authorities have coped with the common pressures of budget and increased customer orientation differently. One municipality has relied on outsourcing; while the other has rationalised home care activities by a Taylorisation of home care tasks (see the following section). The political composition of the municipality seems to play a large role in the nature of the orientation chosen. In the 'outsourcing' municipality, the extensive subcontracting and privatisation process of home care services has been initiated by the radical right-wing party in power in the local authority, strongly in favour of minimising public services. The outsourcing process in this Danish municipality took several years. In the first phase, less demanding home care services such as cleaning and catering tasks were subcontracted to private organisations. 
In the second phase, starting in November 1999, more complex nursing tasks were also subcontracted to private firms. However, the nurses' trade union did not acknowledge the legality of the outsourcing of nursing tasks, and there were lengthy negotiations between the local authorities, the private firms and the trade union of nurses. Finally, in the third phase, starting in April 2000, all of the elderly care activities were subcontracted to private firms. Even if the Danish example may be considered an extreme case and not representative of the Danish home care sector as a whole, it illustrates the emergence of new tendencies in the Nordic social democratic system of eldercare. Similarly, within the UK, the degree to which municipalities have embraced subcontracting is affected by the political orientation of the municipal leaders and local economic conditions and industrial relations.

One of the Finnish municipalities has also chosen to outsource a part of its home care activities. However, the outsourcing process is still in the initial stages, and only 2 per cent of home care services are subcontracted to external care providers. Like the Danish case, the pressures for outsourcing elderly care are coming from local politicians and are often related to the political composition of the municipality. In Finland, the major obstacle to outsourcing home care services has been the lack of suitable private care providers. It is also interesting to note that these outsourcing tendencies are also related to cost considerations and the timing of service during the day and the week, and therefore have an impact upon work organisation. In order to extend service availability and to reduce the cost of a lengthening of operating hours, one of the Finnish municipalities has subcontracted part of evening, night and weekend work to private care providers. In Italy, too, the outsourcing of home care from public sector to social co-operatives responds to cost consideration and service availability. Hence the growing requirement to provide services in the evenings and at weekends are in some local authorities being met by subcontracting part of home care activities to less costly/more flexible private firms (Finland) or third-sector organisations (Italy).

\section{Work reorganisation: rationalisation and Taylorisation of home care jobs}

The country case studies show that municipal home care work is usually organised on the basis of semi-autonomous teamwork, delivered through various forms of fixed or rotating shift patterns, which are discussed separately below. In most countries, the teams are responsible for planning and allocating their own work for their elder clients under the supervision of a team leader. The combination of increasing demands on home care services due to demographic pressures with the financial constraints of public expenditure budgets on service delivery has had a significant impact on the content of home care service jobs and work organisation in several countries. 


\section{D. Anxo and C. Fagan}

As revealed by the Danish, Dutch and British case studies, one major change has been the increased 'task and time' Taylorisation of home care jobs, and hence closer management of service delivery. In these countries, the local authorities have introduced systems that detail the tasks to be performed and how long each task should take as a basis for budget calculations, using precise time allocations. This development is in line with the requirements for a more clear-cut functional division between purchasing and providing departments, for customised, individual 'care packages', and the financial framework of subcontracting comparisons and budget limits mentioned above. In one of the Danish organisations, the primary aim of introducing detailed time indicators was to secure homogeneity and transparency in service provision. Here, the time indications were the result of negotiations between different municipal decision-makers and practitioners. Thus, the time estimates were not based on actual time studies, but on a political basis. In contrast, the time allocations used for budgeting in the British case studies were intended to estimate the actual average time allocated to each task, and hence the number of hours of home care to be provided to the elder client in the overall 'care package'.

The British, Danish and Dutch case studies reveal the limits and drawbacks of the standardisation and Taylorisation of home care activities by identifying a number of tensions arising from the precise detail and time budget of care plans devised by the purchasing units. Often the care plans were not sufficiently flexible to accommodate the needs of the client; the specifications did not allow enough time for daily variation in health and ad hoc tasks or intangible social care. In practice, home care is hardly completely 'plannable', and the rather quantitative approach neglected the quality of care and/or employee satisfaction. In the UK, the Taylorisation of home care activities has resulted in a more intense and hurried workload, with less time for social care and a loss of autonomy for the worker. The functional split between service purchaser and provider also meant that the provider team no longer had the ability to adapt the care plan as the client's needs changed. Instead, the service purchaser had to be notified and a formal review undertaken; and, in the intervening period, the discrepancy between the actual and required care plan affected the service quality and morale of both the worker and the elderly client.

A second change concerns the content of home care services. In Finland, Sweden and the UK, the 'pensions and shopping' model of home care - where this term means that the job primarily involves tasks such as collecting pensions, doing the shopping and cleaning - is being replaced by one which focuses upon personal care tasks. This shift in the nature of the job includes more health-related functions such as the supervision of medication and lifting elderly persons. This is a result of the increased targeting of service provision on those most in need of assistance (the oldest

and most frail), yet for whom it is still feasible and cost-effective to receive care in their own homes rather than in residential care. 


\section{Working-time restructuring}

Home care service provision is characterised by regular, daily peaks in demand associated in particular with helping elder people to rise in the morning and to get ready for bed in the evening, but also with mealtimes and other periods in the day and week for clients in need of more intensive help. This form of service delivery can be met through various working-time arrangements encompassing either part-time or full-time hours and fixed or rotating shift patterns. It is evident from the case studies that working-time arrangements diverge in important ways among the countries studied.

The most striking working-time difference revealed by the case studies is the extent of part-time work in the home care sector. In Finland and Italy, the majority of home care employees are employed on a full-time basis; in Sweden and Denmark, long part-time hours dominate, while shorter part-time jobs are more prevalent in the UK and the Netherlands. These differences in working-time patterns in home care reflect the overall national differences in women's working-time arrangements, as shown in Table 6.4. Hence, the dominant features of working-time patterns in home care seem more related to the gendered working-time patterns prevailing in each country than to productive constraints in service delivery. ${ }^{4}$

The working time of home care employees is regulated by collective agreements in all the countries studied, but the coverage of collective agreement varies among the countries and also between public and private providers. There is some national variation in the normal weekly working hours for full-time employees, ranging between forty hours a week for daytime employees in Sweden and Finland to thirty-six hours a week in the Netherlands. The base period for calculating standard weekly working time varies also between countries, from a thirteen-week period in the Netherlands to a year in some countries (e.g. Finland and Sweden).

Table 6.4 Women's employment patterns in the countries in the study

\begin{tabular}{llllll}
\hline Country & \multirow{2}{*}{$\begin{array}{l}\text { Per cent female } \\
\text { employment rate }\end{array}$} & $\begin{array}{l}\text { Percentage of } \\
\text { employed women } \\
\text { who work part-time }\end{array}$ & \multicolumn{2}{l}{$\begin{array}{l}\text { Average weekly hours of female } \\
\text { employees }\end{array}$} & \\
\cline { 4 - 6 } & & & Full-timers & Part-timers & All \\
\hline Denmark & 70 & 34 & 38.4 & 21.6 & 32.3 \\
Sweden & 66 & 40 & 40.4 & 24.7 & 33.5 \\
Finland & 61 & 17 & 39.3 & 21.1 & 35.5 \\
Netherlands & 59 & 69 & 39.3 & 18.6 & 24.9 \\
UK & 63 & 44 & 41.0 & 18.2 & 31.0 \\
Italy & 37 & 16 & 37.9 & 22.1 & 34.0 \\
\hline
\end{tabular}

Source: European Labour Force Survey, 1999 data. 


\section{D. Anxo and C. Fagan}

In the Nordic countries and the Netherlands, the prevailing collective agreement stipulates in most cases wage compensation and shorter working time for employees working evening and/or night or weekend shifts. National agreements may be partly or entirely replaced by local collective agreements in countries such as the Nordic countries, where union density is high and there is a high coverage rate of collective agreements. In these countries, working-time regulations apply even for the subcontracting firms, and there are no major discrepancies in workingtime regulation and pay between public and private providers. By contrast, in Italy and the UK, working conditions, working-time regulations and pay vary according to the type of service providers (private/public and nonprofit organisation). For example, in the UK, the union density is higher among local authority employees, with national-level agreements for public sector employees in place. This is in contrast to the more fragmented industrial relations system in the private sector in Britain, where union density is low, and agreements are reached at company rather than sector level. Union representation is particularly low in the private service companies offering services such as home care, cleaning and so forth, and very few private-sector home care workers are covered by collective agreements.

Overall, with the exception of the Netherlands, working-time reduction has not been a central issue in recent collective bargaining for home care employees. This is partly related to the extensive use of women employed part-time in four of the countries studied (Denmark, Sweden, the Netherlands and the UK), combined with the low wages that prevail in the home care sector. In the Netherlands, the full-time working week has been reduced in recent years from thirty-eight to thirty-six hours per week in line with widespread negotiated reductions in full-time hours across the economy, but in the home care sector the main result of the reform has been a lengthening of working hours for part-timers. This is because in connection with the working-time reduction of full-time hours, all employees received new contracts. Part-time hours were recalculated in order to avoid unusual numbers of working hours when implementing the collective reduction. The principle adopted was to round the new number of hours upwards.

It is changes in working-time practices and operating hours rather than working-time reductions that have dominated negotiations in the home care sector in most countries in recent years. In Finland, working-time practices and opening hours changed during the 1990s to become more customer-oriented. Until 1993, working time in elderly care was mainly 8 a.m. to 4 p.m. on weekdays, largely organised around full-time schedules. In one of the Finnish municipalities, the home care unit has now extended service hours by introducing evening shifts (until 9 p.m.) and some weekend hours for clients in very poor health. This change in working hours has been implemented largely through reorganising full- 
time working hours rather than through the introduction of part-time contracts. As previously mentioned, due to cost considerations, weekend services are, however, usually subcontracted to private home care entrepreneurs or third-sector organisations.

Similarly, in the UK, the local authorities have faced an increased demand for home care services in the evenings and at weekends. As a result, working-time restructuring has been a major issue for local industrial relations in recent years, but, unlike the situation in Finland, this has been organised around the continued use of part-time contracts. The implementation of this restructuring has been managed in different ways in the two British case studies, reflecting the different local contexts. One municipality has phased in new working-time contracts gradually with new recruits, while retaining existing employees on the old contracts. This strategy was adopted to avoid industrial conflict and recruitment difficulties due to buoyant local labour market conditions. Within the 'best value' competitive framework, the local authority was committed to maintaining in-house provision rather than subcontracted services by ensuring that in-house providers could compete successfully on price and quality comparisons. In the second case study, working-time restructuring had begun more recently and rapidly. The contracts of existing home care workers were being renegotiated to introduce contractual requirements to work evenings and weekends and to give greater scope for the employer to develop a wider range of schedules. For example, 80 per cent of the existing workforce had no contractual obligation to work between 4 p.m. to 10 p.m. The context of this drive for working-time restructuring was that increased operational flexibility was required to compete with the growing use of subcontracted private companies by the local authority's home care purchaser section. Otherwise, job losses were projected in the near future. The reorganisation was unpopular among the home care workers, exacerbated by the limited alternative job opportunities in the stagnant local economy, and the managers who were driving this organisational change were mindful of the need to circumvent the possibility of industrial dispute.

In both of the British local authorities, the new working-time contracts being implemented are exclusively part-time hours of thirty or less per week, which means that up to seven hours of overtime can be worked before the thirty-seven-hour full-time threshold for an overtime premium is reached. The new contracts also contractually obligate home care employees to be available to work between 7 a.m. to 10 p.m., including weekends. Under these new working-time systems, there are no premium additions for working evenings, weekends or bank holidays, in exchange for a higher, consolidated basic rate. The new work schedules have been designed to reduce overtime work and, where extra hours are worked, these will be at basic hourly rates rather than at overtime premium rates. 


\section{D. Anxo and C. Fagan}

\section{Recruitment problems and professionalisation}

In each country, the case studies confirm that the home care service workforce is highly feminised, with women accounting for about 90 per cent or more of the workforce. It is a labour-intensive and low-paid sector. In many countries, the bulk of the workforce is in manual occupations, often with low or no formal qualification requirements. The low level of qualifications of the existing workforce is partly due to the fact that in most countries there were, until recently, no formal skill requirements to enter home care work. However, there are important national differences in the skill requirements. For example, formal entry requirements are higher in the Nordic countries than in the UK. The Netherlands is a particular case where home care is part of the health sector, and there is a clear and established hierarchical difference between the lower skilled home helpers and more highly skilled home nurses. Formal skill requirements exist for home helpers, but are more limited than the high level of vocational education required by home nurses.

Most of the case study organisations were facing either labour shortages $^{5}$ or a mismatch of skills between the existing workforce and the changing job content of home care work. In response, most have introduced more formal qualification requirements for entry and provide more vocational training than previously, giving home care employees the opportunity to upgrade their skill levels and obtain a formal qualification. The rationale for this is to raise the professional status of the occupation. The managers in the case studies explained that this strategy of 'professionalisation' has been adopted for two reasons. One is to improve the quality and efficiency of the service provided, since the job content has shifted and increasingly requires health-related care skills. The second objective is to improve or 'modernise' the status and career path of home care employees, and in turn address labour shortages by reducing turnover and attracting new recruits.

Given that labour shortages have emerged in the home care sector despite the low qualification requirements, managers did not consider it feasible to redress labour shortages by further reducing qualification requirements or conducting a general 'deskilling' of the occupation, which in any case runs counter to the changing job content. Rather the recruitment problem appears to be linked to the low wages, limited promotion ladder, and other poor employment conditions such as limited training opportunities, intensification of workloads and the demanding nature of caring for elderly people. These recruitment difficulties seem to have increased over time as new generations of women enter the labour market with more qualifications and different ambitions, labour market expectations and gender role attitudes. As one manager in the British study explained, the traditional recruitment pool used to be women seeking local home care work as an extension of their domestic activities 
as wives, mothers or daughters, but this pool of potential recruits is shrinking in availability (Fagan and Nixon 2000).

Hence, in order to cope with the increasing imbalance between the growing service demands and recruitment difficulties, managers have developed organisational strategies that focus mainly on training, professionalisation and career enhancement, but with less evidence of wage increases. To illustrate, in the UK a new grade of 'senior home care worker' was introduced, which provided one step on a career ladder. This grade was created in one authority to help managers run teams of home care workers, and in another to deal with specialist tasks. However, the pay is only slightly higher than that of home care workers. Subsequent opportunities for advancement into management are currently limited. The entry requirements for managerial grades are also changing, with a growing emphasis on management skills alongside social work qualifications.

Given the dissatisfaction of employees with respect to career prospects and the large labour shortages, the Dutch organisations have also put considerable effort into increasing career opportunities. A training programme has been developed that offers home helpers several opportunities to specialise and be promoted to care jobs. This new system intends also to stimulate mobility between the home help units and the nursing and care units.

The skill level and skill requirements of the workforce also vary according to the type of service providers. In Italy, for example, the home care workers employed by the local authorities are on average more educated than those in the social co-operatives, associated with the municipalities' higher formal entry requirements. As stressed by the Italian monographs, the social co-operatives provide an entry to the market for less skilled labour (mainly women with low education levels and immigrants ${ }^{6}$ ), where wages are also lower than that received by home care workers in the public sector (Degasperi and Villa 2000). Similarly, in the UK, the subcontracting of home care work has seen the emergence of a labour market increasingly divided into a relatively advantaged sector, on the one hand, made up of public sector employees and a minority of independent sector providers (usually voluntary organisations), and a more casualised sector, on the other hand, of private (for-profit) organisations. The casualised sector is characterised by inferior pay, as reflected in hourly rates and in sickness and holiday entitlements, less training and poorer working hours (i.e. no minimum hours guarantee plus variable and unpredictable working hours) (Ford et al. 1998).

\section{Technological innovation}

Another interesting development revealed by the case studies is the contrasting use of modern information technology within home care. In all 
the countries, some technological innovation in the service has taken place, such as new forms of equipment to assist older persons and the increased use of mobile phones by some home care workers. However, the case studies reveal marked differences among the countries in the extent and form of technological innovation. For example, in Finland, the use of the Internet is being developed for home care workers and service users, while in the UK the use of information technologies is much less developed.

To illustrate, one of the Finnish municipalities has introduced a new Internet-based system of ordering food and other household-related goods, Foodnet. This technical innovation allows home care employees to order groceries and other shop goods through the Internet. Local shopkeepers deliver the ordered goods directly to the customer. Previously, home care workers gathered goods in stores, taking about half an hour per customer, and this new arrangement gives extra time for care at home.

Another example is that the Danish time/task evaluation system described above is supported by a highly developed technological monitoring system. Each client has a bar code attached to the door, which the home care worker uses to check in and out. Furthermore, the home helper has a diary with a bar code attached to each task, so when the task has been completed, the home-helper scans this at once. Thus the group manager has a detailed overview of the tasks performed minute by minute. This system allows a higher transparency, homogeneity and detailed monitoring of the services delivered.

As stressed in the Finnish monograph (Anttila and Nätti 2000), health care is expected to evolve into one of the most information-intensive industries, particularly in home care. The wider use and access to information and communication technology will offer new possibilities for elderly and chronically ill people to live in their own homes instead of in hospitals and institutions. We may therefore expect that the spread of information and communication technologies will reinforce the trend towards externalisation and decentralisation of services in home care and will have large impacts on both the clients' welfare and work organisation. The potential productivity gains associated with these new technologies will make it possible to reallocate resources to a more care-intensive service through rationalising some household-related activities and thus partly alleviate the 'cost disease' of the industry. However, the extent to which the sector makes use of information technologies is likely to vary among countries for some time associated with differences in labour costs, the existing technology infrastructure, and future investments in both technology and related training requirements (for example, the contrast between Finland and Italy or the UK). 


\section{Conclusions}

In order to cope with public expenditure constraints and the growing demand of elderly home care, the countries analysed in this study have followed various strategies, some in common and some divergent. However, the survey of the country case studies reveals that the set of measures undertaken by the local authorities exhibits some convergence that is not necessarily coherent with the identified home care regimes. Hence, even though some form of national path dependency prevails, some similarity is evident in the measures undertaken, such as common tendencies to subcontract part of home care services to private and/or non-profit organisations or efforts to professionalise home care work by creating more formal training and skills enhancement programmes. However, the extent and the form of restructuring that are occurring vary among countries.

Overall, due to the increasing service demands, tighter financial constraints and market competition, public sector home care services are being reorganised and more closely managed and costed. On one hand, the jobs of home care workers have, in some countries like the UK, and to some extent Denmark and the Netherlands, become less autonomous and now involve more evening and weekend work. On other hand, most local authorities have striven to professionalise home care work by creating more formal training and skills enhancement and the introduction of a small promotion ladder. These developments may raise the status of the occupation and partly circumvent the large recruitment problem in the home care sector, but the success of this strategy is likely to be undermined by the lack of planned initiatives to raise the wages of this low-paid manual occupation. Given that a growing proportion of home care services are subcontracted to private companies whose competitive edge is due at least in part to lower wage costs, the remuneration of this occupation may deteriorate, especially in countries with a relatively low union density. It cannot be assumed that labour shortages will in themselves drive up home care wages and thus 'correct' the labour shortages in this sector, at least over the medium term. A clear example is the persistent shortages of nurses in many countries despite interventions to improve wages and career structures, which illustrates how female-dominated workforces in care-related occupations can 'turn their backs' and seek alternative employment opportunities.

Despite efforts to externalise care services to the market or to reinforce family provision in some countries, the state will remain at the centre of public debates and conflicts about the extent and quality of care provision and the working conditions of employees in this field. One suggestion voiced in some political debates is for families to take on more responsibilities for care of the elderly; proponents usually evoke an idealised image of family relationships and support from a previous 'golden age'. 


\section{D. Anxo and C. Fagan}

However, this is not a viable solution, for the family cannot bridge the deficit gap between the resources demanded and those available for caring for both the very young and the elderly population. Another suggested solution is for an increased role for the market, with the state acting as regulator and part-financer of purchased services, rather than direct provider. This approach displaces rather than addresses the issue of service standards and resource levels. Hence, the question remains: What level and type of care do citizens have the right to expect in their older years, and who should provide this care and bear the costs?

\section{Notes}

1 The concept 'care' has a number of dimensions, including legal responsibility, practical tasks, emotional support, financial support and mediation on behalf of the person being cared for (Daly and Lewis 2000; European Commission 1999).

2 Even among those living on their own, 59 per cent declare that they see their children every day; another 20 per cent, more than once a week. However, there is a substantial difference in the type and content of care provided in regular contact in contrast to that available when living with the family (Degasperi and Villa 2000: 8).

3 Article 1 of law 381/91 defines the aim of 'social co-operatives' as to 'pursue the goals of human enhancement and social integration through the management of social-health and educational services' (Degasperi and Villa 2000: 15).

4 These differences are partly attributable to the different welfare state regimes, both as employers of women in the public sector, as Esping-Andersen (1990) has argued, and for the level of care services provided to ease the reconciliation of employment with domestic responsibilities. However, work organisation and working time also influence women's employment patterns, and here industrial relations and employment regulations, education and training systems, and organisational structures and production systems play a key explanatory role.

5 Labour shortage in elderly care is related to a relatively high labour turnover both in terms of voluntary quits connected to heavy workload and stress, and in terms of recruitment problems.

6 Immigrant labour - both legal and illegal - can be a major source of cheap labour in the informal economy of care work, both for the elderly and for children.

\section{References}

Anttila, T. and Nätti, J. (2000) 'Home care in Finland', country report for the New Forms of Employment and Working Time in the Service Economy (NESY) project, Jyväskylä: University of Jyväskylä.

Anttonen, A. and Sipilä, J. (1996) 'European social care services: is it possible to identify models?', Journal of European Social Policy, 6(2): 87-100.

Anxo, D. and Nyman, H. (2000) 'Home care in Sweden', country report for the New Forms of Employment and Working Time in the Service Economy (NESY) project, Gothenberg: Centre for European Labour Market Studies, Göteborgs Universitet.

Bettio, F. and Prechal, S. (1998) 'Care in Europe', Report E-V/2-98-018-EN-C for the European Commission (DGV), Brussels: Office for Official Publications of the European Communities. 
Bettio, F. and Villa, P. (1998) 'A Mediterranean perspective on the breakdown of the relationship between participation and fertility', Cambridge Journal of Economics, 22(2): 137-71.

Csonka, A. and Boll, J.L. (2000) 'Home care in Denmark', country report for the New Forms of Employment and Working Time in the Service Economy (NESY) project, Copenhagen: Danish National Institute of Social Research.

Daly, M. and Lewis, J. (2000) 'The concept of social care and the analysis of contemporary welfare states', British Journal of Sociology, 51 (2): 281-98.

Degasperi, P. and Villa, P. (2000) 'Home care in Italy', country report for the New Forms of Employment and Working Time in the Service Economy (NESY) project, Trent: Department of Economics, Università degli Studi di Trento.

Esping-Andersen, G. (1990) The Three Worlds of Welfare Capitalism, Cambridge: Polity Press.

European Commission (1999) Reconciliation of Work and Family Life and the Quality of Care Services, Luxembourg: Office for Official Publications of the European Communities.

Fagan, C. and Nixon, D. (2000) 'Home care in the United Kingdom', country report for the New Forms of Employment and Working Time in the Service Economy (NESY) project, Manchester: Department of Sociology, University of Manchester.

Ford, J., Quilgars, D. and Rugg, J. (1998) Creating Jobs? The Employment Potential of Domiciliary Care, York: The Policy Press/Joseph Rowntree Foundation.

Hutton, J. and Kerkstra, A. (1996) Home Care in Europe, Aldershot: Ashgate Publishing.

Kovalainen, A. (1999) 'The welfare state, gender system and public sector employment in Finland', in J. Christiansen, P. Koistinen and A. Kovalainen (eds) Working Europe. Reshaping European Employment Systems, Aldershot: Ashgate Publishing.

Lewis, J. (1993) Women and Social Policies in Europe, Aldershot: Edward Elgar Publishing.

- (1998) Gender, Social Care and Welfare State Restructuring in Europe, Aldershot: Ashgate Publishing.

Meyer, T. (2000) 'The role and development of the social care sector in the EU', Paper presented at the COST A13 working group seminar 'Labour Market Marginalisation, Exclusion and Caring', Berlin, 24-25 November, Available online at: www.socsci.auk.dk/cost/gender/index.htm.

Millar, J. and Warman, A. (1996) Family Obligations in Europe, London: Family Policy Studies Centre.

Organisation for Economic Co-Operation and Development (OECD) (1996) 'Caring for frail elderly people: policies in evolution', Social Policy Studies 19, Paris: OECD.

Pfau-Effinger, B. (2000) 'Analyses of gender policies of welfare states in their societal context', Paper presented at the COST A13 working group seminar 'Labour Market Marginalisation, Exclusion and Caring', Berlin, 24-25 November, Available online at: www.socsci.auk.dk/cost/gender/index.htm.

Plantenga, J., van Everdingen, M. and Remery, C. (2000) 'Home care in the Netherlands', country report for the New Forms of Employment and Working Time in the Service Economy (NESY) project, Institute of Economics, Utrecht. 
164 D. Anxo and C. Fagan

Rubery, J., Smith, M., Fagan, C. and Grimshaw, D. (1998) Women and European Employment, London: Routledge.

Sainsbury, D. (ed.) (1994) Gendering Welfare States, London: Sage.

Sipilä, J. (1997) Social Care Services: The Key to the Scandinavian Welfare Model, Aldershot: Ashgate Publishing.

Walker, A. and Maltby, T. (1997) Ageing Europe, Buckingham: Open University Press. 


\title{
7 The reluctant nurses
}

\section{Labour shortage and recruitment crisis in the hospital sector $-\mathrm{a}$ comparison of Belgium, Italy, France, the Netherlands, Sweden and the United Kingdom}

\author{
Christophe Baret
}

\section{Introduction}

This analysis draws on reports from Belgium, Italy, France, the Netherlands, Sweden, and the United Kingdom (Anxo and Nyman 2000; Piovesan 2000; Plantenga and Remery 2000; Plasman and Lumen 2000; Rubery et al. 2000; Villa and Zeni 2000). To compare the situations observed in the six countries investigated, certain methodological choices had to be made, both from the point of view of the population studied that is, individual hospitals - and of the data-gathering process itself.

First, we focused on the public sector, which remains by far the largest player in all the countries. Indeed, in the six countries investigated, the healthcare sector is still largely under state supervision. The private sector is expanding in all the countries, but its share of provision is very much smaller than that of the state, except in Belgium, where the university hospitals are considered to be private-sector organisations, although they are funded in exactly the same way as public hospitals.

In addition to carrying out an overall study of the sector in each country, the research teams also conducted in-depth surveys in a public hospital (see Table 7.1 for the main characteristics of these hospitals), and more particularly in two departments, namely, obstetrics-gynaecology and orthopaedics; that is, one department whose activities can be planned to some extent and one dealing with emergencies. In the departments, semiguided interviews using a standardised interview schedule were carried

Table 7.1 The hospitals investigated

\begin{tabular}{lrrrrrr}
\hline & Belgium & Italy & France & UK & Netherlands & Sweden \\
\hline Number of beds & 858 & 483 & 300 & 962 & 742 & 2,700 \\
Size of workforce (individuals) & 2,680 & 906 & 1,000 & 4,568 & 2,529 & 15,200 \\
\hline
\end{tabular}


out in spring 2000 among nursing managers, nurses and trade union representatives or works council members. These interviews were supplemented by an interview with the hospital's human resources manager and by documentary evidence.

Since the end of the 1990s, researchers in the social sciences have become increasingly interested in the changes in the employment relationship in the public healthcare sector. This sector has undergone profound changes as a result not only of governments' desire to contain healthcare expenditure but also of technological changes, medical advances and public pressure for improved quality of care. Having investigated changes in the organisation of healthcare systems, researchers have gradually turned their attention to changes in human resource management practices.

In investigating these changes, many researchers have drawn on international comparisons (Mossé and Arrowsmith 1999; Bach 2000; ComRuelle et al. 2000). After all, increasing European integration raises serious questions for national healthcare systems. As Letourny (2000) notes, while there are still profound differences in the organisation and working of national systems, as witness, for example, the persistent divide between the Beveridge and Bismarck models, certain developments transcend national boundaries, notably the rationing of expenditure, the shifting of the burden of costs towards households, the increased devolvement of responsibility to individual hospitals and the decentralisation of management.

This tightening of the economic constraints on healthcare systems has gone hand in hand with increased tensions in the employment relationship and the labour market. In many European countries, health workers have denounced the deterioration in their working and employment conditions and demanded greater economic and social recognition for their professions. Weary of the excessive demands on their overloaded working days, nurses are opting for total or partial withdrawal from employment. Part-time working, agency work or self-employment is increasingly being preferred to full-time employment in hospitals. Discouraged by the constraints and pressures, young people are reluctant to embark on careers in nursing.

As a result, a shortage of nursing staff is gradually emerging across Europe, and the actors concerned have not yet managed to find a satisfactory response. What is the cause of the deterioration in employment and working conditions? What impact does the labour shortage have on the actual functioning of hospital departments? How can departments, hospitals and public authorities try to manage this shortage? These are the main questions we will attempt to answer in this chapter, drawing on an analysis of the management of the employment and working time of nursing staff in six European Union (EU) member states.

Having outlined in the following section the theoretical framework, which is based on the societal effect approach, we will compare the 
characteristics of the employment and organisation of working time of hospital nursing and care staff in six EU member states in the third section. We will then go beyond comparative observation to reveal the main factors that are placing employment and the management of working time under stress in the fourth section. In particular, we will see that, while hospitals in the six countries are subject to similar economic and organisational constraints, the responses in terms of working-time management differ considerably from country to country. However, none of them seems to have been able to resolve the fundamental problems of the deterioration of working and employment conditions and the shortage of labour.

\section{Theoretical framework based on societal analysis}

The theoretical framework adopted for this research is based on the societal effect approach developed by researchers at Laboratoire d'Économie et de Sociologie du Travail-CNRS (LEST), in Aix en Provence, France (Maurice et al. 1982).

Drawing on some earlier studies of labour management practices in hospitals (Foulon 1995; Pouvourville 1996; Armstrong-Stassen et al. 1998; Mossé and Arrowsmith 1999) and on international comparative studies of employment and the management of working time in service industries (Baret et al. 1998, 2000), we will seek first to develop an interpretive framework based on four social relationships that interact with employment and working-time management.

\section{The socio-economic relationship}

The demand for healthcare is regarded as socially constructed and at the heart of interactions between hospitals, patients, the healthcare professions, the public authorities and health insurance providers. The construction of this relationship is based on the hypothesis that the increasing economic constraints which weigh heavily on healthcare systems, namely, the ageing of the population, the increasing attention paid to the quality of healthcare by the media and the general public and so on, interact with employment and working time, the content of work, and the competencies and level of involvement demanded of workers.

\section{The organisational relationship}

The hypothesis here is that hospitals' organisational structures (and in particular the centralisation or relative autonomy of individual hospitals), the ways in which new technologies are deployed and the division of labour among the healthcare professions have an important influence on working time, the content of work and employees' competencies. 


\section{Christophe Baret}

\section{The domestic relationship}

The hypothesis presented here is that the domestic distribution of roles, the existence and use of family infrastructures (e.g. crèches, nurseries), and family policies and legislation (e.g. parental leave, health insurance, benefits, and allowances) exert considerable influence on individuals' labour supply and, consequently, on the organisation of working time in hospitals.

\section{The industrial relationship}

It is assumed here that national and sectoral norms with respect to pay, social security contributions, taxation, training, and incentives to create jobs and develop part-time working influence both hospitals' demand for particular work schedules and the supply of labour offered by individuals. These norms are defined by the social partners, including the state, and are therefore the result of power relationships and of national industrial relations systems.

The use of societal analysis as a theoretical framework serves as a basis for developing a multi-dimensional interpretive model that combines the sectoral, hospital and departmental levels of analysis, on the one hand, and, on the other, the four social relationships outlined above. In order to clarify our argument, the presentation of data and actions has been structured by level of analysis, while the social relationships will be introduced into the discussion when the factors placing working time under stress are brought into play.

\section{Employment and working time organisation: figures and reforms}

In any analysis of employment and the management of working time, three interlinked levels of analysis must be considered: the sector, the establishment and the department. Each level is heavily influenced by the level above it but also has its own characteristics shaped by the autonomy of the actors operating at that level.

\section{The sectoral level}

The sectoral level was investigated largely by means of three characteristics: the organisation of national healthcare systems, employment, and the regulation of working time.

\section{The organisation and reorganisation of the healthcare sector}

One initial shared characteristic is the high level of health expenditure relative to each country's GNP. ${ }^{1}$ Since the early 1990s, national governments have fought hard to contain the increase in such expenditure. 
These efforts were made necessary in part by the budgetary constraints that the signatories to the Maastricht agreements imposed upon themselves in an attempt to limit government deficits in the European Union. In order to increase the economic efficiency of national health systems, a process of management decentralisation has been underway in all the countries for some years. Regional authorities and individual hospitals are now allocated budgets to which they have to adhere.

In Italy, for example, the 1992 reform transferred the management of healthcare facilities to the "aziende sanitarie locali. Hospitals (aziende ospedaliere) were given increased autonomy and are now contractually linked to their local health authority.

In the UK, the 1990 reform introduced an internal market within the health service and set up the district health authorities, which were to enter into contracts with service providers on behalf of the local population. Hospitals were given autonomous 'trust' status, with almost complete responsibility for budget management being devolved to individual trusts.

In Sweden, regional authorities and municipalities have become more involved in the management of the healthcare infrastructure. Since 1992, the municipalities have been responsible for managing facilities for the elderly and the handicapped. Hospitals are managed by the regional authorities, which have the power to raise the taxes necessary to fund them. In 1997, central government introduced new budgetary rules for regional and local authorities that impose a strict obligation on them to balance their books. This has led them to take action to reduce expenditure on healthcare.

In France, the ordinances of April 1996 set up Regional Hospital Agencies with the aim of improving the control and co-ordination of hospital services at regional level (introduction of regional plans for the organisation of health and social services). Every hospital, whether public or private, has to draw up its own plan that fits in with the regional plan. The Regional Hospital Agencies are also responsible for budgetary control.

The main consequence of this decentralisation - and this is precisely what was intended - has been to encourage hospitals to control their expenditure, particularly their personnel costs, which make up about 60 per cent of hospitals' operating costs.

In several countries (e.g. France, Belgium, Italy) the supervisory authorities have introduced a system of budgetary control based on the American 'diagnostic-related groups' method, whereby funds are allocated in accordance with the conditions treated by each hospital. The hospital receives a predetermined budget for each case. The introduction of this method of calculating budgets encourages hospitals to:

- Merge in order to achieve economies of scale. As a result, small hospitals are gradually disappearing. In Italy, for example, the number of hospitals fell from 1,848 in 1995 to 1,589 in 1997 (Istat 1998). 
- Reduce the number of beds in order to increase bed occupancy rates. In Belgium, for example, the number of beds fell from 68,404 in 1985 to 57,703 in 1995 (INS 1996).

- Reduce the length of hospital stays. In Italy, for example, the average length of stay fell from 11.1 days in 1993 to 9.4 days in 1996 (Istat 1998).

\section{The structure of employment}

In all six countries, the healthcare systems account for a high share of the economically active population in employment. The share varies from 3.35 per cent in Italy to 6 per cent in Sweden and France. ${ }^{2}$

In terms of the management of employment, therefore, the tendency is to seek a reduction in, or at least a stabilisation of, employment levels. Despite this objective, only Sweden has seen a real reduction in employment levels in the hospital sector, from 451,000 in 1990 to 326,000 in 1997 $\left(-28\right.$ per cent). ${ }^{3}$ This was part of a series of measures ${ }^{4}$ aimed at reducing a government deficit that had become very worrying. However, Sweden is the exception. Elsewhere, employment levels have continued to rise, even though the rate of increase has been much slower than in the 1980s. In the Netherlands, the number of nursing staff employed in hospitals rose by 6 per cent between 1992 and 1996 in full-time equivalents (NIVEL et al. 1998). The increase in Britain was 2.4 per cent between 1995 and 1999, 9.6 per cent in France between 1985 and 1993, and 14 per cent in Italy between 1993 and 1996.

There is also a common trend in the rate of feminisation of nursing staff in hospitals, which is approximately 90 per cent. The exception is Italy, where women account for only 63.5 per cent of nursing staff. ${ }^{5}$ In all six countries, the feminisation rate among hospital doctors is much lower, between 25 per cent in Belgium and 40 per cent in Sweden.

One basic tendency that affects more or less all the countries is the shortage of labour. Health authorities are faced with a shortage of skilled labour, both nurses and midwives (Com-Ruelle et al. 2000). Hospitals are experiencing difficulties in recruiting and retaining young nurses, who are discouraged by what they regard as the inadequate economic and social recognition they receive for the arduous work that they do.

The most extreme situation is perhaps that in the Netherlands, where 75 per cent of hospitals say they have experienced recruitment problems (Van der Aa et al. 1999). The shortages are mainly among specialist nurses. In order to deal with these labour shortages, and for other reasons as well, the social partners in the Netherlands set up a jointly managed fund intended to support initiatives to facilitate the working of the labour market. The fund is subsidised by central government. One of its programmes seeks to encourage the development of new care facilities for 
young children in order to prevent nurses with young children from leaving the labour market.

In the UK, the government is also faced with a serious labour shortage, which is examined at 15,000 full-time equivalents. Several measures have been put in place in order to deal with the situation. They include publicity aimed at young people in order to encourage them to apply for training courses in the health professions, an increase in the entry quotas for training courses leading to healthcare qualifications, and pay raises of +15 per cent between 1997 and 1999 (Com-Ruelle et al. 2000: 2-3). The National Health Service (NHS) has also set up a national nursing agency with the aim of attracting and retaining those individuals who wish to keep control of their working hours. This nursing bank, NHS Professionals, offers agency nurses paid holidays and membership in the NHS pension scheme. British hospitals are also trying to recruit qualified nurses from various countries, including Spain, the Philippines and South Africa.

In France, even though no specific measure has been taken to relieve the labour shortage, the government did increase entry quotas for nurse training schools in 1999 by 43 per cent. In addition, the jobs created following the introduction of the thirty-five-hour week (numerous agreements have already been concluded at hospital level) have further exacerbated the recruitment problems.

In Belgium, the search for a solution to the shortage of nurses was the focus of the negotiations between the government and the social partners in the year 2000 .

\section{The national and sectoral regulation of working time}

In most countries, working time is regulated both by national legislation and a collective agreement specific to the healthcare system (see Table 7.2). The importance of one relative to the other varies from country to country. In France, it is national legislation that is the main source of regulations, while in Belgium, Italy and the UK working time is also strongly influenced by the industry collective agreement. Before analysing the regulations, it would be helpful briefly to describe the industrial relations systems that help to produce them.

Table 7.2 Weekly working time for full-time personnel in the health service

\begin{tabular}{|c|c|c|c|c|c|c|}
\hline & Belgium & Italy & France & $U K$ & Netherlands & Sweden \\
\hline Hours & 38 & 36 & $\begin{array}{l}39 \\
35 \\
\text { for night staff }\end{array}$ & 37.5 & 36 & $\begin{array}{l}38.2 \\
36.2 \\
\text { for night staf }\end{array}$ \\
\hline
\end{tabular}




\section{Christophe Baret}

THE STATE OF INDUSTRIAL RELATIONS

As in other sectors of the economy, the general trend is towards the decentralisation of bargaining, from national to regional and establishment level. Nevertheless, except in Sweden and the Netherlands, local bargaining has not really produced much in the way of agreements. In the public sector in France, the national level is still the main regulatory level. In the UK, bargaining takes place at national level within the framework of the Whitley Council Agreement, and, despite incentives to negotiate at the level of local hospital trusts, nurses and midwives have confirmed their preference for national-level bargaining (Bach 1998). In addition, it is true that, during local negotiations, employers have tried to challenge some of the benefits and entitlements enshrined in the national agreements, notably the bonuses for night work, and work on Saturdays, Sundays and public holidays.

In all six countries, pay, career progression and work intensity are the main points at issue in negotiations between the social partners. Nursing and care staff have traditionally been represented by the large generalist trade union groups - such as CFDT (Confédération Française Démocratique du Travail) and CGT (Confédération Générale du Travail) in France; FGTB (Fédération Générale des Travailleurs Belges) in Belgium; and CGIL (Confederazione Generale Italiana del Lavoro) and CISL (Confederazione Italiana Sindacati Lavoratori) in Italy - which support a global and uniform approach to pay. Since the end of the 1980s, this traditional, generalist form of trade unionism has been shaken by the emergence of 'vertical' trade unions representing specific categories of workers, particularly among nurses, who are demanding a specific approach for their profession and even pay individualisation on the basis of merit and responsibilities actually borne.

In France, the 'Coordination infirmière' played a central role in the disputes of 1988, which led to a significant pay increase and an improvement in nurses' conditions of employment.

In the Netherlands, the NU91 (Nieuwe Unie 91) trade union was founded by nurses in 1991.

In Italy, the 'Nursing UP' trade union was set up in 1993. Its members are mainly 'professional nurses' who qualified after the 1993 reform of nurse training. The union campaigns for the introduction of pay individualisation and greater differentiation among nurses on the basis of responsibilities. The traditional generalist trade unions, for their part, are still very much attached to a collective approach based on qualification level and to a low level of differentiation.

This change in the forms of workforce representation among nursing staff reflects a hardening of union demands with respect to pay and conditions. 
DISCUSSIONS BETWEEN THE SOCIAL PARTNERS ON WORKING TIME

In most of the countries investigated, the duration and organisation of working time are a secondary but nevertheless important issue in negotiations between the social partners.

In the Netherlands, a new national working-time regime specific to the health sector was introduced in 1993 (the Werktijden Besluit voor Verplegings (WBVV)). Its aim was to increase working time flexibility, in particular through annualisation, while at the same time protecting workers from excessive working hours. Moreover, in a collective agreement concluded in 1999, the social partners agreed to reduce weekly working time to thirty-six hours. The agreement stipulates that working time can vary between thirty-two and forty hours, provided that the weekly average of thirty-six hours is maintained over a six-month period. Individual hospitals may also establish working-time accounts, after consultation with the works council.

In France, following labour disputes, a reduction in weekly working time to thirty-five hours (thirty-eight paid hours) was granted in 1991 for all staff working permanent nights. Talks are currently being held in many public and private hospitals on ways of implementing an overall reduction in working time to thirty-five hours per week pursuant to recent legislation on the organisation and reduction of working time.

In Belgium, trade unions involved in negotiating an industry-level collective agreement demanded a reduction in working-time in order to alleviate the pressures on nursing staff. In their view, such a reduction would encourage nurses to remain in the profession. The employers countered this demand by arguing that a general working-time reduction would reduce the overall number of hours worked and therefore exacerbate the labour shortage. Following negotiations, a compromise was found in the year 2000. In order to encourage nurses and nursing auxiliaries over the age of forty-five to remain in the profession, a bonus in the form of extra time off and additional money is paid to those who continue to work full-time. The management of working time in Belgian hospitals has also been strongly influenced by the policies put in place at national level in the 1990s in order to fight unemployment. One programme provides for a subsidy of 75 per cent of labour costs to be paid for each new job created in hospitals in which at least 50 per cent of the personnel work part-time. At the same time, another programme offers partial compensation for any loss of pay incurred by any member of staff aged fifty or over who agrees to work part-time only. These measures have succeeded in encouraging hospitals, which had hitherto been sceptical, to make greater use of part-time jobs as a means of reducing labour costs.

In Italy, the main point at issue is the liberalisation of part-time work. Less use is made of part-time work in service activities in Italy than in any other EU member state, and the government is seeking to promote this 


\section{Christophe Baret}

employment form. Since 1994, part-time working has been a right for all employees in Italy. In the health sector, however, this measure has met with resistance from employers, who fear it will seriously disrupt services and fragment work. The collective agreement covering the health sector that was concluded in the year 2000 does in fact lay down a maximum part-time rate of 25 per cent per department, and limits access to parttime working to employees without managerial responsibilities, which excludes doctors and nursing managers.

\section{Part-time work}

The part-time rate differs considerably from one country to another, ranging from 5.1 per cent in Italy to 74.3 per cent in the Netherlands (see Table 7.3). Apart from the UK, where part-time working seems to have stabilised, the part-time rate rose significantly between 1996 and 1999, particularly in Belgium and Italy. With the exception of Italy, there is considerably more part-time work in the hospital sector than in the economy as a whole.

At this stage of the analysis, we do not have any data that might explain these phenomena. As we have seen, negotiations at sectoral level have focused mainly on full-timers' working hours and on the possibilities for varying working time (except in Italy). Thus we need to take the analysis a stage further, to individual hospital level, in order to examine workingtime management practices, and in particular the factors leading to the expansion of part-time work and the persistence of very significant differences between the countries.

\section{At hospital level}

The management of human resources at hospital level

Hospitals' reactions to the twin constraints of budget restrictions and labour shortages differ significantly from country to country.

It is in the Netherlands that the most distinctive practices were observed. This is undoubtedly related to the fact that it is in this country that the labour shortage has made itself felt most severely.

Table 7.3 Part-time rate among employed nurses and midwives at national level (men and women)

\begin{tabular}{lllllll}
\hline & Belgium & Italy & France & UK & Netherlands & Sweden \\
\hline Economy as a whole 1999 & 15.7 & 7.9 & 17.2 & 24.8 & 39.4 & 23.8 \\
Health 1999 & 50.8 & 5.1 & 23.4 & 40.0 & 74.3 & 39.8 \\
Health 1996 & 37.9 & 2.4 & 20.5 & 40.9 & 65.8 & \\
\hline
\end{tabular}

Source: European Labour Force Survey. 
- The hospital management has expressed a desire to put in place a participatory, total quality management system, with the declared objective of improving employees' job satisfaction.

- A working-time account system (known as 'Flexeuro') has been put in place in order to enable full-time and part-time staff to save up and exchange pay, extra working hours and holiday entitlements. A quarter of the staff have enrolled in this programme, which is explicitly publicised in order to attract job applicants. As a result of this scheme, full-time employees may be asked to work thirty-eight or forty hours per week instead of thirty-six, with the additional two or four hours being credited to their working-time accounts. Employees can clear their accounts by accepting shopping vouchers, extra holidays or training opportunities.

- Several different types of employment contract are offered to staff in an attempt to meet the expectations of as many employees as possible. They range from full-time contracts to zero-hours contracts for those who wish to work only very occasionally. The contracts offering the shortest hours (less than 60 per cent of the full-time norm) are organised by the hospital's temporary work agency (nursing bank), which acts as a central clearing-house for substitute or temporary personnel throughout the hospital.

- The hospital management is seeking to develop employee training, mobility and career prospects. Training modules have been developed that make increasing use of distance learning tools, such as CD-ROMs and the Intranet.

- Finally, to supplement the existing childcare provision (care facilities for young children already exist), the hospital is building a new daycare centre, which will have extended opening hours, particularly in the evening.

The hospitals in France and in the UK have both set up an organisation to manage their temporary personnel needs during peak periods and when cover is required for absent staff. In the French hospitals, this relief pool is made up of nurses who are permanently employed in the hospital but are not allocated to any particular department. They are functionally flexible and allocated to the various departments as needed. In the British hospitals, the nursing bank consists of nurses who have stated they are available for work during a given period. They are nurses permanently employed in the hospital, or in another hospital, who wish to work more hours. This system means that the hospital does not have to pay overtime, while the nurses can supplement their earnings and at the same time retain control of their own working hours. However, the hourly rate is not very attractive, because it is the same as that for the job for which cover is being provided, without any premium.

The Dutch hospitals operate a nursing bank that functions on the same 
principle as a temporary employment agency. It provides work for individuals who are not permanent hospital employees and who wish to work only occasionally. On a yearly basis, this covers about 110 full-time equivalents.

In Belgium, the main development has been the expansion of parttime working during the 1990s. This was not initiated by the hospital management; rather it was a response to pressure from staff and, in particular, to government measures introduced to combat unemployment. In the hospital investigated, 105 individuals have been recruited under the terms of the government-subsidised programmes outlined above.

Reform of the qualification structure and of work organisation

The British hospital studied was also experiencing serious recruitment problems. It had reacted in two ways. First, it had introduced jobs at the lower healthcare assistant level. These assistants carry out a greater number of different tasks than the traditional nursing auxiliaries, whose terms and conditions are more tightly regulated, and in particular several clinical tasks previously held to be the exclusive province of nurses. Its second response was to seek nurses abroad; twenty South Africans had already been recruited at the time of the interviews.

In Belgium, too, unskilled staff have been hired, particularly in order to relieve nurses of some of their administrative work (e.g. admissions, answering the telephone, collecting test results) and less technical tasks. The hospital has recruited forty-three long-term unemployed people under the terms of a government programme (Maribel Social) that offers considerable reductions in employers' social security contributions.

At hospital level, the three main concerns of human resource managers are control of the wages bill, increased working-time flexibility and recruitment. Hospitals have reacted differently to these same concerns from one country to the next. With the possible exception of the Netherlands, it would seem that their responses are influenced more by national policies (e.g. immigration policy, regulation of temporary work, anti-unemployment programmes) than by any deliberate strategy adopted by the management of individual hospitals.

Nor does the expansion of part-time work seem to be the result of a deliberate human resource management policy adopted at hospital level. Thus it would seem to be at the level of the individual departments that a significant part of the regulation of the employment relationship, and in particular the organisation of working time, takes place. 


\section{The department level}

In each of the hospitals studied, a more detailed analysis of employment management and working-time organisation was carried out in two clinical departments: obstetrics and orthopaedics.

The aim was to ascertain the reasons for the rapid development of parttime working among nursing staff. As we shall see, staff in both departments have seen their workloads increase and their working times become less predictable. Even though nursing managers are trying to mitigate individuals' dissatisfaction by introducing a participatory system of work schedule management, relieving nurses of certain tasks by hiring less skilled personnel or using temporary staff as cover, many individual nurses are seeking to work fewer hours in order to achieve a better work/life balance.

\section{The obstetrics department}

Maternity services are not organised in the same way in the six countries. In the Netherlands, for example, most midwives are self-employed, providing prenatal and postnatal services for women in their own homes as well as attending normal home births. They also attend births that are planned to take place in hospital when no complications are expected. Consequently, the department investigated does not employ any midwives, only specialist nurses and so-called maternity assistants. ${ }^{6}$

In the UK, maternity services were reformed in 1993. The Ministry of Health's 'Changing Childbirth Initiative' sought to provide greater continuity of care for pregnant women and to make midwives the key players in the provision of that care. Thus, midwives are attached to hospitals and also provide care in women's homes, including attending home births.

The British hospital department investigated employs 166 midwives, a high proportion of whom carry out some of their activities in their patients' homes.

As far as the organisation of working time is concerned, hospitals in all the countries except France operate a three-shift system (morning, evening and night shifts). Staff work four- or five-week cycles.

As far as the management of work rosters is concerned, individual schedules are usually drawn up several weeks in advance by the department's nursing manager, with account being taken of individual preferences to varying degrees.

It is clear from the interviews conducted in France that individuals frequently swap work and rest days. These local adjustments obviously have the effect of mitigating to some degree the constraints imposed by work schedules.

In Sweden, the method is more participatory. The nursing manager posts the workload for the coming five weeks, and individuals fill in their 
time slots themselves on the work schedules on the basis of their contractual working time. A group made up of a member of the hospital management, two team leaders and two employee representatives then makes the necessary changes and draws up the final roster.

Over and above this common basis, various differences may be observed among the countries.

In France, the midwives in the department investigated work twelve hours at a stretch. This makes it more likely that they will be present at a delivery from beginning to end and also gives them longer rest periods. Their schedules consist of two daytime shifts, a twenty-four-hour rest period, two night shifts and five days off before the cycle begins again. The other employees work the standard $3 \times 8$-hour shift pattern. In the UK, some midwives can choose between a three-day cycle in which they work 12.5 hours a day and a five-day cycle in which they work 7.5 hours a day.

The part-time rate among nursing staff in the obstetric departments varies considerably from one country to another (see Table 7.4). In this department in the Dutch hospital, it is as high as 90 per cent, and management has tried to impose 'long' part-time hours to minimise disruption. A rule was established whereby a minimum of 55 per cent of employees in the department had to work 80 per cent of full-time hours or more. However, this constraint on the reduction of working time was not popular among staff, and more and more of them were quitting. Management decided, therefore, to authorise job shares for part-time positions involving 56 per cent of full-time hours, on condition that the nurses work in 'pairs' and take responsibility themselves for passing on instructions. Seven 'pairs' are now working in the department on this basis. Furthermore, these employees are required to attend department meetings outside their working hours.

In general terms, the expansion of part-time work is driven by individual preferences. Management, concerned that too much time could be wasted passing on instructions, has acquiesced only in order to retain personnel who would otherwise leave and whom it would be difficult to replace because of the labour shortage. In Italy, the part-time rate in the obstetrics department had reached the collectively agreed limit of 25 per cent and management was refusing all new requests, which was perceived as unfair.

In Sweden, workloads have intensified. Midwives are responsible for

Table 7.4 Part-time rates among midwives, nurses, and nursing auxiliaries in obstetrics departments (\%)

\begin{tabular}{lllllll}
\hline & Belgium & Italy & France & UK & Netherlands & Sweden \\
\hline Part-time rate & 75 & 25 & 5 & 55 & 90 & 26 \\
\hline
\end{tabular}


both deliveries and postnatal care. There are no longer any quiet times in the day. The excessive workloads have given rise to significant absenteeism; at the time of the survey, six midwives were on sick leave with back problems. This pressure on the workforce is also reflected in the difficulty in scheduling holidays. Individuals seldom obtain the holiday period they desire.

In Italy, the extra work is done mainly by full-time staff members, ${ }^{7}$ who are reluctant to see an expansion of part-time working. The satisfaction rate in respect of working time is significantly higher among part-timers. Moreover, the department has to face a possible reduction in employee numbers, which has led all staff to become functionally flexible.

The obstetrics department in France has been experiencing a shortage of midwives since the year 2000. This has led management to recruit three nurses in place of three midwives. The nurses have been allocated to the gynaecology department to free up the midwives in gynaecology to be redeployed to obstetrics.

It is at the department level that the issues at stake in the management of working time really emerge. In order to provide round-the-clock care, work schedules are organised in cycles, seven days a week. The considerable time constraints to which the department is subject come into conflict with the constraints arising out of individuals' private lives. Nursing managers are attempting to reduce the constraints by encouraging individuals to play a major role in determining work schedules and by authorising swaps of hours. For their part, individuals are seeking to regain control of their time by reducing their working hours. In all six countries studied, this has given rise in turn to strong demand from nursing staff for an expansion of part-time working.

\section{The orthopaedic department}

The work of orthopaedic departments is less subject to fluctuations, since operations are scheduled several weeks in advance. Consequently, orthopaedic departments make less use of temporary staff to deal with peaks of activity.

The share of part-timers in the orthopaedic departments follows the same pattern as that observed in obstetrics, but is slightly lower (see Table 7.5). The Italian orthopaedic department, for example, employs a large number of men, all of whom work full-time.

Table 7.5 Part-time rate among nursing staff in orthopaedic departments (\%)

\begin{tabular}{lllllll}
\hline & Belgium & Italy & France & UK & Netherlands & Sweden \\
\hline $\begin{array}{l}\text { Part-time rate among } \\
\text { nursing staff }\end{array}$ & - & 13.5 & 20 & 75 & 80 & 27 \\
\hline
\end{tabular}


The work schedules are also structured in the same way, with three teams working shifts that rotate over a four- or five-week period in order to provide a round-the-clock service.

The problems observed in the obstetrics departments also apply to orthopaedics. In the Netherlands, for example, department managers have imposed a minimum working time for part-time contracts of 60 per cent of the full-time norm. Some nurses would like to work fewer hours.

In most of the countries, the drive to reduce costs, combined with technological progress, has led to shorter hospital stays. This has given rise to problems specific to orthopaedic departments.

In France, for example, the average duration of a hospital stay was 7.8 days in 1991; by 1998, this had fallen to only 4.7 days. This has intensified nurses' work: according to one nurse in an orthopaedic department, 'What bothers me as well is that we're always very busy. There's always a lot of work to be done. We're always rushing around.'

In Sweden, this tendency is further exacerbated by management checks on the quality of care and the task of passing on instructions to district nurses who take over responsibility for patients when they are discharged from hospital. In the light of this additional administrative work, nurses have delegated intravenous injections, drips and dressings to auxiliary nurses.

In the UK, 40 per cent of the orthopaedic department staff are healthcare assistants. They are given six months of training in the hospital itself. Their job description is broader in scope than that of nursing auxiliaries. They provide basic care under the supervision of a nurse. In the hospital investigated, they are not paid any premiums for night or weekend working. The hospital management had wanted to increase further the proportion of healthcare assistants it employs, but had had to abandon its plans because of problems with the quality of care.

The shortage of nurses has repercussions on the management of the departments. In the Swedish hospital, the orthopaedic department makes frequent use of temporary contracts in order to fill vacancies. The temporary staff are young, highly mobile nurses who work for just a few months before returning to their studies or starting a family. Nurses in the department also work a lot of overtime because of absenteeism and vacancies. Many considerably exceed the collectively agreed limit of 200 hours of overtime per year. These additional hours are recompensed by extra days off.

In France, rosters are frequently changed in order to deal with absenteeism: as a nursing auxiliary in the orthopaedic department said, 'We have a fourteen-week roster, but it's often changed at the last minute because someone's on sick leave. We often have to change our schedules too.' The head of this department favours the expansion of part-time working because it would increase the number of individuals available to cover for absent colleagues.

As the average length of hospital stays has decreased and employment 
levels have been restricted, so the workload of nursing staff has increased. Nursing managers trying to deal with this excess work look for ad hoc solutions. They may use temporary staff or turn to less skilled staff. The actual solution depends on the possibilities offered by national and sectoral regulations. Nevertheless, nursing managers have an incentive to take individual requests into account, because ignoring them altogether would simply lead to increased absenteeism which, in a vicious circle, would further disrupt the management of working time.

This three-dimensional analysis of working-time management has shown that the expansion of part-time working has been driven not by management but by individual nurses. It seems to arise out of a conflict between the time constraints on hospital departments and the constraints on the private lives of nursing staff, most of whom are women. Thus in order fully to understand the differences in part-time rate from one country to another, we need to focus more on the demand for working time from individuals than on the supply.

\section{The evolution of employment and working time and the context of change}

The preceding analysis has highlighted the influence of the socio-economic relationship, notably budgetary restrictions and the increased autonomy of individual hospitals. It has also revealed the importance of the regulatory aspects. National regulations and collective agreements play an essential role in the management of working time. Since these points have already been discussed at some length, the analysis will now focus on the organisational and domestic relationships, which also seem to introduce tension into the employment relationship of the nursing staff whom we interviewed.

\section{The organisational relationship}

The very nature of a hospital's work requires many departments to operate continuously with a minimum level of staffing in order to guarantee quality of care and patient safety. This fundamental obligation places very considerable pressures on employment and working conditions, particularly since staffing levels are increasingly being kept as low as possible because of the growing financial constraints on hospitals.

In the orthopaedic and obstetrics departments investigated in the six countries, rosters are based on three eight-hour shifts. Individual work schedules are cyclical, and involve night and weekend working. In France in 1998, 40 per cent of nurses worked occasional nights and 80 per cent weekends (own calculations from INSEE 1998). When a member of staff is absent, the already barely adequate staffing levels force department managers to react by requesting additional staff from a temporary employment agency or a relief pool. If the financial or human resources are not 


\section{Christophe Baret}

available, managers have no other option but to require the remaining staff to increase their workloads or to work overtime, which in some cases leads to staff working two consecutive shifts or postponing their days off. The constraints imposed by a cyclical schedule are further compounded by the unpredictability caused by absenteeism, which makes it even more difficult to reconcile paid work and private life. As a nurse in a French orthopaedic department said, 'At home, I'm always in the middle of explaining what's going to happen the next day and then at the last moment I have to change everything ... it's a real juggling act.' Absenteeism in this sector is generally fairly high. In France, the 1999 Roché Report on working time in the public services revealed that the average number of days lost per employee in the hospital sector ranged from twenty-two to thirty-five (Roché 1999). Part-time working and absenteeism seem to be the two principal strategies for reducing working time that individuals use to regain control of their time and to achieve what they regard as an acceptable work/life balance.

The need to ensure continuity of care also means that instructions have to be passed on from one team to the next. This requirement is scarcely compatible with the fragmentation of working time. In Belgium, a ministerial working party produced evidence to show that the expansion of part-time working both increases the volume of instructions that have to be passed on and makes the task more complex. Nurses have to write more reports at the end of their shifts, which impacts adversely upon the quality of the reports. It also makes vertical communications and the transmission of know-how more difficult. While in some sectors, such as retailing, the jobs in question are low-skill and the co-ordination problems can be tolerated, this is not the case in hospitals.

Thus department managers are caught between, on the one hand, their desire to win the loyalty of their workforce and, on the other, the need to ensure that the work of the various teams is well co-ordinated. However, it is striking that these problems with co-ordination were mentioned both in the Netherlands, where 90 per cent of the nursing staff in obstetrics departments were part-timers, and in Italy, where the part-time rate was only 25 per cent. Thus it would seem that managers are learning how to manage part-time workers but that problems of co-ordination still exist.

The division of labour between healthcare professions is an organisational issue. In order to combat the shortage of skilled labour, some countries have introduced less skilled categories of personnel in order to relieve nurses of certain tasks. This is the case in the UK, with the introduction of healthcare assistants, and in the Netherlands, with the use of maternity assistants in the obstetrics departments. In Belgium, more administrative personnel have been recruited. As a result of technological advances and the reduction of the average length of hospital stays, nurses are generally increasingly engaged in technical work and are withdrawing from direct patient contact, with that task falling increasingly to nursing 
auxiliaries and care assistants. However, changes in the division of labour often meet with resistance from professional associations.

The intensification of work is resulting in a growing share of hospital workers seeking to reduce their working time by going part-time. Thus the organisational and socio-economic relationships provide one explanation for the growth of part-time work among nursing staff. Although this trend towards increased part-time working may be observed in all six countries (except in the UK where in recent years the aim has been rather to reduce precariousness), the part-time rate is still very different from one country to another. This leads us to consider the influence of the domestic relationship.

\section{The domestic relationship}

It is the high rate of feminisation in nursing that leads us to hypothesise that the domestic dimension influences employment and working time management in the hospital sector. After all, numerous studies (Plasman 1994; Hantrais and Letablier 1995; O'Reilly and Fagan 1998) have shown that the female labour supply is strongly influenced by the organisation of women's domestic activities. In all six countries, the high rate of feminisation in nursing goes hand-in-hand with a low rate of feminisation among medical staff (about 25 per cent), which means that gender relations play an important role in hospitals. This phenomenon probably tends to exacerbate the claims made by trade unions, which are strongly identified with nursing staff, and to strengthen resistance to change among medical staff, who exert great influence on hospital management.

Thus the tensions generated by time constraints and work intensity tend to be eased by the development of part-time working, which is consistent with a female employment model, rather than by any improvement in working conditions, autonomy and pay, which would constitute nothing less than a challenge to the traditional power relationships. The example of the Netherlands - the country where part-time working is most highly developed but where the problems of dissatisfaction with working time and workloads and of labour shortages persist - leads to the conclusion that acting on working time alone is not sufficient to resolve the problems of nurses' employment relationship. After all, by reducing the number of hours worked by individuals, the development of part-time working merely serves to exacerbate the labour shortage. It seems to us, therefore, that the questions of pay and working conditions should probably be tackled at the same time, even though they seem more intractable.

For the Belgian trade unions, the increase in part-time working among nurses is evidence of a 'flight' from the pressures of the job. Part-time working seems to be the only means available to individuals wishing to regain control over their working time. According to the trade unions, 60 per cent of nurses in Belgium have asked to work part-time at least once in their careers. 


\section{Christophe Baret}

The correlations between the part-time rate in the health sector and that in the economy as a whole tend to make us think that the very considerable differences between the countries can be more readily explained by national models of women's employment than by differences in the organisation of healthcare systems. After all, the 'work-family' relationship takes different forms across Europe, as Hantrais and Letablier (1995) have shown. The various forms taken by that relationship are influenced by cultural factors, such as the role of women in the family and the domestic division of labour, and above all by institutional factors, such as the existence of public childcare facilities, the age at which children start school, the rules governing the taxation of married couples' earnings, and differences in the treatment of full-time and part-time workers in terms of pay and social protection.

In the light of these various factors, Hantrais and Letablier identified the following models.

- The Dutch form of the 'work-family' relationship is termed the 'alternation' model, on the grounds that 'the adjustment between family and paid work is effected mainly through variations in women's economic activity' (p. 48). There is relatively little public provision of childcare, and part-time working is the main mode of adjustment, which explains the high part-time rate in the Netherlands.

- The British model is described as 'non-interventionist'. It is based on the principle that the state should not intervene in families' private affairs. Consequently, women carry much of the burden of caring for young children, the elderly and the sick. As a result, they have to content themselves with part-time work and even have an incentive to do so, since their earnings are exempt from taxation below a certain threshold (£3,765 per annum in 1995) (Daune-Richard 1998). Italy also has this model, although the part-time rate here is, in contrast, very low because the absence of public childcare facilities means there are strong pressures on women to remain at home. In Italy, consequently, participation rates among women with children are low, as is the part-time rate (Plasman 1994).

- France and Sweden have what is termed the 'conciliation' model. The state facilitates the reconciliation of family responsibilities and paid work by making provision for parental leave, providing childcare facilities and guaranteeing equal rights for part-time and full-time workers. These measures enable women to reconcile domestic responsibilities and paid work and to realise their preference for fulltime work, which explains a median part-time rate (see Table 7.3). Belgium may also be included in this model, even though it has a higher part-time rate than France because of the effect of antiunemployment policies, which have given employers strong incentives to make greater use of part-time jobs. 
These institutional constructions of the 'work-family' relationship structure the demand for part-time work from women and contribute to the differences observed between the various countries in part-time rates among nursing staff.

\section{Conclusion}

In all six countries investigated, the socio-economic space has undergone radical change over the past twenty years. The drive to contain healthcare expenditure has led the supervisory authorities to strengthen their control over hospital budgets. As a result, staffing levels are kept to the bare minimum required for safe patient care, bed occupancy rates have increased, and the average duration of hospital stays has fallen. Moreover, a demand for high-quality care is emerging in society, which is reflected, first, in an increase in nurses' administrative workload as the administration of treatments and the conveying of instructions are rigorously monitored, and, second, in patients' requests for information about their conditions and treatment, and demands for psychological support and better alleviation of pain.

This intensification of the workload is further compounded by the increasing number of vacancies. Because of demographic trends and the relative unattractiveness of nursing as a profession, hospitals are experiencing increasing difficulties in recruiting staff. As a result, staff already in post are having to divide the workload of the unfilled vacancies among themselves.

At the same time, increasing time constraints (changing schedules, postponement of days off and holidays) are making the nursing unions more strident in their demands and conflict violently with the domestic constraints of the nursing workforce.

In view of the relative lack of progress being made - for economic and institutional reasons - in talks on raising the economic and social status of nursing, these tensions are eased largely by nurses in all six countries totally or partially withdrawing from hospital work. An increasing proportion of nurses are asking to work part-time, and department managers are reluctantly acquiescing to these requests.

The difficulty of reconciling the time constraints of hospital work (cyclical schedules, night work, postponed rest days) with those of domestic life (school hours, nursery opening times) is an important source of tension for nursing staff. In some cases, these constraints are encouraging nurses to request that their working hours be concentrated in ten- or twelve-hour time slots, as is the case in France with midwives and in the UK for some nurses. These tensions are also partially responsible for young people's reluctance to embark on careers in nursing. They are also encouraging nurses to leave regular waged employment in order to become selfemployed, as is the case in France, for example, or to join a nursing bank, as is the case in the Netherlands and in the UK. 


\section{Christophe Baret}

As the case studies demonstrate, hospital and nursing managers seem to enjoy very little room for manoeuvre in managing duty rosters. On the one hand, they have to take account of the strong financial constraint on staffing levels and the need to provide a round-the-clock service. On the other hand, if they wish to retain their staff and prevent absenteeism, they need to take account of individuals' expectations with respect to working time. According to our investigations, the solutions adopted (see Table 7.6), such as the introduction of less skilled jobs and the expansion of part-time working, are merely palliatives that quickly reveal their limitations in terms of delivering high-quality care and employee satisfaction.

Some more ambitious innovations have been introduced in a bid to alleviate these tensions (e.g. provision of childcare facilities, twelve-hour time slots, job sharing for part-timers, working-time accounts). It is at the local level (that is, within individual hospitals and departments) that the new working-time arrangements are being put into place, making the eventual solutions adopted dependent largely on negotiation and the existing power relationships. However interesting and valuable they may be, these innovations do not seem to offer a lasting solution to the fundamental problem of the economic and social recognition of nursing as a profession.

For many years, hospitals relied heavily on nurses' intrinsic motivation and sense of 'mission'. Now, as educational levels among nursing staff rise and skilled labour is in short supply, hospitals and other healthcare units seeking to attract young people into the profession will need to focus increasingly on pay and working conditions, particularly in comparison with other sectors of the economy.

Table 7.6 Managing the labour shortage: the solutions adopted in the case studies

\begin{tabular}{|c|c|c|c|c|c|c|}
\hline Type of solution & Belgium & France & Italy & $U K$ & Netherlands & Sweden \\
\hline 12-hour days & - & $x$ & - & $x$ & - & - \\
\hline $\begin{array}{l}\text { Participatory working time } \\
\text { management }\end{array}$ & - & $x$ & - & - & - & $x$ \\
\hline $\begin{array}{l}\text { Reduction of full-timers' } \\
\text { working hours }\end{array}$ & - & $x$ & - & - & $x$ & - \\
\hline Part-time working & $x$ & $x$ & $x$ & - & $x$ & - \\
\hline Temporary staff & - & - & - & $x$ & $x$ & - \\
\hline Less skilled jobs & $x$ & - & - & $x$ & - & - \\
\hline Working-time accounts & - & - & - & - & $x$ & - \\
\hline Immigration & - & - & - & $x$ & - & - \\
\hline Division of labour & - & $x$ & - & - & - & $x$ \\
\hline Career management & - & $x$ & - & - & $x$ & - \\
\hline Loyalty bonuses & $x$ & & & & - & - \\
\hline $\begin{array}{l}\text { Increase in admission quotas } \\
\text { for nurse training }\end{array}$ & - & $x$ & - & $x$ & - & - \\
\hline Provision of childcare facilities & - & - & - & - & $x$ & - \\
\hline Pay increases & - & $x$ & - & $x$ & - & - \\
\hline
\end{tabular}




\section{Notes}

1 Nevertheless, it should be noted that the share of health expenditure in GNP varies considerably, indeed almost by a factor of 2, from 5.49 per cent in Italy in 1997 to 10 per cent in France in 1998. The average for EU member states is 8 per cent.

2 These data should be regarded only as orders of magnitude and handled with care, since the realities behind them differ from country to country (in terms of health professions, personnel in the public health service, hospital staff and so on).

3 This reduction in employment levels in Sweden mainly affected nursing auxiliaries ( -33 per cent between 1980 and 1996) rather than nurses and midwives ( +2.5 per cent over the same period) (Landstingsförbundet 1997).

4 The share of health expenditure in GNP in Sweden fell from 8 per cent in 1993 to 7.4 per cent in 1998. The other measures taken in 1993 included, notably, cuts in sickness benefits, the introduction of a qualifying day and a reduction in the average length of a hospital stay.

5 Italy has one of the lowest female participation rates in the EU. Women in Italy account for only 43.6 per cent of the economically active population.

6 This is a new category. The maternity assistants perform less technical tasks and assist with normal deliveries.

7 Under the terms of their contracts, full-timers can work 100 hours of overtime per year, compared with only thirty hours for part-timers.

\section{References}

Anxo, D. and Nyman, H. (2000) 'Swedish health care', country report, New Forms of Employment and Working Time in the Service Economy Project (NESY), Gothenberg: Centre for European Labour Market Studies, Göteborgs Universitet.

Armstrong-Stassen, M., Al-Ma'aatah, R., Cameron, S. and Horsburgh, M. (1998) 'The relationship between work status congruency and the job attitudes of fulltime and part-time Canadian and Jordanian nurses', International Journal of Human Resources Management 9: 1.

Bach, S. (1998) 'NHS pay determination and work re-organisation: employment relations reform in NHS trusts', Employee Relations 20: 6.

- (2000) 'Health sector reform and HRM: Britain in comparative perspective', International Journal of Human Resources Management 11: 5.

Baret, C., Gadrey, J. and Gallouj, C. (1998) 'France, Germany, Great Britain: the organisation of working time in large food retail stores', European Journal of Industrial Relations 1: 27-48.

Baret, C., Lehndorff, S. and Sparks, L. (2000) Flexible Working in Food Retailing. A Comparison Between France, Germany, Great Britain and Japan, London: Routledge.

Com-Ruelle, L., Midy, F. and Ulmann, P. (2000) 'La profession infirmière en mutation. Eléments de réflexion à partir d'exemples Européens', Bulletin d'information en économie de la santé 33: 1-4.

Daune-Richard, A.M. (1998) 'How does the "societal effect" shape the use of parttime work in France, the UK and Sweden', in J. O'Reilly and C. Fagan (eds) Parttime Prospects, London: Routledge.

Eurostat (2000) European Social Statistics: Labour Force Survey Results 1999, Luxembourg: Office for Official Publications of the European Communities. 


\section{Christophe Baret}

Foulon, D. (1995) 'Hôpital: dix ans d'évolution', Solidarité Santé 3: 9-20.

Hantrais, L. and Letablier, M.T. (1995) La relation famille - emploi. Une comparaison des modes d'ajustement en Europe, Dossier (6), Centre d'Etudes de l'Emploi, Noisy le Grand.

Institut National Statistiques (INS) (1996) Statistiques annuelles régionales 1996, Brussels: INS.

Institut National de la Statistique et des Études Économiques (INSEE) (1998) 'Enquête Emploi', database provided on CD-ROM, Paris.

Istituto Nazionale di Statistica (Istat) (1998) Statistiche delle sanita 1998, Rome: Italian Ministry of Health.

Landstingsförbundet (1997) Landstingsanställd Personal 1997, Stockholm: Landstingsförbundet.

Letourny, A. (2000) 'Les politiques de santé en Europe: Une vue d'ensemble', Sociologie du Travail 42: 13-30.

Maurice, M., Sellier, F. and Silvestre, J.J. (1982) Politique d'éducation et organisation industrielle en France et en Allemagne, Paris: Presses Universitaires de France.

Mossé, P. and Arrowsmith, J. (1999) 'Les temps de travail dans les hôpitaux en France et au Royaume Uni', Travail et Emploi 77: 67-77.

Nederlands Instituut voor Onderzoek van de Gezondheidszorg (NIVEL, Netherlands Institute for Health Services), Nzi (Institute for Health Care Management, formerly Nationaal Ziekenhuisinstituut) and Organisatie voor Strategisch Arbeidsmarktonderzoek (OSA, Institute for Labour Studies) (1998) Rapportage arbeidsmarkt zorgsector 1998, The Hague: Dutch Ministry of Health Care, Welfare and Sports.

O'Reilly, J. and Fagan, C. (eds) (1998) Part-time Prospects, London: Routledge.

Piovesan, D. (2000) 'The French health care', Country Report, New Forms of Employment and Working Time in the Service Economy Project (NESY), Université Jean Moulin Lyon 3, GRAPHOS, France.

Plantenga, J. and Remery, C. (2000) 'The Dutch health care', Country Report, NESY Project, University of Utrecht, Institute of Economics, Utrecht.

Plasman, R. (1994) Les femmes d'Europe sur le marché du travail, Paris: L'Harmattan.

Plasman, R. and Lumen, J. (2000) 'Work organization and working time in the health sector in Belgium', Brussels: Université Libre de Bruxelles, Département d'économie appliquée.

Pouvourville, G. (1996) 'Hôpitaux: la double contrainte', Revue Française de Gestion 7: 279.

Roché, J. (1999) 'Rapport sur le temps de travail dans les trois fonctions publiques', Mission Interministérielle, Paris: La documentation française.

Rubery, J., Smith, M. and Carroll, M. (2000) 'UK health care', Country Report, New Forms of Employment and Working Time in the Service Economy Project (NESY), European Work and Employment Research Centre, University of Manchester Institute of Science and Technology (UMIST).

Van der Aa, R., van Nes, P., van der Veen, C., Vos, G. and Zandvliet, K. (1999) Sectoren in de knel: Knelpunten in de personeelsvoorziening, oorzaken en oplossingsrichtingen, The Hague: Elsevier.

Villa, P. and Zeni, E. (2000) 'Italian health care', Country Report, New Forms of Employment and Working Time in the Service Economy Project (NESY), Université de Trente. 


\title{
8 Work hard, play hard? Work in software engineering
}

\author{
Janneke Plantenga and Chantal Remery
}

\section{Introduction}

The advent of the information society is supposed to have far-reaching effects on the organisation and scheduling of work. An animated element in the discussion is the individualisation - alternately called destandardisation or disaggregation - of work, implying a shift from permanent, stable, full-time jobs to individualised, flexible employment (Beck 2000; Carnoy and Castells 1997; Castells 2000). A 'standard' working career remaining with one employer for an individual's entire working life is being replaced by the notion of 'human capital portfolios' (Carnoy et al. 1997) built on a variety of working arrangements such as self-employment, part-time work and temporary work. The development of the Internet especially has been significant, enabling employees to deliver work from places other than their employers' (Autor 2001). To what extent the new technologies indeed will lead to a 'weightless economy' (e.g. Cairncross 1997; Pratt 2000), in which distance and time no longer constitute restrictions and where all employees work flexibly in 'virtual offices', is yet unclear. However, it seems obvious that the developments will have a severe impact upon the organisation of work and working time.

In this chapter, we will investigate the emergence and diffusion of new forms of employment and working time in the information technology (IT) sector. More specifically, we will focus on IT services (i.e. software consultancy and supply, system development, system analysis, and software services). Given their specific product - intangible services that must often be provided on the spot - companies in IT services would be expected to be among the first to practise individualised and flexible employment strategies, since these are both allowed and required by the information technologies themselves. In addition, the industry is new, and the specific employee profile - highly skilled, articulate, and capable of making their own choices with respect to working conditions - enhances the innovative capacity. Despite these expectations, an initial statistical impression of the IT sector, as described in the third section below, seems to indicate that the organisation of work and working time is, in fact, rather traditional. Beyond 


\section{J. Plantenga and C. Remery}

the statistics, however, more innovative elements such as individualised working hours and new control mechanisms do occur, as will be illustrated in the fourth section. In particular, the characteristics of the service, the profile of the workforce and requirements with respect to flexibility appear to be relevant factors for both the organisation of work and working time.

Five countries participated in this research on IT: Denmark, Finland, Germany, the Netherlands and the UK. In each country, IT companies were visited and interviews held. In addition, written materials such as annual reports were used. The case studies (Anttila and Nätti 2000; Csonka and Boll 2000; Plantenga and Remery 2001; Smith 2001; VossDahm 2000) included smaller as well as large IT firms. The large IT firms employed the majority of employees and constituted global players with a significant impact on the economic, technological and social environment. The smaller firms included start-ups where employment practices were not yet established; many of these may represent examples of 'the company of the future'. The interviews took place in spring 2000; that is, in a period of favourable economic circumstances. Undoubtedly, this has influenced the results; yet the forms of employment and working time in IT had a certain singularity, which cannot be entirely traced back to the specific economic climate.

\section{Socio-economic environment and organisational structure}

Within a relatively short period, IT became a sector of significance within Western economies. Especially in the second half of the 1990s, the employment in the sector grew at a high pace. Table 8.1 shows growth

Table 8.1 Share of IT in total labour force, employment growth in IT and size of firms (NACE 72) (\%)

\begin{tabular}{lccccr}
\hline & Denmark & Finland & Germany & Netherlands & UK \\
\hline $\begin{array}{l}\text { Share of IT in total labour force } \\
\text { in 1999 }\end{array}$ & 1.7 & 1.3 & 0.8 & 1.5 & 1.7 \\
$\begin{array}{l}\text { Employment growth in IT } \\
\text { a }\end{array}$ & & & & & \\
1996 to 1999 & 48.0 & 73.0 & 59.0 & 91.0 & 65.0 \\
Size of firms & 75.0 & n.a. & n.a. & 134.0 & 198.0 \\
$<10$ employees $^{\mathrm{b}}$ (1999 & & & & & \\
Tor more employees & 88.7 & 92.3 & n.a. & 93.1 & 96.5 \\
Total & 11.3 & 7.7 & n.a. & 6.9 & 3.5 \\
\hline
\end{tabular}

Notes

a European Labour Force Survey, 1999 (unpublished data); own calculations.

b Figures for Finland, Netherlands and the UK refer to 1996 and are based on Eurostat (1998); figures for Denmark refer to 1997 and are cited in the national report (Csonka and Boll 2000). 
rates for the period 1996 to 1999 and, as far as available, for 1993 to 1999. Between 1996 and 1999, these rates varied from almost 60 per cent in Germany to 91 per cent in the Netherlands. Growth rates were even higher when a longer period is taken into account. Especially in the UK, the number of workers in IT has increased considerably: between 1993 and 1999, the growth was almost 200 per cent. As a result, the share of IT in net new job growth in the UK was disproportionately high: between 1994 and 1999, the sector accounted for 13 per cent of net new job growth (Smith 2001). These figures are limited to NACE 72, which refers to service activities in IT. The significance may be even larger when other information and communications technology (ICT) activities, especially with respect to communication, are taken into account. In addition, all countries reported significant increases in sales turnover. For example, in Germany the sales turnover in the sector NACE 72 increased between 1994 and 1997 by almost 50 per cent. Denmark reported a similar growth. However, despite the high growth rates and the enormous impact of ICT upon daily life, the share of IT in the total labour force was quite limited. In the five countries, it varied between 1 and 2 per cent.

There were several partly related reasons for the growth of the sector. Operations such as the millennium problem and the introduction of the euro stimulated demand for IT services. Furthermore, the level of innovation in software is high: new programs and program languages are being developed and adjusted in new versions. Electronic trade is occurring, and the Internet is creating new applications. In addition, economic growth stimulated demand for IT products and services. However, the real rates may be partly overestimated because there was a tendency in companies to outsource their IT activities (Bosch et al. 2000). This was indicated by the decreasing share of IT workers in other sectors.

A common characteristic for the five countries was the high share of small firms (i.e. firms having fewer than ten employees). With the exception of Denmark, where it is a little less, the share of small firms was more than 90 per cent, with the UK having the highest score of 96.5 per cent. This was related to the high share of self-employed workers, which is partly facilitated by tax regulations in the UK. Self-employed workers could reduce their tax and social insurance bills by drawing low salaries and paying most of their earnings in dividends, though recent changes in tax laws reduced opportunities.

Despite the low share of larger firms within the total number of firms, employment was heavily concentrated in larger firms. For example, while in Denmark the share of IT firms with more than 100 employees was only 1 per cent, these firms accounted for more than 50 per cent of total employment in the sector. Available figures indicated that in Denmark almost 80 per cent of total employment was concentrated in firms with more than ten employees; in the Netherlands, this was 70 per cent. 


\section{J. Plantenga and C. Remery}

A large share of this employment could be found in very large, often internationally operating enterprises.

\section{Industrial relations}

Although data sources are relatively scarce, in all the countries included in the research, the organisation rate among employees as well as employers in IT was below average (see also EIRO 2001). For example, in a highly unionised country such as Finland - about 80 per cent of all employees were members - the trade union density among employees in IT was, at 50 per cent, rather low. The trade union density may be related to the specific employee profile. Most employees are highly educated, and they prefer and have the capacity to negotiate terms of employment on their own. Their market power may be quite considerable, which gives them a strong position in individual negotiations. At the other side of the negotiating table, employers also appear to be organised rather loosely. In the five countries of research, there are several employers' organisations, but these act more as trade associations and are generally not involved in negotiations on collective agreements.

The low organisation rate of both employers and employees in the sector is partly related to its fuzzy profile. The sector is relatively young, and industrial relations are not crystallised fully (yet). There seems to be ongoing debate about 'who represents whom', especially among employers. In Denmark and Germany, for example, this has resulted in several employers' organisations and unions covering parts of the IT industry. The rate of organisation is also hampered by the dynamics in the sector, where many mergers and takeovers take place. At the same time, mergers may also stimulate involvement of trade unions; for example, in the Netherlands trade unions were asked to help unify terms of employment after a merger or takeover (Schilstra 1998).

As a result of the low organisation rate, collective agreements are not very common in the industry. Finland is the only country with a collective agreement that is binding for all companies in IT services. However, with respect to working time this agreement offers the opportunity to negotiate on the local level. Most IT companies that are members of an employers' organisation have made local agreements. This concerns mainly the larger, more traditional firms. Most new and small companies are not associated with an employers' organisation. In Germany, collective bargaining is rather firmly rooted in the framework of industrial relations, but this is much less the case in the IT sector. A few IT firms have their origin in traditional industry or services, such as metal and electrical engineering or banking, and are covered by the collective agreements of these sectors. Traditionally, these are regional collective agreements. In addition, the larger firms seem to have collective agreements more often than do the smaller ones. The situation is more or less similar in the Netherlands: no 
collective agreement for the sector, although some companies have their own collective agreement. In Denmark, there are no collective agreements for the IT sector. In the UK, where industrial relations are weak in the first place, collective bargaining is hardly an issue. To illustrate, one of the British case study companies did not recognise trade unions, and new employees had to give up membership (Smith 2001). In other European countries, industrial relations appear to be similar: a rather low organisation rate and a limited number of (sectoral) agreements (EIRO 2001).

\section{Employment profile and actual working-time patterns}

Table 8.2 summarises several characteristics of employment in the IT sector in the five countries. Characteristics of the total labour force are added for comparison. The figures show that the national dissimilarities with regard to the employment structure are surprisingly small. In all countries the typical employee is male, young and highly educated. Whereas the share of men in the total labour force is about 55 per cent, in IT this share is about 75 per cent. Denmark shows the highest sex segregation in the IT sector: the share of men is almost 83 per cent. With respect to age, especially the share of workers between age twenty-five and thirtyfive is high in IT. In the total labour force, this share varies around 25 per cent, whereas in IT it is at least 36 per cent in Finland and even more than 50 per cent in the Netherlands. In all countries except Denmark, more than half of the workers in IT are highly educated (i.e. International Standard Classification of Education (ISCED) Level 5 or 6 , the first and second stages of tertiary education) compared to between only a quarter and one-third in the total labour force. The share of workers with a low educational level (i.e. ISCED Level 1, primary education or first stage of basic education, or Level 2, lower secondary or second stage of basic education) is much lower compared to the total labour force. In addition, Denmark, Germany and the UK show a significantly higher share of selfemployed workers in IT, compared to the total labour force.

\section{Working arrangements}

Working in IT carries the image of having to work long hours. As Table 8.3 shows, this image seems to be correct. ${ }^{1}$ One indicator is the share of part-timers in the sector, which is rather low in the five countries compared to the total labour force. The highest share (14.3 per cent) is found in the Netherlands, which is also the country with the highest share of part-timers in the total labour force. Another indicator is the share of employees (excluding the self-employed) working very long hours (i.e. more than forty-eight hours per week, which means exceeding the maximum weekly working hours laid down in the EU Directive 93/104/EC of 23 November 1993). Although there is some variation 


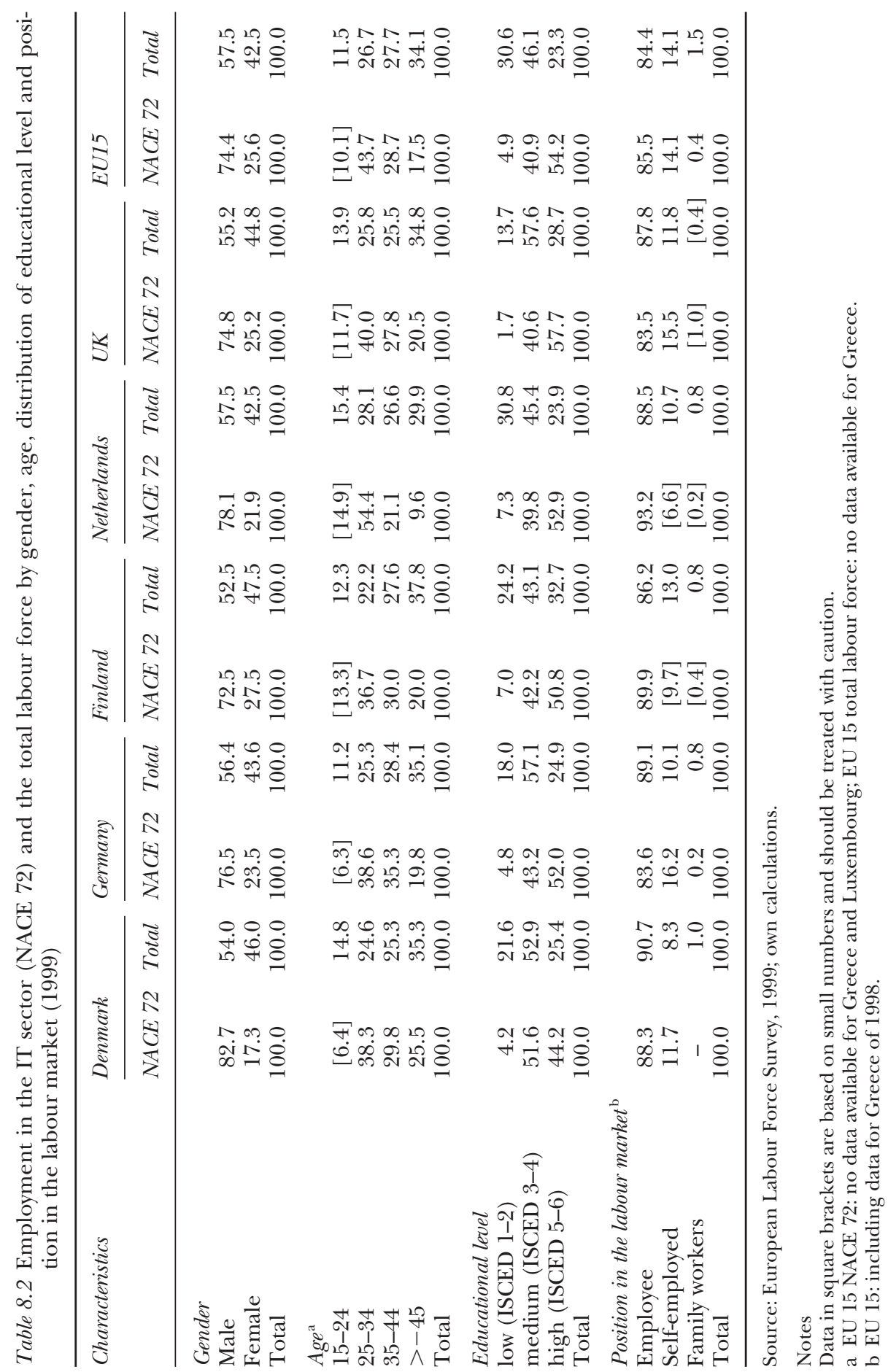


among the five countries, the figures in Table 8.3 suggest that a substantial share of employees indeed work more than forty-eight hours. This is especially the case in the UK where one-fifth of IT employees work long hours. In Finland and the Netherlands, this seems to be less common. Additional information on Finland indicates that long working hours tend to be concentrated in small firms. A survey among Finnish IT employees shows that 36 per cent of employees in small firms (i.e. those with fewer than twenty employees) work regularly for forty-one hours or more per week, whereas this share is less than 14 per cent among employees in larger firms (Anttila and Nätti 2000). Furthermore, the Finnish case studies emphasise that the really long hours were concentrated in certain tasks and individuals. It seems therefore that long working hours are not an inescapable ingredient of the IT work organisation but are also the result of the national particularities of the working-time regime. Working long hours may imply working at non-standard hours (i.e. in the evenings and/or at night and/or at weekends). The figures in Table 8.3 show that, with the exception of the Netherlands, the share of workers in IT who work sometimes or usually in the evening and/or at night is indeed higher than this share in the total labour force. For example, in Denmark more than 50 per cent of the workforce in IT work in the evening and/or at night compared to 41 per cent of the total labour force. Again, the UK seems the most extreme with almost 65 per cent of workers in IT working on a regular basis in the evening or at night.

Working on Saturdays and/or Sundays seems less common; in this respect the IT rates are lower than in the overall economy, though it is still a considerable score. The UK is, again, the leader in this respect: 56 per cent of the workers in IT usually or sometimes work at weekends. The share is much lower in the Netherlands, with a quarter of IT workers.

A permanent contract is the standard in the IT sector in all countries. The share of employees with a temporary contract is substantially lower in the IT sector compared to the total labour force. With respect to hours of work, there are indications that employees seem to be rather flexible. In the Netherlands, approximately 50 per cent of employees have a kind of flexible arrangement; for example, a fifty-hour week can be compensated by working thirty hours the following week (FNV Bondgenoten 2000: 16). Flexible 'office hours' (i.e. giving employees the opportunity to begin their working day at different times within a certain range) also seems to be common practice. For example, in two German case studies, working time may be scheduled between $6 \mathrm{a} . \mathrm{m}$. and 8 p.m. from Monday to Friday (Voss-Dahm 2000).

Telework and/or homework also provide flexibility. Due to technological developments, work becomes less related to a specific location. Employees can simply create a working place by connecting a laptop with the network. In one of the Dutch case studies, the concept of flexible workplaces is introduced in order to use offices more efficiently. This 


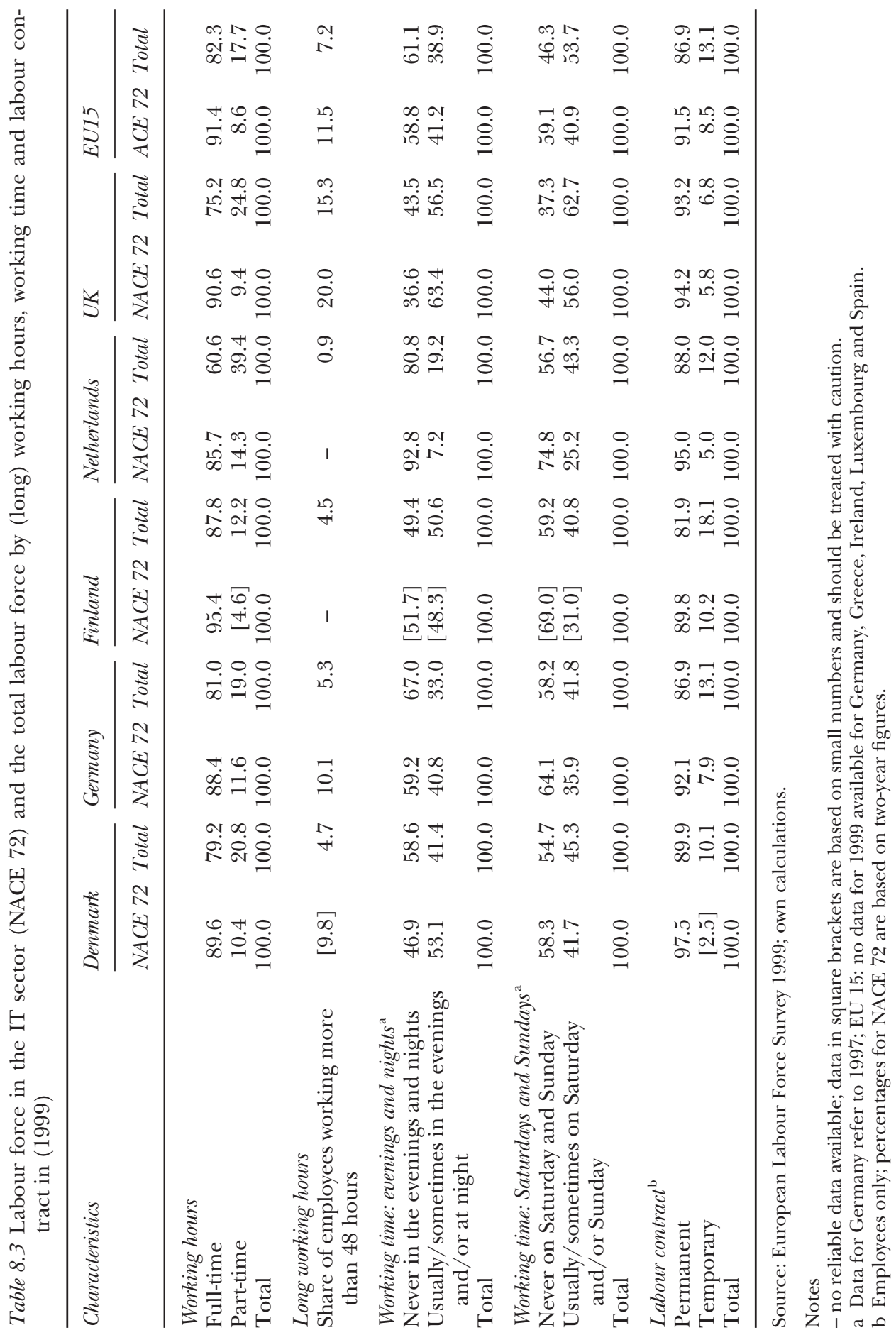


means that (most) employees do not have a permanent workplace any more. Furthermore, it gives employees more flexibility with respect to working time and actual location of work. Dutch research shows that 41 per cent of employees in IT have the opportunity to work from home (FNV Bondgenoten 2000: 15). In Finland telework is an option in onethird of the IT companies. In 7 per cent of the companies, full-time telework is possible (Anttila and Nätti 2000). There is a strong emphasis on the time-saving aspects and flexibility of teleworking. Facilitating work from home is clearly stimulated by traffic congestion and the related increasing travelling time. In practice, however, working from home seems to be used rather 'marginally' - employees try to save time by starting or ending their working day at home to avoid rush-hours. There is no large-scale substitution of work in a traditional setting by work done at home. Finnish research shows, for example, that the number of employees who use the option to telework is rather small: only about 3 per cent of all employees. Especially in larger firms, the share of teleworkers proves to be small (Anttila and Nätti 2000).

In summary, this first statistical impression seems to indicate that the forms of employment and working time are rather traditional. Although there are clear differences in the organisation of working times between, for example, Finland, the UK and the Netherlands, the overall picture seems to indicate that a full-time, permanent contract is still the standard. This seems to contradict authors like Castells, who predict a shift towards more individualised, more casual working-time patterns. It may, however, take some time before new elements are captured in statistics. In addition, statistical surveys may give only a partial picture of the actual organisation of working time, since they are based only on broad statistical categories such as 'full-time work' or 'permanent contracts'. The actual working hours, the flexibility and autonomy of employees are shaped within the context of the individual firm and may not easily be categorised in statistical terms. Therefore, it is necessary to look beyond the statistics and to explore the actual organisation of work and working times in companies in more detail.

\section{Beyond the statistics: determining factors of IT work organisation and working time}

The organisation of work and working time in IT is the result of a complex of interrelating factors. Especially relevant seem to be the characteristics of the service provided, the profile of the workforce and the flexibility requirements. Some of the factors seem to be more or less 'universal'; others are shaped and influenced by national particularities. 


\section{J. Plantenga and C. Remery}

\section{Characteristics of the service provided}

A characteristic of most IT services is that they are intangible, timeconsuming, tailor-made and often provided at the location of the client. IT services vary significantly in terms of their output, ranging from providing IT training to creating IT applications and from solving standard problems to development of tailor-made complex systems with high interests at stake. Each client is unique and services cannot be specified fully in advance (e.g. Yakura 2001). As a result, IT projects are often not exactly plannable, and IT services are characterised to a certain extent by uncertainty with respect to the necessary number of hours needed. Unforeseen difficulties may arise during the process. Moreover, there are no clear quality standards with respect to the final product, and the wishes of the client may evolve or even fundamentally change over time. At the same time, clients are often restricted by their budget. As a result, an accurate planning of the work process is very complex, which will have an impact on working times. This is illustrated in one of the Danish case studies concerning a company that provided Internet solutions and consulting. Because production of websites is a non-standard specialised product, it proved to be difficult for the company to estimate the work process and, at the same time, to balance customer expectations. In this firm, a substantial amount of weekly overtime was common practice. Immediately prior to deadlines, the number of overtime hours was often even higher because the original planning proved to be too tight.

\section{Planning complexities and the frequency of overtime}

At the same time, there appear to be large differences in the frequency of overtime between firms. An important variable in this respect seems to be the type of service provided. Most common are project work and posting of employees. Project work implies that a task has to be completed within a certain period of time, often for a fixed price, while the services of posted employees are sold by the hour. There seems to be a relationship to the nature of the work: projects are often quite complex (e.g. development and implementation of innovative software) and only roughly plannable. Posted work refers more often to more 'standard' IT services such as maintenance. This difference between the types of service offered may have a considerable impact upon the length of working hours and the prevalence of overtime. Overtime seems less common in organisations that are specialised in posting of employees. Working hours are strictly monitored by the company as well as by the client, since every hour has to be paid for. Overtime is limited since it is charged at higher rates and can be very expensive. Although some clients may have no problems with these extra costs, in general, higher rates will limit the probability of overtime. 
Companies that provide their services in the form of project work seem to experience a lot more overtime. Several factors are related to this. Fixed-price projects may be risky for the company, but can also be very profitable. The less human and material resources are used, the more profitable projects are. This may act as an incentive for project managers to deploy fewer employees on a specific project. This creates pressure on the employees in the project and may result in longer working hours. Furthermore, project work usually involves co-operation among IT specialists and requires co-ordination. The more complex a project, the higher the interdependence between employees (and departments) involved and the more co-ordination is necessary. As a result, projects seem to be harder to monitor and increase the risk of potential wasted time and overtime. Of course, the amount of overtime depends heavily on the accuracy of the project planning. The better a project is planned, the lesser the amount of overtime will be. However, given the unpredictability of IT work and the impossibility of accurate planning, the pressure to finish the project in time will often create pressure for overtime.

However, also for firms working on a project basis, overtime is not inevitable. Several case studies address the concern of the management with regard to the consequences of the high workload and overtime for employees and the ways to deal with these. First, especially in the larger firms, a ratio is established with respect to billable and non-billable hours. Billable hours are productive hours that may be invoiced to the client. Non-billable hours refer to unproductive hours such as meetings, sickness, training and underutilisation. This practice enables close monitoring of the actual working hours.

Accurate planning may also reduce the workload and overtime of employees. Of course, this is especially relevant for fixed-price project work, since the risk in case of extension is borne by the company. There are several methods to make planning as reliable as possible. In one of the Finnish case studies, there are guidelines to do planning. Several experienced employees estimate the necessary number of hours of a project on an individual basis and these estimations are compared. Afterwards the planning is evaluated. Furthermore, by monitoring other projects, companies gain more experience in how much time certain tasks take.

Another strategy is to have extra staff available. This prevents an increasing workload due to, for example, illness. However, this is a costly strategy and may also be complicated in case specialist knowledge is required. The Danish case studies make clear that the work not only has to be planned in terms of hours needed but also in terms of resource allocation and responsibilities. If it is not clear who is responsible for what part of the project, it is easy to waste a lot time on discussion and coordination.

It is clear that in larger firms there are more opportunities to reduce a high workload; planning systems may be more advanced, it is easier 


\section{J. Plantenga and C. Remery}

to provide extra employees and so on. This is illustrated in the Finnish report: long working hours are especially concentrated in small companies.

Location of the service provided: the absent employee

An additional characteristic of IT is that a substantial part of the services is provided at the location of the clients. Research among IT employees in the Netherlands indicates that 38 per cent are posted full-time and 6 per cent part-time (FNV Bondgenoten 2000: 26). Furthermore, additional employees who are not posted often work on the premises of the client. This may cover quite extended periods; sometimes employees work at the client's premises for several years. The premises of the actual employer are used only for meetings and contacts with the personnel and/or sales manager. At a practical level, working at the office of clients implies more travelling time for employees. This may increase the high workload of employees even more. Especially in areas with severe mobility problems (i.e. traffic congestion), travel time may take on unacceptable proportions. This raises the question of whether travel time is part of the work. Since working at the office of the client is only temporary, moving is generally not feasible for employees. Companies deal with these issues in several ways. One of the British case study companies tried to do most of the work in the same city. In addition, when work had to be done elsewhere, travel time was paid for as extra time. One of the Dutch firms changed its organisational structure towards a more regional, decentralised system. An important reason was that this enabled the company to deal with the problem of mobility in the Netherlands. In another Dutch company, travel time above ten hours per week was counted as working time and paid as overtime.

A more difficult matter is the absent employee (Plantenga and Remery 2000). Spending most of the time at the client's office bears the risk for a worker to 'go native': the employee may identify more with the client's organisation and may adopt the client company culture (Smith 2001). This risk increases when the employee is working at the client's office on an individual basis instead of with a team and when the geographical distance is higher. It is even more complex when a client outsources the IT activities, including the employees. This raises the question of commitment, with employees feeling quite detached, both from their own company and the client's company (Yakura 2001). Possible setbacks are a low level of commitment and a high turnover.

The case studies show that organisations are quite aware of these dangers. All firms interviewed stress the importance of creating a shared identity and a strong corporate culture. They have developed different strategies, formal as well as informal. A common strategy is to organise meetings with employees on a regular basis. For example, large companies 
in the UK have introduced the 'Road Show', an event which employees can attend and where they can get information about training opportunities, developments within the company and so on. In one of the Danish cases, consultants working off-site meet at the company on a weekly basis to share experiences. In addition, the director has a meeting each month with every employee. A Dutch company organises on a regular basis informal evening meetings on, for example, new technological developments, which employees can attend on a voluntary basis. In addition, there are quarterly meetings to discuss business results where attendance is obligatory. On the one hand, such meetings create an informal and social atmosphere and may strengthen the feeling of a shared identity. On the other hand, they add to the already long working hours.

Companies may also elaborate other communication lines in order to give their employees a feeling of 'being part of the firm'. Technological developments make it easy to offer access to a company's Intranet. This may reduce the feeling of isolation for off-site workers. One case study in the UK, however, showed that clients do not always approve of the use of these facilities during work time. Furthermore, activities and communication lines, such as a monthly newsletter, selection of the "employee of the year', a day out with all employees including family, Christmas dinners and so on, seem to be quite common and may be seen as part of the firm's internal acculturisation process.

Problems of this acculturisation may also give rise to specific personnel management. Several companies have created a special job position whose main duties are to look after the well-being of employees. Job titles vary from field manager to personal/professional development manager to manager of operations. This is a non-commercial position; field managers look after career and personal matters as well as aspects of the daily work. They often visit employees at the clients' offices on a regular basis. They monitor job satisfaction in order to solve any problems as early as possible. Field managers can also protect employees from too much overtime. For example, in Finland, the professional development manager in one of the case studies has to monitor the number of billable hours of employees. These are not supposed to exceed a certain number, because this goes at the expense of time for training. In the Netherlands, in one of the companies the field manager tries explicitly to limit the number of overtime hours in view of the well-being of employees.

Training is another important strategy to attract and commit employees. In addition, training is absolutely essential to keep up with new developments. Most IT companies have explicit policies with respect to training opportunities. For example, a Finnish survey held in 1997 showed that 93 per cent of the companies in computer services trained their employees. The other 7 per cent proved to be smaller companies (Anttila and Nätti 2000). According to another Finnish survey, 70 per cent of all employees working in computer services participated in training in 


\section{J. Plantenga and C. Remery}

1996. This was one of the highest rates of all industries. On average, these employees received six days for training (Anttila and Nätti 2000). The training opportunities offered were more or less comparable in the different countries. Most firms offered employees a standard budget and about five to ten workdays per year for training. In addition, employers bear the costs of training. Employees can also negotiate individually to get more training opportunities. Most companies take a certain number of nonbillable hours into account for activities such as training. This implies that training takes place during work time. However, smaller companies in particular may try to maximise the number of productive hours as far as possible and to expect that employees spend time in the evening and/or the weekends on training. For example, one of the smaller companies in the UK with no formal training policy compressed a five-day course into a three-day course, which took place from Thursday to Saturday. Other courses in this company took place in the evenings. In the German case studies, it was noted that the regular workload was often so high that employees were not able to take up their training days. In addition, in some cases training was offered only to employees considered to be 'high potentials'.

In addition to a formal training policy, several companies offered online training (i.e. interactive courses on the Intranet). Providing relevant literature on new developments on the Intranet also seems to be common practice. The German case studies make clear that this way of learning is in general not formally regulated. Employees are, however, expected to keep up with the information offered on the Intranet and to make use of the possibilities to learn online in their free time. Obviously, these practices result in an increase of the workload.

\section{Profile of the workforce}

When analysing the organisation of work and working time in IT, an important factor that has to be taken into account is the profile of the workforce. Given their specific profile - with a high level of education and in great demand - it may be assumed that the employees in IT have large bargaining power. However, this does not translate into 'normal' working hours; in most countries, working in IT means working long hours. This is no doubt related to the fact that many employees are male, relatively young and have no children (yet). In addition, all case studies emphasise the fact that the intrinsic motivation of employees in IT is very high. Available surveys show that employees in IT are very dedicated to their work. They see complex, technical issues as a challenge, and do not mind working an extra hour or even a weekend to solve a particular problem. In addition, the fact that the sector is rather new seems to attract employees, giving them the feeling that they are pioneers writing history. Long working hours are not considered as problematic; overtime seems - at 
least to some extent - the choice of employees themselves. For example, in a Danish survey among 139 IT employees, respondents were asked why they work more than the standard full-time working week of thirty-seven hours. While 88 per cent answered that 'the work requires it', 58 per cent answered 'because I want to' (Csonka and Boll 2000).

The case studies show that this attitude may be further fuelled by a specific corporate culture. One of the Danish case studies illustrates this strikingly. This company explicitly tries to attract young, dynamic, trendy people. The motto of this company is 'work hard, play hard'. The company setting, an old, large factory hall, is non-traditional and trendy, where leisure activities are also offered (such as a basketball hoop) as well as free meals for those working late in the evening. On a regular basis, parties are held and a leisure weekend for all employees may be arranged. This emphasis on being trendy and dynamic creates an atmosphere in which the feeling of working at the frontline is further strengthened and may easily induce working extra hours.

The highly educated, intrinsically motivated workforce demands a different management style. Firms rely heavily on the autonomy of the informed employee to make the right decisions at the right moment. Employees are required to take initiatives and to dedicate their time in a responsive and reliable manner, sometimes adding a few hours more to the project, sometimes less, and at other times adjusting to flexible schedules. The new ways of disciplinary management emphasise output instead of rules or hierarchy (Weissbach 1997, cited in Bosch et al. 2000); behavioural control shifts towards 'normative control' in order to elicit and direct required efforts. This implies controlling underlying experiences, thoughts and feelings of employees, with the intent that employees will be driven by internal commitment, strong identification with company goals and intrinsic satisfaction from work (Kunda 1992).

Indeed, in all firms visited, there is a strong emphasis on modern, nonhierarchical ways to direct the efforts of employees. All respondents refer to a management style that is supposed to be supportive and non-controlling. There is a heavy reliance on the autonomy of the employee to make the right decision and to act in the interest of the company. An interesting example in this respect is given by a high-level human resources official of a Dutch case study company, who summarised her management style in the words 'freedom, responsibility, and trust; all parts are equally important and equally indispensable'. This is a clear example of a management style oriented towards the intrinsic motivation of the employee. Another Dutch company adhered very explicitly to the model of the inverted pyramid'. Within this pyramid, a distinction is made between three processes: the primary process, the supportive process and the process of management. Usually, management is at the top of the pyramid. However, in this organisation the primary process - the provision of IT services - is considered as absolutely vital and is located at the top. The two other 


\section{J. Plantenga and C. Remery}

processes are supposed to support the primary process and to create an optimal working climate. This management style places a high responsibility at the individual employee level; each member is supposed to take care of the primary process itself. Management is conditional and oriented towards the optimal functioning of the employee and, by implication, of the primary process.

This is not to say, however, that companies completely rely on a reciprocity-based co-operative job attitude of employees and that 'old forms' of direct supervision have completely vanished. Monitoring the performance of the employee is partly externalised to the client and the sales manager, and their information is used in the personnel evaluation system. Given the intangibility of IT services, however, output may be hard to monitor. As a result, hours of work may easily become an indicator of both productivity and commitment (Perlow 1998). In addition, new forms of control - which may be quite subtle - may stimulate employees to work long hours. Grugulis et al. (2000) refer in this respect to 'cultural control' described as an implicit control mechanism that operates by means of organisational culture. Examples are scheduling meetings in the evening, organising social events at the weekends where attendance, while not formally required, is clearly expected, and giving interesting projects to the employees working the longest hours (see also Perlow 1998).

In addition, extrinsic motivational structures are not completely forgotten. On average, the wages are relatively high. This is no doubt an important factor behind the long working hours in this particular part of the IT sector. The IT sector is also quite accustomed to personal rating systems and more or less sophisticated ways to direct the efforts of employees in the right direction. For example, in the Netherlands more than one-third of all employees in IT have a partially variable wage (FNV Bondgenoten 2000: 18). Variable wages, such as a bonus, are related to performance and number of hours worked. The more hours an employee works, the higher the variable part. In one of the Dutch case studies, employees have to work thirty-eight weeks of forty hours (1,520 hours) on a yearly basis in order to be cost-even for the employer. For every hour above this minimum, the employee receives financial compensation. This is an explicit monetary incentive for staying well, for visiting the dentist outside company hours, and, in general, for working hard. Interestingly, the hourly compensation is the same for all employees, based on the idea that this extra compensation is the shared result of all effort of every member of the company. On average, employees work 200 extra hours annually, which translates into an extra month of salary. In the global company the wage package consists of the standard salary and an extra salary depending on the performance of the whole company and the individual rating, which can vary from A (excellent) to $\mathrm{C}$ (sufficient). In this case, therefore, it is not purely the number of extra hours, but also the personal commitment (which, of course, might be related to extra hours), which leads to a higher bonus. 
Management may also wish to experiment with individualised flexible terms of employment in order to signal modern, tailor-made labour circumstances. Flexible terms of employment enable employees, within ranges, to choose their own package. Often, input consists of sources such as wages and bonuses, but also vacation days. Depending on the company, these may be traded for a range of 'targets', such as a more luxurious company car, childcare facilities, leave facilities, pension schemes and so on. The Netherlands in particular has made progress in this respect. In one of the Dutch case studies, the company has standardised all terms of employment per job category. These terms of employment are a company car, pension schemes, partner pensions, health insurance, disability insurance and an arrangement to buy a PC at favourable conditions (and/or compliances) for private use. Each employee can choose a combination from, or all of, these benefits. The difference between the value of the benefits employees are entitled to and the value of the chosen benefits is the 'flex-component', which is transferred to a 'savings box'. Other inputs in this box are, for example, profit-sharing and commission, but also time elements such as unused vacation days and overtime. Employees can save up to a maximum of 10 per cent of their gross annual income. The savings box may be used for extra income, financial compensation for education and 'innovative terms of employment'. This latter category refers to, for example, childcare arrangements and leave facilities. Each year employees must plan how they want to use the flex-package. Buying of extra vacation days is limited to thirteen days per year (or 5 per cent of the total number of workdays per year). The costs depend on the income of the employee. It is the number of hours multiplied by the 'flex-hour price', which consists of the direct costs of an employee divided by the number of available hours. The reasons for the introduction of this system were multiple. The organisation assumes that employees will be more satisfied when they can tune their work and private life; it enables employees to make their own choices; it fits with the strategy of the firm in which respect for the individual is a central idea; and it fits with the style of management, which is directed at decentralised decision-making.

In one of the German case studies, employees can work extra hours on a voluntary basis and credit these hours in a flexi-time account. The credit/debit balance of this account may not exceed forty hours. In addition, when working overtime, employees may choose between receiving financial compensation or credit the hours to a five-year account, which is a separate account from the flexi-time account. The time credits may be used for training or just time off. They may also be saved in a long-term account, which can be used for early retirement. 


\section{J. Plantenga and C. Remery}

\section{Flexibility requirements}

The unpredictability of IT services with respect to the required number of hours makes a strong appeal to the flexibility of companies. Companies also have to be flexible with respect to fluctuation in demand and transitions between contracts with clients. These flexibility requirements also influence the organisation of work and working times.

The contractual full-time working week still structures the number of hours that have to be worked. However, due to the rise of flexible working hours, a full-time day is no longer described in terms of start and finishing times. Actual work hours are, within a certain range, at the discretion of the employees. Many employees also have, formally or informally, flexitime arrangements in the sense that they can vary to some extent the number of working hours per week. The rise of such flexible arrangements indicates that the normal times within which work is performed are becoming vaguer. Traditional instruments to regulate the normal working day and week (e.g. overtime payments and/or compensatory payments for special hours) seem to be less common than in traditional industry. For example, in the global company, overtime above a certain wage level is considered to be inherent to the job and not compensated. Due to the opportunities for autonomous time management by employees, working hours become destandardised, generating flexibility for the employee, the employer and the client. It should be taken into account, however, that this flexibility is generated against a background of long working hours. The result may therefore not necessarily be the flexibility to limit the workload but the flexibility to work at all times and in all places.

Flexibility may also be provided by the introduction of annualised hours. This gives the opportunity to work more hours during periods of high demand and to work less per day or per week during periods of low demand. In one of the case studies in Finland, annualised hours have been introduced. In practice, summer is usually a period of low demand, giving employees the opportunity to extend their holidays. The aim of the Finnish organisation of employers in IT is to introduce annualised hours sector-wide.

In case of a sudden or rather structural high demand of work, overtime is of course the classic flexibility instrument. As is made clear in the previous sections, the amount of overtime in IT is indeed very high. The occurrence of part-time work, on the other hand, is rather low. The tight customer relation is an important reason. Customers hire IT specialists and expect full-time availability. IT companies also prefer full-time employees since more hours can be billed. In fact, part-time work is not seen as a flexibility instrument at all and may only be used to comply with employee preferences.

Apart from overtime, the case studies show that IT companies also use other strategies to deal with the issue of flexibility. One example is the use 
of external employees, who may be 'borrowed' from other IT firms or from specialised temporary labour agencies. External flexibility is also provided by individual freelancers. There are several reasons for the use of external employees. First, it provides flexibility in case the demand for IT work decreases. Second, a project may require specialised knowledge that is not available in the company. In addition, external employees with specific skills may be deployed in order to explore the market for services not yet provided. The extent to which external employees are used varies. In one of the Dutch companies, about one-third of all workers are external employees. A small Danish firm employs more freelancers than permanent employees: ten freelancers versus seven permanent employees.

Subcontracting part of the work to another firm also seems a common strategy. A survey in Finland, conducted in 1997, showed that 46 per cent of the IT companies used subcontractors. However, the share of the services provided by the subcontractors was only 3 per cent of total turnover. This seems to be related to the tight labour market at that time. The survey also showed that subcontractors are used more often by smaller companies (Anttila and Nätti 2000). One of the British case studies makes use of contractors based on six- or twelve-month contracts.

\section{Conclusion}

At the turn of the century and after a decade of substantial economic growth, the IT sector shows an intriguing mixture of traditional and new elements when it comes to the organisation of work and working time. In statistical terms, the employment and working-time forms seem rather traditional. Although there are clear differences in the organisation of working time between, for example, Finland, the UK and the Netherlands, the overall picture indicates that a full-time permanent contract is still the standard. This seems to contradict authors such as Castells, who predict a shift towards more individualised, more casual working-time and employment patterns. Looking beyond the statistics, however, this image needs refining. The characteristics of most IT services - intangible, timeconsuming, tailor-made and often provided on the location of the client require a highly educated, intrinsically motivated, flexible workforce with a fair degree of autonomy. On the work floor, this is facilitated by new approaches to the organisation of work and working time. Examples are telework and flexible working hours, as well as flexible terms of employment. This is backed up by a management style which is more directed at cultural than at behavioural control.

It is tempting to speculate whether or not this specific mixture will survive in the near future. At least two developments point to a further normalisation: the growing 'maturity' of the sector and the economic downturn. The IT sector consists, on the one hand, of a limited number of very large, usually globally active firms; on the other hand, the majority 


\section{J. Plantenga and C. Remery}

of the firms are small, having only a few employees. The large, global players will often have a more institutionalised human resource management policy than the young and hip 'dot com' firms. Given the dynamics in terms of mergers and takeovers, absorption of small firms by large firms may contribute to a further normalisation of working times. The Finnish case studies especially make clear that working-time arrangements in large IT firms are quite 'normal'. These firms have advanced planning and monitoring systems, and are better capable of controlling and facilitating the workload of employees.

A further normalisation may also be the result of the changing economic climate. The research reported here took place during a period of economic upswing. At the moment, the growth of IT seems to have stabilised, and reports on shrinkage or even bankruptcy of IT firms occur on a regular basis. This may have far-reaching consequences for the terms of employment, such as wages and insurances, expensiveness of the company car and so on. The economic downturn may also contribute to a normalisation of industrial relations. Dølvik and Waddington (2002) note that the downturn in Sweden has resulted in increased unionisation among IT workers, whereas in other countries works councils are emerging.

At the same time, the specific characteristics of IT services are rather insensitive to the economic business cycle and the maturity of the sector. In particular, the intangibility of the product, the lack of unambiguous standards with respect to the final product, and the specific interaction between employee and client will leave its mark on the organisation of work and working time. In this respect, it may be expected that a certain singularity of the IT sector with regard to the organisation of work and working time will survive.

\section{Note}

1 Due to differences in the phrasing of questions in the national surveys, Dutch data refer mainly to contractual working hours (overtime excluded), whereas the data for the other countries refer to hours usually worked (overtime included). As a result, the outcome may be distorted. However, the amount of overtime in the total Dutch labour force and in services proves to be rather low. Thus it seems likely that the actual differences in working hours between the Netherlands and the other countries should not be interpreted as the result of a statistical artefact, but as reflecting real differences.

\section{References}

Anttila, T. and Nätti, J. (2000) 'Information technologies in Finland', country report for the New Forms of Employment and Working Time in the Service Economy (NESY) project, Jyväskylä: University of Jyväskylä.

Autor, D. (2001) 'Wiring the labour market', Journal of Economic Perspectives 15 (1): 25-40.

Beck, U. (2000) The Brave New World of Work, Cambridge: Polity Press. 
Bosch, G., Webster, J. and Weissbach, H-J. (2000) 'New organisational forms in the information society', in K. Ducatel, J. Webster and W. Herrmann (eds) The Information Society in Europe: Work and Life in an Age of Globalization, Lanham, MD: Rowman and Littlefield, pp. 99-117.

Cairncross, F. (1997) The Death of Distance: How the Communications Revolution will Change our Lives, Boston, MA: Harvard Business School Press.

Carnoy, M. and Castells, M. (1997) Sustainable Flexibility: A Prospective Study on Work, Family and Society in the Information Age, Paris: OECD.

Carnoy, M., Castells, M. and Benner, C. (1997) 'Labour markets and employment practices in the age of flexibility: a case study of Silicon Valley', International Labour Review 136 (1): 27-48.

Castells, M. (2000) 'Materials for an exploratory theory of the network society', British Journal of Sociology 51(1): 5-24.

Csonka, A. and Boll, J.L. (2000) 'Information technologies in Denmark', country report for the New Forms of Employment and Working Time in the Service Economy (NESY) project, Copenhagen: Danish National Institute of Social Research.

Dølvik, J.E. and Waddington, J. (2002) 'Private sector services: challenges to European trade unions', Transfer 8(3): 356-76.

European Industrial Relations Observatory (EIRO) (2001) Industrial Relations in the Information and Communications Technology Sector. Available online at: www.eiro.eurofound.ie/2001/08/study/TN0108201S.html (accessed 28 August 2002).

Eurostat (1998) 'Business services statistics: software and computer services', Statistics in Focus; Distributive Trades, Services, 1998-9, Luxembourg: Eurostat.

FNV Bondgenoten (2000) Werken in de ICT-sector: onder welke voorwaarden, Amsterdam: Stichting FNV Press.

Grugulis, I., Dubdon, T. and Wilkinson, A. (2000) 'Cultural control and the "culture manager": employment practices in a consultancy', Work, Employment and Society 14 (1): 97-116.

Kunda, G. (1992) Engineering Culture: Control and Commitment in a High-tech Corporation, Philadelphia, PA: Temple University Press.

Organisation for Economic Co-Operation and Development (OECD) (1998) The Software Sector: A Statistical Profile for Selected OECD Countries, Paris: OECD.

- (2000) OECD Information Technology Outlook. ICTs, E-commerce and the Information Economy, Paris: OECD.

Perlow, L. (1998) 'Boundary control: the social ordering of work and family time in a high tech operation', Administrative Science Quarterly 43 (2): 328-57.

Plantenga, J. and Remery, C. (2000) 'The absent employee: the organisation of work and working times in the Dutch IT sector', Paper presented at the conference 'The Economics and Socio-economics of Services: International Perspectives', Lille-Roubaix, 22-23 June 2000.

- (2001) 'Information technologies in the Netherlands', country report for the New Forms of Employment and Working Time in the Service Economy (NESY) project, Utrecht: Institute of Economics, University of Utrecht.

Pratt, A. (2000) 'New media, the new economy and new spaces', Geoforum 31: 425-36.

Schilstra, K. (1998) Industrial Relations and Human Resource Management: A Network Approach, Rotterdam: Tinbergen Institute. 


\section{J. Plantenga and C. Remery}

Smith, M. (2001) 'Information technologies in the United Kingdom', country report for the New Forms of Employment and Working Time in the Service Economy (NESY) project, Manchester: Manchester School of Management, University of Manchester Institute of Science and Technology (UMIST).

Voss-Dahm, D. (2000) 'Information technologies in Germany', country report for the New Forms of Employment and Working Time in the Service Economy (NESY) project, Gelsenkirchen: Institut Arbeit und Technik.

Weissbach, H-J. (1997) 'Europaeische Integrationsmuster und kulturelle Voraussetzungen des Managements in der Informationsgesellschaft', in W. Fricke Jahrbuch Arbeit und Technik 1997, Bonn: Dietz Verlag, pp. 122-31.

Yakura, E. (2001) 'Billables: the valorization of time in consulting', American Behavioral Scientist 44 (March): 1076-96. 


\title{
9 Work organisation and the importance of labour markets in the European retail trade
}

\author{
Florence Jany-Catrice and Steffen Lehndorff
}

\section{Introduction}

The retail trade is one of the largest and most labour-intensive sectors of the economy. It employs around fourteen million people; that is, more than 9 per cent of all those in gainful employment in European Union (EU) member states (European Commission 1999: 147). Understandably, such a large service industry has come to be regarded as a potential source of new jobs. Optimistic assessments of the prospects for employment in the retail trade are based on a widely held view of work in the retail trade as 'simple' service-sector work that offers vocationally less well-qualified women, in particular, opportunities to combine paid work with family commitments. Are such expectations realistic?

The image of the retail trade as the archetype of 'simple' service-sector work has its roots in several fundamental structural characteristics of the industry's labour market. First, qualification levels among retail trade workers are considerably lower than the average in the economy as a whole. As our evaluation of the European Labour Force Survey shows, the lower qualificational levels are over-represented and the higher qualificational levels are underrepresented in the retail trade. Second, the industry is very largely feminised. The feminisation rate in the retail trade is significantly greater than 50 per cent in all six countries included in our study and, in some cases, exceeds two-thirds. It is particularly high among part-timers and as high as 90 per cent among employees in large-scale retail formats. Third, retail trade work is less well paid than most other service jobs. The income level in the retail trade is 70 to 90 per cent of average earnings in the private service sector (European Commission 1999: 76). This of course means that even full-time retail jobs may in many cases offer no more than a modest basis for earning an independent livelihood; on the other hand, however, it is precisely these low wages that are supposed to create many employment opportunities for less well-qualified workers - or at least that is the widely held view.

This chapter calls into question this optimistic assessment. As our studies in the sales departments of large retail companies show, a radical 


\section{F. Jany-Catrice and S. Lehndorff}

change is currently taking place in employment conditions and the demands being made of the retail workforce. The underlying cause of this change is the process of concentration and rationalisation that is taking place at breakneck speed in the industry and the ensuing intense competition between the large retailers, which in all the countries we examined has subjected personnel policy to extremely restrictive cost considerations. The ways in which retailers go about looking for suitable sales personnel vary considerably. More than in virtually any other sector of the economy, the options available to retailers seeking to recruit personnel depend on the attitudes to paid work that predominate among women in a given country and on the institutional environment that helps to shape their labour market participation. For these reasons, retailers' personnel policies target different segments of the labour market in different countries, depending on which ones - including, increasingly, young people - offer a supply of labour for low-paid jobs with high time-flexibility requirements. This is why the share of workers for whom retail employment is only a temporary phase is growing, while the demands and burdens on the core workforce are increasing. The discrepancy between these requirements and the quality of the employment and working conditions, particularly pay and working time, is widening.

In what follows, we seek to shed light from two different perspectives on this multi-layered process of employment restructuring in one of the largest service industries. We begin by outlining the fundamental changes that are taking place in the industry and the main trends we observed in the changes which retailers in the various countries are making to the organisation of work and working time. We then show that these changes are refracted as through a prism by institutions inside the labour market (e.g. wage structures) and outside (e.g. childcare) that play an important role, above all in shaping the female labour supply in the various countries, but also increasingly the labour supply by juveniles. In the third section, we show the consequences that follow from the interplay between retailers' demand for labour and the structures of the labour supply at establishment level. ${ }^{1}$

\section{The restructuring of the industry and of employment by the large retail companies}

Our analysis begins with an examination of the competitive dynamic, the technical and organisational rationalisation of stock management, and the strategies for rationalising personnel structures and deployment that are fundamentally changing work in this major service industry in all the countries we investigated. 


\section{The reorganisation of mass distribution}

Since the introduction of self-service in the food retail trade in the 1960s, the European retail trade has undergone a sweeping process of concentration. This process has progressed furthest in the food trade, although it has now spread to all parts of the retail trade, notably the clothing industry. This structural change has gone hand in hand with an enormous concentration of capital and 'mega-acquisitions', which means that an increasing share of retail employees are working for an ever smaller number of companies, which are themselves becoming ever larger. While these large companies coexist with myriad small, independent firms, employment is to a large and still increasing extent concentrated in the large retail groups, some of which operate internationally. In Sweden, for instance, almost 40 per cent of all retail employees work in companies with more than 500 employees, and in Denmark the large self-service outlets (i.e. department stores, supermarkets and discount markets) account for almost one-third of all retail employees.

The conditions for the triumphant progress of large-scale retail outlets were improved by the abolition of many of the restrictions on shop opening in European Union member states (apart from France, where shop-opening hours have never been directly regulated). In Finland, the loosening of the statutory regulations governing shop opening hours began as early as the 1960s, while in Sweden there has been no state regulation at all in this area since the beginning of the 1970s. In Germany, as in the Netherlands, it was only in the 1990s that shop-opening hours were extended. The fact that the legal constraints on opening hours have been lifted or considerably relaxed has made the decision on the length of opening hours an important factor in competition, which is being used primarily, though not exclusively, by large retail companies to their own advantage.

This concentration of capital gives the large retailers two major options for reducing costs. First, they can exploit economies of scale by concentrating demand, thereby bringing its full power to bear on manufacturers. Second, they can rationalise the entire goods management process, both organisationally and technically. The mass distribution of everyday commodities goes hand in hand with the mass production of those commodities, and vice versa. The common core of this process is the industrialisation of goods management and distribution, with work processes being subjected to a form of 'scientific management' that resembles the classic models of industrial mass production.

This process is being considerably accelerated by the deployment of new technologies. By using scanning technology, the ordering and delivery process can be automated, thereby changing the nature of work in the entire goods management process. From a business management point of view, therefore, it may well be rational to organise goods handling as a 


\section{F. Jany-Catrice and S. Lehndorff}

specialised, Taylorised activity that may in some cases even be subcontracted to outside companies. At the checkouts, scanning has limited cashiers' responsibilities to correctly inputting the displayed price, making the end of the goods management process also highly standardised. At the same time, new technologies are an important means of developing new forms of monitoring, benchmarking and subcontracting, through which competitive pressure is passed on to each and every sales unit. This whole process of restructuring is already far advanced in Northern and Western Europe, whereas it is only just starting in the South (European Commission 1998: 10). Mass distribution through large retail companies leads to an enormous intensification of price competition. This has far-reaching consequences for personnel policy.

\section{Personnel strategies}

In the course of the historical shift to nowadays' mass distribution, the large retail trade organisations have changed their personnel strategies fundamentally. Obviously, the personnel intensity of the act of vending has been decreased substantially. However, in spite of the predominating large self-service organisations, the sale of goods through the retail trade still requires personal service to a greater or lesser extent, depending on the type of outlet. Thus, despite the low level of earnings (see below), the retail trade remains an industry in which personnel costs are of considerable importance. If personnel costs are calculated relative to total operating costs at establishment level, their share, even in hypermarkets such as in Germany and France, is between 40 and 50 per cent. It can reasonably be assumed, therefore, that retail companies will constantly be making great efforts to cut personnel costs. The cost advantages that can be achieved as a result are considerable. For example, the transnational clothing chain that gave us access to stores in France and Denmark has reduced the share of personnel costs in its French branches to up to 50 per cent of the industry average.

Strategies for reducing personnel costs are intended to rationalise both personnel structures and personnel deployment. Once this is achieved, firms have a basis for putting in place what they regard as optimal wage structures.

The focus of attention in the rationalisation of personnel structures lies in the standardisation of tasks, which in turn is facilitated by the rationalisation of goods handling. Firms' efforts are directed towards developing functional differentiation in retail establishments in such a way as to produce a 'skill mix' (Beynon et al. 2002: 234) that is as cost-effective as possible. Outside of the stores themselves, further upstream in the logistics chain, some jobs connected with goods management may actually be upgraded in the course of this rationalisation process. Within the stores, however, management's efforts are directed towards creating areas of 
activity for personnel, with simple, standardised tasks for those not providing services and advice directly to customers (Jacobsen 2001).

It should be borne in mind that, management aside, there are basically three areas of activity in retail stores, namely, customer advice and service, goods handling and checkouts. The more a store is geared to self-service, the more likely it is that the checkouts constitute a separate area of activity. Similarly, the less product knowledge is required for goods handling, the easier it becomes to separate this activity from the work of sales staff and perhaps even to subcontract it. This being the case, retail firms strive to restrict labour-intensive and less easily rationalised customer advice activities to those areas and market segments in which specialist competences and individual sales are regarded as indispensable to a company's success, as in large sections of clothes retailing. This means, as we observed, that the segmentation of employment is considerably further advanced in hypermarkets, for example, than in clothes stores. The ultimately decisive objective from employers' point of view is to extend the share of simple, standardisable tasks as far as possible; that is, to bring such tasks as close to customers as is possible in each individual type of outlet and market segment.

This change in the division of labour can lead not only to organisational rationalisation but also to additional reductions in wage costs through lower pay for workers engaged in standardised tasks. In some cases, firms will choose to go down the route of outsourcing certain functions, such as shelf-stacking. Finally, functional differentiation creates new opportunities to recruit workers of whom what is primarily required is temporal availability. Thus the rationalisation of personnel structures is extremely closely linked to the rationalisation of personnel deployment.

\section{Fragmentation of working time}

In view of the intense price competition to which they are subject, retail companies make every effort to keep staffing levels to a minimum. However, their efforts are made particularly difficult by their very considerable requirements for temporal flexibility. The retail trade in all six countries investigated is characterised by significant fluctuations in turnover and customer flows. Fluctuating customer flows are a fundamental problem for personnel deployment in the retail trade, because the production and purchase of its particular output - that is, the production and purchase of an act of vending - constitute a single action. It is true that the importance of these so-called 'in-person services' can be reduced by the use of technology and self-service, but it cannot be overcome entirely. Thus the retail trade is one of the industries with a high need for numerical personnel flexibility (which is exacerbated by the extension of opening hours). Companies are keen to keep personnel deployment as close as possible to the absolute minimum and to adjust it to match fluctuations in 


\section{F. Jany-Catrice and S. Lehndorff}

customer flows and sales - over the course of days, weeks and years. This applies not only to standardised tasks, such as goods handling, but also, and is particular, to all tasks involving direct customer contact. Thus, as we observed, there is a continuing trend in clothing retail chains, except for those in the upper market segments, to cut back labour-intensive customer advice in favour of a minimum staff 'presence' and to confine fluctuating staffing levels as far as possible to the checkouts or cash tills.

Increasing the part-time rate is the most important instrument used by retail companies to adjust staffing levels to fluctuations in activity. It helps to provide 'time modules that are matched to needs but independent of any individual worker or group of workers' (Herrmann 1996: 10). Parttime work is increasingly becoming one of the defining structural characteristics of employment in the retail trade. The part-time rate in the retail trade is in most cases considerably higher than the part-time rate in the economy as a whole (Table 9.1). Even in Portugal, which in general still has a very low part-time rate, the retailers we investigated are clearly following the trend observed in the other countries; in the hypermarket that was the object of the case study, for example, the part-time rate was 40 per cent.

As the country reports show, part-time work is concentrated to a large extent among women and is most widespread among sales assistants, that is, the retail trade's 'front-line' workers. Its role varies, however, according to type of outlet. Thus in Finland, the part-time rate in supermarkets is 16 percentage points higher than the average part-time rate across the retail sector as a whole, whereas in clothes retailing it is below the average. In Germany, the dynamic of part-time work is particularly strong in the largescale retail formats. In the latter, part-timers are deployed most frequently on the checkouts. Jany-Catrice and Pernod-Lemattre (2000: 14) estimate the part-time rate on the checkouts in French hypermarkets at around 95 per cent.

The full extent of the fragmentation of working times in some countries is evident in the proportion of part-timers working fewer than fifteen hours per week of all part-timers in the retail trade (Table 9.2).

Thus employment and working-time structures in retailing are characterised by mutually intersecting and overlapping lines of differentiation and polarisation. Functional differentiation is being strengthened, the share of standardised tasks is rising, employment is being fragmented into smaller units and adjusted to fluctuations in customer flows, with staffing levels kept to a minimum. In almost all the countries, part-time work plays an above-average and in some cases an ever-growing role, although the differences in level are enormous. Firms' segmentation of the retail labour market is taking place in very different ways from country to country. It is to these differences and their causes that we now turn. 


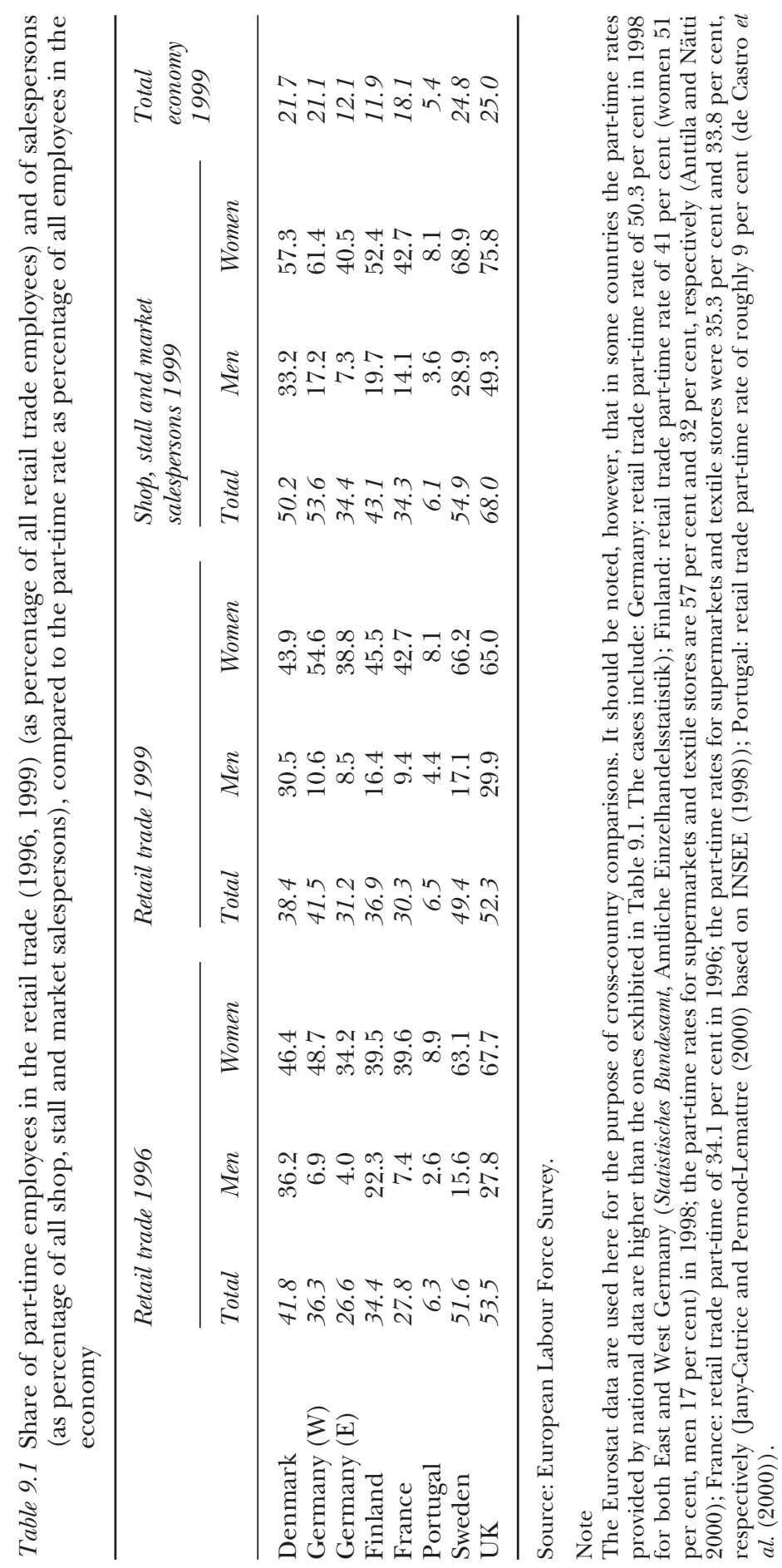




\section{F. Jany-Catrice and S. Lehndorff}

Table 9.2 Breakdown of part-time employees in the retail trade by short weekly working hours (in percentage of all part-time employees, 1999)

\begin{tabular}{lc}
\hline & Usual working hours $<15$ \\
\hline Denmark & 67.1 \\
Germany (W) & 37.9 \\
Germany (E) & 19.9 \\
Finland & 17.7 \\
France & 8.4 \\
Portugal & 6.0 \\
Sweden & $22.6^{*}$ \\
\hline
\end{tabular}

Source: European Labour Force Survey.

Note

* Men: 53.2 per cent, women: 22.4 per cent; age group 16 to 24, men 65.2 per cent, women 49.5 per cent (Anxo and Nyman 2000)

\section{The influence of the labour supply on personnel strategies}

The large retail companies have to implement the changes in work organisation and employment structures they are seeking in their own national and local labour markets. However, the labour supply differs considerably from country to country and from locality to locality, and firms have to adapt their human resource strategies accordingly. This primarily concerns the female labour supply, which is the most important target group for retailer's recruitment strategies. Young people are also a group of increasing importance in those strategies. The recruitment of these two groups for retail work is influenced by regulations of very different kinds. We begin our account of this complex set of conditions with the analysis of the differing structures of the female labour supply, before we turn to the increasing importance of students and pupils.

\section{The retail trade and female labour supply}

The structure of the female labour supply from which retail companies seek to recruit differs considerably from country to country (for more detailed analyses see O'Reilly and Fagan 1998; Lehndorff 2000; Letablier and Lurol 2000). A brief look at the general profiles of female labour market participation in the countries of our sample makes clear that retail trade organisations are facing particular hurdles, or advantages, in the pursuit of their personnel strategies in each of the six countries.

In Sweden, women have long been participants in the labour market. For decades, part-time work used to be of major importance for women; since the late 1980s, the trend has been towards full-time employment. As a result, the average weekly working time of female part-timers in Sweden considerably exceeds the European average. One quarter of part-time 
employees would prefer to work full-time. This mismatch between preferred working time and the hours offered by employers leads to increased working time as soon as companies voice a demand for overtime. In Denmark, the part-time rate is declining to an even greater extent than in Sweden as the participation rate among women rises. In contrast to the situation in Sweden, the labour market position of women in Denmark has developed so favourably that fewer and fewer women are available for part-time employment, and fewer still for marginal part-time work, so that retail companies are more or less forced to turn to the huge labour potential of high school and university students. In Finland as well, with its traditionally very high rate of full-time labour market participation among women, retail companies have had to look elsewhere for part-time employees: 43 per cent of part-timers in the Finnish retail trade state that they choose that type of employment because they are students. However, due to difficult labour market conditions many women are forced to work shorter hours than they would like. As in Sweden, therefore, overtime is often used to extend part-timers' contractual working hours.

The shared basic features of the retail labour market in the three North European countries studied are influenced mainly by conditions in the institutional environment, such as the availability of childcare facilities, that are favourable to equal labour market participation for men and women. A further common characteristic is the high level of trade union membership in the retail trade (80 per cent in Denmark, 68 per cent in Sweden, 57 per cent in Finland). These levels may seem low relative to the general level of unionisation in the three countries, but they are very high compared to the figures in many other countries. Such relatively high levels of unionisation reflect a high commitment of women to labour market participation which makes it less likely than in many other countries that they accept fragmented employment relationships and working times.

As far as women's labour market participation is concerned, France occupies its own particular position between the Nordic countries and most of the other European countries. Full-time work for women has been supported for decades by the widespread provision of childcare facilities. However, during the 1990s, the creation of large numbers of part-time jobs was promoted by means of state subsidies granted to companies. In the wake of the employment crisis, 'involuntary part-time work' among women, including in the retail trade, became a mass phenomenon on a level as high as that in Finland. According to the French government statistical service INSEE, underemployment accounted for 60 per cent of the increase in part-time employment between 1992 and 1998 (Jany-Catrice and Pernod-Lemattre 2000: 21). Consequently, as in Sweden and Finland, every opportunity to work more hours is gladly accepted. In the wake of the working-time legislation introduced by the Jospin government, the transition to the thirty-five-hour week has led to some part-timers in a 
number of retail companies being offered full-time contracts and to an increase in the minimum number of hours' work in part-time contracts, usually in conjunction with the introduction of annualised working times for all employees.

Compared with their French counterparts, women in Germany have much greater difficulty in reconciling paid work and child-raising. The entire institutional framework - from childcare down to the tax and social security system - continues strongly to favour a gender role distribution in which the male partner works full-time and the woman part-time. This is further compounded by the tax advantages associated with marginal parttime work; as a result, there was a vast increase in this form of employment in the (West) German retail trade during the 1990s (Jacobsen and Hilf 1999). According a survey conducted in 1987 (Jungbauer-Gans and Hönisch 1998), about three-quarters of marginal part-timers were women, of whom three-quarters again were married. Furthermore, almost 20 per cent of the women employed in marginal part-time jobs were working in the retail trade. Thus it is clear that German retailers have at their disposal a vast potential supply of female labour, willing to sign up to part-time contracts with a small number of hours and to remain in a job for quite some time.

In contrast to Germany, Portugal has long had very high levels of fulltime labour market participation among women (Ruivo et al. 1998). Thus the trend towards part-time work that may be observed in the Portuguese retail trade, which is still quite weak by current European standards, constitutes a counter-development to the persisting full-time orientation of most women, with approximately 40 per cent of part-timers in the retail trade stating they had been unable to find full-time employment. At the same time, a new area of marginal employment is developing in the Portuguese labour market, in which young school leavers or university graduates take a temporary job in the retail trade 'as a starting point for their working lives or in order to have an occasional connection to the labour market' (de Castro et al. 2000: 43).

This overview may be summarised as follows. In Germany, retail companies seeking to increase their share of female part-timers (traditionally their main target group in the labour market) and to reduce the contractual working times of such employees can rely on considerable assistance from the institutional environment. In other countries, however, retail companies are battling against less favourable institutional environments. This is true, to different degrees, for the Nordic countries as well as for France and Portugal. However, the more difficult it is for retail companies to recruit sufficient female sales assistants on the conditions they are offering, the more they turn to a 'transitional workforce' made up largely of young people. 


\section{The growing importance of juvenile workers}

In most of the countries investigated, the share of employees under twenty-five years of age in total retail employment increased in the second half of the 1990s, and by 1999 in all the countries except for Germany, the share of young employees was considerably higher in the retail trade than on average across the economy as a whole. As the European Labour Force Survey also shows, this has led to extreme differences in the average age of retail employees: the figure for Denmark, at around thirty-three, is seven years lower than in West Germany (Table 9.3).

However, as the six country reports show, a distinction must be made between two major groups of individuals among young retail workers. The first consists of school leavers, for whom employment in the retail trade constitutes a first and often only a temporary job, whether because they are unable to find any alternative employment in a situation of high youth unemployment or because they are still uncertain of their long-term career plans. This group typically plays an important role as a pool of labour for the retail trade in those countries such as Portugal or France where vocational training at a level below higher education is not particularly widespread, and retail companies themselves have no desire to invest in vocational qualifications for large segments of their workforce. This is evident from a comparison between Germany and France, for example. Although the terms and conditions are poor (low pay, short hours, variable schedules), retailers in France offer employment to young women in particular who, given the relatively high level of youth unemployment, are

Table 9.3 Share of workers under age twenty-five (retail trade and total economy, as percentage of all persons in employment (1996 and 1999)

\begin{tabular}{lccccccc}
\hline & $D K$ & $D E(W)$ & $D E(E)$ & $S F$ & $F R$ & $P O$ & $S W$ \\
\hline $\begin{array}{l}\text { Under 25 } \\
\text { Retail trade 1996 }\end{array}$ & 43.2 & 12.7 & 13.8 & 19.7 & 14.9 & 15.6 & 16.0 \\
$\begin{array}{l}\text { Under 25 } \\
\text { Retail trade 1999 }\end{array}$ & $38.0^{*}$ & 13.0 & 16.4 & $25.1^{* *}$ & 15.2 & $17.1^{* * *}$ & 22.9 \\
$\begin{array}{l}\text { Under 25 } \\
\text { Total economy 1999 }\end{array}$ & $15.7^{*}$ & 12.0 & 13.4 & $12.4^{* *}$ & 8.4 & $13.9 * * *$ & 9.0 \\
$\begin{array}{l}\text { Mean age } \\
\text { Retail trade (1999) }\end{array}$ & 33.3 & 40.4 & 38.4 & 36.8 & 37.2 & 40.1 & 38.7 \\
\hline
\end{tabular}

Sources: European Labour Force Survey; country reports for national data.

Notes

* 44.2 and 17.4 per cent according to national data (1997).

** 26.7 and 10.9 per cent of employees according to national data; further: 45 per cent of employees in small establishments but 59 per cent in large establishments under 35 .

*** 24.2 and 18.0 per cent according to national data, including 5 per cent in the age group fifteen to nineteen; in super and hypermarkets 36 per cent under age twenty-five. 


\section{F. Jany-Catrice and S. Lehndorff}

unable to find alternative employment or, especially, vocational training opportunities. In Germany, on the other hand, many young workers in the retail trade and in other sectors of the economy as well receive practical and theoretical training as 'retail salespersons' within the so-called 'dual vocational training system', so that the retail labour market has fewer possibilities to work as a temporary 'collecting basin' for unskilled young people.

The second major group of young people of value to the retail trade as a supply of labour consists of high school and university students looking for casual jobs to finance their university studies or supplement their pocket money (Table 9.4). Increasing participation rates among high school and university students in a number of European countries may be attributed in part to reductions in state support for students (in the case of the Netherlands see van der Meer and Wielers 2001); however, the reasons are likely to go beyond this explanation and would deserve greater attention on the research agenda (see Bowers et al. 1999). The employment of high school and university students is particularly widespread in Denmark, where more than a quarter of all retail employees are high school and university students. High levels of unemployment among this group have long been part and parcel of the country's work culture. In Finland, the share of students in total retail employment is 17 per cent, which is also strikingly high. In Sweden, the high proportion of men in the younger age groups working part-time also indicates the significance of high school and university students for the retail labour market. In Germany, the proportion of students in total employment is still at a very low level, although the importance of students for the retail labour market is growing faster than it is on average across the economy as a whole (VossDahm 2002a).

Table 9.4 The share of students and pupils as percentage of the labour force (retail trade, all sectors)

\begin{tabular}{llll}
\hline & Retail trade & All sectors & Remarks \\
\hline Denmark (1999) & 27.5 & 9.7 & $\begin{array}{l}\text { fluctuating between } 26 \% \text { and } \\
33 \% \text { throughout the } 1990 \mathrm{~s}\end{array}$ \\
Finland (1998) & 17 & n.a. & \\
Sweden (2000) & $\begin{array}{l}25 \% \text { of the } \\
\text { workforce in } \\
\text { the case study } \\
\text { hypermarket }\end{array}$ & n.a. & - \\
& 2.4 & 1.9 & $\begin{array}{l}1995: 0.9 \% \text { of retail trade and } \\
\text { Germany (1999) }\end{array}$ \\
& & & $1.0 \%$ of total labour force \\
\hline
\end{tabular}

Sources: Boll (2000); Anttila and Nätti (2000); Anxo and Nyman (2000); Voss-Dahm (2002a). 
A high importance of students and pupils as retail trade workers leads to lower than average job tenure (Table 9.5). With the exception of West Germany, labour turnover in the retail trade is substantially higher than in the economy as a whole, even though the use of fixed-term employment contracts is no greater in the retail trade than it is across the economy as a whole. ${ }^{2}$ This is particularly marked in Denmark and Finland where, in 1999, almost one-third of dependent employees in the retail trade had been with their current employer for less than one year. Retail companies in these countries depend to a large extent on a 'transitional workforce' (Boll 2001).

The confrontation between the employment strategies adopted by the large retailers and the structures of each national labour supply gives rise to very different patterns of personnel flexibility in the various retail labour markets. However, all the variants have one factor in common: work organisation in retail outlets represents a constant effort to overcome the restrictions created by the dictate of price competition. It is to the problems that this creates for management and employees that we now turn.

\section{Personnel management on the 'shop-floor' - a tightrope act}

Selling at the lowest possible price has become the essential prerequisite for success in the competition between the big retail trade companies. Yet, as the manager of a Portuguese hypermarket put it, in today's retail trade it is 'not enough to just provide low prices if they are not supported by a company with a vocation for good customer service' (de Castro et al. 2000: 33 ). In other words, over and above the absolutely indispensable condition of a low-price regime, retail companies have to find a competitive edge in other parameters of competition in order to retain and expand their market shares. For this reason, the large retail companies try, on the one hand, to minimise personnel costs, particularly by taking advantage of

Table 9.5 Job tenure in the retail trade as compared to all sectors (1999)

\begin{tabular}{llllllll}
\hline & \multicolumn{3}{l}{ Retail trade } & \multicolumn{5}{l}{ All sectors } \\
\cline { 2 - 3 } & O to $<2$ yrs & 2 to $<10$ yrs & $10+$ yrs & & Oto $<2$ yrs & 2 to $<10$ yrs & $10+$ yrs \\
\hline Denmark & 51.3 & 32.1 & 16.7 & & 36.7 & 32.4 & 30.8 \\
Germany (W) & 19.9 & 39.5 & 30.6 & & 24.3 & 35.0 & 40.8 \\
Germany (E) & 33.7 & 56.0 & 10.4 & & 30.4 & 46.8 & 22.8 \\
Finland & 44.6 & 31.9 & 23.5 & & 32.4 & 27.7 & 40.0 \\
France & 33.7 & 37.1 & 29.2 & & 24.7 & 31.5 & 43.8 \\
Portugal & 32.8 & 39.7 & 27.4 & & 26.6 & 35.7 & 37.7 \\
Sweden & 31.4 & 32.0 & 36.7 & & 22.9 & 29.7 & 47.4 \\
\hline
\end{tabular}

Source: European Labour Force Survey. 


\section{F. Jany-Catrice and S. Lehndorff}

the opportunities to do so afforded by the rationalisation of goods management, and, on the other, to present an attractive and unmistakable face to the public. The 'strategic segmentation' of the market - that is, the profiling of companies in order to target specific groups of consumers - is becoming one of the most important options in the competitive struggle in the retail trade (Batt 2000).

This is why the large retailers' personnel policies are based on two connected principles. The first - flexibility at the lowest possible cost - relies on individual employees' willingness to adapt to the flexibility requirements of their employers and on the forms of division of labour that make it possible to exploit pay differentials. Second, this must be reconciled with the implementation of an approach to service appropriate to each particular type of outlet and its sales strategy. Both principles have an implicit precondition: flexibility and service require a certain degree of stability and commitment among the workforce. These are objectives that are difficult to achieve simultaneously. This is illustrated in what follows by means of examples taken from the retail outlets that were the objects of our case studies. We begin by shedding light on the balancing act between flexibility and service, before examining what it requires in terms of personnel, namely a core of full-time workers who act as the 'anchors' in what is otherwise an operation run by part-timers.

\section{At your service at any time}

'We operate without buffers. We can't afford buffers any more, it just can't be done' (Haipeter 2000: 27). These words, uttered by one of the German personnel managers whom we interviewed, would undoubtedly be endorsed by all our interviewees. In order to cover long opening hours while adhering to this condition and to ensure that there is the minimum level of staffing deemed necessary at crucial customer interfaces such as checkouts or cash tills, many of the companies investigated have recourse to two groups of workers who, without exception, work part-time (including some who work a very small number of hours) and may be described as 'gap fillers' and 'time adjusters' respectively. 'Gap fillers' are deployed on regular rotas and work predictable time slots. They are used, for example, to cover fixed delivery times for goods or peak times in the early evenings or on Saturdays. 'Time adjusters', on the other hand, tend to be deployed at variable times and to have variable working hours. In extreme cases, their 'on-call' times vary in accordance with fluctuations in customer flows. More than any other group, they embody that type of flexibility denoted by the term 'passive flexibility' in the contribution of Lehndorff and Voss-Dahm to this volume (Chapter 12), with all the advantages it delivers for firms, but also its limitations. One particularly important limitation from the retailers' perspective is that sheer temporal availability is simply not sufficient when employees are supposed to 
embody the company's approach to service - however low the level of personal service may be in a self-service store.

We encountered 'time adjusters' in the large Portuguese retail outlets, for example. Management in the case study hypermarket had increased the part-time rate to more than 20 per cent, although there is considerable resistance, as one manager whom we interviewed declared: 'There are no more people willing to work that way.' This kind of job is regarded as suitable mainly for new entrants to the labour market. Management would like to recruit older female applicants for this kind of work, but they cannot find any (similar complaints were voiced by Finnish and Swedish personnel managers). Practically the only group willing to accept low pay and part-time work is female school leavers. On the other hand, they are also the ones with a higher propensity to short job tenures, which increases turnover rates. The company is unable to recruit older people already established in their family lives. The manager of a clothes store had been more successful, having managed to raise the part-time rate among its workforce from 0 to 40 per cent in five years. Part-time workers are more willing to be flexible "when one more hour is needed or when morning workers are needed also in the afternoon'. And yet turnover rates among the preferably young women who are recruited for this kind of job are around one-third which, according to the management, 'is similar to that in large supermarkets' and is seen as 'inevitable in this sector'. Because of these high turnover rates, training for young employees is regarded as 'money thrown away'. The existence of a newcomers' handbook and store managers' efforts in providing direct, on-the-job training are seen as sufficient to guarantee good customer service. Greater investment in training is focused on the four or five workers in each store with longer job tenure. The idea is that these core employees should develop sufficient leadership skills to deal with the difficulties associated with long opening hours and high turnover, and thereby overcome the ensuing service quality problems. A high incidence of part-time work makes the tasks of leadership and shop management more complex. This way of organising flexibility can be managed only with a centralised corporate structure (de Castro et al. 2000: 31ff., 37ff.).

In the large French hypermarkets, 'time adjusters' are concentrated primarily on the checkouts, while full-timers working in shifts predominate in shelf-stacking and on full-service counters. Since, the young, predominantly female part-timers are usually forced by high youth unemployment to accept part-time work and ultimately aspire to work longer hours, managers are able to meet additional staffing needs that become apparent at short notice by offering them additional hours at their regular rate of pay (i.e. without overtime premia). The same is true of the French clothes store that was the object of a case study. As the branch manager said: 
Of the twenty part-timers, I have eighteen who want more hours. It's very clear. Real part-timers are very rare. The real part-timers are students who really do want to work only eight hours. The others want to work more.... If we work 30 per cent more hours, we will recruit afterwards, but for short-term adjustments, we increase the parttimers' working times. We deal with all unexpected events that way: sickness, fluctuations in workloads - we do it through amendments to the contracts.

This also offers opportunities for disciplining workers:

I've taken on three people, all of them working eighteen and one-half hours per week, and I won't be able to give them all a full-time job in future, so I tell them the best ones will be offered full-time work, provided they work well and we have the resources.

(Jany-Catrice and Pernod-Lemattre 2000: 21-2)

And yet, as Jany-Catrice et al. (1999) confirmed in several additional case studies, management has not succeeded in avoiding the disadvantages of this mode of organisational flexibility, namely, high labour turnover and the risk of demotivation.

The picture in German hypermarkets, with their high part-time rates, seems at first sight to be similar. The 'time adjusters' are needed to deal with short-term fluctuations in personnel requirements, as the manager of the case study hypermarket confirmed: 'Of course, plan and actuality are two very different things. The plan cannot be corrected. That must happen spontaneously on the spot. The personnel deployment manager has to get on the phone' (Haipeter 2000: 26). In many stores of this kind, the problem for management is exacerbated by the fact that many parttimers in Germany, unlike their counterparts in France, are not interested in working extra hours, so that any overtime they work is often compensated for a few days later by time off in lieu. This leads to what, in an earlier study, we called 'institutionalised improvisation' becoming a permanent phenomenon (Kirsch et al. 2000). For many of the female parttimers, this creates a dilemma: they have chosen this employment form in order to be able to reconcile paid work and family responsibilities. Yet everyday life in the workplace makes this increasingly difficult for them, because many firms shift responsibility for meeting their adaptability requirements and dealing with their unresolved organisational problems on to their employees, thereby encroaching on their private lives. Nevertheless, the higher level of occupational training and the higher average age of part-timers in the German retail trade relative to those in other countries spare German managers the high levels of labour turnover that managers in other countries have to accept as the price of this form of flexibility. Female part-timers in Germany, with their high degree of con- 
scientiousness and experience in dealing with routine difficulties, are able to help resolve organisational problems in the workplace. German retail companies benefit particularly from the informal, unpaid skills that many of their employees possess.

In addition to these various types of 'time adjusters', management in all six countries is relying increasingly on 'gap fillers' in order to cover certain time slots in the long daily opening hours. High school and university students are the primary labour reserve for retail firms, particularly those in Finland, Sweden and, even more so, Denmark, eager to fill the gaps left by the core workforce (which may very well be a part-time workforce for the most part). Regular gaps occur during peak times such as Friday afternoons or Saturdays, in the evenings and particularly on Sundays. This youthful labour reserve is not always described in the case studies as 'flexible' in the sense of having work schedules that vary at short notice. Flexibility here denotes primarily the ability and willingness to work unsocial hours, particularly regular time slots that are unpopular with the core workforce. The individual working times of these young people may well be fairly stable and reliable. In the hypermarkets investigated in the Nordic countries, this practice leads to a highly segmented workforce with a highly developed division of labour.

Over and above the flexibility they deliver, the employment of young people enables management to put in place a system of wage differentiation corresponding to the degree of differentiation between the various areas of activity and the level of work task standardisation. In all the countries investigated, the retail wage structure below management level is relatively undifferentiated. In many cases, there are only two pay scales in sales areas; in Germany, the higher scale is reached automatically through seniority after a few years. The age-wage profile is also generally very flat. For this reason, some large German retail companies, including the one that operates the case study hypermarket, outsource shelf-stacking to subcontractors whose employees are paid below the rate stipulated in the retail trade collective agreement.

The only large-scale, systematic wage differentiation we encountered in sales areas in the retail trade were the special low pay scales for young people in the three Nordic countries (see Anttila and Nätti 2000; Anxo and Nyman 2000; Boll 2000). In Finland, high school students are paid 70 per cent of the lowest collectively bargained starting rate. In Sweden, a 16-year-old, for example, is paid just 60 per cent of the wage of a retail worker with two years' experience, while in Denmark workers under eighteen years of age receive 50 per cent of the minimum pay of unskilled workers. Moreover, since the premiums for evening and weekend work are based on the respective basic remuneration, the deployment of young people during time periods which adult women regard as 'unsocial' is particularly favourable for employers.

At this point, the segment of the workforce that complements the 'gap 
fillers' and 'time adjusters' comes into the picture once again. This is the core workforce, variable in size, which guarantees that establishments with such a complex employment structure operate smoothly. However, before we turn to this segment of the retail workforce, we will look briefly at the other side of the balancing act between flexibility and service, in which the workforce is supposed to be not only available but also at the service of customers at all times.

\section{High commitment at low cost}

Whenever employees communicate with customers, they are personally representing the company that employs them. This is why personnel selection and management are decisive factors in determining a retail company's service profile. In hypermarkets, this management challenge comes to the fore primarily in the service and checkout areas; that is, in precisely those areas where there is also the greatest need for 'time adjusters' and, in some cases, for 'gap fillers' as well.

This conflict of objectives is temporarily resolved to some extent over and over again by employing young people. Boll (2000: 16) illustrates the limits of this approach by taking the example of a Danish hypermarket: less qualified workers who do not need any product knowledge can actually be deployed only to carry, unpack and pile up the endless stream of 'potato goods'. This is where many of the high school students in the Danish retail trade work. Even on the checkouts, consideration must be given to the fact that for many customers the checkout employee is the only contact they have with staff and that the checkout area is very much the face of the store for the majority of shoppers. Thus the checkout manager puts some emphasis on having 'employees with a positive attitude who treat the customers well'. Management would like to deploy older workers here, but they can seldom be recruited for such work. Thus management in Nordic retail companies has to draw on young people's readiness to work and their educational levels in order to acquire the informal, unpaid skills that German retailers find in the life experience of female part-timers. However, the use of students as a labour reserve has the disadvantage that they do not stay long in the store: 'They really get fed up with the work and go on to do something completely different', as one checkout operator put it succinctly when interviewed (Boll 2000: 18).

Workers who are 'fed up with the job' are hardly likely to produce the friendly face that a retail company would like to present to its customers. Thus the strategy of using the informal, unpaid skills of high school and university students for work in sales areas depends on a constant supply of new workers. Thus in these areas, high labour turnover paradoxically becomes one of the prerequisites for a successful approach to service.

Insofar as service orientation does not consist primarily of a 'positive attitude' but also includes a minimum level of product knowledge, firms 
seeking to develop their own specific service image have to make efforts to increase staff commitment. This applies, for example, to clothes stores where, in some of the cases we investigated, management was pursuing a strategy which a German personnel manager described in the following terms: 'We're looking for trained workers who are virtually a mirror image of our target customer groups' (Haipeter 2000: 18). For companies who are targeting the middle age groups, this objective is very difficult to achieve wherever the retail trade is becoming increasingly unattractive as a source of employment for middle-aged women. Thus as Anttila and Nätti (2000: 19) write, the Finnish clothes retailer looks for older workers to match customers' life situation and expectations. However, there is a supply of young job seekers, usually students and aged on average between eighteen and twenty, who want temporary part-time work. As a result, labour turnover is a problem, especially in Helsinki. There is a lack of employees willing to commit themselves to the company. This forces human resource managers to adopt a different strategy of offering longer working hours in order to reduce turnover.

Because many German women tend to seek part-time work only, the German clothes store that was the object of a case study has less of a recruitment problem than its Finnish or Swedish counterparts. Moreover, its market positioning is more upscale, which allows it to present itself as an attractive employer, both in terms of its market profile and socially.

Only the French and Danish stores that were investigated have succeeded in pursuing the 'mirror-image' strategy consistently with young sales staff. Both stores are part of a European chain whose products make it attractive to young people seeking work. As the manager of the Danish store put it, they offer their employees 'some sort of action and fun at work, which make up for the often stressful working conditions' (Boll 2000: 25). In the Danish environment, however, he also has to offer relatively long working times as well as 'fun' - most employees work between thirty and thirty-seven hours per week. For management, this increased stability has to be offset by a loss of flexibility and shorter opening hours. Many young women apply for jobs, and management is in a position to pick out those who have completed a course of vocational training in the retail trade; they are expected to show an above-average willingness 'to be busy and work hard'.

Many young women aged between eighteen and twenty also apply for jobs in the French branch of the 'fun' chain. However, they have no specific training, and management needs to make no concessions in respect of flexibility. As already mentioned, the majority of the young women are working part-time against their wishes. As the branch manager put it:

It's true, their pay is low. They are eighteen to twenty years old, living with their parents. The part-time work schedules are very variable, completely variable in fact, at least in theory. This is why we need very 
flexible people who are prepared to make themselves available as and when required. Certainly, for women with children, this poses major problems.... It's feasible, but for those in their first jobs it's really very difficult. They have to like running ... rather than qualifications.

(Jany-Catrice and Pernod-Lemattre 2000: 20)

The French-Danish comparison shows the extent to which both carrot and stick - that is, 'fun' and youth unemployment - are necessary if the set of personnel policy objectives that might be labelled 'at your service at any time' are to be implemented in all stores where service includes a certain degree of product knowledge and skill. If the stick is not available, management has to lower its sights in respect of one or the other objective, whether it be temporal flexibility or workforce stability. Ultimately, personnel managers are constantly faced with the question of how secure the human resource basis for their balancing act between flexibility and service really is. It is to this that we now turn.

\section{The full-time 'anchors' in a part-time operation}

The greater use is made of 'gap fillers' or 'time adjusters', the greater the responsibility borne, together with management, by members of the core workforce who, though variable in number, are generally full-timers or part-timers working relatively long hours. These employees must be functionally and temporally flexible, since they have to work shifts in order to maintain a presence throughout the store's opening hours, and be strongly committed to the company. They may be described as the 'fulltime anchors in a part-time operation', since the smooth running of the store quite literally depends on them.

In an extreme case, with a highly segmented workforce and fragmented working times, virtually all responsibility falls on the store management's shoulders. The already long hours worked by many store managers are increased still further. The manager of the Danish case study hypermarket works between fifty and sixty hours per week, which is more than just a few years ago. In his view "the long hours have become "part of the job" for this group of employees. This is why some people quit for another job, especially when they start having children' (Boll 2000: 21).

These anchors, on whom everything depends, should not be too few in number. For this reason, management in many of the case study establishments is seeking to broaden the core workforce. Thus in the Nordic countries, more attention is being paid to employees' working-time preferences. In the Swedish clothes store, for example, an increase in the share of full-timers had led to a considerable reduction in the rate of absenteeism. In the Finnish branch of the same chain, where six years previously half of the employees had been on twenty-hour contracts, most of them were working thirty-four hours a week at the time of the case study; 
only the female students working evenings and weekends still had contracts offering between fifteen and twenty hours' work per week.

However, a highly segmented workforce does not have to lead solely to an increased burden for the full-time 'anchors', since it can also bring some degree of relief from particularly unfavourable working times. Boll (2000: 28) describes this other side of the same coin when he examines the reaction of the Danish trade unions who, until a few years ago, were still questioning the extensive use of students instead of 'genuine' fulltime employees: 'The students were said to be taking jobs from those in the real labour market. However, this sort of argument has become increasingly less prominent as the unemployment rate has continued to decline and it has become increasingly difficult to recruit staff for the longer opening hours.' The trade unions have obviously now begun to make a virtue out of a necessity. This is shown not only in the collectively agreed reduced pay scales for young workers. When the legally permitted opening hours were extended in the mid-1990s, it was agreed for the sake of employee protection that no worker in the retail trade could work after 6 p.m. more than twice a week. Since collective bargaining agreements in Denmark are adhered to by the majority of companies, even if they are not legally bound by them (Scheuer 1999), there has been another huge increase in part-time employment in the Danish retail trade. Because most women wish to work full-time, demand for part-timers in the retail trade is focused largely on young people. The fragmentation of employment and working times in the retail trade is exacerbated enormously as a result, yet the largely female core workforce is protected to some extent from unsocial working hours.

Another approach that seeks to reduce the heavy burden of evening and weekend work and irregular work schedules, at least for the core workforce, involves the decentralisation of working-time organisation. Management calculates the staffing levels required for each week, each day and each time slot within the day, and on this basis employees plan their own schedules (using, at least in large departments, special software tools). 'For large-scale food retailers, the introduction of participatory elements into the organisation of working time can become the key element in the implementation of their personnel policy and the crucial factor in determining whether they are able to meet their specific labour requirements from the potential supply of labour in the market' (Voss-Dahm 2000). As an evaluation of the experiment with employee-organised working times in six large Swedish retail firms showed, the opportunity to harmonise working times with personal needs was welcomed, although there were widespread complaints that staffing levels had been reduced since the introduction of the new system (Lowden and Åkerstedt 2000). This confirms experiences in the German case study hypermarket. By increasingly reducing staffing levels, the opportunities that exist in theory for employees to influence the scheduling of their own working times are 


\section{F. Jany-Catrice and S. Lehndorff}

de facto restricted. In employees' eyes, the advantages of this autonomy in the allocation of working time are very severely reduced or even negated altogether by persistently inadequate staffing levels. Workers are faced with a contradiction: the scope of their responsibilities is widened but the resources made available are not sufficient to fulfil those broader responsibilities. They experience 'empowerment' as self-managed work intensification.

In addition to experiments with working-time organisation, attempts are being made, particularly in the Nordic case study outlets, to stabilise the core workforce by increasing wage differentiation in an upward direction. In Sweden, where the collectively agreed pay scale is as 'flat' as in the other countries, more and more retail companies are taking advantage of the decentralisation of the wage bargaining system, which creates opportunities to set up so-called 'local funds' for bonus systems. Premia are paid for seniority, extra responsibilities and further training. In Finland, 21 per cent of all retailers make use of similar bonus systems. The two Danish case studies make clear that premia paid to employees on fulltime and long part-time contracts may be the other side of the coin of workforce segmentation. On the other hand, if this strategy of upward wage differentiation is applied to large parts of the workforce, the company may well come up against the constraints imposed by the prevailing price competition. Thus, according to the personnel manager of the German clothing store that was the object of a case study, and which is positioned in the upper market segment, 'about ten years ago, our employees could earn on average 25 to 30 per cent more than the collectively agreed rate through team-based premia. Over the last few years, however, we have had to trim things a bit in that area' (Haipeter 2000: 37 ). There is obviously only very limited scope for incorporating performance-related incentives into the remuneration system, although it is very much in the interests of a number of retail companies to stabilise their workforce by means of such instruments.

Thus retailers' attempts to win the loyalty of a sufficient number of committed 'full-time anchors' have very limited room for manoeuvre. Wage levels are low, working times unattractive. Staffing levels in many firms have been reduced to the absolute minimum and in many cases head office lays down maximum personnel costs relative to sales as a benchmark for individual stores or even departments. Store managers and full-time anchors alike are aware of these benchmarks and are faced with the task of safeguarding their jobs through good and careful management. They have to be 'service-oriented' in their work, but have increasingly less time to pay proper attention to customers. In the public's opinion, work in the sales function of the retail trade is often regarded as 'simple service work', but, under the conditions outlined above, it requires a high degree of social competence, organisational and decisionmaking ability, and insight into workplace processes and procedures. 
Against this background, "it may justifiably be asked whether sales work in the retail trade can really be regarded as "simple" service work' (VossDahm 2002b: 503). The large retail companies have no strategic solution for this personnel problem, but they have succeeded for the time being in making it a problem for individual employees. It is precisely those workers on whose willingness to work and conscientiousness the success of these companies depends who are seeing the demands of their jobs increasing, and yet their jobs are not being adequately re-evaluated or more generously remunerated.

\section{Conclusion}

The retail labour markets in the six countries studied are being substantially reorganised. The big chains are trying to shape the structure of their workforces in accordance with their cost-cutting and flexibility priorities; in doing so, they are both establishing and making use of new segments in the labour market. In essence, the retail labour market is being reshaped, but the actual forms this reshaping is taking and the question of which categories of workers are putting themselves forward for employment depends above all on the role of women in the various national labour markets. As the comparison of the six countries showed, the more those labour markets facilitate equal participation for men and women, the more difficult it is for retailers to meet their labour requirements from their traditional main target group. For a growing share of workers, employment in the retail trade is not associated with long-term career prospects.

This increases the demands on that segment of the workforce on which the smooth functioning of retail establishments depends. They continue to regard their employment in the retail trade as a means of earning their livelihood. However, these key workers, who work full-time or a substantial part of the working week as part-timers, continue to be poorly paid, while the demands on their temporal flexibility, organisational capacities, social competences, readiness to accept responsibility, and to work as required and individual ability to take stress are rising. The notion of a 'simple', poorly paid activity is obviously no longer appropriate to this type of service work. In view of the price competition that dominates the industry, it will probably become increasingly difficult for companies to recruit and retain sufficient numbers of the skilled 'anchors' they require.

To sum up, it is undoubtedly the case that the retail trade offers many job opportunities that make few demands on workers' skills. However, these jobs are increasingly being filled by individuals who do not regard retail work as a long-term career prospect. The large retail companies are consciously accepting this. At the same time, however, the demands on the skills and qualifications of the core employees on whose work the companies' success largely depends are rising. They are paid as simple service 


\section{F. Jany-Catrice and S. Lehndorff}

workers, and yet their work involves ever-greater responsibilities and demands. It is time to revise the current image of the retail trade as the prototype of 'simple' service work.

\section{Notes}

1 This analysis draws on reports from Finland, Sweden, Denmark, Germany, France and Portugal (Anttila and Nätti 2000; Anxo and Nyman 2000; Boll 2000; Haipeter 2000; Jany-Catrice and Pernod-Lemattre 2000; de Castro et al. 2000). They were based on case studies for which interviews were held with managers and with staff representatives and, whenever possible, with individual employees; a common, semi-standardised questionnaire was used. One hypermarket and one large clothing store were studied in each country; that is, two types of outlets which represent significant and, in some cases, rapidly growing market segments. The stores investigated reflect 'leading-edge' practices in their respective market segments: the hypermarkets represent the mainstream in this rapidly expanding type of outlet (with the partial exception of Germany, since we were able to draw on mainstream cases from earlier research in that country), whereas the clothing stores represent, in four out of the six countries, two rapidly growing transnational retail chains (the stores investigated in Finland and Denmark are operated by one of these chains, those investigated in Sweden and France by the other). The sample as a whole included some of the leaders in their respective market segments. Unless other sources are indicated, the data used in this synthesis report are drawn from these country reports, which is why detailed references have not usually been given. In the case of the German and French retail trades, we have also been able to draw on earlier research of our own (Gadrey et al. 1997, 1999; Kirsch et al. 1999, 2000; Baret et al. 2000).

2 In general, fixed-term employees in the retail trade mainly provide reinforcements during particularly busy periods of the year. Only in Sweden does the role of fixed-term contracts seem to be more important than in other sectors of the economy, since they are the favoured means of filling gaps caused by parental leave. The student support system in this country prohibits university students from being gainfully employed for more than three months per year (in fulltime equivalents). Otherwise they run the risk of forfeiting their right to state support (Anxo and Nyman 2000).

\section{References}

Anttila, T. and Nätti, J. (2000) 'Retail trade in Finland', country report for the New Forms of Employment and Working Time in the Service Economy (NESY) project, Jyväskylä: University of Jyväskylä.

Anxo, D. and Nyman, H. (2000) 'Retail trade in Sweden', country report for the New Forms of Employment and Working Time in the Service Economy (NESY) project, Gothenburg: Centre for European Labour Market Studies, University of Gothenburg.

Baret, C., Lehndorff, S. and Sparks, L. (eds) (2000) Flexible Working in Food Retailing: A Comparison amongst France, Germany, Great Britain and Japan, London: Routledge.

Batt, R. (2000) 'Strategic segmentation in front-line services: matching customers, employees and human resource systems', International Journal of Human Resource Management 11 (3): 540-61. 
Beynon, H., Grimshaw, D., Rubery, J. and Ward, K. (2002) Managing Employment Change: The New Realities of Work, Oxford: Oxford University Press.

Boll, J.L. (2000) 'Retail trade in Denmark', country report for the New Forms of Employment and Working Time in the Service Economy (NESY) project, Copenhagen: Danish National Institute of Social Research.

- (2001) 'The Transitional Workforce: A Source of Time Flexibility in the Danish Retail Trade', Proceedings of the 8th International Symposium on Working Time, 14-16 March, Amsterdam.

Bowers, N., Sonnet, A. and Bardone, L. (1999) 'Giving young people a good start: the experience of OECD countries', Background Report for the Organisation for Economic Co-operation and Development Secretariat, Paris: OECD.

de Castro, A., Figueiredo, H. and González, P. (2000) 'Retail trade in Portugal', country report for the New Forms of Employment and Working Time in the Service Economy (NESY) project, Porto: Universidade Catolica Portugesa.

European Commission (1998) 'Retailing in the European Economic Area 1997', Luxembourg: European Commission.

— (1999) 'Dienstleistungen in Europa', Luxembourg: European Commission.

Gadrey, J., Baret, C. and Gallouj, C. (1997) (in co-operation with German and British teams) 'France, Allemagne, Grande Bretagne: La grande distribution du temps de travail', Research Report, Paris: Direction de l'Animation de la recherche, des études et des statistiques (DARES).

Gadrey, J., Jany-Catrice, F. and Ribault, T. (1999) France, Japon, Etats Unis: l'emploi en détail: Essai de socio-économie comparative, Paris: Presses Universitaires de France.

Haipeter, T. (2000) 'Retail trade in Germany', country report for the New Forms of Employment and Working Time in the Service Economy (NESY) project, Gelsenkirchen: Institut Arbeit und Technik.

Herrmann, L. (1996) 'Kundenorientierter Personaleinsatz', Personalwirtschaft, Supplement Zeitwirtschaft 12: 8-12.

Institut National de la Statistique et des Études Économiques (INSEE) (1998) 'Enquête Emploi', database provided on CD-ROM, Paris.

Jacobsen, H. (2001) 'Produktionskonzepte im europäischen Einzelhandel: Deutschland, Italien und Schweden', in H. Rudolph (ed.) Aldi oder Arkaden? Unternehmen und Arbeit im europäischen Einzelhandel, Berlin: Edition Sigma.

Jacobsen, H. and Hilf, E. (1999) 'Beschäftigung und Arbeitsbedingungen im Einzelhandel vor dem Hintergrund neuer Öffnungszeiten', Expertise commissioned by Bundesministerium für Arbeit und Sozialordnung, Dortmund: Sozialforschungsstelle Dortmund Landesinstitut.

Jany-Catrice, F. and Pernod-Lemattre, M. (2000) 'Retail trade in France', country report for the New Forms of Employment and Working Time in the Service Economy (NESY) project, Lille: Centre Lillois d'Études et de Recherches (CLERSE), Université de Lille 1.

Jany-Catrice, F., Pernod-Lemattre, M. and Ribault, T. (1999) 'Aménagement réduction du temps de travail ou temps partiel: le cas de la grande distribution française', Report, Lille: Conseil Régional du Nord Pas de Calais.

Jungbauer-Gans, M. and Hönisch, P. (1998) 'Dauer geringfügiger Beschäftigungen', Mitteilungen aus der Arbeitsmarkt- und Berufsforschung 4: 697-704.

Kirsch, J., Klein, M., Lehndorff, S. and Voss-Dahm, D. (1999) Darf's etwas weniger sein? Arbeitszeiten und Beschäftigungsbedingungen im Lebensmitteleinzelhandel: ein europäischer Vergleich, Forschung aus der Hans-Böckler-Stiftung, Berlin: Edition Sigma. 


\section{F. Jany-Catrice and S. Lehndorff}

(2000) 'The organisation of working time in large German food retail firms', in C. Baret, S. Lehndorff and L. Sparks (eds) Flexible Working in Food Retailing: A Comparison amongst France, Germany, Great Britain and Japan, London and New York: Routledge.

Lehndorff, S. (2000) 'Working time reduction in the European Union: A diversity of trends and approaches', in L. Golden and D. Figart (eds) Working Time. International Trends, Theory and Policy Perspectives, London and New York: Routledge.

Letablier, M-T. and Lurol, M. (2000) 'Les femmes entre travail et famille dans les pays de l'Union Européenne', La Lettre, Centre d'Études de l'Emploi 63 (July).

Lowden, A. and Åkerstedt, T. (2000) 'Introduction of self-selected work hours in retail work: effects on work satisfaction, health and social life', Zeitschrift für Arbeitswissenschaft 5: 300-5.

O'Reilly, J. and Fagan, C. (1998) Part-time Prospects: Part-time Employment in Europe, North America and the Pacific Rim, London: Routledge.

Ruivo, M., González, M. and Varejao, J. (1998) 'Part-time work in Portugal and Spain: why is it so low?', in J. O'Reilly and C. Fagan (eds) Part-time Prospects, London: Routledge.

Scheuer, S. (1999) 'The impact of collective agreements on working time in Denmark', British Journal of Industrial Relations 3: 465-81.

van der Meer, P. and Wielers, R. (2001) 'The increased labour market participation of Dutch students', Work, Employment and Society 15 (1): 55-71.

Voss-Dahm, D. (2000) " "Service-sector Taylorism" and changes in the demands on working-time organisation: the example of the retail trade', Paper presented at the 'International Conference on the Economics and Socio-economics of Services: International Perspectives', 22-23 June, Lille/Roubaix.

- (2002a) 'Erwerbstätigkeit von SchülerInnen und Studierenden nimmt zu: Bildung und berufliche Praxis laufen immer häufiger parallel', Institut Arbeit und Technik Report no. 2002-06, Gelsenkirchen: IAT.

- (2002b) 'Verkaufsarbeit im Einzelhandel: einfache Dienstleistungsarbeit?', WSI-Mitteilungen 55: 498-504. 


\title{
10 Lean banking \\ Retail and direct banking in France and Germany
}

\author{
Thomas Haipeter and Martine Pernod-Lemattre
}

\section{Introduction}

Flexibility is one of the key terms used to characterise the radical change processes currently observed in many companies within the service and industrial sectors. As early as the 1980s, a 'search for flexibility' had been ascertained in the European context (Boyer 1988). What was meant by that term were the various attempts of companies to break up the Fordistic-era structures and regulations, which were felt to be rigid, in favour of a more flexible adaptation to the challenges of internationalised markets.

The banking industry in France and Germany is no exception to this general trend. What may be observed is a pronounced change of employment relations in banks towards flexibility. This change is a consequence of a shift in company strategies in the course of the 1990s. The new target model, labelled 'lean banking' (Regini et al. 1999), has flexibility of work organisation as its core dimension.

Our survey of retail branch offices and direct-selling organisations furnishes proof that the primary emphasis of flexibilisation attempts made by financial institutions in both countries has been on increasing internal personnel flexibility - a consequence of new market and organisation strategies by the banks. External flexibility plays only a minor role, if any at all. Banks are adapting flexibility instruments, relying heavily on the flexibility of their core workforces, and working-time flexibility - more than functional flexibility - forms the centre of internal flexibility. Basically, French and German banks have found similar answers to the new challenges posed by the markets in this respect. However, differences lurk behind the appearance of shared overall solutions. The concepts of internal flexibility pursued by French banks differ from the German scheme, and the concepts for retail branches differ from the concepts for direct banks.

In what follows, we describe and explain these similarities and differences through examining the role of strategies and structures and comparing the specifics of the banking industry with other industries in the service sector. First, we take a look at changes in the international 
financial markets and the common answers the companies in France and Germany have found to the challenges of globalisation. We turn, second, to the national regulation systems of the labour markets in the banking industries of both countries, which offer the banks different resources. In the third section, we present the findings from our case studies in branch offices and direct banks in both countries about the consequences of the new strategy for the organisation of work and working time. In France, one retail bank and one direct bank were studied; in Germany, two retail banks and two direct banks were subjected to the survey. The case studies are based mainly on interviews conducted with experts and employees located at different hierarchical levels of the banks as well as at the level of customer interfaces of branch offices and direct banks.

\section{International financial markets and the strategy of lean banking}

Throughout the 1990s, the globalisation of financial markets drove the engine of change in the banking industries of France and Germany. It was globalisation that put common challenges in front of French and German banks. There were three immediate consequences of globalisation for financial institutions in France and in Germany.

1 The growing significance of the stock and securities markets. International companies increasingly took advantage of the international financial markets in order to raise equity. Loan-capital financing via banks gradually lost its former significance. Moreover, private investors also discovered the financial markets as a new destination for their capital assets. In the wake of this development, the role of banks changed. Performance of brokerage services in transactions of shares and securities came to replace or to join direct loan financing, which may be inferred from the shift in the banks' sources of income, from interest income to bank charges and commissions (Huffschmid 1999).

2 The importance of shareholder value. In the management and supervisory committees of banks organised as corporations (joint stock companies or limited liability companies), the significance of shareholder interests increased (Hirsch-Kreinsen 1999). Even where no direct pressure from shareholders existed, the norms and expectations of the financial markets formed the attitudes of top management in such a way that a 'financialisation' of decisions took place (Kädtler and Sperling 2001).

3 The increasing competition requirements. The national financial markets were no longer areas protected by regulation, but started to open up to international competition with foreign competitors. In this situation, the profitability of business operations received more attention than ever. Banks were exposed to new forms of price and 
cost pressure. In addition, new fields of competition emerged. Innovations in products and in forms of distribution gained growing importance. The galloping expansion of direct banking as an innovative form of distribution in the 1990s represents an example in this respect.

Interestingly enough, the banks of the two countries reacted to the common challenges of globalisation with very similar reorganisation strategies. In the centre of these strategies was a concept labelled 'lean banking', which eventually came to be a synonym for reorganisation and 'restructuralisation' in the banking industry (Bierer et al. 1992).

The spreading of the concept was fuelled both in France and in Germany with industry-wide discourses about the crisis of the industry (Sperling 1997) in which the hazards of forced competition in international markets were conjured up. French and German banks were accused of lacking competitiveness compared with American and especially Japanese banks (Seyfried 1995). As a consequence, fundamental reorganisation measures were recommended and substantial reductions in employment predicted (Cartellieri 1990). Thus the discourses about crisis created fertile ground for new organisation concepts and company strategies aimed at reforming the structures and organisational forms of the post-war era in banking and at orienting the banking business more than ever along the lines of earnings power (D'Alessio and Oberbeck 1994; Dressen et al. 1997).

Lean banking has been based on certain common elements:

- segmentation by customer groups and products (i.e. the assignment of products to customer groups defined along categories of income and credit and the division of the retail organisations along these customer groups)

- automation of (simple) services

- reduction of branch offices

- cuts in employment and other costs

- centralisation of back-office

- the setting up of new distribution channels such as telephone banking and e-commerce

- the expansion of business hours, leading to flexible working time.

The strategy contains at least three decisive elements concerning work organisation for the traditional retail organisation. First, the segmentation of customer groups divides further integrated organisational structures in retailing and can bring more elements of standardisation in the work for those selling standardised products (Baethge et al. 1999). Second, cost pressure can lead to a pressure on branch staffing. Third, flexible working-time arrangements within longer opening hours are to adapt 
capacity closer to demand. Furthermore, in direct banks as a new business channel, new forms of work and working-time organisation are being implemented, corresponding to standardised products and very long opening hours.

Within this framework, until the end of the 1990s, not all individual components of the concept were given the same attention in the course of practical implementation. For example, branch office closures in both countries did not take place to the extent aimed at by the concept. In France, for instance, 324 branch offices were shut down between 1990 and 1998 (the figure went down from 25,667 to 25,343); in Germany, branch office closures between 1993 (after the effects of the reunification) and 1998 totalled 3,891 (from 49,118 to 45,227 units). In addition, employment during this period was not reduced drastically. Whereas in France overall employment in the banking industry was on a slight decline throughout the 1990s (from 432,927 employees in 1992 to 411,521 in 1998), it was balancing out at a relatively constant rate in Germany (from 744,400 in 1992 to 759,900 in 2000).

In addition, despite the closures of branches and the slight reduction of personnel, dismissals were the exception and not the rule in the banking industries of both countries. On the contrary, the companies tried to stabilise their core workforces. In France as well as in Germany, at the end of the 1990s, company seniority exceeded ten years for more than half of the employees; another 15 per cent and 25 per cent, respectively, had been staying on for periods ranging between five and ten years. Moreover, the companies used new forms of employment such as temporary employment only in marginal shares, as Table 10.1 shows. And the turnover rates in the banking industries are low, so that, even at the margin, external flexibility is of minor importance.

Thus, in the banking scene of Germany and France, internal flexibility played a dominant role in the personnel strategies of the companies. This may be regarded as an element of the lean banking concept, and we will see that working time plays a crucial role in this context. All in all, until the beginning of the new millennium, reorganisation efforts geared to

Table 10.1 Temporary and permanent employment in the banking industry (\%)

\begin{tabular}{|c|c|c|c|c|c|c|c|c|}
\hline & \multicolumn{4}{|l|}{ Men } & \multicolumn{4}{|l|}{ Women } \\
\hline & \multicolumn{2}{|c|}{ Permanent } & \multicolumn{2}{|c|}{ Temporary } & \multicolumn{2}{|c|}{ Permanent } & \multicolumn{2}{|c|}{ Temporary } \\
\hline & France & Germany & France & Germany & France & Germany & France & Germany \\
\hline $1993 / 94$ & 96.4 & 88.3 & 2.9 & 9.1 & 93.1 & 91.4 & 6.9 & 8.0 \\
\hline $1995 / 96$ & 96.6 & 90.4 & 2.9 & 7.6 & 93.5 & 92.3 & 6.3 & 7.0 \\
\hline $1998 / 99$ & 96.0 & 89.1 & 3.7 & 8.0 & 93.1 & 91.3 & 6.9 & 8.0 \\
\hline
\end{tabular}

Source: European Labour Force Survey, Germany, West Germany only. 
other elements of the concept were much more far-reaching than branch closures or personnel reductions. The segmentation according to customer groups and products, the automation of banking services, the centralisation of back-office functions, and the setting up of new distribution channels meanwhile became genuine structural characteristics of French and German banks. In their implementation of lean banking, the financial institutions assumed a new profile.

\section{Impact of national regulations on company strategies}

\section{National regulations}

Globalisation presented common challenges for the financial institutions in France and Germany; and banks reacted with very similar strategic concepts. However, the challenges had to be tackled in a setting of different national institutional systems. The banks had to adapt their strategies to the respective institutional conditions when implementing them into corporate practice. The respective national institutions and regulations offered different resources for the adaptation process as well as different rules and restrictions. In the wake of financial market globalisation, attempts made in both countries at newly regulating their national financial systems have led to a gradual approach of several institutional parameters, especially with regard to the strengthening of capital markets (Lütz 2000). However, there is definitely no question of the fundamental institutional differences between the two countries levelling out. As will be spelled out in what follows, the French system is more state-oriented, whereas the German system is more corporatistic. This is true not only for the differences lingering in the financial systems themselves, but also for the regulation of labour and product markets.

As to the financial systems and product markets, the basic difference between the two systems was pointed out by Zysman (1983). In Germany, the banks historically have acted as central intermediaries of financial transactions and have therefore much room for manoeuvre in their own organisation of financial relationships, whereas financial operations in France historically have been regulated to a much higher degree by the state - on the one hand, in the form of bank nationalisation, and, on the other, in the shape of product market regulations imposed by the state. This fact largely explains the differences in the significance of the universal banking principle. Since the post-war period, universal banking structures in Germany have been formative for all groups of banks: private banks, savings banks and cooperative banks. In France, they have come to gain ground only slowly since the 1970s as a result of legal changes (Deeg 1999).

Thus product market regulations in France were traditionally much more far-reaching than in Germany. Since the 1940s, the state in France 


\section{T. Haipeter and M. Pernod-Lemattre}

has been undertaking substantial interventions in the financial system in order to secure industry political goals. Apart from the nationalisation of large banks, the state aimed at a demarcation of specialised markets by separating deposit-taking banks and equity banks. Some of these regulations were rescinded at the end of the 1960s, so that, from that time on, universal banking structures akin to the German type could slowly develop. However, the French state continues to privilege certain savings products by means of tax exemption, thus creating protected markets. This applies especially to savings banks. In Germany, this sort of product promotion was unknown; however, even there we come across special rules for savings banks ensuing from their specific public mission. Another important regulatory field in France is cheque transactions. The banks are legally bound to offer cheques, cheque processing and maintenance of checking accounts to their customers free of charge. By contrast, German banks have been charging account-keeping fees for the widespread personal current accounts since the 1970s. (Hildebrandt 2000).

As to the labour markets, two regulatory fields deserve special mention: qualification systems on the one hand, and working-time regulations on the other hand. In Germany, the vocational training system obviously has, by tradition, great importance for personnel recruitment. The dual system of vocational training for apprentices, borne and organised jointly by the social partners and the state, seeks to combine schooling and practical training. The state contributes formal education and training in vocational schools; the practical training of the apprentices takes place at the workplace in the companies, based on a training regulation negotiated jointly by the employer organisations and the trade unions. This training regulation for the 'bank clerk' focuses on imparting occupation-related broad expertise about all banking divisions. The 1998 reform of the training directive has confirmed this basic orientation; however, it prioritises market and customer orientation in the personal banking sector (Kreyenschmidt 1997). Initial vocational training is followed by internal opportunities for stepwise further training on which in-house promotion depends. At present, approximately 90 per cent of bank employees have acquired banking-specific qualifications. Although this is quite a stable rate, the pattern is on the move towards the recruitment of people with a higher educational background. Between 1987 and 1995, the share of employees with a university degree in all employees of the industry rose from 4.1 per cent to 7.5 per cent (Kreyenschmidt 1997). By contrast, the apprenticeship rate ${ }^{1}$ was brought down from well over 10 per cent in 1992 to only 7 per cent in 1999 (AGV Banken 2000; Backhaus and Wagner 1999). In addition, between 1995 and 1999, the share of young people with uppersecondary leaving certificates recruited by the banking industry rose from 69.3 per cent to 76 per cent of the workforce; the ratio of others, mostly intermediate school-leaving certificates, went down from 27.9 per cent to 21.9 per cent. However, it has to be kept in mind that these figures do not 
reduce the leaky structure of hierarchies in German banks for in-house promotion of employees with bank clerk and further internal qualifications.

Broad occupational training in Germany contrasts with the narrower training concentrated on sales in France where the system is based on longer education at schools and universities and on shorter job-specific training. Occupation-related training is organised in industry-specific institutions by the banks themselves. Historically the lines of development are strongly influenced by the large recruitment waves launched at the end of the 1960s and the early 1970s. In the wake of these waves, mainly employees without banking-specific qualifications were recruited. Even though the qualification levels for the majority of the employees were higher in France than, for example, in the United Kingdom (O'Reilly 1994) in 1991, 55.3 per cent of employees were still without occupational qualifications (Hildebrandt 2000). In the course of the 1990s, however, a trend towards an increase in professional banking qualifications was observable. In 1998, the share of employees in French private banks without occupation-specific training had dropped to 44.2 per cent. At the same time, the contents of the training have shifted in the direction of social competencies and sales skills that are non-industry-specific and nonoccupation-specific (Hildebrandt 2000). The upward trend in qualification levels is corroborated by the increasing share of individuals with higher ranking educational certificates in the overall share of newly recruited banking employees. Whereas in 1991 over 41 per cent of newly recruited employees still presented graduation certificates in the range of the General Certificate of Education or below without certificates of universities or vocational colleges, this ratio had gone down to 20 per cent by 1998. Thus 80 per cent of the newly recruited employees can present final certificates of a vocational college or a university (Hildebrandt 2000); i.e. the category of the so-called 'cadres' is on the rise.

The basic differences in the regulatory systems of the two countries also characterise working-time regulation. In Germany, working time is the second of the two main policy fields of collective bargaining, second only to wages in importance. Wages and working time are objects of collective bargaining at industry level between the employers' associations and the trade unions. Company bargaining between company management and the works council is possible on topics delegated to the social partners at this level or left open by the bargaining on an industry level (Bosch 2004). In France, formerly it was primarily wages that were regulated in the process of collective bargaining, in fact also at industry level and, intensified in the past decade, at company level. In matters of working time, legislation has the dominating influence, as is highlighted, for example, by the legal regulations of working-time reduction. It is true that there has been an enormous increase in collective bargaining on working-time topics after the introduction of the thirty-five-hour work week. But it has 


\section{T. Haipeter and M. Pernod-Lemattre}

been the details of the implementation, not the reduction of working time as such, that has formed the focus of negotiation by the social partners. In Germany, the state defines only the minimum statutory provisions on working time that collective agreements are bound to comply with.

Until the mid-1990s, the French banking industry was governed by the Working-Time Regulation of 1937, which stipulated that actual working times were not to exceed eight hours per day, that no work was allowed on two successive days including Sunday, and that the weekly working time of forty hours had to be distributed evenly among all employees over five days of the week. Gradual deviations from these stipulations have been agreed upon between the bargaining parties of individual banks since the 1970s, first for back-office functions, then also for customer contact areas, and especially for the direct banking arena. In 1982, a working-time reduction was imposed, and in 1997, further new regulations covering working time were issued. These provided for the possibility of shift operation, staggered working times and a four-day work week based on thirtynine hours.

The minimum standards defined by the German working-time legislation limit daily working time to eight hours, allow options for expansion to a maximum of ten hours, and allow work on six days of the week, excluding Sunday. Deviations from the daily maximum of working time have to be balanced out within six months. The collective agreement in force in the banking industry in 2000, the year our case studies were completed, provided for a weekly working time of thirty-nine hours, a maximum working time of forty-five hours, an equalisation period of six months, and partial permission for Saturday work for 6 per cent of the labour force. Important new settlements, which are not yet reflected in our case studies, include the statutory introduction of the thirty-five-hour week in France and the collective agreement on the establishment of longterm working-time accounts in the German banking industry.

The average actual working times were indeed highly influenced by the collectively agreed working times (Table 10.2). Seen from an overall perspective, collectively agreed working times were stable in the decade of the 1990s, and actual average working hours per week fluctuated accord-

Table 10.2 Duration of actual average weekly working time of financial intermediaries (hours)

\begin{tabular}{|c|c|c|c|c|c|c|}
\hline & \multicolumn{2}{|l|}{1993} & \multicolumn{2}{|l|}{1996} & \multicolumn{2}{|l|}{1999} \\
\hline & Full-time & Part-time & Full-time & Part-time & Full-time & Part-time \\
\hline France & 40.76 & 24.34 & 41.28 & 25.94 & 40.99 & 26.71 \\
\hline Germany (West) & 39.18 & 19.07 & 39.44 & 18.86 & 39.69 & 19.72 \\
\hline
\end{tabular}

Source: European Labour Force Survey (p. 65). 
ing to business cycles. Furthermore, we can see that the working times in France and Germany were gradually approaching each other for fulltimers, owing to a slight increase in the duration of working hours of fulltime workers in Germany. Average working hours of full-timers rose from 39.18 hours in 1993 to 39.69 hours in 1999. In France, they remained more or less constant over the survey period, levelling out at 40.76 hours in 1993 and at 40.99 hours in 1999. A decisive question for the future ahead in France is to what extent the legal change in contractual weekly working hours will be mirrored in actual weekly working times. Since there are to date no promising attempts at implementing further reductions of contractual working hours in Germany, no reductions of actual working times are in sight.

The importance of part-time work in the banking industry in both countries is growing. Companies try to use part-time work on a greater scale for reasons of cost reduction (Dressen et al. 1997). In both countries, part-time work is largely dominated by women, based on a relatively high proportion of women in the workforce in the banking sector (Table 10.3). However, it has to be taken into consideration that, in France, both the proportion of women working full-time and the actual average working time for part-timers in the banking industry, as well as in general, are higher than in Germany.

The higher percentage of women working full-time may be explained at least partly by the different child-raising systems of the two countries the part-time childcare systems and schools in Germany and the full-time childcare systems and schools in France (Dingeldey 2000; Thenner 2000). Furthermore, an expansion of part-time work in Germany seems to be a professed political goal of legislation and the collective bargainers. Thus part-time work in Germany has a deeper anchorage in social and political structures (see Wagner (Chapter 5) and Jany-Catrice and Lehndorff (Chapter 9), this volume).

Table 10.3 Share of full- and part-time employees in the banking industry by sex $(\%)$.

\begin{tabular}{|c|c|c|c|c|c|c|c|c|}
\hline & \multicolumn{4}{|l|}{ Men } & \multicolumn{4}{|l|}{ Women } \\
\hline & \multicolumn{2}{|c|}{ Full-time } & \multicolumn{2}{|c|}{ Part-time } & \multicolumn{2}{|c|}{ Full-time } & \multicolumn{2}{|c|}{ Part-time } \\
\hline & France & Germany & France & Germany & France & Germany & France & Germany \\
\hline 1993 & 99.1 & 98.5 & 0.9 & 1.5 & 83.9 & 73.1 & 16.1 & 26.9 \\
\hline 1996 & 98.7 & 98.3 & 1.3 & 1.7 & 83.9 & 71.8 & 16.1 & 28.2 \\
\hline 1999 & 96.9 & 96.9 & 3.1 & 3.1 & 76.2 & $68.8^{*}$ & 23.8 & 31.2 \\
\hline
\end{tabular}

Source: European Labour Force Survey, Germany, West Germany only.

Note

* difference. 


\section{Country-specific profiles of strategy}

Lean banking has a country-specific colouring. Despite the wide range of similarities with regard to the overall strategy, the country-specific reorganisation profiles differ significantly between the French and the German banking industries because of the different resources and restrictions coupled with the different national institutions and regulations. This fact may be illustrated by way of two indicators which prove highly significant for a comparison of work and working-time organisation in branch offices and direct distribution organisations: the strategy of customer group segmentation and the strategy of setting up new distribution channels (Hildebrandt 2000).

The first weighty difference in customer group segmentation is the subdivision of segments. In German financial institutions, two, or at most, three segments are distinguished - wealthy individual customers are set apart from ordinary personal customers. In contrast, there are four or even five segments in French banks - one segment for wealthy clients and three or four different segments dividing personal customers into different groups according to income, credits, and - unusual for German banks - status. Furthermore, in France, the dividing line between the individual and the personal customer area is more distinctly drawn. The consequences for recruitment and organisation are decisive. In France, account executives for individual customers are mostly recruited directly from the universities, whereas in Germany, 80 per cent of such account managers have worked their way up as bank clerks from the ordinary personal customer segment. Furthermore, French branch offices are characterised by a highly specialised organisational structure in which employees attend only to customers of the segment for which they are responsible. Employee training is also conducted according to such segments; and, since the 1990s, performance appraisal has been clearly based on the evaluation criterion of 'sales' (Dressen et al. 1997). In German branch offices, by contrast, all employees engaged in consultation and service activities are responsible for all types of personal customers. Bank clerks in Germany are more generalists than specialists. This is related to the fact that high-quality counselling retains its significance for personnel appraisal (Hildebrandt 2000).

As to direct banks, they are much more widespread in Germany than in France. There is only one genuine direct bank in France; by contrast, all large private banks in Germany have their own direct banks. A major reason for the low incidence of direct distribution banking in France resides in the obligation of banks to offer charge-free checking and current accounts; direct banks cannot improve their status by means of lower account-keeping fees (Hildebrandt 2000). Furthermore, in Germany, the banks take advantage of spin-offs or disincorporation in order to withdraw direct distribution from the reach of industry-wide collective agreements in 
order to reduce wage costs and with a view to evading collective workingtime regulations. In France, by contrast, individual plant-level arrangements may be obtained only in exchange for large concessions to the trade unions, because deviations from the binding legal regulations have to be negotiated and accepted by the social partners in collective bargaining. A second point is the personnel concepts of call centres. The vocational training system in Germany provides the skills and competencies required for the broad advisory functions of bank clerks, but this is far more qualification than what is needed for the simple sales and information services required in direct distribution. In addition, the banks do not want to recruit the comparatively expensive bank clerks for this job. The French training system, with its emphasis on the selling aspect, seems to fit better for the latter purpose because employees are cheaper. This is not the least reason why mainly employees without any bank-specific training are recruited for jobs in German call centres, whereas in France, employees with completed education and training are taken on.

\section{The case studies: new forms of flexibility in call centres and branch offices}

The impacts of institutions and regulations on the global strategies of the French and German banks also find expression in our case studies of retail and direct banks. ${ }^{2}$ In the case studies, we analysed different forms of personnel flexibility not only between direct and retail banks, but also between the French and the German cases.

It should be noted, as a background, that in both countries, banks are seeking to extend the service hours of their branch offices and of their direct banks. In France, longer business hours constitute a major asset for the management of branch offices. The employer's goal is to open the branch offices on six days out of seven with, at the same time, longer daily business hours. In Germany, the issue of expanding bank hours is also an important topic of discussion, especially regarding the opening on Saturdays allowed by the collective bargaining agreements; but, up to now, practical changes appear to be less advanced than in France. As regards call centres, there are also disparities, but these seem to be more pronounced between the companies than between the countries (see Tables 10.4 and 10.5 for the service hours of our case study organisations).

Of course, the longer opening hours of retail branch offices and the quasi-permanent business hours of call centres force companies to resort to sophisticated flexibilisation strategies and to reorganisations in working time: shift work in the shape of day-off rotation schedules and of systems based on multiple shifts per day. By and large, service hours are a determining factor in the search for flexibility. However, they do not determine the choice of the shape which such temporal flexibility takes and they cannot explain the differences between the countries. It is rather, as we 
Table 10.4 Opening hours of retail branch offices.

\begin{tabular}{|c|c|c|c|}
\hline & \multicolumn{2}{|l|}{ Germany } & \multirow{2}{*}{$\begin{array}{l}\text { France } \\
B F\end{array}$} \\
\hline & $B D 1$ & $B D 2 *$ & \\
\hline Monday-Wednesday & 8:30-16:00 & $8: 30-16: 00$ & $8: 30-18: 00$ \\
\hline Thursday & $8: 30-18: 00$ & 8:30-18:00 & $8: 30-18: 00$ \\
\hline Friday & $8: 30-15: 30$ & $8: 30-15: 30$ & $8: 30-18: 00$ \\
\hline Saturday & Closed & Closed & $\begin{array}{l}\text { Service hours } \\
\text { are becoming } \\
\text { normal practice }\end{array}$ \\
\hline \multicolumn{4}{|l|}{$\begin{array}{l}\text { Note } \\
* \text { Open at noon. }\end{array}$} \\
\hline \multicolumn{4}{|c|}{ Table 10.5 Service times of call centres } \\
\hline & \multicolumn{2}{|l|}{ Germany } & France \\
\hline & $D B D 1$ & $D B D 2$ & $D B F$ \\
\hline Monday-Friday & 24 hours & 8:00-20:00 & 24 hours \\
\hline Saturday & 24 hours & $8: 00-20: 00$ & 24 hours \\
\hline Sunday & 24 hours & Closed & Closed \\
\hline
\end{tabular}

will argue in this chapter, the different institutional resources which banks can make use of that are crucial for the explanation of these differences.

In our case studies, we found different models of flexibility that may best be summarised by way of polarisation (Lehndorff 2001). Flexibility of an 'active' type combines the functional flexibility of a work organisation based on high and general qualifications and temporal flexibility focusing on the aspect of the individual time management based on participation. This participation is based on co-administration of the principal variables of temporal flexibility, choice of duration of work, and choice and better forecasting of the schedules, similar to negotiated flexi-time. Flexibility of a 'passive' type is essentially built on temporal availability (Gadrey et al. 1999), unilateral directed working-time management from above, high functional differentiation and fragmented forms of working time. This form of temporal flexibility consists in exploiting all the variables such as duration, variability, forecasting, and pace of the schedules, and gives little choice to the employee. Corporate flexibilisation strategies are, of course, often located between these two poles. The results of our case studies show that companies combine various dimensions of temporal flexibility according to the developed strategies, the market regulation, and the context in terms of work and working hours. None the less, it will be possible to find main characteristics of temporal flexibility by analysing the common points, as well as the divergences between the two countries and the different channels of distribution. 


\section{Call centres}

In the call centres of the direct banks in both countries, flexibility was based on functional differentiation and working-time directions from above with little room for individual autonomy, which may include elements of (mostly informal) participation in working-time organisation. Thus direct banks stand very much for what has been labelled as 'passive flexibility'.

In the German direct banks, temporal flexibility was based mainly on part-time work. The two centres we studied operated on a flexible rotating shift system with part-time work being the central element. The flexible use of part-time work according to the fluctuations in incoming calls was the main characteristic of this system. Full-time work provided for a stable anchor of the system. Thus, in the first German direct bank, DBD1, fulltime work had a fixed position at least during one week, whereas the position of part-time work could vary freely over the working day or within the same week.

From this similar base, differences in the handling of working-time systems had evolved in the two call centres. In DBD1, planning was effected in a centralised manner by means of sophisticated information technology. An activity forecast based on evolutionary customer flow data was coupled with the working capacity of the team. The planning was done on a monthly basis. In order to cope with short-term fluctuations not included in the planning, three possibilities were used in DBD1: (1) internal functional flexibility within the department, (2) asking for employees who have free time to step in, and (3) internal flexibility of other departments. In the second German direct bank, DBD2, planning was not handled in a centralised manner; rather it was the team leader who established manual planning per fortnight in a more approximate manner. Two further mainstays of flexibility were used in DBD2: the formation of an internal team recruited from the telephone banking section, which constituted a limited element of functional flexibility, and the possibility of varying the duration of daily working time and to work overtime hours beyond the statutory range.

A decisive background for these working-time practices in both direct banks was provided by their personnel recruitment strategies, which were based to a large extent on students or housewives who had an interest in a part-time contract. Management was particularly interested in students, since they were expected to have useful social and communication competencies. In both direct banks, about 50 per cent of the employees in the call centres were students. Their competencies were a free resource used by the banks without generating additional costs. However, it was not only for reasons of cost savings that employees with bank-specific qualifications were rarely recruited in German call centres. As a personnel manager told us, the bank-specific qualification is designed for the retail branches, not 
for the call centres of the direct banks. In this view, a general knowledge of products and processes is not needed in the call centres, but this estimation is valid only for a product strategy of a restricted supply. For instance, if a direct bank tries to sell the same products as a retail branch, bank-specific qualification will be important for the direct bank as well. This consideration was discussed in DBD1 at the same moment as we made our case study, where a closer connection of the direct banking channel to the retail channel of the bank was planned. At any rate, the high percentage of students was coupled with the intention to stabilise the core workforce. Dismissals were not practised, and students could work for many years in the direct banks. Some of them even stopped their studies and took full-time jobs in the direct bank.

The situation was rather different in the French direct bank, DBF. French management thought that the more sales-oriented - i.e. less generalist - qualifications of the employees were a resource worth using in the direct bank. Therefore, about 66 per cent of the staff originally came from traditional retail banks. In DBF, too, passive flexibility reigned. Similar to the direct banks in Germany, DBF had developed autonomous structures in order to circumvent collective agreements on working time. However, thanks to the granting of premiums, salaries were usually more generous than in classical banks - which was not the case in Germany. Furthermore, in the French direct bank, the system of variable working time was not based on part-time work, but rather on staggered working hours based on full-time shifts. Thus, the passive flexibility was different from the one practised in the German call centres, since it did not rest on the development of part-time work.

Again, it is the recruitment strategy of management in the labour market that has to be taken into account in this respect. In contrast to the German cases, French managers did not target primarily housewives or students and preferred a rather stable and young, if relatively lowqualified, workforce (for the labour market background see Jany-Catrice and Lehndorff (Chapter 9, this volume).

Beyond these differences, the common core of the flexibility concepts was that management was primarily interested in the adaptation of staff to customer flows. This included an explicit recourse to functional differentiation in their personnel strategy.

\section{Retail branches}

In contrast to the direct banks, branch offices of German banks make substantially greater use of active flexibility. Working-time flexibility based on autonomous decisions of the employees and functional flexibility based on skills and competencies required for broad advisory functions go hand in hand. This was particularly pronounced in the two case study branches that practised a pilot model of working-time organisation labelled 'trust- 
based working time' (Hoff 2002). The regulation of trust-based working time as applied in the analysed branch banks presented a fairly uniform picture (see Haipeter (2001) for details):

- Goals: On a basis of mutual trust, an autonomous scheduling of working times by employees shall be permitted.

- Time frame: A work or service time frame is fixed, within the bounds of which working-time location may vary. Job hours outside of this time frame are subject to approval and are liable to surcharge.

- Time recording: Time recording is done by the employees themselves. They register daily deviations of the actually performed job hours from the agreed working time. The question of which parts of attendance time are to be considered true working time is left to the employees' estimation and discretion.

- Account management and compensation principles: Working-time accounts are established for the documentation of positive or negative working-time balances. In both banks, so-called balance-reduction dialogues constitute the core of the compensation arrangements. When a defined working time has been hoarded, an agreement concerning the reduction of the time balances has to be made.

Both agreements allow an extraction of three core aspects that are characteristic of the concept of trust-based working time in the branch banks. These read as follows:

1 Delegation of time recording: The employer delegates his responsibility for time recording in accordance with the provisions stipulated by working-time law to his employees. Documentation is done only in the case of deviations from the contractually agreed working time and is limited to major time intervals.

2 Decoupling of attendance and working time: Not the entire attendance time after deduction of unpaid breaks counts as working time, but only that part of attendance time spent productively on achieving work results.

3 The individualisation of working-time conflicts: In the case of strained time-balance limits, the practice of trust-based working time in companies places employees under the obligation (in the words of the personnel manager of BD2) 'to go to the manager with the works agreement in their hands and to demand credit reduction'. The principle of balance reduction seems to be considered as both a right and an obligation at the same time.

In both branches, the degree of autonomy in working-time decisions and the functional flexibility of employees were on a high level. Employees could decide autonomously about their working time, and they worked as 


\section{T. Haipeter and M. Pernod-Lemattre}

a team, which allowed for helping each other in cases of bottlenecks. This was designed as a mechanism of positive feedback loops: the employees can make responsible decisions on working time and they can help each other to fulfil their tasks so that the handling of working time is facilitated.

In both branches, however, we witnessed tendencies that can undermine this flexibility compromise between the companies and the employees. In both cases, retail banking has come under serious cost pressure due to the existence of new distribution channels, the competition with new and highly profitable spheres of business such as investment banking, and the new profit goals developed by management in the course of financialisation. This cost pressure was being passed on to the individual branches in various ways, either by tight budgeting or by means of direct personnel cutbacks. As regards the employees' design options in terms of working-time policy, this development may well entail serious and far-reaching consequences, as was confirmed by one branch manager. Tight personnel budgeting leads to an increased per-capita distribution of the volume of work, to increased performance standards, and to increased time requirements. Structurally, extra work which can no longer be reduced and a shrinking de facto autonomy in working time organisation may be the lasting aftermath.

The French case study banks exhibited a contrasting picture to their German counterparts. Strategies in working-time organisation aimed primarily at the introduction of annual hours, including seasonal adjustment according to demand fluctuations, at the increase in multi-tasking in both back- and front-office areas, and at shift work entailing modifications or changes of the daily schedule or modifications in the number of days worked. In this respect, a working-time reduction at the French retail bank, BF, in 1998, was of particular importance. It was introduced in the framework of the Robien $\mathrm{Act}^{3}$ and allowed for a general cut from thirtynine to thirty-three working hours per week for all branch staff, which gave way to the introduction of several shift systems in the course of longer branch-office service hours. As a result of these reorganisations, the branch office was operated in four shift patterns placed either on daily rosters (par relais) or on the number and location of days worked (par roulement).

Regarding these patterns, it was obvious that working-time organisation was directed very much from above and based mainly on the temporal availability of employees. Functional flexibility played only a minor role, the main reason being the segmentation strategies and the segmentspecific qualifications of the staff provided by the training and recruitment systems mentioned above. Under these circumstances, the main goal of working-time flexibility was to cope with the extension of opening hours. Moreover, working-time reductions were used as a tool for rejuvenation of the workforce: the number of hours worked by the existing staff had been reduced, whereas the development of profit-generating 
commercial functions was subject to targeted recruitments of high-skilled staff (cadres) for the most dynamic business functions rather than the reorganisation of work and the increase in functional flexibility of the existing staff. However, as a consequence, French banking employers are now facing a contradiction. A gap is opening between the higher need for specialisation required by professionals to develop new, sophisticated services, on the one hand, and the search for greater versatility especially on the level of sales networks, on the other (Bruniaux 2001).

To sum up our case studies, in the French and German direct and retail banks we have found that the type of working-time flexibility may differ significantly. Both between the banks in the two countries and between branch offices and direct banks, a clear distinction can be made with respect to the overall flexibility strategy. Most important, the French case study organisations tended towards a 'passive' concept where working-time flexibility is based primarily on rigid shift schedules, whereas the German branch offices tended towards an 'active' concept in which functional flexibility fosters working-time flexibility based on the selfmanaged adaptation of employees to business needs. The respective choice of prime resources of flexibility in either country is highly intertwined with the qualification structures of staff provided by the education and training systems and the recruitment strategies of companies. The German system of occupational training makes it an advantageous choice for companies to rely on the functional flexibility of their staff and to corresponding forms of temporal flexibility, as compared to the more segmented workforce in French banks, which invites companies to a greater functional differentiation and to working-time management 'from above' (Table 10.6).

Table 10.6 Forms of internal flexibility

\begin{tabular}{|c|c|c|}
\hline & France & Germany \\
\hline Direct banks & $\begin{array}{l}\text { - Low degree of autonomy } \\
\text { - Low banking skills and } \\
\text { competencies } \\
\text { - Shift schedules partly flexible } \\
\text { - Flexibility based on full-time } \\
\text { work } \\
\text { - Passive temporal flexibility }\end{array}$ & $\begin{array}{l}\text { - Low degree of autonomy } \\
\text { - Low banking skills and } \\
\text { competencies } \\
\text { - Flexible shift schedules } \\
\text { - Flexibility based on part-time } \\
\text { work } \\
\text { - Passive temporal flexibility with } \\
\text { some active elements }\end{array}$ \\
\hline Retail banks & $\begin{array}{l}\text { - Bank-specific skills according } \\
\text { to segment and orientation } \\
\text { on sales } \\
\text { - High segmentation } \\
\text { - Low autonomy } \\
\text { - Low functional flexibility } \\
\text { - Passive temporal flexibility }\end{array}$ & $\begin{array}{l}\text { - Bank-specific skills with broad } \\
\text { expertise } \\
\text { - Low segmentation } \\
\text { - High autonomy } \\
\text { - High functional flexibility } \\
\text { - Active temporal flexibility }\end{array}$ \\
\hline
\end{tabular}




\section{T. Haipeter and M. Pernod-Lemattre}

\section{Conclusion}

The banking industry in both countries is a service industry in change. The globalisation of financial markets, the new dominance of shareholder value, national re-regulations and the intensification of competition has formed a new market environment, and therefore new challenges for the banks. The banks in Germany and France answered these new challenges with the implementation of a new concept of company strategy, 'lean banking', which nearly took up a status of a 'one best way' concept in the course of the 1990s. Segmentation, automation, new distribution channels and the centralisation of back-offices in the meantime have become standard features of bank organisations.

The same applies to the concepts of personnel policy and work organisation contained in the lean banking strategy. The banking industry historically had a medium- to high-skilled workforce, where the mediumskilled employees occupied most of the customer interfaces, except for the relationships to corporate customers, which were traditionally occupied by a high-skilled workforce. In both countries, the financial system was based on a relatively highly regulated domestic financial market. Furthermore, the Fordistic forms of work and working-time regulation were dominant in both banking industries up to the 1990s. Collectively negotiated long-term working contracts coupled with a social security system, as well as highly standardised working hours concerning duration, distribution, and position of working time, combined with relatively short opening hours of branches, characterised the scene.

In the context of lean banking, the traditional stability of the core workforce was maintained in both countries, but it was used by the companies to enhance the internal flexibility of its workforce as the core concept for work organisation. Thus working time is a cornerstone of personnel flexibility upon which the banks build. This is why the companies needed flexible forms of working-time organisation presented in our case studies. However, functional flexibility as a second possible resource of flexibility is not developed systematically within the lean banking concept. In fact, we found that the high level of functional flexibility in the German retail banks was very much a consequence of the training system rather than of lean banking. Ironically, it was the low degree of segmentation and therefore the incomplete implementation of lean banking that made it possible to introduce integrated tasks and self-managed working-time organisation in German branch offices, taking advantage of the broad bank-specific qualifications of the employees.

This points to the differences between the two countries. Strategies such as lean banking can gain a foothold in company reality only after passing through the filter of different regulations of the national institutional systems. Companies refer to the specific rules and resources which they encounter in their respective national systems. Regulations of 
the financial systems and of the labour and product markets work in the sense of a 'duality of structure' (Giddens 1991) in that they both enable or empower (resources) and constrain (rules). Thus, despite the joint orientation of French and German banks towards a bestpractice strategy, there is no such thing as a 'one best way' of flexibility. On the contrary, the respective forms of strategic implementation in the two countries bespeak the formative power of national institutional systems.

A central role in this respect is played by the education and training systems. French and German banks address, in their recruitment strategies, workforces with different qualification structures. Our case study analysis has shown that qualification influences work organisation and that work organisation itself is highly related to working-time organisation. Thus, if French banks should want to tap employee abilities and skills in the framework of active flexibility concepts, they would need to 're-form' and 're-model' the training system in the direction of a broad polyvalent qualification. Furthermore, if the German banks should want to strengthen the functional flexibility of their workforce, they would need to preserve the firm base of the existing dual system of vocational training, adapt it continuously to the changing conditions of the industry, and develop a strategy of a functional integrated work organisation in its own right.

Against the background of the cuts in branch office staff that are planned and of the shift in staff structures towards higher educational levels, it remains an open question, however, whether German banks will be more likely to head towards a greater emphasis on segmentation of their staff in the future. Moreover, as we have seen, active flexibility in the work organisation of German retail banks contradicts to some extent the rationalisation and cost-cutting procedures that are incorporated into the lean banking concept. In this context, cost pressure may lead to a pressure on working time and on the self-management potential of employees. It is all too obvious that in both countries lean banking is not the end of history.

\section{Notes}

1 The share of apprentices as a percentage of all employees of a company.

2 For the presentation of our case studies, we shall refer to the companies by means of abbreviations for reasons of simplicity. In the following, 'BF' is meant to refer to the French retail bank; 'DBF', to the French direct bank; 'BD1' and 'BD2', to the German retail banks; and 'DBD1' and 'DBD2', to the German direct banks.

3 The Robien Act of June 1996 offered companies the possibility of reducing working hours in order to either create or safeguard jobs in exchange for a reduction of their social security contributions. It was followed in 1998 and 1999 by the two Aubry Acts, which stipulated the step-by-step introduction of the thirty-five-hour week as the legal standard working time. 


\section{References}

Arbeitgeberverband des privaten Bankgewerbes (AGV Banken) (2000) Bericht 1999/2000, Berlin: AGV Banken.

Backhaus, J. and Wagner, R. (1999) Ausbilder-Taschenbuch 2000, Stuttgart: Deutscher Sparkassenverlag.

Baethge, M., D'Alessio, N. and Oberbeck, H. (1999) 'The End of Institutional Stability? German Banking Industry in Transition', in M. Regini, J. Kitay, and M. Beathge (eds) From Tellers to Sellers: Changing Employment Relations in Banks, Cambridge, MA: MIT Press.

Bierer, H., Fassbender, H. and Rüdel, T. (1992) 'Auf dem Weg zur schlanken Bank', Die Bank 9: 500-1.

Bosch, G. (2004) 'The Changing Nature of Collective Bargaining in Germany: Coordinated Decentralization', in H. Katz (ed.) The New Structure of Labor Relations: Tripartism and Decentralization, Ithaca, NY: Cornell University Press.

Boyer, R. (ed.) (1988) The Search for Labour Market Flexibility: The European Economies in Transition, Oxford: Oxford University Press.

Bruniaux, C. (2001) 'L'intégration de la hausse d'éducation dans la dynamique de l'emploi et des qualifications du secteur bancaire: Une comparaison sur cinq pays européens', La Revue de l'IRES 36 (2001/2): 171-200.

Cartellieri, U. (1990) 'Überkapazität erzwingt Auslese', Die Bank 9: 366-71.

D’Alessio, N. and Oberbeck, H. (1994) “Lean Banking”: Klassische Rationalisierung mit anderen Vorzeichen oder Metapher für eine neue Marktorientierung der Finanzdienstleister?', SOFI-Mitteilungen 21: 53-64.

Deeg, R. (1999) Finance Capitalism Unveiled: Banks and the German Political Economy, Ann Arbor: University of Michigan Press.

Dingeldey, I. (2000) 'Einkommensteuersysteme und familiale Erwerbsmuster im europäischen Vergleich', in I. Dingeldey (ed.) Erwerbstätigkeit und Familie in Steuer- und Sozialversicherungssystemen: Begünstigungen und Belastungen verschiedener familialer erwerbsmuster im Ländervergleich, Opladen: Westdeutscher Verlag.

Dressen, M., Roux-Rossi, D. and Blaustein, E. (1997) Restructuration des banques et devenir des salariés, Paris: La Documentation Française.

Gadrey, J., Jany-Catrice, F. and Ribault, Th. (1999) France - Japon - Etats Unis: l'emploi en detail, Essai de socio-économie comparative, Paris: Presses Universitaires de France.

Giddens, A. (1991) Die Konstruktion der Gesellschaft: Grundzüge einer Theorie der Strukturierung, Frankfurt/Main and New York: Campus.

Haipeter, T. (2001) 'Vertrauensarbeitszeit in Bankfilialen', Arbeit 3: 278-85.

Hildebrandt, S. (2000) Jenseits globaler Managementkonzepte: Betriebliche Reorganisation von Banken und Sparkassen im deutsch-französischen Vergleich, Berlin: Edition Sigma.

Hirsch-Kreinsen, H. (1999) 'Shareholder Value: Zum Wandel von Unternehmens-strukturen und Kapitalmarktbedingungen', WSI-Mitteilungen 5: 322-30.

Hoff, A. (2002) Vertrauensarbeitszeit: einfach flexibel arbeiten, Wiesbaden: Gabler.

Huffschmid, J. (1999) Politische Ökonomie der Finanzmärkte, Hamburg: VSA-Verlag.

Kädtler, J. and Sperling, H.J. (2001) 'Worauf beruht und wie wirkt die Herrschaft der Finanzmärkte auf der Ebene der Unternehmen?’, SOFI-Mitteilungen 29: 23-43.

Kreyenschmidt, G. (1997) 'Bankennachwuchs: Differenzierter Bedarf', Die Bank 1: 18-21. 
Lehndorff, S. (2001) Weniger ist mehr: Arbeitszeitverkürzung als Gesellschaftspolitik, Hamburg: VSA-Verlag.

Lütz, S. (2000) 'Die politische Regulierung globaler Finanzrisiken', in R. Czada and S. Lütz (eds) Die politische Konstitution von Märkten, Opladen: Westdeutscher Verlag.

O’Reilly, J. (1994) Banking on Flexibility: A Comparison of Flexible Employment in Retail Banking in Britain and France, Aldershot: Avebury.

Regini, M., Kitay, J. and Baethge, M. (eds) (1999) From Tellers to Sellers: Changing Employment Relations in Banks, Cambridge: MIT Press.

Seyfried, M. (1995) 'Strategische Optionen im Management von Finanzdienstleistungen', in Hans-Böckler-Stiftung (ed.) Konzepte zur Reorganisation von Finanzdienstleistungen, Düsseldorf: Berg-Verlag Bochum.

Sperling, H.J. (1997) Restrukturierung von Unternehmen und Arbeitsorganisation: Eine Zwischenbilanz, Marburg: Schüren.

Thenner, M. (2000) 'Familienpolitik als Politik zur Vereinbarkeit von Familie und Beruf - geldwerte Leistungen, zeitwerte Anrechte, familienunterstützende Infrastruktur und ihre Auswirkungen auf das Familienverhalten', in I. Dingeldey (ed.) Erwerbstätigkeit und Familie in Steuer- und Sozialversicherungssystemen: Begünstigungen und Belastungen verschiedener familialer erwerbsmuster im Ländervergleich, Opladen: Westdeutscher Verlag.

Zysman, J. (1983) Governments, Markets, and Growth, Financial Systems and the Politics of Industrial Change, Oxford: Martin Robertson. 

Part III

Common challenges 



\title{
11 The shaping of work and working time in the service sector
}

\author{
A segmentation approach
}

Jill Rubery

\section{Introduction}

The changing nature of work is a topic much debated from a variety of perspectives but the analysis often lacks an integrated theoretical framework with which to underpin it. The changing nature of work is often treated by the economics profession and by some management theorists as the outcome of unstoppable market or technological forces, involving the diffusion of best practice techniques. In contrast, for political scientists and industrial relations specialists, the driving force for change is the policy agenda, dominated by deregulation, in a context of globalisation and the diminishing power of the nation-state to protect labour (Coates 2000). And for sociologists, changes in work have to be understood within the changing relationship between work and the wider society, including the class structure (Crouch 2000). Economists try to incorporate these different dimensions to employment change within the same framework, and where this is attempted the results are usually at best partial. For example, it is common for economists to note the rising participation of women, but not to explore how this may affect the structure of working time, the pattern of pay and careers, the flexibility strategies pursued by firms or the impact of job generation on open unemployment. ${ }^{1}$ To consider the significance of the studies of the service sector generated by the NESY project for understanding the development of new forms of work and working time, a rather general framework is required. This framework needs to deal with both static comparative issues and dynamic developments. The latter include the shifting dynamics on the demand and the supply side of the labour market, in a context of changing regulatory and institutional environments.

The framework we propose to adopt for this exploration is a segmentation perspective. This theoretical framework has become rather unfashionable for two interrelated reasons: first, it is associated for many people with a specific model of labour markets - the dualist model of Doeringer and Piore (1971) which juxtaposes the bureaucratic internal labour markets on the one hand and the more flexible peripheral sectors on the 
other. This model may be argued to have relevance only to a particular place - the USA - and a particular time period - the 1960s and 1970s. The second argument follows from the first; according to writers such as Cappelli (Cappelli et al. 1997), the conditions for the development of internal labour markets have now disappeared and the collapse of these institutional arrangements has led to an increased role for the market in shaping employment. However, these critiques ignore the contributions by writers in both the USA and Europe, working within a segmentation theory perspective, who have sought to recast the theory into a more general framework, not dependent upon specific institutional forms. For these writers (e.g. Rubery 1978, 1994a, 1996; Wilkinson 1983; Osterman 1984, 1987; Jacoby 1984, 1994; Gospel 1992; Rubery and Wilkinson 1994) employment is always to be understood as an institutional phenomenon, not determined by exogenous market forces. This is the theoretical approach that we adopt here. We outline below the key insights of this reformulated segmentation approach and the reasons for its continued contemporary relevance. However, as an heuristic device, we also take the initial formulation of dualist structures and bureaucratic internal labour markets as a starting point for exploring divergences over space, time and sectors in labour market arrangements, and for identifying the key changes that have taken place in the three decades since the publication of the Doeringer and Piore model.

\section{Revisiting segmentation theory}

The association of segmentation theory with Doeringer and Piore's (1971) dual labour market model ties the theory to the mast of specific organisational structures, rather than providing a general approach to labour markets. The more general approach, as developed by authors such as Osterman, Jacoby, Gospel, Wilkinson and Rubery, strips the theory of both its specificity and its functionality, and instead provides a historically rooted analysis of the institutionalisation of labour markets based on processes of segmentation found within both the industrial system and the social system.

The key insights of segmentation theory that may be argued to have this general rather than specific significance include, first, the proposition that employment relationships are shaped within organisations, not in an abstract labour market. As such, the general forces of supply and demand which characterise the textbook versions of labour economics have at most had an indirect influence on employment organisation, mediated via managerial choices that are influenced but not dictated by external pressures. This power of employers to shape employment conditions means that the labour market does not simply reflect social differentiation but is in fact a potential cause of inequalities and differentiation in access to employment and income. The collapse of bureaucratic internal labour markets, which offered security to employees as well as benefits of continuity to employers, 
could even provide scope for increased, not reduced, employer power over employment conditions. Far from being dictated to by the market, employers may simply be using the rhetoric of the market and the need for flexibility to introduce employment practices where there are fewer collective checks and balances on the actions of employers.

This perspective brings us to the second proposition that may be associated with a more general approach to segmentation theory - that conflicts and contradictions are an inherent element of the employment relationship and are embedded in the institutional arrangements. The dual labour market model has been criticised for its inherent functionalism (Rubery 1978; Jacoby 1984) where there was deemed to be a happy 'coincidence of wants' between employers and employees. Employers benefited from committed employees, employees from the stable and well-remunerated workforce organised according to clear rules and procedures that limited managerial discretion. Even in the secondary sector, employers' need to keep costs down and reduce overheads was apparently matched by a labour supply of contingent workers, willing to work flexibly and for low pay. Under a more general approach, institutional arrangements need not represent a technically efficient outcome. Instead, they emerge out of historically determined power relationships between and within capital and labour. In many cases, internal labour markets were resisted by employers until forced upon them through trade union struggles (Rubery 1978; Jacoby 1984; Gospel 1992). Furthermore, it was not necessarily the inherent level of skill that determined the development of internal labour markets but more the ability to pay of the employer and the bargaining power of labour. Indeed, secondary-sector jobs, organised on a low-pay and casual basis, could still require skilled and committed employees. Employers with low ability to pay may avoid the need to provide high pay and security by recruiting from among workforce groups with weak bargaining power (Craig et al. 1985).

The third proposition of this more general segmentation approach follows from this last point; inequalities in the labour market emerge out of the mutual interplay of segmentation processes on the demand and on the supply side of the labour market. On the demand side, the processes of uneven development, of variations in both market strategies and rates of return between organisations, structure the ability of organisations to offer stable and well-paid employment. On the supply side, social organisation, including divisions by class, gender, race, skill or qualification, leads to the development of segmented or non-competing groups on the labour market. The shaping of employment within organisations is influenced by these wider external divisions and social segmentation processes. For example, the shaping of internal jobs and pay hierarchies may be reflective of the prevailing pattern of gender segmentation in the employment system and is not necessarily congruent with the internal value of jobs in the organisation (Grimshaw and Rubery 1995). 


\section{Jill Rubery}

This reformulation of segmentation theory allows both for a more dynamic analysis and a wider range of employment forms to prevail, over time and space. Historical, institutional and cultural influences are central to a segmentation perspective, but the more general formulation also admits to the possibility of the breakdown of these historical, institutional arrangements both inside and outside the organisation, particularly during periods of rapid social and economic change. Institutional arrangements have historic resilience, but can still be destabilised (Almond and Rubery 2000). This approach therefore provides a dynamic perspective through which to understand recent developments in servicesector work. These developments include responses to competitive, social and political factors whose separate influences on the restructuring cannot necessarily be clearly identified (Grimshaw and Rubery 1998). For example, changes in competition conditions may provide employers with an opportunity for reopening negotiations on the form of labour relations (Beynon et al. 2002). Similarly, moves to new organisational forms (e.g. subcontracting, franchising) may be influenced by both competitive and industrial relations objectives (Marglin 1974).

The co-existence of, and interactions between, both demand- and supply-side segmentation processes allows for a wider spectrum of employment forms and conditions than the dualistic structures in the initial formulation of segmentation theory. This approach brings the segmentation perspective close to that of the societal effect school, where the apparently independent actions of organisations to shape employment are found to both reflect and be embedded in distinctive societal arrangements that contain their own societal logic. Thus, according to the societal effect approach as developed by Maurice et al. (1986) and Sorge and Warner (1980), organisations remain central to the analysis of the emerging patterns of employment, but their composition, governance and functioning emerge out of the societal system in which they are embedded.

The influence of the societal system is found in the structure and organisation of the industrial system, in the patterns of consumption and demand, in the forms of regulation and in the shaping of employment. In comparing the nature of service employment generated within particular countries, it is necessary, therefore, both to consider the structuring of demand for and provision of services as well as differences in labour market institutions such as training or differences in social institutions such as gender relations. Even more importantly, there will be interconnections between these different spheres. Societies with strong provision of public services, for example, may be more likely to have stronger social norms supporting gender equality than in societies where service provision is left to the household or the market.

The introduction of societal systems into the analysis has also extended the range of labour market forms associated with institutionalised employ- 
ment systems: Marsden (1986, 1999), for example, pointed to the fact that if the external labour market was to be relied on to deliver a skilled workforce, there would need to be a comparable or indeed higher level of organisation and institutionalisation of labour markets, this time at the societal level, than that associated with the Internal Labour Markets (ILMs) of the Doeringer and Piore model. Thus, the development of comparative research into the organisation of employment associated with the societal effect school pointed up the weakness of the original segmentation model that was overly influenced by specific conditions and institutions in the US market.

The societal school, for its part, has suffered from a tendency to overstress the functionality of existing arrangements and to understress the continuation of tensions and conflicts, which may reduce the coherence of the system and also serve as a force for change (Rubery 1994b; Smith and Meiksins 1995; Coates 2000). Thus, while the insights of the societal school provide a framework through which the external environment may be seen to be embedded within the internal organisation of employment, there is also a need to incorporate within the societal framework a more explicit analysis of how the interplay of power relations and competition, within and between capital and labour, impacts upon the shaping of the employment system.

The societal perspective also needs to take on board the implications of the growing internationalisation or globalisation of product and service delivery. Increasing international concentration of ownership may provide a means of transfer of certain models of organisational form and service delivery across societies. The weaker institutionalisation of, for example, training and industrial relations traditions in parts of services compared to manufacturing may increase the power of international capital to shape the new forms of work and working time. This suggests that we not only need to trace the ways in which societal systems produce and reproduce difference, but also to examine the ways in which new forms of competition are challenging existing institutional arrangements and labour market regulations.

This revisiting of segmentation theory has suggested three themes which we can take forward: first, the role of organisations in shaping employment change; second, the mutual interactions between demandand supply-side segmentations in the shaping and reshaping of employment; and finally, the role of societal systems and their associated institutional structures in explaining differences in patterns among the selected countries. The empirical work that we draw on includes primarily the case studies and synthesis reports prepared for the NESY project. We also refer to the results of recently completed case study research in the UK on retail and banking that was not included in the NESY synthesis reports, since it was undertaken for a different project (Beynon et al. 2002; Grimshaw et al. 2002a). This provides complete coverage of the UK across the five sectors 
and facilitates the discussion, since, as is always the case, the ideas presented here are no doubt shaped more by the experience in the author's home country, whatever the efforts made to develop a comparative and open perspective.

\section{The role of organisations in shaping employment systems}

Employment is shaped by organisations at both a macro and a micro level. The aggregate or macro-labour market is in fact a reflection of the composition of types of organisations - categorised by size, ownership structure, product or service orientation, technology and so on. These characteristics do not have a deterministic relationship to employment, and the implications of these characteristics vary by country and by sector. Nevertheless, changes across these dimensions may be expected to have an impact on the structure of the labour market. These changes occur both because of firm closure and firm creation and because of the restructuring of existing organisations. Internal restructuring may include product reorientation, changes in governance structures, as well as direct changes to employment policies and practices. Although changes to governance structures and other organisational characteristics will exert some influence on the choice of employment practices, the form and nature of employment is not fully explained by contingent variables. Instead, we need to allow for the influence of policy options, exercised by social agents, albeit constrained by the specific conditions and environment in which an organisation is embedded. Society-wide institutional arrangements, the historical development of the employment culture, the attitudes and actions of trade unions and workers, the orientations and competence of the management, will all impinge upon the actual employment policies and arrangements.

Within this general framework for understanding the role of organisations, we need to incorporate notions of power and power relations both between organisations and vis-à-vis the workforce. It is the relations between organisations and not just their formal structure that may influence the types of employment policies pursued.

\section{The rise of the service economy and the restructuring of inter-firm relations}

Clearly one of the major changes in composition of employing organisations over recent years has been the decline in the share of manufacturing organisations and the rise in service-sector organisations. This change has been accompanied by a destabilisation of large organisations and of their archetypical bureaucratic internal labour markets that provided protection to core workforces (Cappelli et al. 1997). This destabilisation is associated both with the growth of so-called flexible or new forms of 
employment but also with the emergence of new forms of competition, new types of skills and new methods of managing labour.

Segmented labour market theory was modelled initially on the notion of a large manufacturing organisation with the core activities of manufacturing and the periphery associated primarily with subcontracted servicetype work. Actions by manufacturing companies have been in part responsible for compositional changes; their subcontracting of services led to a growth of specialist service activities and organisations (Petit 1986; Esping-Andersen 1993). However, by the end of the twentieth century, the model of core and periphery in many contexts needed turning on its head. Instead of manufacturing organisations being at the core of a subcontract system of small service providers, the relationship between manufacturing and services has in many respects been reversed. For example, retail organisations have, in many contexts, become the dominant organisations in the supply-chain relationships at a global level (Harvey 1999; Jany-Catrice and Lehndorff (Chapter 9, this volume)). Similarly, media and leisure organisations not only dominate the delivery of services but also shape the production of related goods (from videos to sports clothing) sold as manufactured commodities. Service-sector organisations cannot be considered as primarily or mainly subcontractors or subordinate players to the dominant manufacturing sector. Information technology (IT) companies are now some of the largest organisations and may play a controlling and not always a subordinate role in their partnerships with public and private sector organisations (Grimshaw et al. 2002b), where IT systems may be a core determinant of an organisation's efficiency and comparative advantage. At the same time, there has been a growth in small high-technology firms that undermines any characterisation of small firms and their employees as a peripheral, low-skilled or lowpaid workforce. These changes in relationships also reflect the rising importance of financialisation and shareholder value as the driving force for change in production systems (Williams 2000). Employment specialists' traditional concern with the role of labour in maintaining or developing the productive capacity of the economy through skills and expertise may be regarded in financial circles as reflecting a rather quaint attachment to the real economy in a period when the main driving forces of economic flows may be found in the creation of profit out of the creation of new market opportunities unrelated to physical production capabilities (Froud et al. 2000). Examples of this may be observed in the privatisation and subsequent dismemberment of public-sector assets, in the focus on corporate branding but subcontracted production, or in the carving up of satellite and cable broadcasting rights or mobile communication licences.

These changes go beyond simple compositional change to suggest a restructuring of power relations between different types of organisation with potential consequences for employment relations. The early segmentation models assumed a simple correlation between market power, size of 
organisation and worker power. The increasing dominance of servicesector organisations has not so far gone hand in hand with the development of worker power and collective organisation. In some cases, this may be attributed to the relatively low levels of skill associated with work (for example, this could be argued to be the case in retail and increasingly in banking). However, it is also associated with the nature of the labour supply, the weak traditions of both bargaining and training in some service sectors and the new forms of governance adopted often explicitly to evade regulations and to obscure the role of large organisations in shaping employment arrangements. Even where the workforce is highly skilled, such as in the IT industry, the more individualised form of employment relationship may have so far restricted the development of collective countervailing power within the service economy. At the same time, the increasing dependence of much of manufacturing on a complex and powerful distribution system is also undermining the collective power of workers and unions within the manufacturing sector (although manufacturing is not the direct subject of our current study).

The decoupling of the relationship between employer size and power and employment conditions has affected not only the private but also the public sector. The absence of market pressures and the commitment by government to act as a good employer were previously considered sufficient to ensure the establishment of good employment conditions for public-sector workers. Both of these assumptions have been challenged over recent years. Under pressure to contain costs, governments have sought to introduce more market values into the public sector, often with the explicit objective of moving away from the bureaucratic forms of employment arrangements that were deemed to provide too much job security and too high pay. The reputation of the public sector as a good employer may have been partly based on myth, particularly once one considers the traditional wage and employment systems for female-dominated jobs such as those in health and in home care (see Anxo and Fagan (Chapter 6), and Baret (Chapter 7), this volume), but as we discuss below, the new systems of governance are not necessarily acting to overcome these traditional forms of discrimination and may be further exacerbating problems.

\section{The reshaping of organisations: new forms of governance}

The new forms of competition that have emerged over recent years involve greater emphasis both on the development and exploitation of new knowledge (Castells 1996) and on what has been called the economics of time (Best 1990) in the production and delivery of goods and services. These competitive imperatives have been associated with the development of networked or fragmented organisations and the continuing debate on governance structures. Changes in organisational forms 
have consequences for the organisation of work and working time that extend beyond the switch in focus from manufacturing to services.

Within the private sector these new forms of governance include devolved budgetary control systems, the growth of joint ventures, strategic alliances and long-term relational subcontracting, the use of franchises as a mode of expansion and market penetration (Felstead 1993), and the development of corporate service organisations reliant on a whole range of external providers operating under the corporate brand. Examples of this include broadcasting companies that have withdrawn from direct production, department stores that sublet floor space, banks that sublet foreign exchange, universities that provide degrees under licence and so on. This fragmentation of the governance structure calls into question the dichotomy between markets and hierarchies that is the fundamental dichotomy in the transaction cost theory and is also implicit in the dualist Doeringer and Piore model (Rubery et al. 2002, 2003). Williamson (1985) has in fact recognised the need to allow for 'hybrid' arrangements and it is these arrangements between markets and hierarchies that, to a large extent, have dominated the literature in institutional economics and organisational/strategic management literature over recent years. However, the implications of these more complex relationships and the consequent difficulty in many cases of defining where the power in the employment relationship actually lies or even who may be the real employer have tended not to be fully explored within the employment literature (Rubery et al. 2002; Supiot 2001). It is perhaps notable that most research on retailing, including this current project, still focuses on the direct employment relationship of organisations, thereby neglecting the indirect influences of powerful organisations on employment at different stages in the national and global supply chain (Harvey 1999; Klein 2000).

New forms of governance are also becoming evident in the public sector (Grimshaw et al. 2002b), although there are differences in the pace and direction of these changes. These new approaches range from full privatisation of parts of the public sector to new internal governance structures and modes of finance. If the UK is taken as an example of a country that is moving rapidly down this path, we find a range of developments that include: the increased use of subcontracting institutionalised through competitive tendering and in many cases involving the withdrawal of the public sector from areas of service provision, leaving these areas open to private or not-for-profit organisations; the decentralisation and devolution of budgeting and governance structures coupled with centralised performance targets and monitoring (Cutler and Waine 1994); and the development of internal markets within the public sector, resulting in increased internal competitive pressures and the generation of more hybrid funding based on a continual bidding process for both public- and private-sector funds. Furthermore, at the same time as there is increased pressure to meet often constantly changing financial targets, there is political pressure 
to respond more directly to the needs of the public, to become more 'client-focused' or 'customer-focused', and to limit the power of the public sector professional to determine the nature of the service provided. These new modes of management are evident in both the health care and the home care case studies, where new forms of work and working time were being introduced in response to both changes in budget arrangements and incentives or even directives to enter into subcontract or other arrangements with private-sector, for-profit and not-for-profit firms. The mixed welfare state, where provision of public services involves both public and private organisations, is thus becoming a reality in most countries, and increases the range of options or strategies available to managers of public sector services, while not necessarily in any way resolving the fundamental issue of the matching of resources to needs or demands.

The trend towards devolution of accounting and responsibility has been facilitated by new monitoring technology that simultaneously empowers and controls the subordinate units. These potentially contradictory pressures also spill over into the employment relationships of nonmanagerial staff, where they are required both to take the initiative to meet the devolved targets or budgets and at the same time are held accountable to strict centralised budgetary and performance rules and standards. These contradictory requirements are evident in the management of IT staff, who are required to take responsibility to solve clients' problems but at the same time to pay attention to the ratio of billable hours in total hours. They are equally important among home care workers who are both required to provide a higher level of care, associated with the increased importance of the very elderly and the frail among clients, and at the same time to meet new strict performance and time standards which remove the scope for the discretion of the professional in determining what types of work need to be carried out and the time required for the task. In other cases the focus may be more on control than empowerment; in retailing, the new technology plus strict financial and other performance targets are used by central management to ensure a move towards lean staffing at the store level. In banking, the new focus on selling has been facilitated by new technology that allows for more centralisation and reduction in focus on processes. However, whether this liberation from routine processing is used to empower staff to become more multi-skilled or to introduce closely monitored and scripted selling functions is found to vary between organisations and societies (see Haipeter and Pernod (Chapter 10, this volume); and Rubery et al. 2001b).

Organisational form and governance structure will have a major influence on the development of work and career structures with smaller, devolved or fragmented organisations offering less scope for career development than large organisations. However, there may be a reduction in this differentiation where the large organisations have flattened their hierarchies and removed the middle management layers that typified the 
internal labour market system. The fragmentation of governance structures potentially increases interorganisational transfers, including more mobility between public and private sectors. It is in this process of restructuring that we find the apparent move towards boundaryless careers away from the bounded career within an internal labour market (Arthur and Rousseau 1996). One problem with this concept may be that the degree of job instability has been exaggerated and the ideal model of a closed internal career ladder was also not as widespread as believed, and in any case took different forms in different societies (see below). Even with those caveats in mind, it is still clear that changes in governance structures are having their impact on career opportunities. Without the prospect of upward mobility, organisations may need to find new ways of motivating and retaining staff. In some cases organisations are simultaneously needing to find ways to motivate and reward internally recruited and trained staff, and to manage externally recruited staff whose careers fit more with the boundaryless model (see Csonka and Boll 2000).

Fragmentation may also promote polarisation of skills structures if sections of the organisation or external subcontractors specialise in, for example, the less skilled parts of the work process (as in the case of home care and direct banking). De-layering and lean staffing within organisations may also lead to skill polarisation and the removal of opportunities for upward progression (see Beynon et al. 2002; Grimshaw et al. 2002a). In the health and home care sectors, the problem may be perverse. It is in part the historical failure to provide career structures in femaledominated jobs that is exacerbating labour shortages. In many of the countries with labour shortage problems, qualified nurses face a very flat earnings profile, with pay levels in some countries little higher than for nonqualified nurses. These limited upward pay promotion opportunities persist despite ever increasing demands for specialisation. Budget constraints coupled with pressures from lower qualified staff are restricting the development of more appropriate career ladders for university-trained staff.

Home care faces analogous problems. Some attempts are being made to develop more professional training and career structures for home care workers, but these training efforts are not being matched by significantly increased rewards. Moreover, it is primarily in the public sector where this professionalisation is evident at a time when the role of private-sector providers is increasing. However, in Italy the not-for-profit sector is providing training after recruitment, thereby contributing to the pool of trained labour. The increased emphasis on specific education and training is thus either leading to staff shortage or to the continuation of the employment of workers without the requisite skills or qualifications.

Within the IT sector, there are also contradictory developments with regard to the scope for internal career structures. On the one hand, employers wish to retain skilled and motivated staff, but on the other hand, they are conscious of the need to continually renew the knowledge 


\section{Jill Rubery}

base that reduces the incentive to internalise staff. The fragmentation of the industry, in the form of large numbers of small firms and selfemployed or own-account workers, means that the IT workers have a range of career options that do not require commitment to a single organisation in a time of rapid change in company fortunes. In this context, no easy solution to the problems of recruitment and retention may present themselves.

\section{Organisational employment practices: new requirements, and new conflicts and contradictions}

The Doeringer and Piore model focused on two main issues for management: how to secure the retention and motivation of staff with firmspecific skills while at the same time allowing sufficient flexibility in the system to adjust to demand fluctuations. The dualist system apparently provided the answer to both requirements. From Cappelli's perspective, the changes that have occurred are not so much in the requirements of organisations as they still need a committed workforce trained in firmspecific skills. The main change is in the external stability conditions that allowed organisations to offer stable employment arrangements. There is, it appears, an increasing need for the core as well as the periphery to provide organisations with flexible delivery systems and flexible costs. This prediction is supported by the case studies where we find examples of organisations seeking to extend the flexibility of their production and delivery systems in ways that involve core as well as so-called periphery staff. These strategies may vary by type of employee, but the share of employees untouched by requirements to work outside standard working hours or to move flexibly between job areas seems to be on the decline in most sectors and countries.

Nevertheless, the flexibility strategies vary, influenced by the category of employee, by societal approaches to flexibility and regulation (see the section on 'Societal effects and segmentation' below) and by organisational strategy. For the core workforce, the strategy adopted to achieve flexibility may involve a form of apparent empowerment, making the employee responsible for completing tasks to a satisfactory level, whatever the effort required in terms of either intensity or length of work. Under these conditions there is an increasingly blurred division between the directly employed persons and the independent self-employed. This scenario applies in particular force to IT workers. Retail also provides a good example of different strategies by type of employee: long unpaid overtime hours for managers, targeted part-time work for shop floor staff. Banking provides a good example of different strategies by organisation and country: France has focused on changing shift patterns while Germany has focused more on internal or functional flexibility of staff. These different strategies still involve some segmentation between workforce categories, 
but the approach to flexibility no longer only or mainly concerns peripheral staff.

This highlights one of the weaknesses of the dualist approach as it ignored feedback effects over time; as organisations become accustomed to the flexibility offered by non-standard employment, they begin to demand more flexibility from the core staff. It is not necessarily possible to use flexible sectors permanently to protect the rights of the core workforce and strategies may need to be developed, from the perspective of workers and unions, to protect those in the periphery, if the employment conditions for the core are not to be undermined (Rubery 1998). The peripheral workers may and do demand protection in their own right, but the notion that the core sectors will be simply protected by, and not threatened by, the growth of the flexible labour force has been shown to represent a too simplistic understanding of segmentation processes.

Current conditions also appear to involve some rather different human resource management problems with regard to skills and motivation than those envisaged in the internal labour market model. There are two main developments in the nature of skills, evident in some of our case studies and in the wider literature that may suggest a move away from a focus on the development and retention of firm-specific skills as the main driving force of human resource strategies of organisations. The first is the greater emphasis placed on innovation and creativity, associated with the so-called knowledge society. The move towards a more network form of organisation has been attributed to a need for organisations to be able to have access to staff with a wide range of skills and expertise (Nohria and Eccles 1992; Lepak and Snell 1999), wider than those that can be developed within a single organisation. Internalisation under these conditions is not always the most appropriate strategy and indeed may not be feasible if the organisation does not have the internal knowledge base to provide training; the internal labour market model may be considered more applicable to a mature industry where knowledge of the appropriate skills is vested in the existing labour force. In contrast, emerging technologies and industries may need to draw in skills and knowledge from a wide range of sectors.

The second major change has been in the displacement of jobs and tasks through the application of new technology that required specific firm and sector knowledge. These developments may be increasing the importance of tasks that require more general skills; for example, social skills and selling skills that may be less specific to particular organisations or sectors. Such changes have occurred in both banking and retail. These developments form the background against which we can consider the policies of organisations towards recruitment, retention and training. The IT sector is thus torn between the need to internalise its staff to ensure retention and the need to renew skills and knowledge through external recruitment. The banking sector is torn between adopting a policy of 


\section{Jill Rubery}

external recruitment and reliance on general soft skills or retaining the need for extensive sector- and organisation-specific knowledge to ensure reliability and quality of service. Retail seems to have gone down a relatively clear path of focusing on the more general soft skills and not developing an internal promotion ladder to provide staff for its management needs. Yet this lack of an internal structure may be contributing in some countries at least (for example, as indicated by the Danish IT case studies (Csonka and Boll 2000) and in the UK (Smith 2001; Beynon et al. 2002) to problems in developing and retaining managerial staff). What is notable about health and home care is that there has been relatively little development in the past of career ladders and structures to retain skilled staff, at least in comparison to the relatively high levels of skills required, certainly in nursing. Here we come up against the inadequacy of the Doeringer and Piore model in explaining patterns of career structures in areas where skills were required, but the labour force - for example, when consisting mainly of women - could be presumed to be stable irrespective of incentives for stability. The issue of the mutual interactions between demandand supply-side employment structuring is discussed in more detail in the next section.

The third area of the employment relationship where there is evidence of change relative to the Doeringer and Piore model is in that of pay and rewards. The opportunity to use pay in the form of deferred rewards to internalise a workforce has been reduced by the apparent greater uncertainty associated with internal careers and indeed the survival of large organisations. There is an associated move towards paying according to current performance and an expectation that once performance and pay has been maximised, upwardly mobile workers may then move on to new organisations. These pay systems provide an apparent means of motivating staff in the absence of long career ladders but at the same time generate incentives to future mobility, based on often short- rather than longer term assessments of where skills are best developed and nurtured. For example, in some sectors such as IT, the rewards from independent selfemployment may be sufficiently high and immediate that large capital has to match these conditions in the short rather than the longer term. At the same time, large organisations remain under pressure to provide the traditional upward career and earnings opportunities, perhaps pushing the reward package over and beyond the value of the worker to the organisation.

The extent to which this new model has become a reality depends, inter alia, on the nature of collective bargaining, but it is a potential trend even in the most regulated environments. Alongside this trend towards more immediate and variable pay for higher skilled staff, ${ }^{2}$ there has been perhaps an intensification of the tendency for peripheral or lower skilled

jobs to be paid at relatively low flat hourly rates, with no guarantee of earnings sufficient to provide for the living costs of the employee (see 
retail, home care and direct banking). In this sense, Europe may to some extent have been 'catching up' with the USA, where low-paid work, both in terms of hourly wages and variable hours, has been the norm for a longer period of time. There are still marked differences between European countries in the acceptability of what may be referred to as component wage jobs (Siltanen 1994); that is, jobs that do not provide sufficient income to cover the living costs of an adult. Part-time jobs have been growing rapidly in retail in Portugal as a means of staffing longer opening hours, but these jobs still meet with limited acceptance from women. In France, component wage jobs have been accepted in retail but not yet in banking, where even direct banking has been developed within the framework of existing pay and collective bargaining structures. In the UK and the Netherlands, however, the component wage job is now an established feature of almost all sectors where women and young people dominate, including among the cases considered here, namely banking, retail and home care. These variations in pay and job strategies reflect, as we develop in the following two sections, the impact of differences in both labour supply and societal regulations, arrangements, norms and values. It is notable that in Finland, where women expect to work full-time, a means of motivating and retaining staff is to offer longer working hours (for example, in retail), while in the Netherlands exactly the opposite situation applies.

From our discussion, it is becoming clear that there are no simple or clear-cut solutions to many of the labour force management problems confronting current day managers. Indeed the general trends in skill, flexibility and pay requirements tend to be pointing simultaneously in two quite distinct and potentially incompatible directions: on the one hand, towards empowerment of workers, to allow them to use their initiative and their self-organising abilities to resolve unexpected problems, to manage complex inter-firm relationships and to develop the creative and new forms of knowledge required to compete under current conditions. On the other hand, there is the imperative to monitor and control, to use new technologies to ensure compliance with ever more complex contracting conditions or more demanding performance requirements, given budgetary and other pressures. In many ways managers are often unable to choose between these two approaches and instead attempt to combine them in ways which may neutralise the benefits of both or lead to employees being demotivated and stressed (Beynon et al. 2002). These contradictions arise because organisations, while reliant on the skills and expertise of the workforce, seek also to minimise the costs of the workforce and reduce its potential to disrupt performance targets. These conflicts and contradictions are clearly evident in the public sector case studies, where tighter financial structures are leading to leaner staffing which results in intensified burdens on staff, as a result of labour shortages and absenteeism in some cases. The result is sometimes a vicious circle 
when labour shortages increase as work intensity leads to higher quit rates and lower enrolments in training courses.

Further conflicts and contradictions arise through the exercise of collective bargaining and other forms of workers' power, although this resistance can, perhaps paradoxically, provide a solution for management to the first set of dilemmas. Where regulation and collective bargaining restricts or rules out the resort to low-cost strategies, it may be that organisations operate employment systems that are more internally consistent. This is the implicit argument of the initial segmentation model: that trade unions and other institutional pressures helped employers to find solutions to support their long-term interests, even if, without these pressures, the employers would have preferred to continue to seek short-term costbased solutions and other strategies which did not involve ceding power to the workforce. The case studies provide examples of strategies adopted within both strongly regulated and less well-regulated labour markets; the question of whether regulation acts to restrict the development of appropriate strategies or to support the development of coherent and longer term strategies by organisations will be addressed further below.

\section{Introducing the supply side: mutual interactions, path dependency and constraints on adjustment}

When it was first debated, the novel feature of segmentation theory was that it located segmentation and inequality within the uneven development of the employment system. Other attempts to consider segmentation had focused on supply-side differentiation, on the existence of noncompeting labour market groups. This approach had focused policy attention on supply-side issues, absolving the labour market and in particular employers from contributing to inequalities. However, the focus on the demand side was in some respects taken too far, so that the existence of supply-side segmentation was either ignored or assumed simply to fit with and to act to reinforce demand-side segmentation. Thus the groups that were confined to the secondary sector were contingent workers with limited labour market commitments, or were discriminated-against groups, not allowed to find jobs that required skills, responsibility and problem-solving abilities (Doeringer and Piore 1971; Berger and Piore 1980).

A more sophisticated approach to segmentation theory recognises that employers take into account the segmentation of the supply side of the labour market in shaping their employment systems. If we take the case of women, perhaps the most general example of supply-side segmentation ${ }^{3}$ (Rubery and Fagan 1993; Rubery et al. 1999), we find two effects not allowed for in standard or orthodox segmentation models. First the supply side may influence the structure and hierarchy of jobs within the core sector, such that some core jobs are less well paid and accorded lower 
status than others, largely because they are undertaken by women (Grimshaw and Rubery 1995, 1998). Second, some skilled jobs may in fact be found in the so-called secondary or peripheral sector, staffed by disadvantaged groups such as women. As there is no necessary hierarchy of skills that builds up from the periphery to the core, the skills demanded in the periphery may even be higher than in parts of the core, first, because employers have found it possible to place some skilled jobs there and staff them with disadvantaged workers, and second, because there is no necessary presumption that organisations with higher ability to pay always require higher skilled workers. Marginal firms using older technology may be even more reliant on the skills and efforts of their workforces in order to survive than firms operating with newer technology and higher valueadded product and service delivery (Craig et al. 1982). There is equally nothing deterministic about this perverse ordering; it is more the case that the various factors that shape the skills of the jobs and the pay and conditions associated with the jobs need to be kept separate, and that these factors include both demand- and supply-side variables. Pay and conditions may be said to be influenced by the ability to pay of the organisation, the technical and training requirements of the job, and the social construction of the job status.

When we turn to the five sectors and the specific country case studies, we find evidence of this mutual conditioning, both traditional and new. The importance of societal construction of supply-side differentiation is at its most clear in the different working-time patterns for female labour in retail, banking and home care. The strategies used by organisations located in different countries to achieve lean staffing arrangements reflect to a large extent differences in the pattern of female integration into the labour market. Short part-time work, often considered the most obvious solution to lean staffing, is not used universally and is often less common in countries where women's integration has progressed beyond this form of partial and insecure employment. Differences in attitudes towards parttime work among women underpin the observed country differences in the use of part-time work in all four sectors where women constitute the major or a sizeable share of the labour force. However, in retail, an alternative strategy is evident, which is to use a different source of labour supply to take short part-time jobs where the supply of female labour is restricted. The most obvious case here is Denmark, where students and young people provide the bulk of the short part-time labour force. Young people are also providing more of the labour supply for part-time jobs in Portuguese retail; here the rapid growth of part-time work within the more modern parts of the retail sector is going against the grain of expectations among female labour, so that organisations have resorted to alternative supplies in the form of young people. The social norms in Portugal are not, however, sufficient to limit this rapid development of part-time work.

It is not, of course, always the case that there is an alternative labour 
supply to turn to when the traditional labour supply dries up or resists aspects of current arrangements. In the case of health and home care, it is much less obvious where employers would be able to find an alternative labour supply other than women, although efforts are being made in the case of nurses to tap into supplies of foreign trained nurses. Here the case studies do indeed find problems for employers emanating from the embeddedness of social divisions in the employment system, once these divisions become outdated. Labour shortage is a constant theme in the case studies of both care-related sectors, and this labour shortage seems to derive at least in part from the relatively poor terms and conditions offered for these jobs, compared to the work demands. Women are expanding their range of choices on the labour market through their increased education and more permanent integration into work, and the assumptions of a ready supply of female labour for care jobs is being challenged. However, the poor terms and conditions have become embedded in the costs structure of public services and, given the constraints on public sector expenditure, it is difficult for employers to act, even if they recognise the need to change the value attached to these jobs.

These examples demonstrate the inappropriateness of the more static analysis of supply-side segmentation based on apparent differences in preferences. Such analyses are evident in the national action plans produced under the European employment strategy, where part-time work, for example, is held to be a good way of matching differences in preferences between male and female labour (Rubery et al. 2001a). In reality the constraints on some groups' labour market opportunities - as a result of discrimination or objective barriers such as lack of childcare - has enabled employers to construct specific job sectors where they can obtain a stable and reliable labour supply at low cost.

This 'mutual coincidence of wants' hinges on the weak power of women in the labour market and in the domestic division of labour. When these conditions begin to be resisted, particularly by educated women who face wider choices, the apparent neat matching breaks down. One way of attempting to hold the matching together in the case of nurses is to offer yet more flexibility in labour hours. This strategy has contradictory benefits for women; on the one hand, it reinforces women's different domestic roles but at the same time it provides women with more choices over their working and family lives in a context of an occupation involving high levels of stress and potential burnout by the time employees reach their forties or fifties. Furthermore, part-time work involves fewer pay penalties for nurses than in other professions. The pay structure tends to be relatively flat; thus there is less risk of losing out on pay and promotion opportunities by working part-time. However, the benefits for the employers of nurses are less evident as they are effectively operating as monopsonists; total freedom to exercise choice over working time could reduce the overall labour supply, with the volume of labour gained by improved 
retention offset by decreases in the volume of labour provided by nurses opting for shorter hours. These dangers are particularly severe in cases of high-stress jobs such as nursing and where the returns from full-time nursing are still relatively low. Such problems are already evident in Belgium and the Netherlands, and the use of part-time work is apparently increasing the burden on the full-time and administrative staff.

The problems in home care are perhaps even more severe, due to the increasing number of sectors competing for female labour for personal service work that carries a better image than home care services for the elderly. Home care work is becoming more demanding in terms of skills and hours flexibility but is not offering any higher rewards. This is a job area unlikely to attract young female labour and is thus dependent upon the existence of an older, married women labour supply, but, as employment patterns become more continuous, the supply of women returnees for such work is likely to reduce, just as the demand for this work increases. Here we come up against the desire to move beyond traditional segmentation and to recognise a need to provide high wages in return for jobs with poor and difficult working conditions. We have perhaps become so accustomed to the use of segmented labour as the means of filling bad jobs that employers and employment specialists appear to have forgotten about the theory of compensating wage differentials; bad jobs should attract higher not lower pay. However, it is this segmentation perspective on labour supply that still drives much of the privatisation and subcontracting of public services on the expectation that private-sector organisations can secure labour at much cheaper rates than the public sector. These expectations may prove to be false, and instead the private subcontractors may face high rates of turnover, recruit undertrained and unreliable workers, and indeed fail to deliver the full level or quality of services. These problems are already recognised in the UK with respect to areas of male labour - such as the railways - but with female labour areas there is still the assumption that there is a plentiful supply at low-wage rates, and that therefore subcontracting may solve these problems of public service delivery at low cost. ${ }^{4}$ Of course, the increasing supply of migrant labour, both legal and illegal, may provide some temporary respite from these problems for employers, particularly if subcontractors are more able to tap into these supplies of low-paid labour than public sector organisations.

\section{Societal effects and segmentation}

The empirical work carried out within the NESY project has more than demonstrated the need for the analysis of developments in work and working time to be embedded within societal contexts. The sectoral analyses show, through their comparative analyses of the countries where the case studies were conducted, the continued significance of societal factors in shaping the employment and working-time outcomes. The particular 
dimension to the societal system that has explanatory importance may differ. For example, the extent and the organisation of home care is clearly related to the divergent development of welfare states and the different roles for the family and the state. In the banking study, the different systems of training - the apprenticeship system in Germany, in contrast to the continued internal labour market structure in France - are important for understanding the factors leading to a more core/periphery strategy based on functional flexibility in the branches in Germany. The absence of this strategy in France is related not only to the training system but also to product market regulation which limits the incentive to set up direct banking, since checking facilities have to be provided free to the public even within the branch system.

The form of employment regulation plays a major role in explaining differences in retail employment patterns and trends: in Denmark, the growth of short part-time jobs is related to the regulation limiting employees to working only one evening per week, while in France the specific mode of implementation of the thirty-five-hour week, favouring annualisation provides more opportunities for flexibility to be combined with full-time work.

The tradition of bargaining for relatively equal pay in both Sweden and Italy in part explains the lack of pay promotion opportunities for nurses in the two countries. Differences in tax and benefit regulations impact upon the development of non-standard work forms (for example, tax law favouring one-man companies in the UK IT sector, thresholds for tax and social security explaining the growth of direct employment by clients of home helps in the Netherlands). In all five case studies, the societal norms with respect to working time and the differences in the pattern of women's integration into the labour market were found to play a significant role in shaping comparative outcomes. Even in IT, where a superficial analysis points to many areas of similarity - a new sector, staffed by young, highly educated people, with a lot of self-directed, self-organised work involving long working hours - one finds societal norms still influencing what actually constitutes long working hours, with the working hours for British IT specialists being much longer in the UK than in the Netherlands or Finland where on average full-time hours tend to be both shorter and more regulated, even in this sector.

However, the case studies also support critics of a pure societal effect framework; namely, that a comparative focus might concentrate too much on the reproduction of difference and fail to pay sufficient attention to the key driving forces for change. These forces work themselves out within a societal context and are shaped by that context, but are also challenging as well as renewing the societal system. A segmentation approach places at the centre of the analysis the continuing struggles between capital and labour, and the associated patterns of competition among capital and among labour force groups. The case studies provide ample examples of 
divergences in strategies pursued by organisations even within the context of the same societal system and even where the societal system is relatively well institutionalised. For example, to take the case of Germany, divergent strategies at the organisation level were found in all three sectors studied; in retail the case study organisations were pursuing a quality strategy while other organisations were focusing on cost reduction to the extent of evading the collective agreement; in banking, one case study organisation offered full service direct banking based on well-trained staff but the other direct bank only offered a more limited service based on less well-trained staff; IT companies were found to be surviving through, at one extreme, extensive training provision and, at the other, through poaching highly trained staff. In countries such as Portugal where the institutional framework for supporting the societal system is perhaps weaker, the new retail companies studied were introducing human resource strategies quite at odds with the preferences of the labour supply. The scope for organisational strategy in reshaping employment must thus remain centre stage. This applies even within the public sector where individual authorities and public bodies were found to be adopting quite different solutions to new budget constraints, for example, opting for subcontracting in some cases and Taylorisation of public service work in others, even within the same country.

A segmentation approach also focuses on the divisions within a particular society, and how these workforce divisions are used in the process of restructuring, while a societal analysis may overstress the homogeneity of the societal employment system and indeed the neat matching between employment opportunities and the socially constructed labour supply. The need therefore is for an integrated analysis of these two approaches.

This need for an integrated approach may be seen particularly when considering the autonomy of organisations in responding to changes in market and technological conditions. Most work at the organisation level overstresses the autonomy of organisations and fails to see how there needs to be a compatibility between strategies pursued at an organisation level and the existence of a supportive social and economic environment. Support, for example, for a 'high road' strategy, may require a strong institutional environment that pushes most organisations in a similar direction. It is this recognition of complementarity between organisations and their environment that has underpinned the debate on the existence of alternative and potentially better models of capitalism (see Coates (2000) for a review). However, it also follows that where a societal system is strongly instituted, the degree of freedom for the organisation to pursue an alternative strategy at odds with the established norms and conventions of the societal system may be limited. From this framework, the societal system may be seen to act to both support and constrain adaptation.

Such theoretical possibilities are also evident within the case studies conducted here. Banking provides an interesting case where the legacy of 


\section{Jill Rubery}

past institutionalised high-quality employment systems may be restricting processes of adaptation or even encouraging, in the case of Germany, a process of polarisation. In France, the success of the internal labour market system in generating a stable and loyal labour force is evident in the very long tenure of its banking staff. This outcome may have been the desired result when initially instituted, but to some extent it constitutes a barrier to restructuring not encountered, for example, by banks in the UK where labour turnover rates have always been much higher than in France (Crompton et al. 1991; Rubery 1995). Renewing skills and refocusing on selling techniques has thus been facilitated, albeit within a context of a deregulated system providing a low quality of employment. In Germany, there has been a more rapid development of direct banking than in France, in part because product market regulation requiring free checking services has reduced the competitive incentive for direct banking provision. However, in Germany, direct banking has been introduced primarily in separate organisations outside the scope of the collective agreement for the sector. This is resulting in a polarised job structure, between highly trained and functionally flexible branch staff, and younger, sales-oriented, direct banking staff often drawn from the student population. In the UK the restructuring towards direct banking has taken place both within and outside the traditional main labour forces, involving a more radical cutting back of branches and staff than yet experienced in the German and French cases and a reduction in protection provided by collective agreements even for core staff (Rubery et al. 2001b). Here the weakness of the institutionalised training system and collective bargaining arrangements has facilitated a move towards a new sales-oriented culture. This strategy is not without its problems in the UK, and to some extent has led to new policies to improve training and career structures (Beynon et al. 2002). Nevertheless, it is also not clear that the slower pace of adaptation in Germany and France will in the end result in a strong banking sector. This depends in part on regulation and whether cost-cutting financial organisations, from, for example, the UK, are able to enter and destabilise the financial markets in these countries.

A similar dilemma exists with respect to IT. The current weakness of institutions in most countries studied is leading to problems of both sustaining and renewing skill levels and in establishing acceptable workingtime norms compatible, in particular, with long-term careers and with greater gender equality. Some countries, notably Germany and Finland, are showing signs of attempting to institutionalise the sector to solve some of the problems of both skill shortage and excessive working hours. In Finland, working times within the large organisations are apparently effectively regulated by collective agreements. Moreover, attention is being paid to training requirements within organisations, with staff required not to exceed a certain share of billable hours in order to provide time for training and retraining. In Germany, new collective 
agreements have been developed on training and working time in a context where there has been consolidation of employer associations and unions to improve the coherence of regulation for the sector. In addition, a major expansion of apprenticeship training has been undertaken, thereby further institutionalising IT within the dual system.

While these strategies to institutionalise and professionalise the sector should be welcomed, it must be recognised that more exploitative and opportunistic approaches may still win out in the short term. In a context of rapid changes in the nature of skills and the organisation of the industry at a worldwide level, there could be a danger in institutionalising too early, and thereby locking a sector into a set of arrangements that quickly become outmoded. This follows the argument of Lazonick (1991) and others in the Schumpeterian tradition (see Coates (2000: 37-40) for discussion) that the decline of the UK economy may be explained in part by 'entrenched institutions' that constrained the ability of the country to adjust to new conditions. It may only be in maturing markets that it becomes possible to require firms to accept the burden of reproducing the skills on which they rely. However, one solution to this problem is to develop institutions that have a built-in capacity for flexibility and adaptation.

Two arguments are being made here. First, high quality in the area of employment and the real economy does not always lead to economic success. Increased international integration of markets may allow for increased rewards for exploitative behaviour, reducing opportunities to regulate and to create more orderly and sustainable systems. Second, although institutions are necessary to support high-quality employment and to provide the appropriate environment for innovation and creativity, the danger of institutional mismatch still exists. In some contexts they may become outdated and ill-adjusted to new conditions, while in others they may be set up before the sector or labour market matures. While these are certainly risks, failure to re-institutionalise the market represents an even greater danger.

\section{Conclusions}

This analysis of the processes and factors reshaping work and working time in services has been based around the reformulated segmentation theory approach. This reformulated approach continues to stress the importance of the organisation in shaping work and working time but regards the structure and form of organisations as shaped by both the societal system and by the new strategies of competition. These strategies include new ways of reforming and redefining the employment relationship as well as strategies to reduce costs, improve efficiency or gain market share. How services are provided - the organisational and ownership structure - is likely to have the most significant impact upon work and 


\section{Jill Rubery}

working time. However, organisations are embedded in specific societal systems and arrangements (Granovetter 1985), so that the impact of, for example, organisational variables such as size, governance structure or ownership will not take on universal meaning and form.

The segmentation perspective stresses that the forces shaping the processes of change must be considered to be wider than those of meeting new technological and market needs and opportunities; equally important will be the new opportunities to renegotiate the internal power relations associated with the employment relationship. Thus change is not necessarily in the direction of greater technical or organisational efficiency but may be part of a process of redistributing power and access to material well-being. In part, the process reflects and reinforces patterns of labour supply segmentation. However, this segmentation is also in the process of being reshaped, by social as well as labour market trends. It is in this mutual interaction between the structure of jobs (including pay and working-time arrangements) that we find both reinforcement of and challenge to traditional divisions and patterns of segmentation.

This framework has therefore reaffirmed the social construction of the product and labour market and rejected any notion of market or technological determinacy in the structuring of employment patterns. The analysis presented here suggests that there is a need for re-regulation rather than deregulation if we want to improve the ability of organisations to pursue the type of high-road employment and product strategy necessary to secure both European competitiveness and European living standards within the new service economy. However, the analysis has also pointed to the potential limits to this policy agenda; new institutions are needed to provide support for positive developments in the product and labour markets, but the exact form that these institutions need to take is unclear. The employment problems that need to be managed appear to have become more complex and diverse, in comparison to the rather simple problem of internalising firm-specific skills and externalising flexibility that initiated the segmentation and the transactions cost debates. Furthermore, the internationalisation of markets and the political predisposition in favour of deregulation create potential obstacles to the development and renewal of institutions.

\section{Notes}

1 This gender blindness was particularly evident in the initial stages of the development of the European employment strategy, where the fact that new jobs were filled more by the inactive than by the unemployed labour force was not seen to be related to gender issues (see Rubery and Maier 1995) as a critique of the European Commission's White Paper on Growth, Competitiveness, Employment (CEC 1993).

2 But not market-determined pay, as the reward structure may be even more inter- 
nally based where it is linked to the performance or productivity of an individual in a particular organisational environment.

3 The influence of gender in shaping employment arrangements may be greater than that of other equally or even more disadvantaged groups such as migrants, in part because of the sheer size of the female disadvantaged labour force. This leads to many occupations and sectors becoming associated with female labour and indeed, over time, organised according to a different set of social relations reflecting the gender order.

4 The Audit Commission has decided that private subcontractors are more efficient for work in unsocial hours, since it assumes that they are able to provide a supply of labour that does not require compensation for unsocial working hours (Fagan and Nixon 2000). Whether the supply of labour is of sufficient quality and reliability does not seem to be the key issue.

\section{References}

Almond, P. and Rubery, J. (2000) 'Deregulation and societal systems', in M. Maurice and A. Sorge (eds) Embedding Organizations: Societal Analysis of Actors, Organizations and Socio-economic Context, Amsterdam: John Benjamins Publishing.

Arthur, M.B. and Rousseau, D.M. (1996) The Boundaryless Career: A New Employment Principle for a New Organizational Era, New York: Oxford University Press.

Berger, S. and Piore, M. (1980) Dualism and Discontinuity in Industrial Societies, Cambridge: Cambridge University Press.

Best, M. (1990) The New Competition, Oxford: Polity Press.

Beynon, H., Grimshaw, D., Rubery, J. and Ward, K. (2002) Managing Employment Change: The New Realities of Work, Oxford: Oxford University Press.

Cappelli, P., Bassi, L., Katz, H., Knoke, D., Osterman, P. and Useem, M. (1997) Change at Work, New York: Oxford University Press.

Castells, M. (1996) The Information Age: Economy, Society and Culture. Volume 1. The Rise of the Network Society, Oxford: Blackwell.

Coates, D. (2000) Models of Capitalism: Growth and Stagnation in the Modern Era, Cambridge: Polity Press.

Commission of the European Communities (CEC) (1993) Growth, Competitiveness, Employment: The Challenges and Ways Forward into the 21st Century, White Paper, Luxembourg: Office for Official Publications of the European Communities.

Craig, C., Garnsey, E. and Rubery, J. (1985) 'Labour market segmentation and women's employment: a case study from the United Kingdom', International Labour Review 124: 267-80.

Craig, C., Rubery, J., Tarling, R. and Wilkinson, F. (1982) Labour Market Structure, Industrial Organisation and Low Pay, Cambridge: Cambridge University Press.

Crompton, R., Hantrais, L., Le Feuvre, N. and Walters, P. (1991) Women in Professional Occupations in France and Britain, DV/342/91-EN, Brussels: European Equal Opportunities Unit, European Commission.

Crouch, C. (2000) Social Change in Western Europe, Oxford: Oxford University Press.

Csonka, A. and Boll, J.L. (2000) 'IT services in Denmark', Final country report for the New Forms of Employment and Working Time in the Service Economy (NESY) project, Danish National Institute of Social Research.

Cutler, T. and Waine, B. (1994) Managing the Welfare State: The Politics of Public Sector Management, Oxford: Berg Publishers. 
Doeringer, P.B. and Piore, M.J. (1971) Internal Labour Markets and Manpower Analysis, Lexington, MA: D.C. Heath.

Esping-Andersen, G. (1993) Changing Classes: Stratification and Mobility in Post-industrial Societies, London: Sage.

Fagan, C. and Nixon, D. (2000) 'Home care services for the elderly in the UK', country report for the New Forms of Employment and Working Time in the Service Economy (NESY) project, Manchester: European Work and Employment Research Centre, University of Manchester Institute of Science and Technology (UMIST).

Felstead, A. (1993) The Corporate Paradox: Power and Control in the Business Franchise, London: Routledge.

Froud, J., Haslam, C., Johal, S. and Williams, K. (2000) 'Shareholder value and financialisation: consultancy promises, management moves', Economy and Society 29(1): 80-110.

Gospel, H.F. (1992) Markets, Firms and the Management of Labour in Modern Britain, Cambridge: Cambridge University Press.

Granovetter, M. (1985) 'Economic action and social structure: the problem of embeddedness', American Journal of Sociology 91: 481-510.

Grimshaw, D. and Rubery, J. (1995) 'Gender and internal labour markets', in J. Humphries and J. Rubery (eds) The Economics of Equal Opportunities, Manchester: Equal Opportunities Commission.

- (1998) 'Integrating the internal and external labour markets', Cambridge Journal of Economics 22(2): 199-220.

Grimshaw, D., Vincent, S. and Willmott, H. (2002b) 'Going privately: partnership and outsourcing in UK public services', Public Administration 80(3): 475-502.

Grimshaw, D., Beynon, H., Rubery, J. and Ward, K. (2002a) 'The restructuring of career paths in large service sector organizations: "delayering", upskilling and polarisation', The Sociological Review 50 (1): 89-116.

Harvey, M. (1999) 'Innovation and competition in UK supermarkets', CRIC Briefing Paper No. 3, Manchester: ESRC Centre for Research on Innovation and Competition, University of Manchester.

Jacoby, S.M. (1984) 'The development of internal labour markets in American manufacturing firms', in P. Osterman (ed.) Internal Labour Markets, Cambridge, MA: MIT Press.

- (1994) 'Managing the workplace: from markets to manors and beyond', in C. Kerr and P. Staudohar (eds) Labor Economics and Industrial Relations, Cambridge, MA: Harvard University Press.

Klein, N. (2000) No Logo, London: Flamingo Press.

Lazonick, W. (1991) Business Organization and the Myth of the Market Economy, Cambridge: Cambridge University Press.

Lepak, D. and Snell, S. (1999) 'The human resource architecture: towards a theory of human capital allocation and development', The Academy of Management Review 24(1): 31-48.

Marglin, S. (1974) 'What do bosses do? The origins and functions of hierarchy in capitalist production', Review of Radical Political Economy 6: 60-112.

Marsden, D. (1986) The End of Economic Man?, Brighton: Wheatsheaf Books.

— (1999) The Theory of Employment System, Oxford: Oxford University Press.

Maurice, M., Sellier, F. and Silvestre, J-J. (1986) The Social Foundations of Industrial Power: A Comparison of France and Germany, Cambridge, MA: MIT Press. 
Nohria, N. and Eccles, R. (eds) (1992) Networks and Organizations: Structure, Form and Action, Boston, MA: Harvard Business School Press.

Osterman, P. (ed.) (1984) Internal Labour Markets, Cambridge, MA: MIT Press.

— (1987) Comments on H.I. Hartmann, 'Internal labour markets and gender: a case study of promotion', in C. Brown and J.A. Pechman (eds) Gender in the Workplace, Washington, DC: The Brookings Institution.

Petit, P. (1986) Slow Growth and the Service Economy, London: Frances Pinter.

Rubery, J. (1978) 'Structured labour markets, worker organisation and low pay', Cambridge Journal of Economics 2(1): 17-37.

(1994a) 'Internal and external labour markets: towards an integrated framework', in J. Rubery and F. Wilkinson (eds) Employer Strategy and the Labour Market, Oxford: Oxford University Press.

- (1994b) 'The British production regime: a societal-specific system?', Economy and Society 23 (August): 335-54.

— (1995) 'Internal labour markets and equal opportunities: women's position in banks in European countries', European Journal of Industrial Relations 1(2): 203-27.

- (1996) 'The labour market outlook and the outlook for labour market analysis', in R. Crompton, D. Gallie and K. Purcell (eds) Changing Forms of Employment: Organisations, Skills and Gender, London: Routledge.

— (1998) 'Part-time work: a threat to labour standards?', in J. O'Reilly and C. Fagan (eds) Part-time Prospects: Part-time Work in Europe, North America and the Pacific Rim, London: Routledge.

Rubery, J. and Fagan, C. (1993) 'Occupational segregation of women and men in the European Community', Social Europe Supplement 4/94, Luxembourg: Office for Official Publications of the European Communities.

Rubery, J. and Maier, F. (1995) 'Equal opportunity for women and men and the employment policy of the EU: a critical review of the European Union's approach', Transfer: European Review of Labour and Research 1(4): 520-32.

Rubery, J. and Wilkinson, F. (1994) Employer Strategy and the Labour Market, Oxford: Oxford University Press.

Rubery, J., Smith, M. and Fagan, C. (1999) Women's Employment in Europe: Trends and Prospects, London: Routledge.

Rubery, J., Grimshaw, D., Smith, M. and Figueiredo, H. (2001a) 'Gender equality and the European employment strategy: an evaluation of the NAPs for employment 2001', European Expert Group on Gender and Employment Report to the Equal Opportunities Unit, DG Employment. Available online at: www.umist.ac. uk/management/ewerc/egge/egge.htm (accessed 5 July 2004).

Rubery, J., O'Reilly, J. and Morschett, S. (2001b) 'Reorganising internal labour markets: working time flexibility as a process of integration or exclusion in the British and German banking sector', in J. O'Reilly, I. Cebrián and M. Lallement (eds) Working Time Changes, Cheltenham: Edgar Elgar.

Rubery, J., Grimshaw, D., Earnshaw, J., Marchington, M., Cooke, F-L. and Vincent, S. (2002) 'Changing organizational forms and the employment relationship', Journal of Management Studies 39(5): 645-72.

Rubery, J., Grimshaw, D., Earnshaw, J., Cooke, F-L. and Marchington, M. (2003) 'Contracts, co-operation and employment relationships: working in a multiemployer environment', British Journal of Industrial Relations 41 (2): 265-89.

Siltanen, J. (1994) Locating Gender: Occupational Segregation, Wages and Domestic Responsibilities, London: UCL Press. 


\section{Jill Rubery}

Smith, C. and Meiksins, P. (1995) 'System, societal and dominance effects in crossnational organisational analysis', Work, Employment and Society 9(2): 241-68.

Smith, M. (2001) 'Information technologies in the United Kingdom', country report for the New Forms of Employment and Working Time in the Service Economy (NESY) project, Manchester: Manchester School of Management, University of Manchester Institute of Science and Technology (UMIST).

Sorge, A. and Warner, M. (1980) 'Manpower training, manufacturing organization and workplace relations in Great Britain and West Germany', British Journal of Industrial Relations 18: 318-33.

Supiot, A. (2001) Beyond Employment: Changes at Work and the Future of Employment Law in Europe, Oxford: Oxford University Press.

Wilkinson, F. (1983) 'Productive systems', Cambridge Journal of Economics 7: 413-29.

Williams, K. (2000) 'From shareholder value to present-day capitalism', Economy and Society $29(1): 1-12$.

Williamson, O.E. (1985) The Economic Institutions of Capitalism: Firms, Markets, Relational Contracting, New York: Free Press. 


\title{
12 The delegation of uncertainty Flexibility and the role of the market in service work
}

\author{
Steffen Lehndorff and Dorothea Voss-Dahm
}

\section{Introduction}

The great variety and heterogeneity of the service sector are reflected in the equally differentiated reality of service-sector work. The researchers engaged in the project in which this volume has its origins encountered this diversity in a number of different ways. The qualitative studies, which focused on activities at the customer interface, were carried out in areas of the service sector that could not have been more diverse. All the three major types of service work identified by Reich (1991) were represented, from 'symbolic analysts' via 'in-person service workers' to 'routine workers' in so-called 'simple' service jobs. Furthermore, the study included a wide range of different countries, with very different systems of labour regulation. It was precisely this diversity that induced us to look for common trends in the changes taking place in the work process. This is the subject of this chapter.

If we were looking for one word that might sum up the typical demands of work at the customer interface, then 'flexibility' would certainly be one of the prime candidates. The flexibility requirements of service work are in fact considerable, whether the flexibility be temporal, mental or technical in nature. However, in a society in which a 'fetishism of flexibility' (Hyman 1994) prevails, it is reasonable to suppose that there is more to these flexibility requirements than meets the eye, that they are in fact a symbol of the proximity to the market that is allegedly inherent in all service work. The supposed close link between service work, flexibility and the market, which is frequently portrayed as 'natural' and therefore unavoidable, led us to enquire into the connections between 'flexibility' and 'market' in service activities. How are stimuli from the external environment brought to bear on the internal workings of service organisations? What does it mean when we say that the market requires work organisation to be made more flexible? 


\section{Flexibility through competition}

Service organisations and service workers have to adapt qualitatively to individual customer requirements and rapidly shifting market conditions. Moreover, they have to adapt quantitatively to considerable fluctuations in demand over time. Finally, since many services are required and consumed outside normal working hours, more and more people will be forced to work at times when other people are not working. It is true that the need for flexibility is not specific to the service sector. However, it is of particular importance in those services whose product can be stored only to a limited extent since it is produced and consumed more or less simultaneously. The effects of this simultaneity may have been limited to some extent by various rationalisation measures of a technical and organisational nature but its impact continues to be felt at the so-called 'front line', as was observed at the customer interfaces in social services, retailing, banking and IT services in our sample.

These observations, which are set out in detail in Part II of this volume, raise the question of how modern service organisations manage to transfer the need for flexibility created by the uncertainties of changing market conditions and fluctuations in demand on to the shoulders of individual employees.

\section{Beneath the surface of the 'flexible firm'}

Personnel flexibility has long been an object of theoretical and empirical investigation in the extensive literature on organisational flexibility (see the comprehensive surveys in Blyton and Morris (1991) and, more recently, in Igalens et al. (2002)). The reference point for such investigation is frequently Atkinson's notion of the 'flexible firm' (Atkinson 1984). One of the key elements in Atkinson's model is the suggestion that firms should adapt to changes in products and production methods by establishing a core workforce whose "central characteristic ... is that their skills cannot readily be bought in' (p. 29). Fluctuations in volumes, on the other hand, may be more easily absorbed by the use of various supplementary groups of workers with weaker ties to the company. It is assumed that these 'peripheral groups' include temporary and part-time workers who have mostly low-level and therefore readily interchangeable qualifications. In essence, functional and numerical flexibility are provided in this model by different segments of the internal labour market, which, at an early stage of the model's development, raised the question of the possible interactions between such personnel strategies and the external labour market (Rosenberg 1989).

Even though the extent to which human resource management practices actually follow this model is still a matter of some dispute (see Rainnie 1998), it undoubtedly makes sense to begin by systematising the 
instruments which firms can use to increase their flexibility. It soon becomes clear, however, that the model cannot fully explain the methods which firms actually adopt in order to increase numerical and functional flexibility.

There are various reasons for this. In order to understand how firms are able to convert external flexibility requirements into personnel flexibility, a light needs to be shone into the 'black box' of work organisation, including working-time organisation. Firms seeking to increase workforce flexibility cannot simply help themselves to a range of instruments stored in some imaginary toolbox. To take one example, the deployment of agency or other temporary workers in teams of skilled workers may well create more problems than it solves. There is a wide range of possible combinations of instruments that may be used to increase personnel flexibility (Figure 12.1). However, it is only when mediated by the system of work organisation that various 'flexibility configurations' actually emerge (Gadrey et al. 1999). The various elements of these configurations are located within an overall context which interacts with the firm's external environment, and particularly with the labour market. These flexibility configurations may be structured in various ways, and that structuring is guided by models which are 'implicitly or explicitly based on particular approaches to the utilisation of human resources' (Bosch 1995: 5).

The fact that the process of structuring flexibility is dependent on particular models of or approaches to personnel policy can easily be demonstrated by the way service organisations are trying to cope with the need for time flexibility. The crucial aspect here is the devolvement of managerial responsibilities to employees. When tasks are broken down into small units and standardised procedures, as, for example, in the retail trade (see Jany-Catrice and Lehndorff, Chapter 9, this volume), workers can, in theory, be replaced at any time at short notice and staffing levels varied greatly in accordance with need. In this form of work organisation, time flexibility is based essentially on workers, including core staff, making

\begin{tabular}{|c|l|l|}
\hline Internal & \multicolumn{1}{|c|}{ Quantitative (numerical) } & \multicolumn{1}{|c|}{ Qualitative (functional) } \\
$\begin{array}{l}\text { Working-time organisation: } \\
\bullet \text { variable working times }\end{array}$ & $\begin{array}{l}\text { Work organisation: } \\
\bullet \text { multi-tasking, multi-skilling } \\
\bullet \text { job enrichment, job rotation } \\
\bullet \text { delegation of responsibilities }\end{array}$ \\
\hline External & $\begin{array}{l}\text { Outsourcing of working time: } \\
\text { • temporary contracts } \\
\bullet \text { agency staff } \\
\text { - subcontractors }\end{array}$ & $\begin{array}{l}\text { Outsourcing of competences: } \\
\text { • subcontractors } \\
\bullet \text { external companies } \\
\bullet \text { networks }\end{array}$ \\
\hline
\end{tabular}

Figure 12.1 Forms and methods of personnel flexibility (source: own representation, drawing on Atkinson (1984); Gadrey et al. (1999); Merllié and Paoli (2001)). 


\section{S. Lehndorff and D. Voss-Dahm}

themselves available at the times required by the organisation. If we were to apply Boyer's notions of 'offensive' and 'defensive' flexibility (Boyer 1986) to firms' human resource strategies, then this approach would be characterised as 'passive flexibility'. On the other hand, if firms are unable or unwilling to dispense with their employees' individual knowledge, abilities and experience, they tend to rely more heavily on their employees' self-management of work and working time. In contrast to firms' reliance on the mere availability of workers, this approach aims at exploiting the 'active flexibility' of the workforce. Obviously, what is observed in practice is a continuum between the two poles of passive and active flexibility. In large organisations, moreover, different approaches to flexibility are often pursued simultaneously, depending on the sphere of work involved and the specific flexibility requirements.

Finally, as already noted, any attempt to understand workforce flexibility must take into account the interaction with the labour market and its prevailing mode of regulation. The ways in which firms seek to adjust staffing levels to fluctuations in demand are very heavily influenced by national legal and institutional frameworks. Igalens et al. (2002) demonstrate this by taking the example of a European company that reacts to declining demand in a different way in each country in which it operates. The same applies to attempts to increase functional flexibility, which are closely linked to national training systems.

Thus differences in approaches to human resource management, in work organisation strategies and in institutional environments can lead to very different flexibility configurations. Within this diversity, however, there is a great deal of commonality. Beynon et al. (2002: 21) note that 'the distinction between the core and periphery has become increasingly blurred'. This trend is not confined to Great Britain, and in its broadest sense may be regarded as a gradual change in the relationship between external and internal flexibility, with the boundaries between the two becoming more porous. In a sense, external flexibility is the point of entry for a new, market-driven mode of control in service work. It is to this gradual change taking place under the surface of the 'flexible firm' that we now turn.

\section{The internalisation of external pressure}

External flexibility can be increased, in both numerical and functional terms, by means of various forms of outsourcing (see Figure 12.1). In contrast to large sections of the economic and management literature on this topic (cf. Plantenga and Hansen 1999), we approach outsourcing here solely in terms of the effects of external flexibility on service organisations' internal flexibility. The practice of outsourcing highlights a phenomenon that has attracted little comment. The 'outside world' from which an organisation derives its external flexibility is very often made up of 
organisations rather than of casual workers or individual freelancers. In many cases firms seeking to increase their external flexibility will draw on organisations that have no flexibility reserves other than their own internal ones. In short, the external flexibility of organisations relies to a great extent on the internal flexibility of other organisations. External flexibility thus intensifies the total pressure for flexibilisation within service organisations.

Let us take the example of software services. Outsourcing as a form of external functional flexibility is encountered very frequently in the IT industry. Atkinson, contradicting his general definitions of core and peripheral workforces, also mentions this possibility. It is common practice to buy in specialist knowledge that is required only occasionally from small firms or self-employed experts. Moreover, when large numbers of commissions are received, particularly at short notice, larger IT companies also tend to have recourse to external contractors (i.e. the boundaries between external functional and external numerical flexibility may become blurred as well). It must be emphasised that this phenomenon is most widespread in the UK, where until recently the tax legislation in force offered strong incentives for workers to provide services through the intermediary of one-person companies established for the purpose. However, it is encountered in all the countries investigated to a greater or lesser extent, irrespective of whether the external contractors are individuals or larger firms. In some cases this practice is taken even further, with teams within an IT company having to compete with each other as well as with external applicants for commissions.

A comparable process is found in some large retail firms, when the sale of certain products is delegated to concessions within department stores ('shops within shops'). In this type of outsourcing the contracts are awarded to specialists; quite apart from the opportunity to exploit pay differentials, as in other forms of outsourcing, this gives department stores the advantage of fixed rental revenue instead of fluctuating sales. At the same time, internal competition is established within the commissioning company.

Outsourcing is becoming increasingly important in home care services for the elderly. As Anxo and Fagan describe in Chapter 6 (this volume), the increased technical and professional requirements that now characterise the provision of such services frequently go hand in hand with increased functional differentiation, so that certain home help services (e.g. cooking) may be delivered by lower paid workers, thereby reducing overall labour costs. Once they have been split off in this way, non-professional services can be more easily outsourced, preferably to private providers.

This trend was also observed in all the countries investigated. Yet, in some countries, the boundaries between functional and numerical external flexibility become blurred when the provision of professional services in the 


\section{S. Lehndorff and D. Voss-Dahm}

evenings and at weekends is transferred to external subcontractors. This practice is furthest advanced in the UK, where widespread compulsory competitive tendering has been introduced. Private care providers offer longer service hours but, because they pay lower wages, may charge only two-thirds of the cost of public sector care services (Fagan and Nixon 2000). In Italy, too, if for different reasons, the strongly protected labour market in the public care sector has induced many local authorities to award comprehensive care contracts to non-profit cooperatives that employ people without vocational qualifications, preferably female immigrants, and pay lower wages for more flexible working hours than the public sector. The competitive advantage these organisations enjoy in the market for care services is self-evident, as is the pressure they place on the core workforce in local authority care services to adjust (Degasperi and Villa 2000).

It is true that the buying-in of specialist knowledge and the outsourcing of supplementary services may help to stabilise the commissioning organisation's internal processes and to protect them from disruption. However, the empirical studies on which this volume is based suggest that it is more likely that the increasing overlapping and intertwinement of different flexibility instruments will put greater pressure on skilled members of the core workforce to make the decisive contribution to both qualitative and quantitative internal flexibility. In this case, the unspoken implication is: 'What you can do, others can do as well.'

In this way, external flexibility is causing service organisations to be 'opened up' to a certain extent, thereby allowing the effects of market pressure and competition to penetrate organisations' internal processes (Döhl et al. 2000). This applies to competition both in the labour and produce markets. The internalisation of markets is a decisive factor in increasing personnel flexibility. In that sense, internalisation also means the instrumentalisation of markets.

And yet, organisations can internalise and instrumentalise only what is available for such purposes in the external environment. The actual forms of market internalisation and their consequences for employees, firms and customers depend to a large extent on how the relevant product and labour markets are organised in any given society. Drawing on an international comparison of the construction industry, Bosch and Philips (2003) have recently shown how differently countries deal with the longterm costs of construction (i.e. the training of the next generation of workers, the maintenance of health and safety, the compensation of workers for the instability of the industry and so on). In some countries these costs are externalised by firms, while in others political decisions ensure that they are internalised and reflected in product prices. The interrelation between the two may also be summarised as follows: the more opportunities firms have for externalising costs, the greater the pressure on their employees' working conditions generated by market internalisation.

The service industries investigated in this volume also provide some 
clues as to the importance of market structuring for employees' working and employment conditions. For example, if attempts are made to protect service quality, this changes the nature of the competition to which organisations are exposed. This point may be demonstrated by taking care services for the elderly as an example. The Italian cooperatives are subject to quality standards set by the local authorities. The British legislation, too, has recently been amended to stipulate that the decisive criterion in selecting tenders should be 'best value' rather than the lowest price, which is intended to counteract any tendency towards a decline in quality (shift of emphasis from input to output). The importance of both product and labour market quality standards set by the state is best demonstrated by the examples of the Scandinavian countries and the Netherlands, where outsourcing to private companies is indeed widespread, but in fact is limited largely to the provision of basic (i.e. non-professional) services, as care providers have to meet certain product quality standards and, as is the case in Sweden, local authorities award care contracts only to skilled workers with three-years' training.

This does not constitute a weakening of the market principle but rather an adjustment to the nature of markets, which never function in a vacuum. They are social constructs, and the mode of regulation stems from social policy decisions: 'A society has the markets it creates for itself' (Gadrey 2003: 74).

Thus when service organisations internalise markets, they become engaged in an interactive process. On the one hand, they are trying to exploit market pressure for their own ends; on the other hand, however, they are dependent on the structuring of the markets in a given society. Beynon et al. (2002: 241), reporting on the British experience, drew attention to this interrelationship: "The phrase "internalising the market" is often used as a shorthand for the traumatic break-up of structured employment conditions. What is needed is a critical account of the way the management of employment change is designed around the apparent need to meet market conditions.' It is to this subject that we now turn.

\section{Imposing markets on workers}

At first sight, it would seem that the service sector is particularly suited to the internalisation of markets. 'Front-line' service-sector workers deal directly with customers and can only provide their service when the demand for it arises. The need for a market-oriented approach to work appears to be something that many service workers face every day. Interestingly enough, though, it was manufacturing firms that were the first to take advantage of this phenomenon in order to implement market-based control by redefining all steps in the manufacturing process as service work. We begin our examination with a look at the basic ideas underlying this approach. 


\section{S. Lehndorff and D. Voss-Dahm}

\section{The market as an instrument of control}

One of the most remarkable examples of the use of the market as an instrument of control is the introduction of just-in-time production in the automotive industry (Lehndorff 1997). Just-in-time production was one of the major car-makers' key responses to the intensification of competition in markets that had become increasingly tight as a result of globalisation. The fundamental principle of this rationalisation strategy is 'production to order'. The productivity of industrial workers is driven up by turning their work explicitly into a service. They are squeezed between the imperative of reduced inventories, on the one hand, and orders received at short notice, on the other.

Both the reduced inventories and the short notice given for orders are manifestations of the intense cost competition and of car-makers' efforts to increase market share through product differentiation. Unlike their predecessors in the Taylorist mass production systems of previous decades, managers no longer seek to exclude these competitive pressures from their factories in order to disrupt the production process as little as possible and to exploit economies of scale to the full. Just-in-time production obeys a very different principle: the factory gates are opened up and the harsh winds of competition and the marketplace are allowed to blow into the factory's innermost recesses. The crucial point here is that the consequent pressure to rationalise is brought to bear not only on management but on the rest of the workforce as well. Employees come directly face to face with the imperatives of the marketplace and, moreover, under conditions determined by management. They are generally still subject to individual performance monitoring, but the pressure to rationalise is coming increasingly to the fore as a practical necessity. The key management skill in a just-in-time production system is to structure the work environment in such a way that dependent employees, exposed to the pressures of the market, became active agents of rationalisation.

At the same time, the economic imperative of keeping unit costs as low as possible through standardisation, high-capacity utilisation and high-unit volumes still has to be observed. The 'struggle of productive flow against market restriction' (Williams et al. 1994: 97) remains crucial even when inventories are as small and delivery schedules as tight as possible. Given the reduced inventories and the variation in terms of volumes and products, just-in-time production still seeks to maximise economies of scale. Hence, what we are witnessing today in mature product markets such as the automotive industry is a shift away from standardised products towards greater differentiation (i.e. customised, and standardised products based on the concept of modularity).

This model, which may be called 'customised mass production' or even the 'one-off assembly line', has started to appear in a very similar form in contemporary service providers. Work in both manufacturing and services 
is increasingly becoming both 'tailored and Taylorised' (Korczynski 2001: 86). The pressure of competition in various service activities, from retailing through banking to software development, has intensified considerably, and as a result products and processes have to be standardised in order to cut costs, and at the same time customised in order to retain or gain market share. In some cases, standardisation gives rise to forms of work organisation that are reminiscent of Taylorist mass production - we will return to this point below. Customisation, however, immediately places limits again on such neo-Taylorist systems. For as Korczynski (2002: 14) asks: 'What is the contested terrain here? Does the competition revolve around price or service quality?... The answer is that [service firms] have had to compete on both levels simultaneously' (emphasis in original).

This simultaneity poses a major problem. It is true that service organisations can achieve considerable economies of scale by standardising products and processes, and thereby increase their chances of surviving the price and/or cost competition. However, if service quality is to be ensured, then even more wide-ranging changes are required. It is the interaction between employees and customers that largely determines service quality. However, when the quality of a social interaction becomes a significant factor in competition, the opportunities for direct management control of the work process are reduced accordingly. Management is not itself an actor in this important interaction. It can of course lay down rules structuring the interaction and monitor compliance with those rules; after the event, however, 'product faults' can be eliminated only to a limited extent, unlike faults in goods manufactured on a production line. In the case of services at the customer interface, there is no quality control prior to delivery of the 'product', that is, the service itself.

In some service activities, such as call centres, attempts are now being made to compensate for this lack of opportunities for direct management control by increased use of monitoring and surveillance systems. However, Smith and Thompson (1998: 559) rightly point out that 'supplanting the concept of control with that of surveillance is particularly unfortunate in that it leads to a one-sided and top-down approach. Labour therefore disappears from the process partly because of the tendency to believe management monopolizes knowledge and marginalizes other representations and identities.' If management were to try to make surveillance the main means of controlling and monitoring service work, this would ultimately conflict with the goal of harnessing employees' individual attributes and abilities in order to enhance the quality of service provision (Weinkopf 2002). The opportunities for direct control of the work process are limited when service quality is to be achieved through a process of social interaction that is actively and competently structured by employees themselves.

Firms are consequently obliged to look for new ways of managing and 


\section{S. Lehndorff and D. Voss-Dahm}

controlling the work process. By bringing the competition in product and labour markets to bear on their own internal processes, they are turning the market into an instrument of control. However, behind the supposed anonymity of the market stands a more tangible actor, namely company management. It is of course the purpose of firms to interpret and influence current and future market requirements and to translate them into strategy. Indeed, their very existence depends on their success in doing so. Consequently, if the market is to be instrumentalised as a means of controlling decentralised units or individual employees within a firm, the rules governing employee behaviour have to be derived from the competitive conditions in the market and the outcomes desired by the firm. Internal markets are created and operated in accordance with rules laid down by company management. If, in its search for control of the work process, management takes the apparently roundabout route of exploiting market mechanisms, the workforce is faced with a form of indirect control (Peters 2001). As is shown in the next section, this places workers in a contradictory situation.

\section{Mobilising the subject}

The shift of emphasis from direct to indirect control may be observed in a variety of different forms in all the service activities investigated in this volume. Indicators of various kinds are one of the instruments frequently used to transmit the effects of competition into the innermost recesses of organisations.

In the retail trade and in IT services, benchmarks play a particularly important role in competition based on productivity and price, while in banks operating along American or British lines, completely new benchmarks for the profitability of whole corporate divisions have been established (see Haipeter and Pernod-Lemattre, Chapter 10, this volume). Moreover, in large firms in the private service sector, performance in equity markets is acquiring considerable significance as an indicator in its own right. As a result, investors are becoming customers, and, in many cases, customers who have the final say. Social services, such as health care or home care services for the elderly, are subject to similar pressures. For providers of care services, reduced resource allocations from the public purse are the most crucial restriction. The pertinence of Beynon et al.'s observation that 'the state has come to operate as stern a financial regime as the City' (Beynon et al. 2002: 266) extends far beyond Great Britain.

Basic data of this kind are used to create indicators and benchmarks for divisions, departments, teams or projects. Numerical indicators may be broken down into detailed time and task targets; they may also be applied globally, in which case it is left up to individual employees, teams or departments to decide how to meet or indeed surpass these targets. The large-scale retail trade provides an example of this last scenario. In many 
companies, head office provides the individual shops or departments with a benchmark figure for maximum staffing costs as a percentage of sales. This figure can be gradually reduced. It is then left up to the employees in the company's various operating units to manage their own staffing levels in accordance with this target (Voss-Dahm 2002). In many IT companies which provide their services on a project-by-project basis, a fixed price is negotiated with the customer for a particular package of services. This price is calculated on the basis of the expected total number of working hours needed to provide the service. This total number of hours (sometimes together with other indicators such as the percentage of indirect costs) then becomes the key figure in the controlling process.

In the public sector, the introduction of competition between public and private providers and the adoption of the financial controlling methods used by private enterprises have led to the market entering the world of social service provision. A market price now has to be found for goods that in the past were provided exclusively by the state. In the case of home care for the elderly, for example, the number of hours per 'care unit' is established (based on past experience or negotiation), and this indicator is then used as the basis for staff evaluation. As is the case in hospitals, this reference value may be derived from the available public sector budget, but it may also be established on the basis of competitive tendering involving private providers. These attempts are further advanced in the British health and elderly care systems than in other European countries.

If we look at the various forms of market-based control as a whole, they are made up essentially of two elements. On the one hand, individual departments or parts of the value-added chain are given greater responsibility, particularly for costs; in some cases they are made autonomous, and may compete with each other and with other players in the market. On the other hand, this operational decentralisation is closely linked with strategic recentralisation. Senior management defines benchmarks in the shape of quantitative indicators in order to be able to measure the success of decentralised units. Success (or otherwise) in meeting these targets determines the size of the budgets allocated to the various units.

The more rigorously the indicators are applied at the operational level of individual departments, the more strongly the "market-focused mode of control' (Dörre 2003) shapes employees' working days. This applies not only to the customer interface but to back-office activities as well. Marketbased control exposes workers directly to the pressures of the economic environment in which they operate, with a view to harnessing the problem-solving abilities of individual employees and their teams for the benefit of the company. Moreover, necessity being the mother of invention, every employee is to be pushed and driven by the circumstances to further develop his or her subjective potential in order to be able to meet the growing requirements of the work process (Moldaschl 2001). 


\section{S. Lehndorff and D. Voss-Dahm}

This puts workers in an ambivalent position. The challenge to their individual problem-solving potential brings with it considerable opportunities for the development of professional and personal competences. The work makes demands on the whole person. Many employees see this as an opportunity, and also as liberation from an excessively narrow division of labour. However, this challenge is entirely predicated on the firm shifting on to its workforce part of the risk associated with the conversion of manpower into output or performance. 'Employers who hire a worker usually know the price of labour services but do not know exactly what they will get for it. Labour is not a ready-made product but a "productive potential"' (Sengenberger 2002: 48). Employers who institute a system of indirect control that makes use of the market are simply delegating part of this uncertainty (that is, the entrepreneurial risk) to their workforce. When individual workers are given more responsibility and autonomy, a conflictive relationship to the wider work environment may result, particularly with regard to the resources that are required to perform their tasks satisfactorily. 'More freedom creates more pressure' (Glißmann and Peters 2001) is the motto that sums up this contradictory work situation.

However, analysis of this contradiction would be incomplete if we were to ignore the role of customers in the change in the mode of control in service work, and it is to this that we now turn.

\section{Between indicators and customers}

For front-line workers, the market has a physical manifestation in the shape of customers. It would of course be erroneous to equate the market fully with customers. In our view, this is brought out convincingly in the literature on customer service (cf. e.g. Sturdy et al. 2001; Holtgrewe and Voswinkel 2002). Yet if we are fully to understand the effectiveness of market-driven control in the daily life and work of service employees, it has to be remembered that this mode of control is implemented within a triangular relationship between management, workers and customers. Consequently, the increase in their individual output or performance may seem to employees both a practical necessity in the face of competition and a professional obligation vis-à-vis customers, and both can be a burden and a pleasure.

This is shown most clearly by the example of IT services. In software consultancy in particular, where customised solutions are developed or pre-existing and standardised packages are adapted to specific environments, customers are not merely recipients of services. They are frequently closely involved in the work process or in individual projects for long periods of time. In some cases it is senior managers who maintain contacts between the firm and its external environment, but in others it is more junior employees who work directly with customers. Management's remoteness from the operational level is even greater when IT services are 
provided on-site at the customer's premises. In these cases, the employees providing the services may have very little contact with their employers over long periods of time. Such conditions alone make direct management control of the work process difficult. The situation is further complicated by the fact that formal or informal exchanges among team members are an important element in the delivery of such services, particularly when work organisation is project-based. This applies especially to complex IT projects, in which the specialist knowledge of individual team members has to be repeatedly reassembled once partial solutions have been developed (Voss-Dahm 2000). At the same time, team members often enjoy considerable room for manoeuvre in organising their own work, and management is concerned to place as few limits as possible on their ability to realise their potential in their work. Accordingly, one of the Dutch IT service providers in our study has developed a corporate philosophy based on the 'triple V' principle (Plantenga and Remery 2001): vrijheid, verantwoordelijkheid, vertrouwen (freedom, responsibility, trust), a philosophy which could probably be adopted by many companies in this industry.

However, the technical demands of the task in hand are not the only factor that can influence the work process in IT services. The planning and execution of work tasks are also subject to financial and time restrictions that limit the resources available for developing the required technical solutions. The competitive environment in the market and the company's operating profit target are used to calculate the numerical indicators that determine the hard financial boundaries where vrijheid, verantwoordelijkheid, vertrouwen begin and end. Hence, employees' autonomy at work is constrained by the obligation to meet the targets set by the numerical indicators, which represent the company's competitive position. The greater the autonomy employees have in their work, the more important it is for companies to implement this kind of indirect control.

The coincidence of this considerable degree of personal freedom in work relations with colleagues and customers and limited financial and time resources creates contradictory demands. Employees have to respond to two different sets of requirements. On the one hand, they have to be customer-driven and produce high-quality work, both individually and collectively. On the other hand, they are expected to work both profitably and efficiently. In short, they have to reconcile service quality with cost efficiency. This is often not possible without an increase in workload. The room for manoeuvre they have acquired within a more open-ended system of work organisation now turns against them, since it is employees themselves who have to try to resolve the difficulties that have emerged on their own initiative and, in many cases, by putting in more time as well. The greater the restrictions management indicators place on the financial and human resources that may be deployed, the closer the links between 


\section{S. Lehndorff and D. Voss-Dahm}

self-organisation of work and the shifting of risk from the firm to individual employees.

There are striking parallels here with the health and care services sector, although the indirect control is not always immediately apparent there. In some care activities there are numerous regulations that prescribe in detail how the work is to be carried out. The breakdown of care services into individual work units that can be delivered by different groups of workers is actually increasing. In response to rising qualificational levels in care activities, organisations are looking for opportunities to split off simple activities in order to reduce costs. And yet, even when the work is to a large extent pre-structured by formal rules, care is not necessarily provided in accordance with these rules. The case studies reveal time and time again that care workers deliberately disregard rules in order not to compromise their own professional standards. 'When it comes to taking proper care of our clients we will not give in. We will not accept any reductions in quality' (quote from a home-helper in Csonka and Boll 2000a: 28). This concern for the client means that management can, in theory, dispense with precise instructions for the actual service delivery. Such organisations were also investigated in the course of our project. Management here 'merely' laid down the economic framework within which the various tasks had to be carried out and devolved responsibility for planning and executing the actual work to care workers themselves. Ackroyd and Bolton (1999) analysed comparable cases in British hospitals and concluded that management was implementing its economic targets by means of a 'remote control regime'. It fell to employees to use their professional skills in order to resolve the numerous and diverse organisational problems and guarantee service quality, while at the same time remaining within the budget drawn up by management.

This trend is encouraged by the rise in formal qualificational requirements in the care sector. It is most pronounced in Sweden, where the upper secondary school-leaving certificate is a requirement for entry on to nursing courses. The share of nursing personnel who have completed a recognised training course is rising in all the countries in our sample. Qualificational standards are being established or raised in the rapidly expanding home care sector as well, in some cases through legislation. As skill levels and qualificational requirements rise, workers' commitment to the occupation they have trained for and to the associated professional standards is strengthened. Indirect management control is both facilitated and made more effective if workers' professional pride and their need to organise their own activities autonomously and to ensure compliance with professional standards can be turned to good account. As financial pressures on the health and care services sector grow and competition within the sector and with private providers intensifies, this professional attitude to work is becoming a crucial asset that can be more effectively mobilised through the use of indirect forms of control than through the more traditional forms. 
Even in the retail trade - that is, in an industry which, together with call centres, is regarded as the most typical example of 'Taylorisation' in service work - similar trends are emerging. In large-scale retailing, the standardisation and decomposition of work processes, particularly in the areas of logistics and goods handling as well as at checkouts and cash tills, are already far advanced. This development is based on the use of information technology with the aim of putting in place highly standardised and automated goods-handling systems and increasing functional differentiation. At the same time, however, a second rationalisation principle may be seen at work. Hierarchies are being flattened as firms downsize, and planning and organisational tasks are assumed by sales staff. Central management sets targets for sales and return on capital that have to be achieved within a certain time. In sales areas, management by indicators is gaining ground over the traditional system of personal control by supervisors. As a result, staff see it as their responsibility to help to achieve the business targets set by management. If they do not succeed, management reserves the right to transfer sales staff, to reduce the volume of hours or to cut jobs. Only by achieving a certain level of economic success can employees be sure of keeping their jobs.

These two rationalisation principles are to some extent being pursued with a view to segmenting internal labour markets. On the one hand, there are employees engaged in highly standardised work processes that have been broken down into their constituent elements, many of whom are also contracted to work only a small number of hours; some of their co-workers, on the other hand, have deep and extensive knowledge of the company's internal processes. In all areas of retail activity, however, it is customer contact that determines service quality. Even in allegedly 'noncomplex' service jobs, as opposed to the industrial assembly line, 'basic manual work' is being replaced by 'basic communication work' (Bosch 2000). Employees must be present as personalities, as individuals, even if they are often subject to very narrowly defined rules regarding the nature of their communicative and emotional input. Consequently, retail sales staff are also finding themselves increasingly caught between customers and indicators. In order to be able to achieve their business targets, they have to provide a good service and take the customer-driven nature of their work seriously. At the same time, they constantly have to be aware of the fact that customers are being used by management as an instrument against them, since 'the customer is always right'. For this reason, retail sales staff are increasingly having to adapt their work rhythms to a changing situation, to take account of changing customer requirements, to use resources efficiently, and to identify and exploit potential for rationalisation.

As this brief survey demonstrates, elements of market-driven and indirect control may be observed in very diverse service activities. Service organisations are redesigning job tasks, but this redesigning entails 


\section{S. Lehndorff and D. Voss-Dahm}

additional responsibilities up to and including self-management of the actual performance of tasks. If we remember, as Ackroyd and Bolton (1999: 372) rightly point out, that the core of scientific management was the design of jobs, the depth of the change becomes apparent. In order for employees to be guided in their work by the twin objectives of service quality and cost-efficiency, current job design also includes its opposite, namely self-management.

Under these circumstances, organisational problems are being solved less and less by management but being handed on to more junior employees without management necessarily having to make available the required resources. Firms have created working conditions in which employee 'empowerment' is being actively used in order to reduce direct instruction and control. As a result, however, they are all the more dependent on controlling the work process indirectly by establishing a rigorous economic framework within which employees must operate. It is in the stress field between indicators and customers that service workers are being challenged to develop their subjective potential.

Examination of how the risks associated with flexibility are managed will demonstrate the effects this can have on working conditions in service activities.

\section{The risks of flexibility}

The market does not determine how work in a service organisation is structured. It is management's task to translate external stimuli into a strategy, and if, in so doing, it decides to use the market as an instrument of control, it is seeking to internalise and instrumentalise elements that already exist in the external environment. Thus it is that the substance and density of market regulation also impact on the internal workings of organisations. At the same time, however, this also means that firms may be able, as Rubery notes (Chapter 11, this volume), 'to use the opportunities of changes in competition conditions to reopen negotiations on the form of labour relations'. These political opportunities vary from country to country. Examination of the ways in which the risks associated with flexibility are managed allows us to observe both processes: the shifting of unresolved organisational problems on to the shoulders of employees, and the modification of this general trend by national labour market regimes and industrial relations systems.

\section{Availability at any time}

In their attempts to manage their temporal flexibility requirements, service organisations may adopt an organisational paradigm which we characterised above as 'passive flexibility'. Those that do so are interested primarily in workers' temporal availability and try simply to impose their 
requirements on workers. Practices of this kind were encountered most frequently in retailing. The most important instrument used for this purpose is part-time work.

However, this kind of personnel practice needs to take account of the situation in the external labour market. It should not be assumed that part-time work is generally flexible. On the contrary: most women - and hence most part-time workers in the EU - prefer part-time work because (or provided that) it is not flexible. From their perspective, the whole point of part-time work is that it is a means of combining labour market participation with domestic responsibilities, particularly caring for children. The higher the level of female labour market participation is, the more complicated it may be for firms to recruit workers for these noncomplex services. This applies particularly to countries in which the equal participation of women in the labour market is relatively far advanced and institutionally supported. Firms have either to make concessions to their female employees, by making only limited use of marginal part-time jobs, for example, and instead offering part-time jobs with hours close to the full-time level, or look for other target groups on the labour market.

In some countries they may be assisted in this reorientation of their recruitment strategies by high youth unemployment and less welldeveloped vocational training systems. In France, for example, it is often young women who are prepared to accept a retail job for a limited period of time. In Portugal, a country with an extremely low part-time rate, the large retail companies would be quite unable to pursue their part-time strategy if transitional groups, particularly young people, were not present in the labour market. However, drawing on the young unemployed as a last resort may not be the best or most sustainable way of solving the flexibility problem in large service industries. 'You need winners at the front lines, not just warm bodies' (Schlesinger and Heskett 1991: 17) is a piece of advice that many service managers have learned to take seriously, even in an environment characterised by fierce price competition. One compromise that may help to reconcile the fragmentation of working times with a certain level of worker commitment is to look to high school and university students. This recruitment strategy is becoming more and more important in some countries, in particular in Scandinavia, where the pool of economically active women interested in part-time work is shrinking. The value of high school and university students to employers is twofold: they are available to work at times other groups regard as unsocial and they bring with them a certain level of education that they provide gratis. This also makes them particularly sought after among some call centre managers as well (see Haipeter and Pernod-Lemattre, Chapter 10, this volume). However, not even these young people are generally available on call, but only at specific scheduled times. Thus making temporal availability alone a principal criterion of recruitment and HR practice creates precariousness not only for many workers but to some extent for firms as well. 


\section{S. Lehndorff and D. Voss-Dahm}

Ultimately, therefore, there is no getting around the need, even in the retail trade, for a stable group within the workforce, and one that, whenever possible, is not too small. These 'anchor workers' must be both functionally and temporally flexible. The effects of the requirement for temporal flexibility on these employees' working conditions can be influenced by legislation or collective agreements. In Denmark and the Netherlands, the particularly high shares of young part-timers in the retail trade (in 1999, according to the European Labour Force Survey, around 45 per cent of all retail employees in both of these countries were under age twenty-five) go hand in hand with a particularly high level of protection for 'anchor workers', enshrined in collective agreements, against demands for flexibility regarded as excessive. In the Netherlands, the relevant collective agreement stipulates that retail workers cannot be obliged to work after 6 p.m. on more than three evenings per week, while in Denmark the limit is just two evenings (Kirsch et al. 1999: 169; Boll 2000: 18). Retail workers in the Netherlands must be notified of any changes to their planned schedules one week in advance, while their counterparts in Denmark have to be given four weeks' notice. At any rate, in a survey conducted by the Dutch trade unions at the end of the 1990s, around threequarters of respondents stated that these regulations were respected in their individual cases (Kirsch et al. 1999: 170).

\section{Flexibility for free}

Social services offer a wealth of examples to illustrate what may be called the 'flexibility for free syndrome'. As service delivery times are extended, social service organisations are dependent on an increasingly skilled workforce that combines a high level of professional commitment with a willingness to accept the need for considerable time flexibility. The main difficulty is that the financial conditions under which such organisations operate are only imperfectly adapted, if at all, to these increased requirements. The restrictions arise either directly from the budgetary resources available to them or indirectly from competition with other providers. This leads to a sometimes highly problematic interaction between the twin challenges of ensuring high service quality, on the one hand, and recruiting an adequate number of suitable workers, on the other.

At first sight it may seem surprising that it can sometimes be difficult to recruit suitably skilled staff in this sector. After all, the trend towards professionalisation in the social services is in tune with the rising expectations of many women, who still account for the majority of workers in this area. Their skill and qualificational levels are rising and women are accordingly becoming increasingly concerned to use the knowledge, abilities and experience they have acquired in jobs that offer them full professional status. This should, in theory, create favourable conditions for the care service providers, which increasingly have to provide their skilled services 
at times outside the time slots preferred by part-time auxiliaries. Yet it is clear that they frequently do not manage to exploit this potential.

One important reason for this may be observed in the UK, although the practice is not confined to that country. Here, new employment contracts are being concluded without any agreement on the scheduling and distribution of working times, because it has proved impossible to put in place new arrangements for the workforce as a whole that would address the flexibility problem. The idea is to exploit staff turnover in such a way that employees on the new contracts will gradually replace those on the old ones. Qualification requirements for care workers are certainly being raised in Great Britain as well (with the state, surprisingly enough, regulating service quality standards to that end), but there are no national collective agreements that would improve both employment conditions and pay levels. The UK may be a conspicuous example, but the basic problem applies to some other countries as well, albeit to a lesser degree: higher levels of professionalism and a greater willingness to work flexibly are being expected of employees with nothing being offered in return flexibility at zero cost for the employing organisations and for the customers.

Under these conditions, care service providers come up against difficulties in seeking to extend their service delivery times. The outsourcing of services to private organisations occasionally provides a temporary solution. In Great Britain, for example, private care service agencies provide their services especially at times when the local authority providers find it difficult to deliver services. However, this then raises, in a particularly acute form, the problem of service quality in an area in which staff continuity is particularly important for the client/provider relationship. And yet if the pressure this form of external flexibility exerts on the internal organisation of local authority care services is exploited by management in order to rescind the fixed work schedules stipulated in workers' employment contracts, turnover will rise, which also has disastrous consequences for service quality. What is frequently lacking, obviously, are the frameworks - but usually above all the opportunities - for new, better funded compromises on flexibility to be put in place.

However, as may be suggested on the face of it by some examples of 'good practice', the ideal way of reconciling high professional standards with high levels of flexibility may be what we identified earlier as 'active' flexibility. It is true that some local authorities have solved their flexibility problems in the short term through a high degree of employee selfmanagement. In the medium to long term, however, local 'win-win' solutions may suffer from, and be endangered by, the limited financial resources made available to local organisations. This leads us to the third layer of problems involved with the delegation of uncertainties to employees. 


\section{S. Lehndorff and D. Voss-Dahm}

\section{Self-managed intensification and 'extensification' of work}

Work is becoming more intensive and the pace of work is increasing. A whole range of representative studies, including the Third European Survey on Working Conditions (Merllié and Paoli 2001), confirm that this is a widespread and growing phenomenon.

Management rhetoric extolling the value of employee empowerment may be heard in all countries and in all sectors of the economy. Consequently, it is particularly noteworthy that workers in very different industries have reported a gradual decline in the control they have over their own working conditions (defined by means of the following criteria: 'control over the sequence of the tasks to be performed, working methods and pace of work'). According to the survey cited above, 23 per cent of all service and sales workers in EU member states in the year 2000 were working 'continuously at very high speed'. Five years earlier, the figure was 20 per cent. The case studies on which this volume is based provide many detailed illustrations of this tendency.

In many service jobs, the pace of work is increasing while opening or operating hours remain fixed. The opening hours of a retail store, the shifts in a hospital or the hours during which home care must be provided all act as a framework within which work intensity is increasing. However, there are some jobs in which the scheduling and duration of working time are not fixed in advance. Particularly in the case of service providers that encourage and require their employees to use their own initiative and adopt an 'entrepreneurial' attitude, work is becoming more intensive and at the same time working time is also increasing. It is known from various surveys that workers report high work intensity (using such indicators as high speed, tight deadlines and lack of time to complete work) all the more frequently, the longer their usual working times are (Boisard et al. 2003: 19; Gerlmaier and Kastner 2003).

Work intensification and longer working hours are most likely to occur under conditions where only specific targets are defined (e.g. project deadlines, financial targets, goals agreed among individuals or groups) and where the practical implications of meeting those targets within the contractual working hours may become a matter to be resolved by employees themselves. As long as the employer has to pay for each hour actually worked, a precise match between planned work volumes and the resources required is more likely to be achieved. With projects, on the other hand, for which lump sum payments are agreed with clients, there is a tendency for internal work scheduling and, in particular, pay to be driven by results as well. As already noted with regard to market-based control, there is a great tendency under such conditions to make insufficient allowance for overheads. In the absence of formal regulations on overtime limits or pay, a frequent 'solution' is the (in many cases unpaid) extension of working hours. This form of individualisation of working- 
time conflicts reaches its peak in systems relying on so-called 'trust-based working time', which are mushrooming in Germany (Haipeter et al. 2002). Management of the flexibility requirements imposed upon the company becomes a concern for each and every employee. In the extreme case of ' $1: 1$ ', the company's temporal flexibility is translated into the individual's temporal flexibility.

For employees operating in a restrictive environment, increased autonomy to organise their own work and particularly long working times go hand in hand. Paradoxically, these workers are working long hours not despite but because of their autonomy. For them, 'this desperate time situation results directly from the removal of external coercion' (Kadritzke 2001: 4).

And yet, in the long term, this situation is not without its problems for firms as well. Unresolved organisational problems remain unresolved because working-time increases provide a safety-valve that is without cost for firms, at least initially. In the medium to longer term, however, failure to resolve organisational problems may be their downfall.

Thus the problem of extended working hours is obviously that the considerable potential for productivity gains and improvements in service quality created by the self-management of work and flexibility is not subject to any checks and balances within the wider organisational framework that would help to ensure the long-term social sustainability of this form of work organisation. Factors capable of counterbalancing the internal dynamic of working-time increases seem to come largely from external sources: 'Probably the most effective means of controlling working hours is having children, and at the same time to be the main care provider at home' (Csonka and Boll 2000b: 33).

Given certain preconditions, one external factor that can act as a counterweight to the organisational dynamic of working-time extension is the regulation of working time by legislation or collective agreements. A study of the Dutch health care system provides some interesting indications in this respect (Plantenga and Remery 2000: 6). In the mid-1990s, following a series of heated public disputes, the notoriously long working hours of hospital doctors were made subject to a statutory upper limit of forty-six hours per week. An evaluation of the act showed that full compliance with the new norm has not been achieved. However, the working times of junior doctors have been reduced substantially, due to growing public awareness fostered by the hotly debated law. The impact of public awareness or, more generally, societal norms on organisational working-time practices is also emphasised by the spread of part-time working in the Dutch IT sector, where firms have been trying to improve their competitive edge in the labour market for high-skilled specialist staff by offering shorter hours, with a view to attracting more women into this maledominated industry (Plantenga and Remery 2001).

The example of Finland, the home of some of the leading IT service 
providers, is worthy of note in this respect. Finland is the only country in our sample where the IT services industry is fully covered by collective bargaining. Given the distinctive working-time profile of Finland, i.e. an equal distribution of working-times among the working-age population, including a high full-time labour force participation of women and 'the concentration of working-times to the agreed hours', fostered by a large set of institutions (Julkunen and Nätti 1999: 41), even at the peak of the dot.com boom the discrepancies between working times in IT services and the respective national average were much smaller than in most other EU countries (Figure 12.2).

As the Finnish example suggests, societal working-time standards may acquire new significance for firms' organisational and working practices, including those in the IT sector. The need to pay every hour worked encourages Finnish IT service providers, or at least the larger ones, to plan and schedule carefully the number of hours required for each project and the resources necessary to cope with customers' expectations (Anttila and Nätti 2000). Thus even though societal working-time norms may come under pressure from new forms of work and international competition, they have in some cases proved to be powerful enough to deflect the pressure on to firms' internal processes, leading to improvements in the work process. Sengenberger's argument that the 'highperformance economies in Northern Europe' are at the same time world leaders in the firm establishment of 'standards of participation, protection and promotion' can be substantiated, right down to the operational level of the IT services industry. 'It is both necessary and possible for national policy to influence work organisation' (Flecker 2000: 445).

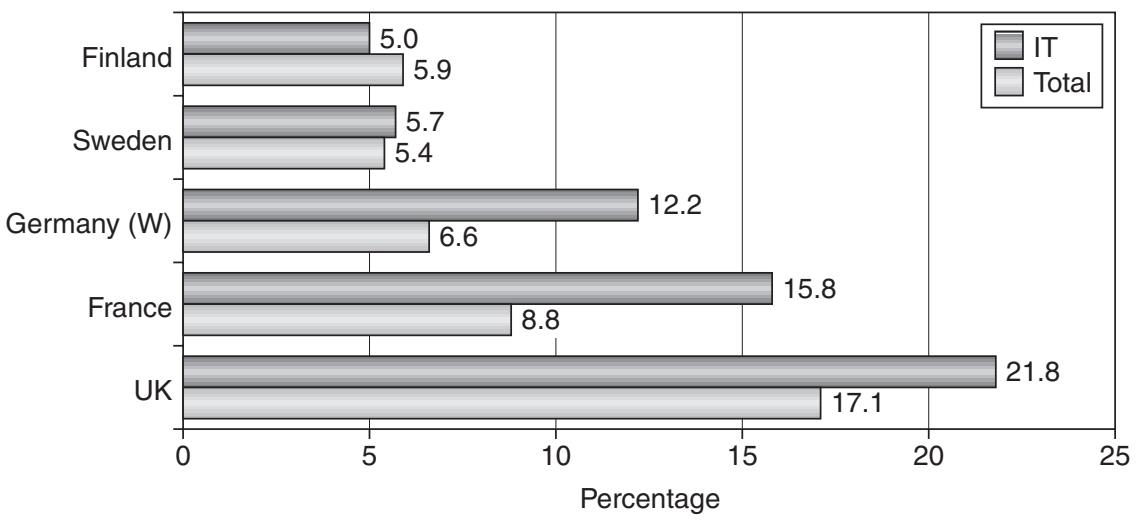

Figure 12.2 Share of employees working usually $48+$ hours per week, IT services and all sectors (1999) (\%) (source: Eurostat Labour Force Survey). 


\section{Conclusions}

The widespread view that service work and flexibility are two sides of the same coin and that closeness to the market is part of the natural scheme of things in service activities is a myth. Organisational flexibility is not synonymous with individual flexibility, and the market and customers are not one and the same thing. And yet there is some truth in the myth. Service organisations are increasingly structuring their external flexibility in such a way as to create a point of entry for the internalisation of the market and of competition, and for the establishment of a new, market-driven mode of control for service work. However, when the market is turned into an instrument for controlling the work process, uncertainties as to the relationship between performance, pay and working time - hitherto elements of entrepreneurial risk - are in part devolved to dependent employees. At the same time, such a policy offers firms new opportunities for calling into question the labour standards established in the so-called 'golden age' of economic growth in the decades immediately following the Second World War. Some of the risks this entails for employees in various areas of the service sector have been described by taking the example of the management of flexibility requirements. The findings presented here support the results of other international comparative studies in which service workers' employment and working conditions, particularly in typically 'feminine' service activities, are generally viewed in a negative light (cf. most recently Webster et al. 2002).

Nevertheless, we have emphasised that market-based control in service organisations has been influenced by policy and, moreover, remains susceptible to influence. This observation is more than a pious wish, since it is grounded not least in the very nature of markets (see Gadrey, Chapter 14, this volume). The history of markets is a history of the battle to regulate them. The market is an abstraction and at the same time, as a concept, an element in a strategy. This applies particularly to markets within organisations, which, as we have repeatedly stressed in this chapter, have to be established initially by senior management in order to be able to operate at all and are then further influenced by the existence (or otherwise) of external regulations.

The extent to which organisational flexibility can, with the aid of market-based control, be turned into a problem for individual employees is influenced by the situation in national labour markets, by labour market regulation and by industrial relations systems. This 'direct' influence on working conditions is of crucial importance, as the case studies in this volume show. However, the use of the market as an element in the control of service work is a form of indirect control that can be matched with 'indirect regulation', particularly in social services. This is shown by the examples given here of the possible effects on work organisation and working conditions of product market regulations. To that extent, the 


\section{S. Lehndorff and D. Voss-Dahm}

price of high-quality services, and particularly of good social services, is ultimately a political matter.

Employees' opportunities to turn to good account the contradictions and ambivalence inherent in the delegation of uncertainty depend largely on how politicians and policy-makers structure the environment to which firms seeking to put in place a form of market-based control have to adapt. Many individuals need a 'secure framework ... in order to be able to decode market risks as positive incentives for action' (Dörre 2003: 27). Market-based control is geared to mobilising employees' problem-solving competences in order to overcome problems within organisations, and, as is shown over the entire spectrum - in IT services, in hospitals, even in the retail trade - this employee competence is considerable. Employees who face the market equipped with only the slenderest resources and who, under increasingly difficult and stressful working conditions, master intricate difficulties on their own, are experts in the work process. They know best how working conditions should be shaped in order to produce goodquality service.

This message is not aimed solely at employers. Trade unions that are looking for ways to make good services part and parcel of their programme in a service society could also make use of this knowledge and these skills.

\section{References}

Ackroyd, S. and Bolton, S. (1999) 'It is not Taylorism: mechanisms of work intensification in the provision of gynaecological services in a NHS hospital', Work, Society E Employment 13(2): 369-87.

Anttila, T. and Nätti, J. (2000) 'IT services in Finland', country report for the New Forms of Employment and Working Time in the Service Economy (NESY) project, Jyväskylä: University of Jyväskylä.

Atkinson, J. (1984) 'Manpower strategies for flexible organizations', Personnel Management, August: 28-31.

Beynon, H., Grimshaw, D., Rubery, J. and Ward, K. (2002) Managing Employment Change: The New Realities of Work, Oxford: Oxford University Press.

Blyton, P. and Morris, J. (1991) 'A flexible future: aspects of the flexibility debates and some unresolved issues', in P. Blyton and J. Morris (eds) A Flexible Future? Prospects for Employment and Organisation, Berlin and New York: Walter de Gruyter.

Boisard, P., Cartron, D., Gollac, M. and Valeyre, A. (2003) Time and Work: Duration of Work, Dublin: European Foundation for the Improvement of Living and Working Conditions.

Boll, J.L. (2000) 'The retail trade in Denmark', country report for the New Forms of Employment and Working Time in the Service Economy (NESY) project, Copenhagen: Danish National Institute of Social Research.

Bosch, G. (1995) 'Flexibility and work organisation', Report of Expert Working Group, Luxembourg: European Commission, Directorate General for Employment, Industrial Relations and Social Affairs. 
'Entgrenzung der Erwerbsarbeit: Lösen sich die Grenzen zwischen Erwerbs- und Nichterwerbsarbeit auf?', in H. Minssen (ed.) Begrenzte Entgrenzungen: Wandlungen von Organisation und Arbeit, Berlin: Edition Sigma.

Bosch, G. and Philips, P. (2003) 'Introduction', in G. Bosch and P. Philips (eds) Building Chaos: An International Comparison of Deregulation in the Construction Industry, London: Routledge.

Boyer, R. (1986) La flexibilité du travail en Europe: une étude comparative des transformations du rapport salarial dans sept pays de 1973 à 1985, Paris: Editions La Découverte.

Csonka, A. and Boll, J.L. (2000a) 'Home care for the elderly in Denmark', country report for the New Forms of Employment and Working Time in the Service Economy (NESY) project, Copenhagen: Danish National Institute of Social Research.

- (2000b) 'IT services in Denmark', country report for the New Forms of Employment and Working Time in the Service Economy (NESY) project, Copenhagen: Danish National Institute of Social Research.

Degasperi, P. and Villa, P. (2000) 'Home care for the elderly in Italy', country report for the New Forms of Employment and Working Time in the Service Economy (NESY) project, Trent: University of Trent Department of Economics.

Döhl, V., Kratzer, N. and Sauer, D. (2000) 'Krise der NormalArbeit(s)Politik: Entgrenzung von Arbeit: neue Anforderungen an Arbeitspolitik', WSI-Mitteilungen 1: $5-17$.

Dörre, K. (2003) 'Das flexibel-marktzentrierte Produktionsmodell: Gravitationszentrum eines “neuen” Kapitalismus?', in K. Dörre and B. Röttger (eds) Das neue Marktregime: Konturen eines nachfordistischen Produktionsmodells, Hamburg: VSA-Verlag.

Fagan, C. and Nixon, D. (2000) 'Home care for the elderly in the UK', country report for the New Forms of Employment and Working Time in the Service Economy (NESY) project, Manchester: University of Manchester Institute of Science and Technology (UMIST).

Flecker, J. (2000) 'Zwischen unerledigter Humanisierung und wettbewerbsorientierter Modernisierung: Zur politischen Gestaltung von Arbeitsorganisation', Österreichische Zeitschrift für Politikwissenschaft 29(4): 433-48.

Gadrey, J. (2003) New Economy, New Myth, London and New York: Routledge.

Gadrey, J., Jany-Catrice, F. and Ribault, T. (1999) France, Japon, Etats-Unis: l'emploi en détail - Essai de socio-économie comparative, Paris: Presses Universitaires de France.

Gerlmaier, A. and Kastner, M. (2003) 'Neue Formen selbstregulativ-flexibler Arbeit im IT-Bereich: Anforderungen, Ressourcenpotenziale und ihre Auswirkungen auf die Arbeits- und Lebensqualität', in M. Kastner (ed.) Neue Selbstständigkeit in Organisationen: Selbstbestimmung, Selbstausbeutung, Selbstäuschung?, Munich: Hampp Verlag.

Glißmann, W. and Peters, K. (2001) Mehr Druck durch mehr Freiheit: Die neue Autonomie in der Arbeit und ihre paradoxen Folgen, Hamburg: VSA.

Haipeter, T., Lehndorff, S., Schilling, G., Voss-Dahm, D. and Wagner, A. (2002) 'Vertrauensarbeitszeit: Analyse eines neuen Rationalisierungskonzepts', Leviathan 30: 360-83.

Holtgrewe, U. and Voswinkel, S. (2002) 'Kundenorientierung zwischen Mythos, Organisationsrationalität und Eigensinn der Beschäftigten’, in D. Sauer (ed.) 


\section{S. Lehndorff and D. Voss-Dahm}

Dienst-Leistung(s)-Arbeit: Kundenorientierung und Leistung in tertiären Organisationen, Munich: ISF Forschungsberichte.

Hyman, R. (1994) 'The fetishism of flexibility: the case of British Rail', in B. Jessop, H. Kastendiek, K. Nielsen and O.K. Pedersen (eds) The Politics of Flexibility, Aldershot: Edward Elgar.

Igalens, J., El Akremi, A., Demery-Lebrun, M. and Vicens, C. (2002) 'La flexibilité dans le secteur aérospatial', Notes du LIRHE, Toulouse: Université de Toulouse.

Julkunen, R. and Nätti, J. (1999) The Modernization of Working Times: Flexibility and Work Sharing in Finland, Jyväskylä: SoPhi Academic Press, University of Jyväskylä.

Kadritzke, U. (2001) 'Manager unter Druck. Zum Zeitnotstand von Managern und anderen Sterblichen', Available online at: www.fhw-berlin.de/fhw2000/index.htm (accessed 5 July 2004).

Kirsch, J., Klein, M., Lehndorff, S. and Voss-Dahm, D. (1999) 'Darf's etwas weniger sein?' Arbeitszeiten und Beschäftigungsbedingungen im Lebensmitteleinzelhandel: ein europäischer Vergleich, Forschung aus der Hans-Böckler-Stiftung, Berlin: Edition Sigma.

Korczynski, M. (2001) 'The contradictions of service work: call centre as customeroriented bureaucracy', in A. Sturdy, I. Grugulis and H. Willmott (eds) Customer Service: Empowerment and Entrapment, New York: Palgrave Macmillan.

- (2002) Human Resource Management in Service Work, New York: Palgrave Macmillan.

Lehndorff, S. (1997) Zeitnot und Zeitsouveränität in der just-in-time-Fabrik: Arbeitszeitorganisation und Arbeitsbedingungen in der europäischen Automobilzulieferindustrie, Munich and Mering: Hampp Verlag.

Merllié, D. and Paoli, P. (2001) 'Third European survey on working conditions 2000', European Foundation for the Improvement of Living and Working Conditions, Luxembourg: Office for Official Publications of the European Communities.

Moldaschl, M. (2001) 'Herrschaft durch Autonomie: Dezentralisierung und widersprüchliche Arbeitsanforderungen', in B. Lutz (ed.) Entwicklungs-perspektiven von Arbeit, Weinheim: Belz.

Peters, K. (2001) 'Die neue Autonomie in der Arbeit', in W. Glißmann and K. Peters (eds) Mehr Druck durch mehr Freiheit. Die neue Autonomie in der Arbeit und ihre paradoxen Folgen, Available online in English at: www.cogito-institut.de.

Plantenga, J. and Hansen, J. (1999) 'Macro- and micro-perspectives on the growth of service activities', New Forms of Employment and Working Time in the Service Economy (NESY), working paper.

Plantenga, J. and Remery, C. (2000) 'Dutch health care', country report for the New Forms of Employment and Working Time in the Service Economy (NESY) project, Utrecht: University of Utrecht Institute of Economics.

Plantenga, J. and Remery, C. (2001) IT services in the Netherlands', country report for the New Forms of Employment and Working Time in the Service Economy (NESY) project, Utrecht: University of Utrecht Institute of Economics.

Rainnie, A. (1998) 'The inevitability of flexibility?', Work, Employment E Society 12 (1): 161-7.

Reich, R. (1991) The Work of Nations: Preparing Ourselves for 21st Century Capitalism, New York: Vintage Books.

Rosenberg, S. (1989) 'From segmentation to flexibility', Labour and Society 14 (4): 363-407. 
Schlesinger, L.A. and Heskett, J.L. (1991) 'Breaking the cycle of failure in services', Sloan Management Review, Spring: 17-28.

Sengenberger, W. (2002) 'Globalization and social progress: the role and impact of international labour standards', report for the Friedrich-Ebert-Stiftung, Bonn.

Smith, C. and Thompson, P. (1998) 'Re-evaluating the labour process debate', Economic and Industrial Democracy 4: 551-77.

Sturdy, A., Grugulis, I. and Willmott, H. (2001) Customer Service: Empowerment and Entrapment, Basingstoke: Palgrave Macmillan.

Voss-Dahm, D. (2000) 'IT services in Germany', country report for the New Forms of Employment and Working Time in the Service Economy (NESY) project, Gelsenkirchen: Institut Arbeit und Technik.

- (2002) 'Verkaufsarbeit im Einzelhandel: einfache Dienstleistungsarbeit?', WSI-Mitteilungen 55: 498-504.

Webster, J., Wickham, J. and Collins, G. (2002) 'Innovations in information society sectors: implications for women's work, expertise and opportunities in European workplaces', SERVEMPLOI Final Report, Employment Research Centre, Trinity College Dublin. Available online at: www.tcd.ie/erc/Servemploi/ reports.htm (accessed 5 July 2004).

Weinkopf, C. (2002) 'Call-centre work: specific characteristics and the challenges of work organisation', Transfer 8 (3): 456-66.

Williams, K., Haslam, C., Johal, S. and Williams, J. (1994) Cars: Analysis, History, Cases, Providence: Berghahn Books. 


\title{
13 Can trade unions meet the challenge?
}

\section{Unionisation in the marketised services}

\author{
Jon Erik Dølvik and Jeremy Waddington
}

\section{Introduction}

In contrast to widespread perceptions that the main threat to trade unions is external, often identified with 'globalisation', this chapter argues that one of the most profound and complex challenges to European trade unions stems from domestic change associated with the employment shift towards marketised services. This challenge is not independent of the broader restructuring of global capitalism, but reflects dynamics that are intrinsic to economic development and modernisation. More than 70 per cent of employment in many OECD countries is found in service industries. As a result of the transfer of jobs from public to private suppliers, the outsourcing of support functions within manufacturing and the introduction of market mechanisms in many public services, the characteristics of work and employment relations associated with private-sector services are spreading throughout the labour market. Private-sector services are marked by a variety of industries with a growing share of small and recently formed firms; new patterns of management-labour relations and work organisation; a diverse workforce, with relatively high rates of labour turnover and participation by women; and difficult structural conditions for collective organisation. In consequence, unionisation rates are often markedly lower than in manufacturing and traditional public services. Struggling with rising work flexibility, erosion of the standard employment relationship, individualisation and social polarisation, traditional trade union movements are thus at their weakest in those parts of the labour market where growth is strongest and many of the most vulnerable groups of workers are found. Different forms of deregulation and privatisation have also weakened collective organisation and brought new pressure to bear on existing collective agreements.

These developments present trade unions with difficult challenges concerning the recruitment and retention of members, together with the renewal of organisational structures and strategies. The crux of this challenge is to encourage participation and to develop new forms of representation appropriate for a heterogeneous workforce. Unless trade union movements can respond to the needs and aspirations of the 
expanding workforce in marketised services, they risk shrinking into a narrow interest group of core workers in manufacturing and certain public services. ${ }^{1}$ Such a scenario would have deleterious consequences for their political legitimacy and influence.

This chapter reviews some of the developments introduced by trade unions in response to the growth of marketised services. It argues that articulated structures and activities are prerequisite to a coherent trade union response, in order that heterogeneous interests may be aggregated and local union organisation empowered, while pressure can still be brought to bear on the state and employers' organisations at national level. ${ }^{2}$ To these ends, this chapter comprises four sections. The first section briefly reviews the impact of tertiarisation on the level and composition of union membership. The second section assesses the scope of the challenge faced by unions if they are to organise marketised services. The third section identifies the features of the trade union response to date. Although we argue that trade union countermeasures are currently inadequate, we accept that certain trade union policies may constitute the basis to forms of organisation and activity appropriate to marketised services. The conclusion thus highlights these features and identifies some parameters for future change.

\section{Tertiarisation of labour and union membership}

The long phase of service employment growth after about 1960 brought a steady increase in union membership and density rates in Western Europe, particularly in the public services, which became relatively highly unionised in most European countries. In the 1980s and 1990s, union membership stagnated or declined, except in Belgium and the Nordic countries. Since the structural decline in manufacturing resulted in membership losses everywhere, a major reason for the declining union density is differences in the capacity of national unions to organise the expanding service sector workforce and white-collar service workers. Estimates suggest that the shift in employment away from manufacturing to privatesector services accounts for about 30 per cent of the total decline in density in the period 1970 to 1992 (Ebbinghaus and Visser 1999), but continued restructuring within the sector suggests that the current figures are substantially higher (see Bosch and Wagner, Chapter 2, this volume). With regard to aggregate union density in the late 1990s, three main categories of countries may be distinguished (see Table 13.1):

1 Union density ${ }^{3}$ low in France (9 per cent) and Spain (17 per cent), although density increased in Spain during the 1990s.

2 Intermediary and showing a downward tendency in Ireland (52 per cent), Austria (39 per cent), Italy (37 per cent), Portugal (36 per cent), UK (30 per cent), Germany (27 per cent), and the Netherlands (24 per cent). 


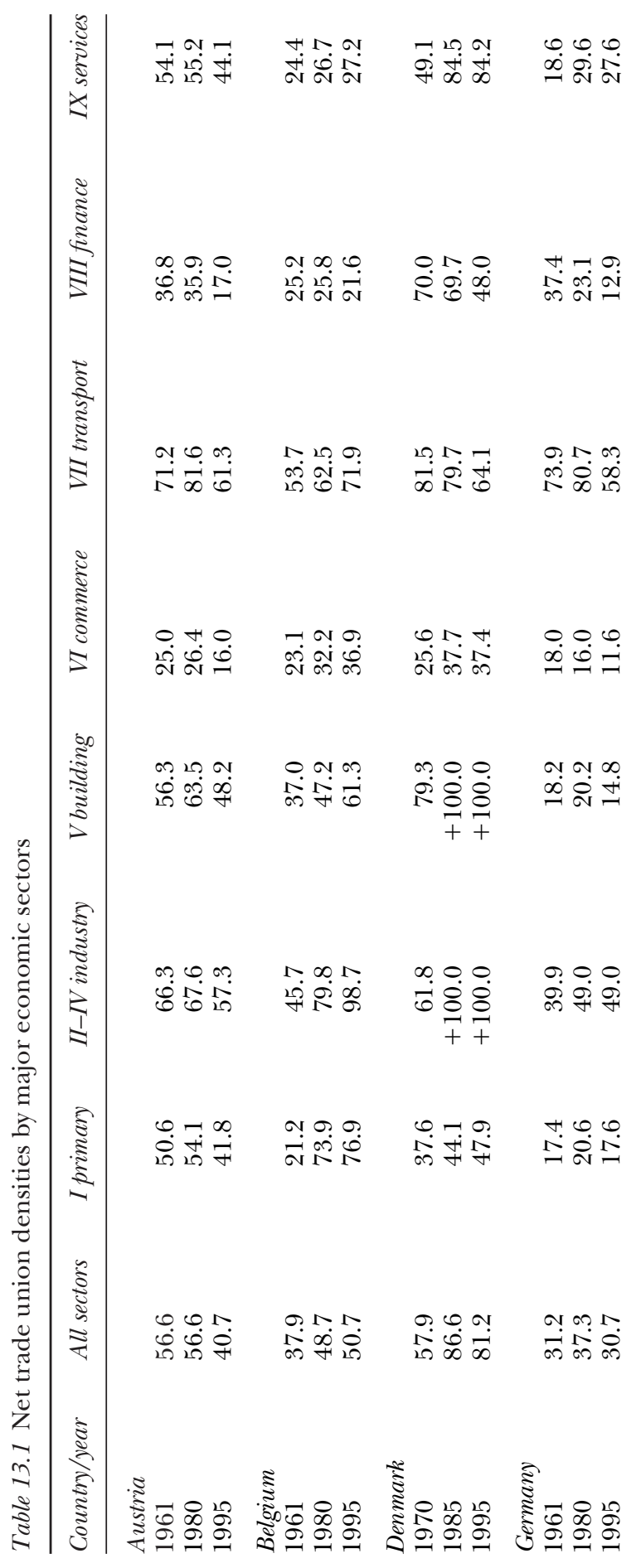




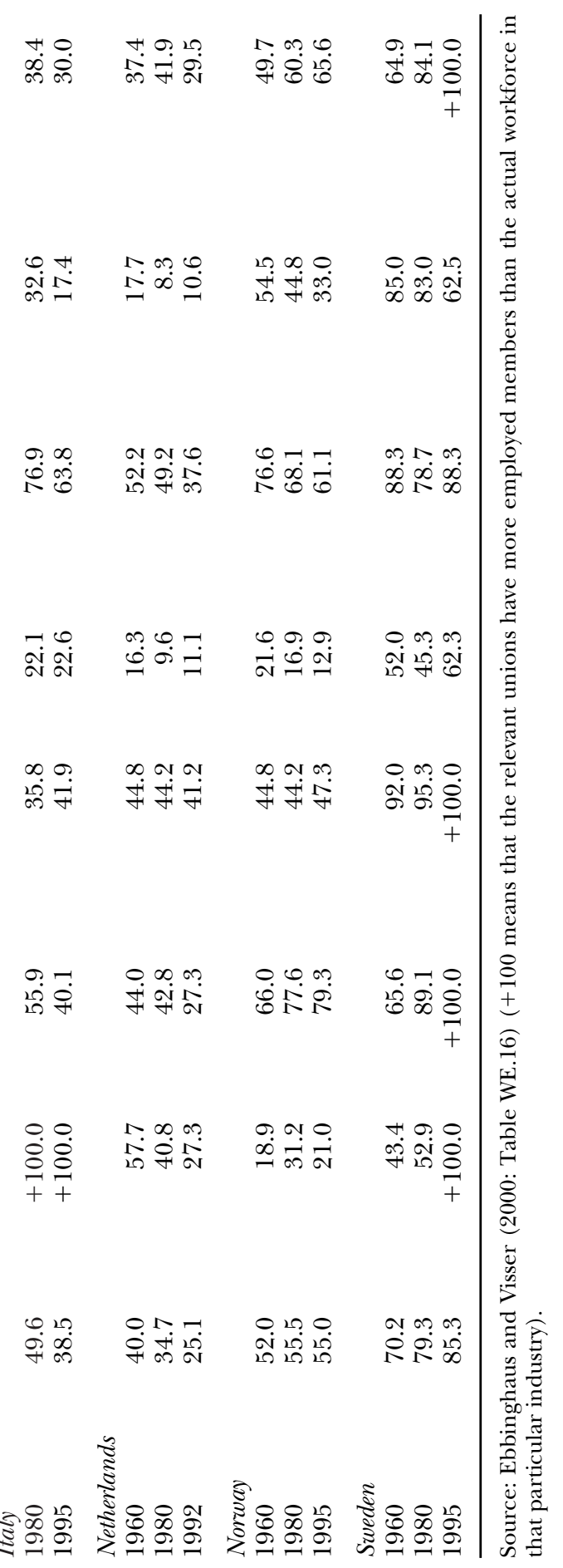




\section{J.E. Dølvik and J. Waddington}

3 High in Sweden (86 per cent), Finland (78 per cent), Denmark (76 per cent), Belgium (53 per cent) and Norway (53 per cent), though with a slight dip in recent years (Ebbinghaus and Visser 2000; Waddington and Hoffmann 2000a).

With the exception of Norway, a common feature of the high-density group is that trade unions undertake a role in administering unemployment insurance schemes (the Ghent system). Within this group, the lower density in Belgium and Norway may, to a large extent, be attributed to lower levels of unionisation in private-sector services.

\section{Industrial variation in unionisation rates}

Unionism in services developed in three waves (Ebbinghaus and Visser 2000: 46) ${ }^{4}$ While unions became entrenched in public services, with an average density of 50 per cent in the EU countries (Boeri et al. 2001), unionisation is generally lower and more uneven in private services. Banking and transport tend to have higher than average density levels, whereas in commerce, such as hotels and restaurants, retail trade, real estate and cleaning, and other non-public social and recreational services, density levels have been relatively low in most countries.

Within this overall pattern, there are notable national variations in density levels in services (see Table 13.1). For example, density levels in retail range from 60 per cent to 80 per cent in Sweden, Denmark and Finland; to around 25 per cent in Ireland and Norway; and to between 10 per cent and 20 per cent in the UK, Netherlands, Germany, Italy and Austria. France is an outlier with minimal unionisation (Dølvik 2001). A similar pattern may be found in hotels and restaurants. The lower density in the female-dominated commerce and retailing industries is usually attributed to the predominance of small workplaces with high turnover and prevalence of part-time and non-standard work, but in the maledominated wholesale trade, with a higher degree of standard work, density also tends to be low (Olberg 2001).

In banking, the picture is different. Apart from the low density, ranging between 8 per cent and 25 per cent, in France, Germany and the Netherlands, the majority of bank employees in the other countries are unionised, with quite stable density levels. These levels range from around 50 per cent in the UK and Austria to around 80 per cent in the Nordic countries (Dølvik 2001). The relatively high and stable unionisation rates in banking reflect the historical tradition of strongly regulated internal labour markets based on lifelong careers and high-trust relations (Lockwood 1957). Although recent restructuring has increased the propensity for unionisation among some bank employees, the fading boundaries vis-à-vis insurance, other financial services and retailing, combined with new processes such as tele-banking, home-banking 
and more part-time work, are likely to raise further challenges for unions in the years to come (Haipeter and Pernod-Lemattre, Chapter 10, this volume).

Within the ICT sector the pattern is varied, resulting in part from variations in company age and size. Apart from the electronics industry where unionism is well entrenched, employment is still concentrated in former state telecommunications companies, where labour relations were regulated and many workers are still unionised. With outsourcing and restructuring, however, density tends to fall rapidly, as shown in Norwegian Telenor, where density halved in a few years (Jordfald and Olberg 2002). Data software and services, marked by many small start-up companies, have been a virtually union-free zone in many countries, but the recent crisis of the industry may bring some change (Plantenga and Remery, Chapter 8, this volume). In Sweden, a significant rise in union density (now 58 per cent) during the 1990s is reported (Kjellberg 2001), and in Denmark, unionisation is also generally high in the ICT sector (EIRO 2001a). In Germany and the Netherlands, emerging works councils tend to undertake union functions, in some cases signing company agreements (Kahmann 2003).

\section{The changing composition of union membership}

The post-industrial employment shift has engendered significant changes in the composition of union membership. Whereas density has fallen among male and young workers, in many countries it has increased among the growing female workforce, especially in public services. In a group of ten West European countries, female density rose from 25 per cent to 30 per cent between 1970 and 1992, and the female share of union membership rose from 34 per cent to 43 per cent (Ebbinghaus and Visser 1999), partly reflecting the high proportion of women in public services. In the Nordic countries, union density is as high among women as among men. By the end of the 1990s, women accounted for 52 per cent of union membership in Sweden, 48 per cent in Finland and 43 per cent in the UK, against 31 per cent in Germany and 28 per cent in the Netherlands (Ebbinghaus and Visser 2000). These figures indicate the potential for membership growth if the expansion of feminised services is met by adequate union strategies. Density is usually also higher among the expanding well-educated groups than among less skilled groups (Boeri et al. 2001).

In all West European countries, service employees now represent a clear majority in the unions, usually between 50 per cent and 70 per cent. This means that the notion of unions as numerically dominated by male manufacturing workers is outdated, and signals the likelihood of contested changes to internal power relations and bargaining priorities. While public service employees are over-represented, the most striking bias in 


\section{J.E. Dølvik and J. Waddington}

union membership today is the under-representation of private service employees, especially among employees with low levels of skill and qualifications. Most European unions face the choice of whether to compete for members among the growing numbers of high-skilled professional and white-collar service employees, who may already be members of independent unions; or to improve radically their organising capacity among the less protected and skilled groups at the lower end of the service labour market.

\section{Changing conditions for collective organisation in services}

This section identifies three features that impinge on the development of collective organisation in services: the growth in less skilled jobs; shifts in patterns of work organisation; and the establishment of new forms of corporate organisation and governance. Details regarding the form and coverage of these features may be found elsewhere in this volume; our task here is to assess the scale of the task faced by unions to organise the workforce in services.

Alongside significant upgrading of the skill structure of employment and marked gender segregation and feminisation of the service workforce (Wagner 2002), there is also growth in less skilled service jobs in certain areas of services, such as care, catering, fast-food, cleaning, call centres and domestic service. These jobs are often occupied by female, young and immigrant labour, and are often associated with low pay, high turnover and non-standard employment conditions. Although the majority of employees in service jobs report better working conditions, pay and job satisfaction than in manufacturing, the distribution of jobs in private services tends to be more polarised than in the industrial sector (OECD 2001: 97).

Associated with the growth in less skilled jobs are shifts in the patterns of work organisation. Compared to the classical fields for union organising, defined by the distinct power structures of the factory and the common social, spatial and temporal conditions of industrial mass production, the pattern of work in many services, with a multitude of small, dispersed workplaces and a more fluid, heterogeneous workforce, is usually less conducive to the development of shared perceptions of interests and collective identity. Many employees, especially the higher skilled, enjoy considerable autonomy, but work processes geared to the interaction with customers or clients imply that market pressures and fluctuations are often brought directly to bear upon employees. This has wide-ranging implications for the patterns of work organisation, workingtime flexibility and the conditions for interaction both among workers and with management (Lehndorff 2002). Yet, in some areas, for example, fast-food outlets and call centres, factory-like, neo-Taylorist modes of service provision occur, which intensify the conflicts between tending to 
customers, helping colleagues and satisfying market-induced managerial performance criteria (Krell 2001; Weinkopf 2002).

The introduction of neo-Taylorist forms of work organisation in certain service industries may facilitate union organising, but such changes often go hand in hand with further fragmentation of the workforce. In many service industries, the traditional patterns of hierarchical command and control of work are replaced by flatter organisations in which employees enjoy greater autonomy in the organisation and undertaking of work. The increase in individual independence, however, is circumscribed by delegation of responsibility to decentralised working teams and individuals, in order to fulfil their obligations within the market-determined economic objectives and requirements of the company (Glißmann and Peters 2001). These contradictory developments have given rise to new categories of 'dependent independent employees' (ibid.) for whom less coercion, paradoxically, often leads to the intensification of work (Lehndorff and VossDahm, Chapter 12, this volume). When employees are personally responsible for the achievement of company objectives and internalise market imperatives, tensions between perceptions of professional standards, employee rights and company profitability tend to occur. These conflicts within the work group and in the mind of the individual worker change the conditions for collective identification within the workforce (Glißmann and Peters 2001). As the achievement and remuneration of each employee becomes dependent on his or her personal performance, as well as the performance of the work group, relationships between colleagues tend to be transformed into ambivalent combinations of competition and interdependence. To cope with these contradictory pressures and resolve the personal quandary of flexibility, many employees work extra hours at greater intensity, often viewing collective regulations of work as troublesome obstacles. For trade unions, such shifts in the organisation and character of work mean significant changes in the basis for collective organisation and action. While trade unions have traditionally relied on notions of worker solidarity, according to which individual workers have similar and common immediate interests, the tendencies outlined above point to situations where the relationship between individual and collective interests becomes more complex, ambiguous and contentious. In such contexts, the issue for trade unions is not to defend the old command and control system and fight autonomy. Instead, trade unions are required to help employees develop notions of solidarity, built on diversity, through which collective commitments are not perceived as restraints for the individual, but as means to enhance personal and group autonomy.

In contrast to the differentiation of the workforce and provision of services, new patterns of corporate organisation and governance result in a growing concentration of corporate decision-making in many industries, a blurring of management responsibilities, and the spread of new kinds of 


\section{J.E. Dølvik and J. Waddington}

triangular employment relationships. International service chains, franchising, malls, outsourcing and delivery networks of interdependent small companies exemplify this pattern of development. A further example is the large malls, resembling huge factories, where workers are employed by each individual boutique or service contractor, which has virtually no capacity to influence the structural conditions of work in the mall. Collective worker voice vis-à-vis those who run the site is effectively precluded, and employees are often beyond statutory codes of industrial democracy. Similar problems arise in franchising chains, thus creating severe obstacles to union organising and collective bargaining. Yet the rise of larger, more professional service employers, which are sensitive to negative public exposure, may provide more opportunities for developing ordered labour relations than the local shop on the street corner. ${ }^{5}$

This complexity is compounded by the increasingly blurred notion of employer counterparts arising from the 'distanced' employment relationships adopted in many segments of services. Many employees and unions face phoney local employers, as decision-making is concentrated in remote headquarters with no direct responsibility for the local employment relationship. Furthermore, the weakness of employers' associations in marketised services compounds the difficulties faced by trade unions, as they often have no national level counterparts through which to seek influence.

For trade unions, these contradictory trends raise the threefold task of combining the pursuit of decentralisation, accommodating the differentiation of member support and empowering local organisation; while also strengthening centralised capacities to represent workers vis-à-vis the polity and business power centres that often operate across industry and union boundaries. At the same time, unions need to strengthen their appeal to the expanding groups of well-educated service employees, without alienating their core constituencies or losing sight of the growing need for organisation and support among the most vulnerable parts of the low-skilled service proletariat.

A particular condition for collective action in services is the growing pressure to take account of the interests and reactions of consumers, clients and the wider public. In the media society, struggles over change in working conditions involve an intricate three-way game, linking politics, collective bargaining and information strategies in new and powerful ways (Dølvik 2001: 488). For trade unions in services, this entails both constraints and opportunities, but suggests that the need to win customer support and public legitimacy, and to build ties with broader societal groups, is a prerequisite for success. 


\section{Trade union challenges and the search for solutions}

The changing dynamics of work and trade union membership in services point to three major challenges for trade union organisation:

1 To reverse the decline in union membership and density by improving the capacity to attract and retain members in marketised services. This challenge is more than simply a question of membership numbers. If trade unions are to broaden membership footholds in services, they will have to attract and accommodate increasingly heterogeneous constituencies, adding to the already growing diversity of membership in many larger unions. This places additional demands on union resources at a time when income from members in many unions is diminishing. Because of high rates of labour turnover and incidence of atypical workers in many service industries, organising is cost-intensive. The recruitment challenge is compounded by the employer structure in marketised services, where many employers have been highly effective in resisting unionisation. The capacity of managers to communicate directly with employees is often cited as underpinning this resistance insofar as it is viewed as 'weakening' the demand for unionisation from workers (Kochan et al. 1997). The growing incidence of small sites requires unions to support members at an ever-increasing number of workplaces, falling under statutory thresholds for recognition of unions and bargaining rights in some countries. Implicit in the membership challenge is thus a requirement to develop forms of organisation that strengthen union capacity for support and representation of female employees at small sites.

2 The issue of recruitment cannot be resolved without creating union agendas and internal channels of representation that meet the heterogeneous interests and conditions for participation among diverse service workers. Besides increasing sensitivity to the needs of women, immigrants and non-standard workers, this raises the complex issues of interest aggregation, intermediation and compromise. The growth of high-skilled professional employees alongside the spread of fluid, non-standard employment in private services and the interconnected difficulties in reconciling work, family and other life commitments, accentuate the need for unions to embrace a wider set of issues. To maintain organisational cohesion, it is necessary to improve internal interest intermediation and to broaden the notion of labour solidarity to incorporate complementarity and diversity rather than uniformity and similarity (Valkenburg and Beukema 1996; Schumann 2001).

3 The decentralised and diversified pattern of service provision, combined with the concentration of corporate power, reinforce the critical importance of maintaining or regenerating articulated trade 
union structures and activities. For our purposes, an articulated trade union is established around cohesive and coherent interrelationships between workplace, regional, national and supranational ${ }^{6}$ levels of organisation and activity (Kjellberg 1983; Crouch 1993). The absence of articulation between different levels of union organisation slows internal reform and often weakens union power, vis-à-vis employers, particularly in service industries with multi-tiered management structures. Furthermore, where unions fail to maintain articulated structures, the coordinating capacity at central level is impaired, and workplace activity is often isolated and relatively ineffective. This is particularly important given that 'the most important factor explaining union growth or decline since 1975 appears to be whether or not, and to what degree, unions were recognised and present in the workplace' (Boeri et al. 2001). Redeploying resources and improving articulation with workplace union organisation is thus an essential priority.

In response to these challenges, trade unions in Western Europe have initiated a vast range of reforms. In the following section, we review three areas of reform: recruitment and organising, structural change, and approaches to bargaining. Underpinning several of these initiatives is the tension between the need to expand organisation into marketised services and the impact of diminishing resources. Examples are drawn from different levels of union activity to highlight the centrality of articulated union organisation.

\section{Servicing or organising?}

Many trade unions have traditionally relied on some variant of the 'servicing' approach to support members at their place of work, to retain them in membership and to extend union organisation. The servicing approach depends on trade union activity external to the workplace to support members. It thus places an enormous burden on full-time officers to undertake these duties. Similarly, many recruitment and retention activities are left to full-time officers to initiate and to conduct. The approach is supported through the central provision of welfare benefits, which are viewed as assisting membership retention. The decentralisation of bargaining and the proliferation of employment at small sites have led many unionists to argue that the servicing approach in its 'ideal' form is no longer viable. There are neither enough full-time officers nor resources to adapt to current circumstances.

This is not to argue that all aspects of the servicing approach have been jettisoned. Unions in countries where the Ghent system operates have extended organisation throughout much of private-sector services and have secured members among part-time, fixed-term contract and temporary workers. Similarly, many unions continue to offer welfare benefits, 
which, although overtaken by state provisions, remain fairly popular among members (Jørgensen et al. 1992; Waddington and Whitston 1997; ICTU 1998). Recent attempts to develop the servicing approach, however, have met with mixed results. The provision of packages of financial services by unions in Belgium, Denmark, Italy, Sweden and the UK proved relatively ineffective as tools for both recruitment and retention (Jørgensen et al. 1992; Di Nicola 1997; Waddington and Whitston 1997). Services focused more centrally on the workplace have tended to have a better reception. The provision of legal services, for example, is highly regarded by British and German trade unionists. Unions that organise highly skilled or professional employees have also recorded recruitment successes through the provision of professional services. Unions of nurses, for example, cite the efficiency of professional indemnity insurance as a means of recruiting and retaining members. Connect, a union that represents senior telecommunications engineers in the UK, offers assistance to members to find new jobs when made redundant, as do several other unions, which act as virtual job agencies. The Internet has opened up new opportunities for direct recruitment and dissemination of union services, including the set-up of 'virtual' or 'digital' unions with direct membership. For example, Handelstjenestemännens Förbund (HTF) in Sweden reports that 3,700 new members joined the union directly through its website in 2001 (UNI 2002). The servicing approach is thus not moribund, but is not suited to address the central reason for joining a union, namely the provision of support if the member has a problem at work (Waddington and Whitston 1997).

To improve union presence, recruitment and member support at workplaces within private-sector services, several unions have adopted an 'organising approach' or participatory forms of unionism. Such approaches originate in the USA and Australia (Conrow 1991; Bronfenbrenner et al. 1998) and assume a shift in union priorities away from the servicing of existing members towards the recruitment, involvement and empowerment of new members. In order to establish workplace union organisation, support from the union may be initially required, often in the form of campaigns directed at specific companies with the aim of achieving recognition for collective bargaining, and raising customer and public awareness. At this stage professional union organisers and public relations support are usually deployed. Once workplace organisation is set up, however, the organising approach assumes that the provision of training and specialist advice are the principal forms of external support provided by the union, as workplace representatives are expected to perform many of the duties undertaken by full-time officers within the servicing approach.

Examples illustrate some of the tactical variation inherent within the approach. In Sweden, the process of 'anchoring' promotes dialogue between union representatives, union members and potential members, 
thereby raising levels of participation (Ahlèn 1994) ${ }^{7}$ Similarly, in Norway, Hotell og Restaurantarbeiderforbundet recently won new members by forcing several non-union firms to sign collective agreements through highly publicised picketing, strike action and boycott threats from supporting unions, although the membership gains were insufficient to offset losses elsewhere. Similar tactics have forced Body Shop in Ireland, and McDonalds and Toys ' $\mathrm{Y}$ ' Us in Sweden to accept collective agreements and recognise unions. A further development of the organising approach is underway in the UK in the form of the Organising Academy, which is run by the Trade Union Congress (TUC). At the Organising Academy, trainee organisers are provided with the skills to undertake recruitment and organising activities, which are then deployed within affiliated unions. Targeting is integral to the Organising Academy insofar as the intention is to ensure that the trainees, in terms of their age and gender, mirror the potential members they will recruit. Initial results, however, suggest that trainees are deployed primarily to deepen density at partially unionised sites rather than to establish organisation at greenfield sites in privatesector services (Heery 2002).

There are considerable difficulties to overcome if the organising approach is to become widespread. Many workplaces where unionists are present, for example, have no workplace representatives to serve as the base on which the organising model might be established (Krieger and O'Kelly 1998). To move away from servicing to organising also requires huge cultural shifts within unions and 'disturbing' vested interests, particularly those of full-time officers, many of whom are embedded in the servicing approach. To date, there is no consistent evidence to suggest that unions are transferring funds from servicing functions to organising functions in sufficient quantities to transform traditional practices. Furthermore, it is far from certain that the organising approach is appropriate for all target groups within private sector services. The notable successes achieved in the USA tend to be associated with relatively homogeneous groups of potential members. The Justice for Janitors Campaign, for example, was targeted at a distinct group of the workforce that undertook the same role, albeit at a huge number of different workplaces, and had similar ethnic origins (Savage 1998; Williams 1999). It remains to be seen whether this approach can be adapted for more heterogeneous workforces or to attract those in the higher skilled jobs.

Many workers in marketised services targeted by trade unions exhibit a greater instrumentality than those in other sectors (Di Nicola 1997; Sverke and Sjøberg 1997). Where union workplace organisation does not provide the support considered appropriate by members, they will leave the union (Waddington and Kerr 1999, 2000). For trade unions, it is thus essential to ensure that the 'quality' of support provided at the workplace matches the expectations and needs of these instrumental groups. Unions in many countries are now examining how the quality of workplace organisation 
may be improved through the provision of new forms of training to workplace representatives and by making available a wider range of support and advisory services. A critical issue is to enable adequate deployment of resources (for example, through the decentralised pooling of infrastructure and personnel). This is likely to require reforms in central union and confederal structures.

\section{Trade union structural adaptation}

The reform of trade union structures shows considerable variation, but a central objective is often to strengthen union presence and member support in marketised services. Besides overcoming union divisions made obsolete by fading industrial and occupational boundaries, not least between public and private sectors, it is argued that the economies of scale released by mergers between unions 'frees' central union resources for decentralised recruitment activities within marketised services. A counter-tendency is the establishment of specialised unions catering for specific, often occupational or professional, interests. The two tendencies reflect the tension between organisational breadth and the specificity of members 'interests inherent within trade unionism.

Mergers involving trade unions in private sector services take several forms. The first of these consolidates existing patterns of organisation within private sector services. The formation of Palvelualojen Ammattiliitto (PAM: Service Unions United) through the merger of four Finnish unions, for example, united union organisation throughout finance, hotels, catering and restaurants. In the UK, the formation of UNIFI by the merger of three unions consolidated organisation in banking. In both of these instances, however, unions remain apart from the merger. In the case of PAM, each of the four constituent unions was affiliated to the Suomen Ammattiliittojen Keskusjärjestö (SAK: Central Organisation of Finnish Trade Unions), the largest of the three Finnish confederations. Unions with related memberships affiliated to the other Finnish confederations stayed outside of the merger. Similarly, the Lloyds-TSB Bank Group Union, which is outside the TUC, remained independent from UNIFI, with the result that union organisation is split within this bank.

A second merger variant for unions from private-sector services involves unions that organise more stable and more unionised sections of the labour force, such as transport or public services, to create a multi-industry union. In the Netherlands, for example, the constituent unions of Bondgenoten included the services union Dienstenbond (DiBo) with members in retailing, commerce, banking, insurance, media, business and professional services, and personal services. DiBo was financially weak compared to the unions from transport, food and, in particular, manufacturing with which it merged (Streeck and Visser 1997). An intention underpinning the merger thus was to use resources from unions in 
relatively densely organised sectors of the economy to fund recruitment activities in marketised services. In Germany, the formation of Vereinigte Dienstleistungsgewerkschaft (ver.di: United Services Union) in 2001 from five unions combines both public and private service organisations to form a sectoral union. In ver.di, the intention is to use income from highly unionised areas to support the extension of union organisation throughout private-sector services. It should be acknowledged, however, that Bondgenoten has yet to record significant breakthroughs, while it is too early to assess the progress of ver.di. It is clear that targeting of recruitment remains a very different issue within the two unions. For Bondgenoten the strategic choice of whether to concentrate on the 'upper' or 'lower' segment of workers within private-sector services remains a 'live' issue. In contrast, the sectoral recruitment base of ver.di assumes that both groups can and should be represented within the same union.

Irrespective of which of these merger variants is pursued, the issue of internal union representation and mergers cannot be readily separated. Mergers are certainly a time during which constitutional innovation and policy change can be introduced. In each of the instances mentioned above, for example, the post-merger constitutions introduced new forms of sectional representation. In ver.di, sectional representation is combined with tiers of geographical structures and institutions introduced specifically to encourage participation among women, ethnic minority, disabled, gay and lesbian members. In addition, ver.di was able to extend the connexx.av project, which targets non-unionised media workers ${ }^{8}$ and has recently started to recruit prostitutes through setting up the first works council in a brothel (EIRO 2002).

Heterogeneous unions, however, require forms of representation that allow 'voice' to specific interests. To facilitate the representation of specific interests, many unions, irrespective of their involvement in merger activity, have introduced sectional forms of representation. ${ }^{9}$ The size, membership heterogeneity and 'distance' from the workplace of many extant unions has also prompted workers in services to set up independent unions with relatively 'closed' recruitment bases; that is, they have rejected the forms of sectional representation offered by larger unions. More recently, there has been a growth in the number of autonomous unions (COBAS: Comitati di Base) as a result of initiatives taken by Italian service workers (Ponzellini and Provenzano 2001). Similarly, in the Netherlands during 1990 Vakbond voor Vervoer, Logistiek en Dienstverlening (VLD: Transport, Logistics and Services Union) was formed in opposition to Bondgenoten with which the FNV-affiliated transport union had merged. The VLD is now one of the fastest growing Dutch unions and pursues a policy of concluding 'tailor-made' company-level agreements appropriate to local interests (Tromp and Beukema 2001). Guild-like clubs for dot.com workers and digital unions for nomadic employees appear also to be emerging in several countries. It remains to be seen whether these initi- 
atives can be sustained. One response from the Italian union confederations, for example, was to set up unions specifically for self-employed workers, many of whom had previously been attracted by the COBAS (Ponzellini and Provenzano 2001; Fullin 2002). A similar union was recently set up in Austria (Blaschke 2001), while artists, musicians, soccer players and others have long had their own unions in many countries. What is clear, however, is that structural change to accommodate the interests of members from marketised services is underway on a large scale.

\section{Reforming the bargaining agenda}

Two developments have dominated collective bargaining in Western Europe during recent years: the conclusion of framework agreements or social pacts at national level and the decentralisation of bargaining. Irrespective of the specific form of these developments, the overall coverage of collective bargaining has remained fairly stable, due to various mechanisms of generalisation (erga omnes), with the exception of the UK, where a marked decline has occurred (Traxler et al. 2001: 194-210). Because the coverage of collective bargaining in many private service industries tends to be low, trade unions have initiated various campaigns to reverse the trend. Attempts have also been made to incorporate more issues of concern to workers in services within the bargaining agenda. These initiatives have been launched at all levels within the bargaining structure, three of which are examined here: national-level social pacts, specific agreements for workers in marketised services, and the shift in the bargaining agenda.

Improving the legal basis for representation and social pacts

While the motives underpinning the social pacts of the 1990s were far removed from those associated with the tripartite and corporatist arrangements of the 1960s and 1970s, the search for greater trade union institutional security is common to both periods (Sisson and Martín Artilés 2000; Waddington 2001). In Ireland the social pact 'Programme for Prosperity and Fairness' (1999-2002), for example, included provisions to encourage trade union recognition by employers. Similarly, union lobbying concurrent with the German Bundnis für Arbeit (Alliance for Jobs) prompted a revision of the Betriebverfassungsgesetz (Works Constitution Act) to the effect that the thresholds are reduced on the scales that determine the number of works councillors and full-time works councillors. The intention is to expand the coverage of works councillors to the smaller workplaces that characterise private-sector services. Measures are also included to promote the representation of women and young workers on works councils, at the centre of which is the so-called Gleichstellungsquote (equality 


\section{J.E. Dølvik and J. Waddington}

quota) (see Behrens 2001). An affiliated union of the Belgian Fédération Générale du Travail de Belgique/Algemeen Belgisch Vakverbond also took action against the Union des Classes Moyennes (employers' association representing small firms and traders), most of which operate within private-sector services, who were viewed as 'persecuting' union activists. The protection of union activists was subsequently an issue in the tripartite intersectoral agreement for 2001 to 2002. Involvement in social pacts has thus enabled some union movements to strengthen their institutional position in a way conducive to extending or strengthening organisation in private-sector services.

Agreements for specific workforce groups

While trade union initiatives taken within the framework of social pacts may facilitate the longer term unionisation of services, trade unions have striven more specifically to conclude industrial agreements that cover particular segments of marketised services. Most of the long-standing industries within marketised services, such as banking, transport and retailing, have been regulated by industry-wide collective agreements in the majority of Western Europe for some time, albeit with variable and, more recently, diminishing coverage. As a result of recent union campaigning, however, the bargaining coverage in private services in Denmark has increased markedly (Scheuer and Madsen 2000). ${ }^{10}$ Even in Ireland and the UK, where the coverage of bargaining is below the European average, company-level agreements cover substantial numbers of the workers in these industries.

Some of the more recent agreements within the sector are designed to embrace the new business areas and employee groups within marketised services. After the deregulation of temporary work agencies in the late 1990s, unions and employers have signed collective agreements for such employees in many countries. In the ICT industry, where, until recently, collective agreements were virtually absent, a sectoral collective agreement, focusing on working-time reduction and regulation, was signed in 1999 between French unions and Branche de l'informatique, de l'ingénierie et $d u$ conseil (SYNTEC: Association of the Information Technology, Engineering and Consulting Sector). The agreement covers 73 per cent of the workforce and was triggered by employers who wished to regulate the introduction of legislation on working time (EIRO 1999, 2001a). In Finland and Sweden there are also specific sectoral agreements for the ICT industry: in Finland covering the entire workforce, and in Sweden encouraging rises in the coverage rate, which stood at 62 per cent in 2000 (EIRO 2001a; Kjellberg 2001). In Austria, the Gewerkschaft der Privat angestellten (GPA: Union of Private Sector White-collar Workers) concluded an agreement for computing and related activities in 2001 (Blaschke 2001), while in Italy an agreement for telecommunications, 
including teleservices, was signed in 2000 (EIRO 2000). ${ }^{11}$ Although issues of pay in these agreements are often left to the company level, a common feature appears to be the regulation of working time and flexibility. In Austria, for example, a central motive for the employers was to obtain rights to negotiate exemptions from statutory working-time regulations.

Other examples in more specific areas include:

- A pioneer agreement for workers in Swedish call centres and telemarketing, which restricted the use of fixed-term contracts and regulated working-time flexibility, was signed in 2001 by Tjänstemannaförbundet (HTF: Salaried Employees' Union) (EIRO 2001b).

- Recently, ver.di signed the first company agreement for the employees in Lufthansa airline's call centre.

- Bargaining over an agreement in Spanish telemarketing in June 2001 prompted strikes and other industrial action (EIRO 2001c).

- French CFDT unions have signed collective agreements intended to protect the lower paid groups employed in call centres, conference centres and debt collection. These agreements set the minimum working week, month and year, as well as the number of daily breaks (Meilland and Dufour 2001).

- The Austrian union for semi-independent media employees recently concluded a framework agreement that specified minimum terms of contracts (Blaschke 2001), and a similar accord has been signed in Italian market research (EIRO 2001d).

- Especially aimed at regulating terms for the lower paid occupations within marketised services, Italian unions have introduced a strategy directed towards territorial bargaining arrangements. Integral to this approach is the targeting of several firms, usually small- or mediumsized enterprises, in the same industry and locality, with the purpose of securing membership and settling agreements. Where it has been successful, this approach has brought workers employed at some very small establishments within the coverage of collective agreements, although the overall coverage of bargaining remains less than 10 per cent (Ponzellini and Provenzano 2001: 320).

Numerous company agreements in emerging industries, often signed by works councils, and the incorporation of various issues related to ICT work in traditional industry agreements (EIRO 2001b; Kahmann 2003), complement these more encompassing agreements. In combination, these cases illustrate union innovations that extend the scope and reach of collective bargaining into new areas of marketised services. Although the software industry is an area where collective organisation and regulation are still largely absent, this review indicates the potential for change if unions seize the opportunity after the bubble has burst and the industry enters a more mature stage (Plantenga and Remery, Chapter 8, this volume). 


\section{J.E. Dølvik and J. Waddington}

Modernising the bargaining agenda

In addition to enhancing institutional security and extending the coverage of collective bargaining, trade unions have attempted to reform the bargaining agenda to ensure that it meets the aspirations of potential members in services. In practice, this has involved supplementing the traditional bargaining agenda with inter alia 'family-friendly' issues, policies on the allocation rather than the duration of working time, training and new trade-offs between the protection of core workers and the inclusion of temporary workers (Weiler 2000). Initiatives have also been taken to make the principles and application of individualised pay systems subject to collective agreements, for example, in the 2002 incomes-policy pact in Finland. Conversely, in Norway, Finansforbundet agreed to a clause in its agreement allowing members to opt for a completely individualised pay setting.

These changes to the bargaining agenda have been wide-ranging and have often been associated with internal trade union reform intended to encourage higher rates of participation among under-represented groups. There is still much progress to be made if this latter challenge is to be met. For example, women members of a negotiating team may act to ensure that equality issues are pursued, but their presence is certainly not a guarantee of such an outcome (Colgan and Ledwith 1996; McBride 2001). Indeed, UK evidence suggests that bargaining issues raised by women through women's committees, or similar structures, are often the first to be dropped during negotiations (Colling and Dickens 1998). To develop mechanisms that treat the agenda items raised by workers in marketised services as integral to, rather than either separate from or a necessary addition to, the traditional trade union agenda is thus the priority. To achieve this goal will certainly require further substantial changes to trade union organisation and, most likely, constitute a challenge to the hegemony of manufacturing unions in collective bargaining.

\section{Conclusions}

In this chapter, we have argued that a principal challenge for trade unions is of domestic, endogenous character, originating from the employment shift towards services and linked to the changing social organisation of work and labour relations within services. This challenge is rooted in the organisation of firms and working conditions, the peculiarities of the workforce, and the deregulated and decentralised nature of employment in private services. The resultant context of shrinking union membership, contradictory trends towards centralisation of corporate power, blurring of boundaries between industries, occupations, companies and markets, and diversification and individualisation of service work, require unions to adjust traditional modes of organisation. If trade unions are not able to 
turn the tide of membership decline and meet the changing needs and aspirations of the expanding service workforce, their political legitimacy and societal influence is likely to be severely impaired.

In different ways, the main response of trade unions in Western Europe has been a twofold move towards greater organisational concentration and scope, on the one hand, and decentralisation of resources and activities, on the other. To the extent that such structural reforms succeed in improving the articulation between different union tiers, strengthening bottom-up 'voice' and improving internal interest intermediation, they may prove to be a step in the right direction. This presupposes a concentration of staff, infrastructure and economic resources at the local level, which might allow greater capacity and flexibility for targeted organisation and recognition campaigns, and the provision of specialised member support in a given area or region. ${ }^{12}$ Despite the impressive range of reforms that has been implemented, the available evidence suggests that many reforms are piecemeal rather than part of a coherent and unified strategic review.

Development of such a two-tier pattern does not necessarily require union mergers, but may also be promoted through bargaining cartels involving independent unions from different confederations. In principle, union restructuring along these lines is conducive to the observed development towards more complex, multi-tiered systems of collective bargaining, in which centralised framework agreements allow greater latitude for company bargaining. At any rate, strengthened union capacity for decentralised coordination seems essential to promote local bargaining, to prevent the undercutting and withering of local agreements, and to develop a stronger union voice in local politics, public debate and coalition-building. It will also be necessary to base such measures in a broader political approach to engage the polity, whether at national or supranational level, in reshaping the legal institutional framework of labour relations in ways that give voice to collective organisation, while also accommodating work and family life in services (Bosch 2000).

The hope is that such union restructuring can also help in overcoming inter-union competition and the problem of fading industrial, occupational and union boundaries, and, through economics of scale, allow room for improved, targeted membership support, and redeployment of resources closer to the workplace (Waddington and Hoffmann 2000b). It is too early to judge whether the multi-industry unions resulting from mergers will succeed, but there is a risk that the benefits of size and scope are dissipated by bureaucratisation, new areas of recruitment competition, and diminishing identification among members and potential members. A key question is whether new structures enhance development of more efficient approaches to the recruitment and retention of members. Some argue that specialised unions with a narrow profile are more flexible and effective in winning support among targeted recruitment groups 


\section{J.E. Dølvik and J. Waddington}

(Olsen 1966). Other views, which criticise the limitations of institutionalised unionism based on the servicing approach, are linked to arguments in favour of the American organising approach (Bronfenbrenner et al. 1998).

While improving conditions for coordination at the sectoral level, the development of multi-industry unions raises thorny questions about the future role of union confederations and the capacity for cross-sectoral union coordination. This question has been accentuated by recent tendencies among service-sector unions, particularly in the Nordic countries, which challenge the bargaining hegemony of manufacturing unions and thus complicate the pursuit of economy-wide concertation. Furthermore, in the case of ver.di, the concentration of German union membership suggests that the future of the DGB is in doubt, since the coordination of union activities and, in particular, relations with government, can be undertaken within the major unions rather than by the confederation (Waddington and Hoffmann 2000b). To offset the risk of union rivalry and segmentation along sector lines, which may pit unions in services against unions in manufacturing, it is important to develop forms of crosssectoral labour solidarity that transcend the old distinction between valuecreating and value-consuming work.

To meet the aspirations of an increasingly diverse service workforce, it is necessary to develop an agenda that accommodates heterogeneity. Instead of the 'one-size-fits-all' pattern of 'mechanical solidarity', associated with mass industrial production, union approaches must aim to develop new forms of 'organic solidarity' that pay greater attention to the needs of individual members and the interests of particular member groups, while also placing a stronger emphasis on the interdependence between individual self-realisation, group cohesion, and collective regulation of the framework conditions under which the former can flourish. Many national unions have started approaching these issues, irrespective of whether their members are in manufacturing or services, by allowing greater leeway for local flexibility within collective agreements. It is, however, a demanding and contested task to move from theory to practice in this area, which touches on deep-seated values and power structures within the trade union movements.

\section{Notes}

1 In public services unions have usually achieved high levels of unionisation among two groups of workers: those employed in large-scale manual or whitecollar work, such as refuse collection and local government administration; and those employed in professional occupations, such as doctors and nurses. Unions organising the second of these categories are often 'professional' associations, with recruitment bases restricted to the one occupation.

2 Although it is not the subject of this chapter, trade union structures and activities also need to be articulated to bring influence to bear on international 
developments. This is particularly the case within the European Union where a new regulatory framework is in the making, and interprofessional agreements and/or directives concerning minimum rights of atypical workers (part-time workers, parental leave, employees on fixed term contract, and distant work) have been settled in recent years (for details see Vigneau et al. 1999).

3 The data refer to 1997 or 1995 (Ebbinghaus and Visser 2000). Except for Ireland and Spain, the data reflect net union density, which expresses working members as a proportion of the dependent labour force. Data for Ireland and Spain reflect gross density (total union membership as proportion of dependent labour force). Data for the UK and Portugal are taken from Waddington and Hoffmann (2000a, Table 1.7).

4 Initially, public employees in schools, railways, post, telecommunications and other public utilities were organised at the turn of the twentieth century, and were followed in most countries by clerical and administrative staff in the private sector. During the 1920s and 1930s engineers, draughtsmen and lower supervisory staff increasingly formed unions. The third wave occurred with the rapid expansion in white-collar occupations and professionals during the 1970 s.

5 For example, prominent British retailers, such as Marks \& Spencer and Body Shop, chose to conclude collective agreements in Ireland in contrast to Britain. Similarly, McDonalds and Toys ' $\boldsymbol{Y}$ ' Us did the same in Sweden, presumably to avoid negative exposure and to make business more predictable.

6 The issue of transnational trade union organisation is not dealt with here, but in recent years, unions in marketised services have established an almost sectorencompassing federation, labelled UNI, which is designated to become the umbrella.

7 'Anchoring' is the process whereby Swedish unions (LO-affiliated unions, in particular) ascertain the views of members and attempt to structure these views. Any congruence between the views of members and the views of union representatives is thus regarded not simply as a measure of representative democracy, but also of the powers of persuasion of union representatives (for details, see Ahlèn 1994).

8 The connexx.av project was initiated by Industriegewerkschaft Medien (IG Medien: Media Workers Union) and Deutsche Postgewerkschaft (DPG: Postal Workers Union), which had members in the media industry. Both unions were part of the ver.di merger. The merger thus enabled a higher profile to be afforded to the project.

9 These take a number of different forms. More long-standing sectional forms of representation allowed specific industrial groups separate systems of representation within larger unions. These were often associated with industrial bargaining and ensured some form of bargaining autonomy to industrial groups within multi-industry unions. Recently these have been supplemented by sectional forms of representation, which are intended to encourage participation among particular groups (such as women, young workers and workers from ethnic minorities) or for specific occupations (such as white-collar or managerial staff).

10 From 1994 to 2000 , the percentage of collective agreement coverage actually rose from 55 to 68 in transport, from 31 to 47 in trade, hotels and restaurants, and from 58 to 82 in finance (Scheuer and Madsen 2000).

11 In response to problems associated with privatisation and fragmentation of the telecom sector, competing company agreements and fading boundaries between different industry agreements, the sectoral agreement was negotiated and signed by Confindustria and the union confederations. The agreement, 


\section{J.E. Dølvik and J. Waddington}

which has been considered an innovation in Italian industrial relations, mainly stipulates central minimum standards for pay, working time, the use of atypical workers, flexibility and so on, and leaves considerable leeway for negotiating adjustments and pay at company level. Thereby it also introduces a two-tier bargaining system, circumventing the industry level (EIRO 2000).

12 For example, Norwegian LO unions have experienced positive effects by creating LO centres at local level, which allow a range of unions to use common facilities and engage in joint organising and political initiatives.

\section{References}

Ahlèn, K. (1994) Unfilled Ambitions: Democratic Legitimacy in Swedish Labor Unions, Stockholm: Arbetslivcentrum.

Behrens, M. (2001) 'Works Constitution Act Reform Adopted'. Available online at: www.eiro.eurofound.eu.int/2001/07/feature/de0107234f.html (accessed 5 July 2004).

Blaschke, S. (2001) 'Corporatist Regulation of Service Labour Markets', in J.E. Dølvik (ed.) At Your Service? Comparative Perspectives on Employment and Labour Relations in the European Private Sector Services, Brussels/New York/London: PIEPeter Lang.

Boeri, T., Brugiavini, A. and Calmfors, L. (2001) The Role of Unions in the 21st Century, Oxford: Oxford University Press.

Bosch, G. (2000) Der Übergang zur Dienstleistungsgesellschaft - Ende oder Neuanfang der Gewerkschaften? 3. Ausserordentlichen HBV-Gewerkschaftstag, Magdeburg, 12-14 September, Manuscript, Gelsenkirchen: Institut Arbeit und Technik.

Bronfenbrenner, K., Friedman, F., Hurd, R., Oswald, R. and Seeber, R. (eds) (1998) Organizing to Win: New Research on Union Strategies, Ithaca, NY: Cornell University Press.

Colgan, F. and Ledwith, S. (1996) 'Sisters Organising: Women and their Trade Unions', in F. Colgan and S. Ledwith (eds) Women in Organisations, London: Macmillan.

Colling, T. and Dickens, L. (1998) 'Selling the Case for Gender Equality: Deregulation and Equality Bargaining', British Journal of Industrial Relations 36(3): 389-412.

Conrow, T. (1991) 'Contract Servicing from an Organizing Model', Labor Research Review 17: 45-59.

Crouch, C. (1993) Industrial Relations and European State Traditions, Oxford: Clarendon Press.

Di Nicola, P. (1997) 'Formal and Informal Representativeness in Italy: Members and Voters of the Confederal Trade Unions', in M. Sverke (ed.) The Future of Trade Unionism, Aldershot: Ashgate.

Dølvik, J.E. (2001) 'Conclusion: The Impact of Post-industrialisation on Employment and Labour Relations: A Comparative Review’, in J.E. Dølvik (ed.) At Your Service? Comparative Perspectives on Employment and Labour Relations in the European Private Sector Services, Brussels/New York/London: PIE-Peter Lang.

Ebbinghaus, B. and Visser, J. (1999) 'When Institutions Matter: Union Growth and Decline in Western Europe 1950-1995', European Sociological Review 15(2): 1-24.

— (2000) Trade Unions in Western Europe since 1945, London: Macmillan.

European Industrial Relations Observatory (EIRO) (1999) 'France: High-tension Negotiations in Information Technology, Engineering and Consulting.' Avail- 
able online at: www.eiro.eurofound.eu.int/1999/04/inbrief/fr9904178n.html (accessed 5 July 2004).

— (2000) 'Italy: Sectoral Agreement Signed in Telecommunications'. Available online at: www.eiro.eurofound.eu.int/2000/07/feature/it0007158f.html (accessed 5 July 2004).

- (2001a) 'Comparative: Industrial Relations in the Information and Communication Technology Sector'. Available online at: www.eiro.eurofound.eu.int/ 2001/08/study/tn0108201s.html (accessed 5 July 2004).

- (2001b) 'Sweden: First Collective Agreement Signed for Call-centres and Telemarketing'. Available online at: www.eiro.eurofound.eu.int/2001/02/ inbrief/se0102183n.html (accessed 5 July 2004).

- (2001c) 'Spain: Strikes in the Telemarketing Sector'. Available online at: www.eiro.eurofound.eu.int/2001/07/inbrief/es0107251n.html (accessed 5 July 2004).

— (2001d) 'Italy: Agreement Signed for Atypical Workers in Market Research'. Available online at: www.eiro.eurofound.eu.int/2001/01/inbrief/it0101171n. html (accessed 5 July 2004).

- (2002) 'Germany: Ver.di Seeks to Give Prostitutes a Voice'. Available online at: www.eiro.eurofound.eu.int/2002/03/feature/de0203203f.html (accessed 5 July 2004).

Fullin, G. (2002) 'The Unions for Atypical Workers in Italy', Transfer 8(3): 531-5.

Glißmann, W. and Peters, K. (2001) Mehr Druck durch mehr Freiheit: Die neue Autonomie in der Arbeit und ihre paradoxen Folgen, Hamburg: VSA.

Heery, E. (2002) 'Partnership versus Organising: Alternative Futures for British Trade Unionism', Industrial Relations Journal 33(1): 20-35.

Irish Congress of Trade Unions (ICTU) (1998) What People Think of Unions, national survey conducted by Research and Evaluation Services, Dublin: ICTU.

Jordfald, B. and Olberg, D. (2002) 'IKT-sektoren - perspektiver på sysselsetting, arbeidsmiljø og interesseorganisering', Fafo-report 391, Oslo: Fafo Institute.

Jørgensen, H., Lassen, M., Lind, J. and Madsen, M. (1992) Medlemmer og Meninger, Copenhagen: Landsorganisationen i Danmark.

Kahmann, M. (2003) 'Trade Unions and the Growth of the Information Economy', ETUI Discussion Paper, Brussels: European Trade Union Institute.

Kjellberg, A. (1983) Facklig organisering $i$ tolv länder, Lund: Arkiv Förlag.

- (2001) Fackliga organisationer och medlemmer $i$ dagens Sverige, Lund: Arkiv Förlag.

Kochan, T., Lansbury, R. and MacDuffie, J-P. (1997) After Lean Production, Ithaca, NY: ILR Press.

Krell, G. (2001) 'Zur Analyse und Bewertung von Dienstleistungsarbeit: Eine Diskussionsbeitrag', Industrielle Beziehungen 8(1): 9-36.

Krieger, H. and O'Kelly, K. (1998) 'The Extent of Participation in Europe', Transfer 4(2): 214-31.

Lehndorff, S. (2002) 'Work Regulation in the Service Sector: Changes in the Organisation of Work: New Challenges for Service Sector Trade Unions', Transfer 8(3): 415-34.

Lockwood, D. (1957) The Blackcoated Worker, London: Allen \& Unwin.

McBride, A. (2001) Gender Democracy in Trade Unions, Aldershot: Ashgate.

Meilland, C. and Dufour, C. (2001) 'Services in France: Heterogeneity of Employment Systems within Common Institutional Frames', in J.E. Dølvik (ed.) At Your 


\section{J.E. Dølvik and J. Waddington}

Service? Comparative Perspectives on Employment and Labour Relations in the European Private Sector Services, Brussels/New York/London: PIE-Peter Lang.

Olberg, D. (2001) 'Nye driftsformer i varehandelen: Organisasjonsgrader og avtaleforhold', Fafo-notat 2001:14, Oslo: Fafo Institute.

Olsen, M. (1966) The Logic of Collective Action, Cambridge, MA: Harvard University Press.

Organisation for Economic Co-operation and Development (OECD) (2001) 'The Quality and Characteristics of Service Sector Jobs', Employment Outlook, Paris: OECD.

Ponzellini, A. and Provenzano, E. (2001) 'Italy: The Services Sector - Towards a More Inclusive and Flexible Labour Market?’, in J.E. Dølvik (ed.) At Your Service? Comparative Perspectives on Employment and Labour Relations in the European Private Sector Services, Brussels/New York/London: PIE-Peter Lang.

Savage, L. (1998) 'Geographies of Organizing: Justice for Janitors in Los Angeles', in A. Herod (ed.) Organizing the Landscape, Minneapolis: University of Minnesota Press, pp. 225-52.

Scheuer, S. and Madsen, M. (2000) 'Mod en ny balance mellem kollektivisme og individualisme', LO-Dokumentation 2/2000, Copenhagen: Landsorganisationen i Danmark.

Schumann, M. (2001) 'Sozialstrukturelle Ausdifferensierung und Pluralisierung der Solidarität', WSI Mitteilungen 9: 531-7.

Sisson, K. and Martín Artilés, A. (2000) Handling Restructuring: Collective Agreements on Employment and Competitiveness, Dublin: European Foundation for the Improvement of Living and Working Conditions.

Streeck, W. and Visser, J. (1997) 'The Rise of the Conglomerate Union', European Journal of Industrial Relations 3(3): 305-32.

Sverke, M. and Sjøberg, A. (1997) 'Ideological and Instrumental Union Commitment', in M. Sverke (ed.) The Future of Trade Unionism, Aldershot: Ashgate.

Traxler, F., Blaschke, S. and Kittel, B. (2001) National Labour Relations in Internationalised Markets, Oxford: Oxford University Press.

Tromp, C. and Beukema, L. (2001) 'The Dutch "Poldermodel": A Flexible Success Story', in J.E. Dølvik (ed.) At Your Service? Comparative Perspectives on Employment and Labour Relations in the European Private Sector Services, Brussels/New York/London: PIE-Peter Lang.

UNI (2002) 'Many Members Sign up Through Website: Sweden's HTF Continues to Grow'. Available online at: www.union-network.org/unisite/sectors/commerce/ Activities/HTF_recruits_through_website.htm (accessed 5 July 2004).

Valkenburg, B. and Beukema, L. (1996) 'The Organisation of Flexibility: Atypical Jobs as a Challenge for the Modernisation of Trade Unions', Transfer 2(4): 738-54.

Vigneau, C., Ahlberg, K., Bercussen, B. and Bruun, N. (1999) Fixed-term Work in the $E U$, Helsingborg: Boktryck.

Waddington, J. (2001) 'Articulating Trade Union Organisation for the New Europe?', Industrial Relations Journal 32 (5): 449-63.

Waddington, J. and Hoffmann, R. (2000a) Trade Unions in Europe, Brussels: European Trade Union Institute.

- (2000b) 'The German Trade Union Movement in Structural Transition: Defensive Adjustment or Setting a New Agenda?', in R. Hoffmann, O. Jacobi, B. Keller and M. Weiss (eds) Transnational Industrial Relations in Europe, Düsseldorf: Hans Böckler Stiftung. 
Waddington, J. and Kerr, A. (1999) 'Trying to Stem the Flow: Union Membership Turnover in the Public Sector', Industrial Relations Journal 29(2): 151-65.

- (2000) 'Towards an Organising Model in UNISON?: A Trade Union Membership Strategy in Transition', in M. Terry (ed.) Redefining Public Sector Unionism, London: Routledge.

Waddington, J. and Whitston, C. (1997) 'Why Do People Join Unions in a Period of Membership Decline?', British Journal of Industrial Relations 35 (4): 515-46.

Wagner, A. (2002) 'Private Services and Female Work: Institutional Conditions for a Better Balance', Transfer 8(3): 43j328

$5-55$.

Weiler, A. (2000) 'Innovative Agreements on Equal Opportunities: New Horizons of Collective Bargaining?', Transfer 6(2): 209-26.

Weinkopf, C. (2002) 'Call-centre Work: Specific Characteristics and the Challenges of Work Organisation', Transfer 8(3): 456-66.

Williams, J. (1999) 'Restructuring Labor's Identity: The Justice for Janitors Campaign in Washington, D.C.', in R. Tillman and M. Cummings (eds) The Transformation of U.S. Unions, Boulder, CO: Lynne Rienner. 


\title{
14 Diversity and regulation of markets for services ${ }^{1}$
}

\author{
Jean Gadrey
}

\section{Introduction}

The subject of this book is the new forms of employment and work organisation in the service sector. It does not focus on services themselves, as products or outputs, on the corresponding markets or innovations in services. Nevertheless, all the various chapters clearly show that the changes affecting work and employment have a 'connection' with those relating to services themselves and the markets for them, in terms of both quantity (volume of employment and of working time) and quality (individual skills, organisational competencies, social status of jobs and so on).

As early as Chapter 2, which describes the 'European landscape', it is clear that the structure and even the total volume of work in services is not unrelated to the share of 'community and social services', which varies considerably among the ten countries investigated. Relatively high shares of such services seem to be conducive to the development of a service economy with an abundance of high-quality jobs. It is also evident that those countries in which skilled production-oriented services are more highly developed are also characterised by quality-based competition. It also emerges from this and subsequent chapters that, despite general trends towards work intensification and a tendency to retreat when the lowest-cost principle regains ground, strong growth in community and social services and in production-oriented services encourages what the co-authors call 'active' flexibility (self-organisation with indirect control) as opposed to 'passive' flexibility and 'service Taylorism'.

Thus the nature of the services on offer in a national economy, as well as the dominant form of competition (and in particular whether corporate strategies are based primarily on quality or cost reduction), influences the nature of work and employment status. This influence is exerted in a complex, non-mechanical way. Chapter 10 on the banking industry, for example, clearly shows that job and work profiles are very different in French and German call centres. The same applies to the very considerable differences between the countries in home care services for the elderly. In all the cases investigated, there are many other factors, both 
inside and outside the organisations in question, that help to determine the nature of work and employment. This is reflected in Figure 1.1, which brings into play four spheres or groups of explanatory factors which are themselves interdependent. They are the product, market and consumption sphere, the labour supply and family and gender structures sphere, the private and public modes of governance sphere, and the labour market institutions and industrial relations sphere.

Let us return to the example of home care services for the elderly (Chapter 6) and the schematic representation drawn up by the authors (Figure 6.1), who have examined the similarities and differences in national employment and work profiles in this sector, which is fairly representative of the tensions encountered in the search for new forms of employment and work organisation in 'relational' services. It is evident from this chapter and the schematic representation that, despite certain converging trends across Europe (professionalisation, marketisation), there is still a great diversity of solutions, reflecting in particular the plurality of welfare state regimes, family and fiscal policies, pay rules and modes of female labour market participation. In many cases, when market solutions gain ground to the detriment of public or non-profit-making solutions, there is no evidence that this is happening because of the market's 'natural' superiority. The decisive reasons are, first, that the state itself offers financial incentives for these market solutions (particularly through the tax system and privatisation) and, second, that private companies in the competitive sector employ workers who are, on average, less well paid (and often less skilled). It is by no means clear that the outcome improves quality of life and employment (in both quantitative and qualitative terms) at the least cost to society. However this may be, there are certainly links between, on the one hand, employment and work in this sector and, on the other, a vast array of institutional forms and regulations governing the services provided. The same observation may be made of the health services sector.

The fairly widespread adoption of a market approach to the production of services is seen as 'the heart of the change in work organisation', particularly from the point of view of 'the increasing exposure of individual workers in their daily work to the competition and restrictions of the market'. In this connection, the authors note that: 'This change affects not only the service sector but manufacturing industry as well. Ultimately, it reflects the trend towards adopting the market as the universal governing principle in as many spheres of human activity as possible.' Although the main emphasis in this analysis is on marketisation within organisations, it is clear that the market approach to services is a much more widespread phenomenon that manifests itself just as forcefully in the privatisation of public services, the substitution of competitive, profitmaking solutions for public or non-profit-making ones and the outsourcing of services in the community and social sector. 


\section{Jean Gadrey}

In this chapter I will confine myself to examining the role of the "northwest' quadrant of Figure 1.1, which encompasses the characteristics of the markets for services and the forms of competition. More specifically, I will attempt to show that the discourse which puts the marketisation of services in a favourable light is fragile, ideological, mythical even, because the pure, perfect market is even more of a chimera in the case of services than in that of manufactures. The markets for services are extremely diverse, due mainly to the diversity of rules, networks, and institutions governing them. Part of the explanation for the diversity of forms of employment and work in services lies in the diversity of regulatory arrangements in markets for services themselves. Moreover, in some cases, particularly when the 'output' of certain services consists almost entirely of the provider's labour, working in direct contact with the customer, there is a very considerable degree of overlap between work rules and market rules. This is particularly true of the more professional and relational services, in which the work rules relate in part to what constitutes the 'value' of the service for the customers, namely the interactive adaptation to a unique, non-standard demand, which is constructed simultaneously by the customer and the person producing the service.

One final point needs to be made before getting to the heart of the matter. To say that part of the explanation for the diversity of forms of employment and work in services lies in the diversity of regulations governing markets for services does not mean - and this really does have to be repeated - that everything can be explained in this way. Far from it. The three other spheres in the schematic representation also play their part, and organisational choices (including choices of working-time arrangements), for example, enjoy relative autonomy as explanatory factors. For example, there are cases in which flexibility is more active than passive and there is a greater or lesser degree of self-organisation, even in markets for services in which competition is based primarily on cost reduction. This does not happen very frequently, but such cases do exist and may indeed constitute viable organisational choices. Similarly, societal conventions and the institutions supporting the family division of labour and roles always exert enormous influence on the social distribution of service jobs in all sectors, without exception.

\section{The 'pure' market is a normative myth}

What is a market? For traditional economists, this question elicits a simple response: a market is the coming together of a supply and a demand expressed independently of each other on the basis of preferences and production choices that are themselves also individual. The encounter between the two leads to equilibrium because, if competition and information are perfect, price acts as an adjustment variable, going down if supply exceeds demand and up if not. It is sufficient for the actors to be 
pursuing their own individual interests for the market to function and, moreover, the result achieved by means of this totally decentralised mechanism is optimal: any attempt to constrain or regulate merely aggravates the situation.

What do contemporary, socio-economic studies of markets in general, and those for services and labour in particular, show us? Essentially that the market as defined by traditional economists cannot be seen to exist anywhere in the market economy! Well, you might say, this is only to be expected: an abstract concept cannot actually exist simply because it is abstract. Nevertheless, even as an abstraction, it can be a simplified or 'purified' but still pertinent representation of 'real world' practices that depart from it to a greater or lesser extent. Granted, real markets have various 'imperfections', but that in no way diminishes the fundamental importance of the 'perfect' model. Indeed, the opposite is the case, since the theoretical perfect market is the reference point that might allow the imperfections of real markets to be corrected. However, the findings of the socio-economic studies on which I draw here point in a completely different direction, since they suggest that virtually all markets in existence today - and the same was true in the past - are characterised by rules, by institutions with their power games, and by social networks that influence both the formation of supply and the expression of demand, the social conditions under which they come together and the determination of prices and quantities. Supply and demand, the alpha and omega of the traditional market, are social constructs that have collective aspects and are virtually never the results of decisions taken independently by individuals. Of course, such individual, decentralised decisions do exist and are very important, but they are always shaped by, or embedded in, social structures that have collective dimensions.

Thus all markets function both through the interaction of these individual, decentralised decisions and under the influence of the social rules, institutions and networks within which they find expression. This is why markets are so diverse and cannot be reduced to a single abstract model, which emerges in fact as more of a normative reference point (that some consider desirable) ${ }^{2}$ than a scientifically based abstraction. True, supply and demand exist, there may be imbalances between the two, and prices exert some degree of influence. Nevertheless, once that statement has been made, there is little in it to help us to conceptualise markets in all their diversity or to guide our decision-making in this area. The examples presented below

illustrate this general notion of markets as systems of rules and networks of exchanges.

\section{The utopia of a market without rules}

Let us begin with the theoretical market of traditional economics, the one based on 'the general equilibrium of pure and perfect competition' and 


\section{Jean Gadrey}

assumed to be devoid of all collective rules. What are the implicit assumptions behind this abstract or normative notion?

The first assumption is that the protagonists have perfect information. However, since information does not fall from the sky, institutions are required to produce and diffuse exhaustive information on products, prices, technologies and so on, together with rules governing access. Kenneth Arrow, undoubtedly the most important of the contemporary economists who formalised general equilibrium theory around the $1950 \mathrm{~s}$, has himself subsequently contributed a great deal to the analysis of this essential public informational context (see Arrow 1984). The provision of information cannot even be left to the tender mercies of a specific market, since it would not be perfect for all agents due to the inevitable inequalities of access.

The second assumption is that people do not cheat or steal, even though such behaviour would in fact be consistent with the dedicated pursuit of individual interest. Thus institutions are required, along with sanctions, a police force, a judicial system, a department of competition and prices, some form of monitoring and enforcement and so on.

Institutions are also needed to establish and enforce the ownership rights that are necessary for market exchanges. The necessity of such institutions is clearly seen today in the fight against the 'pirating' or illegal copying of a wide range of informational goods (e.g. software, CDs, books, brands, trademarks). Such a fight amounts, paradoxically, to 'artificially' (i.e. through institutional means) re-establishing scarcity so that the market can function properly once again, although in other respects the economy presents itself as a fight against scarcity.

Finally, it is assumed that individuals never form alliances in order to defend collective interests, and even that they have no influence over each other. Thus laws and institutions are required in order to prohibit and suppress these alliances, trade unions, trusts and so on.

The list could be extended by including several other crucial hypotheses, all of which require rules and institutions ('visible hands') if the alleged 'invisible hand' of the market is to function properly. Thus even the perfectly competitive market, which is assumed to be devoid of rules, is unable to function without a vast array of rules and institutions. It is sometimes said that a stock exchange is as close as it is possible to get to a perfectly competitive market, with free and individual expression of supply and demand and virtually instantaneous adjustment of these two variables. However, as everybody knows, stock markets are riddled with rules and institutions, they have 'watchdog' committees to oversee their operations and arrangements for stamping out insider trading, there are networks of personal connections and 'tip-offs', alliances, public interventions at national and supranational level, influence exerted by central banks and so on. Thus stock markets are very far indeed from being perfectly competitive. They too are 'embedded'. 
We have available to us a superb study of the conditions that have to be met if a market is to operate in accordance with norms that are as impersonal and competitive as possible and if the principles of the selfregulating market, freed from the social contingencies of local markets and their networks of personal connections, are to be implemented as rigorously as possible. I am referring to a study carried out by Marie-France Garcia of the 'social construction' of a 'modern' market for strawberries in Fontaines-en-Sologne. The study shows how this (successful) experiment proceeded through various phases of heavy investment in institutional and technological development, with the aim of standardising products, behaviours and ways of thinking, and analysing and centralising an auction system. In other words, the closer one seeks to get to a perfectly competitive market, the more old norms and networks have to be replaced by new rules and institutions. This has nothing to do with ordinary 'deregulation' or 'self-regulation' (Garcia 1986).

\section{The case of the labour market}

Things are even clearer when it comes to the actual markets to which I now turn, namely the labour market and the markets for various services. I begin with the labour market, breaking it down for the purposes of analysis into the three stages of price determination, definition of the 'goods' or 'products' to be traded, and the bringing together of users and suppliers.

Wages (that is, prices in the labour market) are not determined freely from day to day through the competitive working of supply and demand (except perhaps in some illegal markets) because of the existence of a multiplicity of rules and institutions: national minimum wage, negotiated wage agreements, promotion rules (some economists speak of 'internal labour markets', but they do so precisely in order to define them as rules not governed by the laws of the competitive market), social security contributions, labour legislation on pay, non-discrimination and so on.

Jobs, positions and working time (that is, the 'products' traded in the labour market) are not competed for every day or every month, as they should be in a completely deregulated market. There are fixed-term and permanent contracts, tenured civil service jobs, corresponding labour legislation and so on.

Even the 'external' market, in which employers recruit and individuals look for vacancies - that is, the market in which the supply of and demand for labour are brought together - does not operate at all in accordance with the principles of the anonymous competitive market. Such a market would take the form of a sort of commodity exchange where standardised announcements from suppliers and users would be listed, rather like the Sologne strawberry market. Such labour markets do exist, but sociologists who specialise in such questions, chief among them Mark Granovetter (1974), have been showing for some time that this 'external' market is 


\section{Jean Gadrey}

largely made up of networks of personal connections and family and social ties which play a dominant role in individuals' attempts to find employment. This applies not only to the managerial and professional categories but also to blue-collar workers. Indeed, as early as the 1950 s, it was shown that manual workers were more likely to find a job through personal contacts than by any other means (e.g. job advertisements, direct approaches to employers).

At this point in the argument, several questions arise. Let us assume that the labour market is indeed highly regulated and integrated into a multiplicity of personal connections and networks. Is this desirable? Should the labour market not be adapted, in part at least, to 'pure' competitive market norms?

If we focus closely on the labour market's many imperfections (e.g. rules, relative job security, promotion, minimum wage, trade unions), one of the major findings of the socio-economic studies referred to above is that these alleged imperfections are not always disadvantages. In many cases, indeed, they are compromises of benefit to both the economy and the wider society, and even have advantages for employers. Thus as early as the late $1960 \mathrm{~s}$, the theoreticians of 'internal labour markets' showed not only that a certain degree of job security, internal promotion prospects, a lack of constant competition for jobs from external candidates and the ability to join trade unions are viewed positively by most 'insiders' but also that these various 'non-competitive' arrangements can also be economically beneficial to firms, for various reasons: they can reduce turnover, recruitment and training costs, promote the development of competencies through the experience effect, and increase productivity and staff motivation (Doeringer and Piore 1971).

\section{The other markets: all regulated to a greater or lesser extent}

These observations on the labour market may also be applied, with a few modifications, to the markets for a wide variety of services, which puts into context Polanyi's notion that the labour market is radically different from other markets. While it is true that it is a market 'unlike others', there are many markets that are also 'unlike others'. Markets for personal and professional services, for example, have many points in common with the labour market, and analyses couched in terms of internal labour markets, relationships based on trust and loyalty, price-setting on the basis of enduring norms, trade unions, recruitment through personal connections and so on can be transposed to them. Polanyi maintained that the labour market is a fiction which cannot be sustained in the long term without destroying society, because of the 'human nature of this supposed commodity'. This humanist point of view is more than worthy of respect, but it is rooted in a confusion that occurs frequently in 'The Great Trans- 
formation' between 'real-world' markets in all their diversity and the ideal type of the self-regulating market, which is, nevertheless, described as utopian. It is true that wage work 'goes hand-in-hand with life itself', but the 'human nature' of what is traded is also found, for example, in the majority of markets for personal and professional services: what the customer purchases is the right to use, for a given period, the 'living' competencies of a service provider who places himself at his or her service. Can we say that markets cannot exist in such cases? Clearly not, even though it is true that the average wage relationship is based on a more lasting commitment and on a greater degree of hierarchical control. The demand for professional status for all, currently mentioned by some European specialists such as Alain Supiot (1999), could even bring the characteristics of the labour market close to those for certain professional services. We can also point, in this regard, to the observation in this book that 'the boundaries between dependent employment and self-employment (are) becom(ing) blurred', at least in some services.

Let us return then to our subject of market regulations, beginning with the markets for so-called professional services (lawyers, architect, doctors, accountants,). They have their professional bodies, codes of professional ethics, entry requirements and rules governing the exercise of the profession, prohibitions on advertising in some cases and networks of personal contacts. The cumulative effect of all these arrangements is to determine how supply and demand are expressed, the conditions under which they are brought together and the rules governing pricing and what constitutes a 'fair price'. In the case of France, the studies of lawyers and, more generally, of 'quality markets' by the sociologist Lucien Karpik (1989, 1996) constitute an essential point of reference in this area. Many other markets for services in the so-called competitive sector are strictly regulated, with controls on prices and on entry to the profession, lists of recognised qualifications, processes of certification, guarantees and so on. This applies even more to tradable public services, such as postal services, water, gas and electricity supply, telecommunications and urban services, with their 'universal service' obligations, to public and private health services, and to community services in the 'third sector', which combine voluntary work, public services and market resources in the provision of non-profit-making services. In reality, this high level of regulation and the shaping of markets through social relations is characteristic of virtually all the activities that have experienced the strongest job growth over the past twenty-five years. In addition to these examples, all of which relate to services, mention could also be made of the regulation of markets for industrial and agricultural products in respect of safety, 'traceability', guarantees, declared prices, the prohibitions of certain discounting practices, differential rates of VAT and so on.

All these markets are regulated to varying degrees and do not operate in accordance with the precepts of the abstract and mythical model of the 
competitive market. They are thoroughly social in nature. While it is true that they are part of a decentralised market economy, they may be defined as $a$ diverse set of market institutions and social networks that determine the form and frequently the success of market mechanisms.

\section{Two types of justifications for rules}

The first justification for these regulations is that, in a large number of service activities (essentially the least standardised), the protagonists - and particularly individual consumers or users - are prey to considerable uncertainties, both as to the nature and quality of outcome of such services, which cannot be fully described in a contract, and in respect of the service providers. How are they going to behave, how committed are they going to be and what are their actual competencies? The uncertainty also extends to the conditions of the transaction: the notion of what constitutes a fair price may well be unclear, and public information on prices is sometimes lacking. Thus an initial set of market rules and institutions seeks to reduce these individual uncertainties, which are mainly technical in nature, and to produce trust and guarantees. Indeed, it is not an exaggeration to say, in contrast to the prejudices of those who advocate perfect competition, that such markets require rules and institutions in order to be able to develop and promote their own commercial interests. These rules are not solely, or even mainly, social and political constraints hampering such development. These characteristics, which are common to many markets for services, also apply to industrial and agricultural goods as soon as various technical uncertainties arise as to their quality and reliability, particularly since consumers tend to become increasingly demanding over time as to the level of risk they are prepared to accept.

A second set of rules and norms governing markets falls within the scope of 'civic' principles regarding social cohesion, or of certain notions of the public interest. Technical or financial norms that allow handicapped people or the unemployed access to certain services are examples of this category of rules. In this case, the aim is no longer simply to reduce individual uncertainties of a technical nature as to the quality of services, goods or transactions, but rather to lessen collective risks in accordance with prevailing notions of the public good or of the long-term future of the community and its environment.

The markets most affected by such regulations based on the public interest and civic principles are probably the labour market (we need think only of the minimum wage, social security contributions, anti-discrimination legislation) and (national or local) markets for public services or sectors that fulfil certain public interest objectives, such as health and education. However, most products and markets are governed by rules derived from this group of justifications. That said, it is not always easy to agree on what actually consists of the 'public interest', an eminently 
historical and political notion that varies considerably depending on national context. Some may take the view, for example, that it includes the rules establishing 'fair' competition in public services, or that regulations seeking to reduce inequalities (of earnings or in access to certain goods and services defined as basic) or to establish a minimum wage are contrary to the public interest. I will confine myself to noting the variability of conventions, which merely reinforces the need for democratic debates on what 'a good society' is. Such debates will contribute to the construction of conventions on the public interest.

\section{A society has the markets it creates for itself}

In other words, and to the extent that it is not dominated by others, a society is largely responsible for the economic and social characteristics of its markets. A society's markets reflect the qualities and faults of that society's rules, laws, institutions and ethical norms. This is particularly true of labour markets and the markets for certain public or private services, including financial and insurance services. ${ }^{3}$ In this respect, the critical 'anti-market' ideology is as one-sided as the ideology of the so-called freemarket economy that seeks to locate all transactions within an individualistic but impersonal and asocial framework, and reduces the intervention of the political and social spheres to limited corrections to competitive economic mechanisms. As Phelps shows (and he is hardly an extreme radical), trust, loyalty, and sometimes even altruism are essential if certain markets are to operate effectively (Etzioni 1988: 206). However, they are not goods that can be bought but rather the result of collective arrangements, of rules, of networks of personal contacts, of ethical codes and so on. As Arrow wrote in 1968, 'One of the characteristics of a successful economic system is that relations of trust and confidence between principal and agent are sufficiently strong that the agent will not cheat even though it may be "rational economic behaviour" (Arrow 1984, vol. IV: 103).

Thus the question is not whether 'market-type mechanisms' are able efficiently to coordinate the majority of acts of production, consumption and saving in a developed society. The real issue lies rather in the political definition, on a case-by-case basis, of the social content of markets and of the rules governing them (and more generally the market economy). This form of 'market governance' requires serious socio-economic evaluations of the possible alternative models and of their impacts on society. Markets are not ends in themselves but one of several means of allocating resources and stimulating social innovation. Should they seek an independent existence of their own, they need to be put in their rightful place, in the knowledge that 'they' actually always denote actors, groups and lobbies whose interests may very well be served by such independence.

As Amitaï Etzioni notes, 'competition is a form of conflict, namely contained conflict' (Etzioni 1988: ch. 12). It is this that explains how it can 


\section{Jean Gadrey}

produce beneficial effects by easing or preventing conflicts of interests, while at the same time requiring rules to contain those conflicts in order to avoid the self-destructive escalations inherent in 'unbridled capitalism'. Depending on the evaluations carried out, this could lead either to the introduction of a large number of strict rules, with certain activities perhaps being withdrawn from the market altogether or public monopolies being maintained, albeit with closer monitoring, or, in other cases, to a 'lighter-touch' regulation that fully recognises the virtues of fair but supervised competition. Such a point of view would be based on principles that go beyond the distinction between market economy and market society in order to highlight the political imperative of civilising markets and competition as a precondition for sustainable social development.

\section{Conclusion}

A virtuous circle for the economy and for society at large denotes a configuration in which there are positive follow-through effects between economic expansion (quantitative and qualitative) and living standards and quality of life. These effects are always mediated through the institutionalised compromises struck between two sets of animating principles embodied in various actors and groups in society: production and supply, on the one hand, and consumption and social progress, on the other. During the so-called 'Fordist' era, which in Europe lasted from the end of the Second World War until the mid-1970s, this virtuous compromise was based principally on the 'sharing of the productivity gains' achieved in manufacturing industry and the role of the welfare state, against the background of a productive system turning out standardised goods and services.

Over and above productivity gains and living standards, it would seem that what is being articulated ever more forcefully in contemporary service societies, particularly in Europe, is a concern with quality (in respect of goods, services, work, the environment). Consequently, the virtuous circles are now to be sought in new compromises between, on the one hand, quality of work (the competencies, autonomy, working hours and pay associated with professional status, right to a job) and quality of life (free time, environment, 'universal' access to essential services, reduction of poverty) and, on the other, the intelligent involvement of workers in the production of services that are both effective and well matched to non-standardised demands. One could speak of a demand for the sharing of quality gains. Now one of the contradictions that makes the current situation societally unsustainable in most services and in most countries is that, in the name of the need to be ever more available for customers and in tune with the market, neo-liberal economic policies and private strategies, with their emphasis on work intensification and functional flexibility, often linked to extended competencies, impose a burden on service 
workers that is unbalanced and disproportionate. All this is done in the name of containing wages and costs, and inhibits the equitable sharing out of quality gains. And yet it may be shown that if the costs of quality are driven out of the door by refusing to pay a fair price for them, they simply come back in through the window, either within the organisation itself (in the form of turnover costs, absenteeism or a loss of motivation that eventually undermines quality) or elsewhere in society (illness, queues, poverty).

In my view, the joint regulation of markets for services and of labour markets with a view to sharing out gains in individual and collective quality summarises fairly well what this book's co-authors call the 'high road' to economic and social development in a modern service economy.

\section{Notes}

1 Part of this chapter is based on Chapter 5 of J. Gadrey (2002) New Economy, New Myth, London: Routledge, reproduced with permission.

2 This was Polanyi's view of the 'self-regulating market' (which equates precisely to the neo-classical market based on perfect competition): it was a 'utopian principle'. See The Great Transformation (1957 [1944]) Boston, MA: Beacon Press.

3 See the distinction proposed by Michel Albert (Capitalisme contre capitalisme, Paris: Le Seuil, 1991) between the Anglo-Saxon and Rhenish models, particularly in the field of insurance.

\section{References}

Arrow, K. (1984) The Collected Papers, London: Blackwell.

Doeringer, P. and Piore, M. (1971) Internal Markets and Manpower Analysis, Lexington: Heath.

Etzioni, A. (1988) The Moral Dimension, New York: The Free Press.

Garcia, M-F. (1986) 'La construction sociale d'un marché parfait: le marché au cadran de Fontaines-en-Sologne', Actes de la Recherche en Sciences Sociales 65: 2-13.

Granovetter, M. (1974) Getting a Job, Cambridge, MA: Harvard University Press.

Karpik, L. (1989) 'L'économie de la qualité', Revue française de la sociologie 30: 187-210.

- (1996) 'Dispositifs de confiance et engagements crédibles', Sociologie $d u$ travail 4: 527-50.

Supiot, A. (1999) Au-delà de l'emploi: Transformations du travail et devenir du droit du travail en Europe, Paris: Flammarion. 


\section{Index}

absenteeism 179-82, 186, 200, 230, 275, 353

Ackroyd, S. 302, 304

ageing population 149, 167

Anttila, T. 229

Anttonen, A. 137

Anxo, D. 35, 119, 121

Arrow, Kenneth 346, 351

Atkinson, J. 290, 293

Austria 331-3

automobile industry 296

banking services 10, 14-15, 237-55, 272-4, 277, 280-2, 298, 320-1; branch closures 241, 282; case studies of 247-53; direct 239, 246, 249-50, 281-2

Baumol, W.J. 6-7, 75, 79, 98

Belgium 165, 171, 173, 176, 182-3

Bell, Daniel 1

'best value' 157, 295

Bettio, F. 139

Beynon, H. 292, 295, 298

Blyton, P. 290

Boeri, T. 328

Boll, J.L. 228, 231, 309

Bolton, S. 302, 304

Bosch, Gerhard 291, 294, 303

Boyer, R. 292

Briefs, G. 2

business-oriented services $47-51,65,70$

call centres 247, 249-50, 297, 305, 333, 342

capitalism 122, 281, 316, 352

Cappelli, P. 262, 272

career structures 159, 172, 271-4

Carnoy, M. 2, 189

Castells, M. 2, 197, 207 childcare facilities 115-17, 120-3, 184, 219-20

collective agreements 155-6, 171-4,

192-3, 231, 282-3, 306-7, 316, 332-4

competitive tendering 269, 294, 299

'component wage' jobs 275

consumer-oriented services 48-50

contracts of employment 157,175 ,

180-1, 223, 231, 254, 307

control of work processes 298-304, 311-12, 323; behavioural, normative and cultural 203-4

convergence theories $3,26-7,35,161$ core workforce 228, 232, 237, 272-3, 276-7, 290-3, 334

Cornetz, W. 40

'cost disease' 6-7, 10, 24, 75, 79, 85-6, $89,95-8,148$

Csonka, A. 309

Dathe, D. 88

decentralisation 151, 160, 166, 169 , 172, 231-2, 269, 299, 324-6, 335

'delegation of uncertainty' 18, 20, 23, $300,307,312$

demand bias $6,74-5$

demographic trends 146, 153, 185

Denmark 6, 8, 21, 42, 61, 65, 70, 83, 91, 114-17, 140, 152-4, 160, 193, 195, $274,277,280,306$; retailing in 213 , 219, 222-3, 227-31

Doeringer, P.B. 261-2, 265, 269, 272, 274

Dølvik, J.E. 208

Dörre, K. 299, 312

dual labour markets 262-3, 272-3

Eberts, R. 88

economies of scale 296-7 
Index 355

employment conditions 2, 8-9, 15-25, 166-7, 183, 205, 295

empowerment of workers 18, 232, 270 , 275, 304, 308

Erickzek, G. 88

Esping-Andersen, Gøsta 7, 23, 35, 103 , $118,121,125,127,136$

Etzioni, Amitai 351

European Commission 26, 35

European Foundation for Improvement of Living and Working Conditions 96

European Survey on Working Conditions 308

European Union (EU) 9-11, 25-6, 278

externalisation of costs 294-5

Fagan, C. 9, 116, 119, 121

family responsibilities 115-16, 125, 161-2, 184-5, 305

feminisation of employment 170, 183, 211,322

feminism 136

Finland 8, 15, 65, 115, 192, 195, 197, 275, 282, 309-10, 329, 332; home care services in 138-40, 152-3, 156, 160 ; retailing in $213,216,219,222-3$, 227

fixed-price projects 199, 299

fixed-term employment 223, 333

Flecker, J. 310

flexible employment practices 56, 99, 175-6, 179, 195-7, 205-7, 263, 272-3, 278, 289-95, 304-11; active and passive 292, 304, 307, 342, 344; in banking 237-40, 248-55; external and internal 292-4, 311; offensive and defensive 292; in retailing 215, 223-33; risks of 304-10; through competition 290-5

Fourastié, Jean 1, 5-6, 75

France 14, 43, 213, 219, 275, 280, 305, 332-3; banking in 237-55, 272, 280, 272; nursing in 169-75, 178-81, 184

franchising 264, 269, 324

Gadrey, J. 295

Garcia, Marie-France 347

Gartner, A. 1

gender segregation and discrimination $9,26,71,120,123-4$

Germany 15, 35-6, 40-3, 48, 64, 83, 86, $88,117,125-6,148,281-3,309$, 330-1; banking in 237-55, 272, 280,
282; retailing in $213,216,220,222$,

226-9

Gershuny, J. 7-8

Giddens, A. 255

Glißmann, W. 300

globalisation 121, 238-41, 254, 261, 265, 296, 316

Goldschmidt-Clermont, L. 82

Gospel, H.F. 262

Granovetter, Mark 347-8

Grugulis, I. 204

Hall, P.A. 35

Hantrais, L. 184

Haußermann, H. 121-2, 126

Hermann, L. 216

Heskett, J.L. 305

Hill, T.P. 76

Hoffmann, J. 35

home care services 10-15, 19-23, 133-61, 271, 274, 277-80, 293-302, 342-3

Hönisch, P. 220

hours of opening 213, 215, 224-7, 230-1, 239, 247, 252, 254, 308

hours of work 13, 15, 20, 37-40, 43-4, 48, 51-2, 75, 85, 90-1, 95-9, 106, 113-16, 126, 156, 282-3, 308-10; annualised 206, 220; in banks 243-5, 252-4; in IT 193-5, 198, 202-6; in nursing 173-4, 178-9; in retailing 215-20, 224, 229-31; time recording of 251; unsocial 227

human resource management 166,176 , 203, 208, 229-30, 273, 281, 290, 292

Hyman, R. 289

Igalens, J. 290, 292

immigrant workers 121, 145, 159, 279, 294

income distribution 80-2

individualisation of work 197, 207, 308-9

inequality, social 2, 8, 25, 85-6, 121; see also income distribution

information technology services 10,13 , $15,20,65,71,159-60,189-208$, 267-8, 271-4, 280-3, 293, 298-301, 309-10, 321, 332-3

innovation 97-9, 189-91, 273

institutional structures 16-19, 24, 120, 184-5, 220, 262-5, 281-4, 292

intensification of work 308, 342, 352

internal labour markets 169, 261-5, 269-71, 282, 290, 294-5, 298, 303, $311,347-8$ 


\section{Index}

Internet, the $160,189,191,198,327$

Italy $6,56,65,70,144-5,159,271,280$, 294-5, 330-3; nursing in 169, 172-4, $179,182,184$

Jacoby, S.M. 262

Jany-Catrice, F. 216, 226

Jungbauer-Gans, M. 220

just-in-time production 17, 296

Kadritzke, U. 309

Karpik, Lucien 349

Klös, H.P. 35, 79

Korczynski, M. 297

labour shortages 158-61, 271, 275-8; in nursing 166, 170-1, 174, 178-9, 182-3

labour supply 12, 92-5, 218, 276-81

Lay, G. 88

Lazonick, W. 283

Lehndorff, Steffen 17

Letablier, M.T. 184

Letourny, A. 166

Luxembourg 47-8, 148

market mechanisms 268, 289, 295-9, 303, 311-12, 316, 343-53

Marsden, D. 265

Martinelli, F. 87

Maurice, M. 264

Meyer, T. 122

Morris, J. 290

Nätti, J. 229

neo-liberal policies 352

NESY project 3-5, 21, 261, 265, 279

Netherlands, the 19, 26, 39-43, 48, 52, 57, 92, 104, 125-6, 195, 197, 213, 275, 295, 306, 309, 329-30; home care services in 137, 140-2, 145-6, 156-9. nursing in $170,173-7,180-4$

network organisation 273

non-standard forms of employment

54-67, 70-1, 125, 273, 280, 325

Norway 8, 328, 334

nursing $10,13,15,19,22,165-86,271$, 274, 278-9, 302

Organisation for Economic Co-operation and Development (OECD) 10, 81-2, 119

Employment Outlook 36, 119

Orloff, A.S. 125-6
Osterman, P. 262

Ott, N. 83

outsourcing 19, 83, 152-3, 191, 215, 292-5, 307, 316, 321, 343

overtime $39,90,116,157,175,180-2$, 198-203, 206, 226, 272, 308

part-time working 9-10, 14-16, 22, 25-6, 39-41, 56-7, 64-5, 70-1, 91, 99, 104-6, 110, 113-14, 117, 125-6, 156-7, 275-80, 305-6; in banking 245,249 ; in nursing $166,173-86$; in retailing 216-20, 224-6, 231

path dependency 24, 35, 151, 161

pay differentials 22, 24, 26, 124, 227, $232,274-9$

peripheral workers 272-3, 292-3

Pernod-Lemattre, M. 216, 226

Peters, K. 300

Philips, P. 294

Piore, M.J. 261-2, 265, 269, 272, 274

Polanyi, K. 2, 348

Portugal 41, 47, 56, 61, 65, 216, 220, $275,277,281,305$

post-industrial society $103,114,121$, 125,127

Prechal, S. 139

privatisation $16,22,26,143,267,269$, 279, 316, 343

productivity bias 6,74

professionalisation of services 19,26 , $123,140,158-61,271,283,302$, 306-7

public interest 350-1

qualifications of workers 89-90, 123, $140,143,158,171,211,241-2,254-5$, $302,306-7$

quality of services $88-9,99,148,167$, $279,295,307,309,352-3$

Rainfurth, C. 88

rationalisation of work practices 152 , 212-15, 223-4, 241-2, 290, 296, 303 regulation and deregulation $2,17,20$, $23,148,171,238,241,261,276$,

280-4, 292, 311, 316, 332, 349-52

Reich, R. 289

Rerrich, M.S. 121

retailing $10,13-15,20,56,65,70$, 211-34, 267, 272-4, 277, 281, 293, 298-9, 303-6, 320

Riessman, F. 1

Robinson, Joan 27 
Rubery, J. 9, 116, 262

Scharpf, F.W. 35, 75, 79

scheduling work 177-82, 186, 231-2, 308

Schlesinger, L.A. 305

Schmid, G. 88

'segmentation of customers and products 239, 241, 246

segmented labour markets 16, 26, 71, 123-4, 215-16, 227, 231-3, 254-5, 261-8, 276-84

self-management of work 308-9

Sengenberger, W. 300, 310

Siebel, W. 121-2, 126

Sipilä, J. 137

skill requirements 158-61, 182, 186, 268, 271, 273, 277, 322

Smith, C. 297

social services $7,10,20-6,48,51-2,56$, 64, 84-5, 98, 108-10, 118-20, 298-9, 306, 311-12

'societal effect' approach 167-8, 264-5, 277-84

Sorge, A. 264

Soskice, D. 35

Stiglitz, J. 23

Storrie, D. 35

students in employment 222-31, 249, 277, 282, 305

subcontracting 207, 214-15, 264, 267-70, 279-81, 293-4; of home care services 143, 148, 151-3, 157-61

Supiot, Alain 349

Sweden 8, 19-20, 40, 61, 86, 91, 114-20, 123-6, 136-40, 152, 213, 218-19, 222, 227, 232, 280, 295, 302, 327-8, 332-3; nursing in 169-70, 177-80, 184

Taylorisation 154, 213-14, 281, 296-7, 303

temporary jobs 56-7, 65-6, 70, 175-6, 180-1, 207, 212, 220, 229, 291, 334

tertiarisation 5-6, 35-44, 51, 88, 317-22

Thompson, P. 297

Townsend, A.R. 56 trade unions 20-1, 24, 94-7, 153, 156, 161, 172-3, 183, 192-3, 219, 231, 247, 263, 268, 276, 312, 316-36

training 19, 143, 151, 159, 161, 171, 180, 201-2, 221-2, 225-6, 229, 241-2, 253-5, 271, 276, 280-3

trust-based working 250-1, 309

turnover of staff 223-9, 240, 282, 307, $316,325,353$

unemployment 27, 92, 305

United Kingdom (UK) 19, 22, 26, 39, 43-4, 48, 61, 65, 120, 193, 195, 274-5, 279, 283, 293-5, 302, 307, 328-31; home care services in $137,142-3$, 151-9; nursing in 169-72, 175-6, 180, 183-4

United States (US) 2, 7-8, 35-6, 77, 88, 92-7, 120, 262, 275, 328

unpaid work 38, 82-3, 120, 122, 124

Voss-Dahm, Dorothea 17, 231, 233

Waddington, J. 208

Warner, M. 264

welfare state regimes $7,10,12,23-4$, 76-7, 86, 97-8, 117-20, 133, 136-44, 270,280

Wilkinson, F. 262

Williams, K. 296

women's employment 9-12, 22-7, 42, $57,62,67,70,83,98,103-18,121$, 125-7, 145-7, 218-20, 245, 261, 271, 276-9, 305

work-life balance 123-7, 177

working conditions $2-3,10,15-17$,

20-5, 121, 161, 212, 279, 295, 308, $311-12,322$; in nursing $166-7$, $181-3,186$

Yeandle, S. 21

young workers 220-31, 250, 277, 305-6

zero-hours contracts 175

Zysman, J. 241 


